\title{
Improved Microalgal Biomass Harvesting Using Optimized Environmental Conditions and Bacterial Bioflocculants
}

\author{
A Master's Thesis Presented to the Faculty of \\ California Polytechnic State University San Luis Obispo
}

In partial fulfillment of the requirements

for the degree of Master of Science in

Civil and Environmental Engineering

By

Derek Conte Manheim

August 2012 
(C) 2012

Derek Conte Manheim

ALL RIGHTS RESERVED 


\section{COMMITTEE MEMBERSHIP}

Title: Improved Microalgal Biomass Harvesting Using Optimized Environmental Conditions and Bacterial Bioflocculants

Author: Derek Conte Manheim

Date Submitted: August 10, 2012

Dr. Yarrow Nelson Committee Chair

Signature

Dr. Tryg Lundquist

Committee Member

Signature

Dr. Chris Kitts

Committee Member

Signature 


\section{ABSTRACT \\ IMPROVED MICROALGAL BIOMASS HARVESTING USING OPTIMIZED ENVIRONMENTAL CONDITIONS AND BACTERIAL BIOFLOCCULANTS DEREK CONTE MANHEIM}

The cost and energy balance of microalgae biofuel production is sensitive to the algae harvesting method, among many other factors. Bioflocculation and settling of suspended microalgae cultures is a harvesting method with potentially low cost and energy input. However, bioflocculation (the spontaneous flocculation of algal cells without chemical addition) has not been a reliable process with cultures grown in ponds. To provide insights to help improve algae settling, factors affecting the settling of algae were investigated in the laboratory using pure cultures of two common microalgae species: Scenedesmus sp. and Chlorella vulgaris. Bioflocculation of these algae was studied with and without the addition of bioflocculants produced by the bacterium, Burkholderia cepacia, to improve settling efficiencies. The bioflocculant produced by this bacterium was used in two different forms: a cell suspension including capsular and dissolved extracellular polymeric substance (EPS) components of B. cepacia, and dialyzed filtrate of the bacterial culture (only dissolved EPS fraction). The effects of algal growth phase, mixing time, bioflocculant dose, and environmental conditions such as $\mathrm{pH}$ and nutrient deprivation of bacterial bioflocculant cultures on settling of the algae species were studied. 
Settling characteristics were different for the two algae cultures, and their settling was affected differently by the many factors studied. Scenedesmus settling was best in later growth stages, while Chlorella settled much better in early growth phases. Addition of B. cepacia cells as a bioflocculant improved settling of Scenedesmus, with the greatest effect during mid to late exponential growth of the Scenedesmus. In contrast, addition of B. cepacia filtrate as a bioflocculant best improved Chlorella settling during stationary growth of Chlorella. Longer mixing times (contact time between the algae cells and bacterial bioflocculant) improved the settling of Scenedesmus, while Chlorella settled better with a shorter mixing time. Reducing the $\mathrm{pH}$ to 3 (a typical isoelectric point for microalgae) improved the settling of both algae cultures, with and without bioflocculant addition. Increasing the $\mathrm{pH}$ to 11 autoflocculated Scenedesmus cultures, but not Chlorella cultures, at early growth stages.

EPS produced by the algae, bacteria, and wastewater organisms was quantified using dialysis separation followed by total organic carbon (TOC) analysis. Wastewater organisms were included because wastewater is a potential growth medium for biofuel algae. Improved settling of both species of algae depended on both the quantity and type of EPS (dissolved or capsular) produced by both the bacterial bioflocculant, and the algae themselves. Scenedesmus settled the best during late growth phases while its own EPS production was high, and combined EPS (capsular and dissolved) from B. cepacia improved settling at a higher dosage of bacterial cells to algae (1:2 B. cepacia cells to algae cells). Since Chlorella settling was not improved at later growth stages when its own EPS production was greatest, 
it appears that Chlorella's settling rate was less affected by the production of its own EPS. For Chlorella, B. cepacia EPS addition (capsular and dissolved) was effective only in low doses (1:6 B. cepacia cells to algae cells).

Settling results with the addition of bacterial bioflocculants with the pure algae cultures were compared to settling results of lab experiments with algae pondwater sampled from high-rate algae ponds (HRAPs). These algae samples were used to test the addition of return activated sludge (RAS) to improve settling. RAS addition improved the settling of Chlorella, which was the dominant algae species in the HRAP during the time of this study, at two different doses (a ratio of RAS to algae pond water of $1: 3$ and 1:6).

Nutrient deprivation of B. cepacia cells before use as a bioflucculant was found to improve settling for Scenedesmus, especially during early phases of growth when EPS production of Scenedesmus was low. The EPS produced by the starved bacterial cells was about $30 \%$ greater than that produced by cultures which were not nutrient-limited. For the bacterial cultures, EPS production peaked at mid stationary phase for non-starved cultures and during early stationary phase for starved cultures. Chlorella settling improved in early growth with starved bacterial cell addition and in later growth with non-starved bacterial cell addition.

These results suggest that the settling of microalgae can vary dramatically by species and that the settling of different species is affected differently by growth phase and environmental conditions. In addition, species of algae respond differently to addition of bacterial bioflocculants. Given the dramatically different 
settling behavior of the two species of algae used in this research, more research should be directed to studying settling of other microalgal species. Based on this research, the use of bacterial bioflocculants is promising for improving algae settling and may contribute to the development of a reliable, low cost harvesting process for commercial biofuel production from microalgae. 


\section{ACKNOWLEDGMENTS}

I would like to thank Dr. Nelson first and foremost for his wisdom and guidance throughout the course of research. This research would not have been possible without

his dedication and perseverance for editing such a lengthy and detailed document, listening each step of the way, and providing the best advice anyone could ever ask for. Also, I graciously appreciate Dr. Lundquist and Dr. Kitts for enthusiastically helping me improve this research to the best of my ability. They also showed me that anyone can achieve anything as long as they work hard and show the utmost appreciation for the next task at hand. Also, I am very grateful for the funding of this research from the Office of Naval Research through the Cal Poly C3RP program.

To fellow grad students: I thank Ankita Kashyap, for always being there and showing me how to succeed in the laboratory; Kyle Fooks, for all of his knowledge with the TOC analyzer operation; as well as James Kelley and Franco Trabucco, for showing me the best procedures for growing algae and for answering all of the biology related questions concerning my research. I thank Louis Lefebvre for his help with the RAS addition results, as this study involved incorporating the use of his wastewater samples. All of the preparation of the samples and the design of the RAS addition experiments used were also paralleled in his thesis. To all other graduate students in the laboratory who I didn't mention, again, I enjoyed your company and friendship and wish you the best in the next step of your lives. Finally, I show great appreciation for my undergraduate student helpers: Perry Ng, Mehreen Siddiqui, and Jason Hull, for being so reliable and helping the data collection run both smoothly and successfully. I know that your dedication will accomplish big things in the future for Cal Poly, San Luis Obispo and the world. 
To my friends and family, I can't even describe the feelings I have for the support I have received this past year. I express deep gratitude and thanks for my parents especially, who have always wished the best for me and provided me with the tools and the knowledge to succeed. To my girlfriend, Francesca, you have always believed in me from the start and I know that your effort and guidance kept me on track through this whole year, even during the times we were apart. I can't believe all of the editing you helped me with, and the time spent helping to make sure I was healthy and functioning. I know I will do the same for you when it comes time for your master's degree. To everyone that helped me achieve, thank you again for your kindness and inspiration and always remember the following to live your life to the best of your ability:

"If you keep doing what you have always done, you will keep on being what you have always been. Do the right thing."-Anonymous 


\section{TABLE OF CONTENTS}

LIST OF TABLES _ XV

LIST OF FIGURES $\quad$ xvii

CHAPTER 1: INTRODUCTION $\quad 1$

1.1 RESEARCH IMPORTANCE AND PROCESS GOALS 1

\begin{tabular}{lc} 
CHAPTER 2: BACKGROUND & $\mathbf{8}$ \\
\hline
\end{tabular}

$\begin{array}{lc}\text { 2.1 MiCROALGAE IN WASTEWATER TREATMENT } & 8\end{array}$

2.2 POTENTIAL FOR PRODUCTION OF ALGAL BIOFUELS FROM WASTEWATER TREATMENT HIGH RATE $\begin{array}{ll}\text { ALGAL PONDS } & 13\end{array}$

$\begin{array}{ll}2.3 \text { METHODS FOR HARVESTING OF ALGAL BIOMASS } & 16\end{array}$

2.3.1 PhysiCAL MEthods 16

$\begin{array}{lr}\text { 2.3.2 CHEMICAL METHODS } & 18\end{array}$

$\begin{array}{lr}2.3 .3 \text { BIOLOGICAL METHODS } & 20\end{array}$

\begin{tabular}{l}
2.4 CHARACTERISZATION OF ALGAL EXUDATES \\
\hline
\end{tabular}

2.4.1 ALGAL EPS 22

2.4.2 ALGAL EXUDATES: TRANSPARENT EXOPOLYMERIC PARTICULATE 27

2.4.3 EFFECTS OF GROWTH CONDITIONS ON ALGAL EPS PRODUCTION

2.4.3.1 EFFECT OF NUTRIENT LIMITATION ON EPS PRODUCTION 32

2.4.3.2 EFFECT OF AUTOFLOCCULATION EPS EXUDATE PRODUCTION 32

2.4.3.3 EFFECT OF LIGHT INTENSITY AND DARK CONDITIONS ON ALGAL EPS AND SETTLEABILITY

2.4.3.4 EFFECTS ON SETTLING OF ALGAL SURFACE CHARGE, MORPHOLOGY AND SIZE $\quad 48$

2.4.3.5 Effects of Algal EPS on Settling and Flocculation 52

$\begin{array}{ll}2.5 \text { BIOFLOCCULATION AND EPS } & 55\end{array}$

2.5.1 LARGE-SCALE BIOFLOCCULATION STUDIES TO IMPROVE HARVESTING OF MICROALGAE $\quad 57$

2.5.2 SETTLING CHARACTERISITCS OF ACTIVATED SLUDGE

2.5.3 ADDITION OF BIOFLOCCULANTS TO IMPROVE MICROALGAL HARVESTING 63

2.5.3.1 ADDITION OF BACTERIAL FLOCCULANTS TO IMPORVE MICROALGAL HARVESTING 63 
2.5.3.3 ADDITION OF RETURN ACTIVATED SLUDGE (RAS) TO IMPROVE MICROALGAL HARVESTING

4.1.1 GROWTH CURVES OF SCENEDESMUS AND CHLORELLA: EXPERIMENT 1

4.1.2 EFFECT OF GROWTH PHASE ON SETTLING OF SCENEDESMUS: EXPERIMENT 1

4.1.3 EFFECT OF GROWTH PHASE ON SETTLING OF CHLORELLA: EXPERIMENT 1

4.1.4 GROWTH CURVES OF SCENEDESMUS AND CHLORELLA: EXPERIMENT 2

4.1.5 EFFECT OF GROWTH PHASE ON SETTLING OF SCENEDESMUS: EXPERIMENT 2

4.1.6 EFFECT OF GROWTH PHASE ON SETTLING OF CHLORELLA: EXPERIMENT 2

4.1.7 GROWTH CURVES OF SCENEDESMUS AND CHLORELLA: EXPERIMENT 3

103

4.1.8 EFFECT OF GROWTH PHASE ON SETTLING OF SCENEDESMUS: EXPERIMENT 3

4.1.9 EFFECT OF GROWTH PHASE ON SETTLING OF CHLORELLA: EXPERIMENT 3

4.1.10 SETtLing OF OLDER CULTURES OF SCENEDESMUS AND CHLORELLA WITHOUT BIOFLOCCULANT ADDITION

4.1.10.1 EPS CORRELATION WITH SETTLING OF OLDER CULTURES OF SCENEDESMUS AND CHLORELLA WITHOUT BIOFLOCCULANT ADDITION 
4.2 SETtling OF SCENEDESMUS AND CHLORELLA With B. CEPACIA BIOFLOCCULANTS

4.2.1 GROWTH CURVES OF B. CEPACIA CULTURES USED FOR BIOFLOCCULANT ADDITION

114

4.2.2 EFFECT OF B. CEPACIA BIOFLCOCULANT ADDITION ON SETTLING OF SCENEDESMUS AND CHLORELLA : EXPERIMENT 1

118

4.2.3 EFFECT OF B. CEPACIA BIOFLOCCULANT ADDITION ON SETTLING OF SCENEDESMUS

AND CHLORELLA: EXPERIMENT 2: VARYING CONTACT TIMES

121

4.2.4 EFFECT OF B. CEPACIA BIOFLOCCULANT ADDITION ON SETTLING OF SCENEDESMUS

AND CHLORELLA: EXPERIMENT 3: VARYING DOSAGE OF BIOFLOCCULANTS

132

4.2.5 RESULTS OF EPS ANALYSIS AND CORRELATION WITH ALGAL SETTLEABILITY:

EXPERIMENT 2

135

4.2.6 RESULTS OF EPS ANALYSIS AND CORRELATION WITH ALGAL SETTLEABILITY:

EXPERIMENT 3

138

4.3 Settling OF Mixtures of Algal Pond Water and Primary Treated

WASTEWATER WITH RAS TREATMENT

141

4.3.1 EFFECT OF RAS ADDITION ON SETTLING OF MIXTURES OF ALGAL POND WATER AND PRIMARY TREATED WASTEWATER: EXPERIMENT 1

4.3.2 EFFECT OF RAS ADDITION ON SETTLING OF MIXTURES OF ALGAL POND WATER AND PRIMARY TREATED WASTEWATER: EXPERIMENT 2

4.3.3 CORRELATION OF EPS WITH RAS ADDITION TO WASTEWATER SAMPLES:

EXPERIMENT 2

4.4 Effect of Light and Dark Cycles During Growth ANd Light and Dark Settling Conditions on the SetTling of Scenedesmus and Chlorella

4.4.1 EFfect of Light and DaRk Settling Conditions on Algal Settleability: 
4.4.2 EFFECT OF LIGHT AND DARK CYCLES DURING GROWTH AND LIGHT AND DARK SETTLING CONDITIONS ON THE SETTLING OF SCENEDESMUS AND CHLORELLA: GROWTH CURVES

4.4.3 EFFECT OF LIGHT INTENSITY AND LIGHT/DARK CYCLES DURING GROWTH ON SETTLING OF

SCENEDESMUS WITHOUT B. CEPACIA BIOFLOCCULANT ADDITION 155

4.4.4 EFFECT OF LIGHT INTENSITY AND LIGHT/DARK SETTLING CONDITIONS ON SETTLING OF CHLORELLA WITHOUT B. CEPACIA BIOFLOCCULANT ADDITION

4.4.5 EFFECT OF LIGHT AND DARK CYCLES AND LIGHT AND DARK SETTLING CONDITIONS ON SETTLING OF SCENEDESMUS WITH B. CEPACIA BIOFLOCCULANT ADDITION

4.4.6 EFFECT OF LIGHT INTENSITY AND LIGHT/DARK CONDITIONS ON SETTLING OF CHLORELLA WITH B. CEPACIA BIOFLOCCULANT ADDITION

4.4.7 EPS CORRELATION BETWEEN VARYING LIGHT INTENSITY AND LIGHT/DARK SETTLING CONDITIONS ON IMPROVED SETTLEABILITY OF SCENDESMUS AND CHLORELLA

4.5 VARYING PH TO IMPROVE SETTLEABILITY OF SCENEDESMUS AND CHLORELLA

4.5.1 GROWTH CURVES OF B. CEPACIA, SCENEDESMUS AND CHLORELLA USED IN PH EXPERIMENTS

4.5.2 EFFECT OF GROWTH PHASE ON THE SETTLEABILITY OF SCENEDESMUS

WITH VARYING PH

\subsubsection{EFFECT OF GROWTH PHASE ON THE SETTLEABILITY OF CHLORELLA}

WITH VARYING PH

4.5.4 Effect of B. cepacia Cell Addition on the Settleability of Scenedesmus with Varying $\mathrm{pH}$

4.5.5 Effect of B. cepacia Filtrate Addition on the Settleability of Chlorella with Varying $\mathrm{pH}$

4.5.6 EPS Correlation with Settleability of Scenedesmus and Chlorella at Varied pH

4.6 Addition of Nutrient Starved B. CePaCia Cultures to Improve the SetTleability of SCENEDESMUS AND CHLORELLA 
4.6.2 EFFECT OF STARVED B. CEPACIA CELL ADDITION ON THE SETTLEABILITY

OF SCENEDESMUS

179

4.6.3 EFFECT OF STARVED B. CEPACIA FILTRATE ADDITION ON THE SETTLEABILITY

OF CHLORELLA

180

4.6.4 EPS PRODUCTION BY NUTRIENT-STARVED B. CEPACIA CELLS, CHLORELLA, AND SCENEDESMUS AND CORRELATION WITH IMPROVED SETTLING

4.7 EFFECT OF CaRbon DiOXIDE AdDITION ON THE SETTLEABILITY OF SCENEDESMUS

AND CHLORELLA

187

4.7.1 GROWTH CURVES OF B. CEPACIA, SCENEDESMUS AND CHLORELLA

4.7.2 EFFECT OF CARBON DIOXIDE ADDITION ON THE SETTLEABILITY

OF SCENEDESMUS

192

4.7.3 EFFECT OF CARBON DIOXIDE ADDITION ON THE SETTLEABILITY

OF CHLORELLA

192

4.7.4 EFFECT OF CARBON DIOXIDE AND B. CEPACIA CELL ADDITION ON THE

SETTLEABILITY OF SCENEDESMUS

193

4.7.5 EFFECT OF CARBON DIOXIDE AND B. CEPACIA FILTRATE ADDITION ON THE

SETTLEABILITY OF CHLORELLA

196

4.7.6 CORRELATION OF EPS WITH CARBON DIOXIDE ADDITION ON THE SETTLEABILITY

OF SCENEDESMUS AND CHLORELLA

198

CHAPTER 5: CONCLUSIONS

REFERENCES

APPENDIX: SECTION 1: CoMPILATION OF RESUltS

216

APPENDIX: SECTION 2: COMPILATION OF MICROGRAPHS

221

APPENDIX: SECTION 3: COMPILATION OF SUPPLEMENTAL FigURES

226 


\section{LIST OF TABLES}

Table 2.1: Comparison of Pond technologies (Source: US EPA, 2011)

Table 2.2: Production and quantification of EPS for different species of green microalgae (Source: Lewin, 1956)(S, C-1, C-2, C-3b refer to different amounts of polysaccharide for a specified series of precipitations)

Table 2.3: Yields of polysaccharides and dry weight for 8 species of green microalgae (Source: Moore, 1964) EP=extracellular polysaccharide, $C P=$ capsular polysaccharide, $I P=$ water soluble intra-cellular polysaccharide, $T P=$ total polysaccharide

Table 2.4: Increasing polysaccharides produced over the growth curve for Anabaena cultures (Source: Moore, 1964)

Table 2.5: Measurements of biopolymers produced as a function of culture age for two different cultures of Porphyridium aerugineum (Source: Ramus, 1980)

Table 3.1: Composition of WC medium and concentration of chemical components

(Source: Andersen, 2005)

Table 3.2: Table 3.2-Composition of Vitamin Stock solution for WC medium

(Source: Andersen, 2005)

Table 3.3: Table 3.3-Composition of Trace Metals stock solution for WC medium

(Source: Andersen, 2005)

Table 3.4: Composition of Bristol Medium used for plating of algal cultures (Adapted from the UTEX website

Table 3.5: Composition of Nutrient Broth BD 23400, added to 1 Liter of DI, and pH adjusted to 6.8 (Source: ATCC website)

Table 3.6: Modified MMS-3 Media (Source: Nelson et al., 1996)

Table 3.7: Concentrations of different compounds used to adjust ionic strength to .05 M (in modified MMS-3 media)

Table 3.8: Approximate dimensions of rectangular settling apparatus built 
Table 3.9: Approximate dimensions of cylindrical settling apparatus built

Table 4.1: Composition of WC Media for Autoflocculation Analysis 112

Table 4.2: Defined Volumes of Wastewater samples used compared to RAS addition for comparison of settling in this study

Table 4.3: Classification of samples used for analysis with and without RAS addition 144 


\section{LIST OF FIGURES}

Figure 1.1: Outline of experimentation to achieve Process Goals/Objectives

Figure 2.1: Interdependence of algae and bacteria in a waste stabilization pond (Source: Lundquist, 2010)

Figure 2.2: Schematic of a facultative wastewater stabilization pond (Source:

Tchnobanoglous, 2003)

Figure 2.3: Side view of a typical HRAP with carbon dioxide addition (Source: Park, 2011)

Figure 2.4: New HRAP facility operating under Cal Poly, San Luis Obispo Civil \& Environmental Engineering Program (Source: SLO Tribune)

Figure 2.5: Yields of extracellular polysaccharides versus dry weight for 8 species of green microalgae (Source: Moore, 1964)

Figure 2.6: Photomicrograph depicting TEP particles (from a freshwater source) and string like arrangements stained with Alcian Blue dye (Source: Berman, 2005)

Figure 2.7: Measurements of concentrations of various extracellular products of Scenedesmus obliquus over the growth curve, both $A$ and $B$ represent two different batch cultures of Scenedesmus obliquus (Source: Lavoie, 1987)

Figure 2.8: Effect of culture age on algal sedimentation in A) Darkness and B) Under illumination. Sedimentation duration was 1 hour (closed circle), 2 hours (open circle) and 4 hours (closed box). The arrow denotes onset of declining growth phase (early stationary) (Source: Lavoie, 1987)

Figure 2.9: $p H$ variation with algal removal \% in the outdoor Scenedesmus obliquus cultures (Source: Sukenik, 1984)

Figure 2.10: Simulated algal flocculation with A) algae concentration and cells zeta potential and B) dissolved calcium and orthophosphate after flocculation and sedimentation (Source: Sukenik, 1984)

Figure 2.11: Variation of algal removal \% and $\mathrm{pH}$ values for algal culture (Source: Pavoni, 1974)

Figure 2.12: Effect of growth phase on cationic polyelectrolyte dosage to attain 50\% flocculation/removal of algae (Source: Tenney, 1973)

Figure 2.13: Effect of algal concentration at a fixed $\mathrm{pH}$ of 3 for cationic polyelectrolyte doses to increase algal removal (Source: Tenney, 1973)

Figure 2.14: Effect of $\mathrm{pH}$ on algal removal with constant dosage of cationic polyelectrolyte (Source: Tenney, 1973) 
Figure 2.15: EPS production response of a microalgal species to changes from $A$ ) heterotrophy to mixotrophy and B) mixotrophy to heterotrophy (black box with dashed line is EPS production; filled circle with black solid line is algal biomass production) (Source: Shipin, 1999)

Figure 2.16: Variation of charge density with pH of a species of Chlorella (Source: Ives, 1959)

Figure 2.17: Measured settling velocities of different problem species of algae (the circled points represent Scenedesmus). The left figure includes the diatom species studied (Source: Choi, 2006).

Figure 2.18: Relation of growth, flocculation and carbohydrate production of a Chlamydomonas culture (Source: Schenck, 1976)

Figure 2.19: Algal concentration plotted against extracellular metabolites (algal EPS) over the growth curve for Chlorophyta (Source: Tenney, 1969)

Figure 2.20: Flocculation of AM49 with different species of Microalgae with a fixed dose of bioflocculant (Ana-Anabaena flos-aquae; Mic-Microcystis aeruginosa; BotBotrycoccus braunii; Sce-Scenedesmus quadricada; Sel-Selanastrum capricornutum; Chl-Chlorella vulgaris)

Figure 2.21: Photomicrographs of results observed with different flocculating microalgae, $(A)$ and (B)-Chlorella vulgaris; (C)-Neochloris oleoabundans; (D)Ankistrodesmus falcatus; (E)-Scenedesmus obliquus; (F)-Tetraselmis suecica; (G)-C. vulgaris with A. falcatus; (H)-C. Vulgaris with S. obliquus; and (I)-N. oleoabundans with T. suecica (Source: Salim, 2011)

Figure 2.22: Settleability of biomass (algal and bacterial) with different RAS inoculation ratios (Source: $\mathrm{Su}, 2012$ )

Figure 3.1: Light rack apparatus used for algal illumination for growth 75

Figure 3.2: Light rack apparatus in use in the laboratory 75

Figure 3.3: Calibration curve used to regulate airflow and carbon dioxide input for Mattheson Model 602/603

Figure 3.4: Growth of algae in a 4-L bioreactor equipped with filter flask for sample removal

Figure 3.5: Relationship developed between dry weight and optical density of Scenedesmus

Figure 3.6: Relationships developed between dry weight and optical density of Chlorella 
Figure 3.7: 2-liter bioreactor setup used to grow B. cepacia cultures

Figure 3.8: Figure 3.8-Visual representation of rectangular settling columns constructed

Figure 3.9: Visual representation of cylindrical settling column

Figure 3.10: Illustration of Settling Columns in use

Figure 3.11: Representation of a typical hemocytometer counting grid seen at 400x magnification

Figure 3.12: TOC calibration curve used for EPS Analysis and corresponding r-squared value

Figure 4.1: Growth curve of Scenedesmus over an 18-day growth period using optical density at $625 \mathrm{~nm}$

Figure 4.2: Growth curve of Chlorella over a 14-day growth period using optical density at $625 \mathrm{~nm}$

Figure 4.3: Settling based on normalized cell concentration remaining over A) a twenty four hour period for the Scenedesmus culture B) a two hour period C) Over eighteen days of growth plotted against the growth curve. The red line indicates optical density results over certain days sampled at $625 \mathrm{~nm}$ by a spectrophotometer

Figure 4.4: Settling based on normalized cell concentration remaining over A) a twenty four hour period for the Chlorella culture B) a two hour period C) over fourteen days of growth plotted against the growth curve. The red line indicates optical density results over certain days sampled at $625 \mathrm{~nm}$ by a spectrophotometer

Figure 4.5: Normalized cell concentration plotted against time over a twenty hour period for both the Chlorella and Scenedesmus cultures. The results are compared when Scenedesmus completed 10 days of growth and Chlorella 8 days.

Figure 4.6: Growth of Scenedesmus over a fourteen-day period, with optical density taken at $625 \mathrm{~nm}$

Figure 4.7: Growth of Chlorella over a fourteen-day period, with optical density taken at $625 \mathrm{~nm}$

Figure 4.8: Settling based on normalized cell concentration remaining of Scenedesmus control columns (no cell or filtrate addition) over growth curve (10 day period) for $A$ ) a twenty four hour period $B$ ) a two hour period and C) compared with growth phase (plotted against optical density at $625 \mathrm{~nm}$ ) (Experiment 2) 
Figure 4.9: Settling based on normalized cell concentration remaining of Chlorella over growth curve for $A$ ) a 24 hour period B) a 2 hour period and C) compared with growth phase (plotted against optical density at $625 \mathrm{~nm}$ )(Experiment 2)

Figure 4.10: Growth Curve of Scenedemus using Optical Density at $625 \mathrm{~nm}$ over a fifteen day period

Figure 4.11: Growth Curve of Chlorella using Optical Density at $625 \mathrm{~nm}$ over a fourteen day period

Figure 4.12: Settling based on normalized cell concentration remaining for the same Scenedesmus culture over the growth curve with no bioflocculant addition for $A$ ) a twenty four hour settling period B) a two hour settling period and C) a comparison of growth phase (plotted against optical density at $625 \mathrm{~nm}$ over the growth curve) (Colors correspond to days of growth on all graphs) (Experiment 3)

Figure 4.13: Settling based on normalized cell concentration remaining for the same Chlorella culture over the growth curve with no bioflocculant addition for A) a twenty four hour settling period $B$ ) a two hour settling period and C) a comparison of growth phase (plotted against optical density at $625 \mathrm{~nm}$ over the growth curve) (Colors correspond to days of growth on all graphs-note color change from Scenedesmus) (Experiment 3)

Figure 4.14: Settling of Young (mid stationary phase-15 days) versus Old (death phase30 days)cultures based on normalized cell concentrations remaining of $A$ ) Scenedesmus B) Chlorella and C) Comparing settling between cultures over a 2-hour time period (instead of 24 hours)

Figure 4.15: EPS productions of old (over 30 days of growth) and young (mid stationary growth phase-15 days old) cultures of Chlorella and Scenedesmus

Figure 4.16: Growth curve of B. cepacia over a 250-hour growth period using optical density

Figure 4.17: Growth curve of a second batch culture of B. cepacia over a 250-hour growth period using optical density

Figure 4.18: Growth of B. cepacia over a 250-hour period, with optical density taken at 625 nanometers

Figure 4.19: Growth curve of B.Cepacia at $26^{\circ}$ Celsius using optical density at $625 \mathrm{~nm}$ over a 350-hr period

Figure 4.20: Comparison of B. cepacia cell, filtrate and no cell addition to an 18-day old Scenedesmus culture using normalized cell concentration remaining as a function of settling time over A) a 24- hour period and B) a 2-hour period

Figure 4.21: Comparison of B. cepacia cell, filtrate and no cell addition to a 14-day old Chlorella culture using normalized cell concentration remaining as a function of settling time over A) a 24-hour period and B) a 2-hour period 
Figure 4.22: Effect of B. cepacia cell addition on settling of Scenedesmus using normalized cell concentrations remaining after 6 days of growth over A) a 24-hour settling period and B) a 2-hour settling period

Figure 4.23: Effect of B. cepacia cell addition on settling of Scenedesmus using normalized cell concentrations remaining after 8 days of growth over a A) 24-hour settling period and B) over a 2-hour settling period

Figure 4.24: Effect of $B$. cepacia cell addition and contact time on the measured settling rate of Scenedesmus based on normalized cell concentration remaining after 6 and 8 days of growth over a 2-hour settling period. The legend denotes contact time between cells (Experiment 2)

Figure 4.25: Settling of Scenedesmus using normalized cell concentrations remaining with and without B. cepacia filtrate addition after 10 days of growth over a A) 24-hour settling period and B) 2- hour settling period

Figure 4.26: Effect of B. cepacia cell addition on settling of Chlorella using normalized cell concentrations remaining after 6 days of growth over a A) 24-hour period and B) 2hour settling period

Figure 4.27: Effect of $B$. cepacia cell addition on settling of Chlorella using normalized cell concentrations remaining after 8 days of growth over a A) 24-hour settling period and B) 2-hour settling period

Figure 4.28: Effect of B. cepacia cell addition and contact time on settling of Chlorella based on normalized cell concentration remaining after 6 and 8 days of growth over $a$ 2-hour settling period. The legend denotes contact time between cells (Experiment 2)

Figure 4.29: Settling of Chlorella based on normalized cell concentrations remaining with and without B. cepacia filtrate addition after 10 days of growth over a A) 24-hour settling period and B) 2-hour settling period.

Figure 4.30: Comparison of settling based on normalized cell concentration remaining over a two hour settling period for a Scenedesmus culture with no B. cepacia addition, cell addition, and filtrate addition, and $1 / 2$ filtrate addition over 15 days of growth (Colors refer to columns in the legend) (Experiment 3)

Figure 4.31: Settling of Chlorella based on normalized cell concentrations remaining after a 2-hour settling period compared over 6,13, and 15 days of growth for no $B$. cepacia cell addition, with $B$. cepacia cell addition, with $B$. cepacia filtrate addition, and with B. cepacia $1 / 2$ cell addition (Experiment 3 )

Figure 4.32: Dissolved EPS concentration of Scenedesmus plotted against its growth curve measured until 12 days of growth. Green arrows represent days in which settling tests were run (Experiment 2)

Figure 4.33: Dissolved EPS concentration of Chlorella over a 12-day growth period plotted against the growth curve measured at 625 nanometers by optical density. Green arrows represent days when settling tests were run (Experiment 2) 
Figure 4.34: Dissolved EPS concentration of B. Cepacia over a 12-day growth period plotted against the growth curve measured at 625 nanometers by optical density. Green arrows represent days when settling tests were run (Experiment 2)

Figure 4.35: EPS measurements compared to dry weight observed over a 15 day growth period for Scenedesmus (Green arrows indicate when settling tests were run) (Experiment 3)

Figure 4.36: EPS measurements compared to dry weight observed over a 15 day growth period for Chlorella (Green arrows indicate when settling tests were run) (Experiment 3)

Figure 4.37: EPS measurements compared to optical density observed over a 15 day growth period for B. cepacia (Green arrows indicate when settling tests were run)

Figure 4.38: Effect of adding a certain fixed dose of RAS to A) an non-aerated mixture of raw primary municipal wastewater samples and algae pond water from the San Luis Obispo Wastewater Treatment Facility over a 2-hour settling period and B) an aerated sample with and without RAS treatment over a settling period of 2 hours

Figure 4.39: Normalized cell concentration as a function of settling time over a 24-hour period for different wastewater pond cultures with or without RAS addition at a A) 2:1 ratio $B$ ) 1:1 ratio and C) 1:2 ratio of primary wastewater to algae pond water (Red line signifies no RAS addition, blue line signifies RAS addition)

Figure 4.40: Comparison of settling based normalized cell concentration remaining after a 2-hour settling period for samples with RAS/Aeration and without addition, and with varying volumetric ratios of primary wastewater to algae pond water

Figure 4.41 Dissolved EPS measurements for samples with and without RAS addition or aeration, also including a sample of pure algal pond water:

Figure 4.42: Normalized cell concentration remaining as a function of settling time for Scenedesmus settling in the light or dark over a A) 24-hour settling period and B) a 2hour period

Figure 4.43: Normalized cell concentration remaining as a function of settling time for Chlorella settling in the light or dark over a A) 24-hour settling period and B) a 2-hour period

Figure 4.44: Comparison of settling over a 2-hour period for both Scenedesmus and Chlorella cultures settled in the light/dark

Figure 4.45: Growth Curve of Sc. 1 culture used in light/dark testing

Figure 4.46: Growth Curve of Sc. 2 culture used in light/dark testing

Figure 4.47: Growth Curve of Chlorella culture used in light/dark settling

Figure 4.48: Growth Curve of B. cepacia 1 culture used in light/dark settling 
Figure 4.50: Comparison of settling based on normalized cell concentration remaining for an average of Scenedesmus cultures (1 and 2) over 18 days of growth under light and dark conditions of settling over the growth curve with no bioflocculant addition. Before each test, each culture was exposed to 48 hours of constant light intensity and then settled in the light (not covered) or dark (covered). For Day 6, replicates were run and the error bars indicate the differences in results

Figure 4.51: Comparison of settling based on normalized cell concentration remaining for Chlorella over the growth curve of 18 days. Before both tests, light exposure was increased to 48 hours and settling took place in either the light or the dark (covered or uncovered).

Figure 4.52: Comparison of settling for Scenedesmus with and without B. cepacia cell addition and constant light exposure of 48 hours before settling in the light or dark (covered or uncovered) over 18 days of growth. Error bars indicate samples that were replicated, with the average normalized cell concentration remaining after 2 hours shown

Figure 4.53: Comparison of settling based on normalized cell concentration remaining over a 2-hour settling period for Chlorella with and without B. cepacia bioflocculant additions, with one sample mixed under a different intensity, using both light and dark conditions and over a 15-day growth period. The bioflocculant addition is based on the order of the legend. All cultures were exposed to a 48-hour period of constant light intensity prior to settling.

Figure 4.54: EPS concentrations plotted against dry weight expressed as TSS with A) Sc. 1 culture and B) Sc. 2 culture

Figure 4.55: EPS concentrations plotted against optical density at $625 \mathrm{~nm}$ with A) $B$. cepacia 1 culture and B) B. cepacia 2 culture

Figure 4.56: Summary of EPS concentrations (Figure 4.75-4.76) plotted over 18 days of growth for both Scenedesmus and B. cepacia cultures used during settling tests. Error bars indicate replicates used with different cultures of bacteria and algae. Samples were taken from each culture separately before settling tests were run

Figure 4.57: Summary of EPS concentrations plotted over the growth curve for Chlorella and B. cepacia cells and filtrate used during settling tests. Samples were taken from each culture separately before settling tests were run

Figure 4.58: Growth Curve of A) Scenedesmus 1.1 used in pH testing and B) Scenedesmus 1.2 used in pH testing

Figure 4.59: Growth Curve for Chlorella culture used in pH testing (Chl 2.1)

Figure 4.60: Growth curve of A) B. cepacia used with Scenedesmus settling test \# 1 for pH variations, B) B. cepacia used in Chlorella settling test \#1 and Scenedesmus settling test \# 2 for $\mathrm{pH}$ variations, and C) B. cepacia used in Chlorella settling test \# 2 for $\mathrm{pH}$ variations 
Figure 4.61: Comparison of settling based on normalized cell concentration remaining after a 2-hour settling period with variation in $\mathrm{pH}$ for Scenedesmus without cell addition over a growth period of 14 days

Figure 4.62 Comparison of settling based on normalized cell concentration remaining after a 2-hour settling period with variations in $\mathrm{pH}$ for Chlorella without cell addition over a growth period of 14 days:

Figure 4.63: Comparison of settling based on normalized cell concentration remaining after a 2-hour settling period for Scenedesmus with B. cepacia cell addition over a wide range in pH during $A$ ) Early growth (5 days) and B) Late growth (14 days)

Figure 4.64: Comparison of settling based on normalized cell concentration remaining after a 2-hour settling period for Chlorella over a varied $p H$ range with and without $B$. cepacia filtrate addition during A) Early growth (6 days) and B) Late growth (14 days) 173

Figure 4.65: Comparison of EPS production for settling tests involving pH changes of both Scenedesmus and B. cepacia cells over 14 days of growth

Figure 4.66: Comparison of EPS production for settling tests involving pH changes of both Chlorella and B. cepacia cells and filtrate over 14 days of growth

Figure 4.67: Growth curve results for Scenedesmus Cultures 1 and 2 used in bacterial nutrient starved settling tests

Figure 4.68: Growth curve results for the Chlorella culture used in bacterial nutrient starved settling tests

Figure 4.69: Growth curve results for nutrient starved and non-starved B. cepacia cultures used for Scenedesmus settling tests

Figure 4.70: Growth curve results for nutrient starved and non-starved B. cepacia cultures used for Chlorella settling tests

Figure 4.71: Comparison of settling based on normalized cell concentration remaining after a 2-hour settling period between the addition of starved cells, non starved cells, no cell addition, and starved filtrate addition for Scenedesmus 2 over 15 days of growth. Error bars indicate which tests were replicated

Figure 4.72: Comparison of settling of Chlorella with and without bacterial bioflocculant cell/filtrate addition (starved for nutrients and not-starved for nutrients) based on normalized cell concentration remaining after a 2-hour settling period for Chlorella during $A$ ) Early growth (10-12 days) and B) Later growth (21-23). Error bars indicate which settling tests were replicated

Figure 4.73: EPS production of A) nutrient starved B. cepacia and B) non-starved B. cepacia with optical density measurements over the growth curve (green arrows indicate when settling tests were run) 
Figure 4.74: EPS production of A) Scenedesmus Culture 1 and B) Scenedesmus Culture 2 with dry weight measurements over the growth curve (green arrows indicate when settling tests were run)

Figure 4.75: Summary of EPS concentrations (Figure 4.117-4.120) plotted over 15 days of growth for both Scenedesmus and B. cepacia cultures used during settling tests. Samples were taken from each culture separately before settling tests were run. Error bars indicate differences in EPS production of both Scenedesmus cultures used

Figure 4.76: Summary of EPS concentrations of Chlorella and B. cepacia cultures used in settling tests for early stationary growth of Chlorella (10-12 days) and later stationary growth of Chlorella (21-23 days). Samples were taken from each culture separately before settling tests were run. Error bars indicate replicates of EPS measurements for both settling experiments

Figure 4.77: Effect of carbon dioxide on growth for Scenedesmus cultures

Figure 4.78: Effect of carbon dioxide on growth for Chlorella vulgaris cultures

Figure 4.79: Growth of non-starved B. cepacia culture for use in Chlorella settling tests without carbon dioxide addition

Figure 4.80: Growth of starved B. cepacia culture for use in Chlorella settling tests without carbon dioxide addition

Figure 4.81: Growth of B. cepacia culture for use in Scenedesmus settling tests without carbon dioxide addition

Figure 4.82: Growth of B. cepacia culture for use in Scenedesmus and Chlorella settling tests with carbon dioxide addition

Figure 4.83: Growth of B. cepacia culture for use in Scenedesmus and Chlorella settling tests with carbon dioxide addition

Figure 4.84: Comparison of settling based on normalized cell concentration after a 2hour settling period for Scenedesmus with and without carbon dioxide addition from early (10-11 days) to late stationary phases (24-27 days) of growth

Figure 4.85: Comparison of settling based on normalized cell concentration after a 2hour settling period for Chlorella with and without carbon dioxide addition from early stationary (10-11 days) to late stationary (23-32 days) phases of growth

Figure 4.86: Comparison of settling based on normalized cell concentration remaining after a 2-hour settling period for Scenedesmus with and without carbon dioxide addition, with and without $B$. cepacia cell addition at various doses and mixing intensities from A) Early growth (11-12 days) to B) Late growth (24 to 27 days)

Figure 4.87: Comparing settling based on normalized cell concentration remaining after a 2-hour settling period for Chlorella with and without carbon dioxide addition, with different doses of filtrate, mixing intensities, and diluted samples of Chlorella (1/2) during A) Early growth (10-11 days) and B) Late growth (23-32 days) 
Figure 4.88: EPS concentration of Scenedesmus and B. cepacia cells used in settling tests over $A$ ) early stationary phase of growth (10-11 days) and B) late stationary phase of growth (24-27 days). (W or W/Out CO2 for B. cepacia corresponds to EPS production of bacterial cells used with either algal culture during settling tests)

Figure 4.89: EPS concentration of Chlorella and B. cepacia cells used in settling tests over A) early stationary phase of growth (10-11 days) and B) late stationary phase of growth (23-32 days) 


\section{CHAPTER 1: INTRODUCTION}

\section{Section 1.1: Research Importance and Process Goals}

The Intergovernmental Panel on Climate Change has reported that to stabilize atmospheric carbon dioxide levels to a "safe" range of 445 to $490 \mathrm{ppm}$, global emissions must peak before 2015 and a total reduction of $50-85 \%$ will be required by 2050 (cited in Schenk et al., 2008). Achieving a carbon dioxide emission reduction of this magnitude is an immense challenge that must be undertaken by humanity to prevent further impairment to the global environment. Second generation biofuels, such as microalgal biofuels, have received attention over the past few years as having the potential to be renewable, carbon dioxide neutral fuels (Schenk et al., 2008). Algae have a theoretical potential of up to forty times more oil extracted per unit land area compared to other feedstocks such as soy or canola (Park et al., 2011). Algal biofuels are projected to be substantially more costly than fossil fuels (Lundquist et al., 2009), as would be expected from any process that requires production instead of extraction of oil. One option for lowering cost is the optimization of large-scale algal biofuel production in conjunction with high rate pond wastewater treatment systems (Benemann and Oswald, 1996).

What contribution to United States transportation fuel consumption can be made by algae biofuel produced using domestic wastewater? The US uses over 378 million gallons of transportation fuel per day (as cited in Christenson et al., 2011), and according to the 2008 Clean Watersheds National Survey, the total wastewater flow (estimated from combined flows of Publicly Owned Treatment Works only) in the U.S. is 32,345 million gallons per day (Christenson et al., 2011). With algae based wastewater treatment, using medium strength domestic wastewater values as an estimate, enough nitrogen and phosphorus exists in wastewater to produce 77.6 million kilograms of algae per day without recycling of fuel extraction residuals (Christenson, 2011). This amount of wastewater produced per day can, 
under the right cultivation conditions for algae in wastewater, contribute to 1.7 million gallons per day of biodiesel. Although this is $<1 \%$ of the total 378 million gallons of transportation fuel consumed in the U.S., this technology could contribute to reduced greenhouse gas emissions as part of the solution to mitigate global climate change.

Greenhouse gas abatement can also result from the savings in energy consumption compared to electromechanical processes used in wastewater treatment (Craggs, et al. 2011). In terms of energy use, Benemann et al. (1981) estimated that, "under suitable climate conditions, a high rate pond system employing bioflocculation-sedimentation for algal removal would require less than one-half the direct energy input of an equivalently sized activated sludge or trickling filter plant. High rate treatment pond systems, as opposed to facultative ponds, are designed as shallow (typically one to three feet deep), raceway single-loop ponds with constant mixing requirements to enhance sunlight penetration, wastewater treatment, and algal biomass production (Park et al., 2011). Moreover, the energy requirement for high rate pond treatment, not biofuel production, could be provided entirely through use of produced biogas from anaerobic digestion of the primary sludge obtained" (Benemann et al., 1981).

Indeed, the U.S. Department of Energy reported that, "Inevitably wastewater treatment and recycling must be incorporated with algae biofuel production" (U.S. DOE, 2010). Revenues from wastewater treatment services might substantially decrease the cost of algae feedstock production (Lundquist et al., 2010). Therefore, scale-up research on algal biofuels in conjunction with wastewater treatment should be a high priority (Lundquist et al., 2010).

A fundamental challenge for scale-up of microalgae technology is improving the cell harvesting process (Christenson et al., 2011). The typically poor settleability of algae means 
that more costly and energy intensive methods must be used currently. For example, centrifugation and/or addition of chemical flocculants have proved much too costly and energy intensive (Benemann and Oswald, 1996). Microalgae are characteristically small (520 microns), low in cell concentration (less than $500 \mathrm{~g} / \mathrm{m}^{3}$ in HRAPS), have densities similar to water, and often form stable suspensions due to a net negative surface charge (Craggs et al., 2011). These characteristics make settling algae from wastewater treatment systems difficult.

Genera of green microalgae commonly seen in wastewater treatment ponds include Scenedesmus, Micractinium, Actinastrum, and Pediastrum (Craggs et al., 2011). These genera have been found to settle reasonably well under quiescent conditions, with removals in the range from 50 to $90 \%$ (Craggs et al., 2011). However, these settling efficiencies have been reported to be extremely variable and difficult to predict for scale up (Benemann et al., 1981). Natural flocculation or bioflocculation-sedimentation processes are the most cost effective harvesting systems for wastewater treatment (Craggs et al., 2011). Therefore, a focus on the development of natural settling processes, such as bioflocculation, has received increased attention over the past few years.

Bioflocculation relies on the spontaneous aggregation of algal particles due to bridging effects created apparently by extracellular polymers excreted by both the algal and bacterial cultures in a wastewater environment (Pavoni et al., 1974). These extracellular polymers, which are composed of long chain, high molecular weight polysaccharides, nucleic acids, or proteins, are essential to the aggregation of colloidal particles (including algae) to form dense, highly settleable flocs (Tenney et al., 1969; Pavoni et al., 1974). Studies have found the bioflocculant, or dissolved EPS component of bacteria, can be used to improve the settleability of algal cultures (Kim et al., 2011; Lee et al., 2009). Similarly, 
effects of return activated sludge conditioning on algal cultures for improved wastewater treatment and settleability have been demonstrated (Valigore et al., 2012; Gutzelt et al., 2005). Related studies have focused on using flocculating cultures of algae as potential sources of bioflocculants, or using activated algae recycle to improve algal species domination and settleability within high rate wastewater ponds (McKinney, 1969; Salim et al., 2011; Park and Craggs, 2011).

Algae are known to exude both a dissolved EPS component as well as a dissolved precursor for the development of a particulate substance known as transparent extracellular particles (Passow et al., 2001). TEP are sticky, like EPS, but larger in size and structure, and formed from the dissolved organic matter excreted naturally from algae (Passow, 2001). However, studies have not yet identified the formation of a TEP-like substance in freshwater environments (Berman, 2005). Dissolved EPS from algae, on the other hand, has been shown to influence the needed dosage of cationic coagulants, as well as to contribute to the widespread aggregation of clay particles (Avnimelech et al., 1982; Tenney et al., 1969). Furthermore, algal biopolymer production has been presented as a patent (two times) for production in nitrogen limited environments (Schenk, 1976; Ramus, 1980).

Environmental factors also play a role in both algal and bacterial exudate formation as well as algal and bacterial bioflocculation to improve settling (Benemann and Oswald, 1996). Generally, in nutrient limited environments, both algae and bacteria have been shown to naturally flocculate (Benemann and Oswald, 1996). Algae, under various light intensities or dark conditions, will produce more EPS to enhance settleability (Shipin et al., 1996). Moreover, differences in $\mathrm{pH}$ (at extremes) have shown to positively affect the settling of algae (Lavoie et al., 1987). Growth phase is also another important factor. 
Pavoni provided evidence that algae produced EPS during later stages in growth (early stationary phases, similar to bacteria), possibly due to nutrient limitation (Pavoni et al., 1974).

The present research was a wide-ranging screening study to explore ways to improve bioflocculation and settling of microalgal cultures. Within wastewater, a diverse community structure is known to exist of many different types of bacteria and algae. With all of the complex relationships among different microorganisms, it is difficult to pinpoint any individual mechanism or environmental condition that may lead to improved settling or bioflocculation. Thus, studying the effects of one individual species within a given wastewater sample interacting with another species under multiple environmental conditions may provide solutions to improved settling and bioflocculation using more complex communities of microorganisms present in wastewater. With this in mind, the research described here emphasized the use of pure cultures of algae and bacteria to study the effects of bioflocculation.

The two species of algae used in this research were Scenedesmus sp. and Chlorella vulgraris. The bacterium used in this research was Burkholderia cepacia, which is known to produce EPS (Nelson et al., 1996). This bacterium was cultured for use as a potential algal bioflocculant to improve the settleability of both pure cultures mentioned above. The goals of this present research were to achieve faster settling of algae with and without the use of a bioflocculant, under multiple environmental conditions including different ranges of $\mathrm{pH}$, nutrient deprivation, and light/dark conditions of settling. The effects of bacterial EPS and algal exudates on settling, as well as environmental conditions that affect EPS production were other factors studied. The results using pure cultures were also compared to the settling of algae in actual high rate treatment ponds with RAS addition to possibly gain 
clearer insight into the improved settleability of mixed algal cultures in treatment ponds. Specific objectives of this screening study are presented below:

1) To investigate the effect of growth phase on settleability of two species of algae without bioflocculant addition

2) To improve settling with bioflocculant addition produced by the bacterium $B$. cepacia (cells or filtered broth)

3) To achieve improved settling with bioflocculant use by optimizing physical characteristics such as the ratio of bioflocculant and algal dose, mixing intensity, and mixing times

4) To quantify the dissolved EPS concentrations of both bacteria and algae and to correlate these concentrations with improved settling

5) To determine the effects of environmental conditions (nutrient starvation, $\mathrm{pH}$, light/dark intensity, carbon dioxide supplementation) on the production of EPS for both bacteria and algae and to observe effects of varying environmental conditions on the settleability of algae alone

6) To compare settling and EPS production by pure cultures and actual pond wastewater treatment cultures treated with RAS

The organization of the experiments created to achieve these objectives is outlined in the figure below. The experiments were conducted in three phases. 


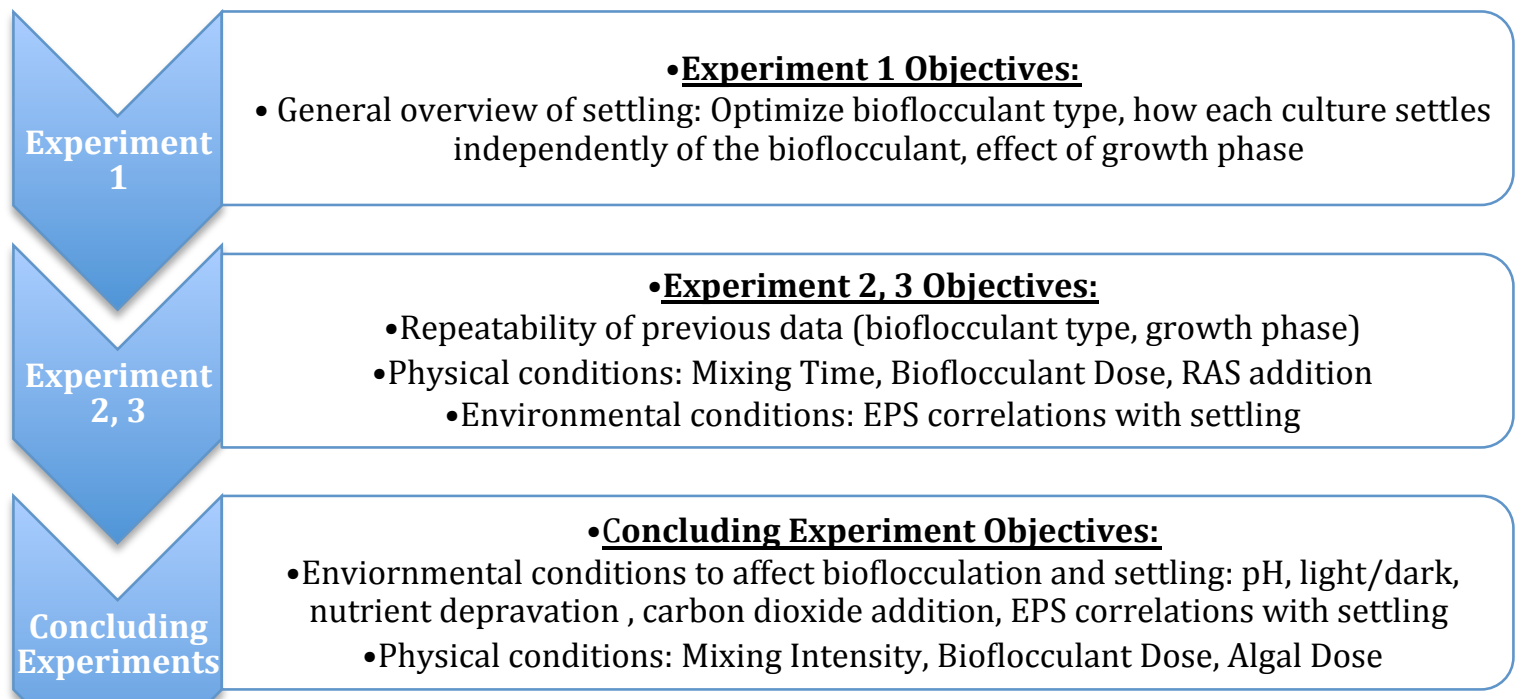

Figure 1.1-Outline of experimentation to achieve Process Goals/Objectives 


\section{CHAPTER 2: BACKGROUND}

\section{Section 2.1 Microalgae in Wastewater Treatment}

Microalgae have been used widely for the treatment of both municipal and industrial wastewaters (Benneman et al., 1980). The treatment occurs in a system of engineered ponds typically designed to remove biochemical oxygen demand (BOD) and total suspended solids (TSS), while containing and digesting wastewater sludge. Partial removal of soluble nutrients also often occurs. Such treatment processes involve a symbiotic relationship between both the algal and bacterial communities present (Figure 2.1). To carry out growth and development, along with carbon dioxide in the wastewater and any entering from the atmosphere, the algae rely on the carbon dioxide produced by the bacteria from the consumption of organic constituents in the wastewater (Tchobanoglous, 2003). In turn, some of the oxygen produced by the algae through photosynthesis is used by the bacteria to oxidize organic matter. Algae, aside from consuming carbon dioxide for growth, also require nutrients for growth from the wastewater such as nitrogen and phosphorus, as well as energy from sunlight to complete photosynthesis.

In a typical treatment pond, a portion of both algal and bacterial cells will flocculate and settle to the bottom of the pond, forming an anaerobic layer of sludge along with settled wastewater solids. In this sludge layer, anaerobic bacteria break down the settled biomass, producing methane, carbon dioxide, sulfides and many other reduced compounds (Tchobanoglous, 2003). From these complex microbial interactions occurring within various areas of a pond, a relatively efficient, low cost, and low energy intensity wastewater treatment system can be achieved (Tchnobanoglous, 2003). 


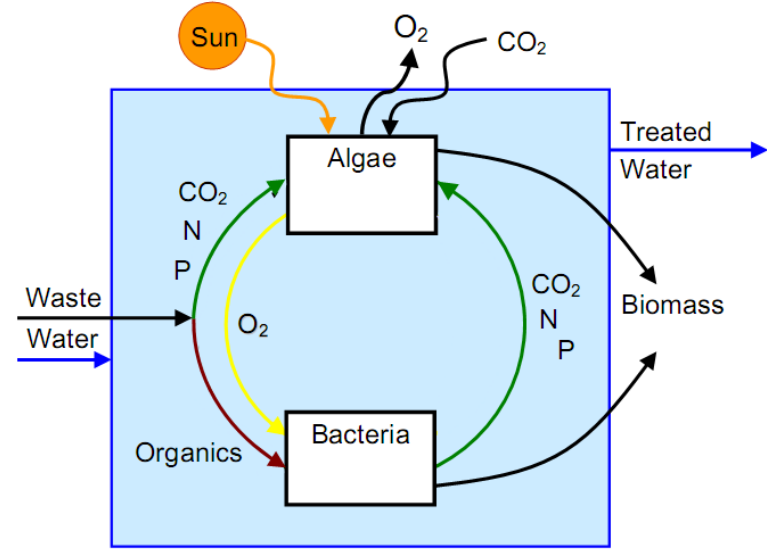

Figure 2.1-Interdependence of algae and bacteria in a waste stabilization pond (Source: Lundquist, 2010)

Wastewater stabilization pond types used today vary widely in applications and design. Depending on process design options such as pond depth and organic loading, the amount of oxygen received in the wastewater can be controlled (Tchobanoglous, 2003). In this way, based on the desired application, many types of wastewater stabilization ponds have been constructed (Table 2.1). Of the classifications illustrated in the table, it is important to distinguish between both the facultative and low to high rate aerobic ponds. Facultative ponds involve three zones of treatment according to the presence or absence of dissolved oxygen as seen in Figure 2.2. They also have much longer detention times and treat smaller loads of BOD as compared to strictly aerobic ponds. The distribution of the aerobic zone (where dissolved oxygen concentrations are limiting) within this type of pond depends mainly on the loading of BOD, as well as other environmental conditions such as the amount of sunlight (Tchnobanoglous, 2003). 
Table 2.1-Comparison of Pond technologies (Source: US EPA, 2011)

\begin{tabular}{|c|c|c|c|c|c|}
\hline Pond & Application & $\begin{array}{l}\text { Typical } \\
\text { Loading } \\
\left(B O D_{5}\right)^{*}\end{array}$ & $\begin{array}{l}\text { Typical } \\
\text { Detention } \\
\text { Time (d) }\end{array}$ & $\begin{array}{l}\text { Typical } \\
\text { Depth (m) }\end{array}$ & Comments \\
\hline Anaerobic & $\begin{array}{l}\text { Industrial } \\
\text { wastewater }\end{array}$ & $\begin{array}{l}280-4500 \mathrm{~kg} / \\
1000 \mathrm{~m}^{2} / \mathrm{d}\end{array}$ & $5-50$ & $2.5-4.5$ & $\begin{array}{l}\text { Subsequent } \\
\text { treatment normally } \\
\text { required. }\end{array}$ \\
\hline Facultative & $\begin{array}{l}\text { Raw municipal } \\
\text { wastewater. Effluent } \\
\text { from primary } \\
\text { treatment, trickling } \\
\text { filters, aerated } \\
\text { ponds, or anaerobic } \\
\text { ponds. }\end{array}$ & $\begin{array}{l}22-56 \mathrm{~kg} / \\
1000 \mathrm{~m}^{2} / \mathrm{d}\end{array}$ & $7-50$ & $0.9-2.4$ & $\begin{array}{l}\text { Most commonly used } \\
\text { wastewater treatment } \\
\text { pond. May be aerobic } \\
\text { through entire depth if } \\
\text { lightly loaded. }\end{array}$ \\
\hline Aerobic & $\begin{array}{l}\text { Generally used to } \\
\text { treat effluent from } \\
\text { other processes. } \\
\text { Produces effluent } \\
\text { low in soluble } \mathrm{BOD}_{5} \\
\text { and high in algal } \\
\text { solids. }\end{array}$ & $\begin{array}{l}112-225 \mathrm{~kg} / \\
1000 \mathrm{~m}^{2} / \mathrm{d}\end{array}$ & $2-6$ & $0.18-0.3$ & $\begin{array}{l}\text { Maximizes algae } \\
\text { production and, if } \\
\text { algae are harvested, } \\
\text { nutrient removal. }\end{array}$ \\
\hline
\end{tabular}

${ }^{*} \mathrm{BOD}_{5}=$ Biochemical Oxygen Demand measured over 5 days

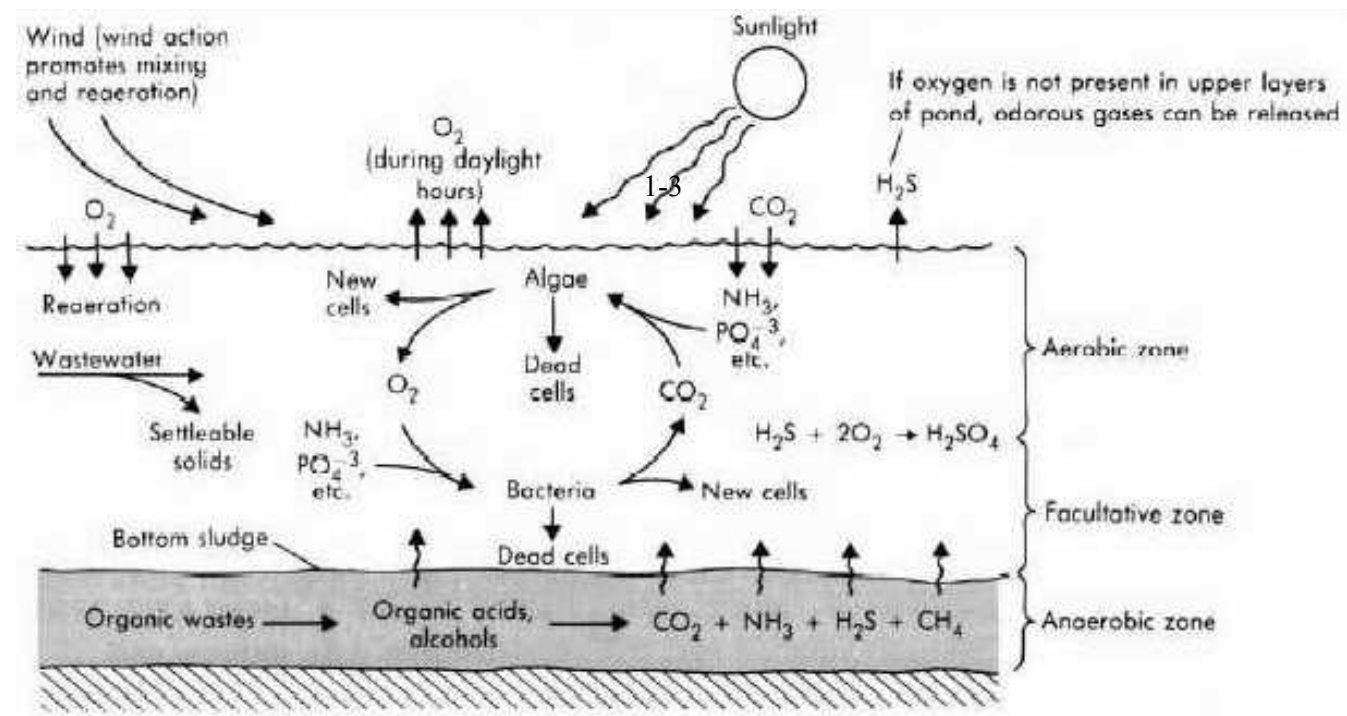

Figure 2.2-Schematic of a facultative wastewater stabilization pond (Source: Tchnobanoglous, 2003)

High rate algal ponds (HRAPs) produce more algal biomass than conventional deep ponds. Their purported advantage is greater photosynthetic oxygen production than deep ponds, along with some soluble nutrient assimilation by the algae (Craggs et al., 2011). 
HRAPs for wastewater treatment are designed to increase algae exposure to sunlight through use of highly mixed, shallow single loop configurations (Figure 2.3 and 2.4). Present day research in HRAPs focuses on $\mathrm{CO}_{2}$ addition to promote more complete soluble nutrient assimilation.

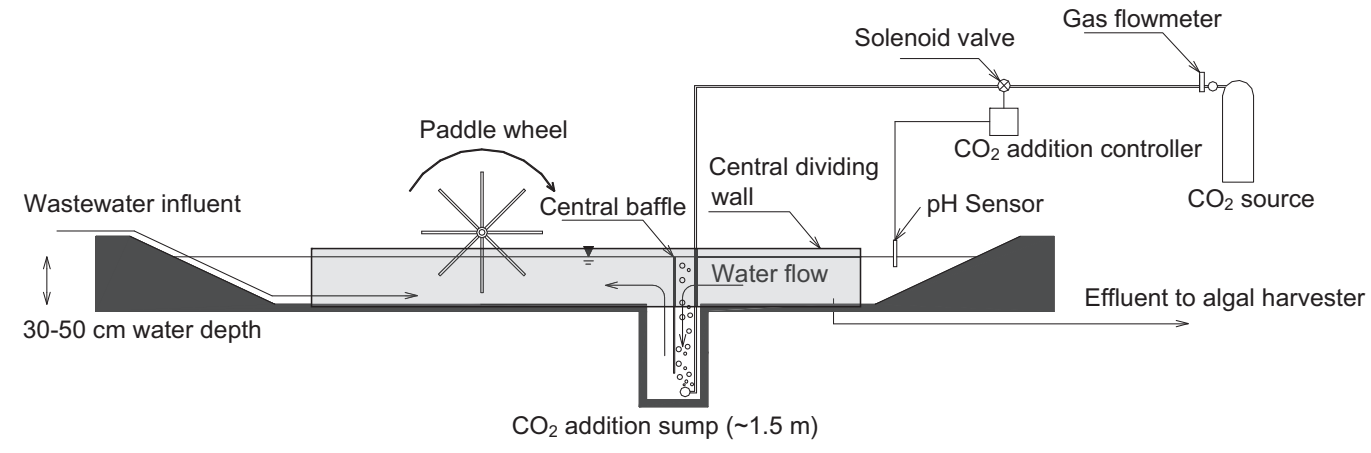

High Rate Algal Pond

Figure 2.3-Side view of a typical HRAP with carbon dioxide addition (Source: Park, 2011)

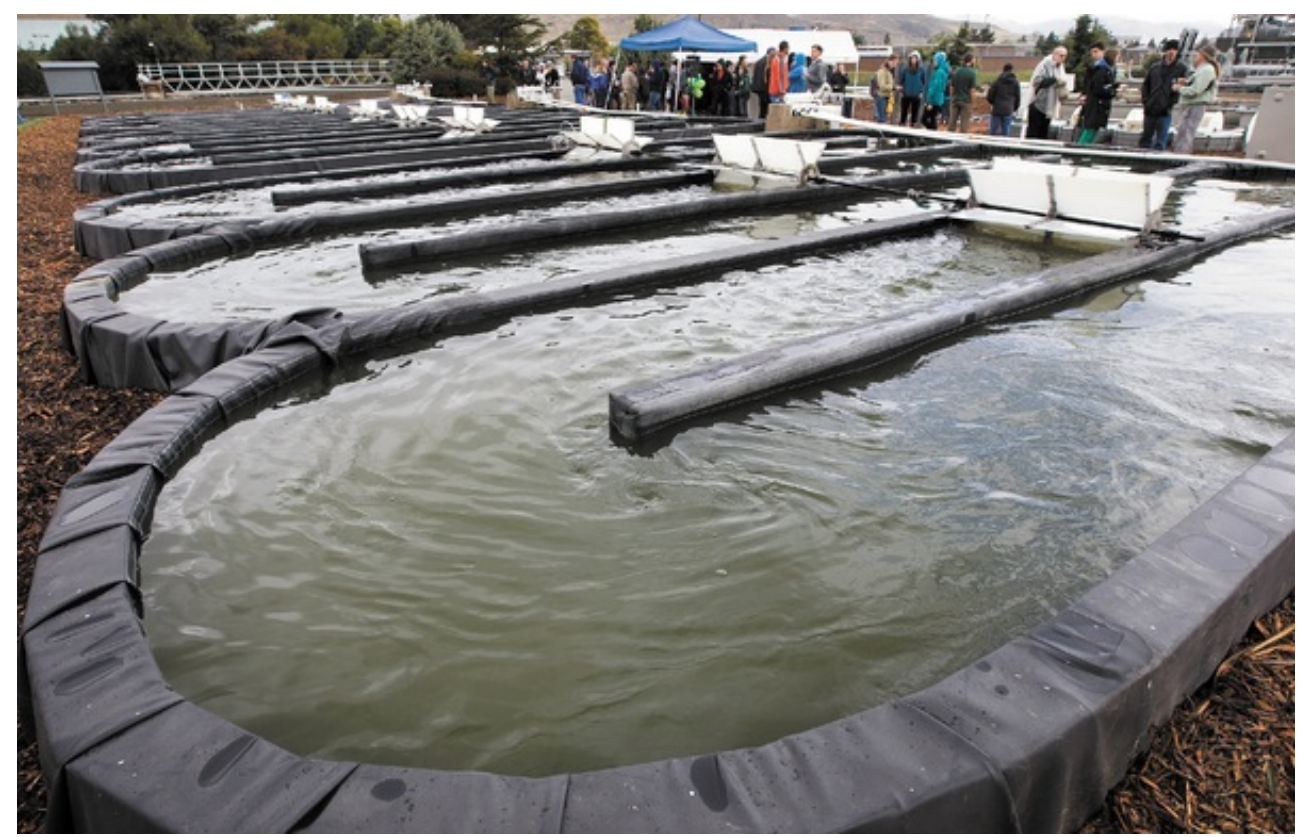

Figure 2.4-New HRAP facility operating under Cal Poly, San Luis Obispo Civil \& Environmental Engineering Program (Source: SLO Tribune) 
Figure 2.3 shows a schematic of a typical pond and paddlewheel HRAP system. The average depth ranges from 20 to $40 \mathrm{~cm}$ to improve cell exposure to sunlight and promote evaporative cooling during especially hot periods. HRAPs are also mixed with paddle wheels and typically cover up to 1 ha (Lundquist et al., 2010). One of the main factors in HRAP operation is mixing, which involves a channel flow velocity of 15 to $30 \mathrm{~cm} /$ second (Lundquist et al., 2010). Wastewater HRAPs have been typically part of a system with facultative ponds followed by HRAPs operating in parallel, followed by algal "settling" ponds and maturation ponds (Park et al., 2011).

HRAPs have been observed to produce algal concentrations of about 0.2 tonnes/ML (million liters) of wastewater, which is between two to three-times that of facultative wastewater treatment ponds (Craggs et al., 2011). Given that domestic wastewaters have low $\mathrm{C}$ : $\mathrm{N}$ ratios compared to algal biomass, carbon limitation in wastewater treatment HRAPs is evidenced by a much higher daytime pond $\mathrm{pH}$, when algae consume carbon dioxide and release hydroxide ions, increasing the pH (Craggs et al., 2011). Increased free ammonia concentrations, as a result of a greater $\mathrm{pH}$, inhibit the growth of both algae and aerobic heterotrophic bacteria, ultimately hindering both biomass productivity as well as wastewater treatment (Craggs et al., 2011). Thus, the addition of carbon dioxide enhances algal biomass production in HRAPs (Craggs et al., 2011).

Wastewater treatment within HRAPs is focused on the oxidation of organic matter (BOD removal) and removal of soluble nutrients (Craggs et al., 2011). Typical organic loadings of HRAPs range from 100 to $150 \mathrm{~kg} \mathrm{BOD}$ per hectare-day. Nutrient assimilation can reach from $24 \mathrm{~kg}$ total nitrogen/hectare-day to $3 \mathrm{~kg}$ total phosphorus/hectare-day (Craggs et al., 2011). With these relatively high rates of removals, a smaller capital and 
operating cost compared to conventional mechanical treatment technologies is acquired (Craggs et al., 2011).

\section{Section 2.2: Potential For Production of Algal Biofuels From Wastewater Treatment High Rate Algal Ponds}

Combined wastewater treatment and production of algal biofuel is an old idea that has received renewed attention. In 1960, Oswald and Golueke first proposed large-scale production of microalgae as a biofuel feedstock using HRAPs, with wastewater providing water, nutrient, and carbon for algae production (Oswald and Goluenke, 1960). It was not

until the US Department of Energy Aquatic Species Program in the late 1970s that extensive progress was made on the concept (Sheehan et al. 1998). More recently, multiple pilot scale studies have shown that wastewater treatment in HRAPs with carbon dioxide addition could provide nutrient removal with the co-benefit of algal biomass production for biofuel use (Park et al., 2011). Similarly, Pittman et al. (2011) concluded that algae cultivation for biofuels without the use of wastewater is unlikely to be viable or provide a positive energy return. Further, Lundquist et al. (2010) reviewed different scenarios of algae-based wastewater and reported that cases that emphasized wastewater treatment were able to produce cost-competitive biofuels.

Algae, compared to existing biofuel feedstocks such as soy or canola, show the promise in that they have demonstrated up to forty times more oil extracted per unit land area (Park et al., 2011). In terms of biomass, algae can exhibit annual average high productivities of about 60 tonnes/ha, nearly 10 -fold higher than other terrestrial biomass crops (Craggs et al., 2011). Moreover, a 25\% to 50\% oil (triglycerides) content is thought to be achievable, with the lower value obtainable by current standards of technology and the higher value not consistently possible until breakthroughs in new research methods in 
molecular biology and mass cultivation of microalgae (Lundquist et al., 2010). However, with photoautotrophs, extremes in oil content and productivity are not possible simultaneously due to thermodynamic limits (Lundquist et. al., 2010).

Currently, wastewater treatment HRAPS are considered the only economical way to produce algal biomass for conversion to biofuels with minimum environmental impact (Park et al., 2010). Commercial algal production in HRAPs requires many resources in which wastewater provides naturally such as nitrogen and phosphorus. For example, commercial farm's resources such as water, nutrients, and carbon dioxide, contribute to about $10-30 \%$ of total production costs (Park et al., 2011). To reduce these costs, commercial farms may recycle the growth medium for following algal harvest (Kim et al., 2011). This reuse of growth medium, however, leads to a decline in overall algal productivity and an increased risk of algal pathogens or the accumulation of inhibitory secondary metabolites (Park et al., 2011). In addition, the wastewater contains substantial amounts of carbon and is necessary in large quantities necessary for extensive algal growth (Lundquist et al., 2010). Thus, as compared to commercial production (dedicated production for biofuel only), wastewater proves a more economical option for biofuel production. Still, creating and operating HRAPs dedicated to produce algal biomass for conversion to biofuels has been considered as a large environmental impact in its own right (Park et al., 2011).

Several significant issues exist for successful operation of algal biomass production in wastewater HRAPs. A major challenge is economical harvesting of algae (Christenson et al., 2011). Due to their small size, colloidal nature, and similar density to water, algae are generally difficult to remove or separate from a dilute suspension of water (Park et al., 2011). Traditional chemical and physical flocculation, such as synthetic polymer addition or 
filtration techniques have proved too expensive and complicated for affordable biofuel production (Park et al, 2011). Thus, natural aggregation or bioflocculation of algal cells grown in wastewater treatment HRAPs is important to pursue for cost-effective harvesting (Park et al., 2011).

Other challenges of algal biomass production include nutrient supply, gas transfer and exchange, culture integrity, environmental control, as well as land and water availability (Christenson et al., 2011). Algal biomass production is primarily limited by environmental factors (light and temperature), operating parameters $(\mathrm{pH}$, carbon dioxide supply, dissolved oxygen and nutrients) and biological conditions (zooplankton grazing, viral infection, etc.) (Park et al., 2011). Environmental factors such as temperature and light vary daily and seasonally. Adjusting hydraulic residence time and/or pond depth are common means to maintain the cultures over the seasons (Park, et al., 2011). In terms of biological operating parameters, a topic of study is maintaining a desirable colonial algal species to attain reliable harvest within a HRAP wastewater treatment system (Park et al., 2011). This species dominance can be achieved by recycling algae from settling basins to develop an activated algae process (Park and Craggs, 2011).

Challenges such as obtaining a reliable source of carbon dioxide and optimizing carbon dioxide mass transfer $\left(\mathrm{CO}_{2}\right.$ delivery) between the gas-liquid interfaces further pose a hindrance to algae production (Lundquist et al., 2010; Christenson et al., 2011). Removing oxygen to prevent the inhibition of photosynthesis, especially for closed reactor systems, at the same time of elevating the transfer efficiency of carbon dioxide, also remains an engineering problem (Christenson et al., 2011). Obtaining reliable sources of carbon dioxide, such as flue gas from power plants, also are not always available (Lundquist et al., 
2010). Lastly, large-scale production involves a large expanse of land with an available water or wastewater resource.

\section{Section 2.3: Methods for Harvesting of Microalgal Biomass}

The harvesting of microalgae is one of the most difficult, and thus far least satisfactorily resolved, problems in algal mass culture (U.S. DOE, 2010). Microalgal cultures are dilute, typically less than $500 \mathrm{mg} / \mathrm{L}(0.05 \%) \mathrm{w} / \mathrm{w}$ on a dry organic weight basis and cells are small (sometimes less than five microns) (Benemann and Oswald, 1996). In addition, extraction of one ton of dried biomass requires the extraction of these small cells from over 2,000 tons of medium (Benemann and Oswald, 1996). Here, a short comparison is made on harvesting processes found in the literature.

\section{Section 2.3.1 Physical Methods}

Physical harvesting methods include simple settling, lamella settling, centrifugation, filtration, micro straining, membrane filtration, and dissolved air flotation, as well as electrical based (electrophoresis) methods. Of all types of physical methods of separation, centrifugation is the most rapid and reliable method of recovering suspended algae (Christenson et al., 2011). However, high investment and operating costs must be considered. The U.S. Department of Energy concludes that the current level of centrifugation technology is cost-prohibitive for any large-scale use involving algae in the U.S. (U.S. DOE, 2010).

Filtration and microscreening of algae has also been considered as a potential harvesting technique (Benemann and Oswald, 1996). There are three major drawbacks to filtrations methods of unicellular algae: small size of the cells, spherical shape, and other extracellular material that continually clogs filter pores (Benemann and Oswald, 1996). In 
addition, the relatively high concentration of cells in algae cultures required frequent filter cleaning. Thus, filtration is best carried out with filamentous or large colonial algae, readily handled by mesh screens (Benemann and Oswald, 1996). Further, the non-colonial algae, including Scenedesmus and Chlorella, may remain in suspension even when the filtration is applied due to their small size and non-colonial nature (Benemann et al., 1980). Thus, filtration methods are not practical for separation of dense algae cultures from the liquid stream on a large-scale basis.

Membrane filtration is a harvesting technology that includes a high cross-flow of wastewater across the surface to prevent excess accumulation of algae and solids (Shelef et al., 1984). Even though the effluent quality is superior compared to other filtration processes (up to twenty-fold concentration of the algae had been reached with very high quality effluent), the high power consumption required to provide a trans-membrane pressure differential proved much too costly, at least with earlier technology (Shelef et al., 1984).

Lamella settlers, as used in wastewater treatment, have also been investigated (Shelef et al., 1984). This type of clarifier provided more efficient clarification as compared to normal gravity settling (Shelef et al., 1984). In one study by Mohn (reported in Shelef et al., 1984), algae separation was concentrated to $1.6 \%$ TSS and addition of flocculent was required when algae were fed to the lamella settler. This method of separation was determined to have a fair operational reliability and additional concentration of the alga slurry was usually performed, requiring more expense for dosages of flocculants/polymers alike (Shelef et al., 1984).

Dissolved air flotation (DAF), another prominent physical method of separation used in wastewater treatment, has also been explored for algae harvesting. DAF uses 
saturation of air at a pressure higher than atmospheric followed by subsequent flotation of algal solids under atmospheric conditions (Shelef et al, 1984). Algae separation by DAF should be operated in conjunction with chemical treatment in order to increase the flocculation efficiency (Shelef et al., 1984). Algal oxidation pond effluents, which contain a wide variety of microalgal species, may be successfully clarified by DAF and thickened to create an algal slurry of up to $6 \%$. However, power and energy consumption costs as well as costs for chemical pre-treatment may be too costly for mass separation of algae on the wastewater scale (Benemann and Oswald, 1996).

Separation methods based on electrical methods such as electrophoresis of algal cells have also been considered. Typically, movement in an electric field concentrates algal cells, where negatively charged algae move towards a positively charged cathode (Christenson et al., 2011). The major advantage of this electrical approach is that no chemical addition is required (Christenson et al., 2011). However, major drawbacks to electrical separation include the high power requirements and electrode costs (maintenance/replacement) that do not make electrical harvesting methods economically feasible for micro algae harvesting (Christenson et al., 2011).

\section{Section 2.3.2 Chemical Methods of Harvesting}

Chemical-based methods for harvesting are usually methods of pretreatment or conditioning to allow the cells to chemically flocculate and increase in particle size before another method of harvesting is performed (i.e. sedimentation) (Benemann et al., 1980). Both metal salts and synthetic polymers are added as a chemical treatment method to coagulate (neutralize the charge) and to flocculate the cells (Christenson et al., 2011). The various chemicals used can be classified into two groups: 1) inorganic agents 2) polymeric organic flocculants, which may be cationic, non-ionic or anionic (Shelef et al., 1984). The 
term polyelectrolyte is used to describe the polymeric flocculants including the nonionic species and synthetic/natural polymers (Shelef et al., 1984). Costs for chemical coagulation/flocculation can be $40 \%$ less than centrifugation (Benamnn and Oswald, 1996). However, certain disadvantages exist that will be discussed in more detail below.

Both aluminum and ferric cations are often used for coagulation processes and compose the inorganic side of chemical coagulants (Christenson et al., 2011). However, the use of aluminum sulfate has been shown to inhibit anaerobic digestion of algae biomass, which is a possible biofuel pathway (Christenson et al., 2011). In addition, the major problem with alum and lime treatment is the very high amounts of chemicals required (Benemann and Oswald, 1996). Dosages of over $100 \mathrm{mg} / \mathrm{L}$ of alum were required to achieve over a $90 \%$ clarification after initial gravity sedimentation, and attempts to recover the alum proved unsuccessful (Benemann and Oswald, 1996). Also, the algae-chemical sludge produced is a disposal problem and should be discouraged for fuel production (Benemann and Oswald, 1996).

Polyelectrolyte addition has been studied and demonstrates several advantages over inorganic chemical coagulants (Benamann et al., 1980). Of the polyelectrolytes tested, synthetic cationic polymers proved to be the most efficient flocculants (Shelef et al., 1984). The major advantage of cationic polymers is the relatively small dosages required, typically less than $10 \mathrm{mg} / \mathrm{L}$ as well as the ability to use the biomass for additional applications (Benemann and Oswald, 1996). The major drawback to polyelectrolytes is the high chemical costs as compared to inorganic coagulants and flocculants (Benemann and Oswald, 1996). Improvements in the costs of polyelectrolyte flocculants, suggest that the economics of polyelectrolytes have improved somewhat (Benemann and Oswald, 1996). Thus, the application of synthetic polyelectrolytes has expanded to aid in both 
bioflocculation processes and sludge conditioning for dewatering aspects used throughout municipal wastewater treatment (Benemann and Oswald, 1996).

Lastly, natural polymers (not synthetic polyelectrolytes) are another source of chemical flocculating agents (Christenson et al., 2011). These polymers such as alginate, chitosan, and cationic starches have been shown to be effective flocculating agents (Christenon et al., 2011). However, as these polymers are from natural, organic sources, the cost of purchase is much higher compared to synthetic polyelectrolytes and inorganic flocculants. For this reason, natural polymers are not prevalent in harvesting methods today (Christenson et al., 2011).

\section{Section 2.3.3 Biological Methods of Harvesting}

Biological methods of harvesting encompass techniques such as autoflocculation or self-induced bioflocculation of algal cells, and bioflocculation through the addition of bioflocculants (both microbial, algal and floc-forming) (Benemann and Oswald, 1996). Harvesting costs could be greatly reduced with bioflocculation because no chemical costs are incurred as with chemical addition, and little to no energy consumption is necessary (Christenson et al., 2011).

Defined acceptable settling rates are in the range of about $10 \mathrm{~cm} / \mathrm{hr}$ or higher to produce a biomass concentrate typically 1.5 to $4 \%$ solids (Beneman, 1982). Natural settling rates can be in fact either positive or negative, where the negative term is defined as natural flotation (Benemann and Oswald, 1996). The characteristic of some species of algae to exhibit natural flotation could be caused by gas vacuoles (blue-green algae), simple cellular respiration, or high lipid contents (Benemann and Oswald, 1996). Therefore, unlike colloidal particles, algal cells tend to show characteristics of re-suspension during natural 
sedimentation. However, natural flotation usually occurs with individual cells, where bioflocculation covers the behavior of aggregated or floc forming organisms.

Autoflocculation relies on the ionic composition of the culture medium, as well as photosynthetic $\mathrm{pH}$ increase to cause precipitation of calcium phosphate minerals leading to sweep flocculation (Benemann et al., 1980). This process will be further evaluated in later sections.

Bioflocculation usually refers to the naturally induced flocculation due to secreted biopolymers by either the algal or bacterial cells (Christenson et al., 2011). The presence of high molecular weight EPS and exudates of both algae and bacteria, like polyelectrolytes in chemical addition, have been proven to bridge and flocculate algae and bacterial cells in solution (Pavoni et al., 1972; Pavoni et al., 1974). Therefore, optimizing the conditions for EPS production can aid in enhancing bioflocculation and enhance sedimentation/harvesting efficiencies of microalgal species in the long run (Benemann and Oswald, 1996). Many studies suggest EPS production of both bacteria and algae are maximal at the end of the growth phase (early stationary phase). EPS production is additionally controlled by environmental conditions such as light, pH and temperature (Christenson et al., 2011).

Finally, the addition of bioflocculants, or bacterial microorganisms that naturally produce flocculants, to a culture of algae has been shown to enhance bioflocculation processes and to ultimately improve the harvesting efficiency of multiple microalgal species (Christenson et al., 2011). Microbial flocculants can include any type of bacteria or floc forming microorganism that is a known high EPS producer (Benemann et al., 1981). In addition, bioflocculants can include diatoms and microalgal species themselves that are also known exudate producers under certain environmental conditions or stresses (Salim et al., 
2011). Multiple studies are reviewed in the upcoming sections on the effectiveness of bioflocculant addition to enhance the harvesting efficiency and settleability of microalgae.

\section{Section 2.4 Characterization of Algal Exudates}

The topic of microalgal exudates was reviewed to better understand improved algal flocculation and harvesting methods. Algae produce polysaccharides and other polymers (Avnimelech et al., 1982). The amounts released may represent 15 to 60 percent of the total photo-assimilated carbon (Avnimelech et al., 1982). Literature suggests that algae exude two main types of extracellular products: transparent extracellular particulates (TEP) and extracellular polymers (EPS) (Passow, 2002; Lewin, 1956).

\section{Section 2.4.1 Algal EPS (Extracellular Polymeric Substances)}

Initial studies in the late 1950s by both Lewin and Moore suggest that algae, like bacteria, are producers of extracellular polymeric substances. Lewin observed that eighteen unicellular or colonial green microalgal cultures characteristically formed both mucilaginous capsular EPS and dissolved, soluble EPS (Lewin, 1956). Lewin observed their EPS production, both capsular and dissolved, from the eighteen Chlamydomonas species (Lewin 1956). About fourteen of the Chlamydomonas species isolated were seen to produce a capsular EPS slime layer, while the other species did not (Lewin, 1956). To date, this study provides one of the more detailed analysis of algal polymeric exudates found in the literature. The results of the yield of polymers are presented in the table below (Table 2.1) Different total polysaccharide levels were observed for both non-mucilaginous and mucilaginous species, suggesting that different species of algae produce a very broad (order of magnitude) range of EPS. 
Chlamydomonas mexicana produced the largest amount of soluble polymer ranging as high as $1 \mathrm{~g} / \mathrm{L}$ in a culture of $500 \mathrm{mg} / \mathrm{L}$ algae, which represented 20 to $25 \%$ of the total organic matter produced (Lewin, 1956). In addition the mucilage around C. parvula and $C$ peterfi represented 40 to $60 \%$ of the total organic matter produced (Lewin, 1956). The chemical composition of the polysaccharide components of EPS for the Chlamydomonas species included galactose and arabinose (Lewin, 1956). Both cellular and capsular EPS productions were shown to increase following the growth curve of the algae. The capsular EPS was also observed as being comparatively lower to the soluble fraction (Lewin, 1956).

Table 2.2-Production and quantification of EPS for different species of green microalgae (Source: Lewin, 1956)(S, C-1, C-2, C-3b refer to different amounts of polysaccharide for a specified series of precipitations)

\begin{tabular}{|c|c|c|c|c|c|c|c|c|c|}
\hline & \multirow{2}{*}{ Genus and Species } & \multicolumn{4}{|c|}{ Polysaccharide in extract $(\mathrm{mg} / \mathrm{L})$} & \multirow{2}{*}{$\begin{array}{c}\text { Total Polysaccharide } \\
(\mathrm{mg} / \mathrm{L})\end{array}$} & \multirow{2}{*}{ Cell Residue $(\mathrm{mg} / \mathrm{L})$} & \multirow{2}{*}{$\begin{array}{l}\text { Total Organic } \\
\text { Matter (mg/L) }\end{array}$} & \multirow{2}{*}{$\begin{array}{c}\% \\
\text { Polysaccharide }\end{array}$} \\
\hline & & $S$ & $C-1$ & $\mathrm{C}-2$ & $c-3 b$ & & & & \\
\hline \multirow{3}{*}{$\begin{array}{c}\text { Non- } \\
\text { mucilaginous } \\
\text { species }\end{array}$} & $\begin{array}{c}\text { Chlamydomonas } \\
\text { dysosmos Moewtus }\end{array}$ & 24 & 0 & 0 & 0 & 24 & 533 & 557 & 4 \\
\hline & " "moewusii Gerloff & 43 & 0 & 0 & 0 & 43 & 514 & 557 & 8 \\
\hline & " "philotes nom. Prov. & 14 & 17 & 6 & 0 & 37 & 451 & 488 & 8 \\
\hline \multirow{13}{*}{$\begin{array}{l}\text { Mucilaginous } \\
\text { Species }\end{array}$} & $\begin{array}{l}\text { Chlamydomonas } \\
\text { acidophile Negoro }\end{array}$ & 55 & 0 & 0 & 0 & 55 & 305 & 360 & 15 \\
\hline & $\begin{array}{l}\text { " "applanata } \\
\text { Pringsheim }\end{array}$ & 106 & 0 & 89 & 0 & 195 & 310 & 505 & 39 \\
\hline & " "callosa Gerloff & 4 & 16 & 73 & 176 & 269 & 497 & 766 & 35 \\
\hline & $\begin{array}{l}\text { " "debaryana } \\
\text { Goroschankin }\end{array}$ & 36 & 37 & 85 & 0 & 158 & 629 & 787 & 20 \\
\hline & " "inflexa Prinsheim & 61 & 14 & 46 & 0 & 121 & 514 & 635 & 19 \\
\hline & " "aff. Infleza (TT. 1/19) & 27 & 0 & 54 & 181 & 262 & 706 & 968 & 27 \\
\hline & " "mexicana nom. Prov. & 141 & 14 & 86 & 0 & 241 & 471 & 712 & 34 \\
\hline & " " " & 170 & 0 & 47 & 0 & 217 & 438 & 655 & 33 \\
\hline & " "parvula Gerloff & 51 & 15 & 155 & 0 & 221 & 318 & 539 & 41 \\
\hline & " "pelerfi Gerloff & 53 & 0 & 391 & 0 & 444 & 335 & 779 & 57 \\
\hline & " "sphagnophila Pascher & 27 & 19 & 22 & 255 & 323 & 358 & 681 & 47 \\
\hline & " "ulvaensis nom. Prov. & 73 & 120 & 143 & 158 & 494 & 650 & 1144 & 43 \\
\hline & " "sp. (B.5) & 124 & 0 & 20 & 0 & 144 & 262 & 406 & 35 \\
\hline
\end{tabular}

In a similar study, Moore measured the yields of both capsular and dissolved EPS

from eight species of green and blue-green algae (Moore, 1964). The range of extracellular polymeric substance observed was from $174 \mathrm{mg} / \mathrm{L}$ to $557 \mathrm{mg} / \mathrm{L}$ (Moore, 1964). The dry weight of cells, as seen in the Table 2.3 below, ranged from about $1-3 \mathrm{~g} / \mathrm{L}$ for all of the species (Moore, 1964). This result demonstrates that the EPS production may have a 
correlation with density of algal cultures as well as increased carbon dioxide input. Across algal cultures of a similar density, however, different EPS productions were observed (Figure 2.5). Overall, a yield of $344 \mathrm{mg} / \mathrm{L}$ of EPS for Chlorella vulgaris, $224 \mathrm{mg} / \mathrm{L}$ of EPS from Chlamydomonas, and $174 \mathrm{mg} / \mathrm{L}$ of EPS from Chlorella was achieved (Moore, 1964). For all three species, capsular polymer was about one third less than the soluble polymer produced, agreeing with Lewin's previous results on capsular polymers. Again, with all cultures, the production of the extracellular polymer was dependent on the age of the culture (Moore, 1964). The most significant production was observed for all cultures during the late exponential to early stationary phase (8-10 days). This differed from Lewin's results, where the most significant increase occurred during mid to late stationary phase of growth (Moore, 1964). Therefore, the effect of algal growth stage and maximum production or increase in EPS varies across different species of algae. A typical data set for EPS production over a growth curve is seen in Table 2.4 for this same study using a culture of Anabaena flos-aquae (Moore, 1964).

Table 2.3-Yields of polysaccharides and dry weight for 8 species of green microalgae (Source: Moore, 1964) EP=extracellular polysaccharide, $C P=$ capsular polysaccharide, IP=water soluble intra-cellular polysaccharide, $T P=$ total polysaccharide

\begin{tabular}{|c|c|c|c|c|c|c|}
\hline Algal Culture & $\begin{array}{c}\text { Incubation } \\
\text { Temperature (Deg. } \\
\text { Celsius) }\end{array}$ & $\mathrm{EP}(\mathrm{mg} / \mathrm{L})$ & $\mathrm{CP}(\mathrm{mg} / \mathrm{L})$ & IP (mg/L) & $\mathrm{TP}$ (mg/L) & $\begin{array}{c}\text { Cells } \\
\text { (mg/L) }\end{array}$ \\
\hline Anabaena flos-aquae & 40 & 557 & 13 & 126 & 696 & 1379 \\
\hline Nostoc sp. & 40 & 415 & 15 & 23 & 453 & 1315 \\
\hline Palmella muscosa & 25 & 271 & 36 & 196 & 503 & 2133 \\
\hline Chlorella Vulgaris & 25 & 235 & 34 & 75 & 344 & 3203 \\
\hline C. ellipsoidea & 25 & 234 & 15 & 26 & 275 & 1959 \\
\hline Chlamydomonas sp. & 25 & 234 & 19 & 62 & 305 & 1391 \\
\hline Oocystis sp. & 25 & 197 & 22 & 48 & 267 & 2206 \\
\hline Chlorella sp. & 25 & 174 & 15 & 26 & 215 & 1959 \\
\hline
\end{tabular}




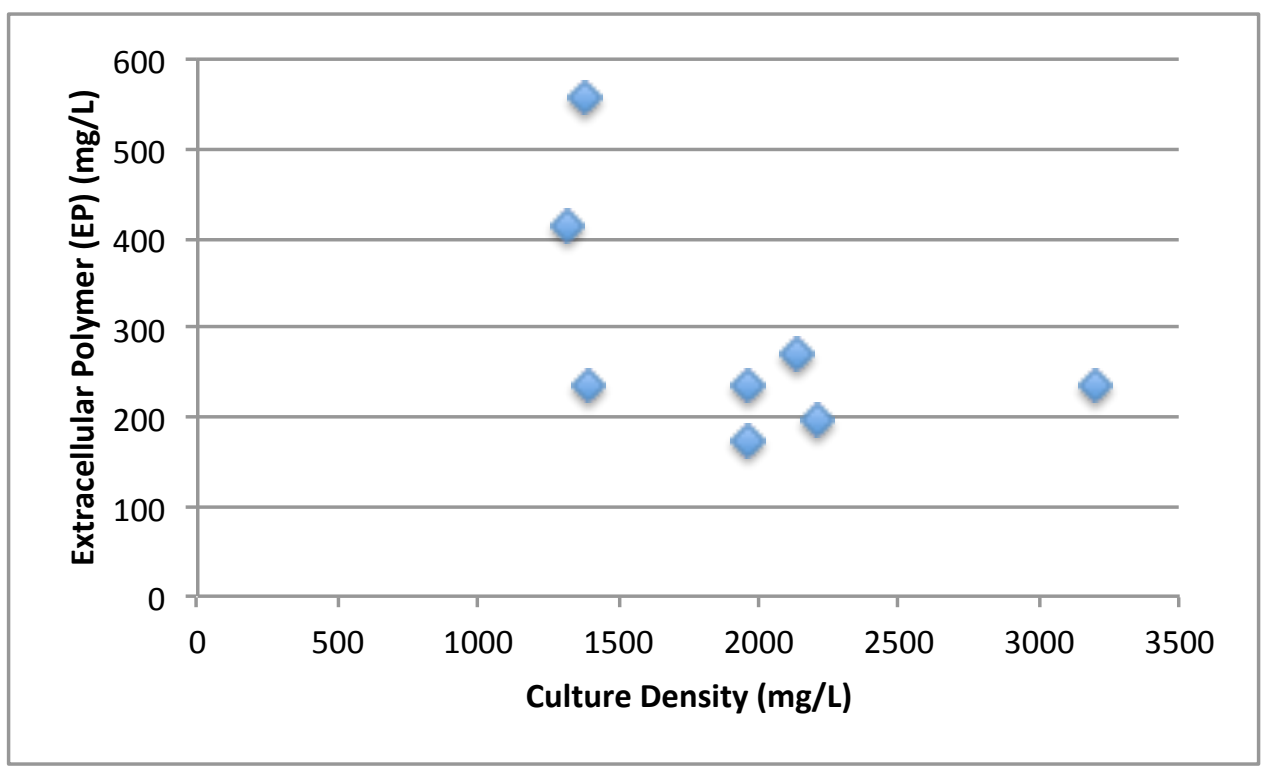

Figure 2.5-Yields of extracellular polysaccharides versus dry weight for 8 species of green microalgae (Source: Moore, 1964)

Table 2.4-Increasing polysaccharides produced over the growth curve for Anabaena cultures (Source: Moore, 1964)

\begin{tabular}{|c|c|r|}
\hline Time (days) & $\begin{array}{c}\text { Extracellular } \\
\text { Polysaccharide } \\
\text { (mg/L) }\end{array}$ & \multicolumn{2}{|c|}{ Cells (mg/L) } \\
\hline 2 & 25 & 268 \\
\hline 4 & 44 & 1128 \\
\hline 6 & 50 & 1203 \\
\hline 8 & 77 & 1748 \\
\hline 10 & 138 & 2068 \\
\hline 12 & 205 & \\
\hline
\end{tabular}

Moore's study indicated that the composition of extracellular polymer produced by two species of Chlorella differed significantly (Moore, 1964). The monosaccharides of Chlorella vulgaris were composed of galactose, xylose, glucronic acid, and rhamnose, while the composition of Chlorella sp. was glucose, arabinose, glucuronic acid, and rhamnose (Moore, 1964). This varied chemical composition across species might induce different effects in terms of settling and flocculating abilities. 
In a more pertinent study to wastewater treatment, Allen (1956) observed that the growth of Chlamydomonas species in wastewater treatment ponds increased the dissolved oxidizable organic material present (Allen, 1956). Allen measured the oxidizable organic material of the exudates by dichromate oxidation similar to the method used in chemical oxygen demand testing (COD) for wastewater treatment. The excretion of oxidizable organic matter from 6 Chlamydomonas species studied paralleled the growth of the alga (Allen, 1956). Similar to the observations of Lewin (1956), again about 10 to $45 \%$ of the organic material present was soluble (Allen, 1956). The organic oxidizable matter filtrate was determined to have polysaccharide but little nitrogen content (Allen, 1956), assuring the presence of high molecular weight polymers, and specifically not proteins.

The studies reviewed above involved some error of disrupting the cell wall of the microalgal species during the EPS extraction processes. Some physical and chemical extraction processes used in the procedures above have been known to lyse the cell walls of algal species, releasing intracellular products, and interfering with extracellular byproduct analysis. Inadequate separation of these cellular byproducts between low and high molecular weight polymeric components was another problem not addressed. A study by Whitton in 1965 examined the soluble extracellular materials produced by Anabaena cylindrical, focusing on polypeptide production. Of the species analyzed, 15 species produced extracellular material (polypeptides) detectible by dialysis (Whitton, 1965). About 14 to $50 \%$ of the EPS produced by the algae in this species was dialyzable, indicating that the other half consisted of high molecular weight compounds (Whitton, 1965). In addition, prolonged dialysis of microalgal samples showed that the culture filtrate had more precipitable EPS or more polyypeptides accumulated (Whitton, 1965). This study reveals further that all above results reviewed are valid based on the procedures used, but may be subject to error based on non-elimination of lower molecular weight polysaccharides as 
dialysis achieves. If algal EPS is indeed composed of higher molecular weight polymers greater than 6,000 to 8,000, as these multiple studies suggests (arabinose, rhamnose, xylose, etc.), a fraction of low molecular weight polymers may be included but not detected in the earlier studies. These results may explain why the relatively high extracted polymers were attained (higher EPS measurements). Thus, the requirement for dialysis of algal exudates is an issue investigated by this research.

\section{Section 2.4.2 Algal Exudates: Transparent Exopolymeric Particulates (TEP)}

TEP are large, discrete, transparent particles that form from the polysaccharides released by many microalgal and some bacterial microorganisms (Passow et al., 2001). In marine and some freshwater environments, diatoms release TEP precursors abundantly. These precursors are responsible for TEP formation and the aggregation of diatoms after an algal bloom (Passow et al., 2001). In addition, TEP play a role in formation of biofilms on water treatment membranes (Berman, 2005; Berman, 2007). TEP have been found to facilitate the formation and subsequent sedimentation of fast sinking aggregates (called "lake snow") from individual TEP particles too small to sink to a great depth individually (Passow et al., 2001; Berman, 2005). TEP range in size from about $2 \mu \mathrm{m}$ to 100-200 $\mu \mathrm{m}$ and appear in many forms: amorphous blobs, clouds, sheets, filaments, or clumps (Berman, 2007). TEP are also composed of deformable, gel-like particles suspended in the water (as they sometimes do not adhere to surfaces as EPS does), thereby considered a "planktonic" subgroup of EPS (Berman, 2007).

The photomicrograph in Figure 2.6 below illustrates the particulate, gel-like nature of TEP, which was found in freshwater and marine environments (Berman, 2007). In marine environments, TEP concentrations range from 3,000 to 4,000 TEP particles/mL (Berman, 2005). In freshwater environments, TEP concentrations range up to 20,000 TEP 
particles/mL. Although TEP is comprised mostly of polysaccharides, other organic compounds such as proteins are incorporated into these particles (Berman, 2005). Some TEP is also created from the mucous envelopes that surround bacterial and algal cells (Berman, 2005). Bacteria also colonize TEP, using the TEP as a source of nutrition to grow and develop (Berman, 2005).

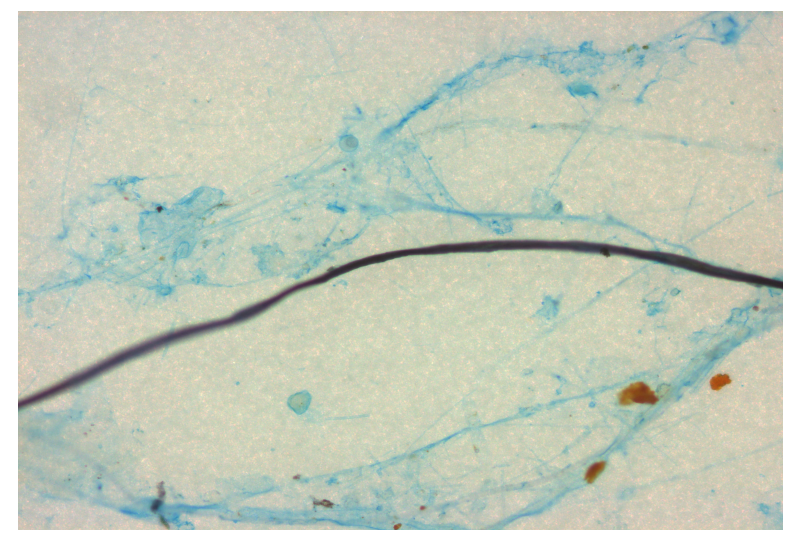

Figure 2.6-Photomicrograph depicting TEP particles (from a freshwater source) and string like arrangements stained with Alcian Blue dye (Source: Berman, 2005)

Quantification of TEP relies on either a colorimetric method or enumeration by a microscopic technique (Passow et al., 2001). The colorimetric method relies on staining the negatively charged groups on the surface of polysaccharides with an Alcian blue dye (Passow et al., 2001) and comparing the samples colorimetrically to stained, known concentration standards of xanthan gum. However, both of these methods for quantification proved too extensive for TEP analysis; therefore, TEP production and quantification were not done in the current study of this thesis.

In aquatic environments, the formation of TEP involves bridging the colloidal and dissolved organic substances, as well as larger particulate organic materials (Passow, 2002). The production involves two separate steps: one abiotic and one biotic (Passow, 2002). The biotic step involves dissolved precursor substances and is affected by various environmental conditions such as turbulence, ion density, and concentration of inorganic 
colloids (Passow, 2002). The abiotic step consists of the coagulation of colloids to form submicron aggregates and also to form submicron gels by gelation and annealing processes (Passow, 2002).

The environmental factors affecting the release of TEP precursors and the formation of TEP aggregates parallel the factors affecting the release of EPS from both algae and bacteria (Passow, 2002). The release of TEP precursors depends on the species, as well as the individual physiological state and environmental growth conditions, as was observed for EPS (Passow, 2002). TEP are generated during exponential growth, stationary phase, and senescence of most algal species (Passow, 2002). However, it has been observed in freshwater algal cultures that maximum TEP production is reached during senescence or late stationary phase of growth (Passow, 2002). In addition, TEP production can vary according to light intensity and duration, carbon dioxide concentration, growth rate, and nutrient (nitrogen-limiting) or trace metal depletion (Passow, 2002; Mari, 1999).

TEP formation depends on physical factors such as turbulence, where a turbulent environment provides a large amount of shear forces that serve to enhance coagulation of TEP precursors (Passow, 2002). The surface charge of the algae and bacteria, as well as the ionic strength of the water affects the formation of TEP (Passow, 2002). Aquatic environments with higher ionic strengths decrease the electric double layer of the colloids and allow more rapid formation of TEP (Passow, 2002).

During a study in the Santa Barbara channel between May 1995 and June 1997, the flux of TEP in a marine environment was measured to investigate whether TEP is necessary for the aggregation and sedimentation of particles (Passow, 2001). During the testing period, phytoplankton appeared to be the most significant source of TEP, showing that some species of marine algae will produce this sticky, particulate substance (Passow, 2001). 
In addition, bacteria, along with phytoplankton were observed to add an appreciable amount of TEP to the aquatic environment and this allowed the diatoms to aggregate. This result suggests that the presence of bacterioplankton in conjunction with algae (phytoplankton) may be necessary for TEP formation and aggregation to occur (Passow, 2001).

A study detailing TEP quantification in freshwater environments and in a controlled laboratory setting was also reviewed (Grossart et al., 1998). This study discovered TEP aggregates from the filamentous cyanobacteria Aphanizomenon ovalisporium and from green algae Scenedesmus quadricada present in detectable amounts ranging from 3 to 30 $\mathrm{mm}$ in diameter in Lake Kinneret, Israel. The dry weight of the TEP aggregates was found to be between 2 and 297 micrograms per aggregate, and the abundance of TEP aggregates was found to range between 1 and 100 aggregates per liter of freshwater depending on the time of year, phytoplankton standing stock, and wind conditions (Grossart et al., 1998). The corresponding number of TEP particles (individual, not aggregated) reached up to 6,915 particles per milliliter of freshwater (Grossart et al., 1998). Pure cultures of the cyanobacteria Aphanizomenon ovalisporium studied in the laboratory showed that these algae released individual TEP upon reaching stationary phase (Grossart et al., 1998). A large fraction of the TEP was capsular (attached to the surface), and only a smaller fraction detached as individual TEP (Grossart et al., 1998). Also, rapid flocculation of the cultures of filamentous algae occurred in less than 2 hours in the laboratory setting used. This result showed TEP from pure cultures have been observed to possess flocculating capabilities (Grossart et al., 1998). 


\section{Section 2.4.3 Effects of Growth Conditions on Algal EPS Production}

The environmental growth conditions can induce algal exudate production of many algal species (Benemann and Oswald, 1996; Salim et al., 2011). These conditions include applying extreme $\mathrm{pH}$, nutrient depletion in the growth media, temperature changes and the concentrations of dissolved oxygen and carbon dioxide (Salim et al., 2011).

Autoflocculation, or self-induced flocculation of algal cells due to $\mathrm{pH}$ changes and mineral composition of the media, allows improved flocculation efficiency (Benemann et al., 1980) and may have an effect on algal exudate production. The effect of light intensity and dark or light culture conditions has been seen to have an effect on algal exudate production in some species of algae (Lavoie, 1987). Therefore, investigation into algal exudate production through changes in environmental growth conditions would be beneficial to understand the mechanisms behind improved algal flocculation and harvesting efficiencies.

\section{Section 2.4.3.1 Effect of Nutrient Limitation on Algal EPS Production}

Nutrient limitation has been shown to improve algal exudate production and flocculation processes (Benemann et al., 1980). Benemann et al. (1980) observed that certain nitrogen-limited algal cultures often clump and settle, although this phenomenon has neither been widely studied nor reported. This result was observed by Benemann and Weissman in laboratory experiments with several fresh-water algal species including Porphyridium and Dunaliella cultures, where flocculation was studied over the various growth conditions (Benemann, 1980). The most important growth factor observed was nitrogen limitation, which induced the cells to flocculate and settle (Benemann, 1980).

Other studies also indicate nitrogen limitation improves algal flocculation as well as exudate production (Fogg, 1965). Schenck and Ramus developed patents for nitrogen starvation of algal cultures followed by subsequent harvesting of biopolymers (Ramus, 
1980; Schenck, 1976). Lastly, algal flocculation has been observed during phosphorus limited algal growth (Schenck, 1976). These studies will be further reviewed in upcoming sections.

\section{Section 2.4.3.2 Effect of Autoflocculation on Algal EPS Production}

Autoflocculation is defined as a naturally induced $\mathrm{pH}$ increase in culture medium and subsequent carbon limitation resulting in co-precipitation of magnesium, calcium, phosphate, and carbonate salts with microalgae (Benemann, 1980). An increase in culture $\mathrm{pH}$ due to carbon dioxide consumption by algal photosynthesis or by direct addition of alkali substances leads the culture medium to a supersaturation state with respect to calcium and phosphate ions (Lavoie, 1987). This supersaturation allows calcium phosphate ions to precipitate. The algal cells, serving as a solid negatively charged surface, adsorb to the calcium phosphate precipitate, which results in a dense, settleable floc (Lavoie, 1987). Oswald and Golueke first observed this phenomenon for microalgal cultures photsynthetically active in a shallow oxidation pond during warm and sunny days (Oswald, 1960). Several studies to further prove this observation by Oswald and Golueke soon followed and will be discussed below to address the significance of algal flocculation as a result of different culture conditions.

One of the first studies reviewed to scientifically prove the autoflocculation phenomenon involved the analysis of the microalgal species Scenedesmus obliquus (Lavoie, 1987). This strain of algae was isolated from a wastewater treatment plant and grown with the addition of secondary effluent wastewater for investigation of both improved bioflocculation and autoflocculation (Lavoie, 1987). Autoflocculation experiments were focused on algal culture growth conditions such as $\mathrm{pH}$, culture age, and the influence of calcium and orthophosphate addition to the culture medium (Lavoie, 1987). The growth of 
Scenedesmus obliquus was characterized over a 22-day period. Ammonium was observed to be exhausted from the culture medium by day 6 , and phosphate uptake continued until day 9. The declining growth phase and beginning of stationary growth phase was attained around day 11 (Lavoie, 1987). Algal biomass continued growth up until day 22 (Lavoie, 1987).

Effective flocculation of around 50\% was observed at pH 11 and 12 during the earlier days of growth (Lavoie, 1987). However, after Day 6 there was no flocculation observed between a pH range of 7 and 11, and the flocculation efficiency at a pH of 12 dropped to around 25\% (Lavoie, 1987). This result was explained through analysis of residual phosphate concentrations within the culture medium. A better flocculation efficiency at pH 12 was observed at the stationary phase of growth for cultures showing high residual phosphate concentrations, demonstrating that phosphate concentrations in the culture medium have an effect on the autoflocculation of microalgal species (Lavoie, 1987).

Next, the addition of extra phosphate and calcium to the culture medium at various pH levels and culture ages was investigated. The addition of calcium or phosphate significantly raised the autoflocculation efficiency at $\mathrm{pH}$ values of 10 and 11 . Also, the simultaneous addition of these two ions allowed an autoflocculation efficiency of $80 \%$ to be reached at pH values of 8 and higher (Lavoie, 1987). Again, the onset of stationary phase decreased the autoflocculation efficiency across the $\mathrm{pH}$ ranges studied. This was observed even with the addition of extra phosphate and calcium ions into the culture medium (Lavoie, 1987).

In the same study, bioflocculation with native bacteria to the wastewater was also investigated. With the same species of algae, the quantities of extracellular polymers and 
proteins varied during the course of incubation and did not appear to be correlated with the age of the cultures (Lavoie, 1987). As seen in Figure 2.7 below, extracellular polymers, proteins, extracellular sugars and capsular sugars were measured from the culture medium. Both extracellular sugar and capsular sugars seemed to increase continually until the end of the culture growth period (Lavoie, 1987). The EPS concentrations never exceeded 120 $\mathrm{mg} / \mathrm{L}$, the range of extracellular protein was between 0 and $7 \mathrm{mg} / \mathrm{L}$, and the maximum concentrations for extracellular sugar and capsular sugar were 5.2 and $25.4 \mathrm{mg} / \mathrm{L}$ respectively (Lavoie, 1987).

The appearance of capsular sugars in the Lavoie study coincided with a loss of flocculation efficiency. The capsular biopolymers were postulated to protect the algal surface charges and hinder the ability of calcium and phosphate ions to co-precipitate with the algal cells (Lavoie, 1987).

Microalgal sedimentation improved with ageing, increasing drastically around the declining growth phase for both cultures as seen in Figure 2.8 (Lavoie, 1987). The percentage of algal recovery (settling efficiency) was lowest during the exponential growth phase, increasing rapidly during the onset of the declining growth phase, and staying constant around the stationary phase of growth (Lavoie, 1987). 

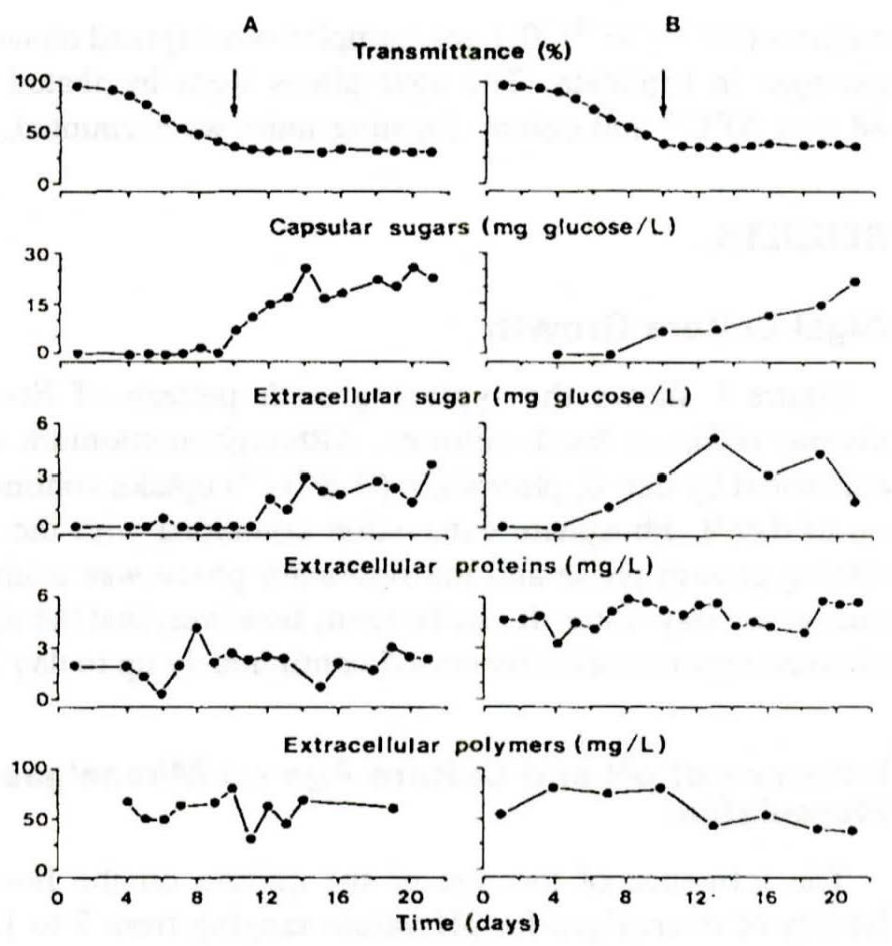

Figure 2.7-Measurements of concentrations of various extracellular products of Scenedesmus obliquus over the growth curve, both $A$ and $B$ represent two different batch cultures of Scenedesmus obliquus (Source: Lavoie, 1987)

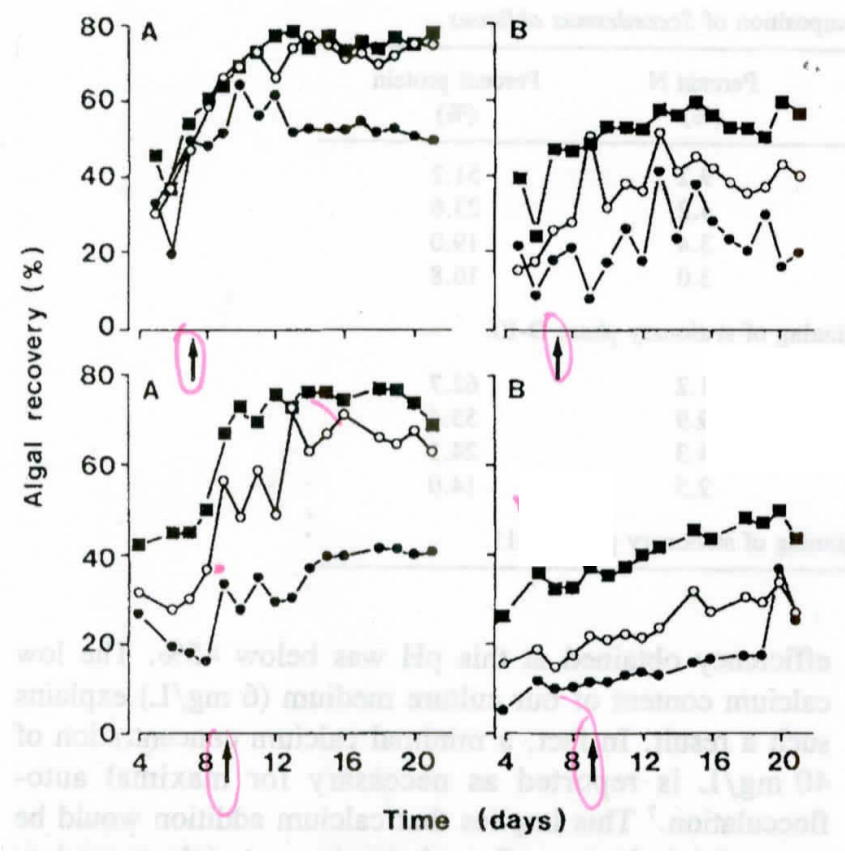

Figure 2.8-Effect of culture age on algal sedimentation in A) Darkness and B) Under illumination. Sedimentation duration was 1 hour (closed circle), 2 hours (open circle) and 4 hours (closed box). The arrows denote the onset of declining growth phase (early stationary) (Source: Lavoie, 1987) 
The Lavoie study concluded that the amounts of EPS produced during the ageing of cultures or the low calcium and phosphate concentrations in the secondary effluent medium were insufficient to allow adequate bioflocculation or autoflocculation (Lavoie, 1987). The EPS produced at $120 \mathrm{mg} / \mathrm{L}$ was much less than the $500 \mathrm{mg} / \mathrm{L}$ observed by Pavoni (1974). Also, the relatively low native bacterial population (as measured in the wastewater) in the Scenedesmus batch cultures reduced the possibility of algal-bacterial bioflocculation (Lavoie, 1987). However, using controlled laboratory conditions of pH and known addition of certain concentrations of calcium and phosphate ions to the wastewater medium, the Scenedesmus cultures were shown to autoflocculate (Lavoie, 1987).

Autoflocculation also studied by Sukenik and Shelef (1984), using both laboratory and outdoor experiments with cultures of Scenedesmus dimorphus and Chlorella vulgaris. In the outdoor experiment, a pure culture of Scenedesmus dimorphus was grown in a HRAP with a specified amount of calcium chloride and magnesium sulfate, to affect the autoflocculation process of the algae (not a wastewater medium as in the Lavoie study). After eight days of batch growth, the carbon dioxide was turned off, and the Scenedesmus were observed to aggregate and form fragile flocs that settled to the bottom with a corresponding rise in $\mathrm{pH}$ to around 9. After initiation of autoflocculation in the outdoor ponds (a 24 hour time period), the Scenedesmus removal was up to $96 \%$ with a corresponding decrease in alkalinity, calcium, and orthophosphate concentrations (Sukenik, 1984). To further test the effects of $\mathrm{pH}$ on algal flocculation and settleability, the outdoor pond $\mathrm{pH}$ was varied in the range of 2.5 to 10.5 . A small algal cell removal percentage of $40 \%$ was observed for the outdoor culture at $\mathrm{pH} 3$ (Figure 2.9). No flocculation was observed for $\mathrm{pH} 5$ to 7.5, while above $\mathrm{pH}$ 8.5, 98\% removal of algae was achieved (Figure 2.9). These results the outdoor cultures of algae suggest that $\mathrm{pH}$ is an important factor in the induction of autoflocculation of algal cultures (Sukenik, 1984). 
In the Sukenik study, laboratory experiments found three ions were specifically responsible for the autoflocculation phenomenon: magnesium, calcium, and phosphate (Sukenik, 1984). Calcium ions caused flocculation at pH 8.5 and above, while magnesium only caused flocculation at pH 10.5 and above (Sukenik, 1984). In addition, the absence of orthophosphate with calcium addition only did not allow for flocculation over the entire alkaline range (Sukenik, 1984). The absence of calcium with only orthophosphate in the medium also did not cause any flocculation within the same pH range (Sukenik, 1984). Magnesium, on the other hand, did not require the presence of either calcium or phosphate at the pH range of 10.5 and above for effective flocculation to occur (Sukenik, 1984). Therefore, calcium and phosphate ions must be present together for autoflocculation within the $\mathrm{pH}$ range of 8.5 to 10.5 .

The algal surface charge during a flocculation and sedimentation test was measured in the Sukenik study over the pH range shown in Figure 2.10. The algal surface electric charge was neutralized at a $\mathrm{pH}$ around 9.0 and above this value a positive surface charge was measured according to Figure 2.10 below (Sukenik, 1984). The precipitate formed with the algal cells had a net positive surface charge and was observed to be composed of primarily calcium and orthophosphate ions (Sukenik, 1984). As the pH increased past 9, the dissolved concentrations of both orthophosphate were shown to decrease rapidly. This result showed that these two ions are only available to form a precipitate past the critical pH of 9 (Figure 2.10) (Sukenik, 1984). 


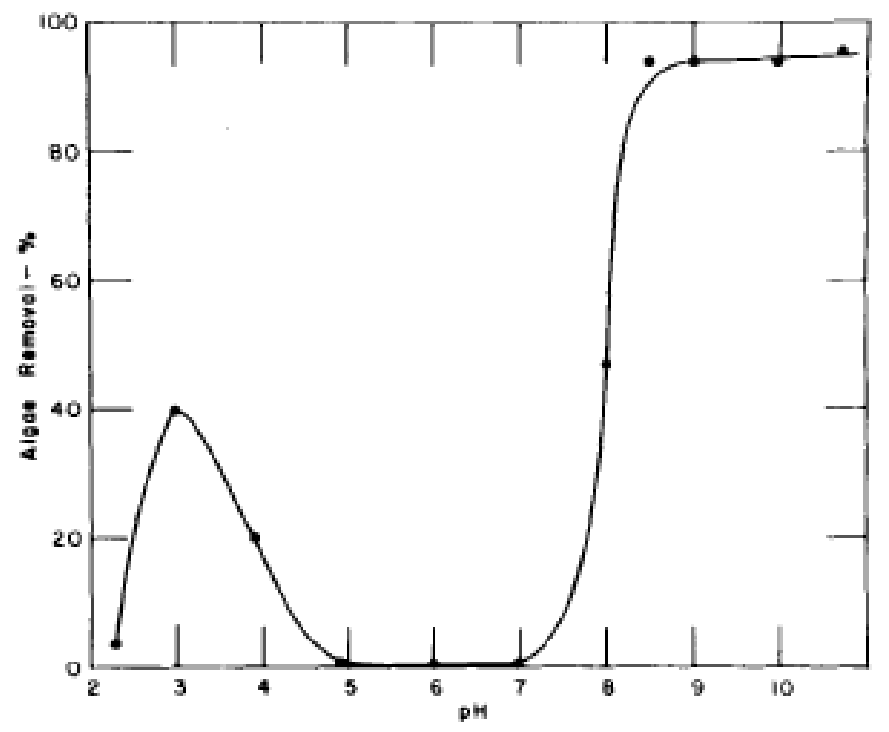

Figure 2.9-pH variation with algal removal percent in the outdoor Scenedesmus obliquus cultures (Source: Sukenik, 1984)
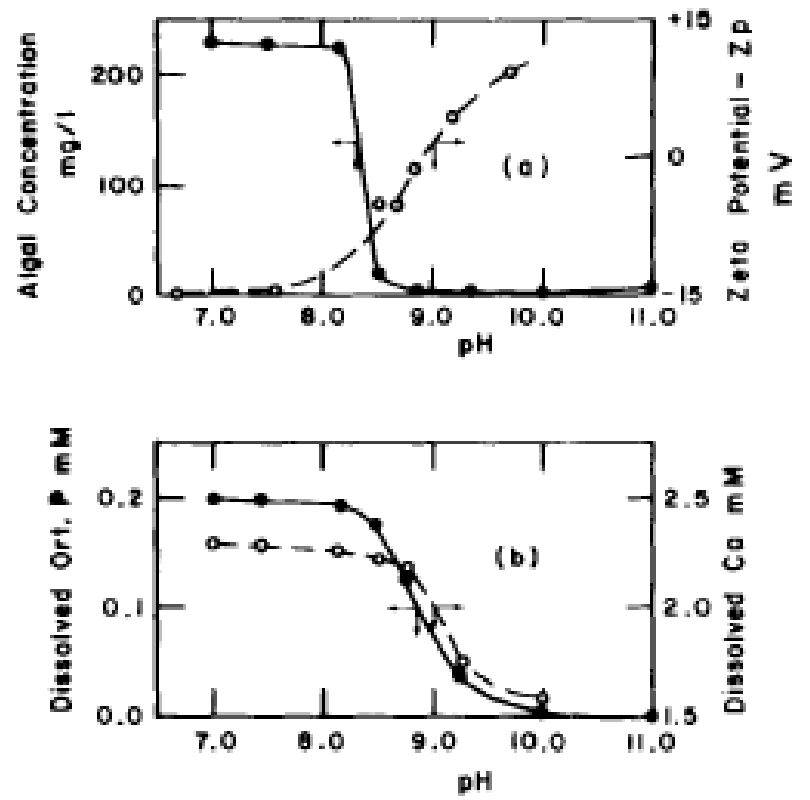

Figure 2.10-Simulated algal flocculation with $A$ ) algae concentration and cells zeta potential and B) dissolved calcium and orthophosphate after flocculation and sedimentation (Source: Sukenik, 1984)

Similar to the outdoor results found in the Sukenik study, Pavoni (1974) found that $\mathrm{pH}$ ranges affected algal removal efficiencies. Maximum algal autoflocculation occurred at a pH of 3 as seen in Figure 2.11 (Pavoni, 1974). This study indicates that natural flocculation 
is maximized when the surface charge of the algal biocolloid is minimized or at/around the isoelectric point (Pavoni, 1974). At this point, electrostatic repulsive forces will be reduced to a minimum, thereby allowing the bio-colloids to assume interparticle distances sufficient for Van der Waals forces to promote optimum flocculation (Pavoni, 1974). Similar results were obtained for addition of catioionic polymers, where optimum algal removal was achieved when the pH was reduced to around 3 (Pavoni, 1974). Adequate removal was also found to take place at pH values above 9 and up to 11 (Pavoni, 1974).

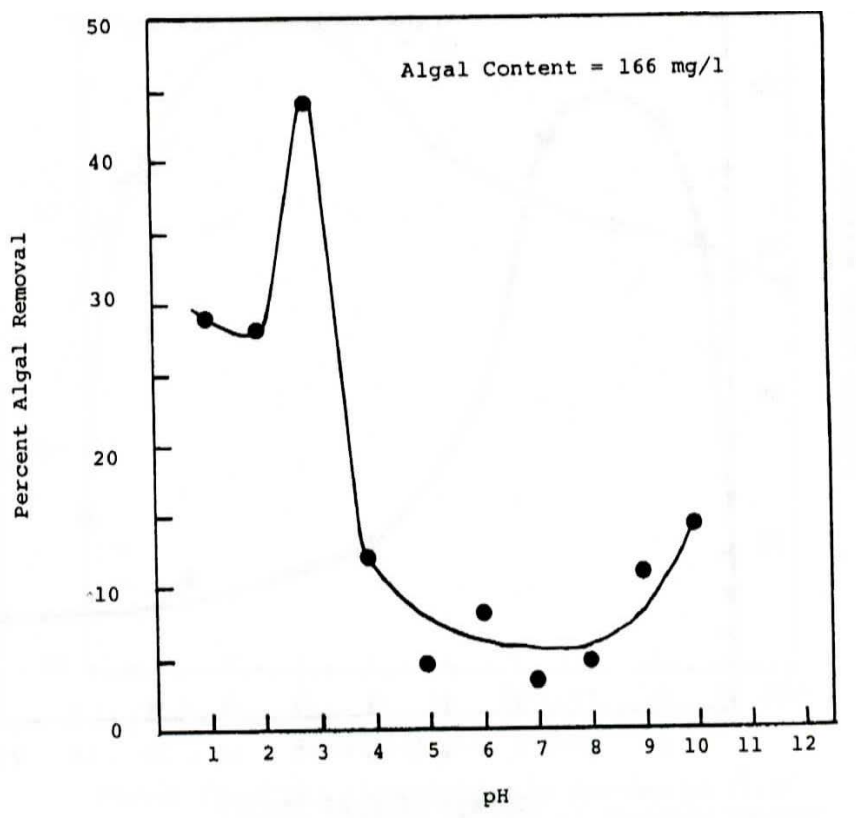

\section{Figure 2.11-Variation of algal removal percent and pH values for algal culture (Source: Pavoni, 1974)}

Pavoni extended his main theory of bioflocculation to algae in addition to bacterial cells (Pavoni, 1974). Pavoni (1974) reported that algal flocculation was governed by the physiological state of a microorganism, where the algae did not produce EPS until they entered a restricted phase of growth (stationary phase) (Pavoni, 1974). Second, a direct correlation was found between algal extracellular polymer production and bioflocculation, 
since the EPS to algal biomass ratios dramatically increased during algal flocculation (Pavoni, 1974). The surface coverage phenomenon, where $50 \%$ of the algal cell surface must be covered, was postulated as the mechanism for bioflocculation (Pavoni, 1974). Third, cell surface charge investigations indicate that surface potential reduction is not a necessary precursor to algal bioflocculation (Pavoni, 1974). Fourth, the major compositional makeup of algal EPS is polysaccharides, proteins, RNA, and DNA, which impart negative surface charge characteristics (Pavoni, 1974). Finally, the mechanism of algal bioflocculation can be seen as the interaction of EPS, accumulating at the surface during stationary phase of growth, and electrostatically or physically bridging the cells into a three-dimensional matrix dense enough to settle under quiescent conditions (Pavoni, 1974).

For the culture of algae used (remained unidentified in the study), EPS production was highest at early stationary phase of growth, and leveled off into later stationary phase of growth (Pavoni, 1974). Moreover, the ratio of algal EPS to algal cells decreased drastically until later stages of growth (Pavoni, 1974). This result suggests that some cultures of algae exude more EPS during earlier stages of growth as compared to the algal cells present. Both culture turbidity and cell dry weight were shown to peak late after around 40 days of growth, showing that the culture was very dense (almost zero percent transmission).

Tenney (1973) observed that the mechanisms behind chemical and autoflocculation of algae were essentially the same. Tenney reported that long chain, high molecular weight polymers exuded by both algae and bacteria attach themselves between particles and divalent metal ions (bridging), causing flocculation (Tenney, 1973). Tenney found that as the algae reaches early stationary phase (declining growth), less cationic polymer was needed to improve flocculation up to fifty percent (Figure 2.12). This may be due to the 
measured fact that algae studied produced sufficient amounts of extracellular polymer to induce bioflocculation during late log to early stationary phases.

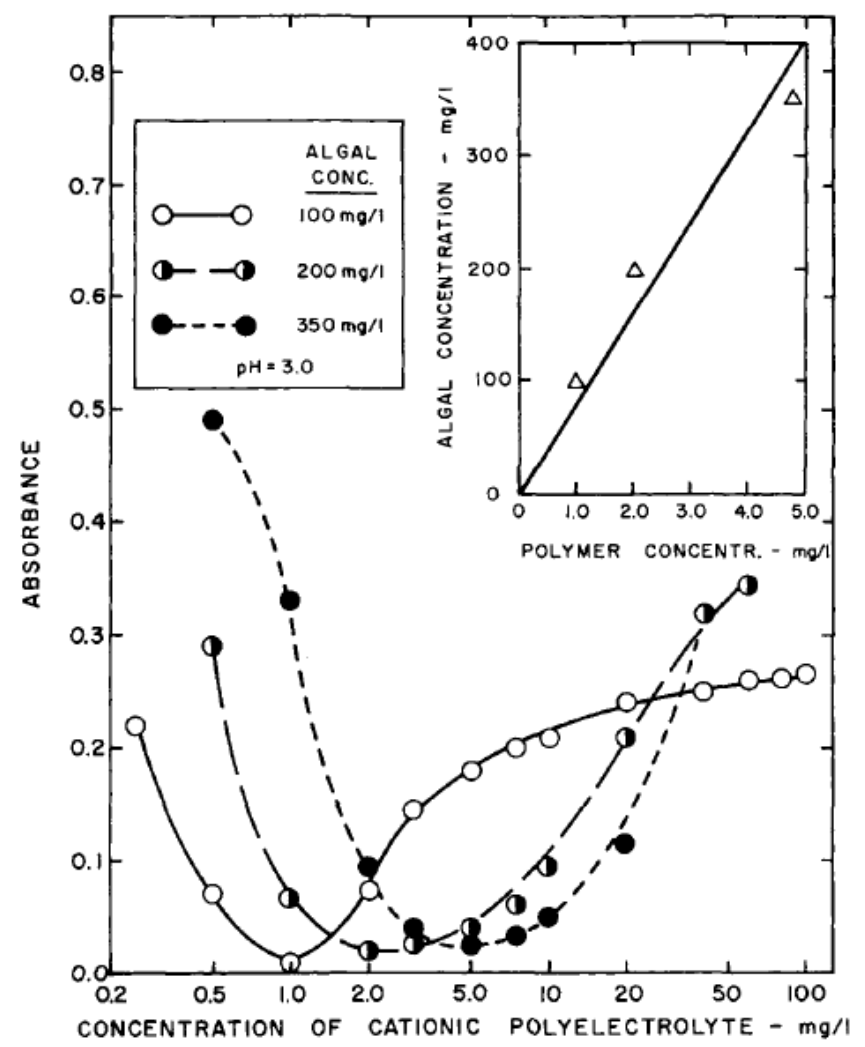

Figure 2.13-Effect of algal concentration at a fixed $\mathrm{pH}$ of 3 for cationic polyelectrolyte doses to increase algal removal (Source: Tenney, 1973)

Tenney also studied the effect of surface coverage of algal cells on the

bioflocculation processes. Through increasing the available surface area (or available sites for polymeric bridging-the area for bioflocculation to occur) by increasing cell concentration, it was found that more cationic polymer was required (Figure 2.13 above). According to the same Figure (2.13), Tenney studied algal density up to $350 \mathrm{mg} / \mathrm{L}$ with a pH of 3 , and concluded that algal concentration differences promote differences in dosages and effectiveness of cationic polymer. Similar to Pavoni's results, Tenney observed that optimum cationic flocculant dosage was achieved at lower $\mathrm{pH}$ values ( 2 to 4 ), and not 
higher to moderate values (Figure 2.14). Tenney concluded that this effect was due to: 1) due to the isoelectric point of algae around $\mathrm{pH}$ of 2 to 3 , electrostatic repulsion is lowest, and 2) polymeric bridging will be greater due to a greater polymer expansion.

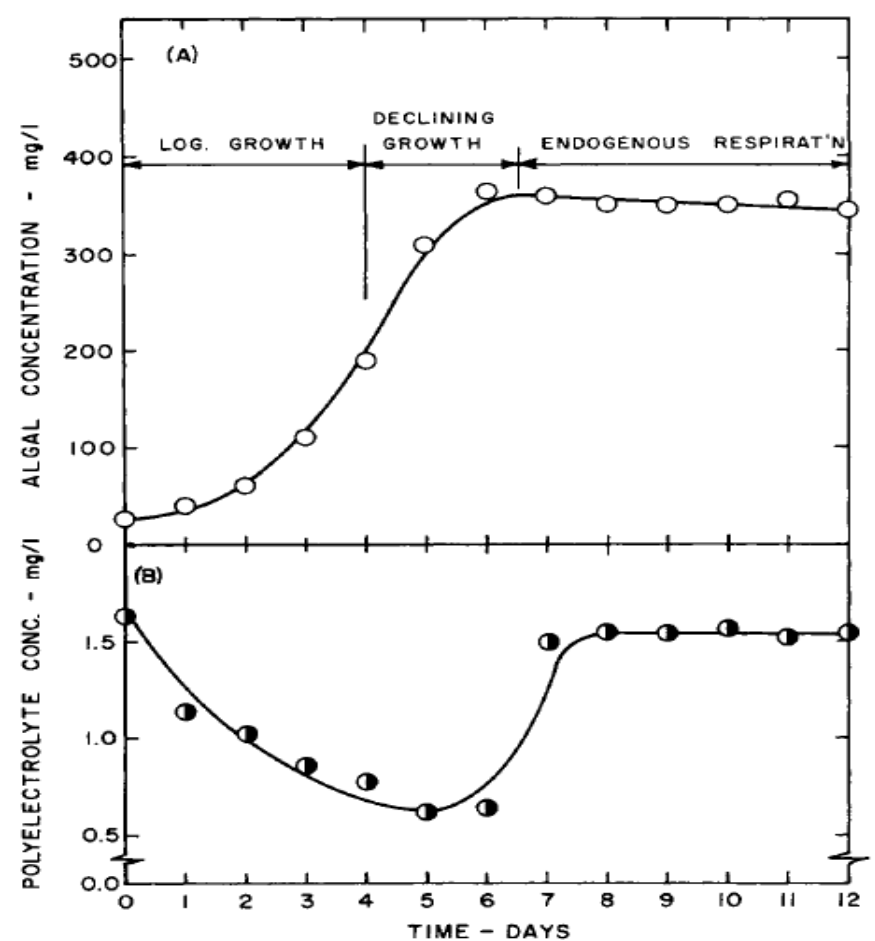

Fig. 7. Effect of growth phase on algal flocculation with cationic polyelectrolyte (Dow C-31): (a) algal growth curve; (b) concentration of polymer required for $50 \%$ flocculation.

Figure 2.12-Effect of growth phase on cationic polyelectrolyte dosage to attain $50 \%$ flocculation/removal of algae (Source: Tenney, 1973) 


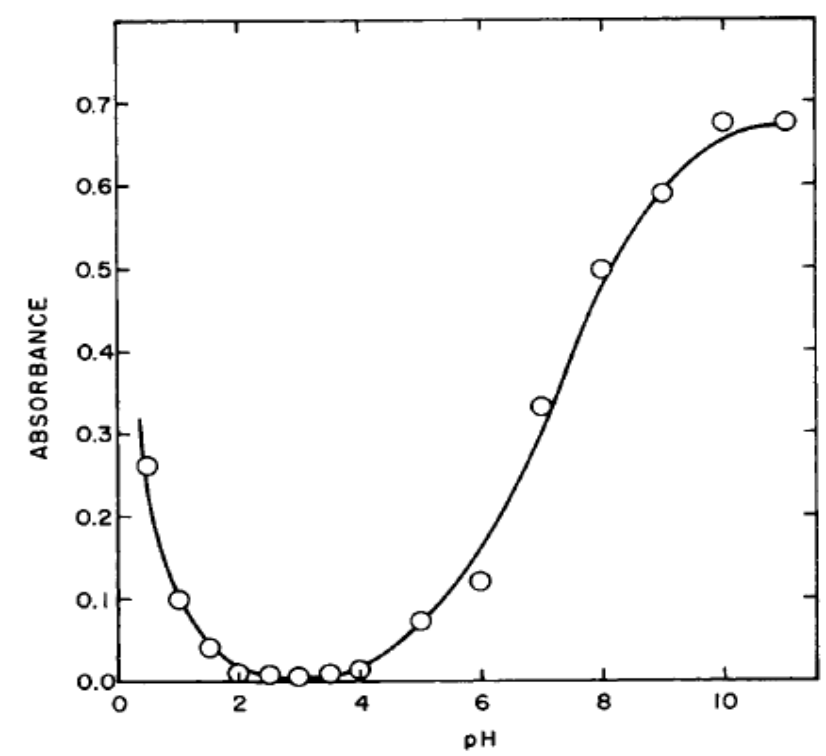

Fig. 5. Effect of pH on algal flocculation with constant dosage of cationic polyelectrolyte (10 mg/liter, Dow C-31).

\section{Figure 2.14-Efect of $\mathrm{pH}$ on algal removal with constant dosage of cationic polyelectrolyte (Source: Tenney, 1973)}

\section{Section 2.4.3.3 Effect of Light Intensity and Dark Conditions on Algal EPS and}

\section{Settleability}

Light intensity during algal growth and darkness during settling also have been investigated to improve algal settleability. In natural situations, only a fraction of light (often as low as $1 \%$ ) penetrates the water column and is available for algae for photosynthesis (Shipin, 1999). Several adaptive and metabolic strategies are exhibited by microalgae to overcome light limitations (Shipin, 1999). To obtain a secure light source in these situations, algae are known to excrete flocculating substances of polymeric nature, which are usually acidic (Shipin, 1999). These algal EPS exudates allow suspended solids such as clay particles to flocculate and sink, thereby reducing the turbidity and allowing more light to be obtained. Thus, manipulating light intensity by varying exposure periods during growth could have an effect on improved bioflocculation. Benemann (1980) also observed the potential of a "dark sedimentation" process in which $90 \%$ removal of 
algal TSS was achieved (compared to a control settling pond exposed to the light) by the operation of facultative, high rate and covered settling ponds in series, but the mechanism of this process was uncertain.

The application of light and dark conditions to enhance algal settleability was investigated in integrating ponds and activated sludge systems using the PETRO concept (Shipin, 1999). The PETRO system consists of oxidation ponding to treat the bulk organic load of wastewater (up to 70\%) followed by a trickling filter or activated sludge process as a polishing step, hence the name, "Pond Enhanced Treatment and Operation" (Shipin, 1999). Effective microalgal removal using the trickling filter process was a main emphasis of the PETRO design (Shipin, 1999). In fact, microalgae acted as heterotrophs in the dark, contributing to mucilage production in the trickling filter itself (Shipin, 1999). Biofilm slime, predominantly EPS in nature, was produced by the microalgae experiencing stress transfer from two different types of growth (mixotrophy and heterotrophy) (Shipin, 1999). Under light conditions, algae followed mixotrophy (growth on organics in the light) and turned heterotrophic in the dark, in which microalgae used low molecular weight organics such as amino acids, monosaccharaides and volatile fatty acids (Shipin, 1999). A full-scale plant study and corresponding laboratory scale study were completed to better understand the process behind the improved treatment efficiency achieved from the trickling filter variant in the PETRO concept. The field study showed that seasonal algal blooms in the oxidation ponds preceding the activated sludge process characteristically resulted in an enhanced EPS content of the sludge flocs (Shipin, 1999). Moreover, the EPS content directly fluctuated with the algal concentration, showing the algae in the ponds contribute to the EPS produced in the activated sludge process variant (Shipin, 1999). 
In this same study, experiments were carried out in the lab with Chlamydomonas species (Shipin, 1999). Chlamydomonas was observed to grow heterotrophically in the dark on a variety of organic compounds used in the lab such as glucose, amino acids, glycerol, ethanol, and acetate and to produce EPS when these conditions were altered. EPS production was more significant when the transition was from light to dark, confirming findings that some algae produce EPS after the stationary phase transfer from the mixotrophic to heterotrophic mode of growth (Shipin, 1999). In this way, stress-induced flocculation was one reason for algal removal in the PETRO activated sludge process and trickling filter (Shipin, 1999). In addition, EPS production was observed to start gradually in the mid logarithmic phase of growth and accelerate rapidly reaching a peak during stationary phase of growth (Figure 2.15) (Shipin, 1996). Algal EPS concentration was found to increase in magnitude after 10 days of growth if growth was switched from mixotrophy to heterotrophy. Overall, the microalgae from the oxidation ponds (grown mixotrophically) enter the trickling filter or activated sludge process (heterotrophy encouraged), which induces stress conditions to provide a stimulus for EPS overproduction (Shippin, 1996). 

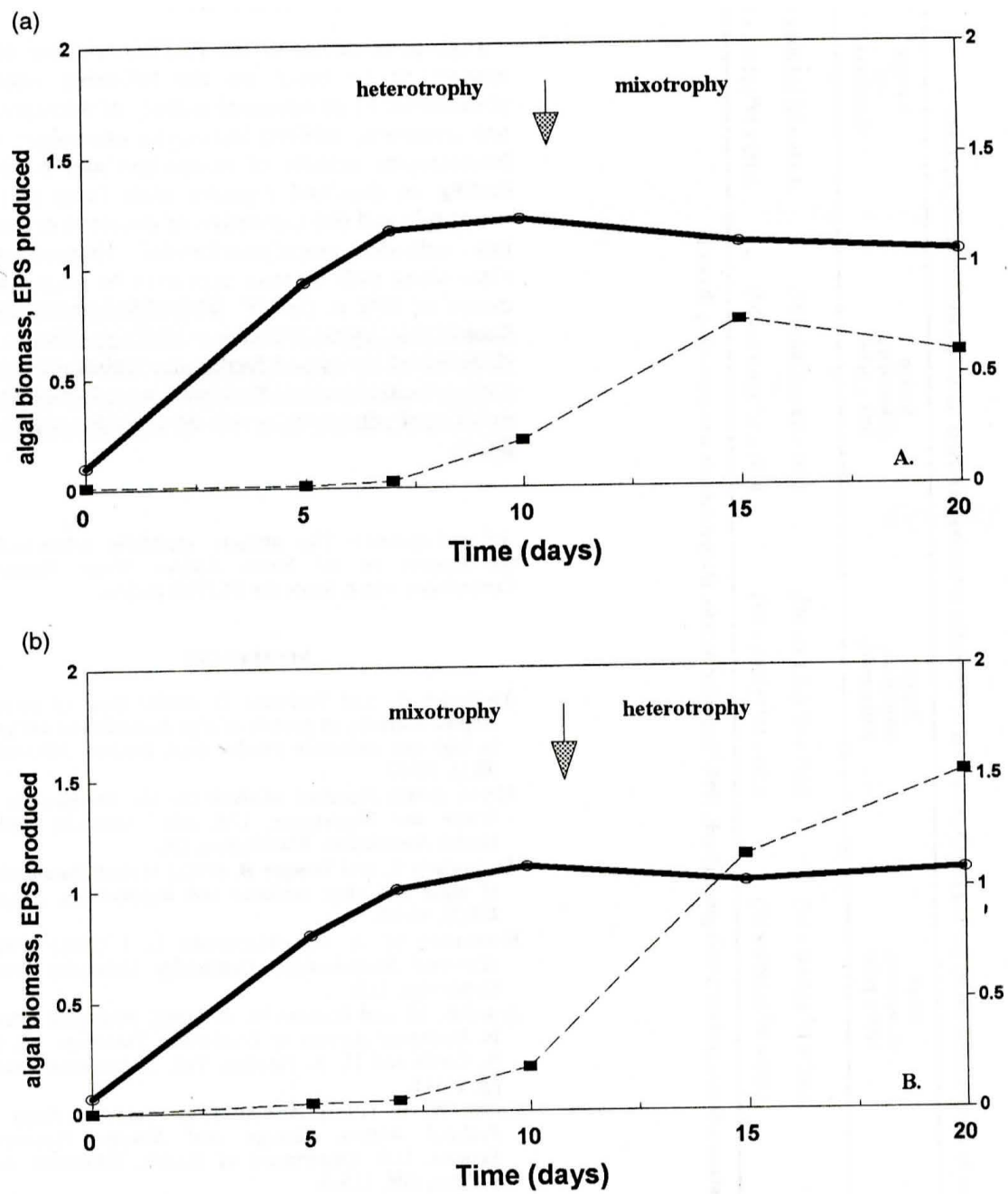

Figure 2.15-EPS production response of a microalgal species to changes from $A$ ) heterotrophy to mixotrophy and B) mixotrophy to heterotrophy (black box with dashed line is EPS production; filled circle with black solid line is algal biomass production) (Source: Shipin, 1999)

Another study involving Scenedesmus obliquus produced similar settling results to the PETRO system's light and dark conditions (Lavoie, 1987). When cultures were settled under dark conditions, the Scenedesmus was observed to settle more rapidly (Lavoie, 1987). Settling tests under illumination, on the other hand, caused the $\mathrm{pH}$ to rise to 10 , under which conditions floc formation or enhanced settleability were not observed (Lavoie, 1987). 
Two explanations were postulated for better in the dark. First, illumination, as a physical factor, is known to cause thermal convection currents within the settling apparatus (Lavoie, 1987). Second, algae continue photosynthesizing, even during settling conditions under illumination, and produce oxygen bubbles that could cause the algal cells to re-suspend or float to the surface (Lavoie, 1987).

Sukenik (1984) also studied light dependency during autofloccuation for outdoor cultures of Scenedesmus dimorphus. To determine the effects of light on autoflocculation, the cultures were first grown autotrophically for six days (Sukenik, 1984). Following this period, one pond was covered, while the other was left open to the sunlight, and the autoflocculation experiment was begun (Sukenik, 1984). In the light exposed cultures, the removal of algae was much quicker and autoflocculation was achieved with a rise in $\mathrm{pH}$ to 9 (Sukenik, 1984). However, in the covered pond cultures, pH did not rise, autoflocculation was not observed, and the culture settled rather poorly (Sukenik, 1984). Thus, it was determined that light is necessary for autoflocculation. This result was the opposite of that reported in the Lavoie study of Scenedesmus obliquous. However, better settling of dark cultures from the Lavoie study could have resulted from a difference in the medium used in the Sukenik study (wastewater versus a defined medium), where autoflocculation was not observed in either the dark or illuminated cultures. Therefore, the effect of light on settling may depend on both the culture medium and presence of elevated levels of calcium and phosphate. These factors may allow the illuminated samples to settle better than dark samples due to the autoflocculation phenomenon. Above all, both studies indicate that the algae possess inherent individual qualities of settling under light and dark conditions, and cannot be grouped or classified based on one attribute. 


\section{Section 2.4.3.4: Effects on Settling of Algal Surface Charge, Morphology, and Size}

Surface charge, morphology and size of algae cells have a tremendous impact on their ability to flocculate and to settle (Pieterse, 1978). Algae cells, like colloidal particles, are negatively charged and relatively small under all $\mathrm{pH}$ conditions. Due to these like charges and the development of an electric double layer around the cells, algal cells often repel one another and stay in suspension (Pieterse, 1978). However, unlike their abiotic colloidal counterparts, algae cells possess characteristics that make them flocculate and settle differently (Pieterse, 1997). Algae cells may be elongated in shape or may be arranged in filaments or colonies, or the cells can have long spines that could affect the efficiency of flocculation (Pieterse, 1978). Same algal cells swim with flagella, further affecting the way algal cells flocculate and settle (Pieterse, 1997). In addition, algal cells are alive, as compared to colloidal particles, and metabolic processes move the cells (Pieterse, 1978).

One important difference between abiotic colloidal particles and algal cells is the physiological ability of the cells to respond to differences in conditions concerning their immediate environments (Pieterse, 1978). These metabolic processes include assimilation of carbon dioxide and other nutrients, production of oxygen, as well as exudation of cell byproducts such as EPS (Pieterse, 1978). In general, these metabolic processes have been shown to affect the flocculation ability and settling characteristics of most microalgae species (Pieterse, 1978).

Surface charges of algal cells are characterized by charged organic surfaces from carboxyl or amino groups that react with water and accept or donate protons (Pieterse, 1978). Thus, the $\mathrm{pH}$ of the solution affects the surface charge through protonation or deprotonation. For example, the measured charge density of a species of Chlorella over a 
wide $\mathrm{pH}$ range (2.5 to 11.5) showed an isoelectric point around a $\mathrm{pH}$ of 7-8 (Figure 2.16; Ives, 1959). At a constant $\mathrm{pH}$, the zeta potential and charge density are reported to vary from genus to genus of algae (Ives, 1959). Thus, the intensity of the surface charge is a function of $\mathrm{pH}$, algal species, ionic strength of the medium, and other environmental conditions (Shelef, 1984). Algal surface charge can be further influenced by ionization of inorganic functional groups at the algal cell wall and the selective adsorption of ions from the culture media (Shelef, 1984).

SURFACE ELECTRIC CHARGE

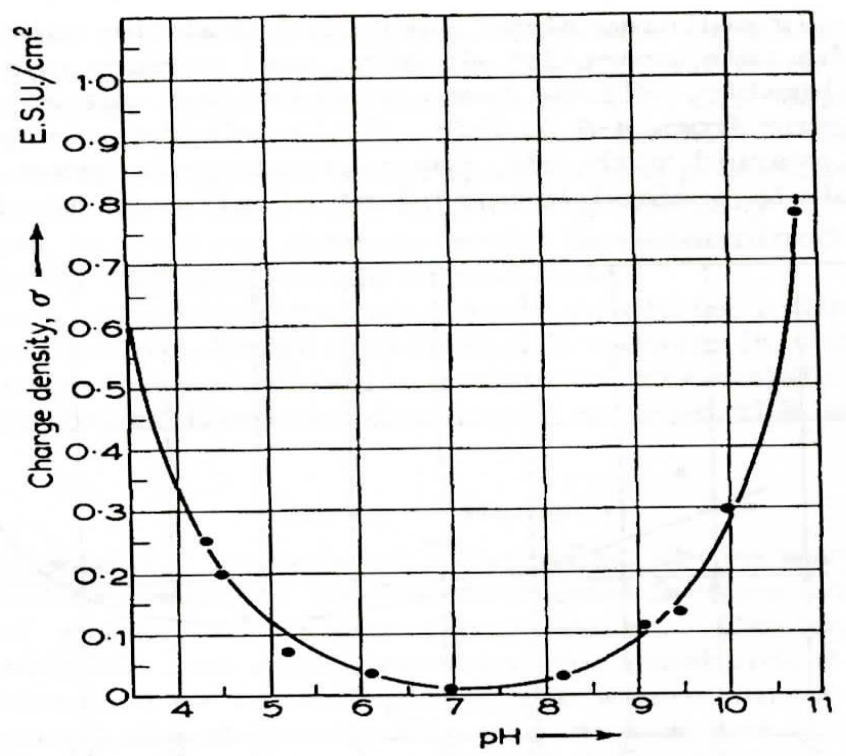

Fig. 1. Chlorella: Charge density $-\mathrm{pH}$ graph

\section{Figure 2.16-Variation of charge density with pH of a species of Chlorella (Source: Ives, 1959)}

Algal size and morphology can also affect settling. One study examined 30 species of problem algae in coagulation and sedimentation processes in the water treatment plants throughout Korea (Choi et al., 2006). Most of the algae selected were found to be difficult to settle due to needle or long cylinder morphology, which created a greater buoyancy effect in the water since the longer algae made less dense flocs (Choi et al., 2006). The problem algae 
studied were diatoms including Syndra acus, Nitzschia acicularis, N. fruticosa, and other types included green algae such as Scenedesmus and Ankistrodesmus (Choi et al., 2006). Removal rates of these problem algae were measured using a settling column while taking samples at a predetermined height before and after adding the algae cells (Choi et al., 2006). Removal rates ranged from 31 to $98 \%$, and settling velocities were different for each species and gradually increased with age, algal size and volume, and water temperature (Figure 2.17; Choi et al., 2006). Moreover, the settling velocities of algae were closely correlated with changes in morphology rather than algal density of the cell itself, with the most extreme morphology being a needle-like morphology (Choi et al., 2006). Lastly, the effect of morphology was related with growth phase, where longer algae improved settling and smaller algae decreased settling later in growth during stationary phase (Choi et al., 2006).
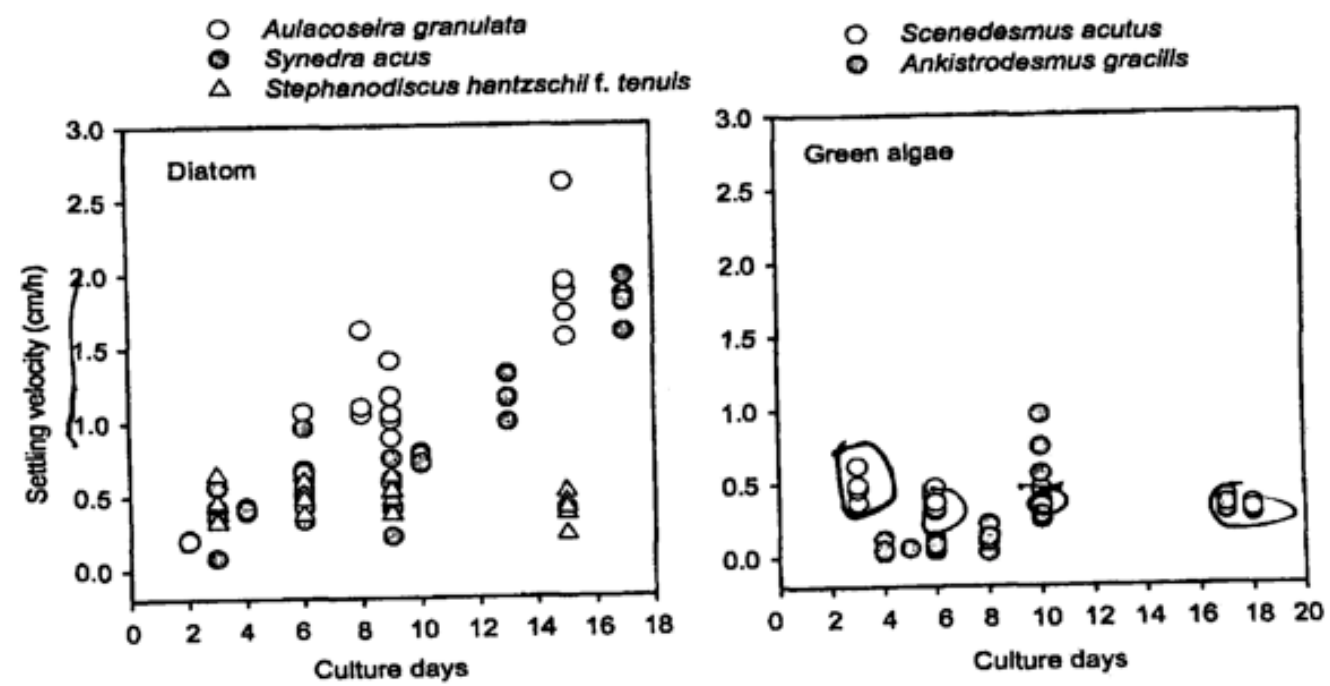

Figure 2.17-Measured settling velocities of different problem species of algae (the circled points represent Scenedesmus). The left figure includes the diatom species studied (Source: Choi, 2006) 


\section{Section 2.4.3.5: Effects of Algal EPS on Settling and Flocculation}

The effect of algal exudates alone (primarily biopolymer) on settling was first reported in a patent by Schenck (1976). In this work, algae were cultivated until high culture densities were achieved. After this phase of growth, the patent proposed placing the algae in an environment limited in nitrogen, causing the cells to shift from a growth phase in which protein production dominated to a growth phase where extracellular polymer production dominated (Schenck, 1976). The deficiency in nitrogen was found to produce high molecular weight polymers exhibiting strong flocculating activity (Schenck, 1976). The polymers exuded by the species of Chalmydomonas and Chlorella were found to be ethanol precipitable, anthrone sugar reacting materials, having a molecular weight of approximately 100,000 (Schenck, 1976). Several experimental approaches validated the patented findings of Schenck (1976).

The first experiment reported in Schenck's approach involved the green algal species of Chlamydomonas mexicana. Over a growth period of 10 days, the carbohydrate production, flocculation value (how well the algae cells flocculated) and viscosity of the algal culture all increased after growth ceased during the end of the exponential growth phase (Figure 2.18). At the end of the exponential growth phase, the cellular nitrogen dropped to $5 \%$ of the dry weight, which corresponded with an algal flocculant production phase. For this particular species of Chlamydomonas, no flocculant was produced until the cellular nitrogen content fell below $5 \%$. In addition, in this study the rate of flocculant production during exponential growth was one third less than that during stationary phase of growth (Schenck, 1976). 


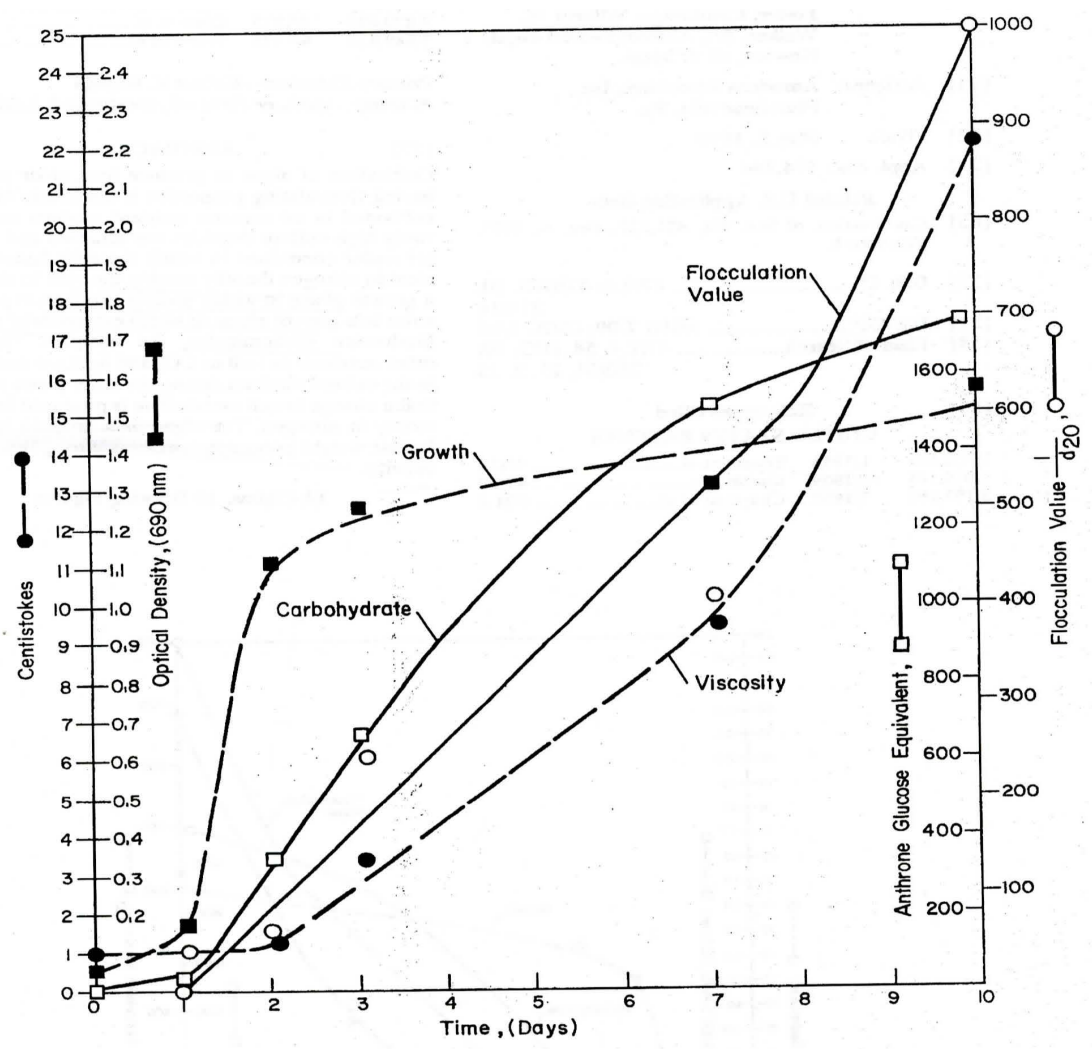

\section{Figure 2.18-Relation of growth, flocculation and carbohydrate production of a Chlamydomonas culture (Source: Schenck, 1976)}

The second approach used by Schenck involved inoculating two different cultures of the same species of Chlamydomonas, but doubling the nutrient medium composition of nitrogen of one culture. The culture inoculated with lower nitrogen content in the media was shown to reach a cellular nitrogen content of below $5 \%$ and to produce flocculant. The culture with twice the nitrogen content did not reach below $10 \%$ cellular nitrogen content, and no flocculant was produced. This result demonstrated that manipulating the nitrogen content of the medium allowed more desirable flocculant properties of the green algae species (Schenck, 1976).

Phosphorus effects were further also in the Schenck patent. A culture of Chlorella pyrendoidosa was grown under two conditions: one with sufficient nitrogen and 
phosphorus, and the other with sufficient nitrogen but limited phosphorus. Even though identical growth kinetics were observed, the low phosphorus level in the second culture resulted in an absence of flocculating activity. These results suggest that low cellular phosphorous levels cause depolymerization of polysaccharides or inhibit their formation (Schenck, 1976). However, under certain circumstances, the cells with low phosphorus were shown to reverse their behavior when exposed to light. The study suggested that this species of Chlorella was composed of "D" or "dark" cells that were small but with high photosynthetic and low respiratory activity. When these "D" cells were transferred to a medium deficient in nitrogen, they were transformed into "L" cells or "light" cells with comparatively higher respiratory activity and lower photosynthetic activity. "L" cells were capable of producing polysaccharides at much lower cellular phosphorous concentrations. Therefore, the L cells were observed to produce flocculants when the phosphorous levels were deficient (Schenck, 1976). Overall, this study determined that cellular phosphorus levels should be maintained above $0.5 \%$ in all species of green algae if flocculent production is desirable (Schenck, 1976).

The final approach of the Schenk patent focused on the abilities of certain species of Chlamydomonas to enhance coagulation and flocculation with solids in wastewater. Results indicate stronger, larger and denser flocs were formed with all species observed due to the flocculant produced by the algae upon addition with lime to each of the specified wastewater samples (Schenck, 1976). The jar test procedure used illustrated that a rapid mixture period, followed by a gentle flocculation allowed the algae and lime combination to form more readily settleable flocs as compared to the mixture of wastewater with lime addition alone. 
Ramus (1980) devised a similar method to enhance algae biopolymer production by nitrogen limitation. Ramus developed a framework for a new and improved process for the synthesis of algal biopolymers by shifting from a growth phase favoring growth to a stationary phase where biopolymers are produced under nitrogen limitation (Ramus, 1980). The Ramus patent was based on a two-stage production system. The first stage relied on cultivating the algae in a continuous growth system and keeping the growth phase at a fixed exponential rate (Ramus, 1980). The next stage of growth was under batch operation with a nitrogen-starved medium that allowed the algae to stop cell division and focus on biopolymer production (Ramus, 1980). As seen in the Table 2.5, biopolymer production increased dramatically during the 20 days of batch growth for the species Porphyridium aerugineum (Ramus, 1980). Yields of biopolymers reached 1.73 and $4.22 \mathrm{~g} / \mathrm{L}$ respectively for two different cultures (Ramus, 1980).

Table 2.5-Measurments of biopolymers produced as a function of culture age for two different cultures of Porphyridium aerugineum (Source: Ramus, 1980)

\begin{tabular}{|c|c|c|c|}
\hline \multicolumn{2}{|c|}{ Culture A } & \multicolumn{2}{c|}{ Culture B } \\
\hline $\begin{array}{c}\text { Batch } \\
\text { Culture Age } \\
\text { (days) }\end{array}$ & $\begin{array}{c}\text { Biopolymer } \\
\text { (g/L) }\end{array}$ & $\begin{array}{c}\text { Batch } \\
\text { Culture Age } \\
\text { (days) }\end{array}$ & $\begin{array}{c}\text { Biopolymer } \\
\text { (g/L) }\end{array}$ \\
\hline 9 & 0.06 & 9 & 0.06 \\
\hline 10 & 0.07 & 10 & 0.13 \\
\hline 11 & 0.1 & 11 & 0.23 \\
\hline 12 & 0.16 & 12 & 0.39 \\
\hline 14 & 0.55 & 14 & 0.94 \\
\hline 16 & 0.65 & 16 & 1.59 \\
\hline 18 & 0.9 & 18 & 2.49 \\
\hline 20 & 1.73 & 20 & 4.22 \\
\hline
\end{tabular}

Tenney et al. (1969) reviewed the parameters affecting flocculation and settling with cationic polyelectrolytes. This early study focused on three parameters including algal growth phase, algal concentration, and $\mathrm{pH}$ on optimum cationic flocculant dosing (Tenney et al., 1969). Other factors such as degree and extent of agitation, algal size, temperature 
and electrolyte concentration were included in research but are not discussed here. Effect of growth phase was studied using a batch culture of Chlorophyta over a growth period of 12 days. As the algae entered the declining growth phase, the concentration of added cationic polymer was much smaller due to the accumulation of more extracellular polymers by the algae themselves (Tenney et al., 1969). Tenney et al. observed that the accumulation of algal extracellular material occurred during the stationary phase to early declining growth phase (Figure 2.19). Moreover, these algal biopolymers were of sufficient length, like cationic polymers, to form bridges between the algal particles (Tenney et al., 1969).

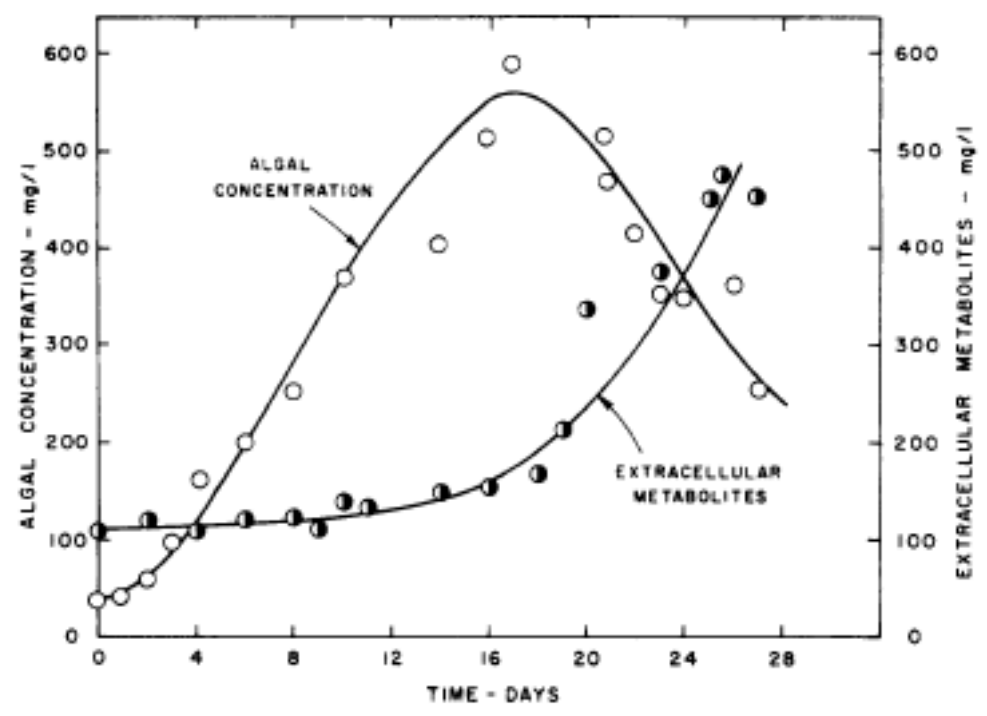

Figure 2.19-Algal concentration plotted against extracellular metabolites (algal EPS) over the growth curve for Chlorophyta (Source: Tenney, 1969)

\section{Section 2.5 Bioflocculation and EPS}

Bioflocculation is termed as the spontaneous flocculation of both algal and bacterial cells to form readily settleable flocs to improve gravitational sedimentation and microalgal harvesting without the use of chemical or physical methods of separation (Benemann and Oswald, 1996). Previous sections covered studies concerning flocculation without the addition of other bioflocculants or microorganisms to improve microalgal harvesting. 
Bioflocculation studies, as covered in the upcoming sections, included the use of other biological agents that were native or non-native to the wastewater environment incorporating bacterial EPS from bioflocculants or return activated sludge. These microorganism provided an additional source of EPS to improve microalgal harvesting.

EPS production has been shown to occur in both prokaryotic and eukaryotic (algae, fungi) microorganisms (Wingender, 1999). EPS is defined as, “...an extracellular polymeric substance of biological origin that participates in the formation of microbial aggregates" (Wingender, 1999). Moreover, the broader term polymeric substance now incorporates a varied composition of proteins, nucleic acids, phospholipids and humic substances other than polysaccharides (Wingender, 1999). EPS is known to exist in two main forms: capsular or tightly bound and dissolved or loosely bound (Wingender, 1999). Capsular EPS attaches to the cell surface by either non-covalent interactions or covalent interactions through binding with lipid-A molecules or phospholipids (Wingender, 1999). Functions of both capsular and dissolved EPS include mediation between the cell and the environment, serving as a protective barrier to prevent desiccation, as well as aggregating bacterial cells to form either flocs or biofilms to increase cell density and culture stability (Wingender, 1999).

A direct correlation has been observed between EPS accumulation and microbial flocculation as reviewed by Pavoni et al. (1972). Pavoni et al. (1972) first observed that bacterial flocculation takes place only after the microorganisms have entered stationary phases of growth. Pavoni et al. (1972) also determined that extraction of EPS from a wellflocculated bacteria suspension followed by a subsequent re-addition of extracted polymer resulted in re-flocculated suspensions. The addition of the same extracted EPS to stable 
inorganic dispersions of silica, alumina and kaolinite produced well-flocculated suspensions.

Throughout the Pavoni et al. (1972) investigation, pH was found to be the most important factor in determining the appropriate dosage and efficacy of extracted polymer. It was observed that bacterial supernatant polymer had increased flocculation ability at $\mathrm{pH}$ ranges above 7 and below 3 . Throughout $\mathrm{pH}$ ranges of 3 to 7 , especially at $\mathrm{pH} 7$, flocculation ability was not as prevalent (Pavoni et al., 1972). Pavoni's study inferred that exuded polymeric material contains functional groups that are primarily anionic and nonionic in most neutral pH ranges (Pavoni et al., 1972). Thus, polymer colloid bonding occurs when both constituents possess negative charges, implying that a physical interaction, as opposed to electrostatic, is the primary mechanism of attachment (Pavoni et al., 1972). Pavoni observed that the interaction of high molecular weight exocellular polymers could bond either electrostatically or physically to bridge the cells of a dispersion forming a threedimensional floc matrix large enough to settle. However, a reduction in electrostatic repulsion is not necessary for bioflocculation to occur (Pavoni et al., 1972).

\section{Section 2.5.1 Large-Scale Bioflocculation Studies to Improve Harvesting of Microalgae}

Full-scale bioflocculation for the harvesting of algae has already been studied extensively Benemann $(1980,1981)$. Benemann's experiments in 1976 to 1981 focused on both "pond isolation" for algae removal and "high-rate pond bioflocculation" techniques (Benemann \& Oswald, 1996). Pond or phase isolation proposed by Benemann et al. (1981), involves the retention of oxidation pond effluent as a batch culture until a large proportion of the algal cells settle out of suspension. Due to isolation, the algal cells settle as a result of improved conditions for bioflocculation with native bacteria present in the wastewater, including increased physical interactions from an increase in contact time. Isolation also 
was postulated to introduce a nutrient limited environment for a specified period of time, which allows both the bacteria and algae to produce more EPS, thereby enhancing bioflocculation (Benemann et al., 1981). In a different approach for high-rate pond bioflocculation, Benemann et al. (1981) used a flocculent culture of algae and maintained conditions suitable for that flocculent culture to be dominant and to improve settling within the high rate pond itself.

Benemman et al. (1981) found that removals in isolation ponds ranged from $81 \%$ to 95\% TSS and averaged $88 \%$. Benemann et al. also found that factors such as the behavior of cultures with large grazing organisms, mixing approach, and physical parameters of the pond (depth, shape, etc.) had little or no effect on algal removals. The greatest effects on settling were algal sludge seeding and manipulation of growth conditions during pond operation (Benemann et al., 1981). For instance, when algal sludge was recovered at the end of the previous experiment and seeded into the growth pond culture, bioflocculation was more rapid. An algal removal of $80 \%$ was reached in 21 days in the seeded pond compared to 29 days in the control (Benemann et al., 1981).

Manipulation of growth conditions was found to be the most effective means for reducing the required length of the isolation periods (Benemann et al., 1981). Growth conditions such as nutrient stress shortens the time the algal culture takes to enter the stationary growth phase, where polymer accumulation is largest, thereby shortening the isolation periods (Benemann et al., 1981). Growth at relatively high light intensity tended to reduce required isolation periods due to increased algal photorespiration and loss of algal cell viability (Benemann et al., 1981). The combination of bacterial and algal extracellular polymers was found to be important to reduce pond isolation periods (Benemann, 1981). 
Benemann et al. (1981) developed another technology termed high rate pond bioflocculation in which flocculent algal cultures could be produced within properly operated high rate ponds. Using flocculent cultures of Microactinium, Benemann et al. (1981) showed that cultures grown with a moderate dilution rate were more settleable than those with a high dilution rate ( $80 \%$ for moderate to $76 \%$ removal for high). Benemann et al. concluded that a combination of both of these techniques (pond isolation and high rate pond bioflocculation) is the most feasible option for the harvesting of microalgae (Benemann et al., 1981). Pond isolation is hindered by the long detention time necessary and high rate bioflocculation is variable in the degree of settleability it can maintain (Benemann et al., 1981). Thus, control of bioflocculation processes have shown modest success, but it still remains hard to scale up to achieve year round harvesting efficiencies of above $95 \%$ with concentrate around 1.5 to $3 \%$ solids (Benemann and Oswald, 1996; Pavoni et al., 1972).

Similar studies by Al-Shayji in Kuwait showed that algal production (kg/ha.d) depended on the efficiency of floc formation and settling (Al-Shayji, 1994). These studies used pilot scale high rate algal ponds fed by municipal wastewater followed by a sedimentation tank. Scenedesmus species dominated the culture growth (Al-Shayji, 1994). A minimum of a 2-hour residence time was needed in isolating settling tanks to achieve adequate separation of the algae (Al-Shayji, 1994). Most of the time during pilot scale operation, effluent suspended solids were less than 20 to $30 \mathrm{mg} / \mathrm{L}$ (Al-Shayji, 1994). This study showed that the floc formation depended on the weather and operational conditions including variations of the flow rate and pond depth (Al-Shayji, 1994). In many cases, the settled material varied by the hour of the day by as much as $20-30 \%$, illustrating that these results were highly variable with the relatively short detention times used for separation (Al-Shayji, 1994). Like Benemann et al.'s (1981) results, Al-Shayji found that using pond 
isolation required a multiple day retention time for increased algal removal efficiency. Since Al-Shayji's study only relied on a fixed isolation time of two hours, results using the isolation technique were more variable according to the operational conditions encountered (Al-Shayji, 1994).

The effect of carbon dioxide addition on algal bioflocculation in experimental high rate ponds was also studied (Park, 2010). The predominant algal cultures included Scenedesmus, Microactinium, and Pediastrum (Park, 2010). Using a high rate algal pond with a short four-day hydraulic retention time, nearly double the algal production was observed with carbon dioxide addition compared to the control pond with no carbon dioxide addition (Park, 2010). Overall, using a simple gravity settler and three-hour retention time , a consistent settling efficiency of greater than $60 \%$ was achieved for the carbon dioxide supplemented culture (Park, 2010). Park concluded that the algal biomass grown in wastewater treatment high rate algal ponds with carbon dioxide addition may be harvested efficiently with a retention time of three hours or less (Park, 2010).

\section{Section 2.5.2 Settling Characteristics of Activated Sludge}

Settling in activated sludge wastewater treatment systems is reviewed briefly in this section to provide context for algae settling. In activated sludge, microbial EPS is a major component of the activated sludge floc matrix (Li, 2007). Different stages of growth in the activated sludge process correspond to better treatment performance and settling (and bioflocculation) of the microorganisms present as a result mainly of the microbial EPS produced. The logarithmic and lag phases of growth are not significantly associated with any floc formation; rather, bioflocculation is observed during later stages of growth during declining growth (Gerardi, 2002). Bacterial floc formation is greatest when the maximum bacterial population is reached and the bacteria have aged significantly to produce fibrils, 
polysaccharides, and polyhydroxybutyrate (PHB) granules (Gerardi, 2002). In addition, changes in the microbial community structure can influence settling. For example, during endogenous phase of growth, the formation of filaments extends the floc formation to form dense, strong flocs (Gerardi, 2002). The presence of rotifers also serves to provide significant cropping of the dense flocs, allowing the flocs to become heavier and more tightly bound (Gerardi, 2002).

One study examined the microbial EPS within the activated sludge matrix as a function of solids retention time (SRT) and carbon source addition (Li, 2007). Li found that the activated sludge EPS includes both loosely bound and tightly bound components (Li, 2007). The production of tightly bound EPS component was not affected by the SRT, but the loosely bound EPS content increased as the sludge SRT increased (Li, 2007). Li also found that sludge fed on glucose contained more EPS than sludge grown on acetate. Even though the glucose-fed sludge had more available EPS, the acetate-fed sludge performed better in terms of bioflocculation, sludge sedimentation and compression, as well as sludge dewaterability (Li, 2007). As the SRT was increased for both of the carbon sources, the sludge flocculation and separation improved (Li, 2007). In the case of acetate-fed sludge the loosely bound EPS was shown to have a negative effect on the bioflocculation and sludge water separation (Li, 2007). Li's study argued that type and composition of EPS is essential for strong, dense floc formation, as floc formation and cell attachment was weakened by excessive loosely bound EPS resulting in weaker bioflocculation, greater cell erosion and retarded sludge water-separation (Li, 2007).

Badireddy et al. (2010) investigated the effects of EPS composition on activated sludge settling and showed that bioflocculation improved with total carbohydrates and proteins in the activated sludge sampled. Flocculation of the bacteria was inhibited during 
exponential growth phase when EPS content was low and acidic in nature (Badiredy et al., 2010). This poor bioflocculation performance was attributed to the combination of decreased polymeric interactions and electrostatic repulsion (Badireddy et al., 2010). Similarly, a higher fraction of uronic acids to total EPS was found to increase the negative charge of the microorganisms during exponential growth, thereby reducing their ability to flocculate (Badireddy et al., 2010). However, enhanced bioflocculation was achieved during stationary growth phase given greater amounts of EPS were present over the uronic acids present (uronic acids with respect to EPS was low) (Badireddy et al., 2010). Therefore, better bioflocculation was obtained with higher concentrations of proteins and carbohydrates (EPS), possibly because the polymeric interactions and bridging cancelled out the electrostatic repulsions (Badireddy et al., 2010). Badireddy et al. also found that EPS compounds such as proteins, carbohydrates and alcohols promoted microorganisms to flocculate, while functionalities such as carbonyl, carboxylate, acetal, and hemiacetal/hydrocarbons hampered bioflocculation (Badireddy et al., 2010).

In a study by Pan et al. (1999), algal biomass was shown to improve the dewatering characteristics and bioflocculation capability of activated sludge. In this study, sludge with Pediastrum, Ankistrodesmus, and some diatom algal species was aged in a container free of sunlight. After 5 days of sludge storage, significant flocculation was found between the sludge particles and the algae by microscopic analysis (Pan et al., 1999). On the tenth day, the flocculation began to breakdown and the algae and its exudates were degraded by the bacteria (Pan et al., 1999). It was found that as the algae aged, more EPS was released and the flocs became larger due to more advanced flocculation (Pan et al., 1999).

Over the course of the sludge storage, the $\mathrm{pH}$ and the total solids content remained unchanged (Pan et al., 1999). The TOC, zeta potential, and bound water content, however, 
decreased throughout storage (Pan et al., 1999). The zeta potential was shown to decrease until the fifth day, where algae and the largest presence of EPS, bearing negative charges, were shown to be responsible (Pan et al., 1999). After this period, the charge reversed due to the fact that the bacteria gradually degraded both the algae and its exudates (Pan et al., 1999). Given that the TOC stayed constant during the first six days, algal biomass and EPS degradation was seen to stabilize before dropping for the remaining period as bacteria degraded the EPS components (Pan et al., 1999). Sludge conditioning through use of a cationic polymer also was observed to be best after 5 days of ageing when the most algal exudates were present (Pan et al., 1999). Thus, over the aging process algae and its exudates significantly changed the surface properties of the algae-containing sludge, affecting the conditioning by allowing more bioflocculation to occur with less cationic polymer dosage (Pan et al., 1999).

\section{Section 2.5.3 Addition of Bioflocculants to Improve Microalgal Harvesting}

Multiple researchers have developed bioflocculants that can significantly improve flocculating efficiency and settleability of algal cultures. Bioflocculants studied include organisms such as autoflocculating microalgae and floc-forming bacteria of activated sludge matrices (Salim et al., 2011). This section will discuss studies using first bacterial bioflocculants (Section 2.5.3.1), then algal bioflocculants (Section 2.5.3.2), as well as flocforming bioflocculants (i.e. RAS addition, Section 2.5.3.3) isolated from wastewater treatment plants.

\section{Section 2.5.3.1 Addition of Bacterial Flocculants to Improve Microalgal Harvesting}

Harvesting of algae with the addition of bacterial bioflocculants has been studied recently by several research groups (Oh et al., 2001; Kim et al., 2011; Lee et al., 2009). For example, Oh et al. (2001) conducted a study on the harvesting of Chlorella vulgaris using the 
bacterium Paenibacillus (AM49) as a bioflocculant. In this study, the strain AM49 increased flocculating efficiency by up to 93\%, with flocculation efficiency increasing with increasing concentration of bioflocculant (Oh et al., 2001). The culture age of Chlorella vulgaris used was fixed at 6 days (early stationary phase) and the study did not investigate settling at different algal growth phases (Oh et al., 2001). The AM49 strain was tested with a variety of other microalgae, including Scendesmus quadricada and Anabaena flos-aquae, and flocculation efficiency ranged from 39 to $95 \%$ as compared to $93 \%$ for Chlorella vulgaris (Figure 2.20) (Oh et al., 2001). Poor settling with bioflocculant addition was observed for Anabaena flos-aquae and Microcystis aeruginosa, which shows that improved harvesting of microalgae, depends on the type of bioflocculant used (Figure 2.20).

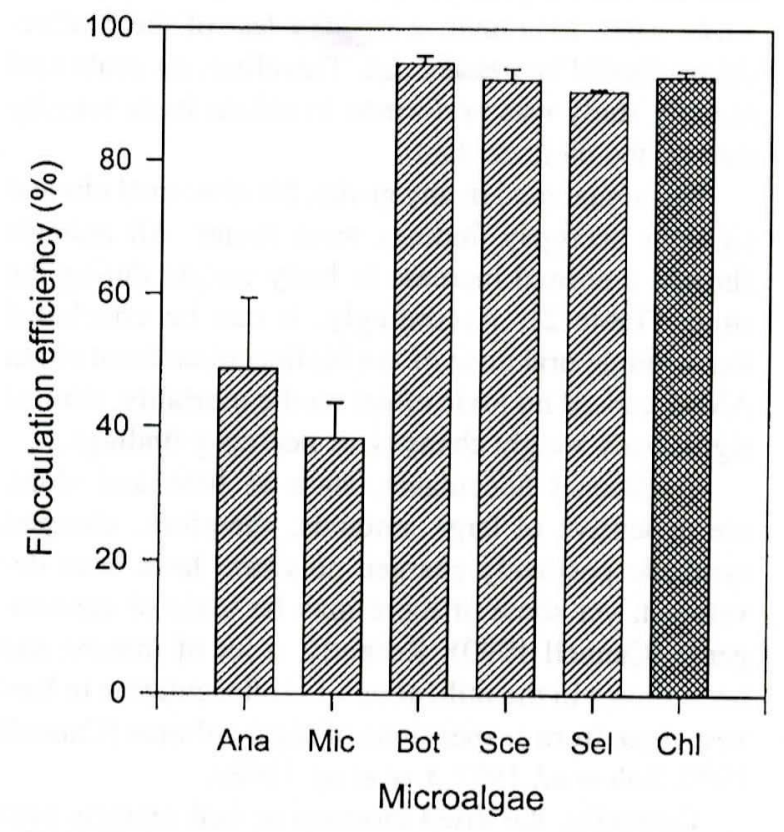

Figure 2.20-Flocculation of AM49 with different species of Microalgae with a fixed dose of bioflocculant (Ana-Anabaena flos-aquae; Mic-Microcystis aeruginosa; BotBotrycoccus braunii; Sce-Scenedesmus quadricada; Sel-Selanastrum capricornutum; Chl-Chlorella vulgaris) (Source: Oh et. al, 2001)

A parallel study was conducted on the harvesting efficiency of a bacterial bioflocculant added to a pure Scenedesmus culture (Kim et al., 2011). The same bacterial 
strain used in the study above, Paenibacillus polymyxa AM49, was researched as the principal bioflocculant. The bacterial culture was added to a high-density, late stationary phase, culture (16 days of growth) of Scendesmus species at a concentration of $1 \%(\mathrm{v} / \mathrm{v})$. Bioflocculant production by this bacterium, as measured by EPS concentration of the bacterial strain used, increased to the late exponential growth phase and then remained constant during the stationary phase of bacterial growth, following a close relationship with its growth curve (Kim et al., 2011). In this study, flocculation was monitored with addition of chemical co-coagulants, such as ammonium chloride, potassium chloride, calcium chloride, ferric chloride and ammonium sulfate. These co-coagulants had a significant effect on the settling of Scenedesmus and the flocculation increased with increasing electrical charges of the cations (Kim et al., 2011). However, increasing the concentration of the inorganic coagulants used, especially at higher culture densities of Scenedesmus, resulted in higher flocculation efficiencies (Kim et al., 2011).

An earlier study focusing on bacterial flocculation for algae harvesting used a mixed microbial culture to improve the flocculation of a marine microalgae (Lee et al., 2009). This study involved growing a marine species of algae, Pleurochrysis carterae, in a photobioreactor, where cultures near the end of logarithmic phase of growth and beginning stationary phase were used for flocculating experiments (Lee et al., 2009). Cultures of Pseudomonas stutzeri and Bacillus cereus were added as potential bioflocculants (Lee, 2009). This study varied the substrate type (glucose, acetate, and glycerine) and concentration ( 0.1 and $0.5 \mathrm{~g} / \mathrm{L})$ for growth of the microbial bioflocculants as well as the mixing time for addition of bioflocculants to the microalgae (between 6 and 24 hours). Marine microalgal flocculation using all three types of substrate was substantially enhanced at longer mixing times with around 90 to 95\% removal of algal cells (after 24 hours) (Lee et al., 2009). At shorter mixing times, flocculating efficiency was worse for all substrate types 
and concentrations, with a 45 to 55\% range in removal of algal cells. At higher doses of organic carbon, larger volumes of flocs were evidenced, but the recovery efficiency (percent algal cells removed) remained relatively constant (Lee et al., 2009).

In this study a lack of nutrients was identified as a major factor that stresses the microbes to form more EPS (Lee et al., 2009). However, the volume of EPS produced was not related to the flocculation observed, as a more tightly bound EPS was more desirable given that this type of EPS produced the best flocculation (Lee et al., 2009). This study also concluded that tightly bound EPS can be achieved by reducing the organic carbon, increasing the mixing time and using the right dosage of microbes (Lee et al., 2009). Lastly, proper mixing time was crucial to increase the frequency of contact between the microalgae and the EPS, where too little mixing resulted in poor floc formation and over mixing caused the flocs to break into smaller fragments (Lee et al., 2009). Without this mixing intensity, $P$. carterae was allowed to settle under gravity, and researchers found that the flocs formed were too loose and difficult to separate properly from the culture media (Lee et al., 2009).

\section{Section 2.5.3.2 Addition of Algal Flocculants to Improve Microalgal Harvesting}

Bioflocculation of a non-flocculating microalgal culture can also be induced by adding flocculating microalgae (Salim et al., 2011). A preliminary study used the naturally flocculating diatom Skeletonema to successfully flocculate a non-flocculent culture of Nannochlorposis (Salim et al., 2011). Similarly, Chlorella vulgaris and Neochloris oleoabundans (non-flocculent cultures) were grown and combined with the following flocculating microalgae: Scenedesmus obliquus, Tetraselmis suecica, and Ankistrodesms falcatus in order to improve microalgal harvesting (Salim et al., 2011). All three flocculating microalgae improved recovery efficiency of the two non-flocculent cultures when they were applied at a higher concentration, although doubling the concentration of flocculating 
microalgae did not double the recovery efficiency of the previously nonflocculent culture (Salim et al., 2011). Mixing of the flocculating microalgae with the nonflocculent cultures prior to sedimentation increased the initial settling rates considerably (Salim et al., 2011). Micrographs from this study (e.g., Figure 2.21) show the improved algal flocculation over an eight-hour period for different combinations of flocculating and non-flocculating microalgae. Pictures A-C taken represent the non-flocculating microalgae that are present as single cells before floc formation is observed. Similarly, pictures D-F show flocculating species of microalgae used. After sedimentation, non-flocculating microalgae can be observed embedded into the flocs formed by the flocculating microalgae, supporting the observation that the addition of flocculating microalgae improves the recovery of nonflocculating microalgal species (Salim et al., 2011). 

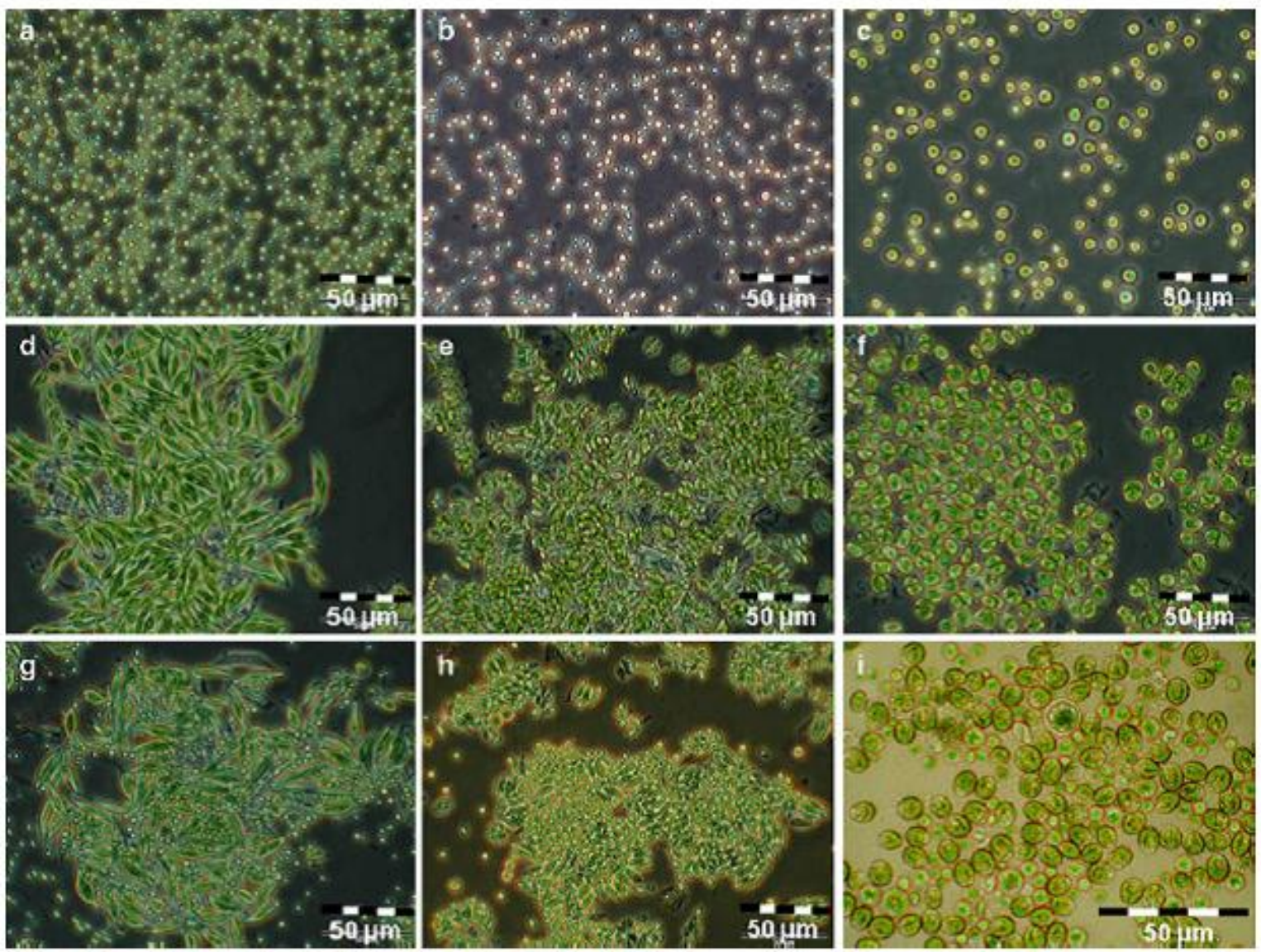

Figure 2.21-Photomicrographs of results observed with different flocculating microalgae, (A) and (B)-Chlorella vulgaris; (C)-Neochloris oleoabundans; (D)Ankistrodesmus falcatus; (E)-Scenedesmus obliquus; (F)-Tetraselmis suecica; (G)-C. vulgaris with A. falcatus; (H)-C. Vulgaris with S. obliquus; and (I)-N. oleoabundans with T. suecica (Source: Salim, 2011)

Another promising strategy is recycling of settled algal species in high rate algal ponds as proposed by Park and Craggs (2011). Recycling settled algal biomass resulted in an increased dominance of Pediastrum species (76 to $99 \%$ dominance) as compared to the control HRAP (0-98\% dominance) (Park \& Craggs, 2011). In this study, recycling harvested algal biomass was found to preferentially select algae that settle more rapidly. The increased dominance of the Pediastrum species allowed an improved harvest efficiency of greater than $85 \%$ as compared to the control pond, which demonstrated an efficiency of 
only 60\% (Park \& Craggs, 2011). The settling results depended on the extent of algal species domination within the algal HRAP's. If Pediastrum was dominant at least $80 \%$ over all other species, it exhibited 99.2\% harvesting efficiency over a 24 -hour period and resulted in 2.5 to $3 \%$ solids after twenty-four hours of gravity sedimentation (Park \& Craggs, 2011). If Pediastrum was less dominant and the culture was afflicted by poor settleable unicellular algae (Thalassiosia species), only about 1.5 to $2 \%$ solids were reached after 24 hours of gravity sedimentation (Park and Craggs, 2011). Recycling increased the average size and biovolume of the dominant Pediastrum by $13-30 \%$ and $50-80 \%$ respectively, which further suggests good settling (Park and Craggs, 2011). Thus, recycling of harvested algal biomass is a simple and effective operational strategy to maintain dominance of readily harvestable algal species (Park and Craggs, 2011).

\section{Section 2.5.3.3 Addition of Return Activated Sludge (RAS) to Improve Microalgal}

\section{Harvesting}

An early study focusing on return activated sludge (RAS) addition to improve the settling of microalgae involved culturing a readily settleable algal-bacterial biomass that provided high-level treatment for use in HRAP’s (Gutzelt et al., 2005). Using both a laboratory scale and pilot scale reactor system, Gutzelt et al. (2005) grew a suspension of Chlorella vulgaris and added activated sludge from a municipal WWTP. The laboratory system was run as a sequential batch reactor (SBR) and the pilot scale system as a continuously stirred tank reactor (CSTR). Within four weeks of operation, the ratio of Chl. A of the supernatant phase to the total Chl. A. in the laboratory reactor decreased from $95 \%$ to $0.26 \%$ (Gutzelt et al., 2005). In addition, the effluent biomass TSS of the lab scale SBR system was 1 to $1.5 \mathrm{~g} / \mathrm{L}$ (Gutzelt et al., 2005). Sludge volume indices of 80 to $120 \mathrm{ml} / \mathrm{g}$ and sedimentation after only ten minutes of the entire biomass proved that the pilot scale 
system also functioned well (Gutzelt et al., 2005). Results indicated that in both the laboratory and pilot-scale systems, algal bacterial aggregates could be developed successfully with Chlorella vulgaris and wastewater species (Gutzelt et al., 2005).

Another study using the same sequencing batch reactor (SBR) approach was operated in New Zealand to reproduce the Germany study (Valigore et al., 2012). The SBRs were operated with a combination of native microalgae to the wastewater treatment oxidation ponds as well as bacteria fed from primary treated wastewater (Valigore et al., 2012). The solids retention times over the time course of the experiment were varied from 4 to 40 days (Valigore et al., 2012). Results signified that longer SRTs in the SBR system enhanced biomass settleability, while shorter HRTs enhanced productivity (Valigore et al., 2012). Together, the greatest settleability and productivity of algal biomass was attained when settleable flocs were recycled to achieve longer SRTs than HRTs (Valigore et al., 2012). Therefore, the longer SRTs were more effective due to biomass recycling which reduced the growth rate, thereby facilitating better floc formation and sedimentation (Valigore et al., 2012). Finally, at these long SRTs, biomass productivity was found to be up to $31 \mathrm{~g} /$ day $/ \mathrm{m}^{2}$ of solids, corresponding with a biomass settleability ranging from 70 to 95\% (Valigore et al., 2012). This study proved that SBRs operating with longer SRTs and short HRTs allow the production of a large amount of biomass for conversion to biofuel, as well as a corresponding improved bioflocculation and sedimentation of the biomass grown (Valigore et al., 2012).

In a similar study on RAS addition, effects of bacterial community, algal settleability, and carbon/nutrient removals in a series of photobioreactors were investigated (Su et al., 2012). The inoculum ratios of each bioreactor used ranged from 1:1 algae to activated sludge, 1:5 and 5:1 respectively (Su et al., 2012). In this study, activated sludge alone settled 
the best, while the algae alone settled the worst (Figure 2.22; Su et al., 2012). The 1:5 algae to sludge ratio performed the second best, followed by 1:1, 5:1 and 10:1 indicating that activated sludge improved algae settling (Figure 2.22; Su et al., 2012). Analysis of the bacterial community structure for different inoculum ratios of RAS showed that differing algae to bacteria inoculation ratios had an effect on the bacterial community composition, possibly contributing to improved removal efficiencies (Su et al., 2012).

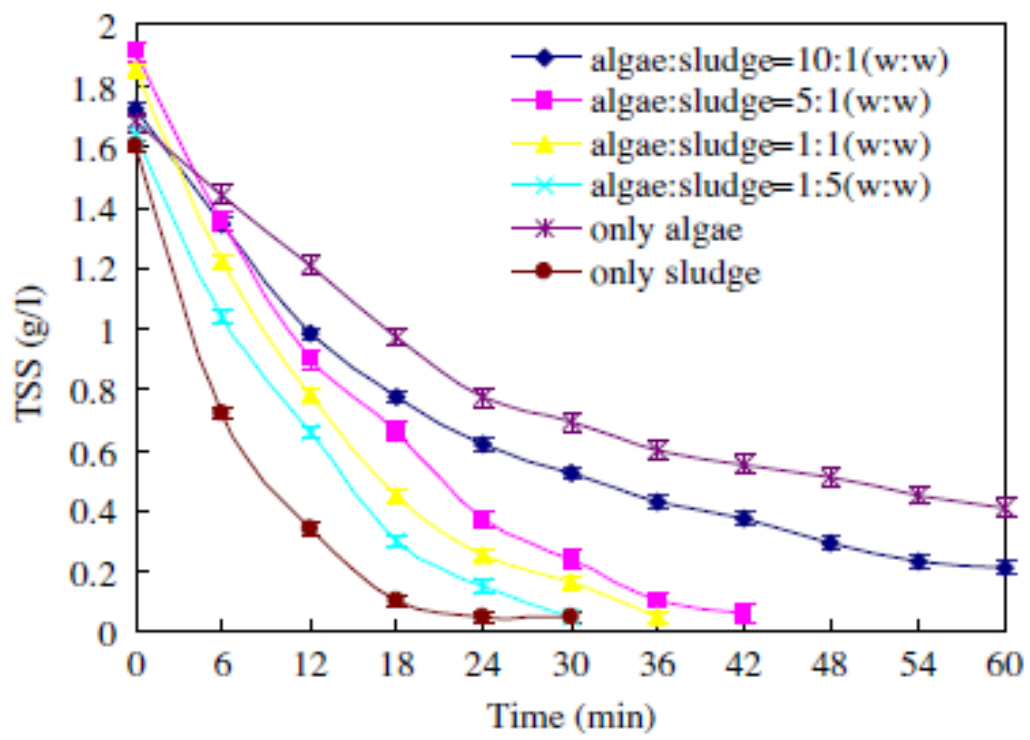

Figure 2.22-Settleability of biomass (algal and bacterial) with different RAS inoculation ratios (Source: $\mathrm{Su}, 2012$ ) 


\section{CHAPTER 3: METHODS AND MATERIALS}

The methods and equipment for microalgal and bacterial growth, settling test procedures, evaluation of settleability performance, as well as EPS quantification are described in this chapter. This research was focused on culturing and analyzing the settling characteristics of two species of algae: Scenedesmus sp. and Chlorella vulgaris with use of the bacterium Burkholderia cepacia as the bioflocculant.

\subsection{Initial Growth of Algal and Bacterial Cultures}

Algal cultures obtained from the UTEX collection were first grown in 250 mL flasks using WC media, as described in Table 3.1 below. The two species of algae were Chlorella vulgaris (UTEX \# 265) and Scenedesmus sp. (UTEX \# 1589). WC medium is a defined growth medium, designed for use with most fresh water, green microalgal species (Andersen, 2005). In these experiments, Tris base was used as the primary buffer, instead of Glycylglycine. Additional stock solutions of vitamins and trace metals were also required at concentrations listed in Tables 3.2 and 3.3. The only procedure that differed for the preparation of the media, was preparing the vitamin stock solution, which required filter sterilization by a $0.2 \mu \mathrm{m}$ filter, and then needed to be stored at $-20^{\circ} \mathrm{C}$. 
Table 3.1-Composition of WC medium and concentration of chemical components (Source: Andersen, 2005)

\begin{tabular}{|c|c|}
\hline Component & Concentration in Medium (M) \\
\hline Tris (Buffer) & $4.13 \times 10^{-3}$ \\
\hline $\mathrm{NaNO}_{3}$ & $1.00 \times 10^{-3}$ \\
\hline $\mathrm{CaCl}_{2} \cdot 2 \mathrm{H}_{2} \mathrm{O}$ & $2.50 \times 10^{-4}$ \\
\hline $\mathrm{MgSO}_{4} \cdot 7 \mathrm{H}_{2} \mathrm{O}$ & $1.50 \times 10^{-4}$ \\
\hline $\mathrm{NaHCO}_{3}$ & $1.50 \times 10^{-4}$ \\
\hline $\mathrm{Na}_{2} \mathrm{SiO}_{3} \cdot 9 \mathrm{H}_{2} \mathrm{O}$ & $1.00 \times 10^{-4}$ \\
\hline $\mathrm{K}_{2} \mathrm{HPO}_{4}$ & $5.00 \times 10^{-5}$ \\
\hline Vitamin Stock & See Table 3.2 \\
\hline Trace Metal Stock & See Table 3.3 \\
\hline
\end{tabular}

Table 3.2-Composition of Vitamin Stock solution for WC medium (Source: Andersen, 2005)

\begin{tabular}{|c|c|}
\hline Component & Concentration in Final Medium (M) \\
\hline Thiamine $\cdot \mathrm{HCl}($ vitamin B1) & $2.96 \times 10^{-7}$ \\
\hline Biotin (vitamin H) & $2.05 \times 10^{-9}$ \\
\hline Cyanocobalamin (vitamin B12) & $3.69 \times 10^{-10}$ \\
\hline
\end{tabular}

Table 3.3-Composition of Trace Metals stock solution for WC medium (Source: Andersen, 2005)

\begin{tabular}{|c|c|}
\hline Component & Concentration in Final Medium (M) \\
\hline $\mathrm{Na}_{2} \mathrm{EDTA} \cdot 2 \mathrm{H}_{2} \mathrm{O}$ & $1.17 \times 10^{-5}$ \\
\hline $\mathrm{FeCl}_{3} \cdot 6 \mathrm{H}_{2} \mathrm{O}$ & $1.17 \times 10^{-5}$ \\
\hline $\mathrm{CuSO}_{4} \cdot 5 \mathrm{H}_{2} \mathrm{O}$ & $4.01 \times 10^{-8}$ \\
\hline $\mathrm{ZnSO}_{4} \cdot 7 \mathrm{H}_{2} \mathrm{O}$ & $7.65 \times 10^{-8}$ \\
\hline $\mathrm{CoCl}_{2} \cdot 6 \mathrm{H}_{2} \mathrm{O}$ & $4.20 \times 10^{-8}$ \\
\hline $\mathrm{MnCl}_{2} \cdot 4 \mathrm{H}_{2} \mathrm{O}$ & $9.10 \times 10^{-7}$ \\
\hline $\mathrm{Na}_{2} \mathrm{MoO}_{4} \cdot 2 \mathrm{H}_{2} \mathrm{O}$ & $2.48 \times 10^{-8}$ \\
\hline $\mathrm{H}_{3} \mathrm{BO}_{3}$ & $1.62 \times 10^{-5}$ \\
\hline
\end{tabular}


To keep conditions sterile for the algae, the 250-mL flasks and the WC media were autoclaved for 50 minutes at $121^{\circ} \mathrm{C}$. The algae from the agar slants received from UTEX were revived in the WC media by transferring with a sterilized inoculating loop into sterile medium. The algae were placed in 250 -mL flasks with sterile silicone enclosures and mixed under an 8-hour illumination using a light rack apparatus with specifications according to the Figure 3.1. The temperature and $\mathrm{pH}$ were not controlled during these initial inoculumgrowing procedures. Optical density was monitored daily for both the Scenedesmus and Chlorella cultures for 2 weeks of the first batch culture using a Spectronic 20 spectrophotometer (Milton Roy Company, remanufactured by Update Instrument, Inc. Madison, WI). Illumination was provided by eight fluorescent Vita Lite ${ }^{\circledR} 40$-Watt light bulbs, equivalent to $403 \mathrm{~W} / \mathrm{m}^{2}$ per bulb (or $1610 \mathrm{~W} / \mathrm{m}^{2}$ for the entire light rack assuming the distance from the bulb to the flasks was 3.5 inches). Lithonia Lighting manufactured the four ballasts. This process of growth of inocula was continued for two more batch inoculations using the same technique described above before stepping up growth to larger 2-L Schott Duran bioreactors, and later 4-L jar bioreactors that are described in more detail in the following section (Figures 3.2). 


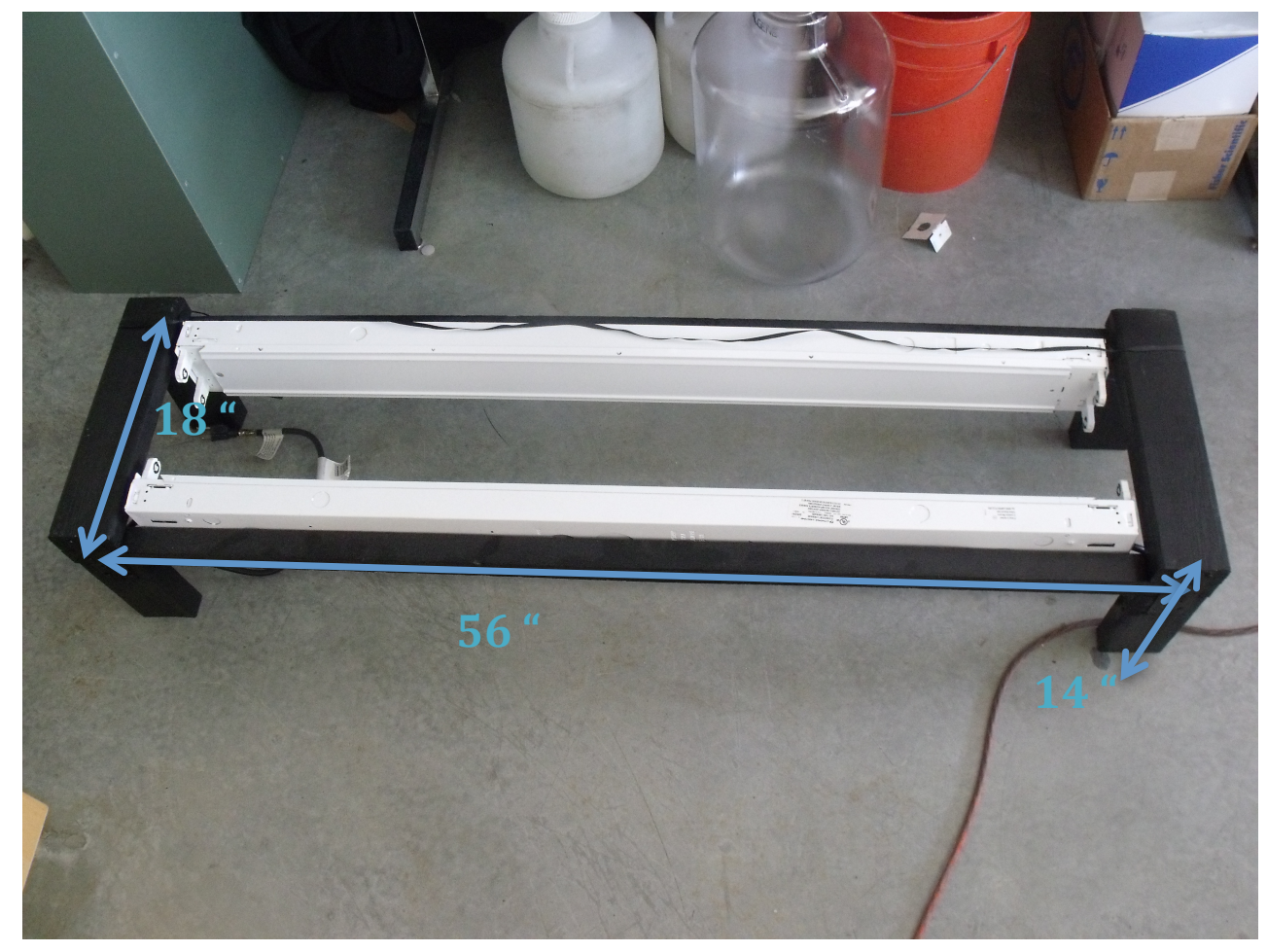

Figure 3.1- Light rack apparatus used for algal illumination for growth

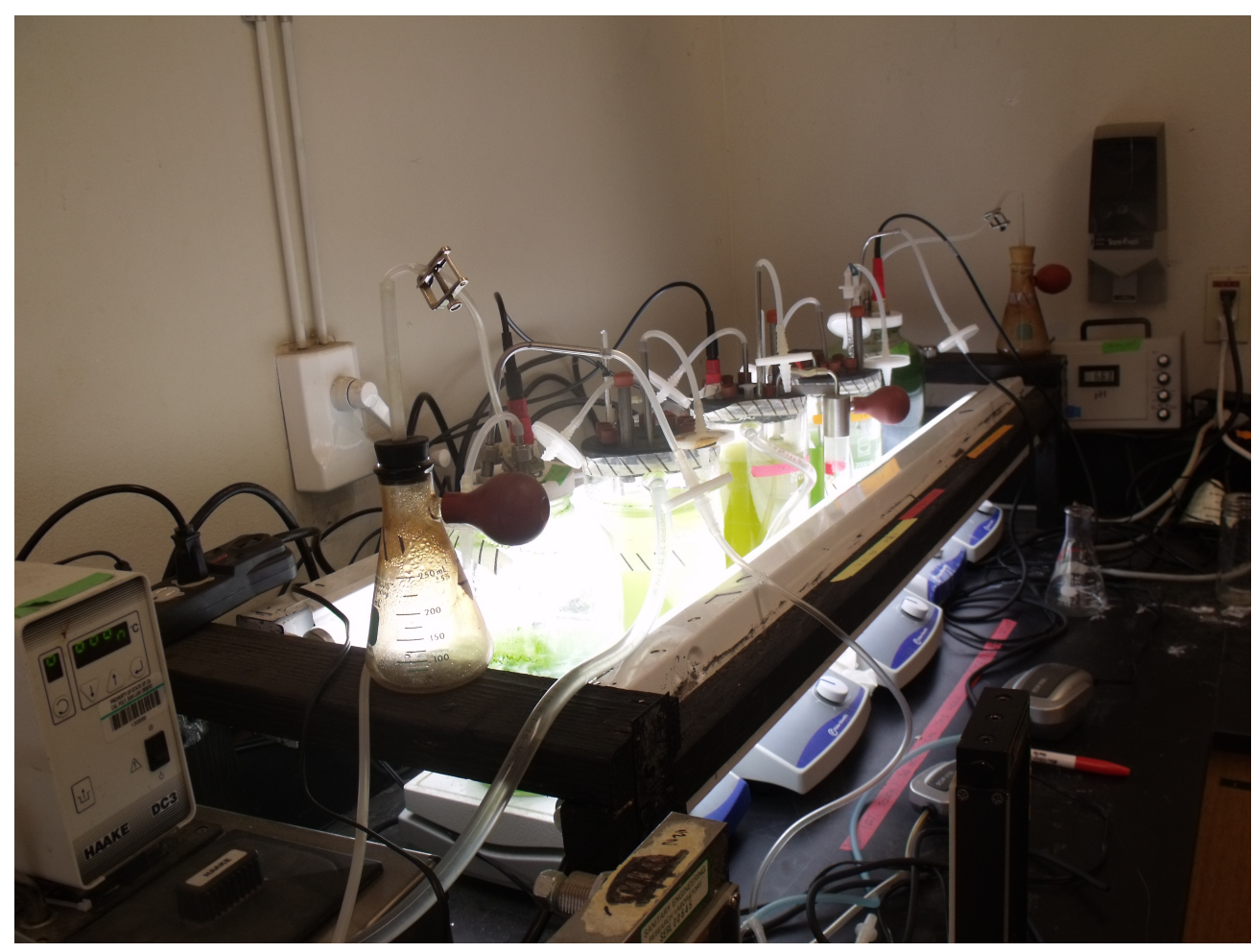

Figure 3.2-Light rack apparatus in use in the laboratory 
To preserve the newly obtained cultures, the algal cultures from the first batch culture broth were inoculated onto sterile petri dishes (Fisher) using two different media recipes: WC medium as described above and Bristol Medium as specified by the UTEX website and described in Table 3.4. To each 1-L of media, $1.5 \%$ agar or 15 g were added, mixed sufficiently, and autoclaved at the same conditions specified above. The plates were then inoculated with first batch culture of algae from the broth growing for 6 days, and algae were allowed to grow on the agar under illumination for two weeks. The plates were then refrigerated at $4^{\circ} \mathrm{C}$ until future inoculation was needed. This process of plating was completed for several batch inoculations.

Table 3.4 - Composition of Bristol Medium used for plating of algal cultures (Adapted from the UTEX website)

\begin{tabular}{|c|c|c|c|}
\hline Composition & $\begin{array}{c}\text { Amount } \\
\text { (mL/L) }\end{array}$ & $\begin{array}{c}\text { Stock Solution } \\
\text { Concentration } \\
\text { (g/400 mL DI) }\end{array}$ & $\begin{array}{c}\text { Final Concentration } \\
\text { (mM) }\end{array}$ \\
\hline $\mathrm{NaNO}_{3}$ & 10 & 10 & 2.94 \\
\hline $\mathrm{CaCl}_{2} * 2 \mathrm{H}_{2} \mathrm{O}$ & 10 & 1 & 0.17 \\
\hline $\mathrm{MgSO}_{4} * 7 \mathrm{H}_{2} \mathrm{O}$ & 10 & 3 & 0.3 \\
\hline $\mathrm{NaCl}$ & 10 & 1 & 0.43 \\
\hline $\mathrm{KH}_{2} \mathrm{PO}_{4}$ & 10 & 7 & 1.29 \\
\hline $\mathrm{K}_{2} \mathrm{HPO}_{4}$ & 10 & 3 & 0.43 \\
\hline
\end{tabular}

The bacterium Burkholderia cepacia was grown to provide EPS for bacterial bioflocculation experiments. The B. cepacia was obtained as a lyophilized culture from the ATCC culture collection (ATCC \#10856). The ATCC culture tube filled with $20 \mathrm{~mL}$ of nutrient broth (BD 23400) as directed by the ATCC guidelines. The nutrient broth had a composition shown in Table 3.5. With addition into the culture test tube and sufficient agitation, $5 \mathrm{~mL}$ of the bacterial culture was transferred into four different, $250 \mathrm{~mL}$ flasks containing $75 \mathrm{~mL}$ of the nutrient broth. The four flasks were covered with sterile closures and incubated on a Junior Orbit shaker (Labline Instruments, Inc. Melrose Park, Illinois), shaking at constant 
rotational speed of $200 \mathrm{rpm}$, and allowed to grow for 4 days. Following this growth period, the B. cepacia cells were transferred from the nutrient broth to $75 \mathrm{~mL}$ of MMS-3 media (Table 3.6).

Table 3.5-Composition of Nutrient Broth BD 23400, added to 1 Liter of DI, and pH adjusted to 6.8

(Source: ATCC website)

\begin{tabular}{|c|c|}
\hline Composition & Concentration $(\mathrm{g} / \mathbf{L})$ \\
\hline Peptone & 5 \\
\hline Beef Extract & 3 \\
\hline
\end{tabular}

The ionic strength was adjusted to $0.05 \mathrm{M}$ with sodium nitrate. Sodium chloride was substituted two times during growth with sodium nitrate and the calculated adjusted concentrations for both species can be viewed in the Table 3.7. Finally, the pH was adjusted to 6 before autoclaving.

Table 3.6- Modified MMS-3 Media (Source: Nelson et al., 1996)

\begin{tabular}{|c|c|}
\hline \multicolumn{2}{|c|}{ Composition of Modified MMS-3 } \\
\hline Composition & Concentration (mg/L) \\
\hline $99 \%$ Anhydrous Glucose & 79 \\
\hline $\mathrm{CaCl}_{2} * 2 \mathrm{H}_{2} \mathrm{O}$ & 30 \\
\hline $\mathrm{MgSO}_{4} * 7 \mathrm{H}_{2} \mathrm{O}$ & 35 \\
\hline $\mathrm{KNO}_{3}$ & 15 \\
\hline$\left(\mathrm{NH}_{4}\right)_{2} \mathrm{SO}_{4}$ & 120 \\
\hline $\mathrm{KH}_{2} \mathrm{PO}_{4}$ & 7 \\
\hline $\mathrm{NaHCO}_{3}$ & 0.84 \\
\hline
\end{tabular}

Table 3.7 - Concentrations of compounds used to adjust ionic strength to 05 M (in modified MMS-3 media)

\begin{tabular}{|c|r|}
\hline Composition & Concentration $\mathbf{( g / L )}$ \\
\hline $\mathrm{NaCl}$ & 2.635 \\
\hline $\mathrm{NaNO}_{3}$ & 3.832 \\
\hline
\end{tabular}

The second batch inoculation of bacteria was aseptically inoculated with $3.75 \mathrm{~mL}$ of bacterial broth from the four initial $250-\mathrm{mL}$ flasks into four new $250-\mathrm{mL}$ flasks each filled with $75 \mathrm{~mL}$ of defined MMS-3 medium. Growth was maintained for 3 days before the third batch culture was created, scaling up growth to 2-L bioreactors. During this 
same time, the B. cepacia cultures were inoculated on sterile petri dishes (Fisher) for culture preservation with MMS-3 medium. First and second batch cultures were inoculated onto the plates aseptically, and grown for 4 days at room temperature. Each new batch culture was inoculated monthly onto defined media MMS-3 plates for culture preservation.

\subsection{Scale-Up of Growth of Algal and Bacterial Cultures}

From the second batch culture, initial scale up of both the Chlorella and Scenedesmus cultures to the third batch culture was done in 1-L flasks grown in sterile conditions with defined WC medium. These third batch cultures were sparged with a blend of air and 5\% carbon dioxide (v/v), blended with a Matheson gas controller (Model 665). This ratio was maintained using a calibration curve of the airflow device shown in Figure 3.3. The red line indicates the relationship between the average velocity of the calibration device and the flowmeter readings at higher flowrates, while the blue line indicates the same trend at lower flowrates.

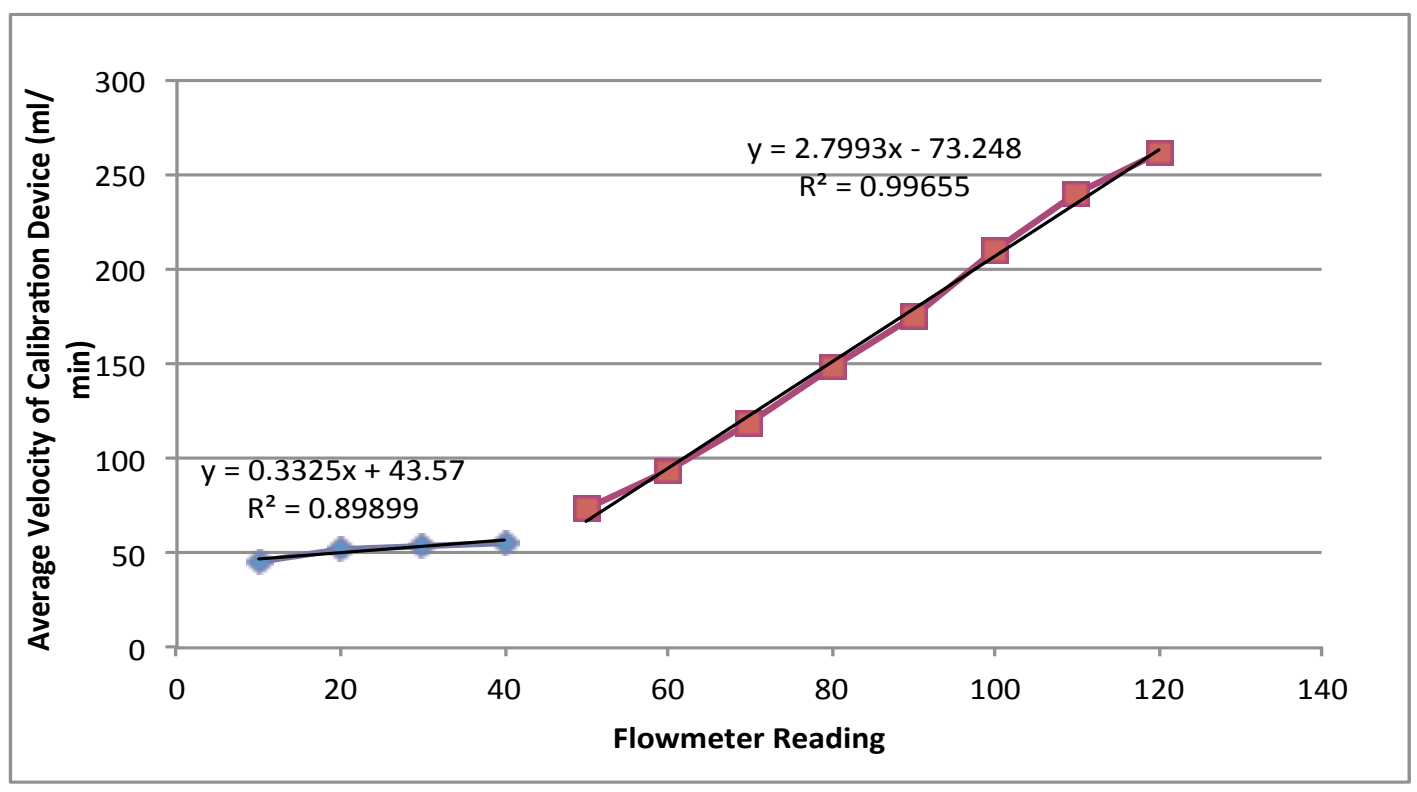

Figure 3.3-Calibration curve used to regulate airflow and carbon dioxide input for Mattheson Model 602/603 
The air was obtained from an aquarium pump (Top Fin) and was consistently allowed to enter the flaks. However, the carbon dioxide was restricted during hours when photosynthesis was not taking place to maintain $\mathrm{pH}$ control. Thus, carbon dioxide inputs were stopped or partially closed with a metal clamp when $\mathrm{pH}$ dropped below 6.5 and was started again when the $\mathrm{pH}$ climbed to around 9 or 10 . The $\mathrm{pH}$ was monitored daily with an autoclavable probe (Mettler Toledo, Cole Parmer: Vernon Hills, Illinois). Optical density was monitored during growth using a UV 1700 Pharma Spec model spectrophotometer (Shimadzu) at 625 nanometers.

Following two to three weeks of growth, scale up of the algal cultures involved transferring $100 \mathrm{~mL}$ of third batch culture inoculum into autoclaved 2-L bioreactors filled with $1800 \mathrm{~mL}$ of autoclaved WC media. The bioreactors were constructed using waterjacketed beakers (Schott Duran) to allow temperature control with a Haake model DC3 water bath. As above, carbon dioxide was blended at $5 \%$ with air and $\mathrm{pH}$ was constantly monitored with a Mettler Toledo probe. Cultures were stirred at $150 \mathrm{rpm}$ using a stir bar and stir plate (Fisher). Temperatures were maintained at $25^{\circ} \mathrm{C}$. Temperature was also monitored with a thermometer placed inside the bioreactor to confirm readings with the water jacket system. Again, the fourth batch culture growth was monitored with optical density readings taken daily using the Spectronic 20 spectrophotometer.

To obtain a larger volume of algae for settling tests, a final scale up of growth consisted of transferring $100 \mathrm{~mL}$ of fourth batch culture inoculum into autoclaved 4-L clear glass jars filled with 4-L of autoclaved WC media (Figure 3.4). The tops of these jars had ports for filter sterilized air inlets, sterilized filter air outlets, as well as a $\mathrm{pH}$ probe/sampling port that was attached to another autoclaved 250-mL filter flask (Fisher) with a bulb to transfer samples out of the reactor. Millipore air filters, with pore size of 0.2 microns, were used to filter the air in and air out. From this fifth batch culture on, carbon 
dioxide input was not needed, because air addition by an aquarium pump was sufficient for algal growth. No temperature control or $\mathrm{pH}$ control was used in the 4-L bioreactors, and growth of the cultures was usually sustained at a pH between 8 and 9, and an average room temperature of $21^{\circ} \mathrm{C}$. Growth of these cultures was monitored daily using optical density at 625 nanometers with a UV 1700 Pharma Spec model spectrophotometer (Shimadzu). Dry weight and optical density measurements were correlated well for both Scenedesmus and Chlorella (Figures 3.5 and 3.6) with $\mathrm{r}^{2}$ values of 0.96 to $0.99 .15-20 \mathrm{~mL}$ samples were taken for EPS analysis once every other day.

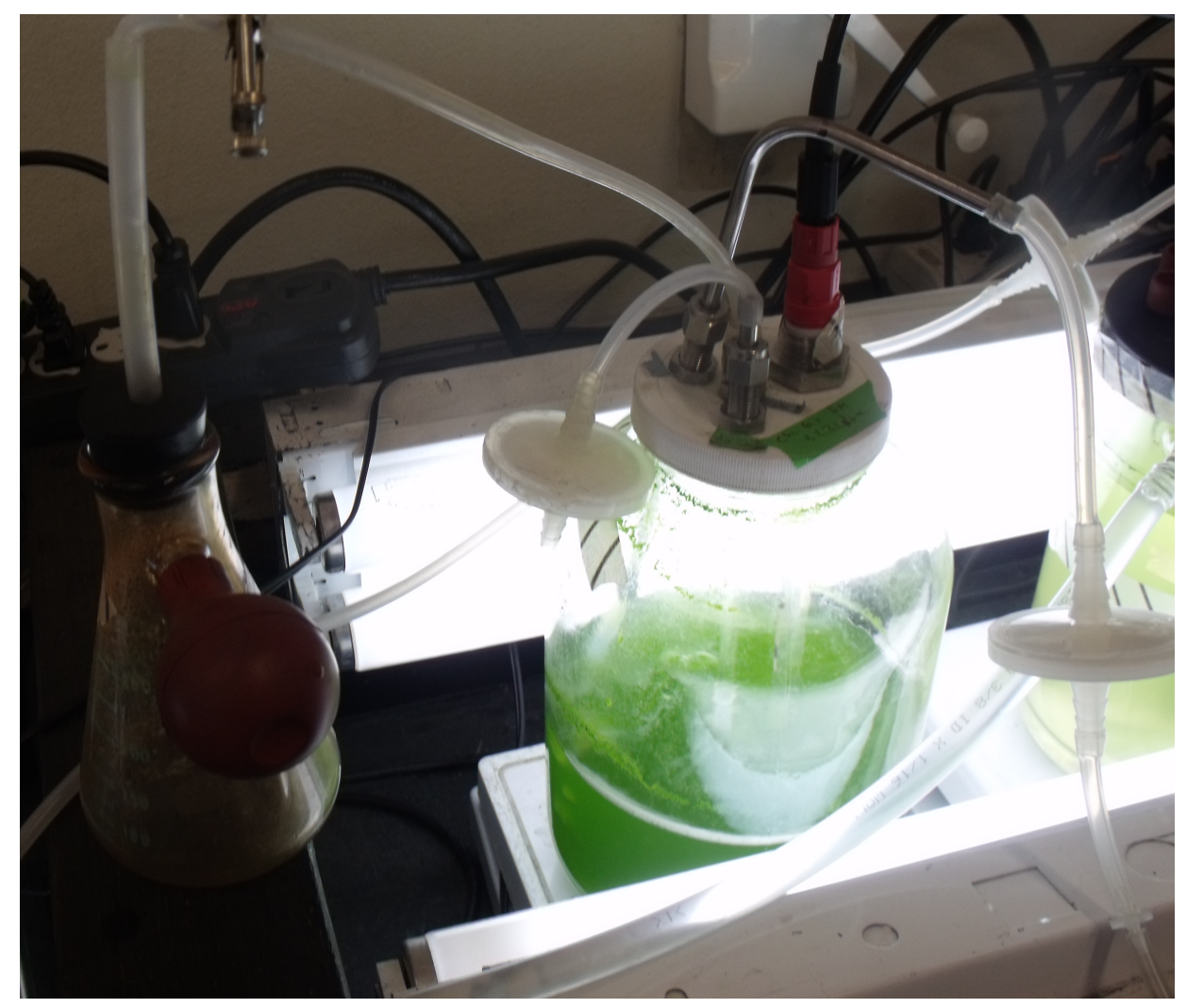

Figure 3.4-Growth of algae in a 4-L bioreactor equipped with filter flask for sample removal 


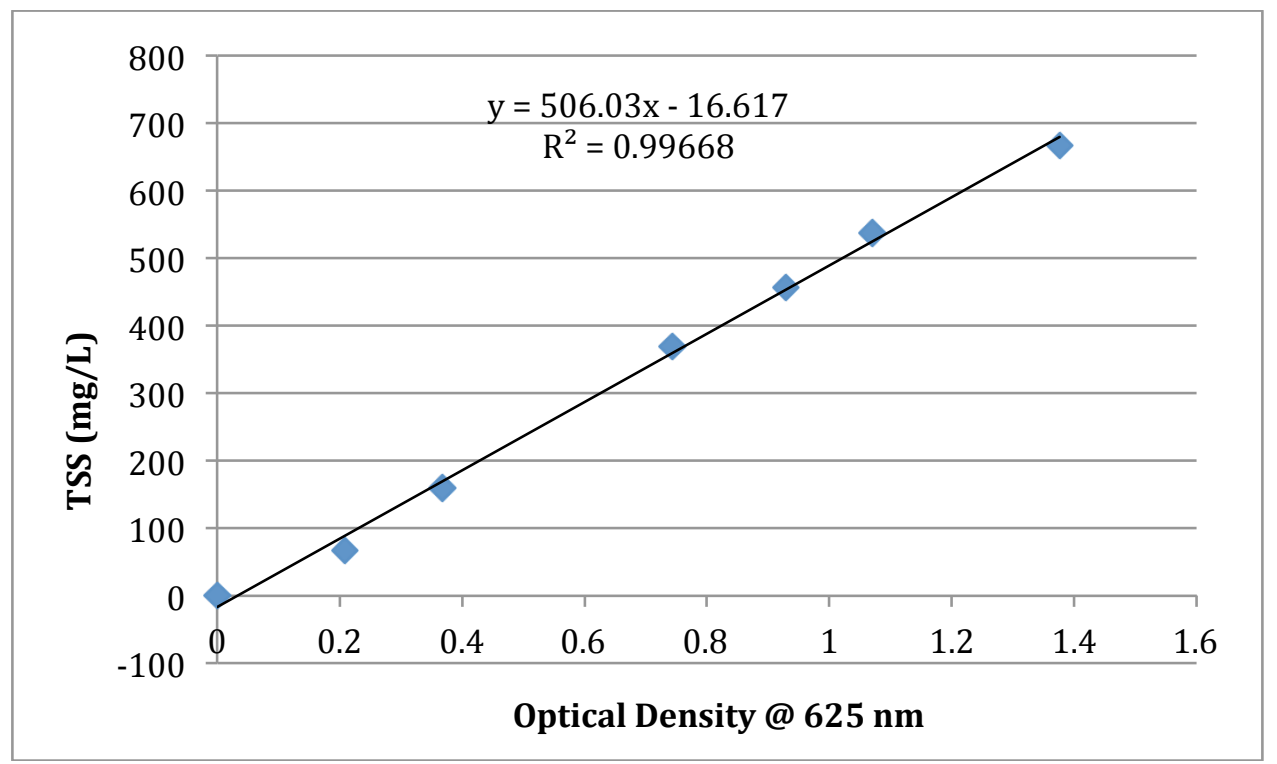

Figure 3.5-Relationship developed between dry weight and optical density of Scenedesmus

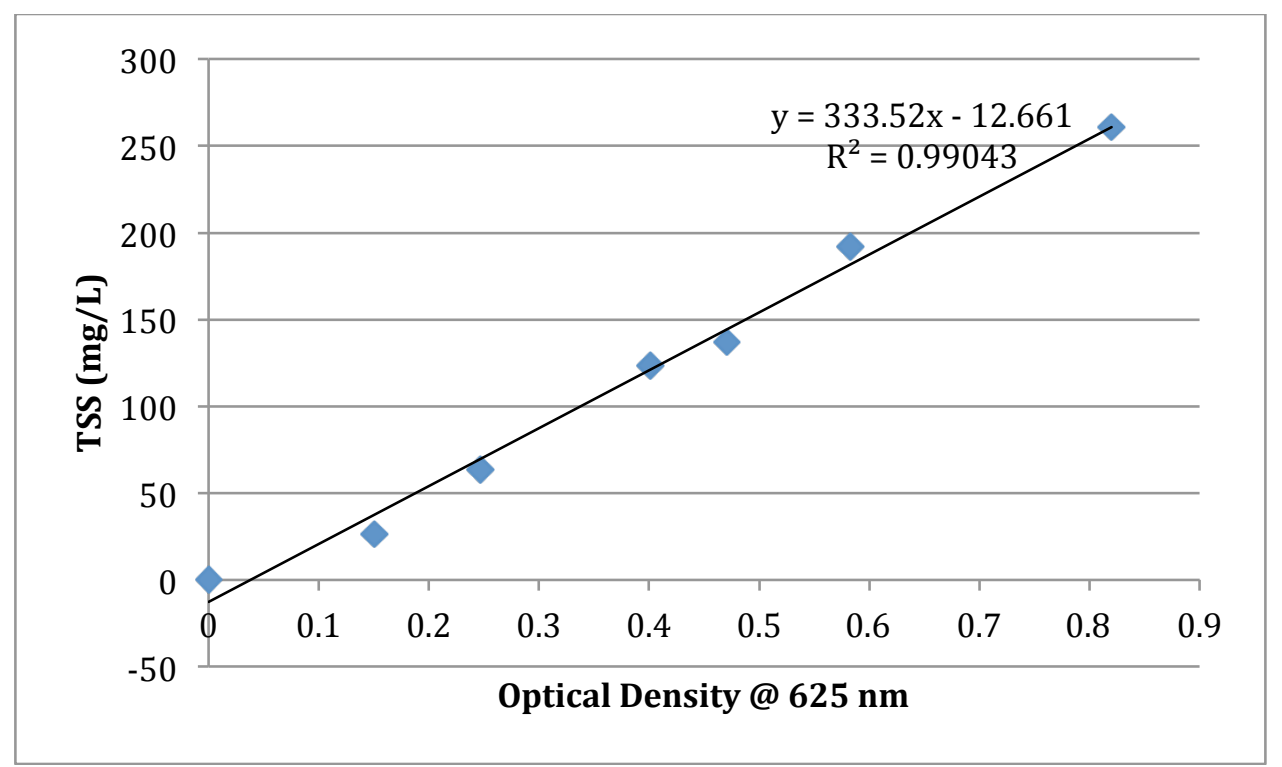

Figure 3.6-Relationships developed between dry weight and optical density of Chlorella

The scale up of B. cepacia from second to third batch cultures also involved growing the bacteria in a sterile, 2-L bioreactor with air addition and a constant monitoring of $\mathrm{pH}$. Figure 3.7 shows the two-liter bioreactors used with B. cepacia cultures. The scale up consisted of transferring $75 \mathrm{~mL}$ of the bacterial broth in MMS-3 with $1800 \mathrm{~mL}$ of autoclaved 
MMS-3 media. Water was circulated and heated or cooled by a VWR Scientific Products by Polyscience model 1162 circulation heater. Unlike the algal cultures, if pH dropped below 6.0 , a solution of $10 \%$ sodium hydroxide was added drop wise into the bioreactor to maintain a $\mathrm{pH}$ of at least 7.0. B. cepacia growth was consistent in first dropping the $\mathrm{pH}$ during exponential growth, and raising the $\mathrm{pH}$ during the onset of declining growth and stationary growth phases. Thus, $\mathrm{pH}$ generally needed only to be increased, as during later stages of growth, the pH remained constant at around 8.5. Like the algal bioreactors, a sampling flask was attached to the bioreactor apparatus and controlled with a bulb. Optical density was measured daily using a UV 1700 Pharma Spec model spectrophotometer (Shimadzu). In addition, samples were taken every other day for EPS measurement.

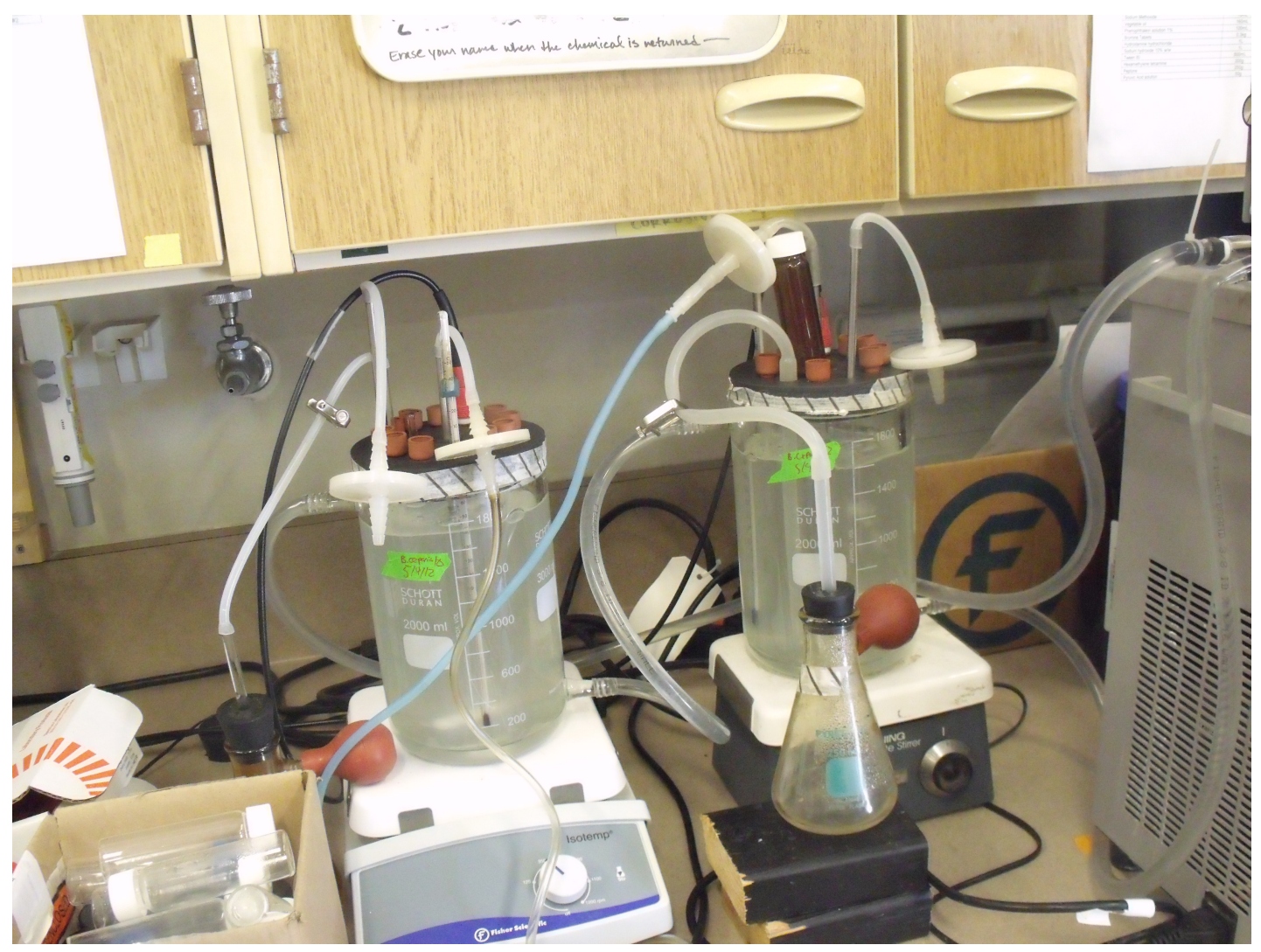

Figure 3.7 - 2-liter bioreactor setup used to grow B. cepacia cultures 


\subsection{Settling Test Procedures}

Settling tests were conducted to measure the settling efficiencies for Scenedesmus and Chlorella cultures. Settling and bioflocculation effects were measured at different stages of growth, with and without bioflocculant addition. Effects of $\mathrm{pH}$, light intensity and light vs. dark settling conditions were also tested. Experiments concerning nutrient deprivation of bioflocculant added and the effect of augmenting the carbon source though the addition of $\mathrm{CO}_{2}$ were also performed.

To make best use of the relatively small volume of algae grown, modified settling apparati were constructed out of acrylic using silicone glue. The modified settling apparatus has the same vertical dimensions as a traditional "squared beaker" test apparatus (Philips \& Bird), but is scaled down to a volume of 400-mL (circular model) and 300-mL (square model) (Figures 3.8 and 3.9 and Tables 3.8 and 3.9). The sampling ports were constructed to be 1.875 inches above the bottom of the settling column to prevent any effects due to resuspension. The outlets of the settling columns were equipped with glass tubing and rubber stoppers, and a clip to control the flow out of the columns. The complete set-ups are shown in Figure 3.10. To prevent excess algae and bacteria accumulation, the columns were cleaned thoroughly with $70 \%$ ethanol before and after each settling test. 


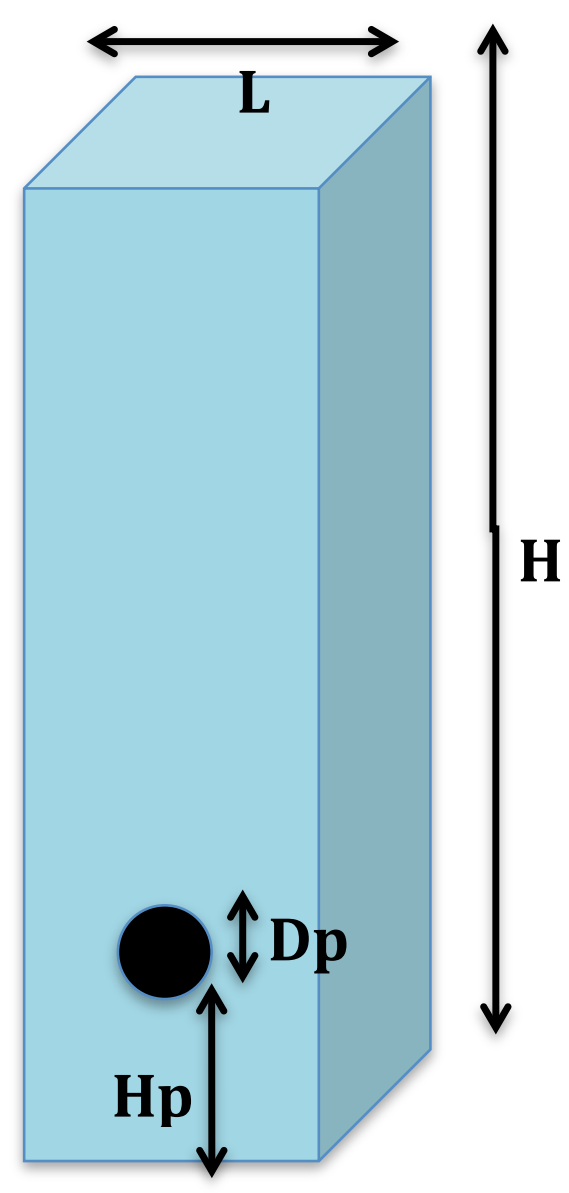

Figure 3.8-Visual representation of rectangular settling columns constructed

Table 3.8-Approximate dimensions of rectangular settling apparatus built

\begin{tabular}{|c|c|}
\hline Feature & Dimensions \\
\hline Height $(\mathbf{H})$ & 8 inches \\
\hline Top Width $(\mathbf{L})$ & 1.5 inches \\
\hline Area of Top & 2.25 inches squared \\
\hline Height to Bottom of Sampling Port $\left(\mathbf{H}_{\mathbf{P}}\right)$ & 1.875 inches \\
\hline Diameter of Sampling Port $\left(\mathbf{D}_{\mathbf{p}}\right)$ & 0.5625 inches \\
\hline Approximate Volume & $300 \mathrm{~mL}$ \\
\hline Shape & Rectangular \\
\hline
\end{tabular}




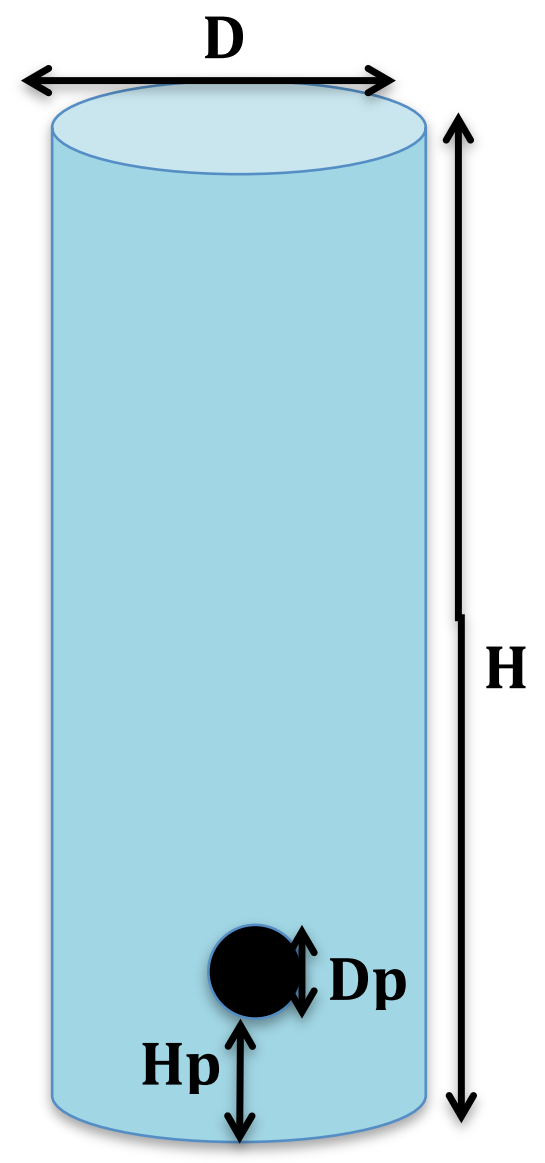

Figure 3.9-Visual representation of cylindrical settling column

Table 3.9 - Approximate dimensions of cylindrical settling apparatus built

\begin{tabular}{|l|l|}
\hline Feature & Dimensions \\
\hline Height $(\mathbf{H})$ & 8 inches \\
\hline Diameter $(\mathbf{D})$ & 2 inches \\
\hline Height to Bottom of Sampling Port $\left(\mathbf{H}_{\mathbf{p}}\right)$ & 1.875 inches \\
\hline Diameter of Sampling Port $\left(\mathbf{D}_{\mathbf{p}}\right)$ & 0.5625 inches \\
\hline Approximate Volume & $400 \mathrm{~mL}$ \\
\hline Shape & Cylindrical \\
\hline
\end{tabular}




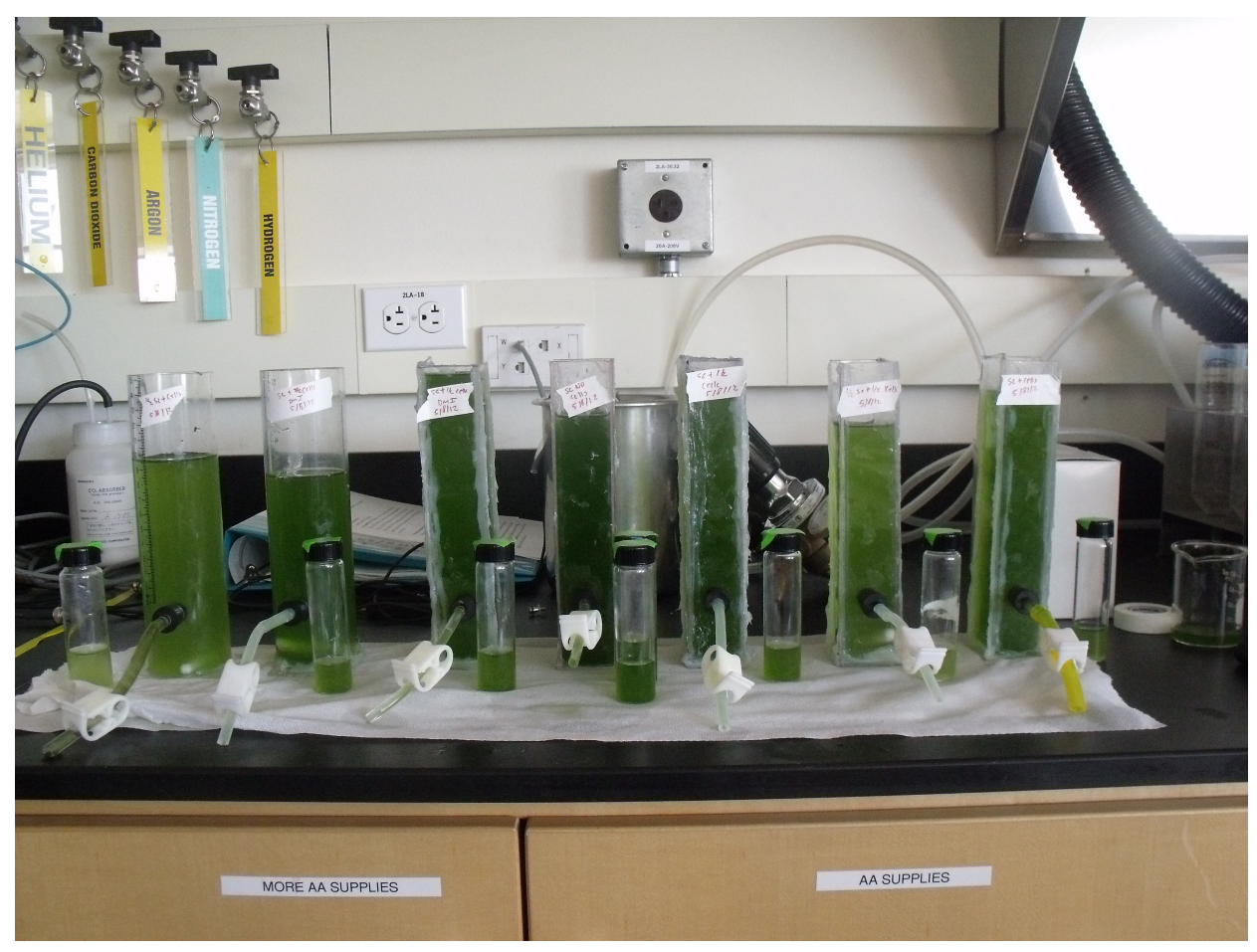

Figure 3.10-Illustration of Settling Columns in use

Each settling test was conducted over a 24- hour time period. Samples were collected once at the beginning, and after $0.5,1,2$ and 24 hours. Before each sampling, the outlet tube was drained for about 5-10 seconds to flush the outlet tube. After the 2-hr and 24-hr samples were collected, they were labeled and refrigerated immediately until cell counting was conducted.

Suspended algae in the settled samples were quantified by cell counts using a hemocytometer (Fisher) with an Olympus microscope at 400X magnification, using phase contrast. The Olympus microscope used was a CX4RF model equipped with an Infinity 2 digital camera and Infinity Analyze/Capture software. Prior to counting, the algal and bacterial samples were deflocculated using sonification with a Branson Sonifer Model 250 at half of the full output (setting 6 to 8 ) for 8-10 minutes for the Chlorella cells and 6 to 8 minutes for the Scenedesmus cells. The Scenedesmus cells required a shorter time for deflocculation because the flocs were less dense compared to the tiny, densely packed 
clusters of Chlorella. In some cases, samples needed to be repeatedly sonified (usually not more than twice). Each sample was counted at least 5 times to provide adequate statistics. Extreme outliers, calculated by a relative standard deviation of greater than $90 \%$, were not included.

The hemocytometer counting grid consists of a middle grey square area surrounded by four equally sized grey areas (Figure 3.11). Within this middle grey area, there are 25 individual boxes. The area of the entire counting grid is $1 \mathrm{~mm}$ by $1 \mathrm{~mm}$ and the depth is 0.1 $\mathrm{mm}$. Therefore, the volume of the area counted is $0.1 \mathrm{~mm}^{3}$. Thus, counting a sample within a known area of the grid allows one to calculate the number of cells per milliliter by multiplying the cell counts in the grid by a factor of 10,000 .

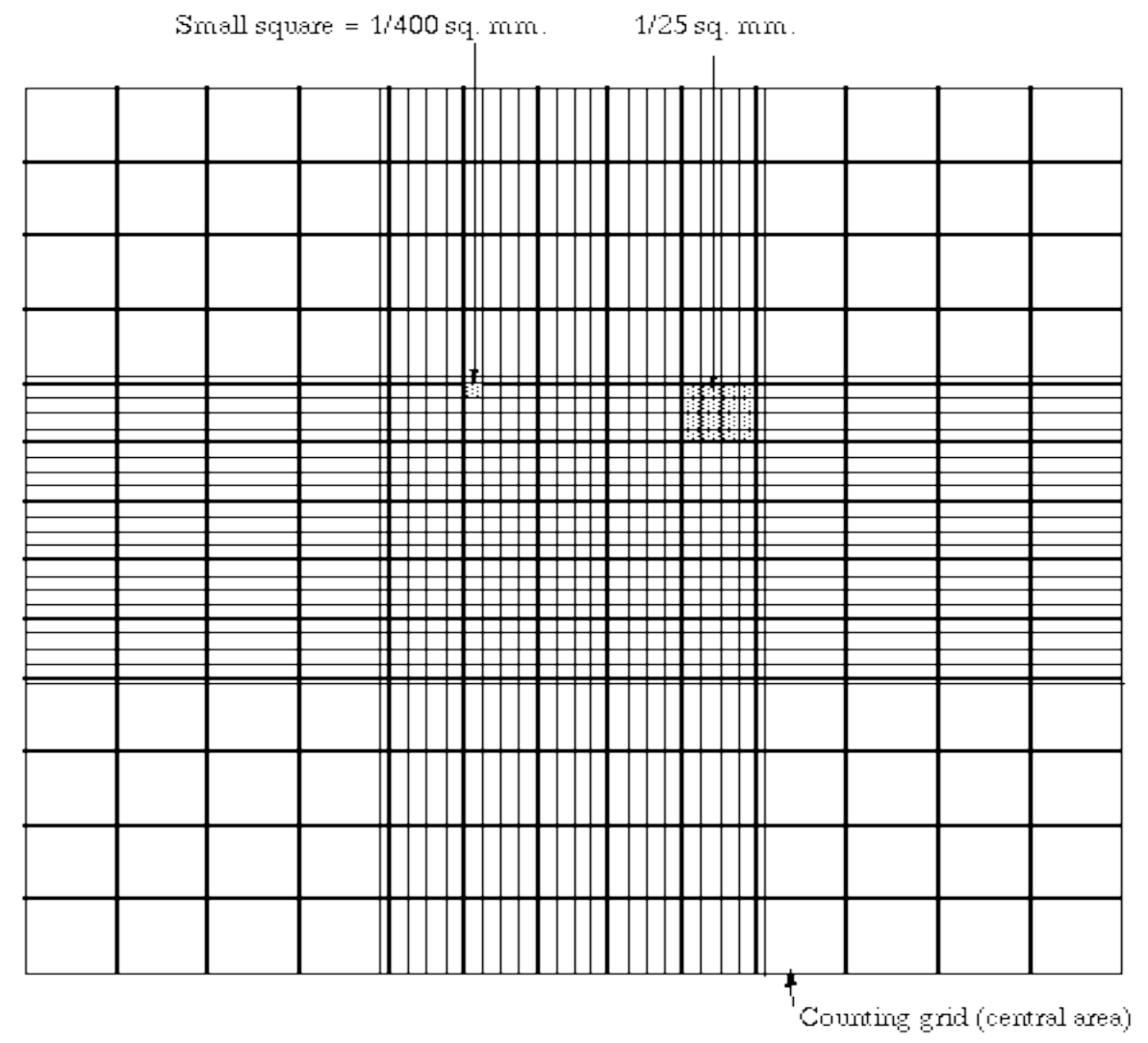

Figure 3.11-Representation of a typical hemocytometer counting grid seen at 400x magnification

Cell counts were normalized to provide a consistent comparison to unsettled counts. For good statistics, counts had to be at least 100 to 130 cells. For less dense samples 
(usually during earlier stages in the growth curve), counting 100 cells usually involved counting the entire grid of the hemocytometer. For more dense samples (usually found during later stages of the growth curve), counting usually involved one or two rows of the hemocytometer for Scenedesmus, and one large box to two rows within the large box of a hemocytometer for Chlorella. Before counting Chlorella cells, the samples had to set for approximately three minutes for the amount of Chlorella cells to stabilize. For an unknown reason, Chlorella cells seemed to multiply considerably for the first three minutes when the samples were placed on the hemocytometer.

The settleability of algae was evaluated by graphing the normalized cell concentration vs. settling time. Normalized cell concentration was calculated by dividing the average counted cell concentration by the original concentration $\left(\mathrm{C} / \mathrm{C}_{0}\right)$. Throughout this research, normalized cell removal efficiency will refer to the percentage of cells removed by settling in the specified time.

\subsection{EPS Analysis (Dissolved EPS/Filtrate Only)}

Both bacterial and algal EPS were quantified by a filtration and dialysis method. The 20-mL to 30-mL samples were filtered through 1.2- $\mu$ m glass fiber G4 filters (Fisher) to remove cells, and then placed in dialysis tubing with a 6,000 to 8,000 MWCO (Fisher Brand). Low molecular weight compounds pass through the selective membrane of the dialysis tubing, while high MW polymers such as EPS are retained. The samples were exhaustively dialyzed in the refrigerator at 4 degrees Celsius by changing the DI water daily for 7 days straight. This allows for the elimination of low molecular weight compounds, leaving the higher molecular weight polymers to analyze by total organic carbon (TOC) analysis.

TOC was analyzed using a Shimadzu TOC-VSH TOC analyzer coupled with ASI-V sampling port and TN measuring unit. A calibration curve was made using standards from $15 \mathrm{mg} / \mathrm{L}$ and $5 \mathrm{mg} / \mathrm{L}$ stock solutions of organic carbon. The results of the calibration 
demonstrate that the correlation between these points is linear (Figure 3.12, $\mathrm{r}^{2}=0.976$ ). All samples were acidified using $1 \mathrm{~N} \mathrm{HCl}$ to allow the instrument to remove any inorganic carbon in the form of carbonate or bicarbonate. The samples were run with continual standard checks, as well as a blank DI sample for Quality Assurance/Quality Control.

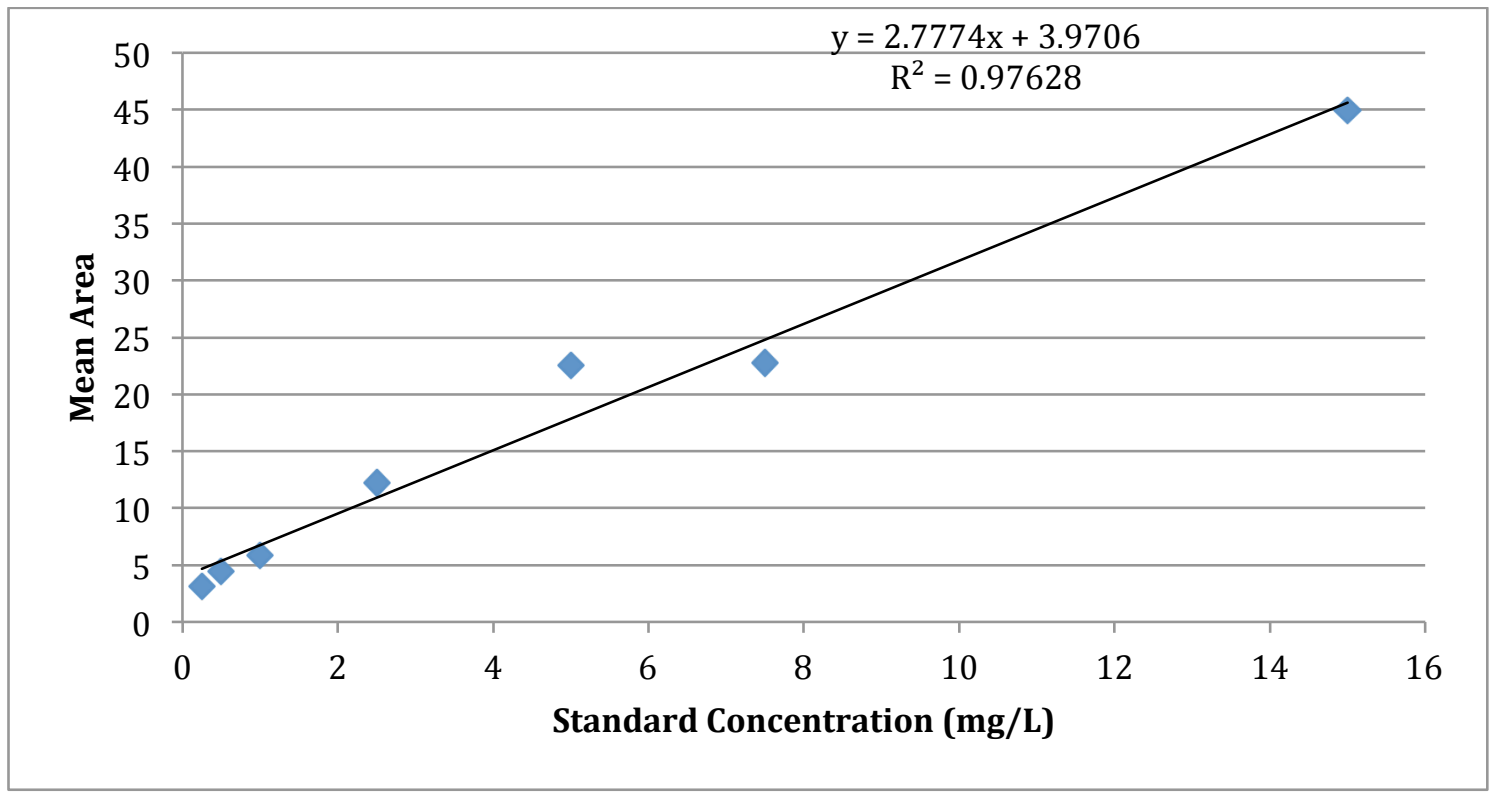

Figure 3.12-TOC calibration curve used for EPS Analysis and corresponding r-squared value 


\section{CHAPTER 4: RESULTS AND DISCUSSION}

To examine repeatability of data, the following experiments were repeated in three separate sets. The first set of experiments focused on observing settling of Chlorella and Scenedesmus over their growth curves with and without B. cepacia addition. Experiment 1 examined settling up to early stationary phase of growth. Experiment 2 followed up on this approach to assess the repeatability of the data, and presented new physical methods to improve settling focused on mixing time of the B. cepacia and algal cells. Experiment 2 also prolonged the settling tests to focus on later growth stages (up to mid stationary phase). Experiment 3 further repeated the two initial experiments, but expanded on the physical factors such as dosage of $B$. cepacia bioflocculant and effect of settling during later growth stages (up to late stationary). Both experiment 2 and 3 quantified EPS production for both algal and bacterial cells over the growth curve to evaluate the effects of EPS production on settling. These first three experiments are described in Sections 4.1 and 4.2.

After the first general experiments, results focused on the effects of different environmental conditions on algal settleability. Wastewater samples with and without RAS addition and aeration were analyzed to compare results achieved within the laboratory and based on real world applications (Section 4.3). Conditions investigated included light/dark conditions during settling and light intensity during growth (Section 4.4), pH (Section 4.5), starvation of B. cepacia cells (Section 4.6), and carbon dioxide supplementation for algal growth (Section 4.7). In addition, settling was observed for older cultures of both algal species without bioflocculant addition (up to death phase) (Section 4.8). Within these results, effects of certain physical factors such as mixing intensity, and dilution of algal cells were incorporated. All of these experiments also included quantification of EPS and the correlation between EPS and improved settling. Detailed graphs depicting all results with 
labeled section headings are provided in the Appendix (Page 227). In addition, a compilation of micrographs for several experiments taken is presented in the Appendix section (Page 217).

\subsection{Settling of Scenedesmus and Chlorella Without Added Bioflocculant}

The first investigations focused on measuring the settling of pure Chlorella and Scenedesmus cultures without any bacterial cell addition or EPS. Both cultures were grown under batch conditions, so one of the objectives was to determine the effect of growth phase on settling. Results and discussion included cover Experiments 1, 2, and 3 beginning with the growth curves, followed by settling results with Scenedesmus and Chlorella without cell addition, and ending in EPS correlation with settling (Experiments 2 and 3). Settling of older cultures of Scenedesmus and Chlorella (close to the death phase) without added bioflocculants was also explored in Section 4.1.10. In addition, autoflocculation of algal cells was investigated for both cultures of microalgae at a higher pH (Section 4.1.11) by comparing results to studies found in the literature.

\subsubsection{Growth Curves of Scenedesmus and Chlorella: Experiment 1}

Growth curves exhibited in preparation of cultures of Scenedesmus and Chlorella are shown in Figures 4.1 and 4.2. The growth of Scenedesmus was slower than that of Chlorella, but both reached a maximum OD of 0.4 to 0.5 . As OD data is missing for Chlorella it is difficult to tell what growth pattern was obtained after 7 days of growth. Similarly, growth for Scenedesmus after sixteen and up to eighteen days of growth from the graph is not discernible. Thus, analysis of results for this experiment reflects growth of Chlorella cultures observed in Experiments 2 and 3 as a reference. 


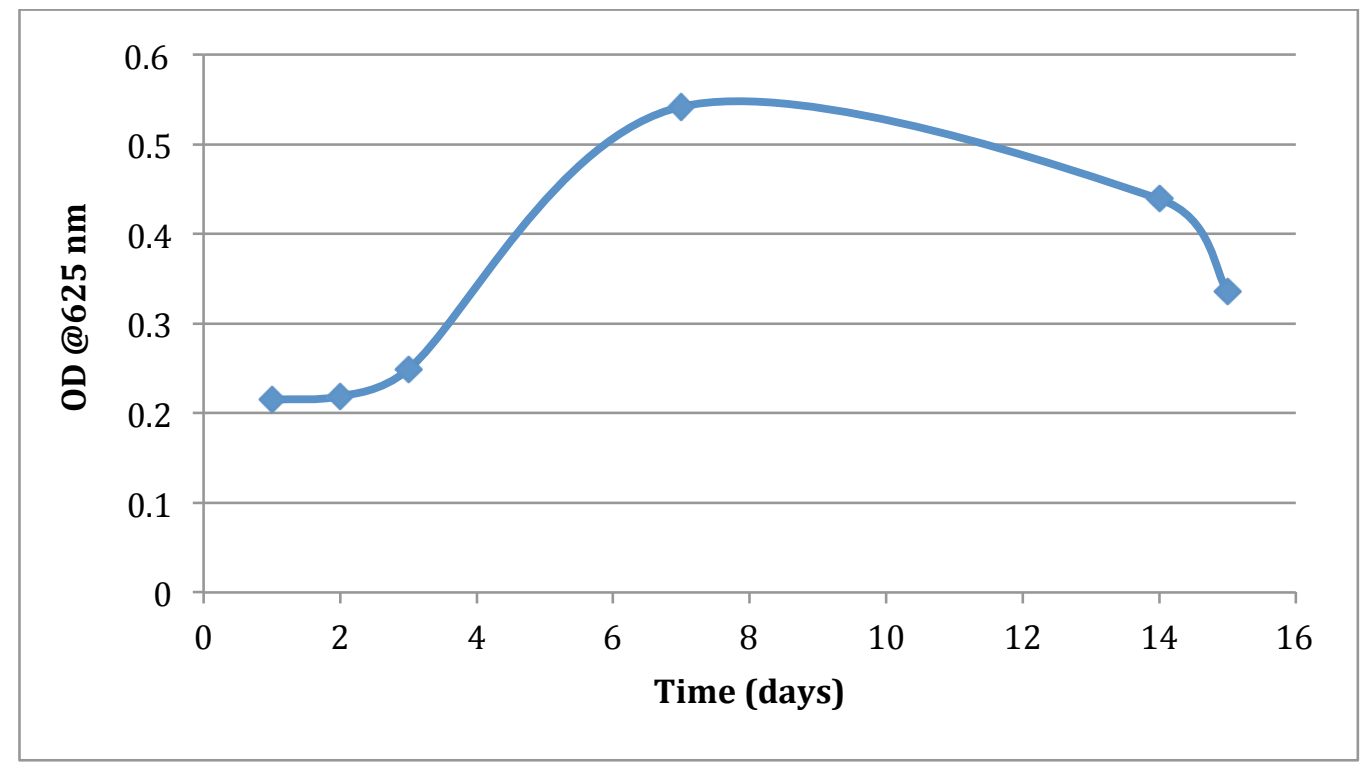

Figure 4.1-Growth curve of Scenedesmus over an 18-day growth period using optical density at $625 \mathrm{~nm}$

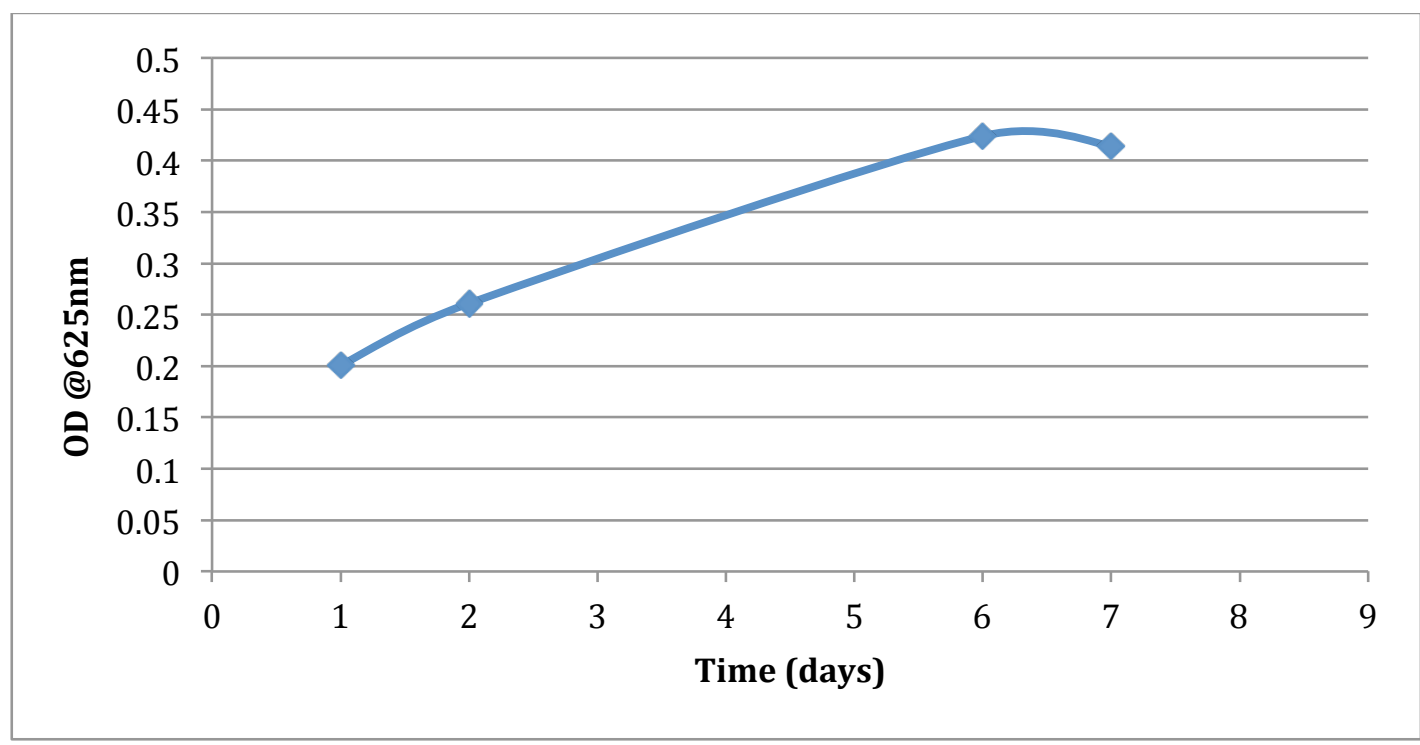

Figure 4.2-Growth curve of Chlorella over a 14-day growth period using optical density at $625 \mathrm{~nm}$ 


\subsubsection{Effect of Growth Phase on Settling of Scenedesmus: Experiment 1}

Settling of Scenedesmus alone were measured as a baseline and to establish the growth period where harvesting is most feasible. Figures $4.3 \mathrm{~A}$ through $4.3 \mathrm{C}$ show the settling of Scenedesmus at varying growth stages. Figure 4.3 A shows normalized cell concentration after settling up to 24 hours, while Figure $4.3 \mathrm{~B}$ shows detailed settling over two hours, and Figure $4.3 \mathrm{C}$ summarizes the results for two hour settling. Days 4 and 5 of settling are not included on part B since 2-hour samples were not taken for this experiment. It is apparent that the oldest Scenedesmus culture, grown for 18 days, exhibited the best settling based on normalized cell concentration $\left(\mathrm{C} / \mathrm{C}_{0}\right.$; lower value is a better settling rate). At the end of 2-hour settling about 50\% removal was observed after 18 days of growth (Figure 4.5 B and C). This corresponds with the latest time on the growth curve, or the onset of mid stationary phase. This result indicates that settling of Scenedesmus cultures improves in later phases of growth. 

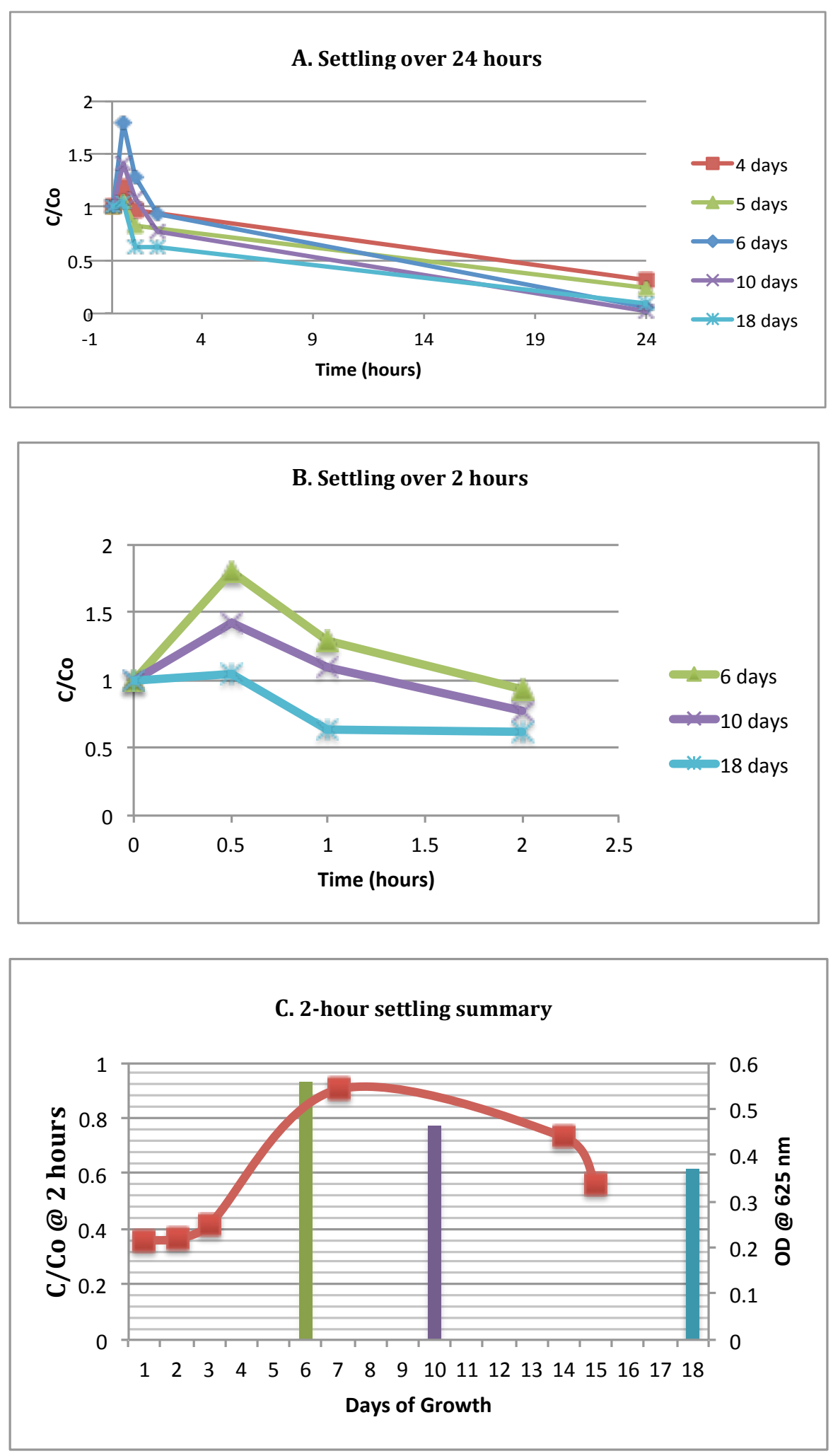

Figure 4.3-Settling based on normalized cell concentration remaining over A) a twenty four hour period for the Scenedesmus culture B) a two hour period C) Over eighteen days of growth plotted against the growth curve. The red line indicates optical density results over certain days sampled at $625 \mathrm{~nm}$ by a spectrophotometer 


\subsubsection{Effect of Growth Phase on Settling of Chlorella: Experiment 1}

Figure 4.4 (A, B,C) depicts a normalization of the settling of Chlorella at three different stages of growth. The youngest culture after 7 days of growth has the best removal overall with over $90 \%$ removal by settling in a two hour period. In contrast to Scenedesmus, Chlorella settled better earlier in its growth curve (mid exponential phase of growth). Results from both 24 hours of settling and 2 hours of settling (Figure $4.4 \mathrm{~A}$ and B) indicate that the younger cultures of Chlorella have the most potential for harvesting without the use of any type of bioflocculant. Settling was much better than for Scenedesmus cultures, with above $90 \%$ removal after only two hours of settling for cultures with 7 days of growth. Figure 4.4 C shows the cell removal over a 2-hour period across the entire 14-day growth period. Again, a higher value indicates a lower removal rate.

Figure 4.5 after illustrates how much more efficient Chlorella settles than Scendesmus at similar stages of growth curve without the addition of a bioflocculant. After two hours of settling, Chlorella exhibits almost ten times the removal as compared to Scenedesmus based on the remaining cells after settling for a 2-hour period. However, 24hour results are almost identical based on the normalized cell concentration remaining. 

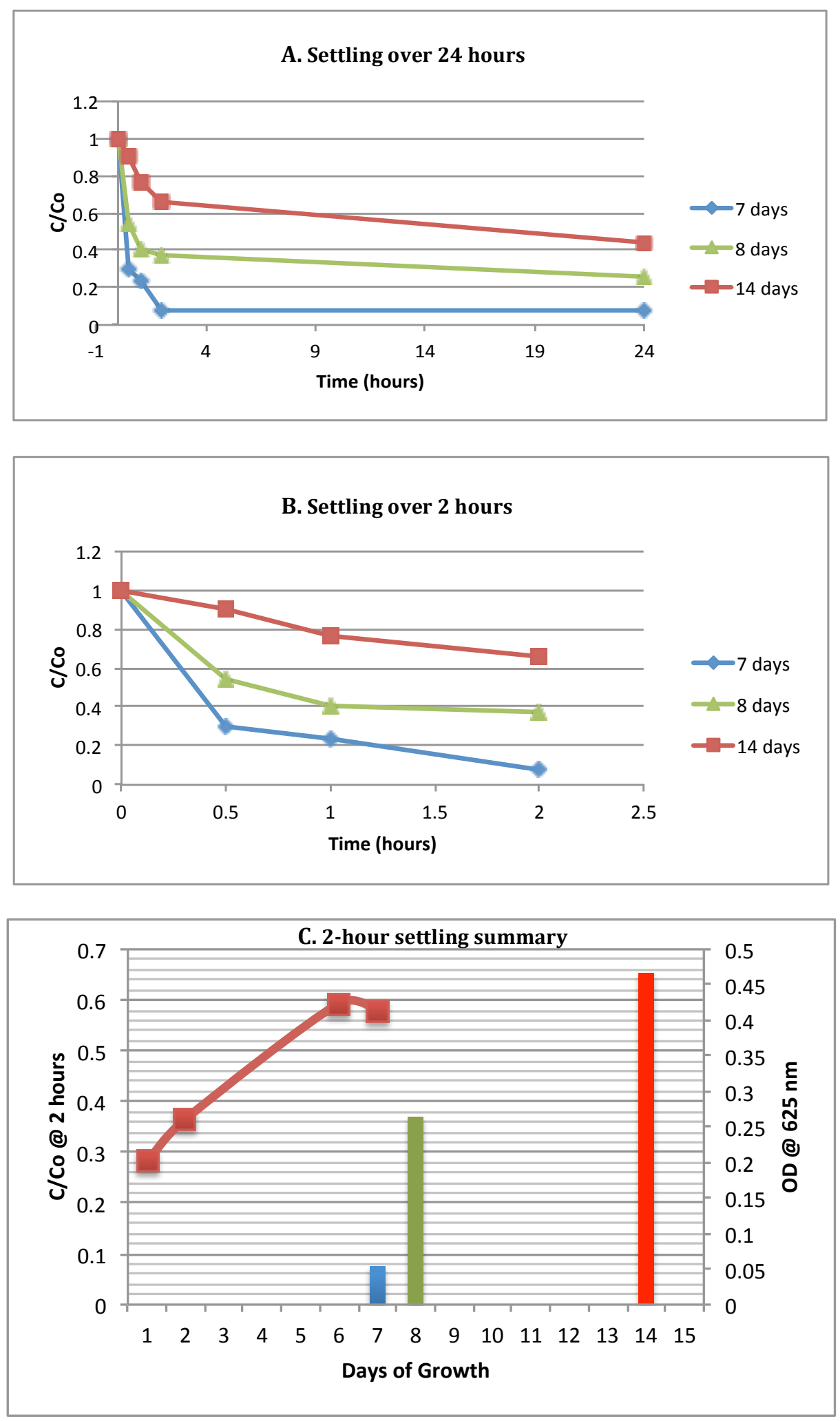

Figure 4.4-Settling based on normalized cell concentration remaining over A) a twenty four hour period for the Chlorella culture B) a two hour period C) over fourteen days of growth plotted against the growth curve. The red line indicates optical density results over certain days sampled at $625 \mathrm{~nm}$ by a spectrophotometer 


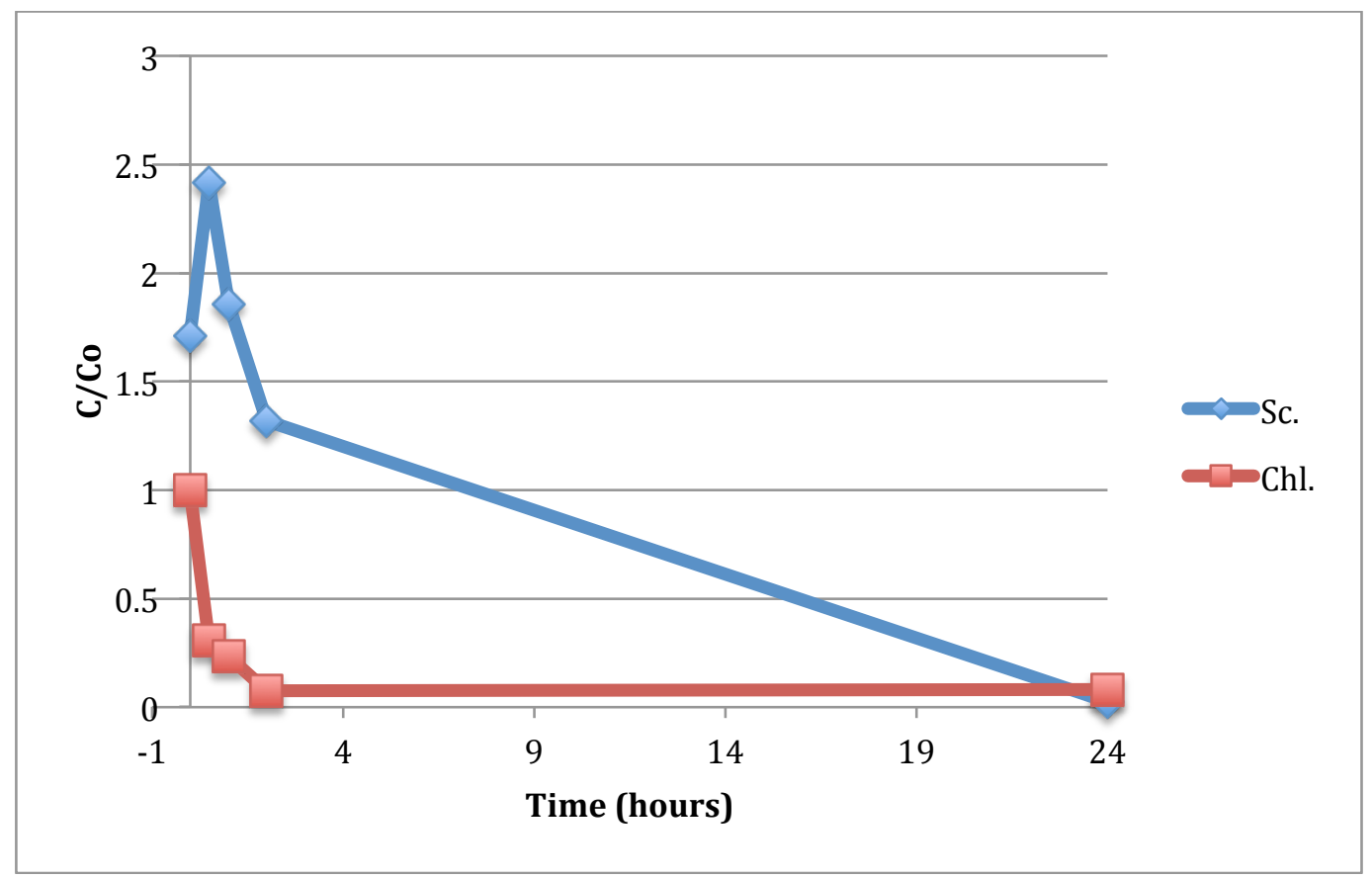

Figure 4.5-Normalized cell concentration plotted against time over a 24-hour period for both the Chlorella and Scenedesmus cultures. The results are compared when Scenedesmus completed 10 days of growth and Chlorella 8 days.

\subsubsection{Growth Curves of Scenedesmus and Chlorella: Experiment 2}

Settling tests with Scenedesmus and Chlorella were repeated under the same conditions as Experiment 1 to determine the reproducibility of the previous results on the effect of growth phase on settleability. Growth curves for Scenedesmus and Chlorella are shown in Figure 4.6 and 4.7 for Experiment 2. The algae cultures were harvested in similar stages of late exponential growth to mid stationary growth when the settling tests were run, similar to Experiment 1. Higher growth of both cultures differs from Experiment 1 due to a switch in instruments used to measure optical density (Spec 20 to UV Pharma Spec 1700). In addition, the growth of cultures is more clearly defined as compared to Experiment 1. 


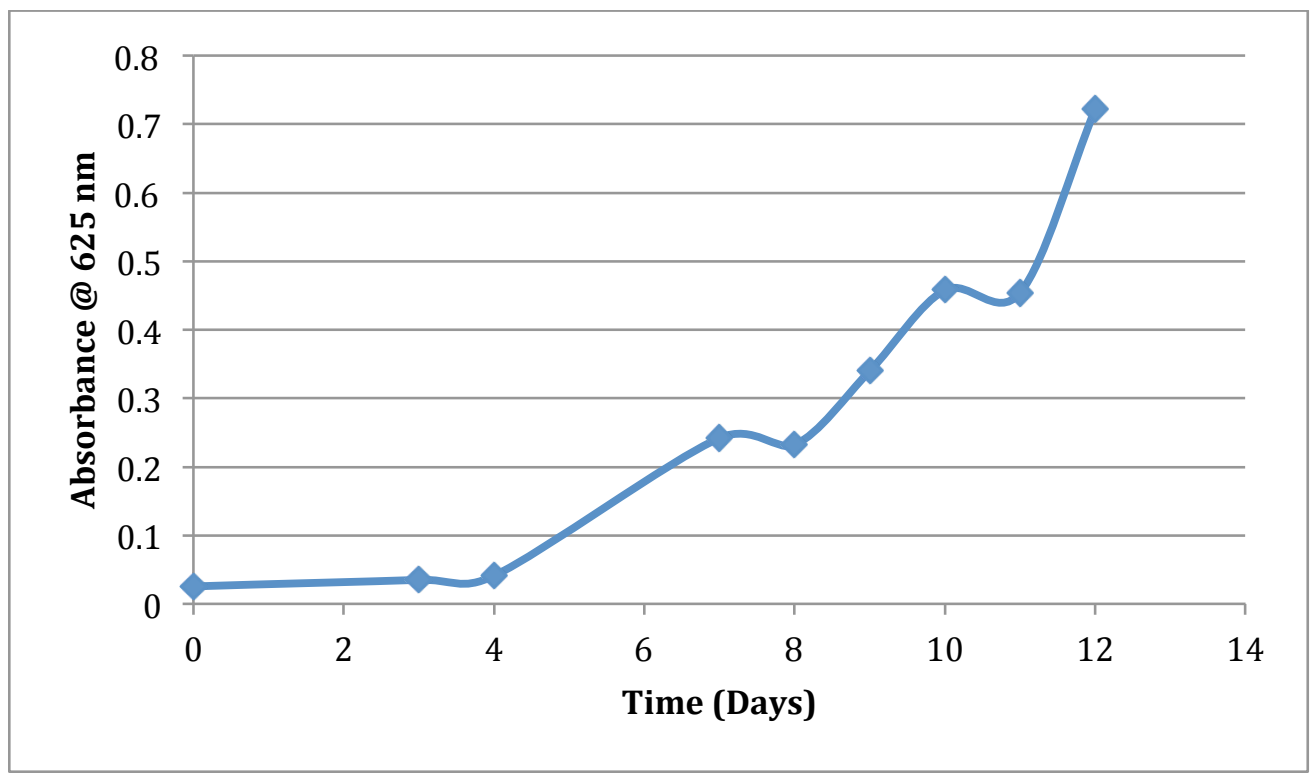

Figure 4.6-Growth of Scenedesmus over a fourteen-day period, with optical density taken at $625 \mathrm{~nm}$

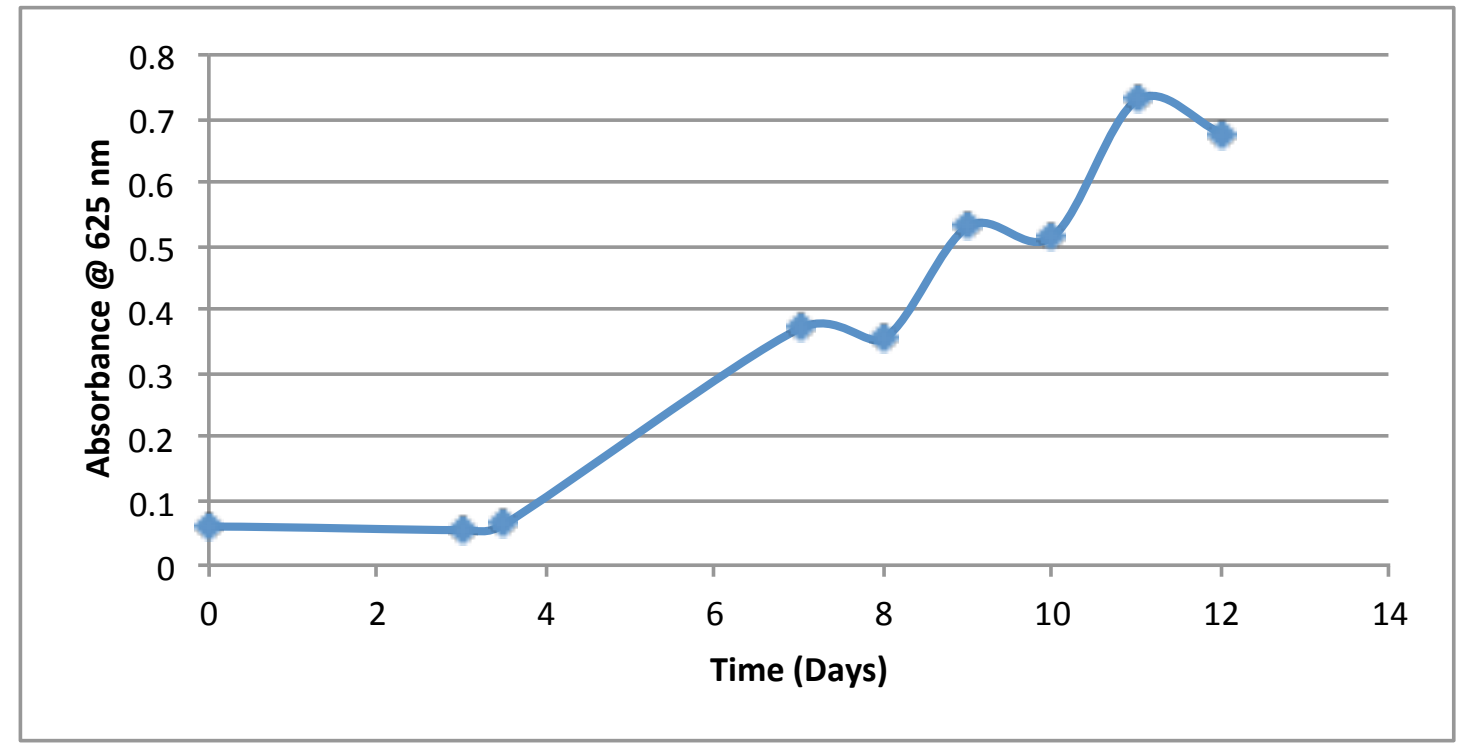

Figure 4.7-Growth of Chlorella over a fourteen-day period, with optical density taken at $625 \mathrm{~nm}$ 


\subsubsection{Effect of Growth Phase on Settling of Scenedesmus: Experiment 2}

The settling results of Scenedesmus during three different phases of growth are shown in Figure 4.8. The more mature Scenedesmus cells showed improved settling (Figure 4.8 A and B). These results match the earlier Experiment 1, reaffirming the conclusion that Scenedesmus settles better towards the early to mid stationary phase of growth. Figure 4.11 C explicates, over the entire growth curve, the measured settling efficiency based on normalized cell concentration remaining increased dramatically (from $\mathrm{C} / \mathrm{C}_{0}$ of 0.96 to 0.40 ), just within a range of four days. Thus, results from settling Experiment 2 with no addition of B. cepacia cells or filtrate support the initial finding during Experiment 1 that Scenedesmus settles the best towards the middle of stationary growth phase (past 10 days of growth). 

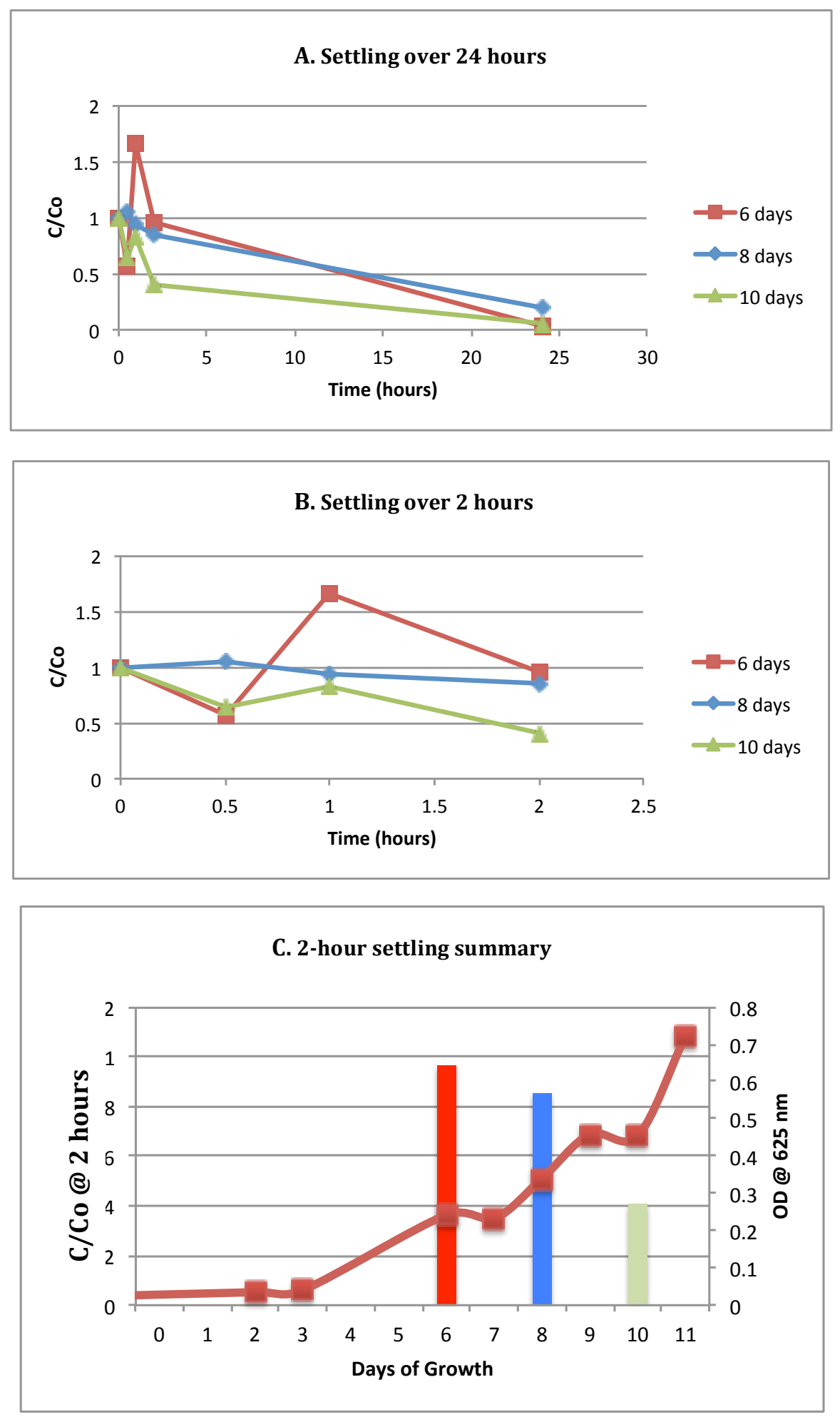

Figure 4.8-Settling based on normalized cell concentration remaining of Scenedesmus control columns (no cell or filtrate addition) over growth curve (10 day period) for A) a twenty four hour period $B$ ) a two hour period and C) compared with growth phase (plotted against optical density at $625 \mathrm{~nm}$ ) (Experiment 2). 


\subsubsection{Effect of Growth Phase on Settling of Chlorella: Experiment 2}

In Experiment 2 Chlorella's settling without B. cepacia cell addition was again far better at early stages of growth (Figure 4.9 A, B and C). At mid exponential growth phase it is evidenced that Chlorella will settle faster than in late exponential/early stationary phases. Again this result concurs with Experiment 1 data, which suggested that Chlorella's settling was hindered during later stages in the growth curve (i.e. early to mid stationary phases). 

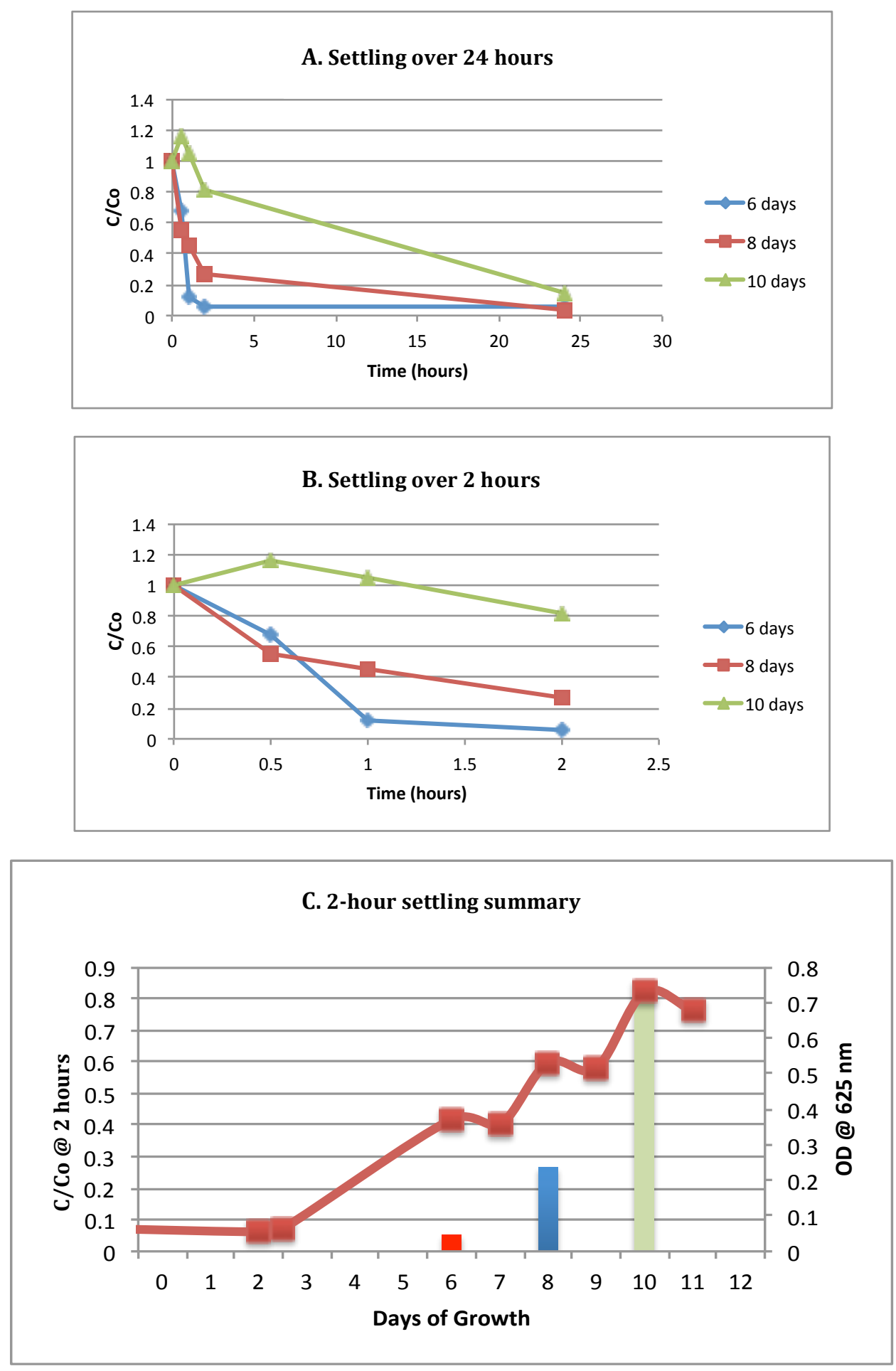

Figure 4.9- Settling based on normalized cell concentration remaining of Chlorella over growth curve for A) a 24 hour period B) a 2 hour period and C) compared with growth phase (plotted against optical density at $625 \mathrm{~nm}$ )

(Experiment 2) 


\subsubsection{Growth Curves of Scenedesmus and Chlorella: Experiment 3}

A third set of settling experiments was run to further demonstrate the reproducibility of the results of Scenedesmus and Chlorella settling. A focus of the new experiments was to investigate algae settling during later stages of growth including mid to late stationary phases. Since these growth phases had not been covered completely, longer waiting time between settling tests was instigated to allow for more culture to be available during later stages of growth with minimal disruption of cell concentration. As seen in growth curves for Scenedesmus and Chlorella below (Figures 4.10 and 4.11), growth was steady without abrupt changes in cell density. From both growth curves it appears that stationary phase is reached by day 12 to 14 . 


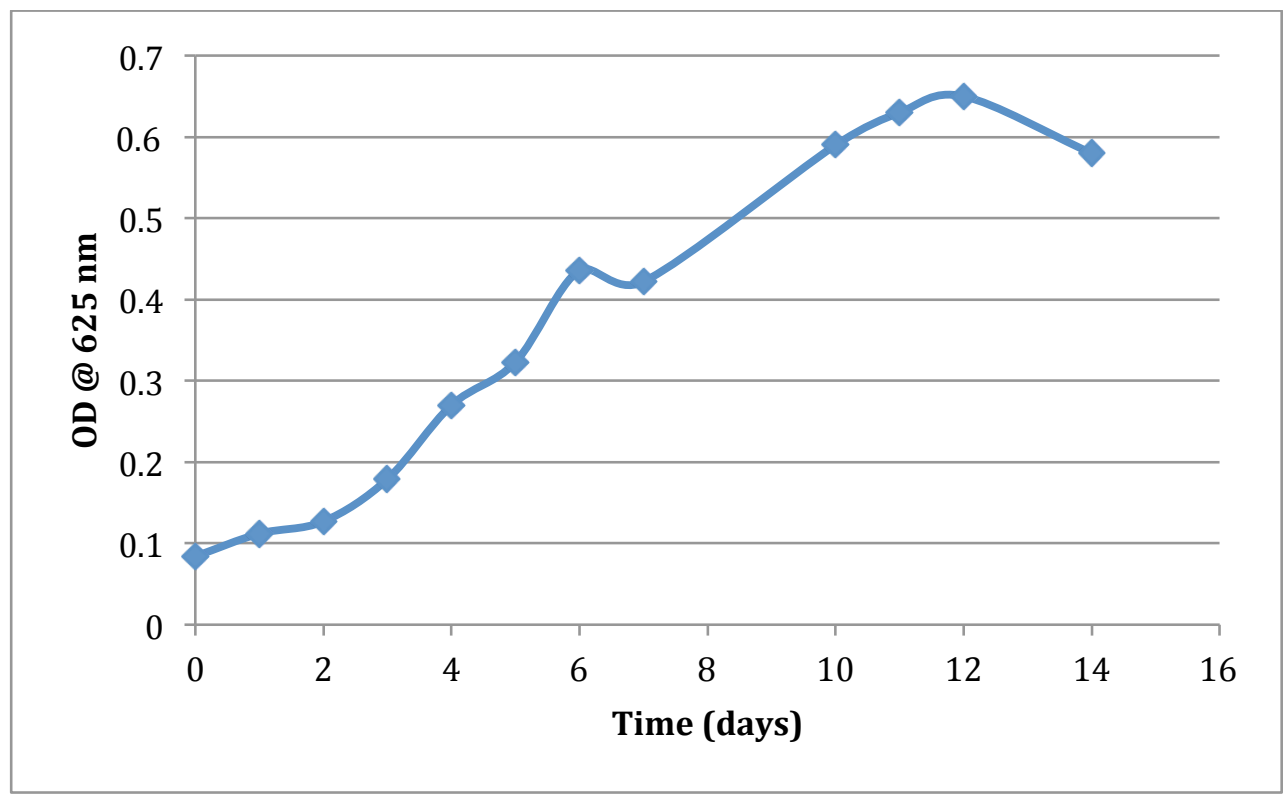

Figure 4.10-Growth Curve of Scenedemus using Optical Density at $625 \mathrm{~nm}$ over a fifteen day period

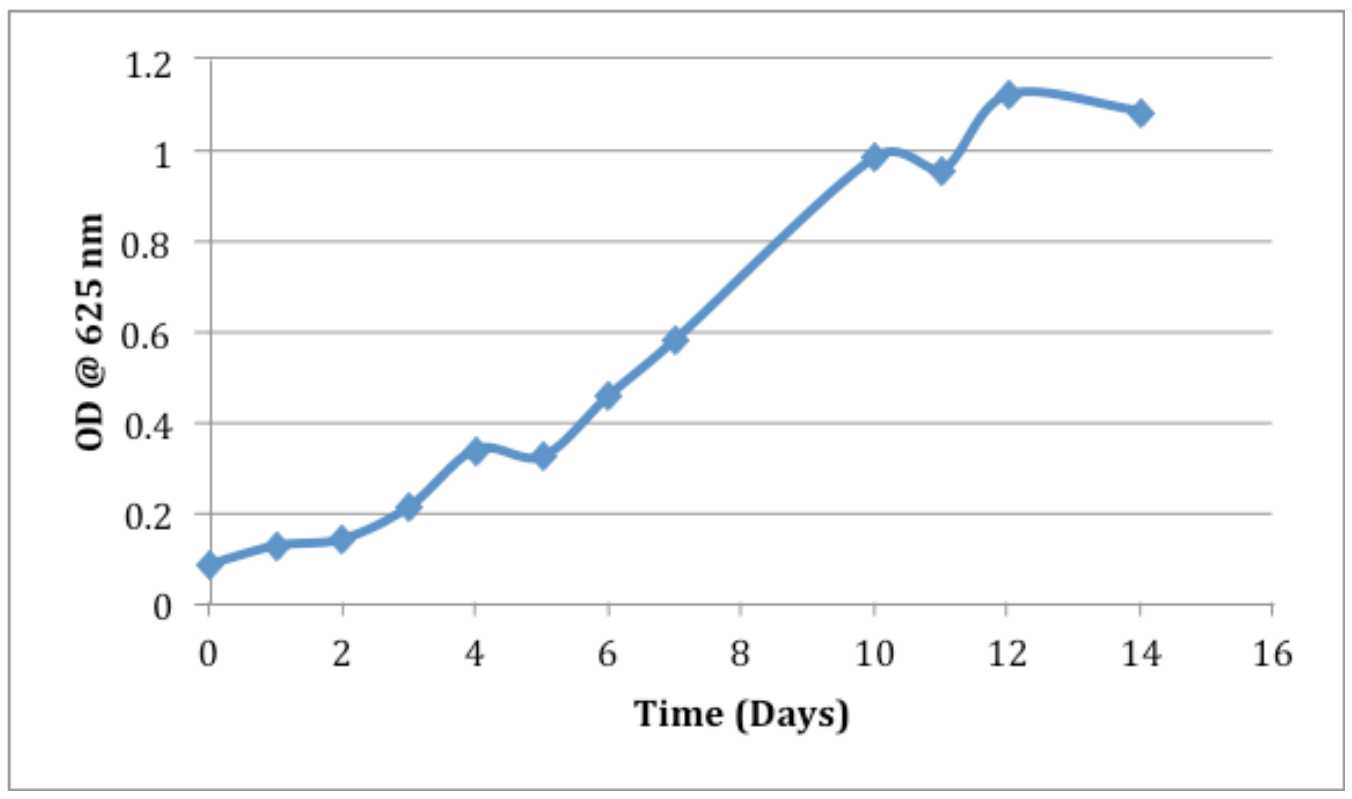

Figure 4.11-Growth Curve of Chlorella using Optical Density at $625 \mathrm{~nm}$ over a fourteen day period 


\subsubsection{Effect of Growth Phase on Settling of Scenedesmus: Experiment 3}

Settling of Scenedesmus was best after 15 days of growth for both 24 and 2 hours of settling (Figure 4.12 A,B,C). Maximum cell removal of up to $70 \%$ was observed at 15 days of growth, which based on the growth curve, Figure 4.10, corresponds inbetween early to mid stationary phase. These results are similar to results seen in previous Experiments $(1,2)$, except that this new experiment extended into longer growth periods. 

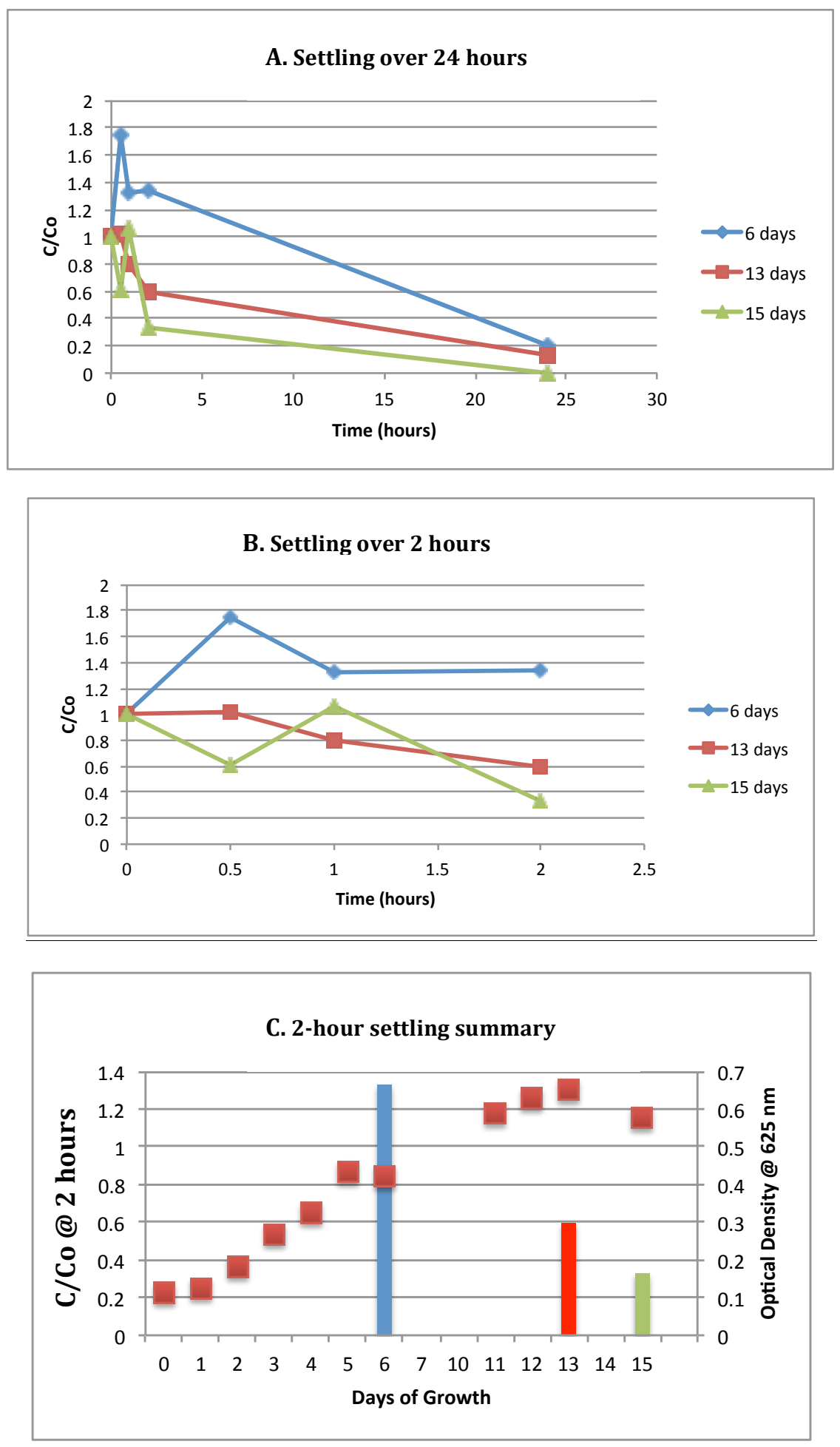

Figure 4.12-Settling based on normalized cell concentration remaining for the same Scenedesmus culture over the growth curve with no bioflocculant addition for $A$ ) a twenty four hour settling period B) a two hour settling period and C) a comparison of growth phase (plotted against optical density at $625 \mathrm{~nm}$ over the growth curve) (Colors correspond to days of growth on all graphs) (Experiment 3) 


\subsubsection{Effect of Growth Phase on Settling of Chlorella: Experiment 3}

For Chlorella, normalized cell removal efficiency was again observed in the mid exponential phase of growth (Figures $4.13 \mathrm{~A}, \mathrm{~B}, \mathrm{C}$ ). This result is in agreement with the previous Experiments (1 and 2) with Chlorella. However, cell removal efficiency increased from Day 13 to Day 15 of growth, a result that was not observed in the previous experiments (Figure $4.13 \mathrm{C}$ ). Thus, three spearate experiments all exhibited significantly better settling of Chlorella in exponential growth (mid exponential growth). 

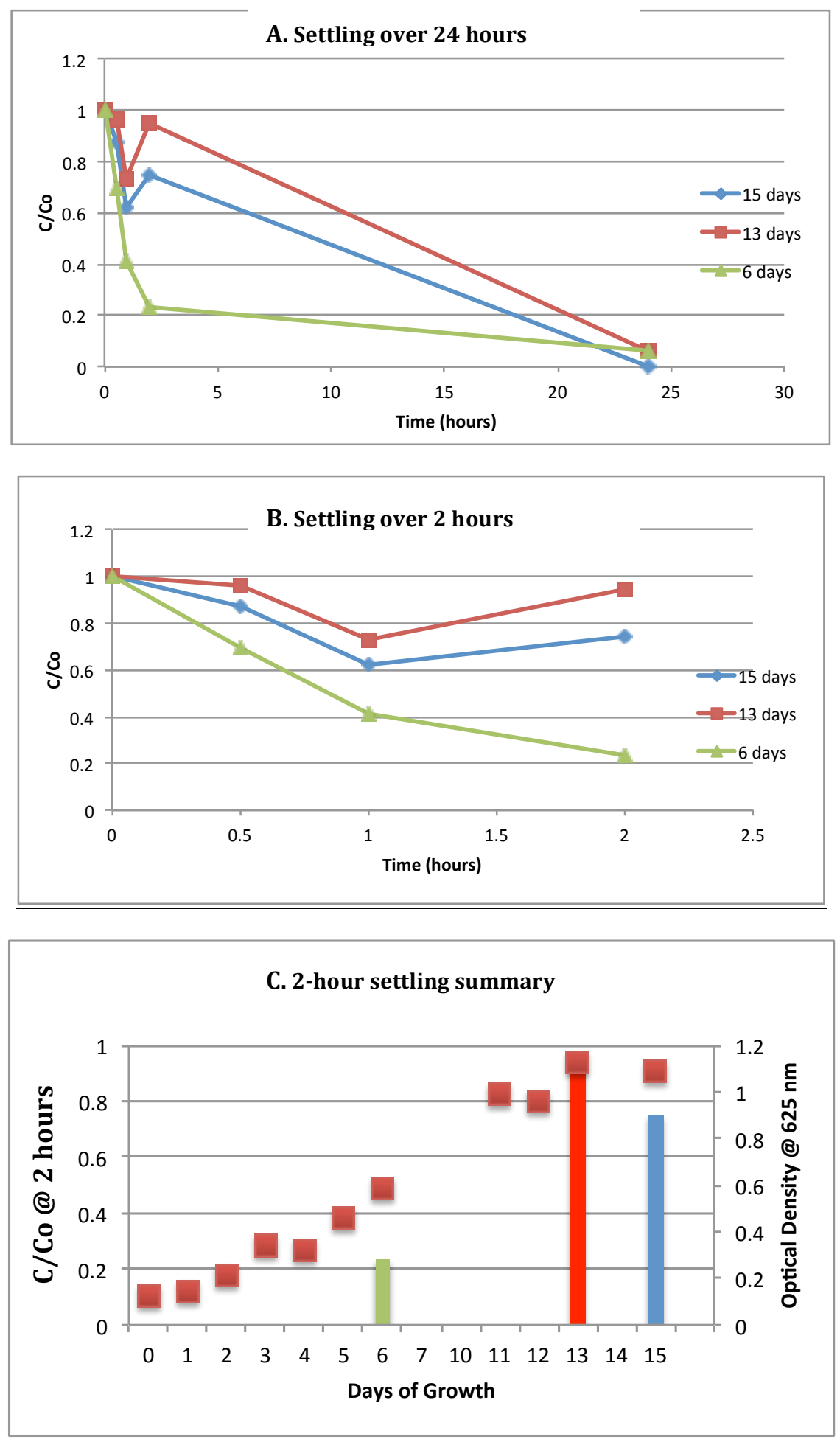

Figure 4.13-Settling based on normalized cell concentration remaining for the same Chlorella culture over the growth curve with no bioflocculant addition for A) a twenty four hour settling period B) a two hour settling period and C) a comparison of growth phase (plotted against optical density at $625 \mathrm{~nm}$ over the growth curve) (Colors correspond to days of growth on all graphs-note color change from Scenedesmus)

(Experiment 3) 


\subsubsection{Settling of Older Cultures of Scenedesmus and Chlorella Without Biofloculants}

Settling of the oldest Scenedesmus and Chlorella samples used in this research were compared to the settling of cultures at mid stationary phase of growth. This analysis was used to investigate whether partially dead cells in the samples help the settling of either algal culture. Older cultures (around 30 days old) of Scenedesmus were observed to settle about the same as young cultures, although the older culture settled slightly better in the 2-hour period and slightly worse over the 24 hour period as compared to cultures at mid stationary phase of growth (Figure $4.14 \mathrm{~A}$ and B). The older culture of Chlorella was very dense (large dry weight) and more difficult to measure cell concentration. The older culture of Chlorella settled very slowly as compared to the younger culture, with the largest cell concentration observed after 2 hours of settling $\left(\mathrm{C} / \mathrm{C} .{ }_{.0}=2.5\right)$. Cells from the top of the column were so slow in reaching the sampling port that after 2 hours of settling the cell concentration at the port was very high (Figure $4.14 \mathrm{~B}$ ). 

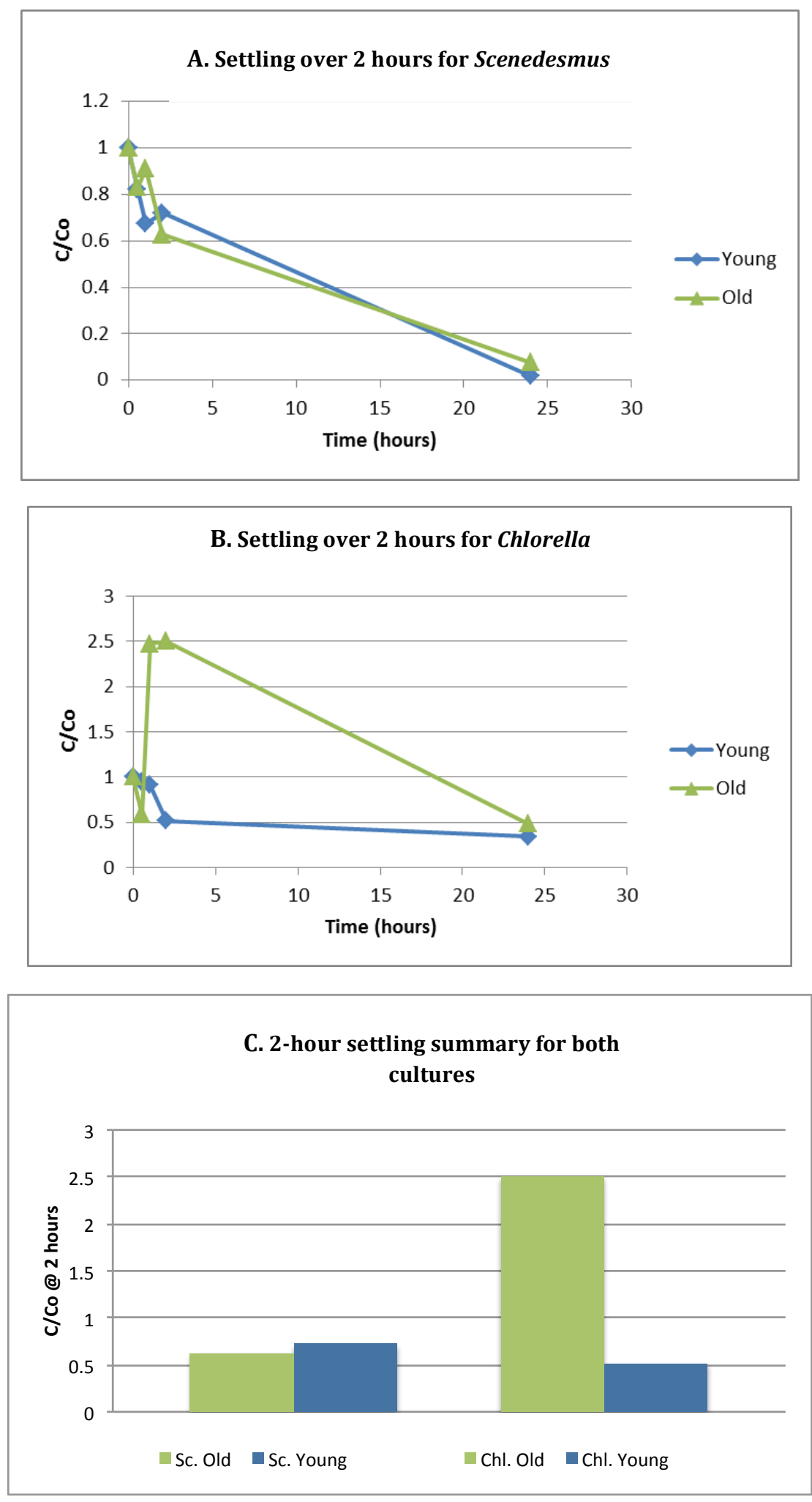

Figure 4.14-Settling of Young (mid stationary phase-15 days) versus Old (death phase-30 days)cultures based on normalized cell concentrations remaining of $A$ ) Scenedesmus B) Chlorella and C) Comparing settling between cultures over a 2-hour time period (instead of 24 hours) 


\subsubsection{EPS Correlation With Settling Results of Older Cultures of Scenedesmus and Chlorella Without Addition of Bioflocculants}

EPS was measured for the older cultures to determine the realtionship, if any, of EPS concentration with settleability for older cultures. Older cultures (past 30 days of growth) produced almost twice the EPS as mature cultures in mid stationary phase (Figure 4.15). For Scenedesmus, settling of cultures in the death phase was similar to that in mid stationary phase (Figure 4.14) even though the EPS concentration was much higher in the death phase (Figure 4.15). For Chlorella, settling was poor for cultures in the death phase (Figure 4.14) even though the EPS concentration was much higher (Figure 4.15). Clearly, some other factor is affecting settling of the algae cultures in the death phase other than the EPS.

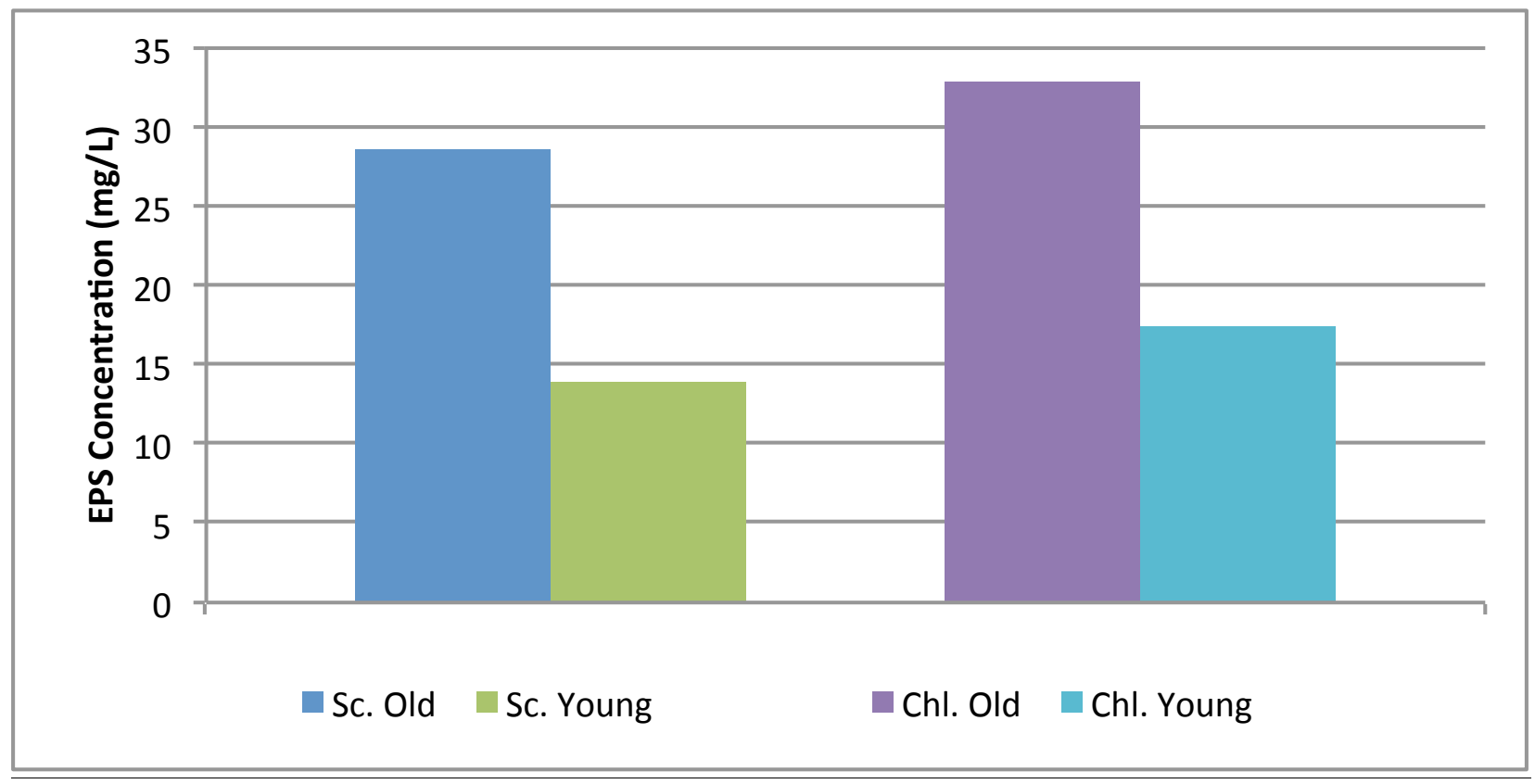

Figure 4.15-EPS productions of old (over 30 days of growth) and young (mid stationary growth phase-15 days old) cultures of Chlorella and Scenedesmus 


\subsubsection{Analysis of the Autoflocculation Phenomenon}

Autoflocculation was postulated to rely on the presence of three ions in certain concentrations: calcium, magnesium and orthophosphate (Sukenik, 1984). Sukenik (1984) used a culture medium with similar concentrations of calcium, magnesium and orthophosphate ions of 25,75 , and $17.5 \mathrm{mg} / \mathrm{L}$ respectively. To examine the autoflocculation phenomenon in this study the composition of the WC medium (Table 4.1) used in these experiments was compared to the solution chemistry of autoflocculation experiments reported in literature. The WC medium used in this study lacked an extra $2.25 \mathrm{mM} \mathrm{(250}$ $\mathrm{mg} / \mathrm{L})$ of calcium chloride and $0.6 \mathrm{mM}(72.22 \mathrm{mg} / \mathrm{L})$ magnesium sulfate relative to the Sukenik (1984) medium concentrations. In another study, Lavoie used secondary effluent from a wastewater treatment plant as the medium, containing $9.5 \mathrm{mg} / \mathrm{L}$ ammonium and 2.2 mg/L of orthophosphate (Lavoie, 1987). Both studies covered autoflocculation concerning two Scenedesmus species.

Table 4.1-Composition of WC Media for Autoflocculation Analysis

\begin{tabular}{|c|c|c|}
\hline Component & $\begin{array}{c}\text { Concentration } \\
(\mathbf{m} \mathbf{M})\end{array}$ & Concentration (mg/L) \\
\hline Tris (Buffer) & 4.13 & 500.30 \\
\hline $\mathrm{NaNo}_{3}$ & 1.00 & 84.99 \\
\hline $\mathrm{CaCl}_{2} \cdot 2 \mathrm{H}_{2} \mathrm{O}$ & 0.25 & 36.75 \\
\hline $\mathrm{MgSO}_{4} \cdot 7 \mathrm{H}_{2} \mathrm{O}$ & 0.15 & 36.97 \\
\hline $\mathrm{NaHCO}_{3}$ & 0.15 & 12.60 \\
\hline $\mathrm{K}_{2} \mathrm{HPO}_{4}$ & 0.05 & 6.8 \\
\hline
\end{tabular}


Lavoie (1987) found that natural flocculation with the wastewater medium (much lower concentrations of orthophosphate compared to WC) was possible for this Scenedesmus culture up to a pH of 11 and before stationary phase. This was due to the fact that orthophosphate concentrations were used up at the beginning of stationary phase (Lavoie, 1987). This result parallels results obtained with this research, were Scenedesmus settling was improved after seven days of growth (in the same range as Lavoie) to achieve up to $50 \%$ sedimentation (Figure 4.87). However, as the culture age increased, the orthophosphate in the WC medium was likely used up. This is proved given after 14 days of growth, no settling of Scenedesmus was observed at a pH of 11 without B. cepacia cell addition (Figure 4.82). This result corresponds with Lavoie's study, where low orthophosphate concentrations in the medium during later Scenedesmus growth resulted in poor autoflocculation and settling.

Sukenik's (1984) study also showed that necessary conditions within the culture medium needed to be met prior for autoflocculation to occur. These conditions include a concentration of orthophosphate between $0.1 \mathrm{mM}$ to $0.2 \mathrm{mM}$ and $1.5 \mathrm{mM}$ to $2.5 \mathrm{mM}$ calcium in the medium and a pH at or above a range of 8.5 to 9 (Sukenik, 1984). It was determined that these conditions were met by the Scenedesmus culture used in this research early on in the growth phase (when the $\mathrm{pH}$ was raised to 11), before orthophosphate concentrations were limiting. Poor settling results for Chlorella, on the other hand, indicated that possibly orthophosphate ions were used up faster, providing less of a chance for autoflocculation to occur. However, without measuring the concentrations of these two ions, there was no way of directly proving this hypothesis. Based on the published literature, autoflocculation might be improved during later stages in growth by enrichment of the culture media with additional calcium, magnesium and phosphate. This research proved that during early 
stages in growth, enrichment of the culture media was determined not necessary for improved autoflocculation of Scenedesmus cultures only.

\subsection{Settling of Scenedesmus and Chlorella with B. cepacia Bioflocculants}

This section focused on measuring the settling based on normalized cell removal of pure Scenedesmus and Chlorella cultures with B. cepacia bacterial bioflocculant addition and were covered in Experiments 1, 2 and 3. The effect of bioflocculant addition over the growth curve of both algae cultures is discussed in Experiment 1 (Section 4.2.2). Physical factors such as the mixing time were also explored as an important treatment studied throughout Experiment 2 (Section 4.2.3) to find the optimum time for the bacterial and algal cells to adhere together, overcome surface repulsion, and rely on physical forces (Van der waals) of attraction. In addition, physical factors affecting settling such as the dosage of B. cepacia cells or filtrate required further investigation in Experiment 3 (Section 4.2.4).

\subsubsection{Growth Curves of B. cepacia cultures used for Bioflocculant Addition}

The growth curves of B. cepacia cultures used in Experiment 1 are shown in Figures 4.16 and 4.17. It was important to establish the bacterial growth curve because more EPS is reported during stationary growth phase (Pavoni, 1972). Bacterial growth curves are similar for this experiment in that they peak after 100 hours of growth and level off accordingly (signifying the onset of stationary growth phase), although the maximum OD was different.

The B. cepacia bacterial growth curve for Experiment 2 is shown in Figure 4.18 and characteristically peaked around 72 hours of growth and into mid stationary phase. $B$. cepacia was harvested during early to mid stationary phases of growth, when EPS production was expected to be optimal. The OD values are smaller in comparison to other growth curves since this experiment used an older spectrophotometer (Spec 20) as 
compared to the UV 1700 Pharma Spec spectrophotometer (Shimadzu) used in the other experiments. Growth was also uncharacteristically high at later stages (Figure 4.18).

In previous Experiments (1,2), B. cepacia cultures showed not as much growth as desired. Therefore, new techniques were empoyed to assure better growth, presumably for higher EPS production. New methods included innoculating the bioreactor with an older culture of B. cepacia to ensure the cells would be conditioned to whatever new environment they would be placed in. This improved technique resulted in a much higher cell density, as indicated in Figure 4.19. The growth characteristically hit a maximum after 48 to 72 hours and declined steadily until around ten days, where OD increased. This increase in OD could be attributed to a number of possible effects; for example, OD may have been affected by changing cell size. Thus, after 10 days of growth, death phase could have been reached given the OD increased as cells became smaller (due to a lack of nutrients). The resulting smaller cells could have contributed to a greater light scattering effect. 


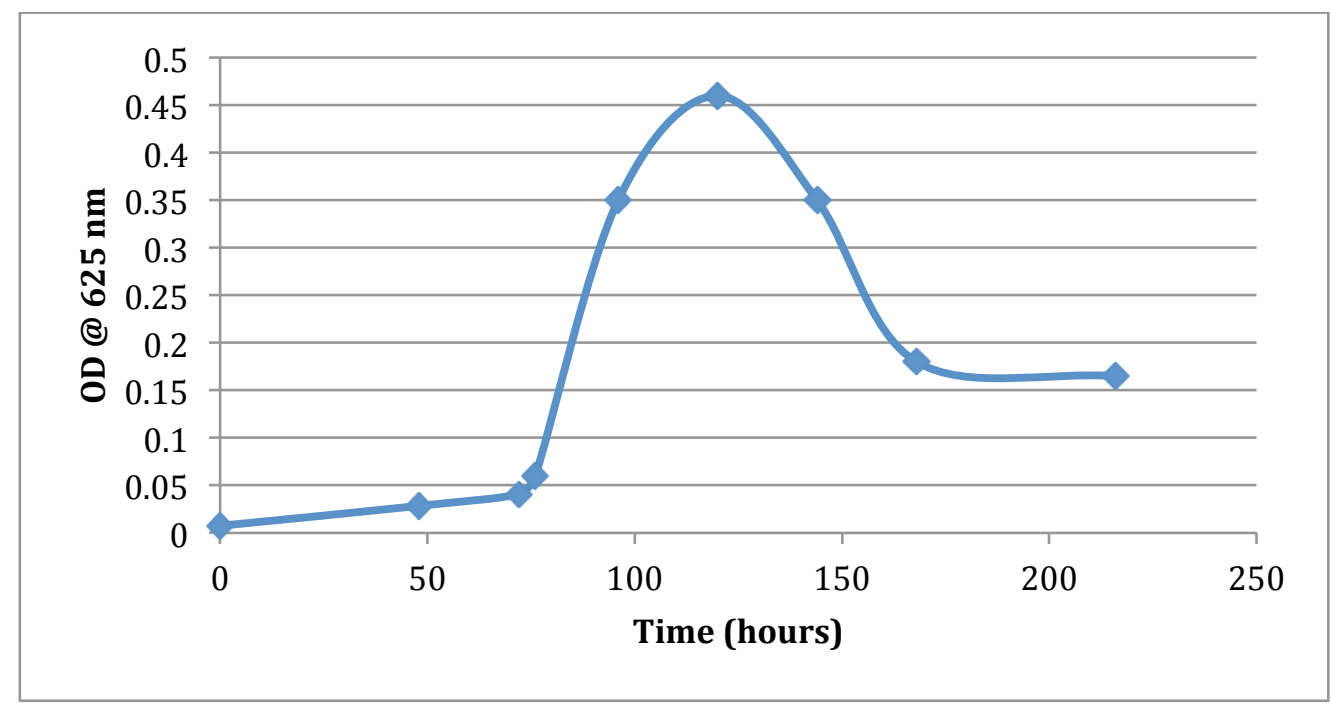

Figure 4.16-Growth curve of B. cepacia over a 250-hour growth period using optical density

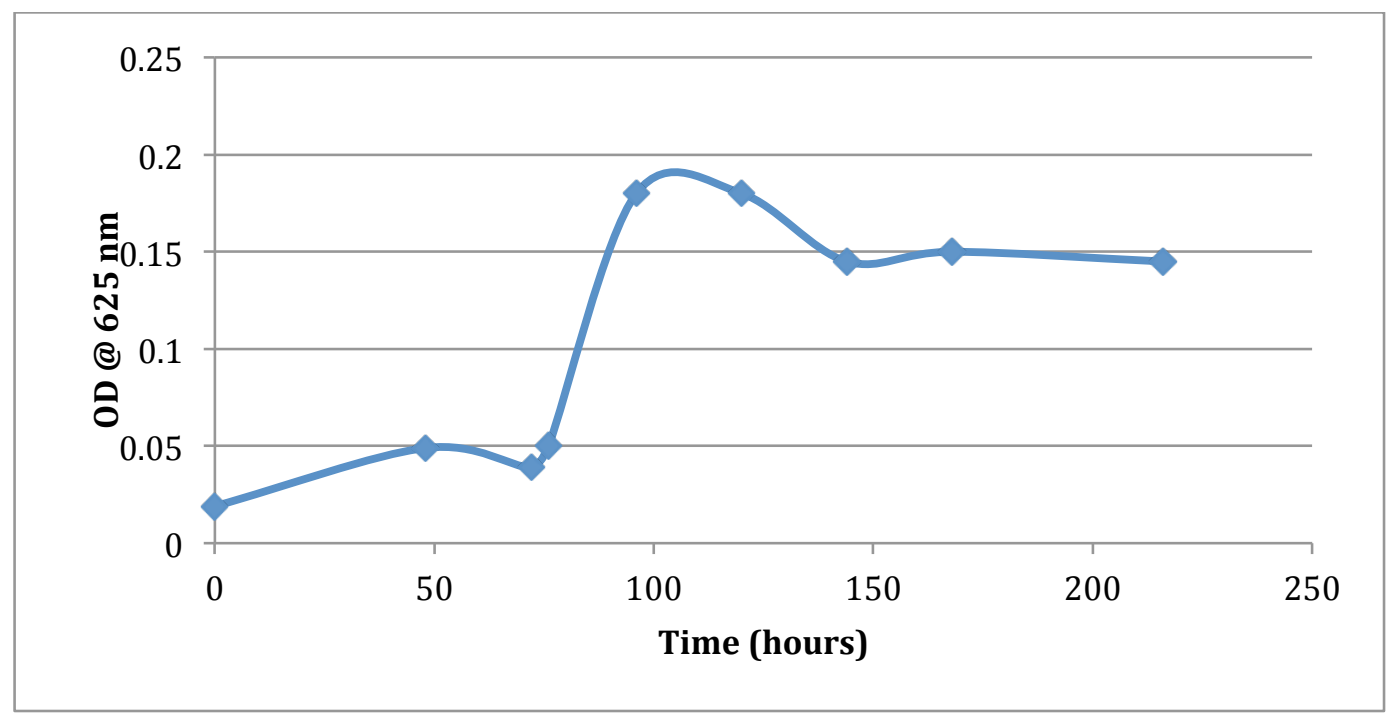

Figure 4.17-Growth curve of a second batch culture of B. cepacia over a 250-hour growth period using optical density 


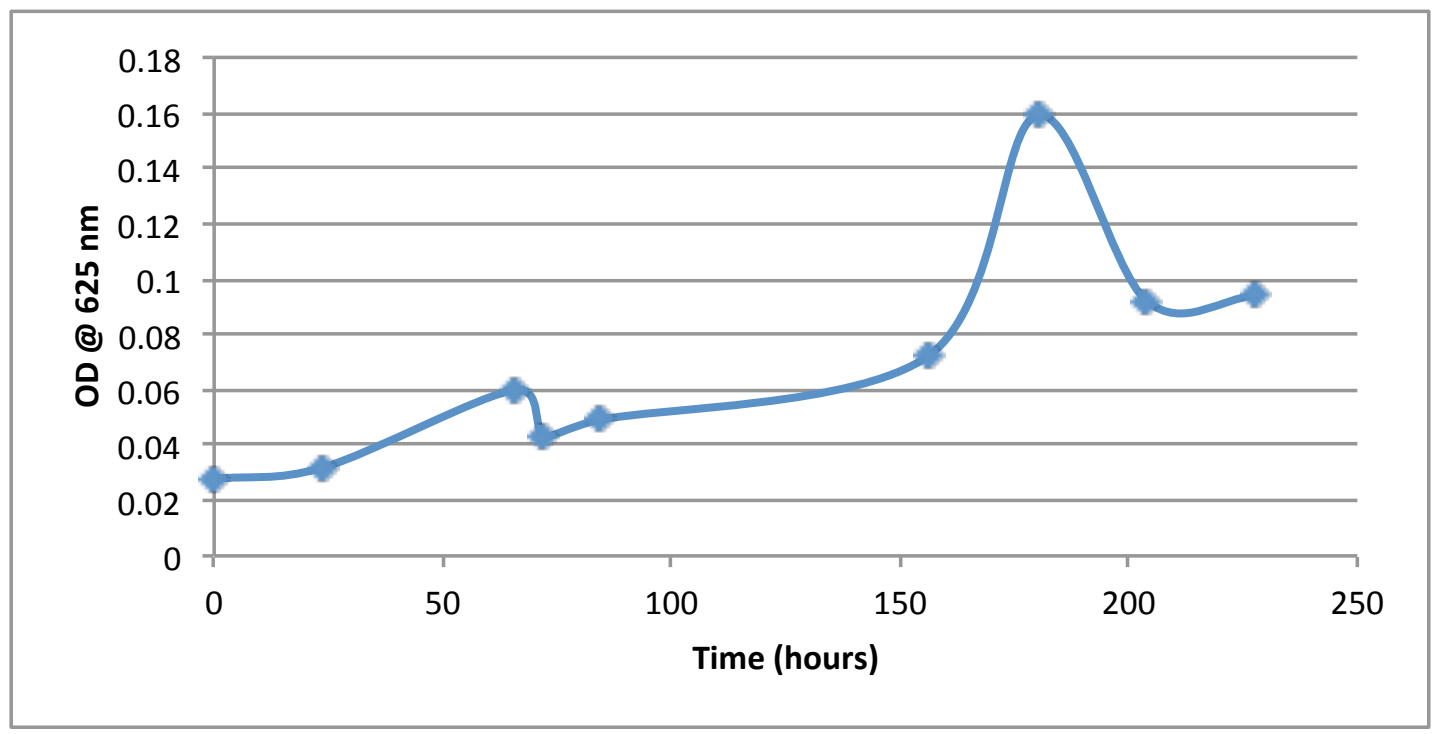

Figure 4.18-Growth of B. cepacia over a 250-hour period, with optical density taken at 625 nanometers

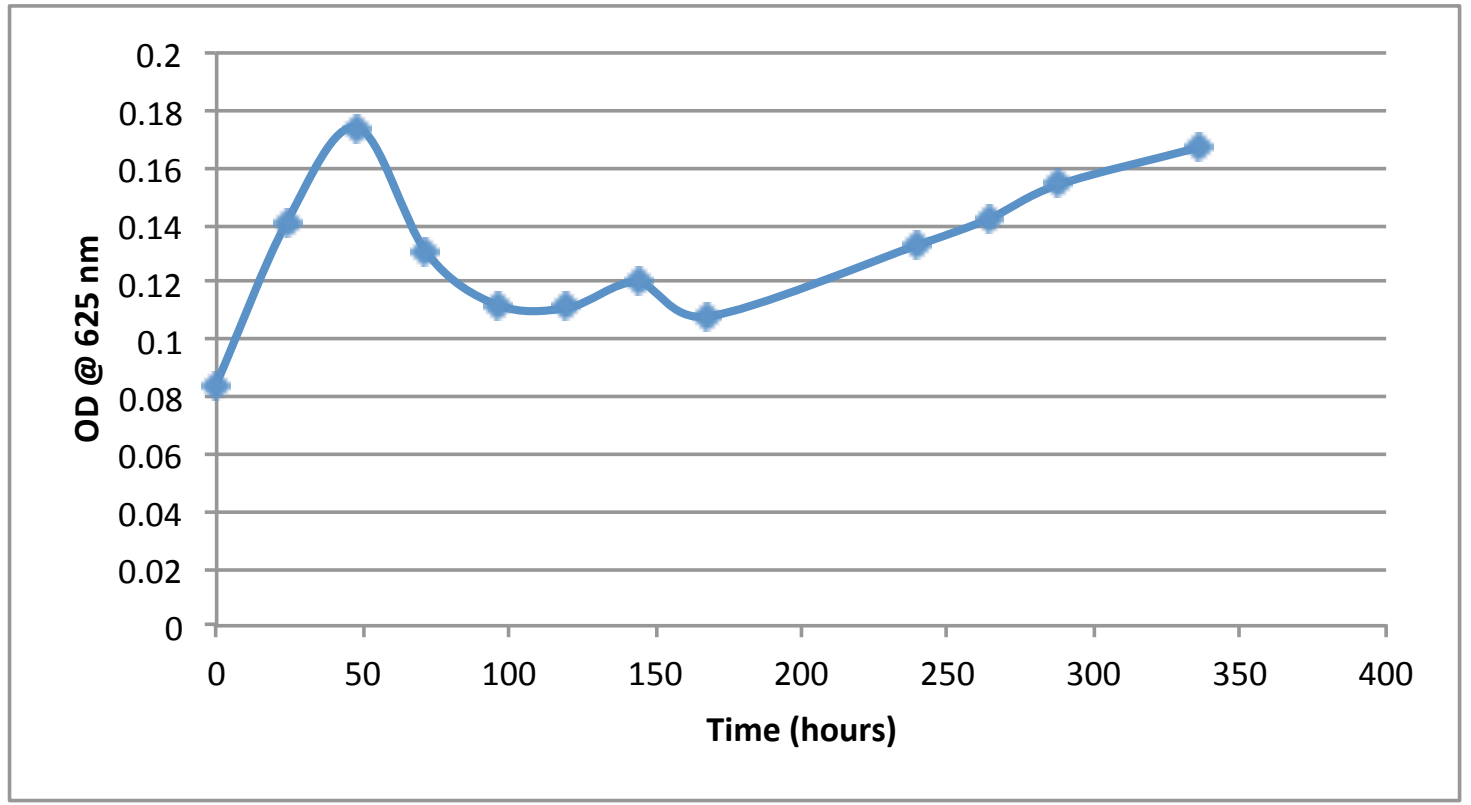

Figure 4.19-Growth curve of B.Cepacia at $26^{\circ}$ Celsius using optical density at $625 \mathrm{~nm}$ over a 350-hr period 


\subsubsection{Effect of B. cepacia Bioflocculant Addition on Settling of Scenedesmus and}

\section{Chlorella: Experiment 1}

Settling of both Chlorella and Scenedesmus were measured after mixing with $B$. cepacia cells or B. cepacia filtrate. The filtrate contained high molecular weight presumed to be dissolved EPS from B. cepacia. In this first experiment a fixed mixing time of five minutes was used. Figure 4.20 (A, B) illustrates the same algal culture of Scenedesmus as used in previous experiments settled with and without B.cepacia bacterial cells and filtrate over 24hour and 2-hour settling periods. The culture of Scenedesmus used was in the late stationary phase (18 days of growth) and the B. cepacia was harvested during early stationary phase of growth.

The observed-settling rate of Scenedesmus was greater than that observed previously for the controls without B. cepacia or filtrate. Addition of B. cepacia cells allowed Scenedesmus to settle at a higher rate during the course of the 24-hour period as well as the 2-hour period (Figure 4.20). Cell filtrate addition also improved Scenedesmus settling, although not as much as cell addition. Thus, both the capsular fraction and dissolved fraction of the B. cepacia EPS appears to enhance settling.

Results for Chlorella mixed with B. cepacia cells and filtrate can be observed in Figure 4.21 (A, B) depicting normalized cell concentration removal over a twenty-four and two hour period, respectively. An older culture of Chlorella was used (after 14 days of growth), which resulted in relatively decreased settling for the control without cell or filtrate addition. For Chlorella cultures, B. cepacia cell addition made settling worse than the control over a 2-hour period. Filtrate addition, on the other hand, significantly improved the settling of the Chlorella culture over both the 24- hour and 2-hour period. These results suggest that B. cepacia filtrate, with dissolved EPS, enhanced settling. The effect of B. cepacia 
cells was quite different for Chlorella compared to Scenedesmus. The B. cepacia cells improved the settling of Scenedesmus and hindered the settling of Chlorella.

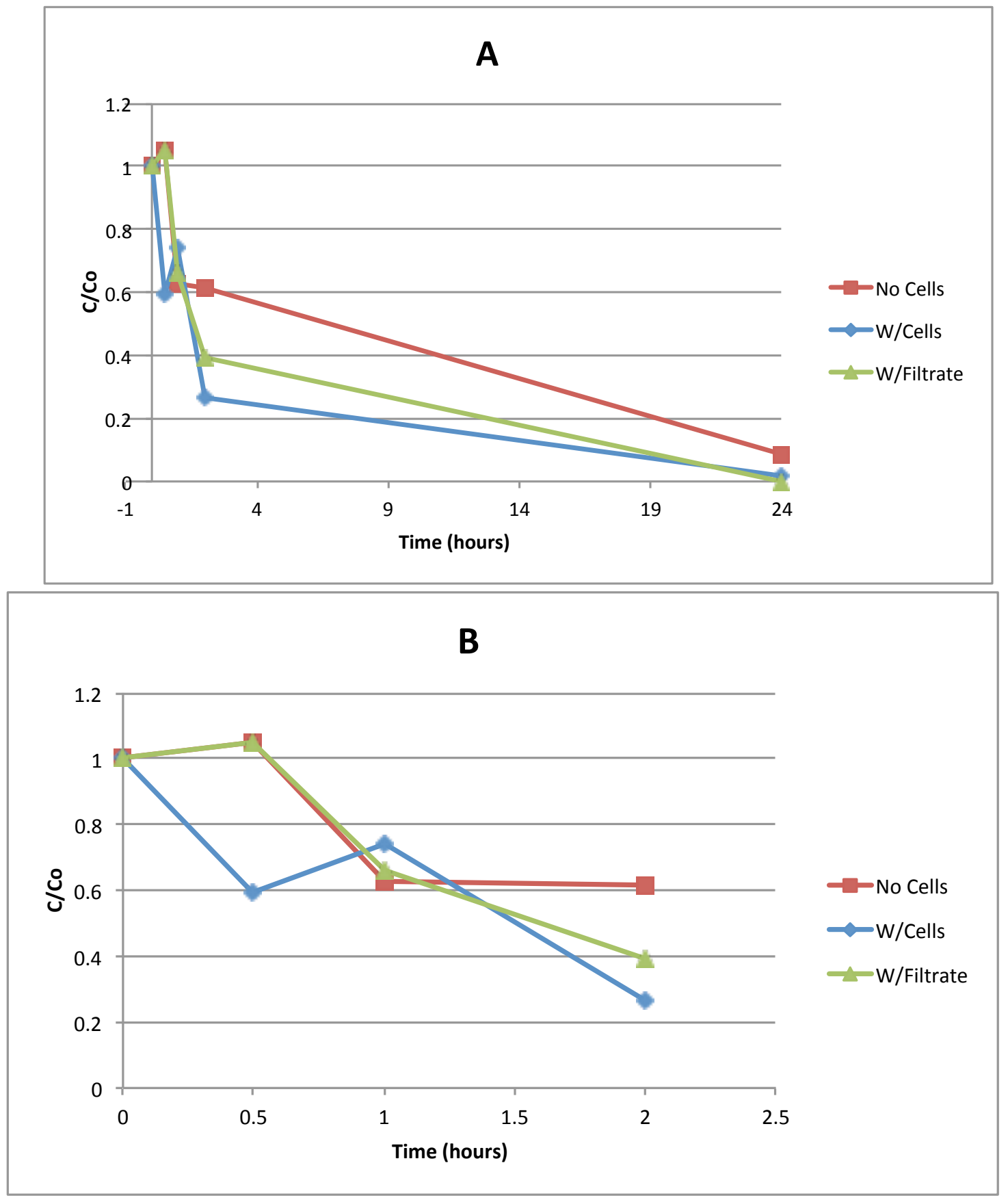

Figure 4.20-Comparison of B. cepacia cell, filtrate and no cell addition to an 18-day old Scenedesmus culture using normalized cell concentration remaining as a function of settling time over A) a 24- hour period and B) a 2-hour period 

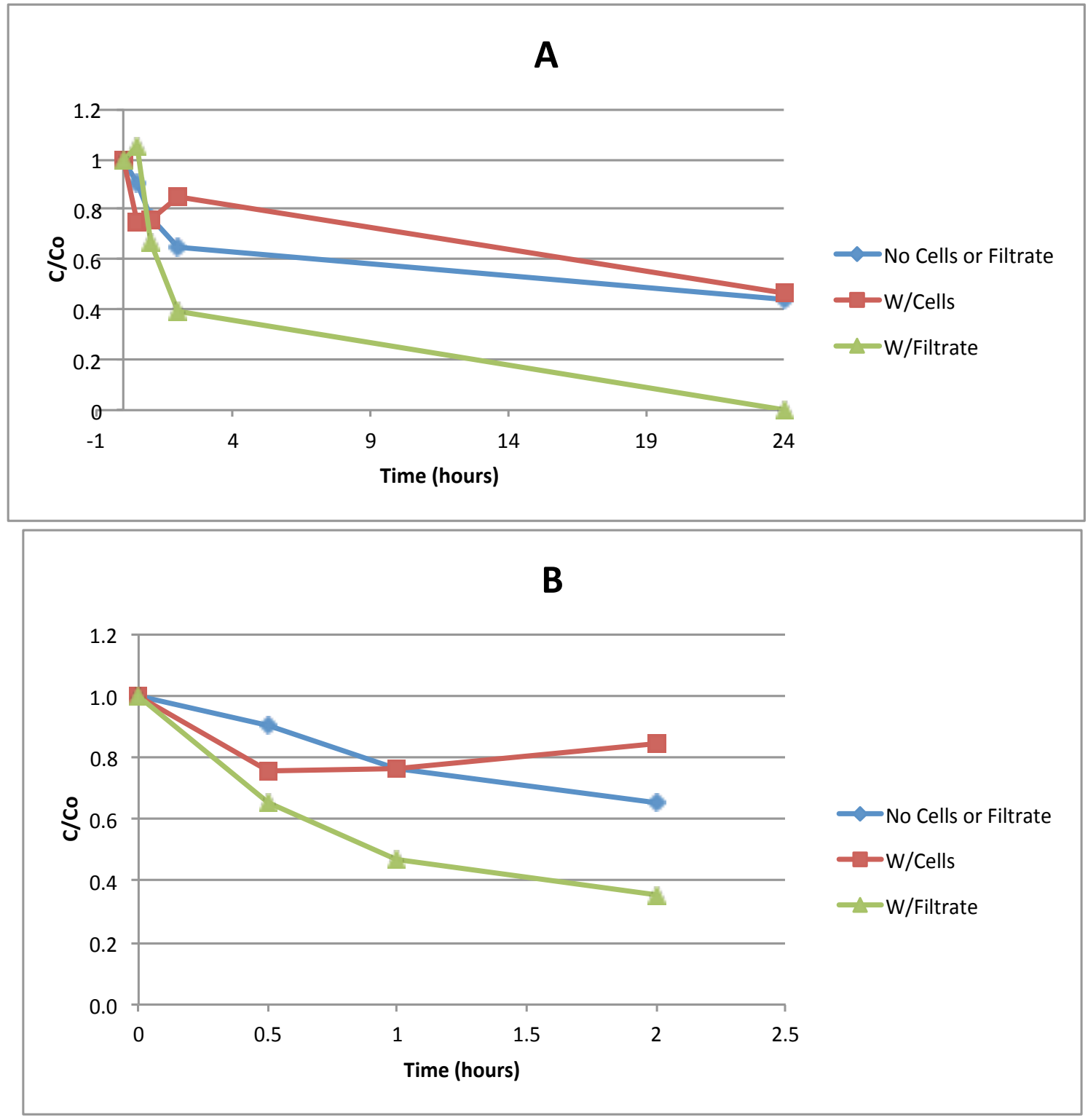

Figure 4.21-Comparison of B. cepacia cell, filtrate and no cell addition to a 14-day old Chlorella culture using normalized cell concentration remaining as a function of settling time over A) a 24-hour period and B) a 2-hour period 


\subsubsection{Effect of B. cepacia Bioflocculant Addition on Settling of Scenedesmus and}

\section{Chlorella: Experiment 2: Varying Contact Time}

In addition to repeating Experiment 1, Experiment 2 also was used to investigate the effect of varying contact times between B. cepacia cells, filtrate and algae before settling tests were conducted. For experiment 2 , three settling tests were run using algae samples collected during days 6 and 8 of growth.

The first settling test involved Scenedesmus and Chlorella cells along with the addition of B. cepacia cells on Day 6 of growth. For Scenedesmus, varying contact times with B. cepacia cells of 5 and 15 minutes were used. Contact times for Chlorella with B. cepacia cells were 5, 15, and 30 minutes. All algae and bacterial cells were mixed uniformly during the various contact times using stir plates at $750 \mathrm{rpm}$ and then added immediately to the settling columns.

This second settling test, like the first, involved addition of B. cepacia cells at different contact times on Day 8 of growth. In this test, Scenedesmus and B. cepacia were mixed at 5,15, and 30-minutes. Chlorella and B. cepacia cells were mixed at 5 and 15minutes

The third settling test, for Scenedesmus, focused on settling with B. cepacia filtrate at 15 and 30-minute contact times on Day 10 of growth. Chlorella was mixed with B. cepacia filtrate at 5, 15 and 30 minute contact times. It is important to note that the third settling test contacted the algae with B. cepacia filtrate, not cells.

The effects of B. Cepacia cells on the settling of Scenedesmus with different contact times are shown in Figures 4.22 (A, B), and Figure 4.23 (A, B). Figure 4.22 (A, B) is for Scenedesmus cells after 6 days of growth at two contact times of 5 and 15 minutes with $B$. cepacia, while Figure 4.23 (A, B) is for Scenedesmus cells after 8 days of growth with three 
different contact times (5, 15 and 30 minutes). These results are summarized in Figure 4.24. For the 6-day-old Scenedesmus culture, the addition of B. cepacia cells increased two hour settling significantly (Figure 4.22 B) similar to that observed in Experiment 1. However, at least with a 5 -minute mixing time, the 24 -hour settling was actually hindered by B. cepacia cells (Figure 4.22A). B. cepacia cells also improved the settling for the 8-day-old Scenedesmus culture, but the effect was much smaller (Figure 4.24).

For the 6-day-old Scenedesmus culture, the effect of increasing the mixing time was small (Figure 4.24). Figure 4.22 (A, B) shows that the B. cepacia cells work the best to settle the Scenedesmus at a contact time of around 15 minutes for both settling time periods. For the 8-day-old culture, longer contact times increased settling, where up to 30 minutes was best (Figure 4.24). However, as compared to the 6-day-old culture the overall settling efficiencies were low (Figure 4.24). The effect of B. cepacia cells addition was more pronounced for Scenedesmus harvested at 6 days, when settling without B. cepacia were observed to be poor. These results suggest that a longer contact time of around 30 minutes, at a growth phase closer to early stationary, coupled with the addition of B. cepacia cells might have a positive effect on the settling of Scenedesmus.

The effect of adding B. cepacia filtrate on the settling rate of Scenedesmus after 10 days of growth is shown in Figure 4.25 (A and B). In this case, filtrate did not improve the settling rate of Scenedesmus. (Figure $4.25 \mathrm{~A}, \mathrm{~B}$ ). In fact, both the 15 and 30-minute contact times made the settling between 0 and 2 hours worse compared to no filtrate added at all. After 24 hours of settling, the filtrate had little to no effect on the settling rate of Scenedesmus (Figure 4.25 A). 

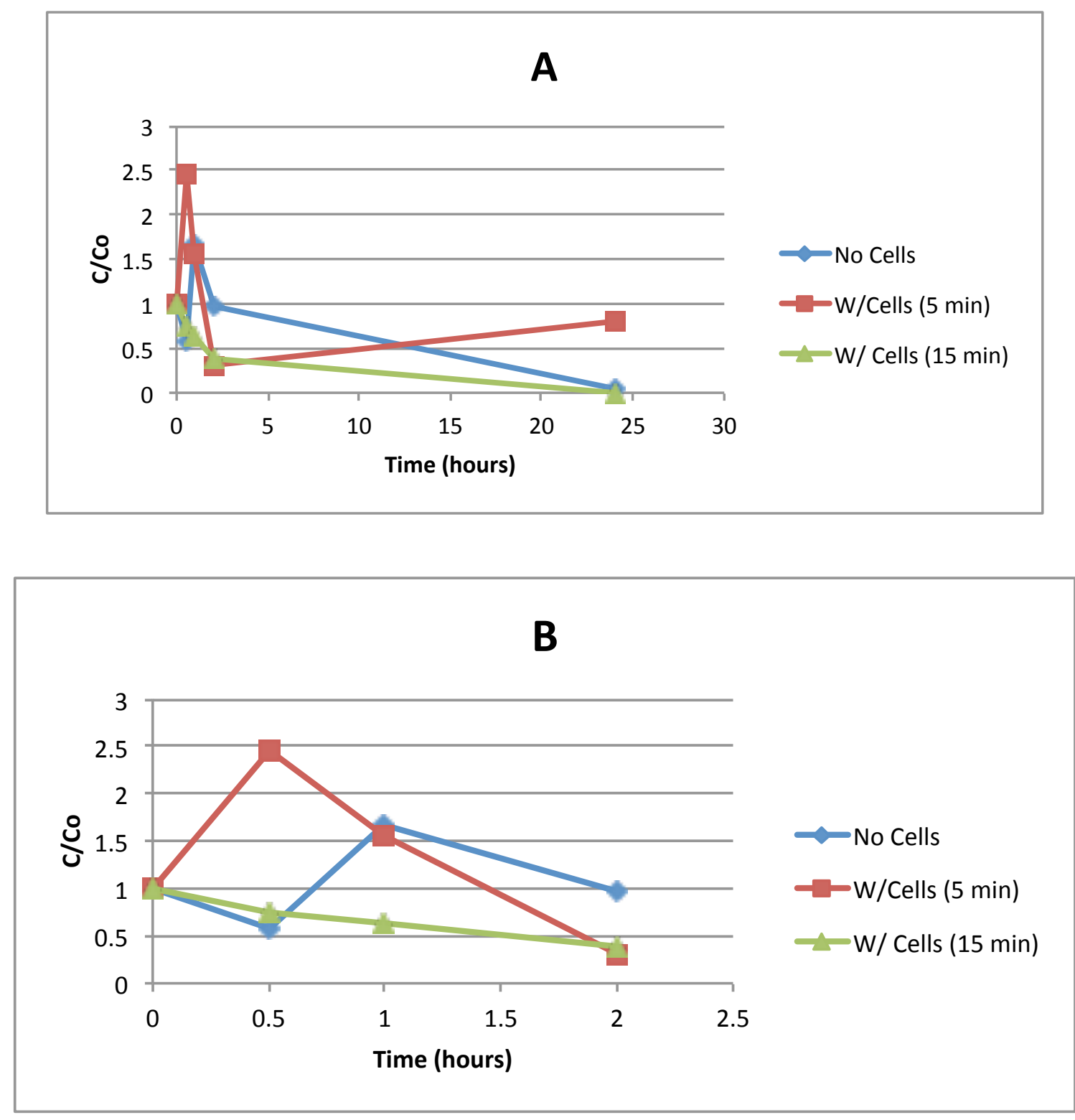

Figure 4.22-Effect of B. cepacia cell addition on settling of Scenedesmus using normalized cell concentrations remaining after 6 days of growth over A) a 24-hour settling period and B) a 2-hour settling period 


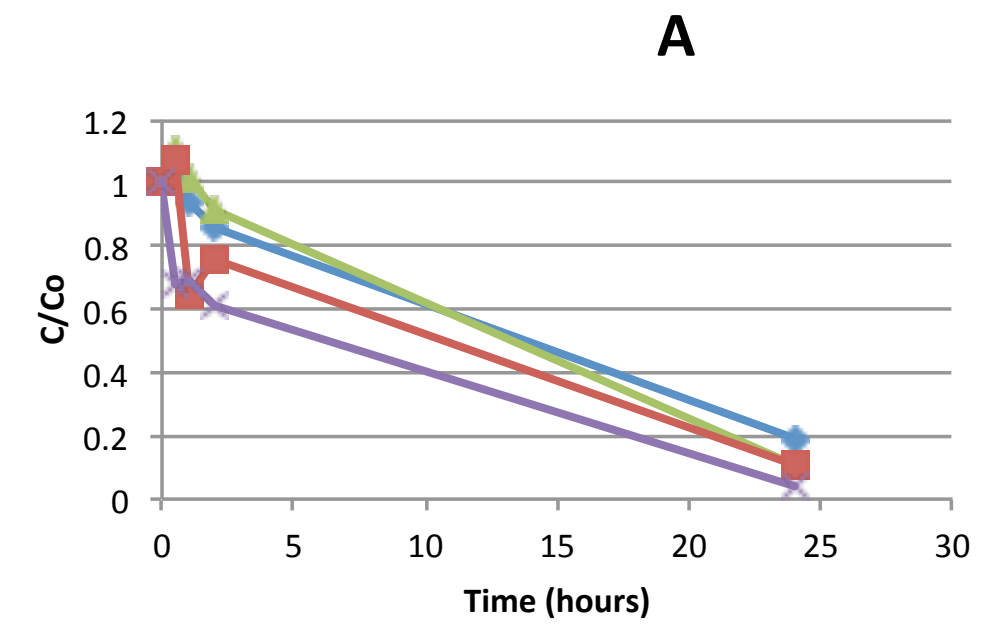

$\sim$ No Cells

W/Cells $5 \mathrm{~min}$

$-\mathrm{W} /$ Cells $15 \mathrm{~min}$

$\therefore \mathrm{W} /$ Cells $30 \mathrm{~min}$

B

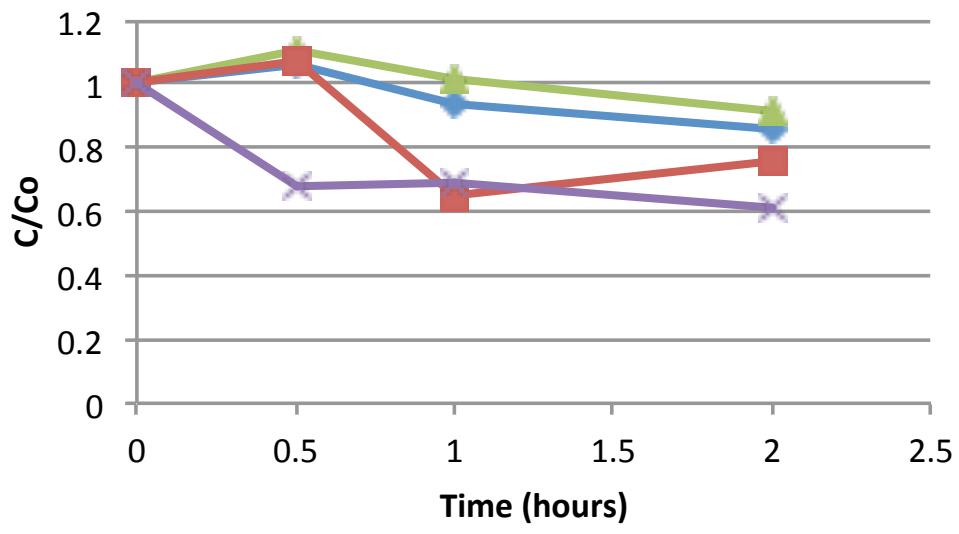

$\sim$ No Cells

$\longrightarrow$ W/Cells 5 min

$-\mathrm{W} /$ Cells $15 \mathrm{~min}$

$\leftarrow \mathrm{W} /$ Cells $30 \mathrm{~min}$

Figure 4.23-Effect of B. cepacia cell addition on settling of Scenedesmus using normalized cell concentrations remaining after 8 days of growth over a A) 24-hour settling period and B) over a 2-hour settling period 


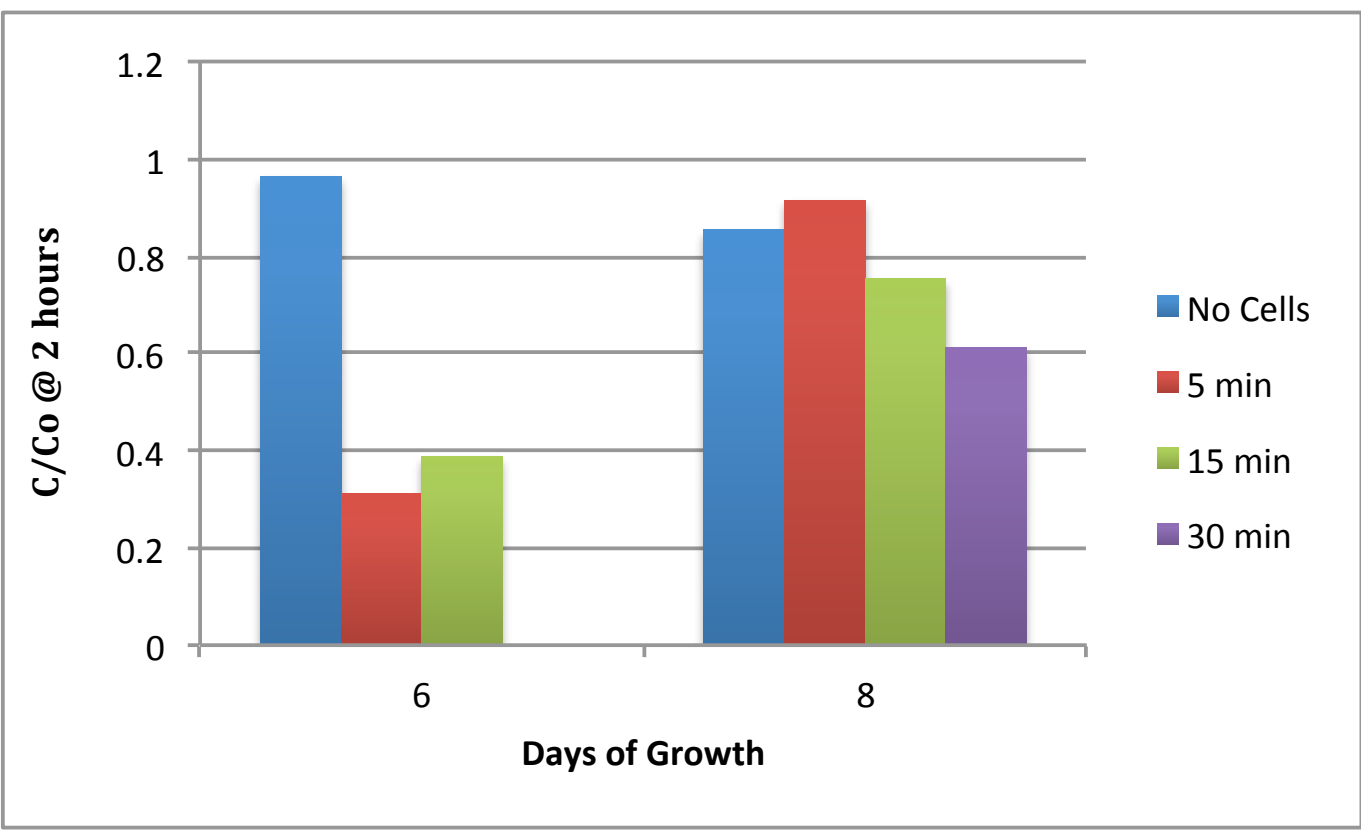

Figure 4.24-Effect of $B$. cepacia cell addition and contact time on the measured settling of Scenedesmus based on normalized cell concentration remaining after 6 and 8 days of growth over a 2-hour settling period. The legend denotes contact time between cells (Experiment 2) 


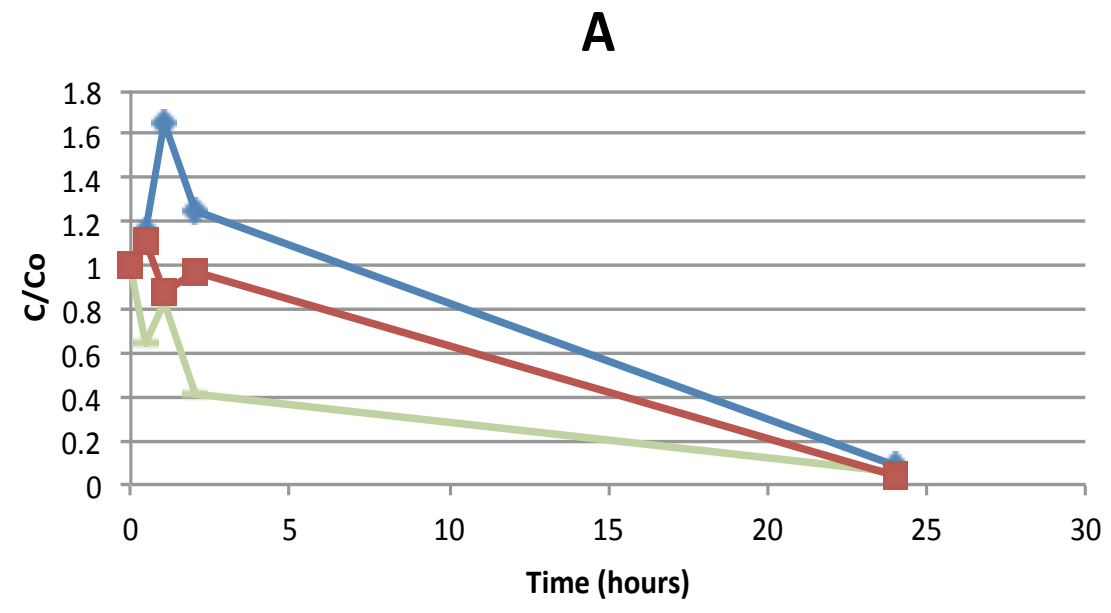

No Filtrate

Filtrate/15 min

-Filtrate/ $30 \mathrm{~min}$

B

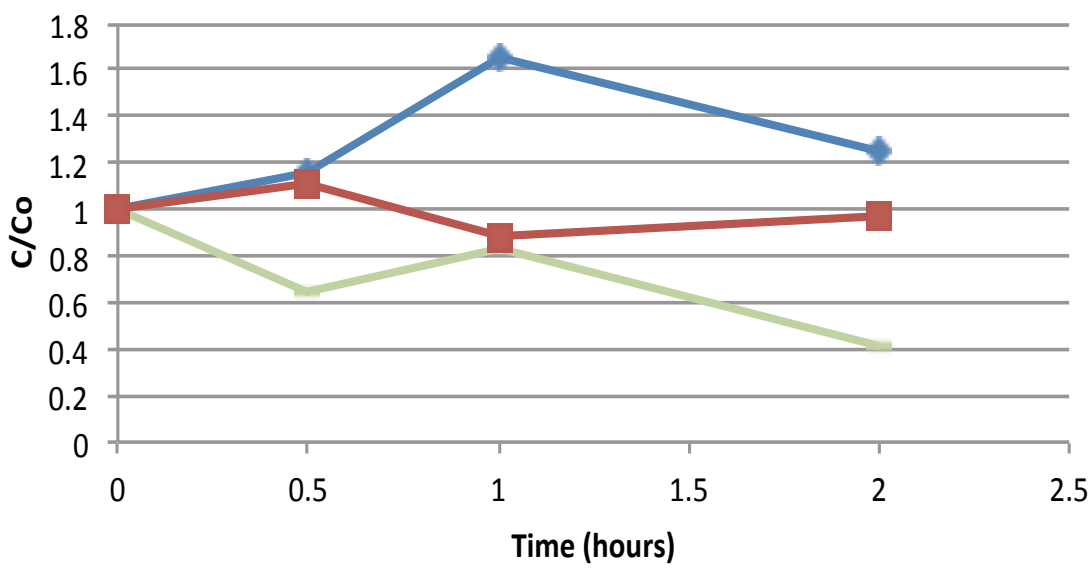

No Filtrate

$\sim$ Filtrate/15 min

Filtrate/ $30 \mathrm{~min}$

Figure 4.25-Settling of Scenedesmus using normalized cell concentrations remaining with and without B. cepacia filtrate addition after 10 days of growth over a A) 24-hour settling period and $B$ ) 2 - hour settling period 
The effect of B. cepacia cell addition on settling of Chlorella is shown in Figures 4.26 and 4.27 at various mixing times. For Chlorella, the effect of adding of B. cepacia cells was very different for Chlorella cultures harvested at 6 days compared to 8 days (Figure 4.28). For the 8-day-old Chlorella culture, B. cepacia cells improved settling, while 6-day-old Chlorella cultures actually settled worse with B. cepacia cells (Figure 4.28). Negative results were also observed for Chlorella in Experiment 1. In general, longer mixing times tended to accentuate the B. cepacia cell effect, whether positive or negative.

Figure 4.29 (A, B) shows the settling of Chlorella with and without B. cepacia filtrate added. Filtrate added at a contact time of five minutes (shorter contact time) had the most beneficial effect on settling over both a 2 and a 24 - hour settling period. This result agrees with earlier results from Experiment 1 that filtrate addition has a beneficial impact on the settling of Chlorella. This result also concurs with the effect of mixing time observed with $B$. cepacia cell addition (shorter mixing time has a better effect). The extent of improved settling at this mixing time of five minutes, however, was more pronounced for Chlorella with the addition of B. cepacia filtrate. The greatest cell removal was observed with filtrate addition after ten days of growth with a contact time of five minutes, removing about $75 \%$ of cells within two hours, and up to $99 \%$ of algal cells within 24 hours of settling. 

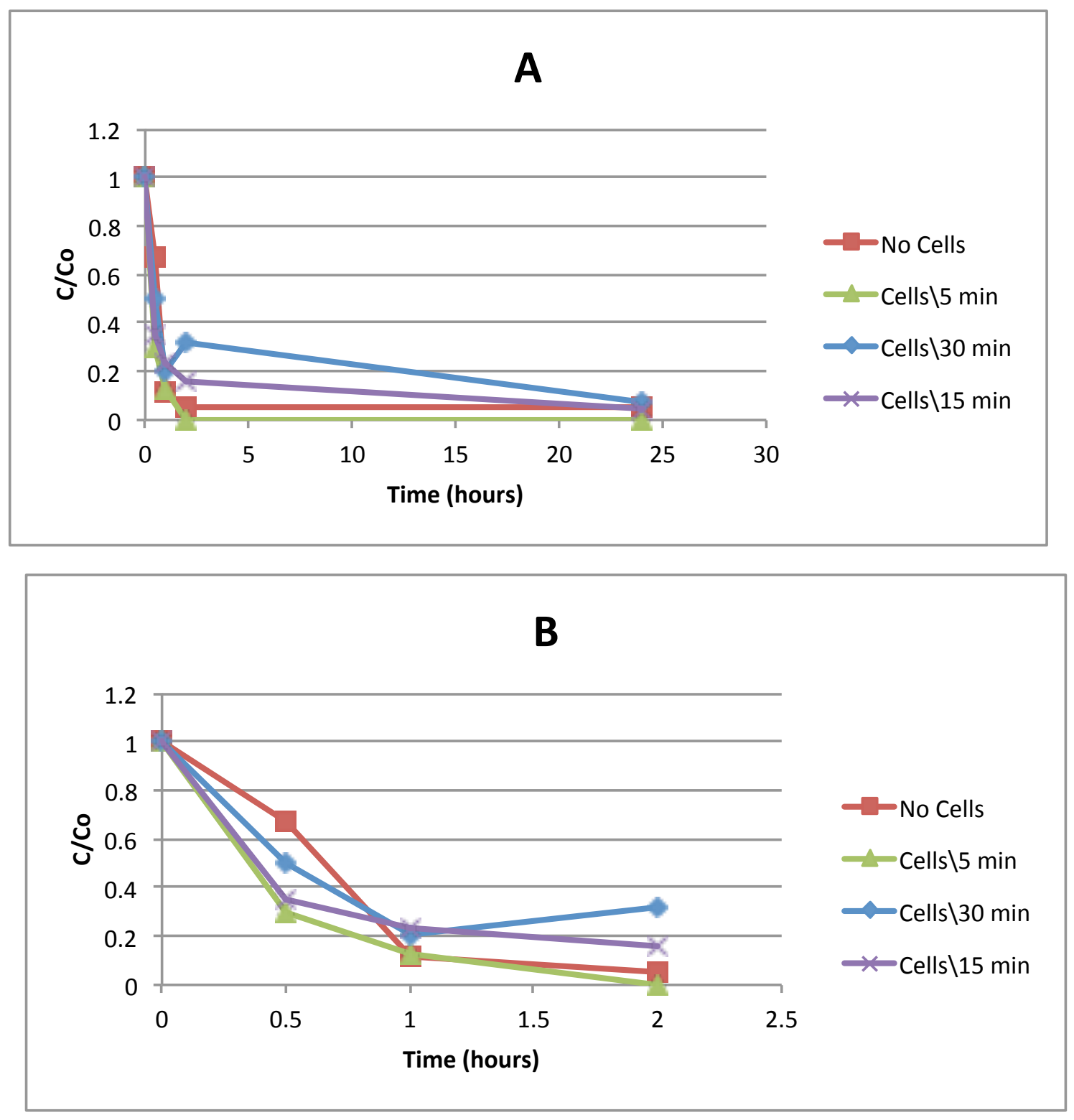

Figure 4.26-Effect of B. cepacia cell addition on settling of Chlorella using normalized cell concentrations remaining after 6 days of growth over a A) 24-hour period and B) 2hour settling period 

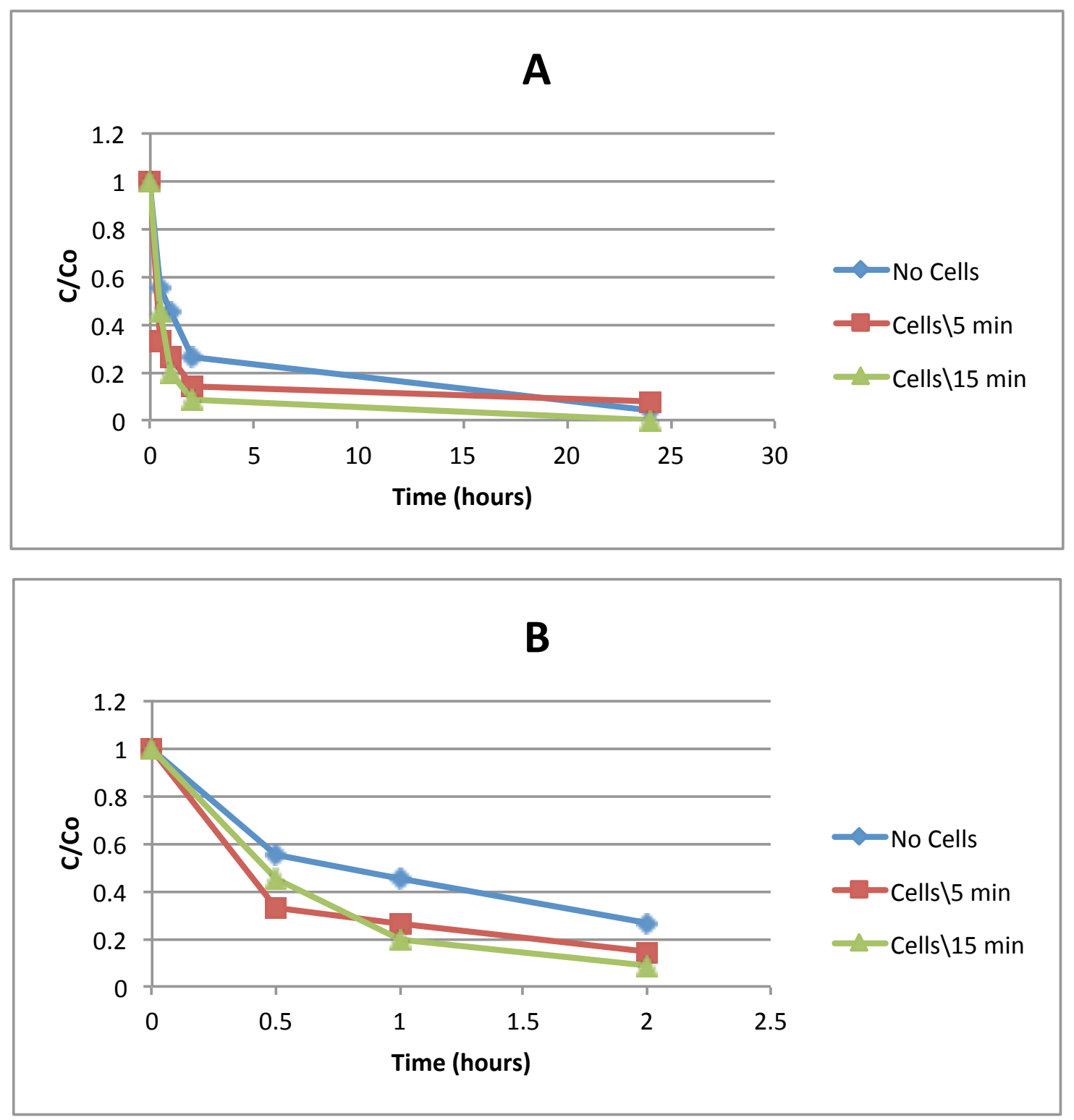

Figure 4.27-Effect of B. cepacia cell addition on settling of Chlorella using normalized cell concentrations remaining after 8 days of growth over a A) 24-hour settling period and B) 2-hour settling period 


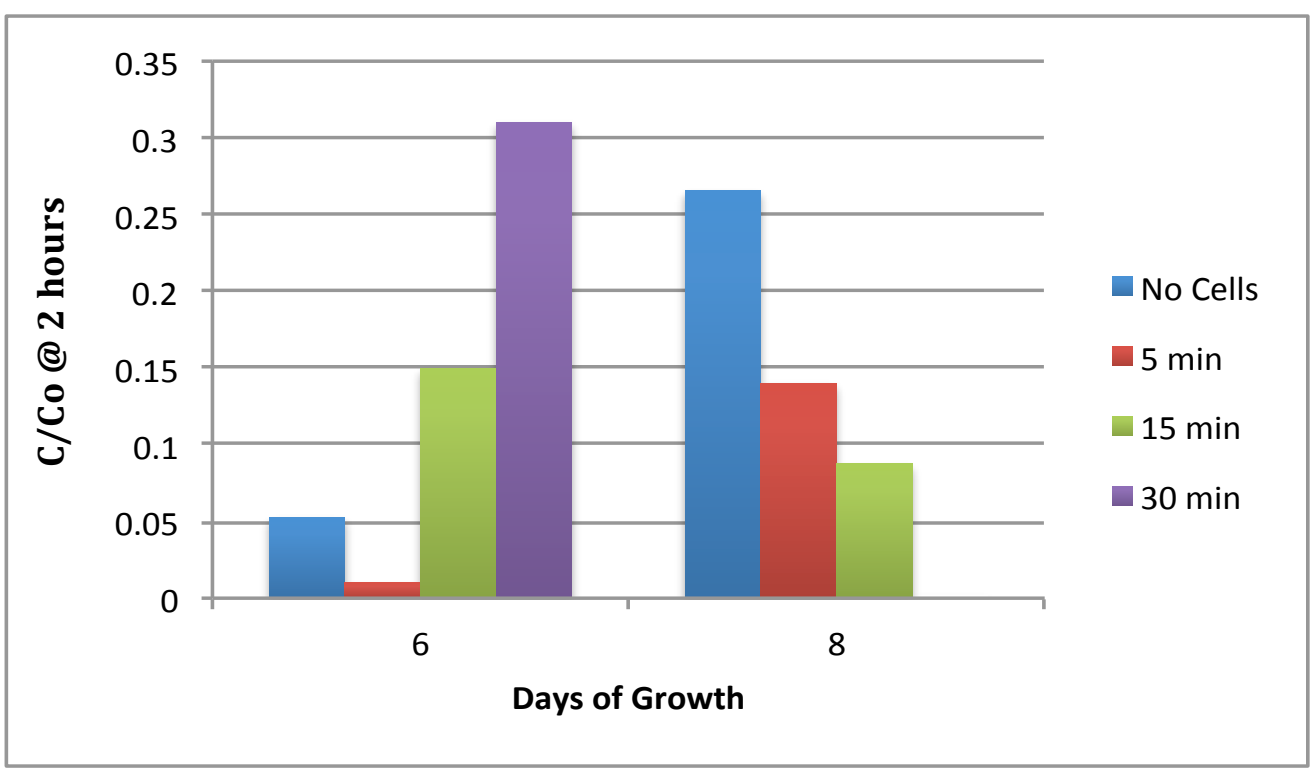

Figure 4.28-Effect of B. cepacia cell addition and contact time on settling of Chlorella based on normalized cell concentration remaining after 6 and 8 days of growth over a 2-hour settling period. The legend denotes contact time between cells (Experiment 2) 

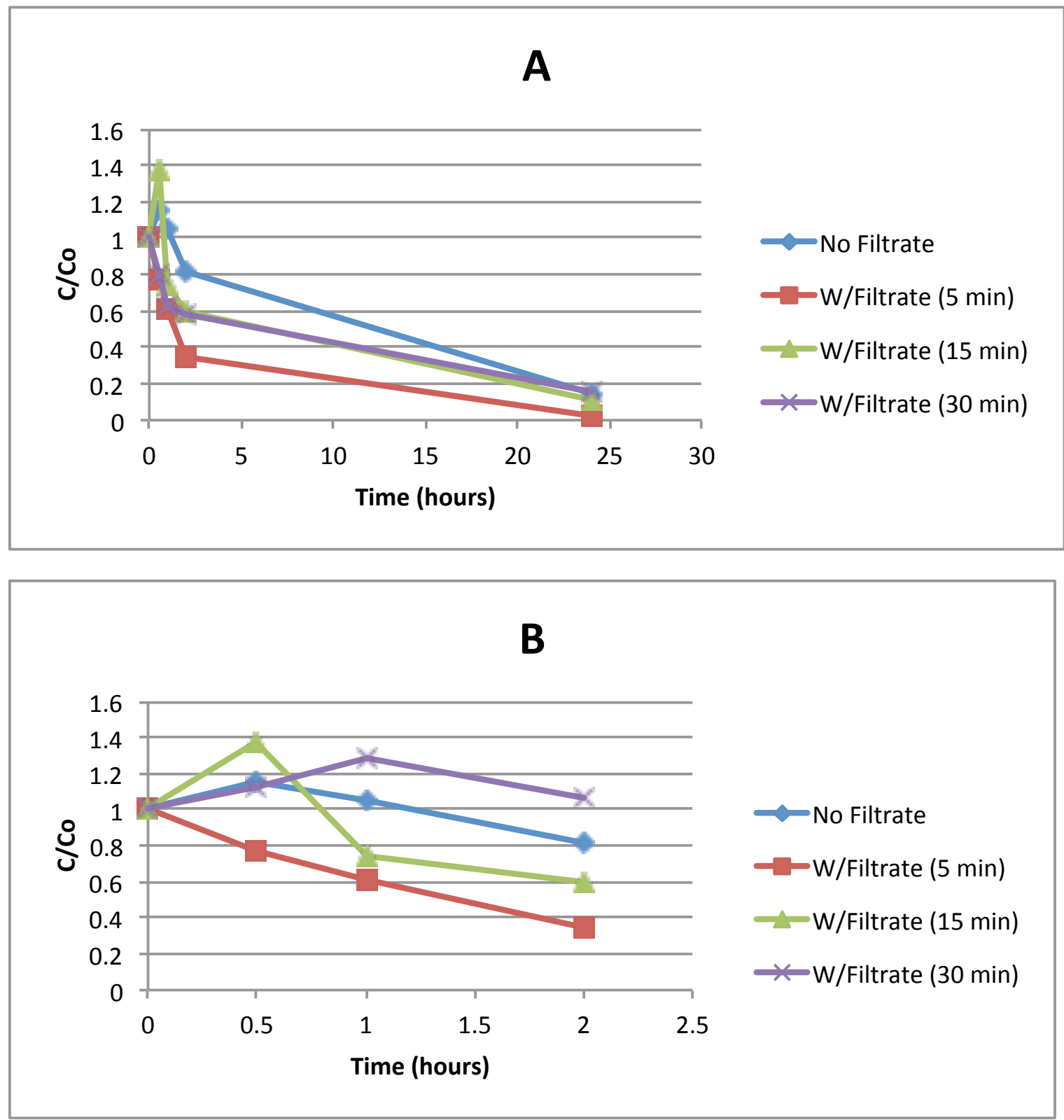

Figure 4.29-Settling of Chlorella based on normalized cell concentrations remaining with and without $B$. cepacia filtrate addition after 10 days of growth over a A) 24-hour settling period and B) 2-hour settling period. 


\subsubsection{Effect of B. cepacia Bioflocculant Addition on Settling of Scenedesmus and}

\section{Chlorella: Experiment 3: Varying Dosage of Bioflocculants}

In Experiment 3, bioflocculation experiments with B. cepacia cells and filtrate were reported, this time using different doses of bacterial cells and filtrate. In prior experiments, a volumetric ratio of $100 \mathrm{~mL}$ of bacterial cell suspension was added to $200 \mathrm{~mL}$ of each algal culture prior to settling (1:2). The volumetric ratio of bacterial filtrate was also generally 1:2, but sometimes 3:5. In Experiment 3, the ratio of $B$. cepacia cells to Chlorella was decreased, as was the ratio of B. cepacia filtrate to Scendesmus. The new ratio was set by halving the exisitng B. cepacia input to $50 \mathrm{~mL}$ and increasing the Scenedesmus to $250 \mathrm{~mL}$ for a ratio of 1:5. A ratio of $100 \mathrm{~mL}$ of $\mathrm{B}$. cepacia filtrate to $300 \mathrm{~mL}$ Scenedesmus (1:3) was also used.

Addition of B. cepacia cells increased the setling of Scenedesmus signifcantly for all stages in the growth curve (Figure 4.30). Figure 4.28 details the results summarized in Figure 4.30 for cell adition and is included in the Appendix section as a reference. The effect was particularly dramatic when the Scenedesmus culture reached 15 consecutive days of growth (Figure 4.30). In fact, the removal efficiency increased by a factor of 7 with $B$. cepacia cell addition at this later stage in algal growth (Figure 4.30).

With B. cepacia filtrate addition, the rate of Scenedesmus settling also increased with increasing algal growth as seen in Figure 4.30. Figure A.2 (Appendix) details the results summarized in Figure 4.30 for filtrate addition and is included in the Appendix section as a reference However, the settling rate did not improve as 
drastically with filtrate addition as it did with whole cell addition. Filtrate addition helped the 15 day old culture the least, suggesting that B. cepacia requires some form of capsular EPS in later stages of growth to improve settling (Figure 4.30). Again, detailed Figures (A.1, A.3, A.4 and A.5) are available in the Appendix section that illustrate both the 2 and 24 hour settling of cell and filtrate addition over the growth curve for Scenedesmus.

The effect of reducing the dose of B. cepacia filtrate by about one half on settling of Scenedesmus can also be seen in Figure 4.30, which show the results of a settling test performed on Scenedesmus during the middle stage of stationary algal growth. Reducing the dose of B. cepacia filtrate actually improved settling for Scenedesmus over a 2-hour period (not 24) as compared to full strength filtrate addition.

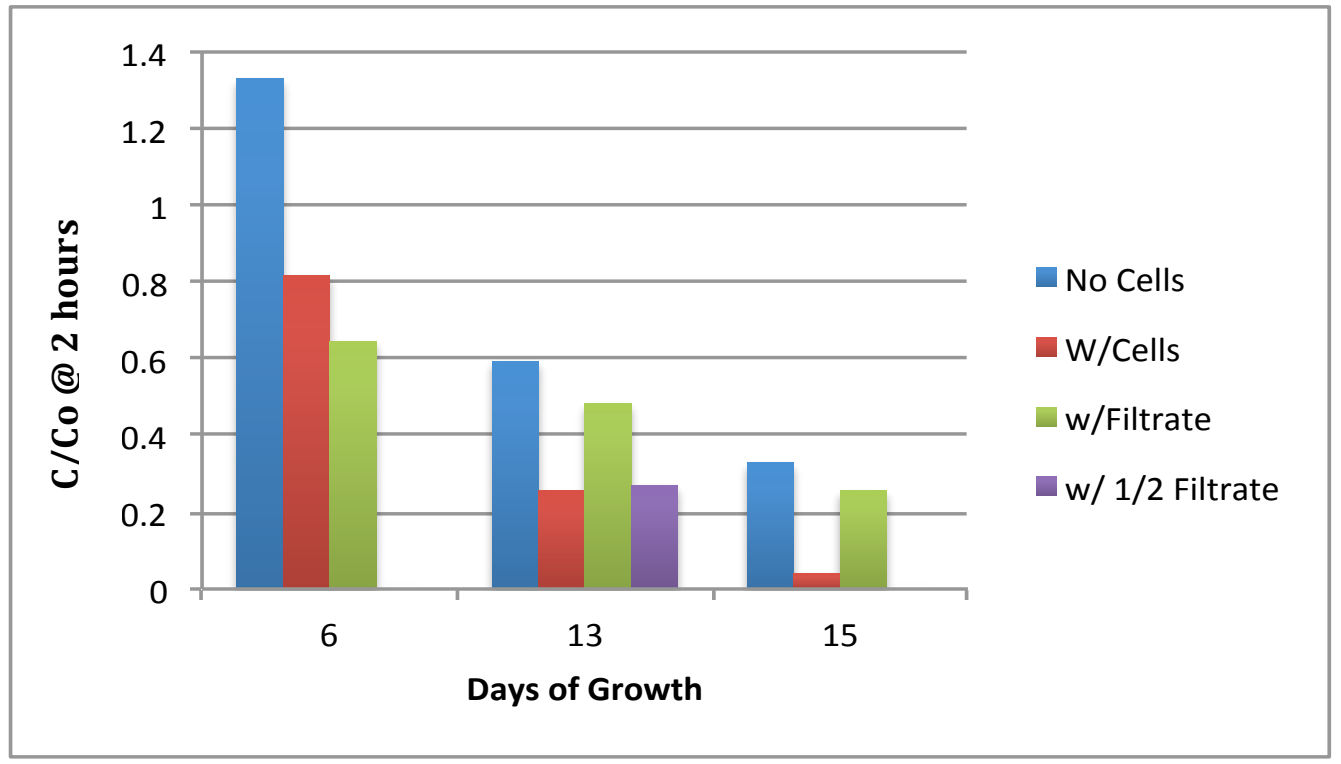

Figure 4.30-Comparison of settling based on normalized cell concentration remaining over a two hour settling period for a Scenedesmus culture with no B. cepacia addition, cell addition, and filtrate addition, and $1 / 2$ filtrate addition over 15 days of growth (Colors refer to columns in the legend) (Experiment 3 ) 
For Chlorella, B. cepacia cell addition in Experiment 3 during earlier stages of algal growth resulted in better normalized cell removal, but only when a half dose of cells was used (Figure 4.31). After 15 days of Chlorella growth, B. cepacia had no effect on settling (Figure 4.31). Similar results were observed in Experiment 2 in which B. cepacia cells enhanced settling of a 6-day-old Chlorella culture with a short mixing time. Again, detailed Figures (A.6, A.7 and A.8) are available in the Appendix section that illustrate both the 2 and 24 hour settling of cell addition over the growth curve for Chlorella. Also, in Experiment 2, less effect of B. cepacia cells was observed for the 8-day-old Chlorella compared to the 6-day-old Chlorella, but Chlorella cells were not used after 8 days of growth (only filtrate during 10 days). The additional growth time employed in Experiment 3 showed the continuuing trend of less effect of B. cepacia cells later in the growth curve of Chlorella.

B. cepacia filtrate addition greatly improved setling of Chlorella early in growth (late exponential stages) (Figure 4.31). Detailed Figures (A.10, A.11 and A.12) are available in the Appendix section that illustrate both the 2 and 24 hour settling of filtrate addition over the growth curve for Chlorella This result proves that B. cepacia filtrate has the most prominent effect on improving the settling of Chlorella as compared to cell addition or no cell addition at all (agreeing with previous results from Experiment 1 and 2). After 15 days of growth, however, settling of pure algal cells was not affected by filtrate (Figure 4.31 ). Thus, filtrate addition has little effect on Chlorella in later growth phases (mid stationary). 
B. cepacia cell and filtrate additions had reverse trends for Scenedesmus and Chlorella. For Chlorella, B. cepacia cells and filtrate had a greater effect for early growth phases (mid exponential), while for Scenedesmus this effect was greater for later growth phases (up to mid stationary).

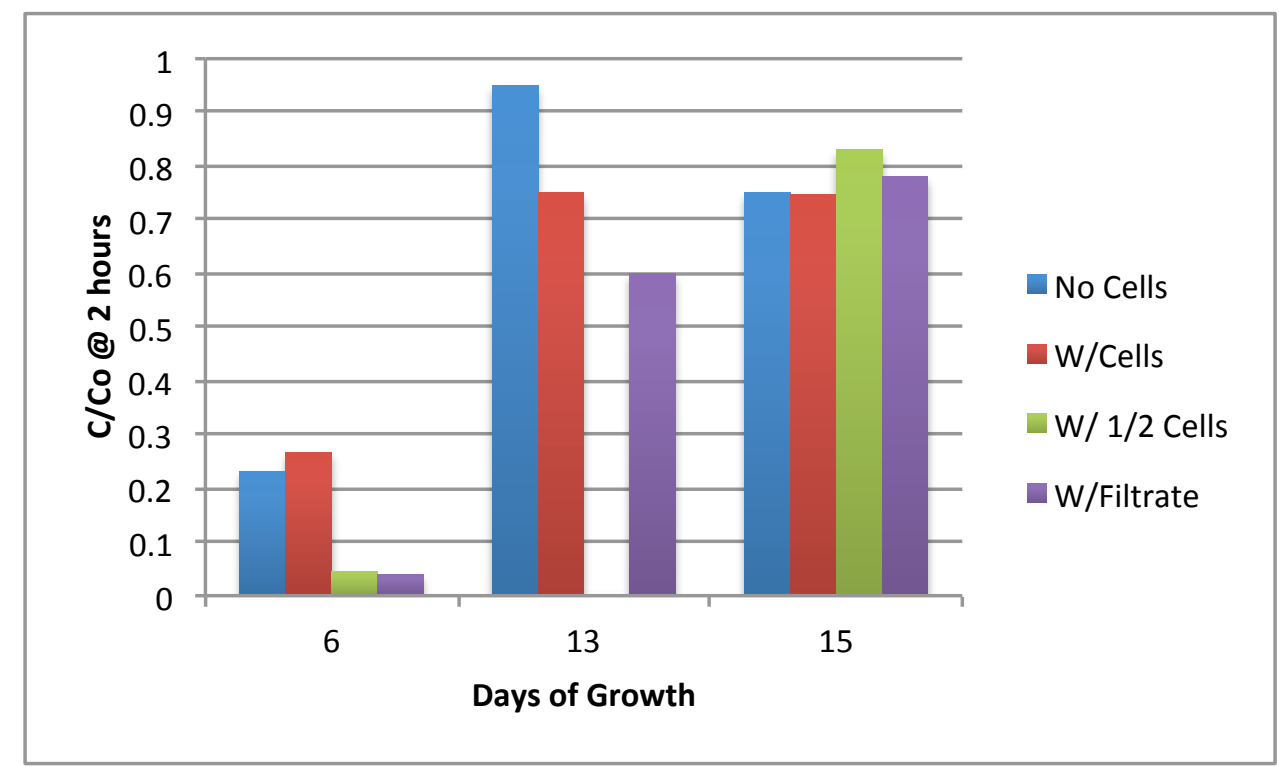

Figure 4.31-Settling of Chlorella based on normalized cell concentrations remaining after a 2-hour settling period compared over 6, 13, and 15 days of growth for no $B$. cepacia cell addition, with $B$. cepacia cell addition, with $B$. cepacia filtrate addition, and with B. cepacia $1 / 2$ cell addition (Experiment 3 )

\subsubsection{Results of EPS Analysis and Correlation with Algal Settleability: Experiment 2}

Both the bacterial EPS and algal exudates (polymeric in nature) were quantified to determine if EPS played a role in improving bioflocculation. Quantifying EPS was achieved through a standard filter and dialysis method as described in the Methods and Materials chapter. Samples were taken every other day during growth of all bacteria and algae cultures to analyze polymeric exudates. Filtrate measurements of dissolved EPS were also taken when settling tests were run with filtrate addition. When settling tests were run, samples of all cells (bacterial and algal) were ran in order to allow correlation of settling with EPS measurements 
EPS production by Scenedesmus was sporadic and reached an apparent peak EPS concentration above $20 \mathrm{mg} / \mathrm{L}$ at 8 days during mid exponential phase of growth (Figure 4.32). Chlorella, contrarily, produced more EPS later on in its growth curve, around early stationary phase (Figure 4.33). At 10 days of growth, Chlorella produces more EPS than Scenedesmus, around $25 \mathrm{mg} /$ L. B. cepacia produces most of its EPS around 10 days of growth or middle to late stationary growth phase at a concentration similar to Chlorella around $25 \mathrm{mg} / \mathrm{L}$ (Figure 4.34).

At 10 days of growth, EPS production of Scenedesmus was moderate to high (Figure 4.32) and this corresponds to when better settling was observed for Scenedesmus (Figure 4.30). Thus, Scenedesmus exhibits improved settling during later stages of growth when its own EPS production is high. Addition of B. cepacia filtrate at this same time of growth (10 days) hindered settling of Scenedesmus cells. At this day in growth (10), dissolved EPS of the filtrate was around $25 \mathrm{mg} / \mathrm{L}$ (Figure 4.34). Thus, Scenedesmus does not benefit from the increased dissolved EPS from B. cepacia at later stages in growth. During later stages of growth, when EPS production of Scenedesmus is larger, capsular EPS, rather than dissolved EPS from B. cepacia filtrate, seems to aid in the settling of Scenedesmus the most.

For Chlorella, EPS concentration increased to early stationary phase (Figure 4.33). The best settling without B. cepacia addition was observed at eight days of growth, when EPS production was not at a maximum. Settleability also decreased into mid stationary phase where EPS production was maximum. Therefore, the settling of Chlorella is less affected by the production of its own EPS. However, after 10 days of growth (where settling is judged poor) Chlorella settled better with addition of B. cepacia filtrate. Therefore, dissolved EPS (from bacteria in later stages of growth) aids in the settling of Chlorella 
vulgaris, with a maximum effect during early stationary phase. These tests are repeated in Experiment 3 to assess the repeatability of these initial EPS correlations with settleabiity.

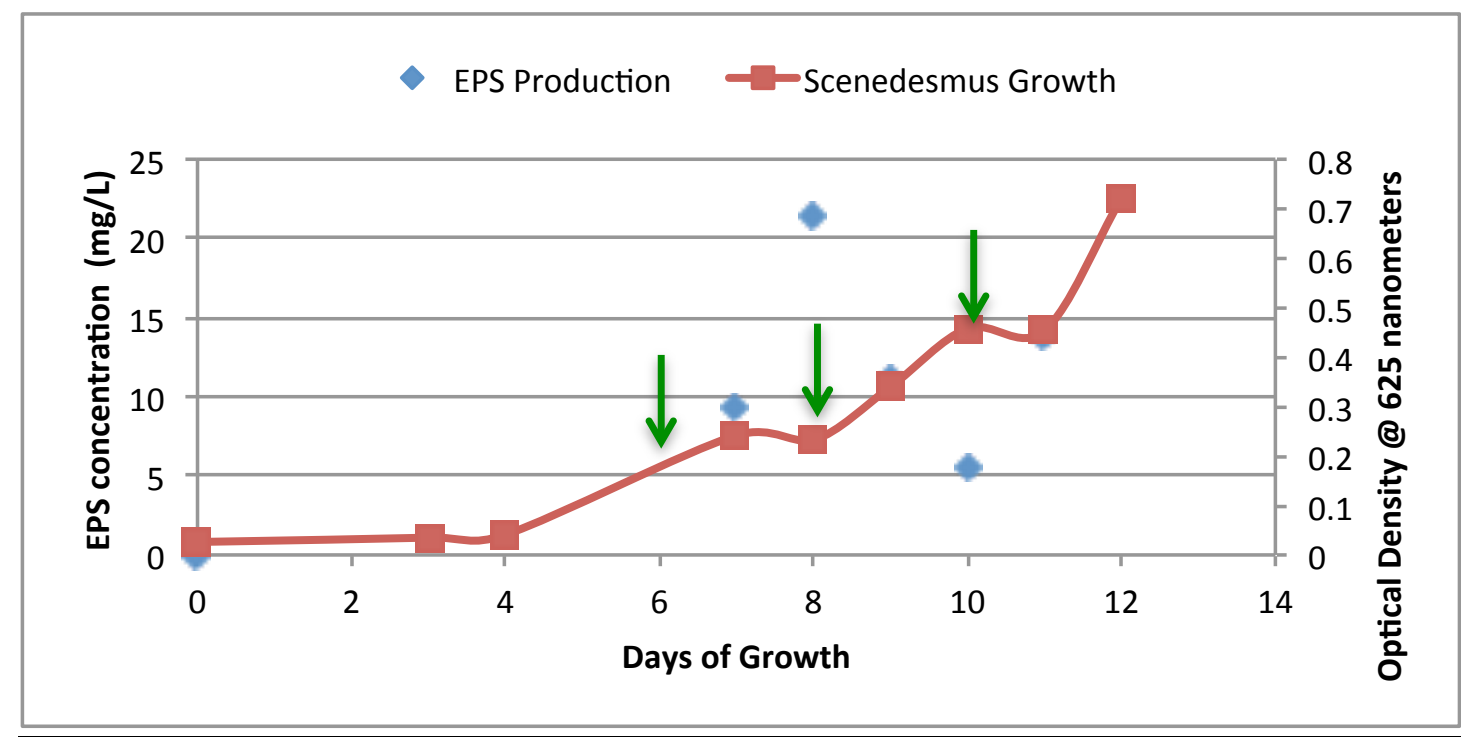

Figure 4.32-Dissolved EPS concentration of Scenedesmus plotted against its growth curve measured until 12 days of growth. Green arrows represent days in which settling tests were run (Experiment 2)

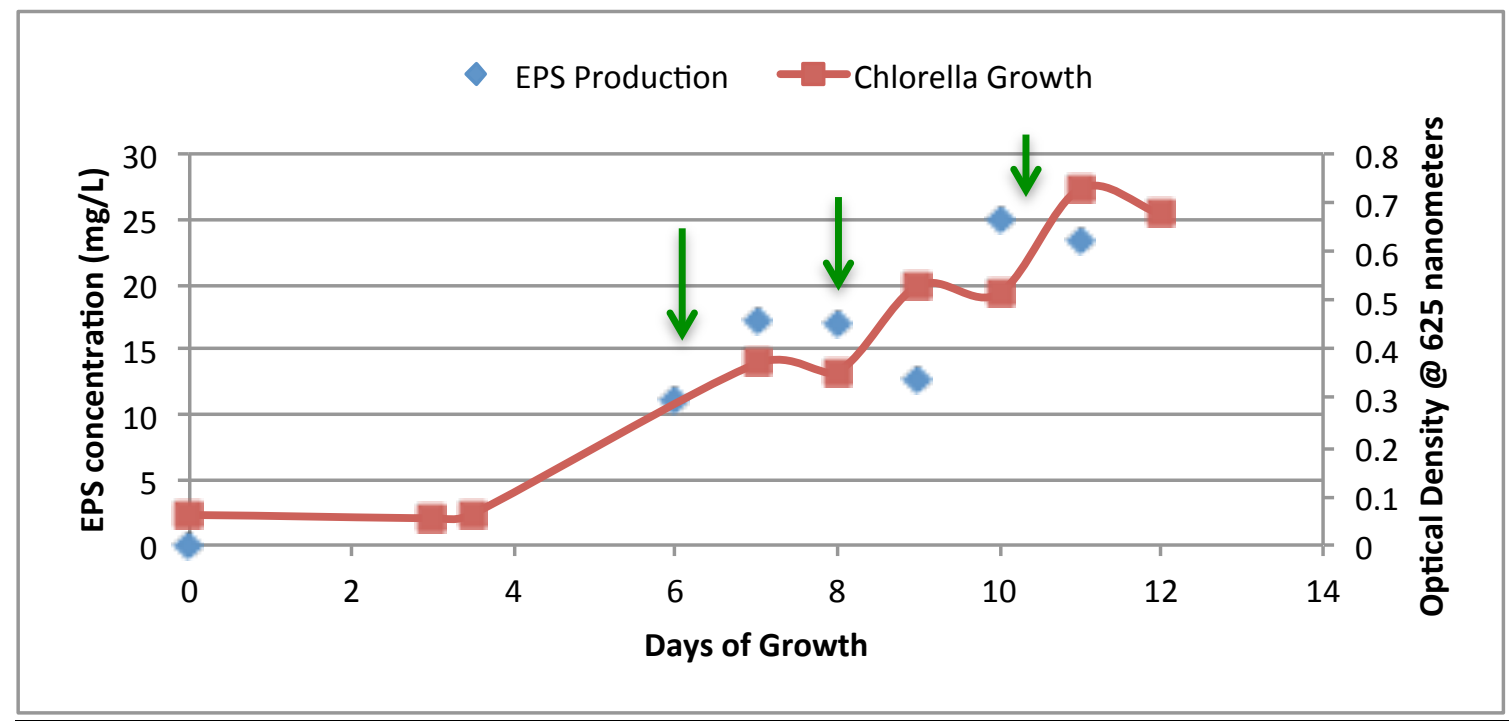

Figure 4.33-Dissolved EPS concentration of Chlorella over a 12-day growth period plotted against the growth curve measured at 625 nanometers by optical density. Green arrows represent days when settling tests were run (Experiment 2) 


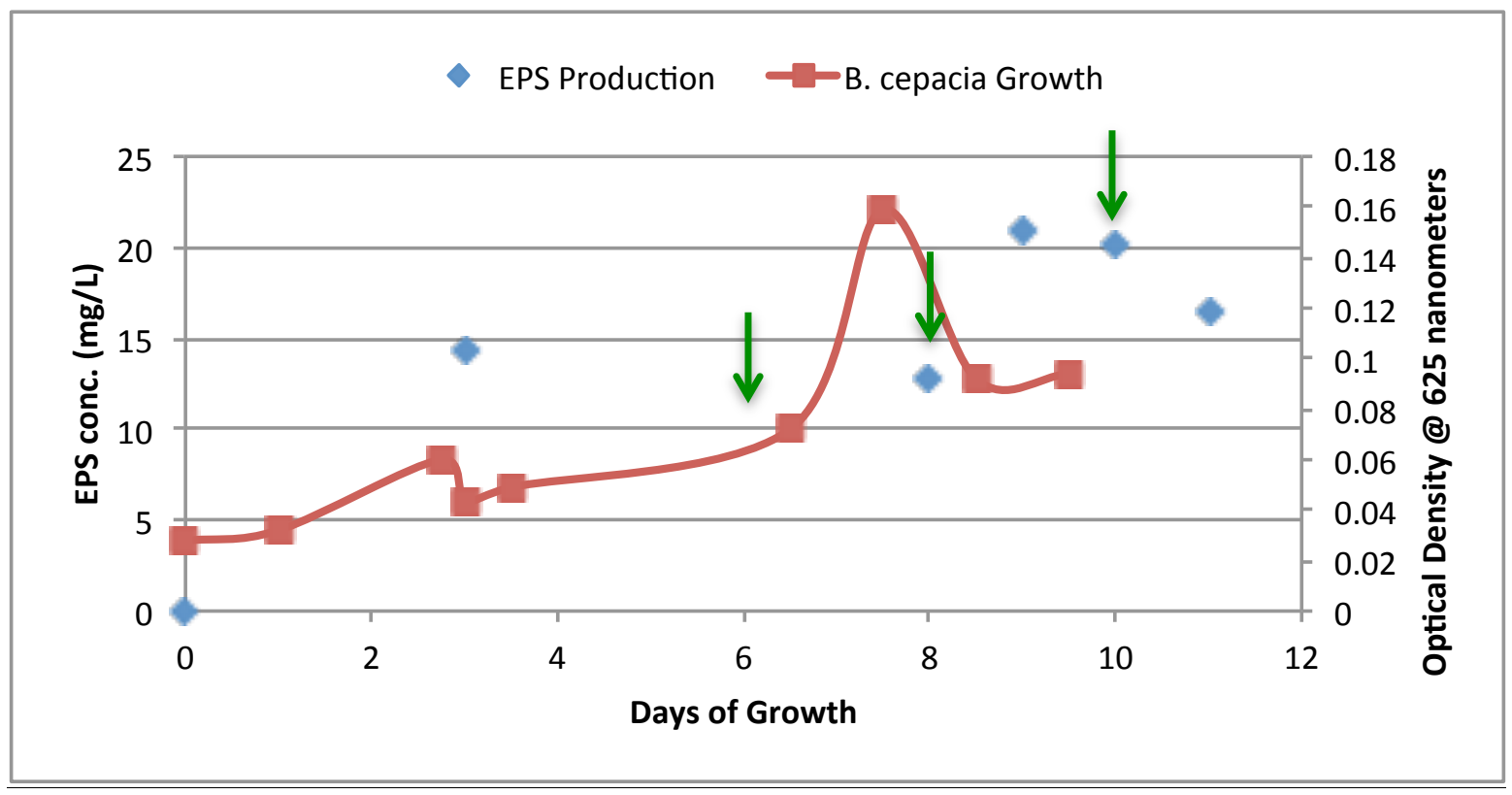

Figure 4.34-Dissolved EPS concentration of B. Cepacia over a 12-day growth period plotted against the growth curve measured at 625 nanometers by optical density. Green arrows represent days when settling tests were run (Experiment 2)

\subsubsection{Results of EPS Analysis and Correlation with Algal Settleability : Experiment 3}

EPS concentrations produced over the growth curves of Scenedesmus, Chlorella and B. cepacia are presented in Figures 4.35 through 4.37 . The dry weight is included for each of the algal cultures for comparison. The EPS concentrations fluctuated but an increasing trend was observed in EPS production of Scenedesmus, Chlorella and B. cepacia (Figures 4.35-4.37). Settling of Scenedesmus after 15 days (stationary phase) of growth was confirmed to be much better than earlier growth phases. This result suggests that during mid stationary phase of growth, settling of Scenedesmus without B. cepacia addition is influenced greatly by its own dissolved EPS (Figure 4.35). This result concurs with the previous Experiment 2 results.

B. cepacia cell addition in later growth stages for Scenedesmus improved the settling rate of Scenedesmus to almost twice that with no cells. Dissolved EPS in the B. cepacia filtrate, added after 15 days of growth did not significantly improve the settling rate of Scenedesmus as compared to cell addition alone. For this reason, it is assumed that 
Scenedesmus benefits more at later stages in growth from B. cepacia capsular EPS, and not dissolved EPS. From results in the previous section, B. cepacia filtrate addition (dissolved EPS) has more of an effect on settling during earlier stages of growth (Figure 4.30), where Scenedesmus dissolved EPS production is at a minimum (Figure 4.35 below). Current results also illustrate that when Scenedesmus produced smaller amounts of EPS, filtrate helped in improving settling, especially earlier on in growth, just not to the same extent.

EPS correlations with Chlorella settling were found much different than that for Scenedesmus. Even though dissolved EPS production by Chlorella was at a maximum after 13 days of growth, settling was poor. Settling of Chlorella were highest early on in the growth curve, when EPS concentrations were low. Thus, the settling rate of Chlorella does not appear to be affected by its own dissolved EPS production. This result agrees with previous Experiment 2 results.

Chlorella demonstrated improved settleability with filtrate addition during the mid exponential growth phase (Figure 4.31). The effect of $B$. cepacia filtrate on settling is not as prononounced during early to mid stationary phase of growth when Chlorella is observed to be affected by a higher amount of its own EPS (Figure 4.31). These results again concur with Experiment 2 results that Chlorella was more affected by filtrate in mid exponential phase, when production of its own dissolved EPS was at a minimum. In addition, the settling of Chlorella was improved greatly with one half the cell addition during early stationary phase of growth (Figure 4.31). This corresponded to about $6 \mathrm{mg} / \mathrm{L}$ of dissolved EPS from $B$. cepacia and $12 \mathrm{mg} / \mathrm{L}$ EPS of dissolved produced by Chlorella itself (Figure 4.36). This result also shows that at later stages in growth, Chlorella improves settling with less dissolved EPS and may be more affected by B. cepacia capsular EPS (from cell addition). 


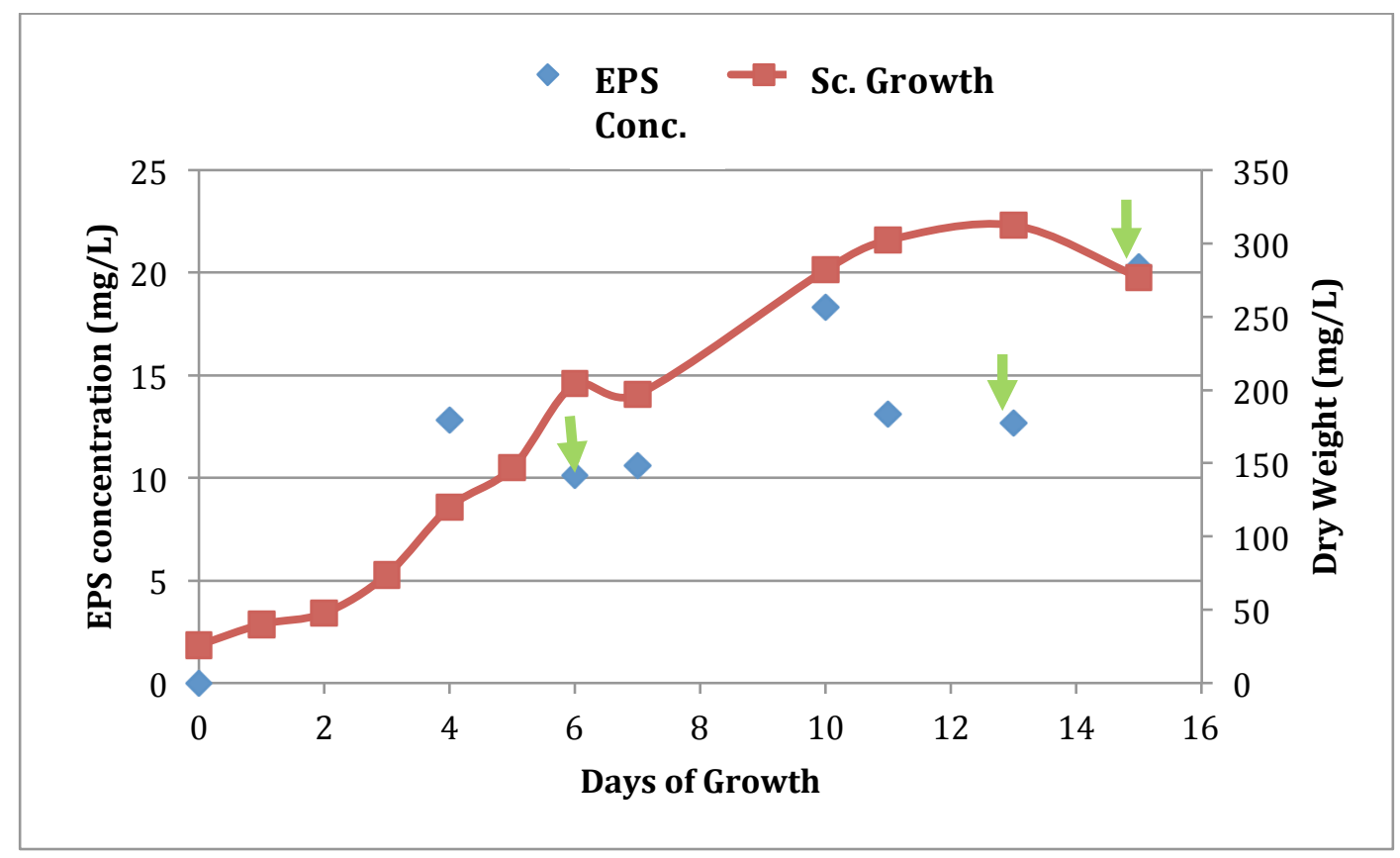

Figure 4.35-EPS measurements compared to dry weight observed over a 15 day growth period for Scenedesmus (Green arrows indicate when settling tests were run)

(Experiment 3)

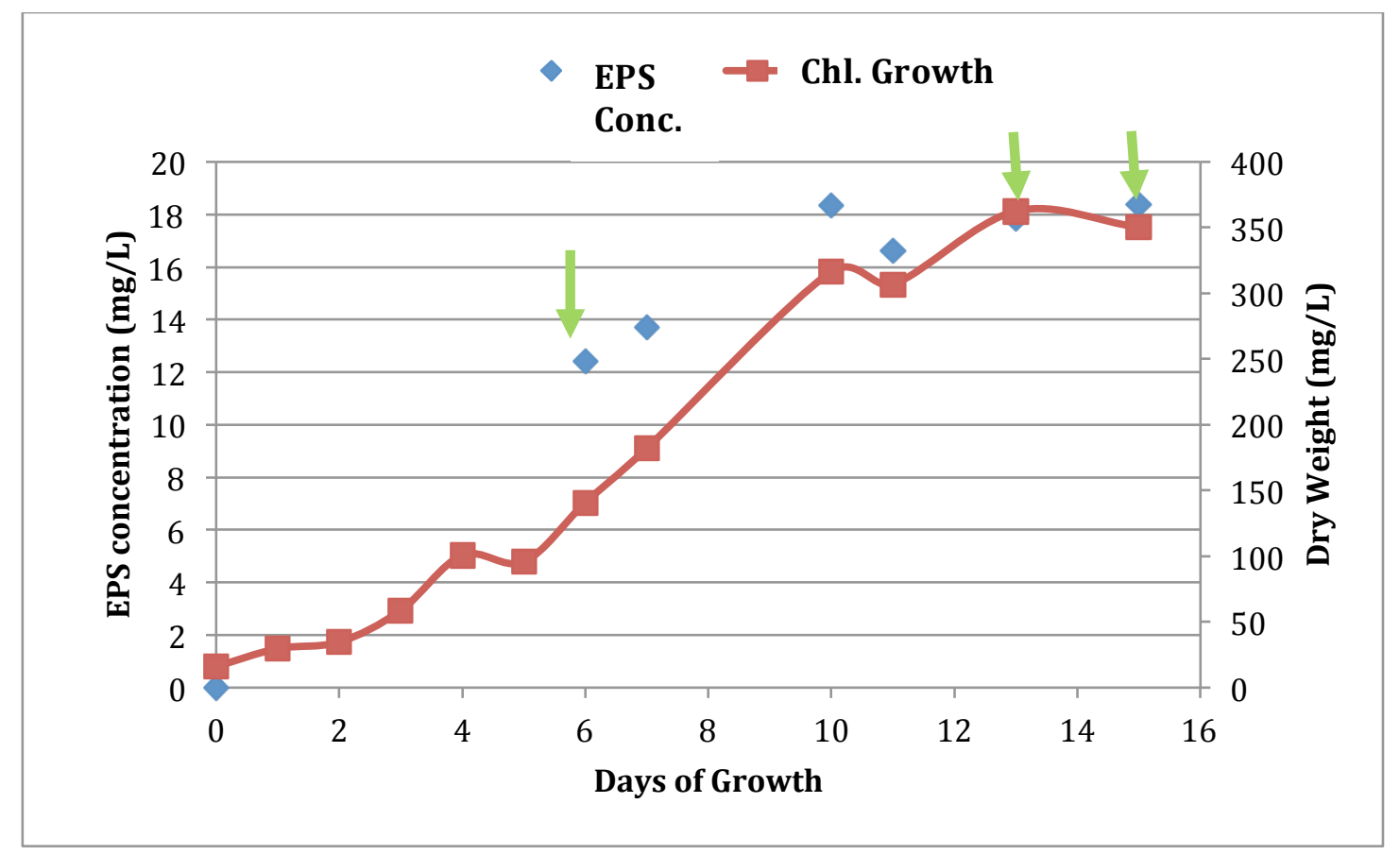

Figure 4.36-EPS measurements compared to dry weight observed over a 15 day growth period for Chlorella (Green arrows indicate when settling tests were run)

(Experiment 3) 


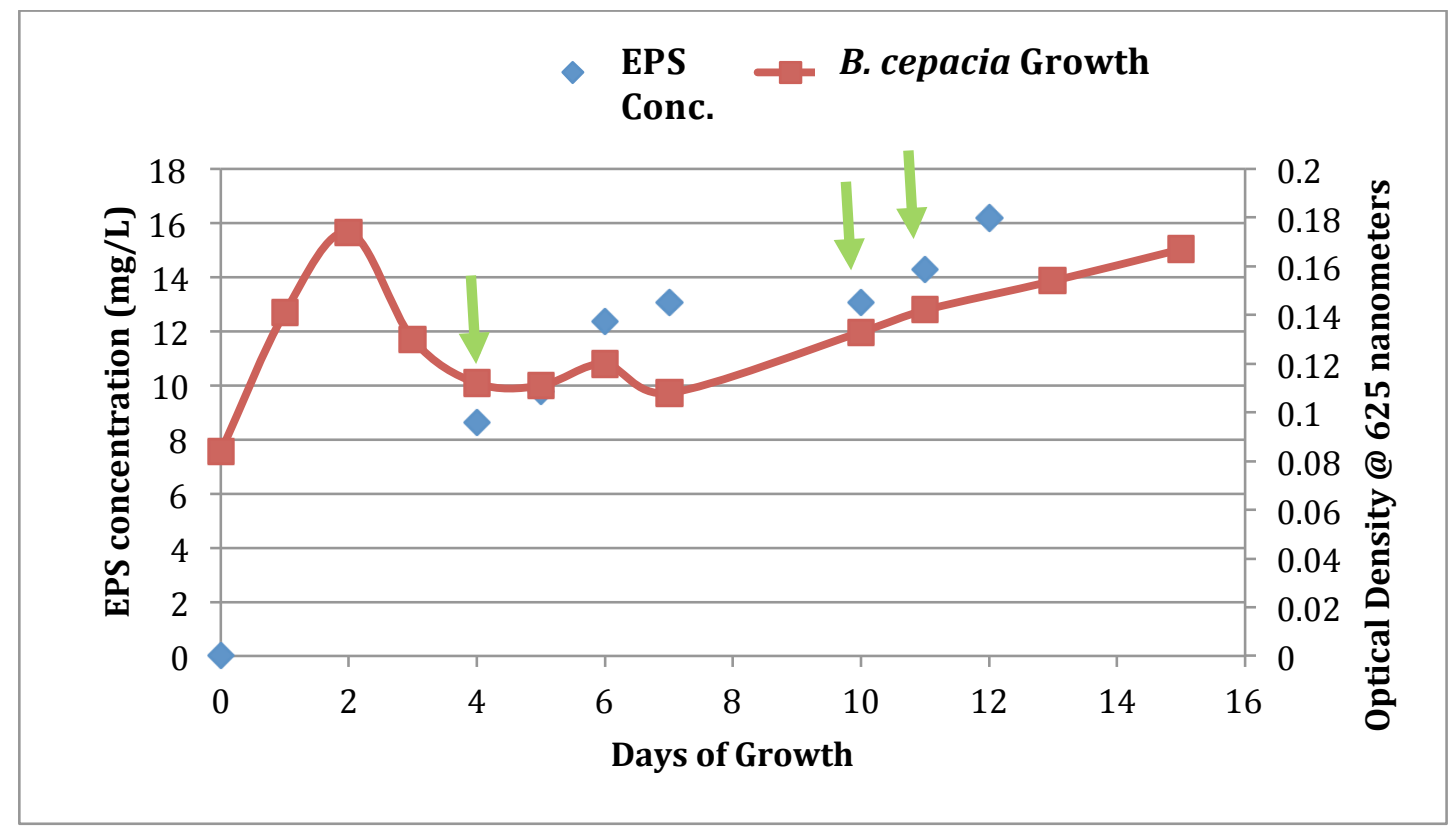

Figure 4.37-EPS measurements compared to optical density observed over a 15 day growth period for B. cepacia (Green arrows indicate when settling tests were run)

\subsection{Settling of Mixtures of Algal Pond Water and Primary Treated Wastewater With \\ RAS Treatment}

\subsubsection{Effect of RAS Addition on Settling of Mixtures of Algal Pondwater and Primary \\ Treated Wastewater: Experiment 1}

The first experiment conducted on wastewater samples from the San Luis Obispo wastewater treatment facility focused on a fixed RAS ratio addition, where samples were either aerated or not. The wastewater samples included a defined volume of algae pond water blended with primary wastewater. RAS addition was also varied to determine the optimal dose to increase algal settleability. Mixture compositions were calculated as algal pond water: food (primary wastewater) and food: RAS ratios. Table 4.2 shows the different combinations used in this experiment. A defined ratio of about 4:1 for algae pond water to primary wastewater (food) was used for each of the four samples. The difference between 
both samples $1 \mathrm{a}$ and $2 \mathrm{a}$ compared to 1 and 2 was that $1 \mathrm{a}$ and $2 \mathrm{a}$ were aerated for a specified period of time with RAS addition.

Table 4.2-Defined Volumes of Wastewater samples used compared to RAS addition for comparison of settling in this study

\begin{tabular}{|c|c|c|c|c|c|}
\hline Sample & $\begin{array}{c}\text { Volume } \\
\text { of Pond } \\
\text { water } \\
\text { (mL) }\end{array}$ & $\begin{array}{c}\text { Volume of } \\
\text { Primary } \\
\text { Wastewater } \\
(\mathbf{m L})\end{array}$ & $\begin{array}{c}\text { Volume of } \\
\text { RAS (mL) }\end{array}$ & $\begin{array}{c}\text { Total } \\
\text { Volume } \\
\mathbf{( m L )}\end{array}$ & Aeration \\
\hline $\mathbf{1}$ & 800 & 200 & 0 & 1000 & None \\
\hline $\mathbf{2}$ & 728 & 182 & 91 & 1000 & None \\
\hline $\mathbf{1 a}$ & 800 & 200 & 0 & 1000 & Aerated \\
\hline $\mathbf{2 a}$ & 728 & 182 & 91 & 1000 & Aerated \\
\hline
\end{tabular}

Samples 1 and 1 a did not have any RAS addition. RAS addition was set at $10 \%$ of the total volume for both samples 2 and 2a. For samples 2 and 2a with RAS addition, the defined ratio of primary wastewater (food) to RAS (bacteria) was 2:1.

Without aeration, little or no settling was observed with or without RAS addition (Figure 4.38 A). RAS addition slightly improved the settling of these non-aerated samples (Figure 4.38 A). Aeration improved settling significantly (Figure 4.38 B). With aeration, settling was initially improved slightly with RAS addition over the first half hour, but after two hours of settling, the solids settled better without RAS addition (Figure 4.38 B). 

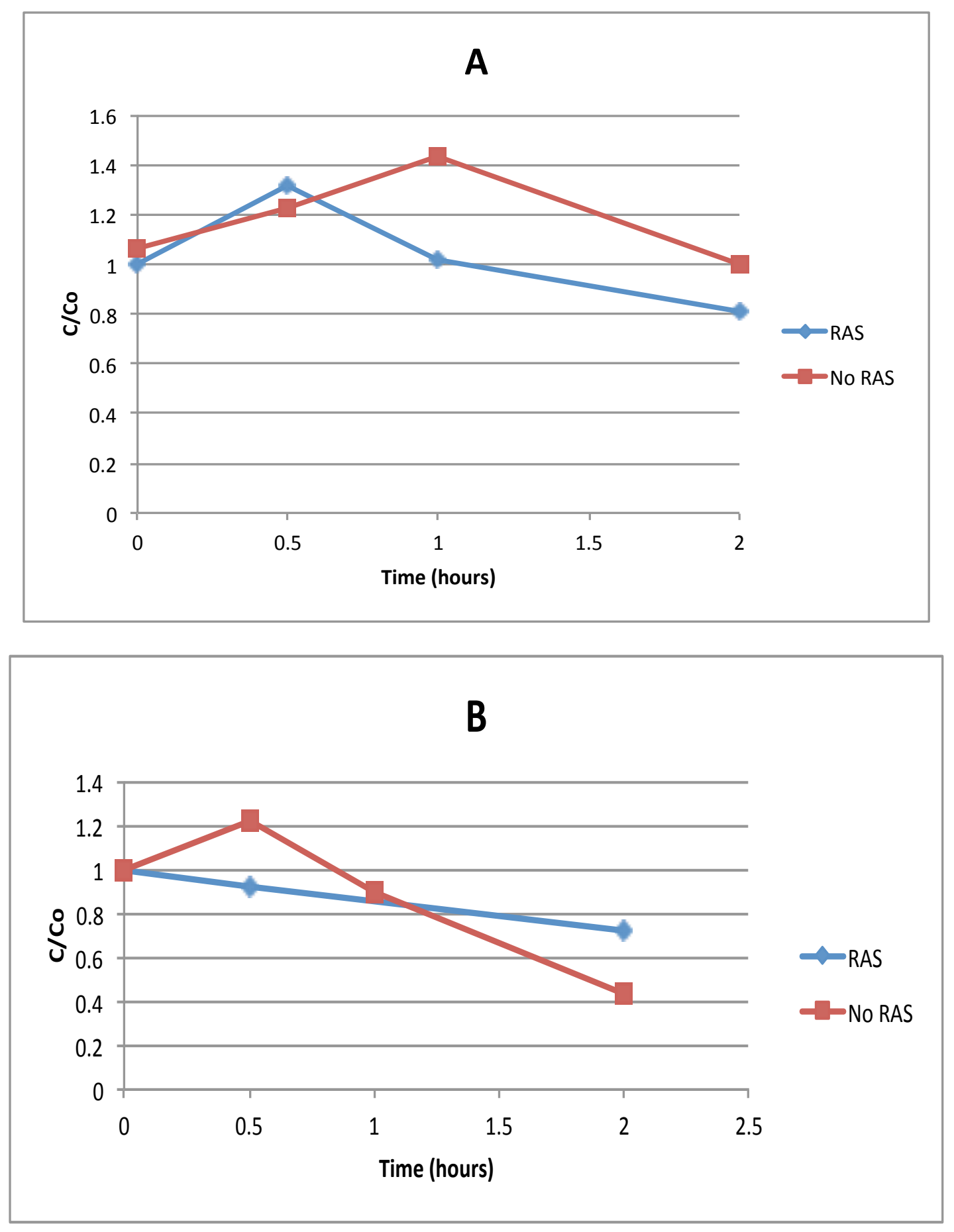

Figure 4.38- Effect of adding a certain fixed dose of RAS to A) an non-aerated mixture of raw primary municipal wastewater samples and algae pond water from the San Luis Obispo Wastewater Treatment Facility over a 2-hour settling period and B) an aerated sample with and without RAS treatment over a settling period of 2 hours 


\subsubsection{Effect of RAS Addition on Settling of Mixtures of Algal Pond Water and Primary Treated Wastewater: Experiment 2}

For RAS experiment 2, samples were collected in February and all samples aeratated prior to performing settling rate experiments. The ratio of RAS to algae pond water to primary wastewater for each sample is shown in Table 4.3. The amount of RAS in samples with RAS addition was fixed as in Experiment 1, at around $10 \%$ of the total volume. Dilution with primary wastewater resulted in algae pond water (greater) to RAS volume ratios of 1:1, 1:2 and 2:1. A pure algal pond water sample was also tested as collected from the SLO wastewater treatment plant with no primary wastewater addition.

Table 4.3: Classification of samples used for analysis with and without RAS addition

\begin{tabular}{|c|c|c|c|c|}
\hline $\begin{array}{c}\text { Primary } \\
\text { Wastewater: } \\
\begin{array}{c}\text { Algae Pond } \\
\text { Water }\end{array}\end{array}$ & $\begin{array}{c}\text { Volume of } \\
\text { Algae Pond } \\
\text { water } \\
\text { (mL) }\end{array}$ & $\begin{array}{c}\text { Volume of } \\
\text { Primary } \\
\text { Wastewater } \\
\text { (mL) }\end{array}$ & $\begin{array}{c}\text { Volume of } \\
\text { RAS } \\
\text { (mL) }\end{array}$ & $\begin{array}{c}\text { Total Volume } \\
\text { (mL) }\end{array}$ \\
\hline $\mathbf{2 : 1}$ & 300 & 600 & 0 & 900 \\
\hline $\mathbf{1 : 1}$ & 500 & 500 & 0 & 1000 \\
\hline $\mathbf{1 : 2}$ & 600 & 300 & 0 & 900 \\
\hline $\mathbf{2 : 1}$ W/RAS & 300 & 600 & 100 & 1000 \\
\hline $\mathbf{1 : 1}$ W/RAS & 450 & 450 & 100 & 1000 \\
\hline $\mathbf{1 : 2 ~ W / R A S ~}$ & 600 & 300 & 100 & 1000 \\
\hline
\end{tabular}

The cell concentrations measured included all countable bacterial and algal cells. The algae treatment pond during this period was characterizied by mostly algal species of Chlorella and Ankinastrum, with very little Scenedesmus present. 
Normalized settling over 24 hours, with and without RAS addition, is presented in Figure 4.39 and the 2 hour settling efficiencies are summarized in Figure 4.40. For algae pond water alone, settling was mediocre, with about $30 \%$ of cells removed after 2 hours (Figure 4.40). When algae pond water was mixed with primary wastewater (without RAS addition), the 2 hour settling efficiencies either got better or worse, depending on the ratios used (Figure 4.40). Without RAS addition, little or no settling was observed for the 2:1 and 1:2 primary wastewater to algae pond water samples (33\% algae and $66 \%$ algae, respectively) at 2 hours (Figure 4.40), but nearly 60\% solids removal was observed for the 1:1 sample with 50\% algae. However, after 24 hours, all three mixtures settled with over $80 \%$ removal of cells (Figure 4.39).

RAS addition dramatically improved the settling of the 1:2 and 2:1 wastewater to algae pond samples at 2 hours, but actually made settling worse for the 1:1 samples (Figure 4.40). Similarly, after 24 hours of settling, RAS addition improved the settling of the $2: 1$ ratio, but made settling worse for the $1: 1$ ratio (Figure 4.39). At 24 hours, RAS had no observable effect on settling of the 1:2 ratio (Figure 4.39). 

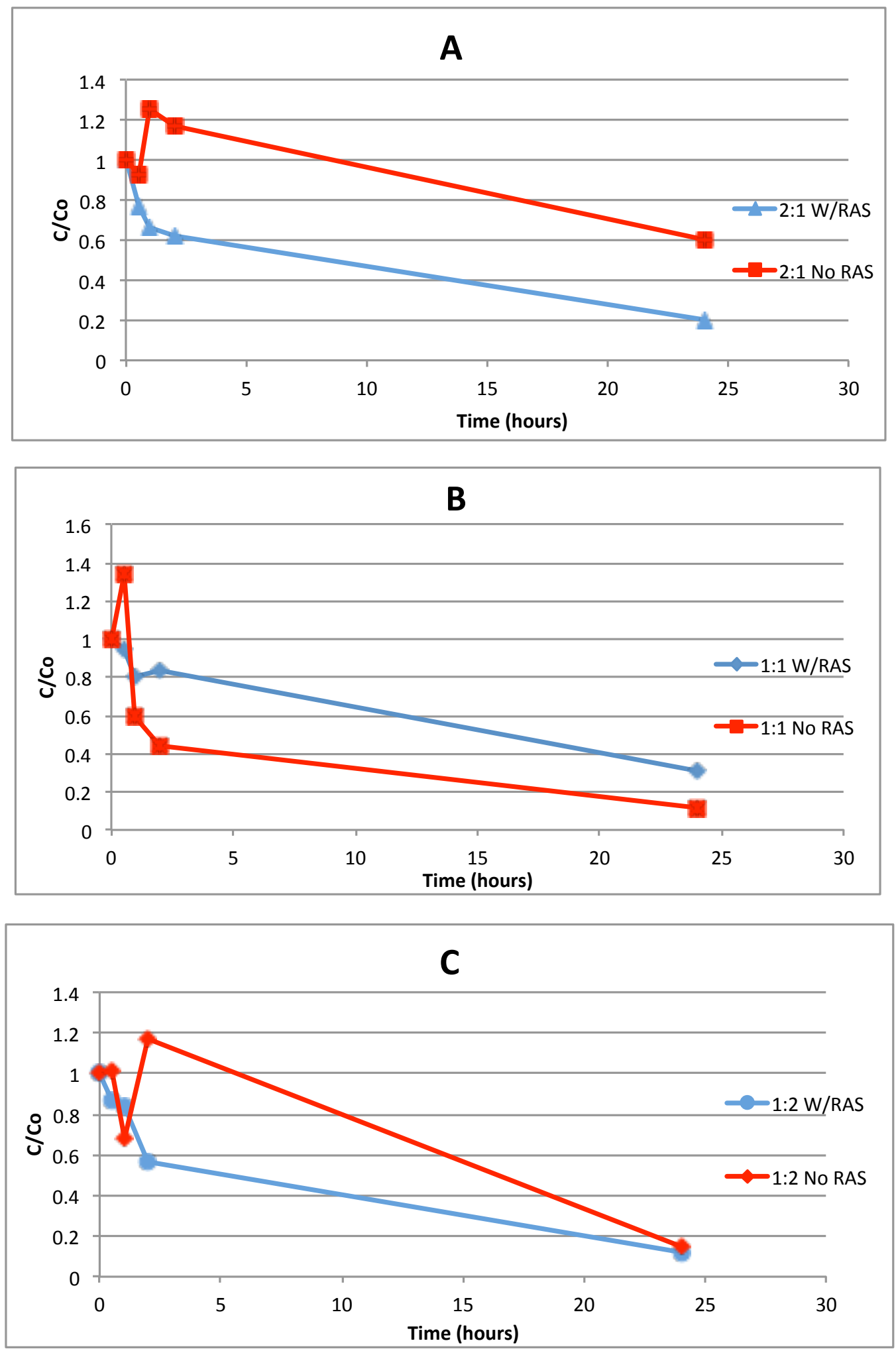

Figure 4.39-Normalized cell concentration as a function of settling time over a 24-hour period for different wastewater pond cultures with or without RAS addition at a A) 2:1 ratio $B$ ) 1:1 ratio and C) 1:2 ratio of primary wastewater to algae pond water (Red line signifies no RAS addition, blue line signifies RAS addition) 


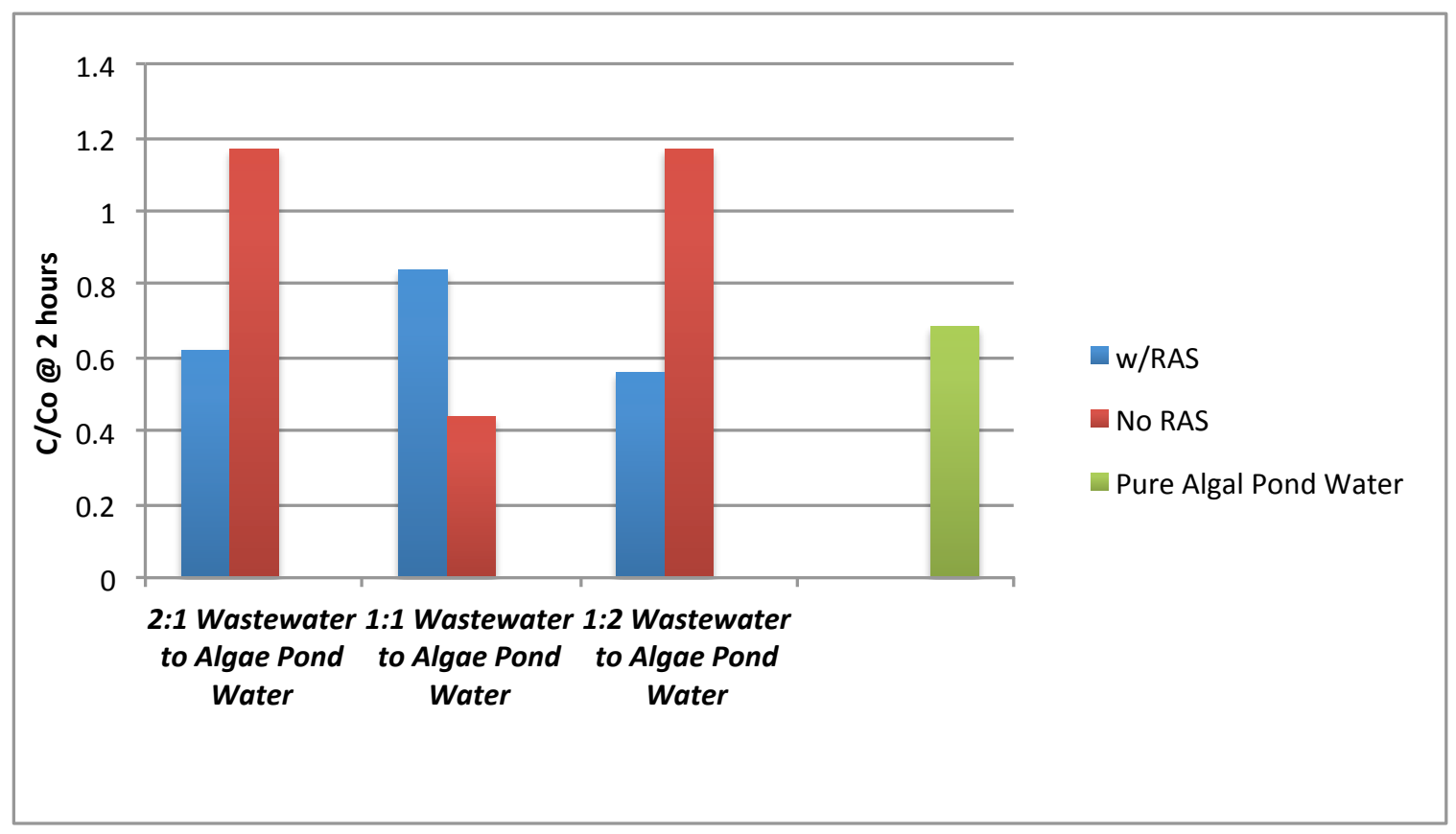

Figure 4.40-Comparison of settling based normalized cell concentration remaining after a 2-hour settling period for samples with RAS/Aeration and without addition, and with varying volumetric ratios of primary wastewater to algae pond water

\subsubsection{Correlation of EPS with RAS addition to Wastewater Samples:}

\section{Experiment 2}

Measured EPS concentrations were similar for all samples, including pure algae pond water (Figure 4.41). The 1:1 mixture without RAS addition had slightly more dissolved EPS than the sample with RAS addition itself and this could possibly explain why settling was better without RAS addition for this ratio. For other the 1:2 and 2:1 ratios of primary wastewater and algae pond water, samples with RAS had slightly higher dissolved EPS concentrations and for these ratios RAS addition helped settling. Therefore, it appears that increased EPS aids in settling, but it is difficult to make this conclusion from these data because large variations in EPS concentration were not observed. 


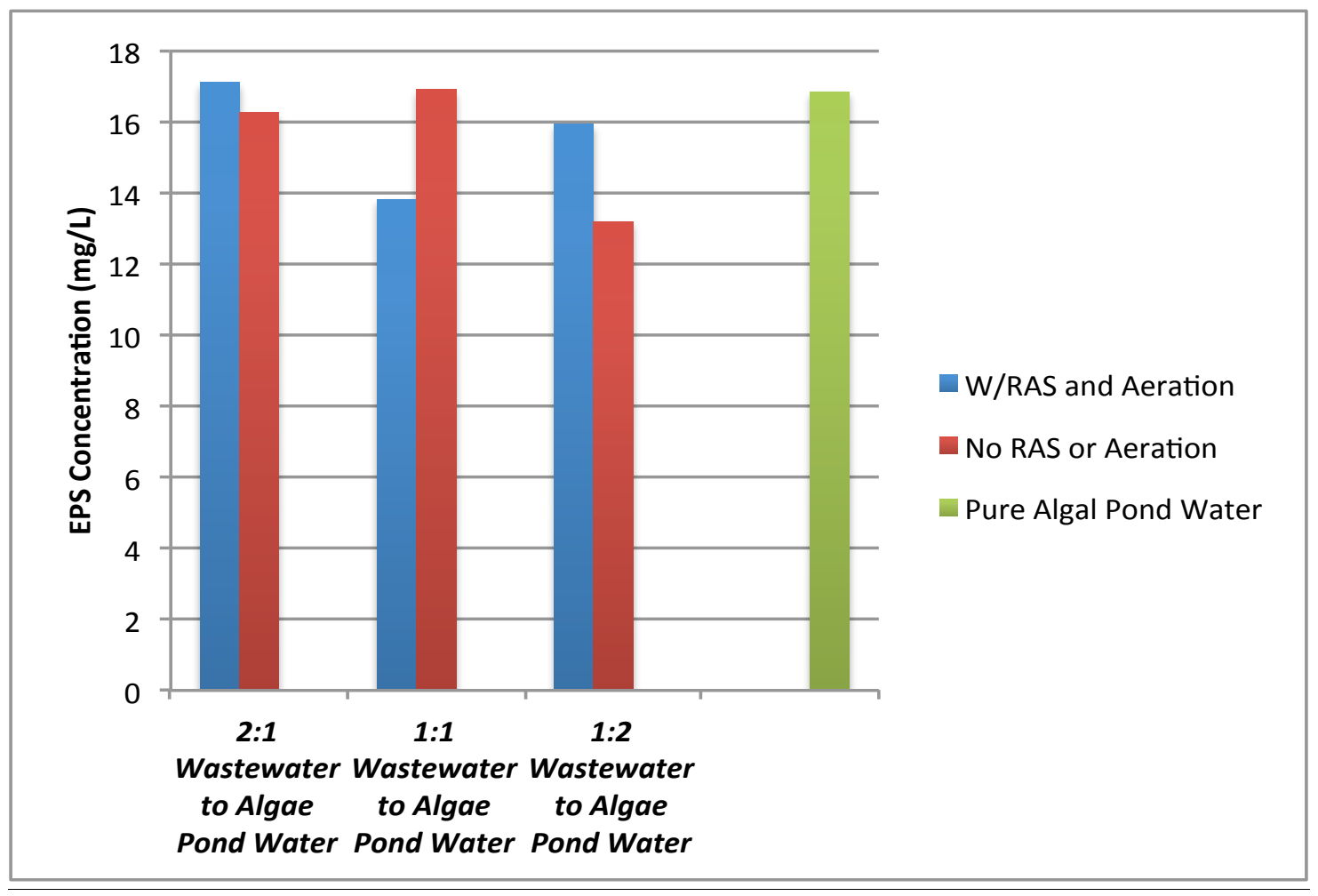

Figure 4.41-Dissolved EPS measurements for samples with and without RAS addition or aeration, also including a sample of pure algal pond water

\subsection{Effect of Light and Dark Cycles During Growth and Light and Dark Settling Conditions on the Settling of Scenedesmus and Chlorella}

This section focused on improving the settling of Scenedesmus and Chlorella by first changing the light and dark exposure periods during growth (light/dark cycles). Light intensity (brightness) was not varied, but kept constant throughout growth. Normal light/dark cycles during growth consisted of an 8-hour illumination period followed by a 16-hour dark period. The following experiments, for both Scenedesmus and Chlorella, focused on changing the light (illumination) period to 48 hours of constant intensity prior to settling tests, with the elimination of a dark period. After this exposure, the algae were either settled in the light or in the dark without B. cepacia bioflocculant addition (Section 4.43, 4.44), or with B. cepacia 
bioflocculant addition (Section 4.45, 4.46) to improve settling. During settling, dark conditions simply implied that the settling columns were covered to prevent light exposure, and light conditions implied the columns were not covered. Also, a control experiment with algae in mid stationary growth phase was conducted to compare settling trends in the light and dark without a change in light exposure during growth (Section 4.41). In addition, EPS measurements were made during growth to observe the effects of changing the light and dark cycle on EPS production and settling of algal cultures (Section 4.47).

\subsubsection{Effect of Light and Dark Settling Conditions on Algal Settleability: Preliminary Analysis}

A preliminary analysis of settling in light and dark environments was conducted. Two refrigerated samples of both algae species in the mid stationary phases of growth were taken, mixed for five minutes at $750 \mathrm{rpm}$ and settled in either the light or dark. Scenedesmus cultures settled much better in the dark than in the light over 2 hours of settling (Figure 4.42 B). After 24 hours, settling was efflcient regardless of light exposure during settling (Figure 4.42 A). For Chlorella, settling was similar in the dark and in the light (Figure $4.43 \mathrm{~A}, \mathrm{~B}$ ), but settling was slightly better in the light for both settling times ( 2 and 24 hours).

The effect of light on settling of Scenedesmus and Chlorella is summarized in Figure 4.44. Here it is clear that light had the opposite effect on the two algae species with Scenedesmus settling best in the dark and Chlorella cells settling slightly better in the light. 

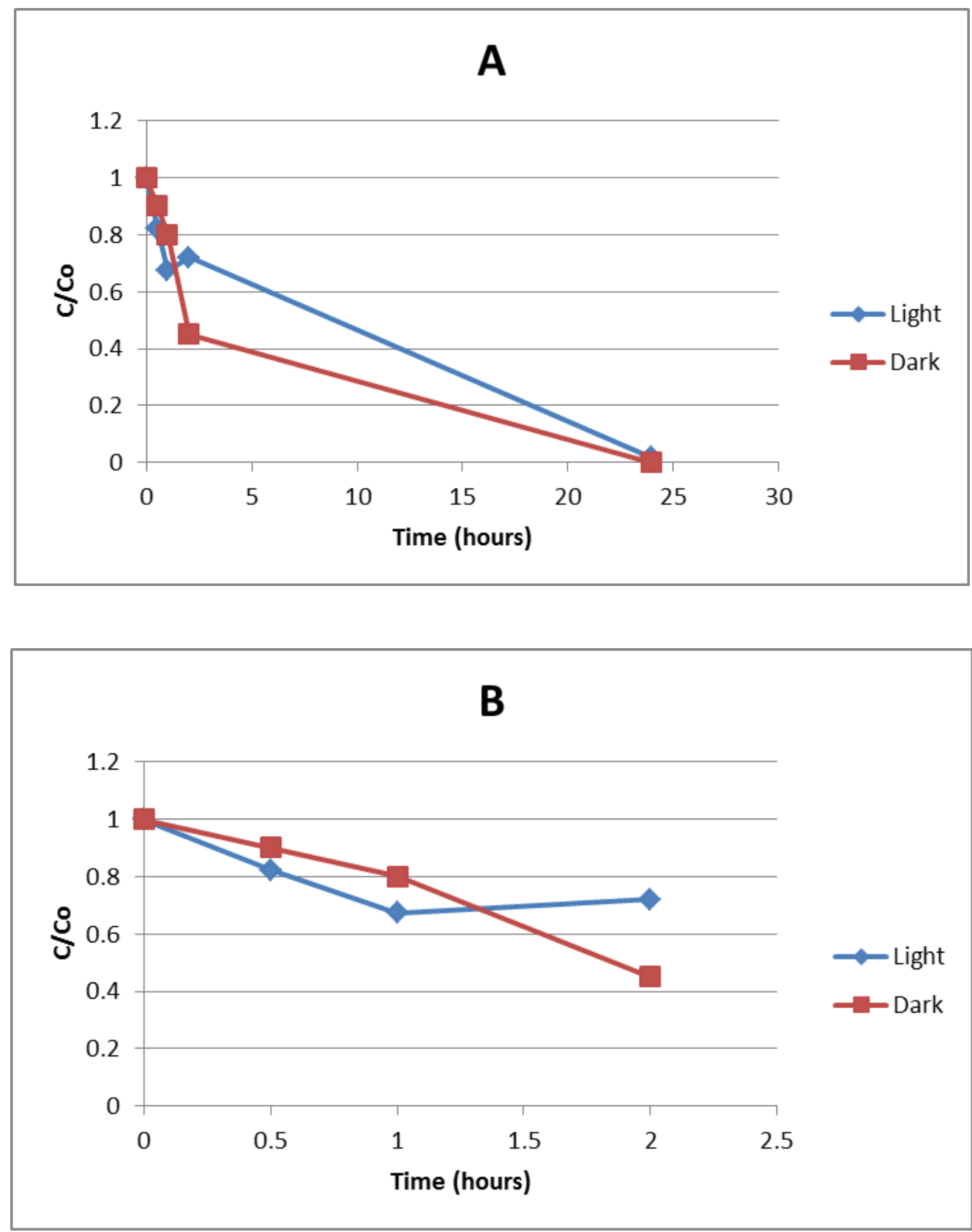

Figure 4.42-Normalized cell concentration remaining as a function of settling time for Scenedesmus settling in the light or dark over a A) 24-hour settling period and B) a 2hour period 

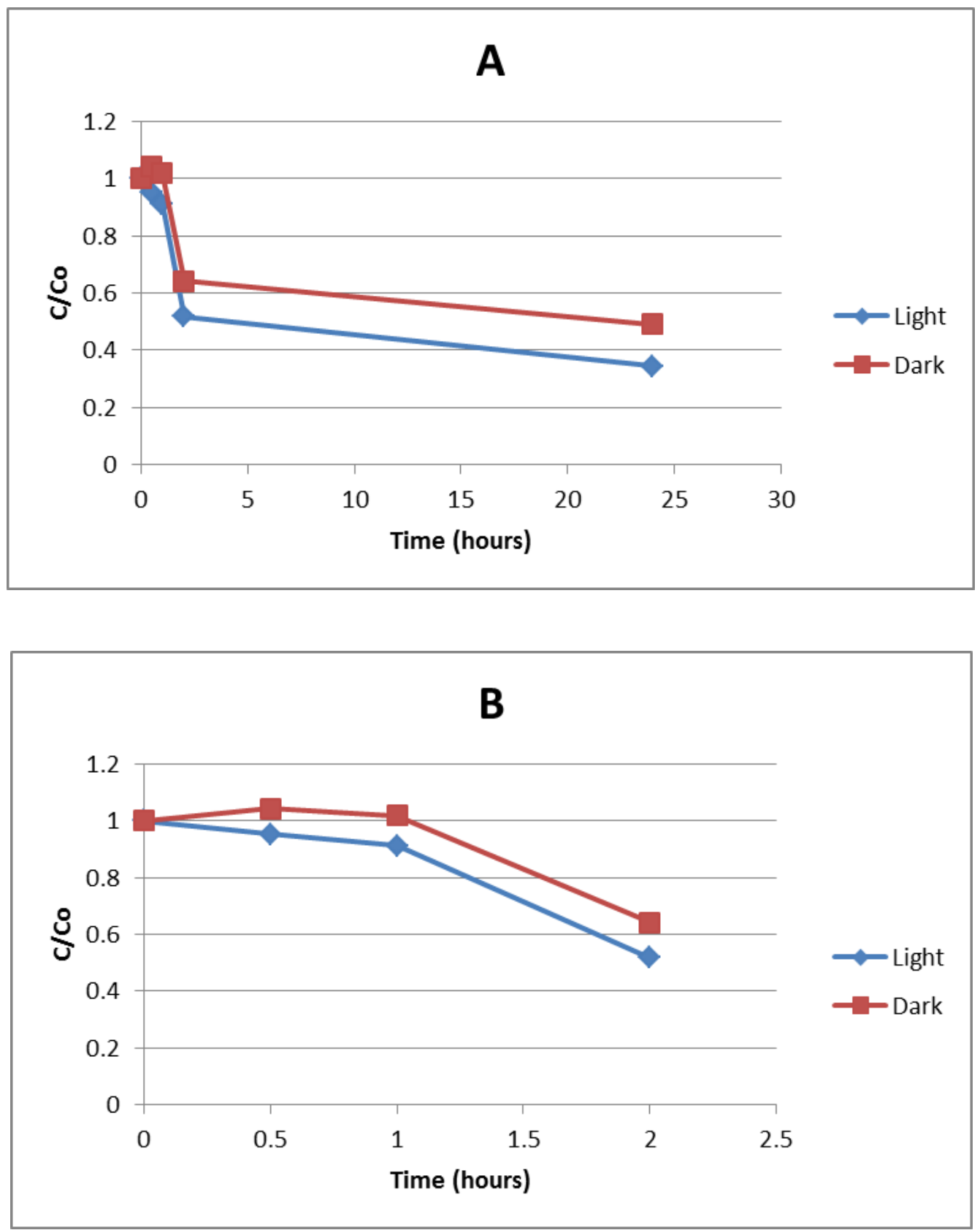

Figure 4.43-Normalized cell concentration remaining as a function of settling time for Chlorella settling in the light or dark over a A) 24-hour settling period and B) a 2-hour period 


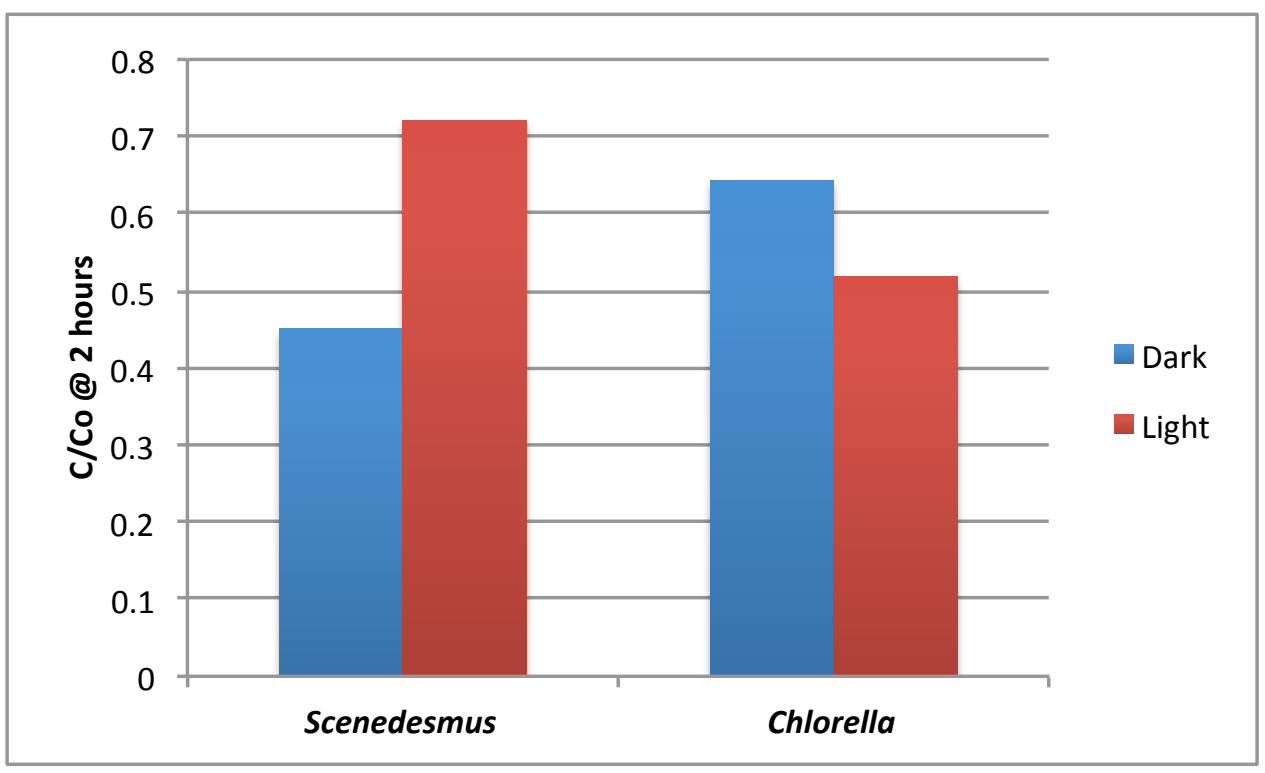

Figure 4.44-Comparison of settling over a 2-hour period for both Scenedesmus and Chlorella cultures settled in the light/dark

\subsubsection{Effect of Light and Dark Cycles During Growth and Light and Dark Settling Conditions on the Settling of Scenedesmus and Chlorella: Growth Curves}

Scenedesmus settling tests during these experiments were conducted with two cultures of similar densities. For both cultures throughout growth, illumination periods before settling tests were changed to 48 hours with no dark periods on 6,11 , and 18 days of growth. Settling was then run in either the light or in the dark and with or without bioflocculant addition. The second culture was a replicate of the first to compare settling results. Chlorella followed a different procedure where only two experiments were run both after 8 and 15 days of growth, but with the same light/dark cycles used above. A replicate culture was not used due to time constraints, but should be considered for future experimentation.

Growth curves for the two cultures of Scenedesmus, Chlorella and bacteria used in the light/dark experiments are shown in Figures 4.45, 4.46, 4.47, 4.48, and 4. 49. Growth for both cultures of Scenedesmus reached a maximum after eighteen days, but Scenedesmus culture 2 was a little denser (Figures 4.45, 4.46). Chlorella's growth was consistent even 
though light and dark cycles were differed (Figure 4.47). B. cepacia cell growth was similar for both cultures, reaching optical density levels above 1 within 5 days (Figures 4.48 and 4.49).

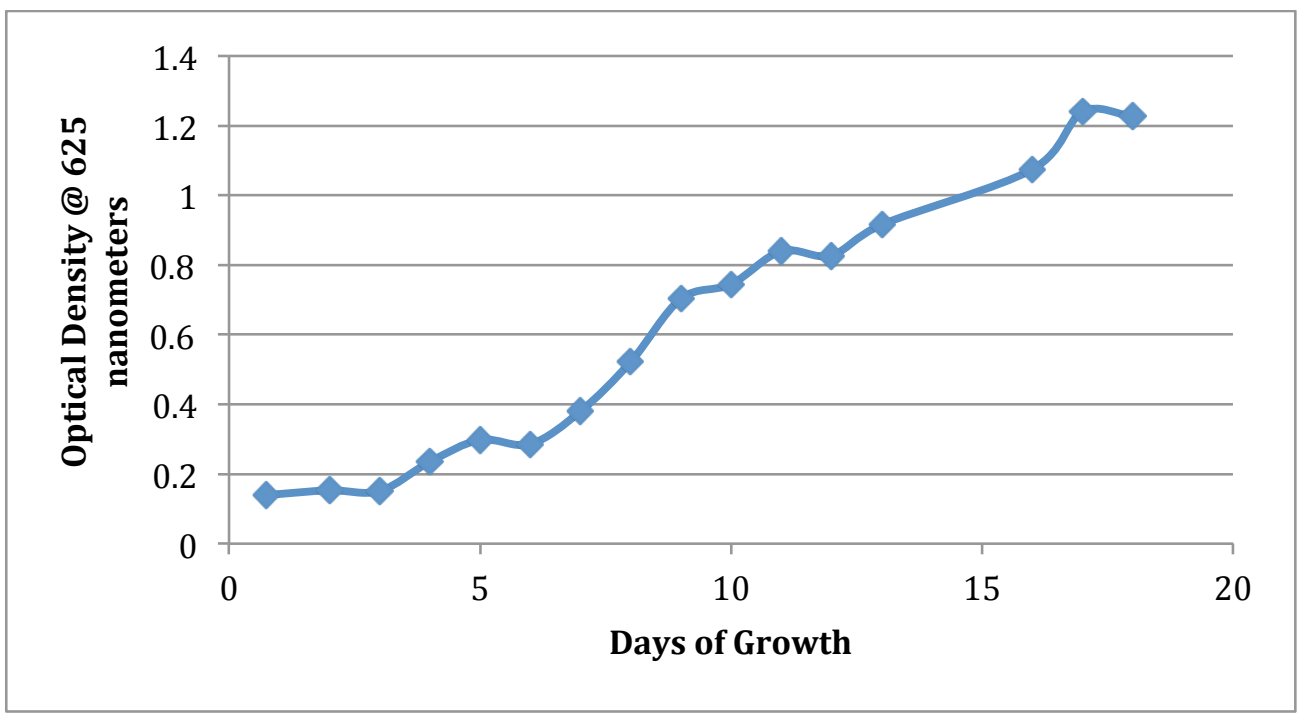

Figure 4.45-Growth Curve of Sc. 1 culture used in light/dark testing

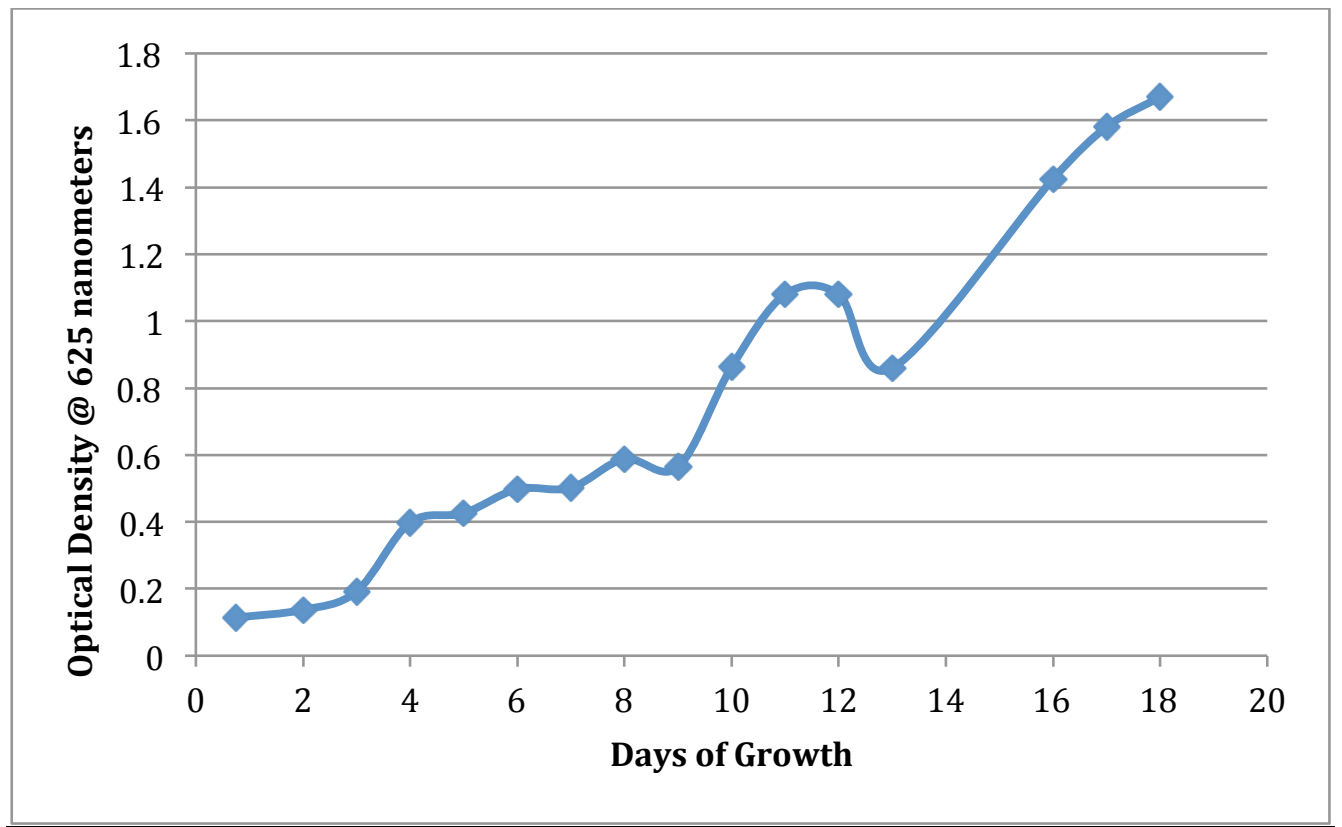

Figure 4.46-Growth Curve of Sc. 2 culture used in light/dark testing 


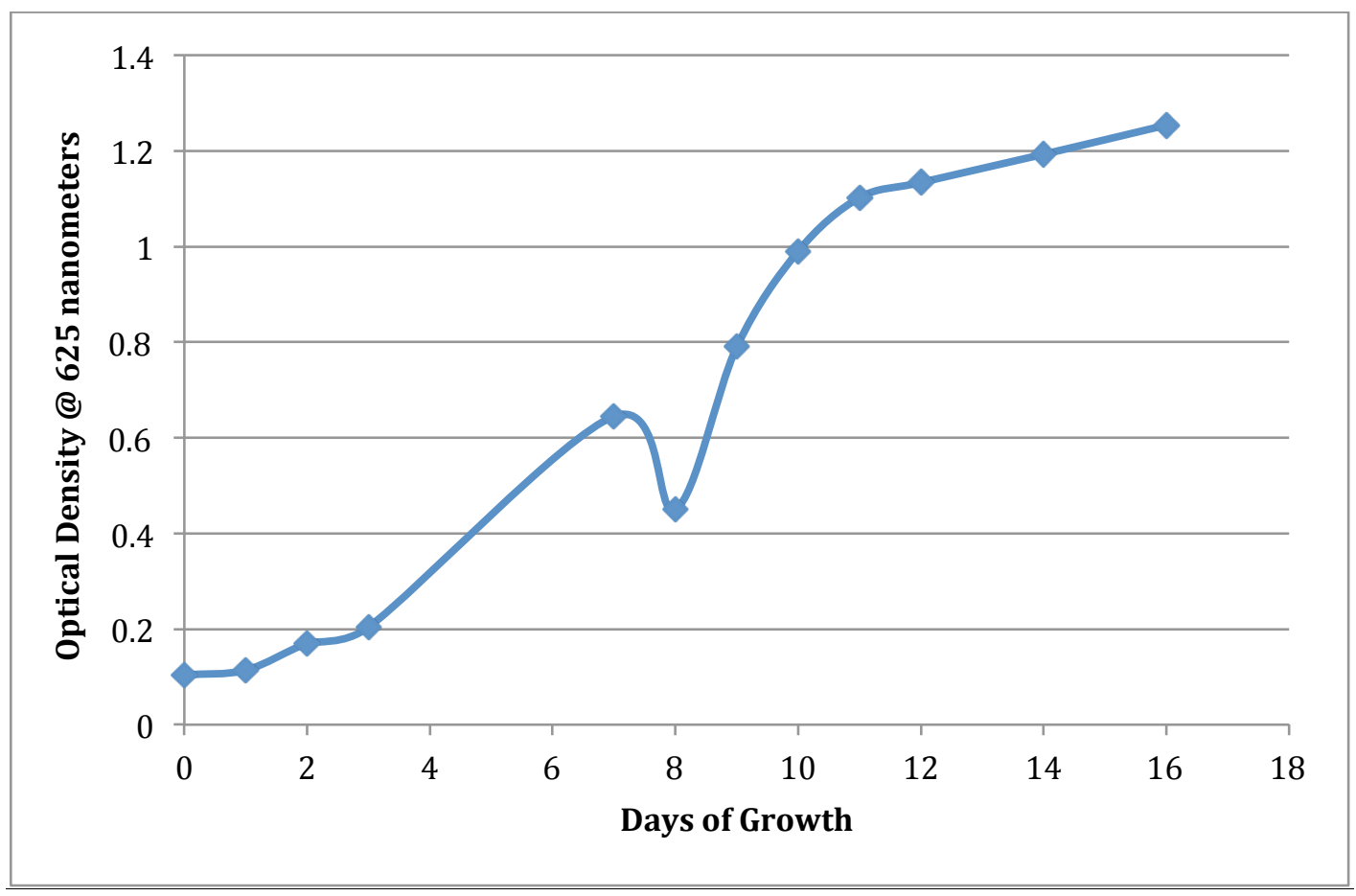

Figure 4.47-Growth Curve of Chlorella culture used in light/dark settling

(Chl 1.1)

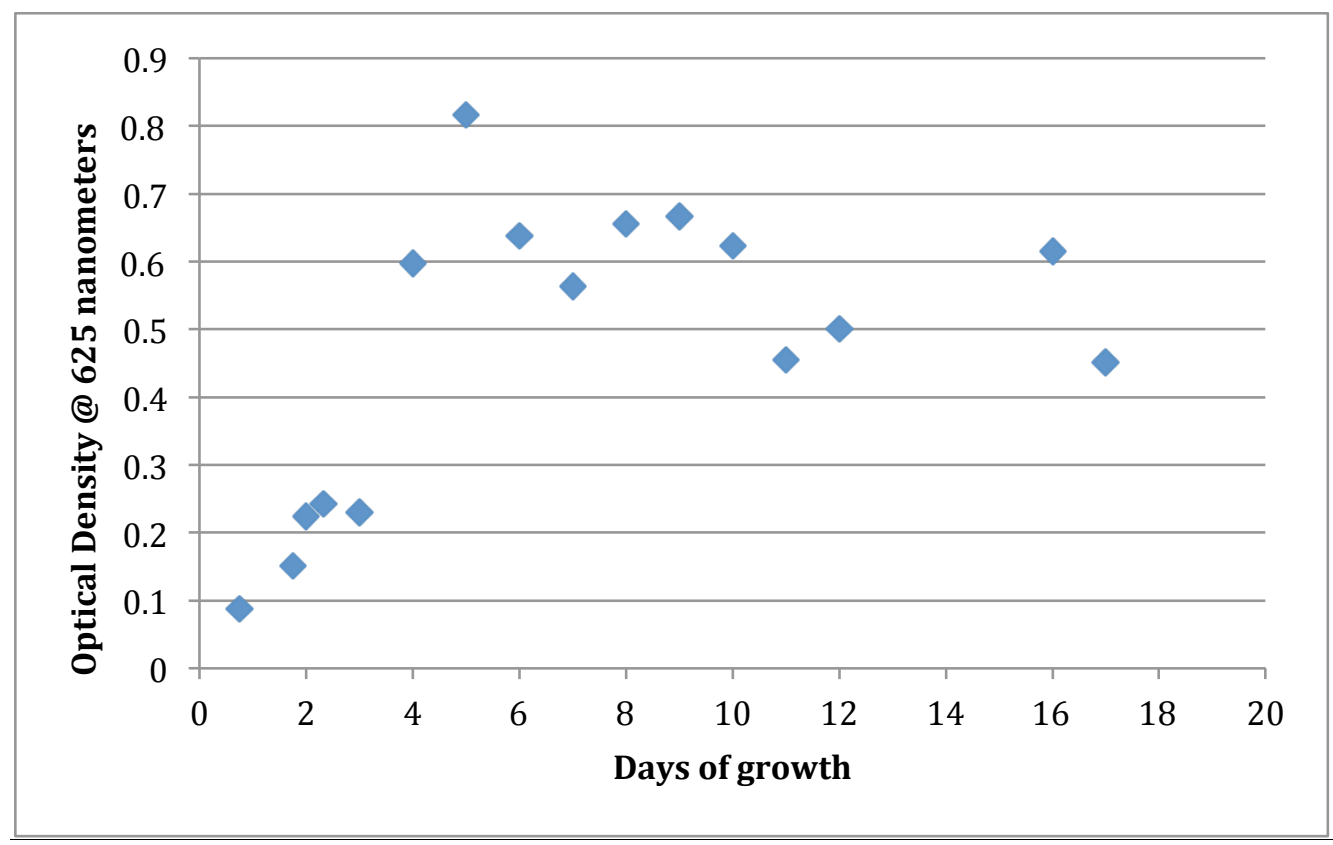

Figure 4.48-Growth Curve of B. cepacia 1 culture used in light/dark settling 


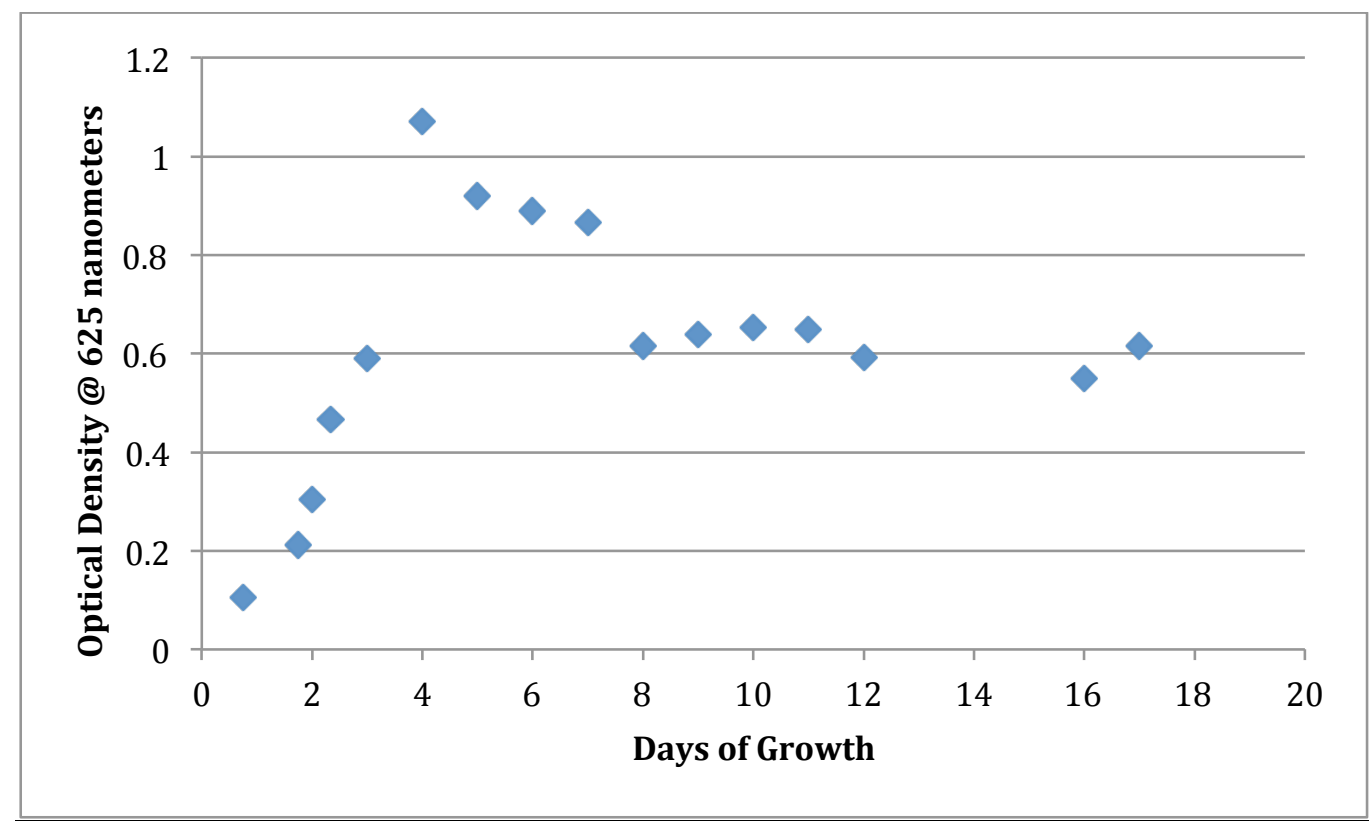

Figure 4.49-Growth Curve of B. cepacia culture 2 used in light/dark settling tests

\subsubsection{Effect of Light Intensity and Light/Dark Cycles During Growth on Settling of Scenedesmus Without B. cepacia Bioflocculant Addition}

For Scenedesmus, cultures harvested at 6 days, there was no significant effect of increased light exposure during growth or light exposure during settling (uncovered) on the average 2-hour settling efficiency between the two cultures (4.50). For cultures with the same increased exposure to light but settling in dark conditions (covered), better settling was observed earlier on in growth (Figure 4.50). In later stages (11 and 15 days), Scenedesmus cells settled better when they were exposed to additional light during growth and when they were settled uncovered.

These results were different than those observed in Section 4.4.1, which showed that Scenedesmus cells without additional light exposure settled better in mid stationary phase of growth (15 days) in dark (covered) conditions. Therefore, increasing the exposure to a constant light intensity with different light/dark cycles during growth affects the way 
algae settle when exposed to either light or dark conditions of settling. It appears increasing the exposure to a constant light intensity helps Scenedesmus the most during early stages of growth, where previous settling was observed to be poor. In addition, settling in the dark after this additional light intensity may further improve the settling of Scenedesmus in earlier stages of growth.

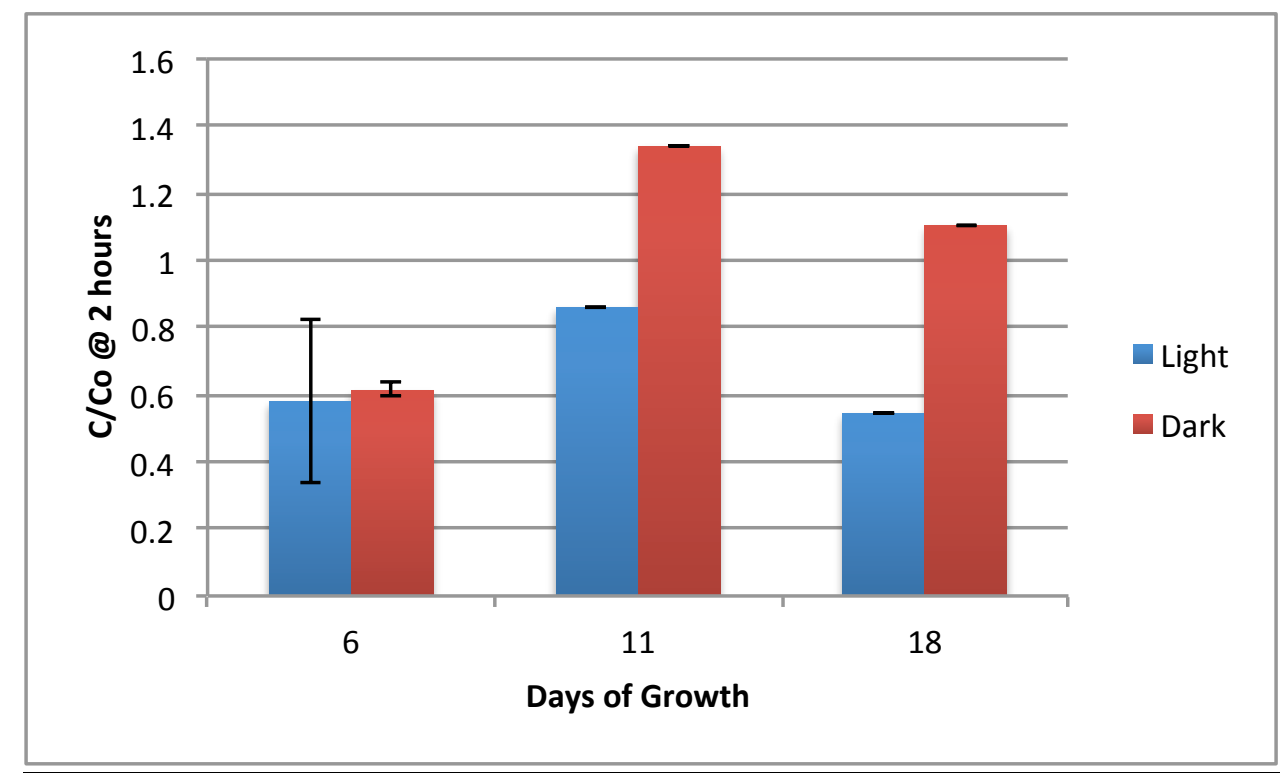

Figure 4.50-Comparison of settling based on normalized cell concentration remaining for an average of Scenedesmus cultures (1 and 2) over 18 days of growth under light and dark conditions of settling over the growth curve with no bioflocculant addition. Before each test, each culture was exposed to 48 hours of constant light intensity and then settled in the light (not covered) or dark (covered). For Day 6, replicates were run and the error bars indicate the differences in results

\subsubsection{Effect of Light Intensity and Light/Dark Settling Conditions on Settling of Chlorella Without B. cepacia Bioflocculant Addition}

Overall, with additional light exposure, Chlorella settled better in early growth for both cultures settling in the light and in the dark (Figure 4.51). As compared to settling in the dark, extra light had little or no effect to improve settling in the light (uncovered) during early growth (8 days) (Figure 4.51). After 15 days of growth, settling was much lower for Chlorella settling in both the light and the dark exposed to additional light and settling in the 
light and dark (Figure 4.51). Therefore, dark-settling conditions (covered) combined with an increased light exposure (up to 48 hours) improved the settling of Chlorella during later stages of growth (mid stationary phase) when settling was previously judged poor. Again, like Scenedesmus, results were opposite compared to the Chlorella culture in mid-stationary phase that was not exposed to an increased amount of light prior to settling (Section 4.4.1). This culture was observed to settle better in the light as compared to the dark during later stages of growth. Thus, increasing exposure to a constant light intensity appears to have an effect on the settling of both Scenedesmus and Chlorella during stages of growth where settling was previously inadequate for harvesting of algae cells.

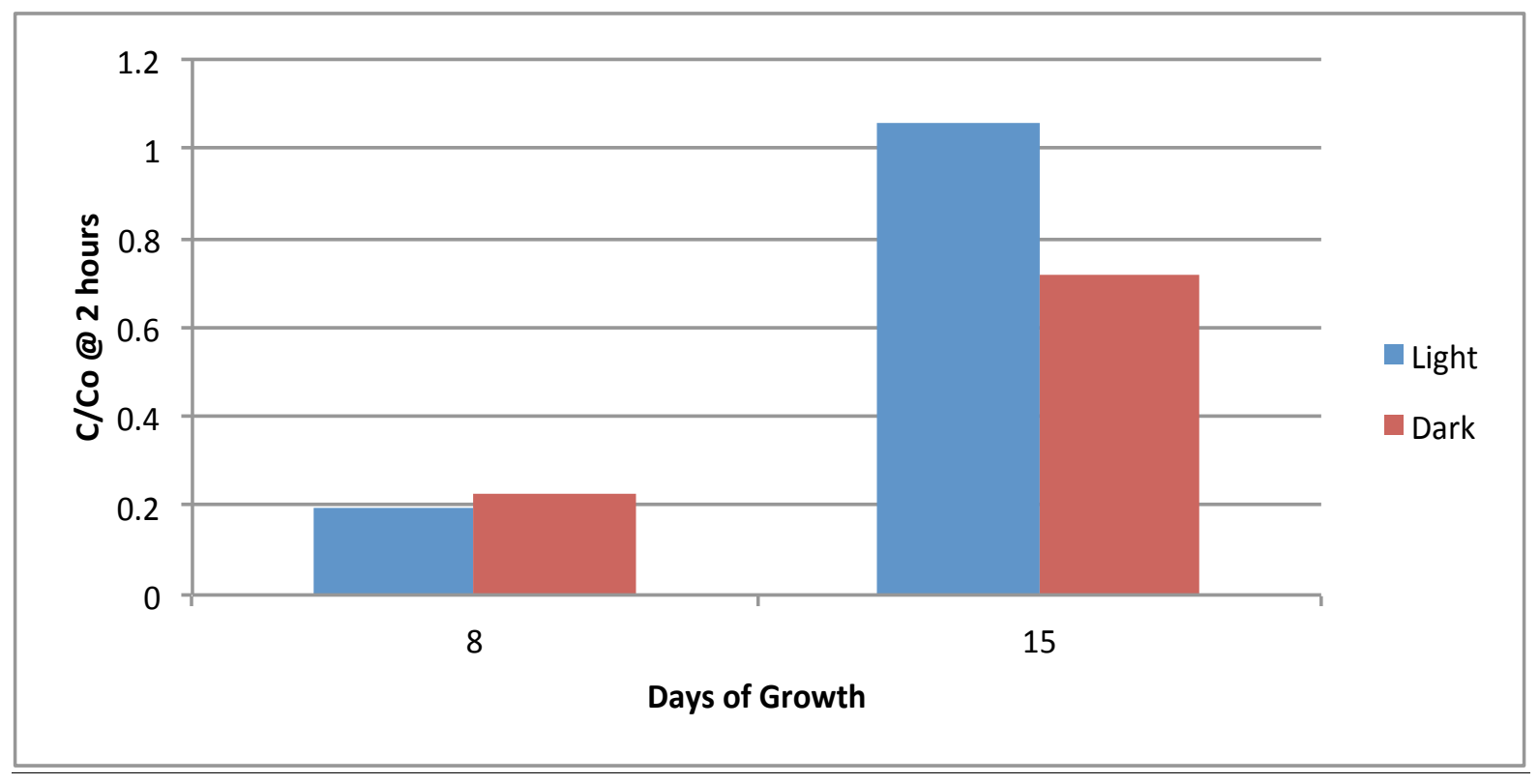

Figure 4.51-Comparison of settling based on normalized cell concentration remaining for Chlorella over the growth curve of 18 days. Before both tests, light exposure was increased to 48 hours and settling took place in either the light or the dark (covered or uncovered) 


\subsubsection{Effect of Light and Dark Cycles and Light and Dark Settling Conditions on Settling of Scenedesmus With B. cepacia Bioflocculant Addition}

Early in the growth phase of Scenedesmus (6 days) without B. cepacia bioflocculant addition, there was an increased settling effect of extra light during growth either for cultures settling in the light or dark (Figure 4.52). As compared to normal light/dark cycles after 8 days of growth for Scenedesmus (Figure 4.24), settling was most improved without bioflocculant addition with an increase in exposure to light and settling in the dark. However, when B. cepacia cells are added as a bioflcculant, Scenedesmus cells appear to settle much better in the dark and with extra light as compared to without bioflocculant addition (Figure 4.52).

For mid stages of growth (early stationary phase of 11 days), Scenedesmus with $B$. cepacia bioflocculant settled better in the dark with added light during growth, but the effect was less than that observed after 6 days of growth (Figure 4.52). In addition, the higher mixing intensity (DMI), as indicated by Figure 4.52, improved settling for algal cells in the dark with extra light addition during early stationary phase of growth. After 18 days of growth (mid stationary phase), cell removal of Scenedesmus is still improved by cell addition with extra light under dark settling conditions, but the effect is still diminished compared to earlier stages of growth (Figure 4.52). The different (higher) mixing intensity also made settling worse later on in growth (Figure 4.52).

These results demonstrate that the settling of Scenedesmus are improved by adding B. cepacia cells as a bioflocculant, particularly under dark conditions of settling, when algal cells have been treated with extra light during growth (up to 48 hours). Moreover, this effect is diminished for longer periods of growth. 


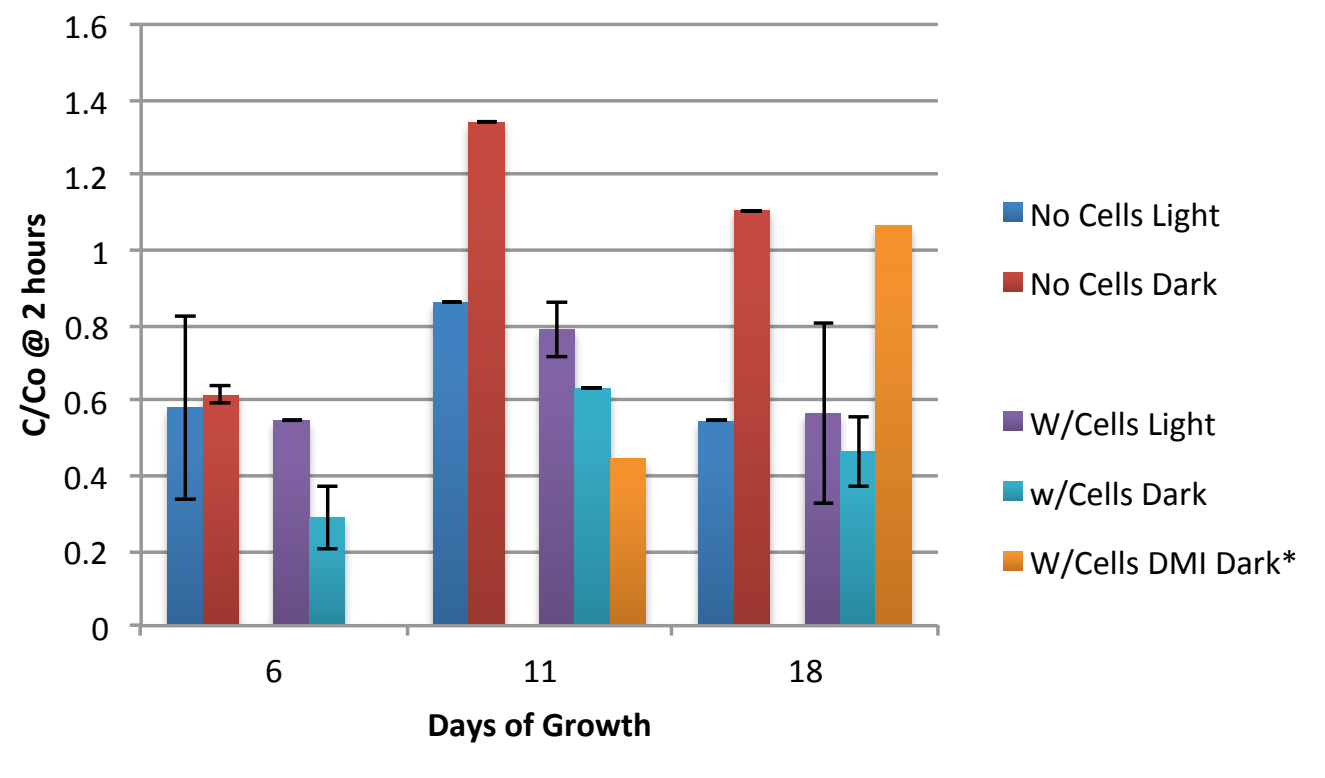

Figure 4.52-Comparison of settling for Scenedesmus with and without B. cepacia cell addition and constant light exposure of 48 hours before settling in the light or dark (covered or uncovered) over 18 days of growth. Error bars indicate samples that were replicated, with the average normalized cell concentration remaining after 2 hours shown

* DMI-Indicates the cell addition had a 1,000 rpm initial mixing intensity for 5 minutes followed by a 100-rpm flocculating period for the remaining 25 minutes before settling in the dark

\subsubsection{Effect of Light Intensity and Light/Dark Conditions on Settling of Chlorella With B. cepacia Bioflocculant Addition}

Addition of B. cepacia cells as a bioflocculant improved the settling of Chlorella under light and dark settling conditions during early growth (Figure 4.53). This effect was slightly better under dark conditions. Filtrate additions under light and dark conditions did not improve settling of Chlorella under any conditions. Thus, for both Scenedesmus and Chlorella settling under dark conditions with additional light was improved early on in growth with B. cepacia cell addition, not filtrate. For 15 day-old Chlorella cultures (mid stationary phase of growth), the best settling in the dark and the light was observed without cell or filtrate addition. These results, even with an increase in light exposure, were consistent with previous results in Figure 4.31, where at 15 days in growth (mid 
stationary), bioflocculants from B. cepacia did not help improve settling to a significant extent.

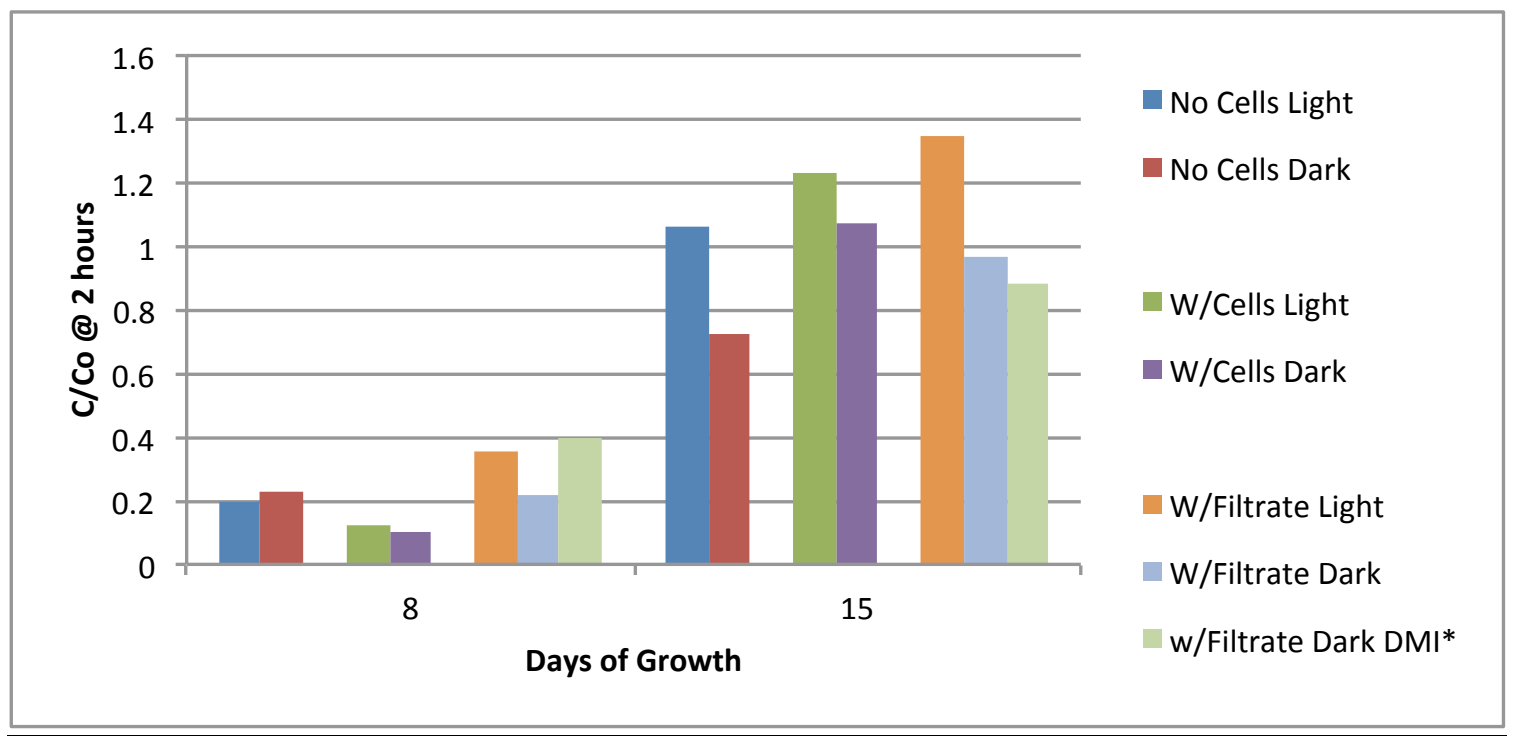

Figure 4.53-Comparison of settling based on normalized cell concentration remaining over a 2-hour settling period for Chlorella with and without B. cepacia bioflocculant additions, with one sample mixed under a different intensity, using both light and dark conditions and over a 15-day growth period. The bioflocculant addition is based on the order of the legend. All cultures were exposed to a 48-hour period of constant light intensity prior to settling

* DMI-Indicates the cell addition had a 1,000 rpm initial mixing intensity for 2 minutes followed by a 100-rpm flocculating period for the remaining 3 minutes before settling in the dark

\subsubsection{EPS Correlation Between Varying Light Intensity and Light/Dark Settling Conditions on Improved Settleability of Scendesmus and Chlorella}

EPS concentrations were measured in the light/dark experiments to see if EPS production was affected by prolonged exposure to a constant light intensity and to see if bacterial cell and filtrate addition increased the EPS to improve settling. EPS concentrations over the growth curve for both Scenedesmus cultures were similar, peaking later in mid stationary growth around $12 \mathrm{mg} / \mathrm{L}$ (Figure 4.54). This concentration of dissolved EPS was similar to that observed previously for growth at shorter exposure periods to light (different light/dark cycles). This suggests that varying exposure periods to a constant light 
intensity does not have an effect on EPS production. Similarly, Chlorella showed no signs of increased EPS production due to changes in exposure to a constant light intensity (Figure 4.57).

Increased growth of B. cepacia cultures further increased dissolved EPS concentrations to values much higher than the typical values seen in previous experiments in this study (Figure 4.55 A and B). Figure 4.56 shows that B. cepacia 1 cells had the highest EPS production and increased over the growth curve while B. cepacia 2 cells had a more variable EPS production. The differences in EPS by the bacterial cultures may have resulted in differences in settling between both of the Scenedesmus cultures observed with larger error bars in Figure 4.52. For instance, during settling tests in later stages of growth of Scenedesmus, B. cepacia 1 had twice the dissolved EPS than the other culture. Also, dissolved EPS between the two cultures of Scenedesmus was similar. Thus, more of an error was observed in settling efficiencies with B. cepacia added to Scenedesmus cells in the light (Figure 4.52) than any other time throughout growth. This suggests that differences in EPS between the bacterial cultures resulted in improved settling of one culture of Scenedesmus over the other. 

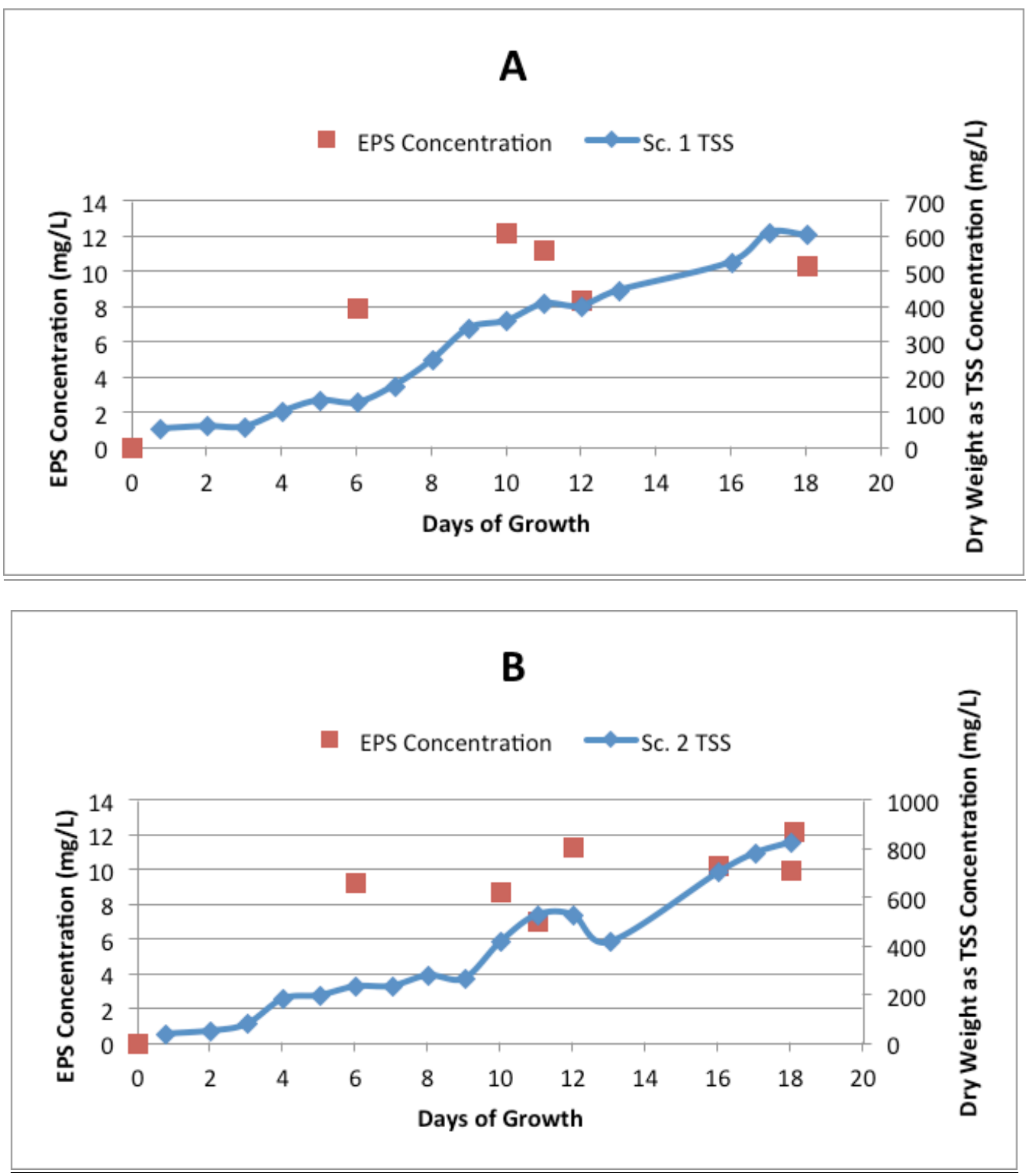

Figure 4.54-EPS concentrations plotted against dry weight expressed as TSS with A) Sc. 1 culture and B) Sc. 2 culture 

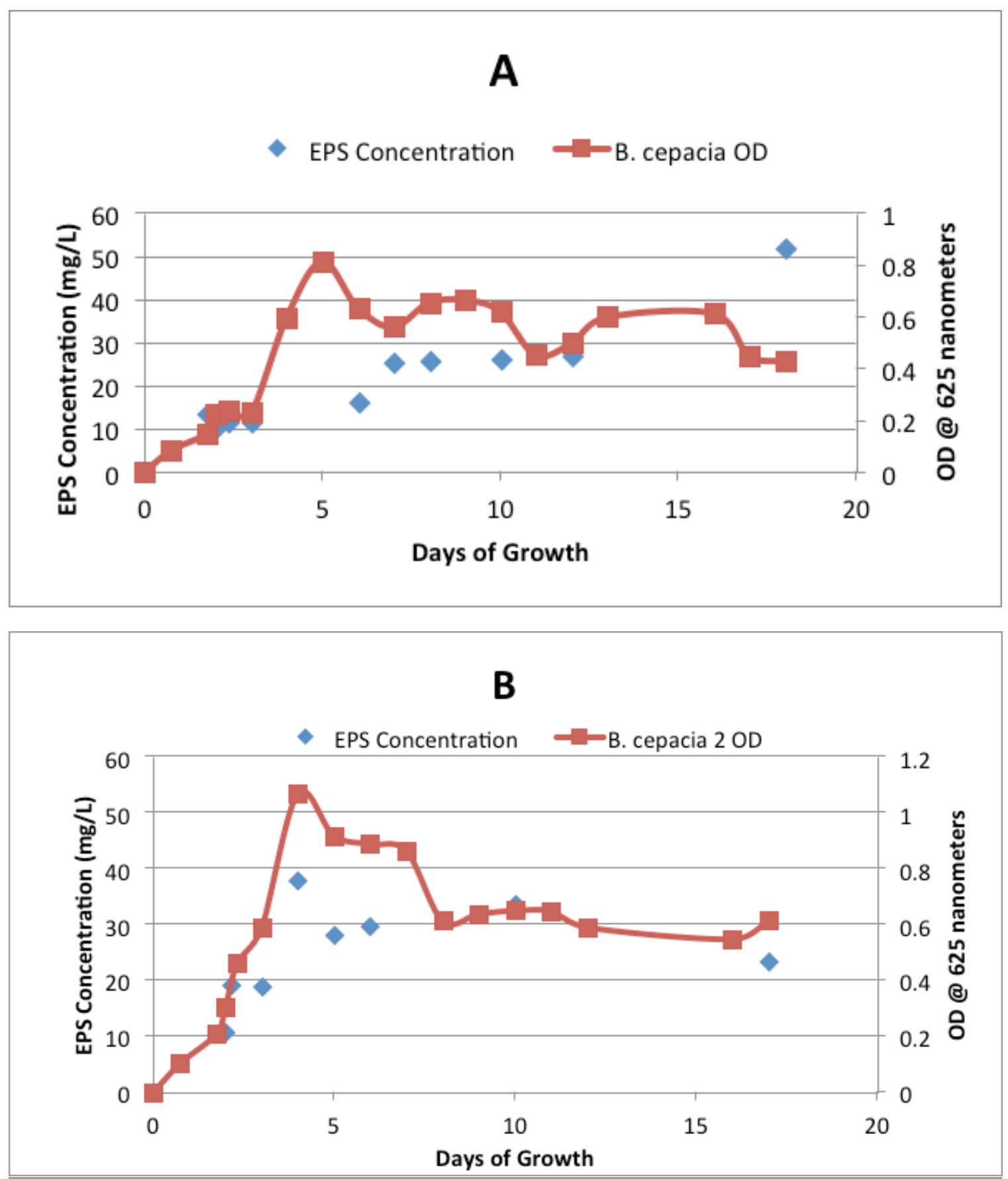

Figure 4.55-EPS concentrations plotted against optical density at $625 \mathrm{~nm}$ with A) B. cepacia 1 culture and B) B. cepacia 2 culture 


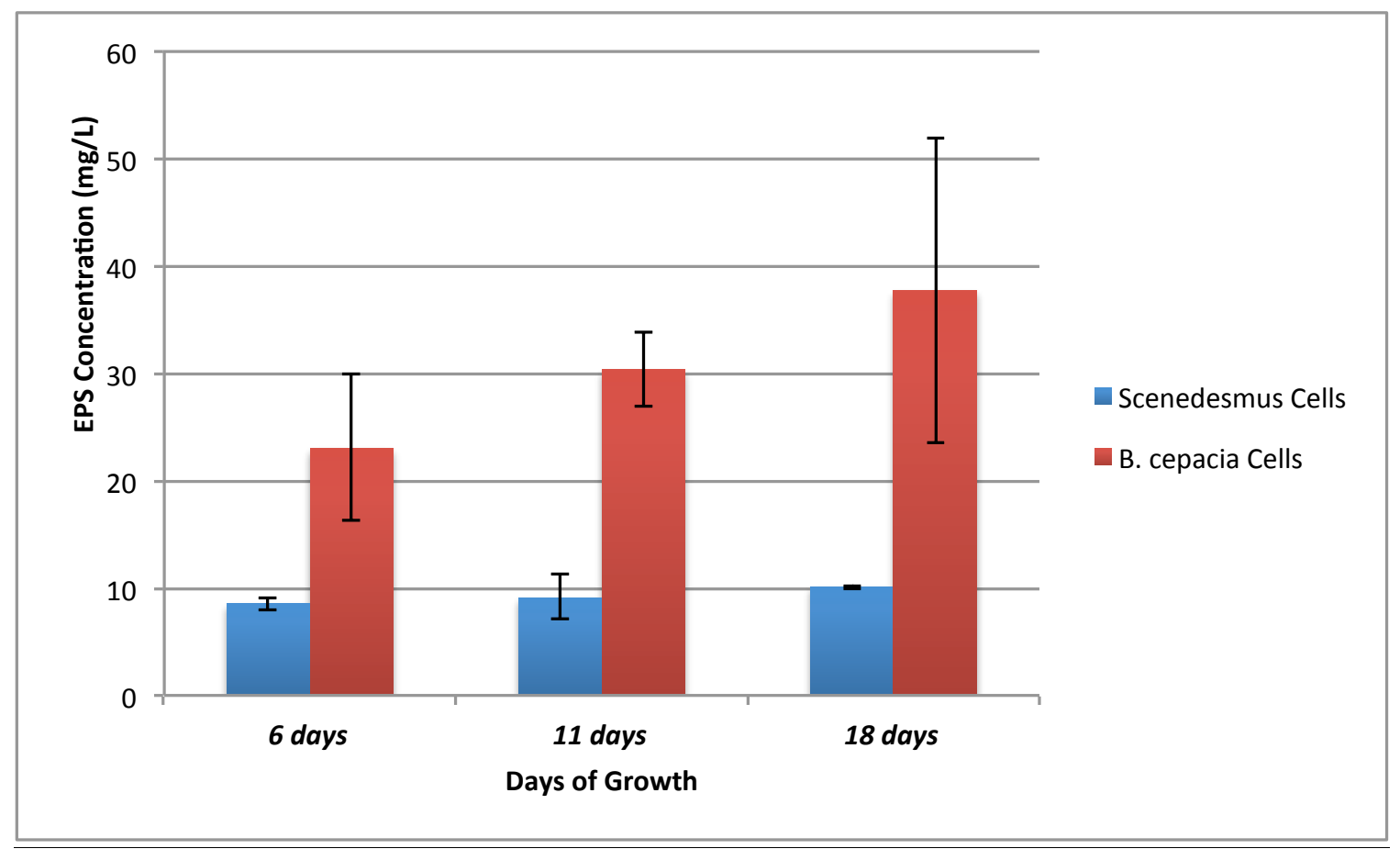

Figure 4.56-Summary of EPS concentrations (Figure 4.75-4.76) plotted over 18 days of growth for both Scenedesmus and B. cepacia cultures used during settling tests. Error bars indicate replicates used with different cultures of bacteria and algae. Samples were taken from each culture separately before settling tests were run

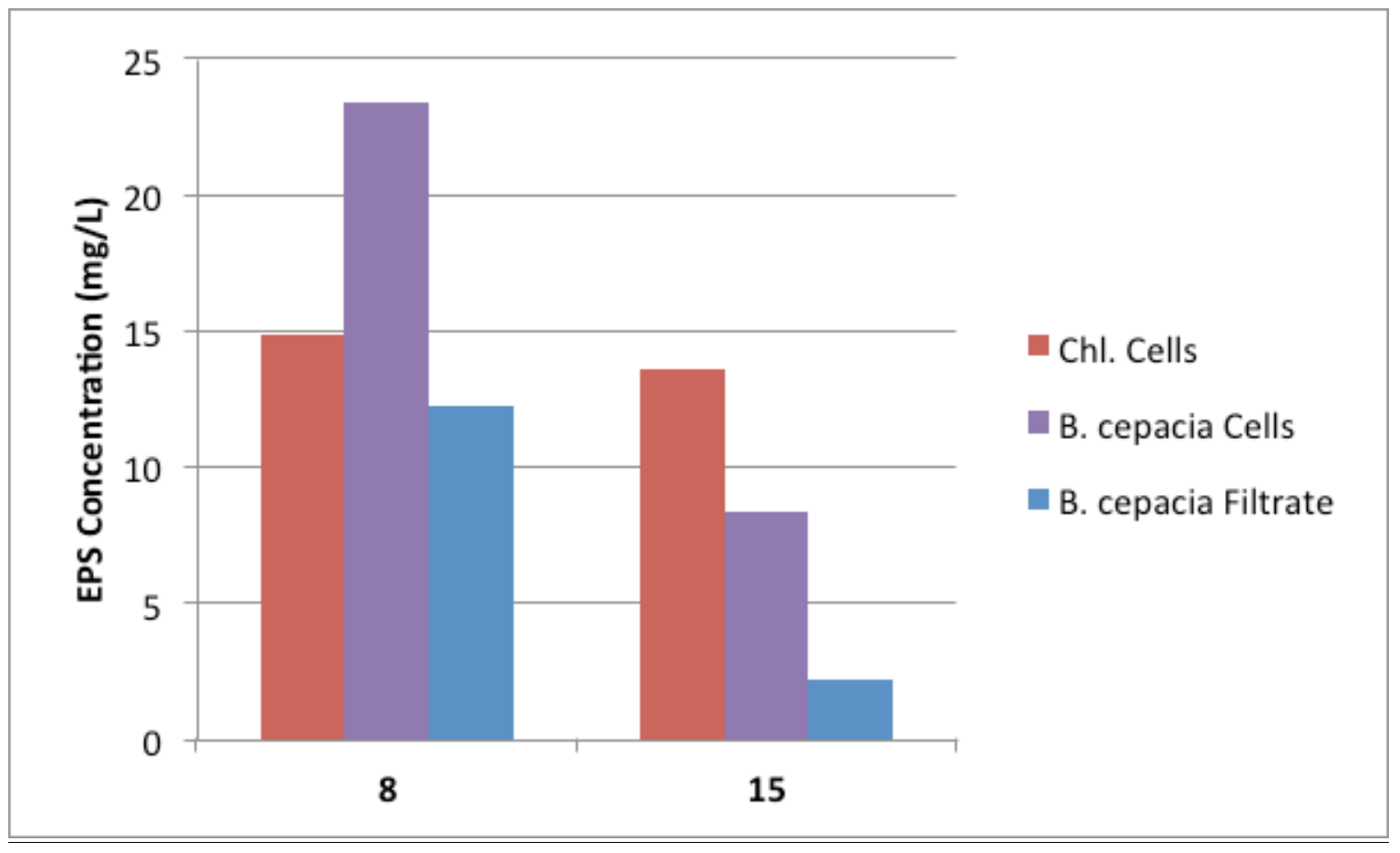

Figure 4.57-Summary of EPS concentrations plotted over the growth curve for Chlorella and B. cepacia cells and filtrate used during settling tests. Samples were taken from each culture separately before settling tests were run 


\subsection{Varying pH to Improve Settleability of Scenedesmus and Chlorella}

The pH during settling was varied from 3 , to 7 , to 11 without bioflocculant addition (Sections 4.5.2, 4.5.3) and with bioflocculant addition (Sections 4.5.4, 4.5.5) to test the effect of $\mathrm{pH}$ on settling of Scenedesmus and Chlorella. In these experiments, Scenedesmus cultures were treated with $B$. cepacia cells as compared to filtrate given that settling was improved to a greater extent in earlier experiments $(1,2,3)$ with $B$. cepacia cell addition. Likewise, Chlorella cells were treated with B. cepacia filtrate as opposed to cells due to similar results in previous experiments $(1,2,3)$. Dissolved EPS from both algae cultures and the bacterial bioflocculants used was measured and correlated with settling to further determine if there was an optimal pH for bioflocculant addition.

\subsubsection{Growth Curves of B. cepacia, Scenedesmus and Chlorella used in pH experiments}

Two cultures of Scenedesmus were grown for these two experiments with similar growth curves (Figure 4.58). Only one Chlorella culture was used, with the growth curve shown in Figure 4.59. Three cultures of bacteria were used over the course of this testing and their respective growth curves can be seen in Figure 4.60. Growth was not as great as observed in earlier experiments (light and dark experiments) for the B. cepacia cultures. The figures also show when the cultures were used for different $\mathrm{pH}$ settling tests (included in the captions). 

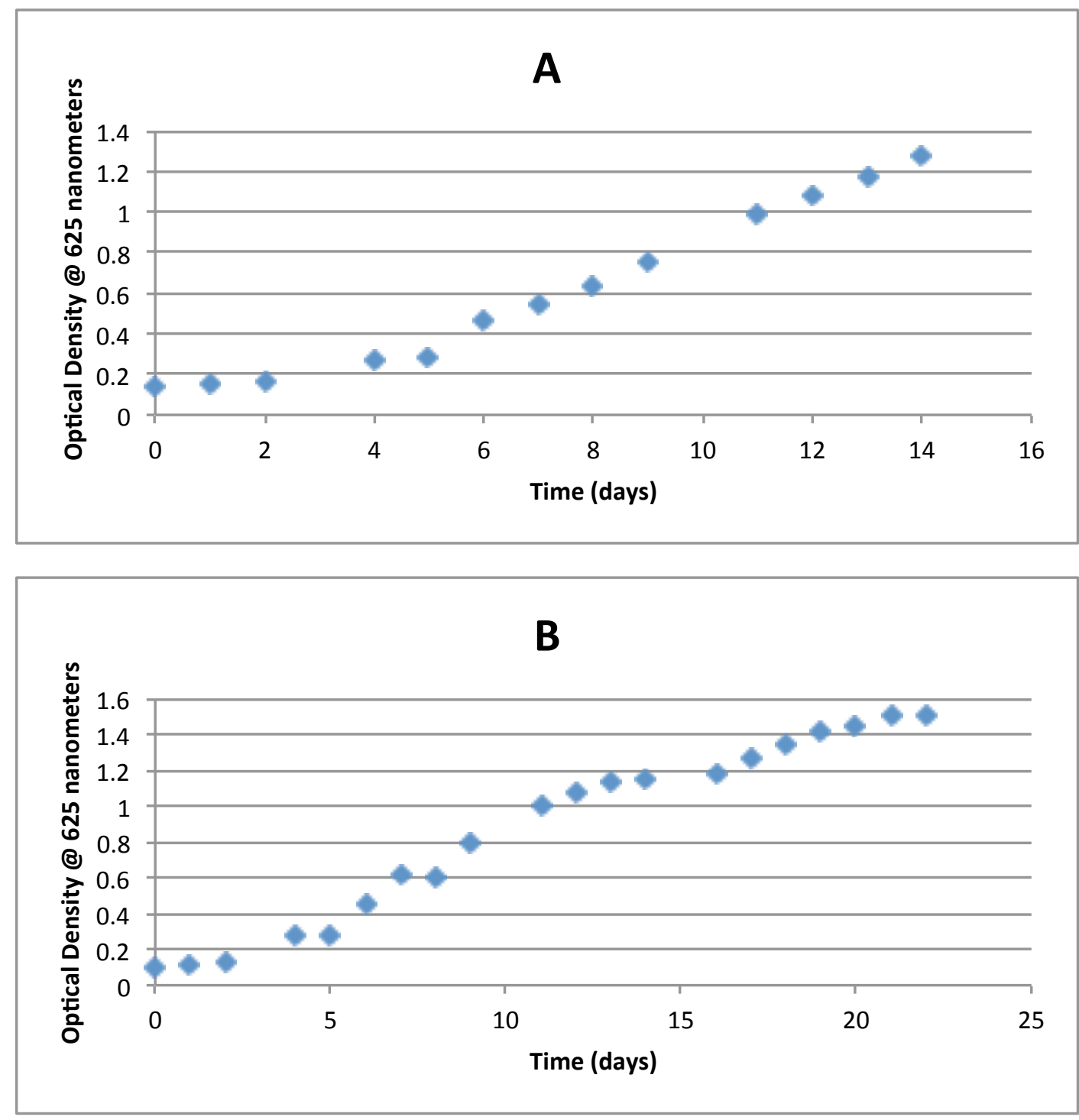

Figure 4.58-Growth Curve of A) Scenedesmus 1.1 used in pH testing and B) Scenedesmus 1.2 used in pH testing 


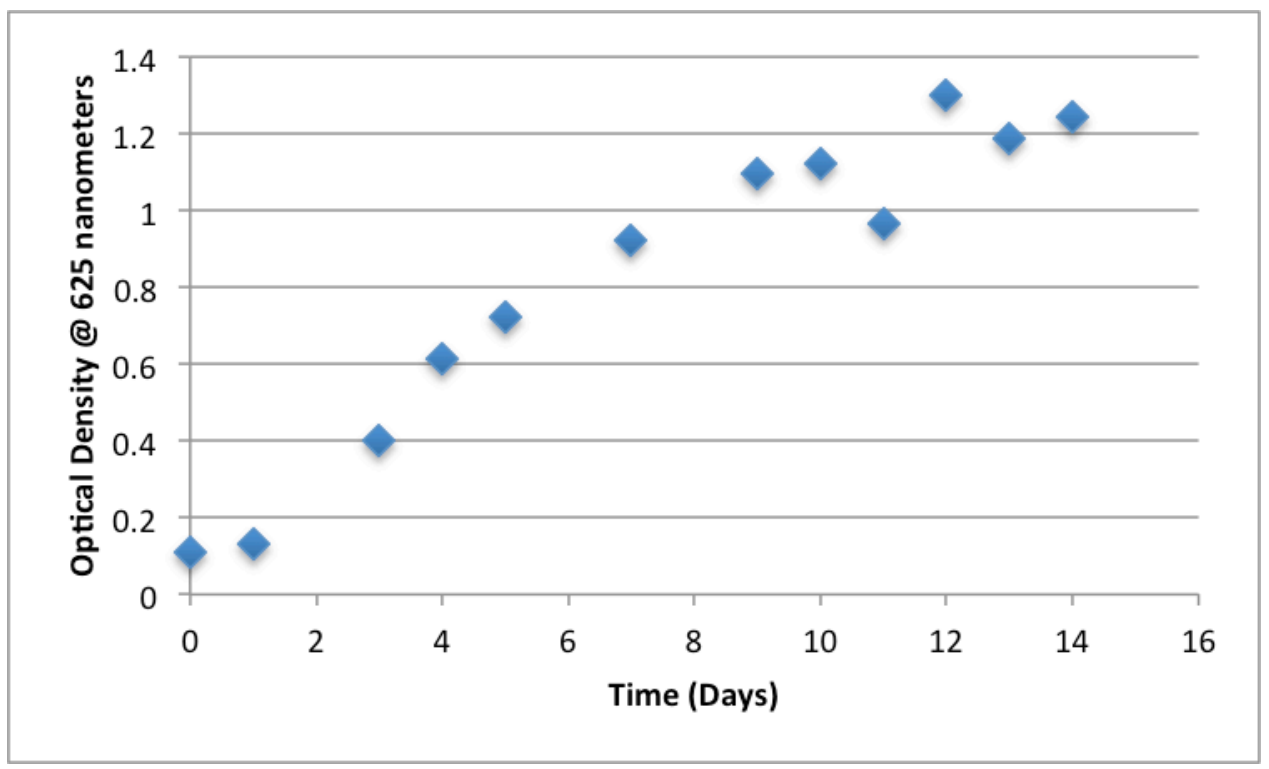

Figure 4.59-Growth Curve for Chlorella culture used in pH testing (Chl 2.1) 

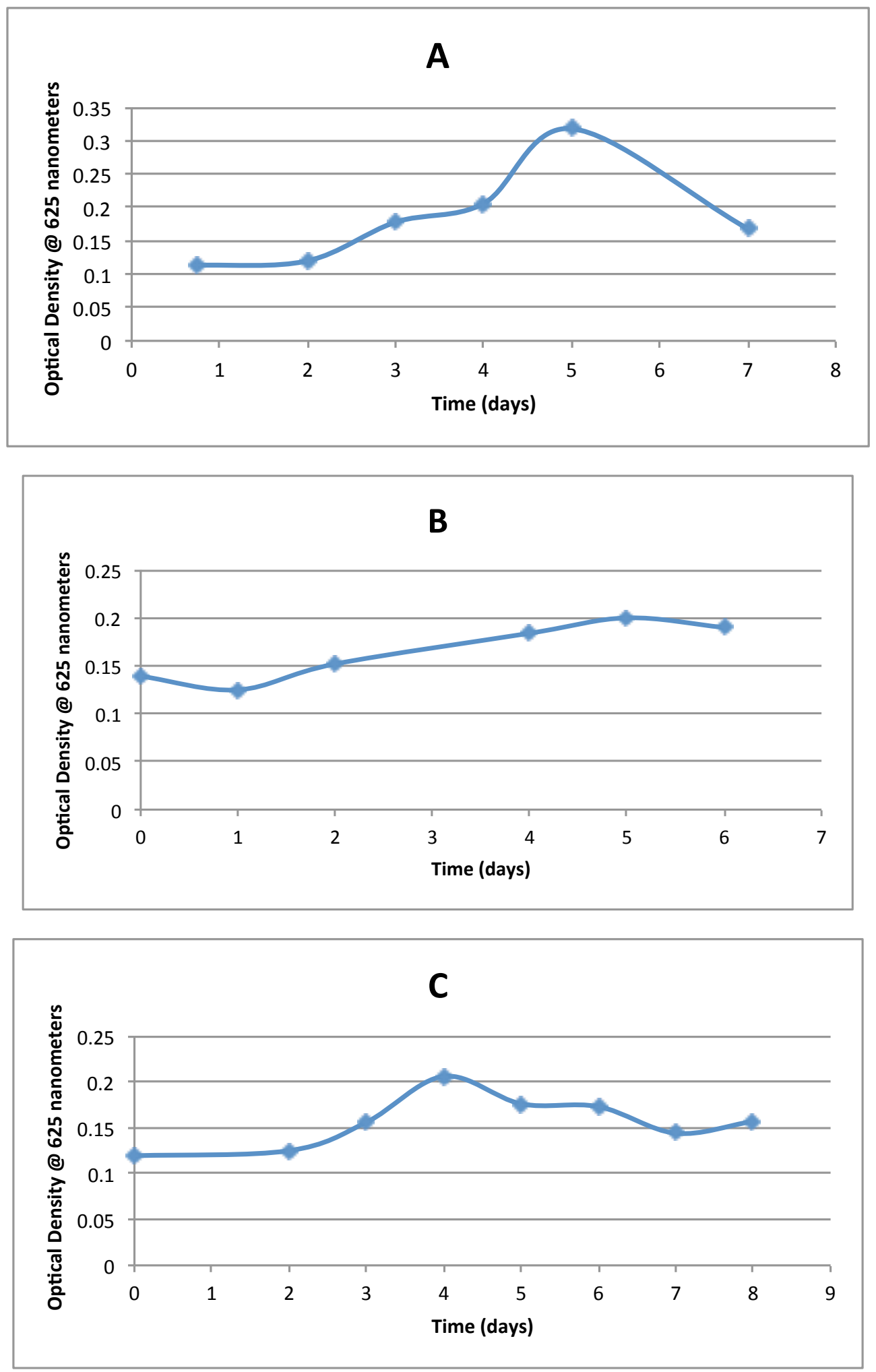

Figure 4.60-Growth curve of A) B. cepacia used with Scenedesmus settling test \# 1 for pH variations, B) B. cepacia used in Chlorella settling test \#1 and Scenedesmus settling test \# 2 for $\mathrm{pH}$ variations, and C) B. cepacia used in Chlorella settling test \# 2 for $\mathrm{pH}$ variations 


\subsubsection{Effect of Growth Phase on the Settleability of Scenedesmus with Varying pH}

Lowering the $\mathrm{pH}$ to 3 without B. cepacia cell addition greatly improved the settleability of Scenedesmus early in the growth curve (5 days) (Figure 4.61). Increasing the pH to 11 only slightly enhanced settling of Scenedesmus (Figure 4.61). All cultures did not settle well at 14 days of growth regardless of pH (Figure 4.61). This poor settling late in growth was different than that observed in earlier experiments. At earlier stages in growth, the $\mathrm{pH}$ effect may be due to Scenedesmus reaching an isoelectric point where all charge is neutralized. As the culture increased in density, this effect was observed to diminish.

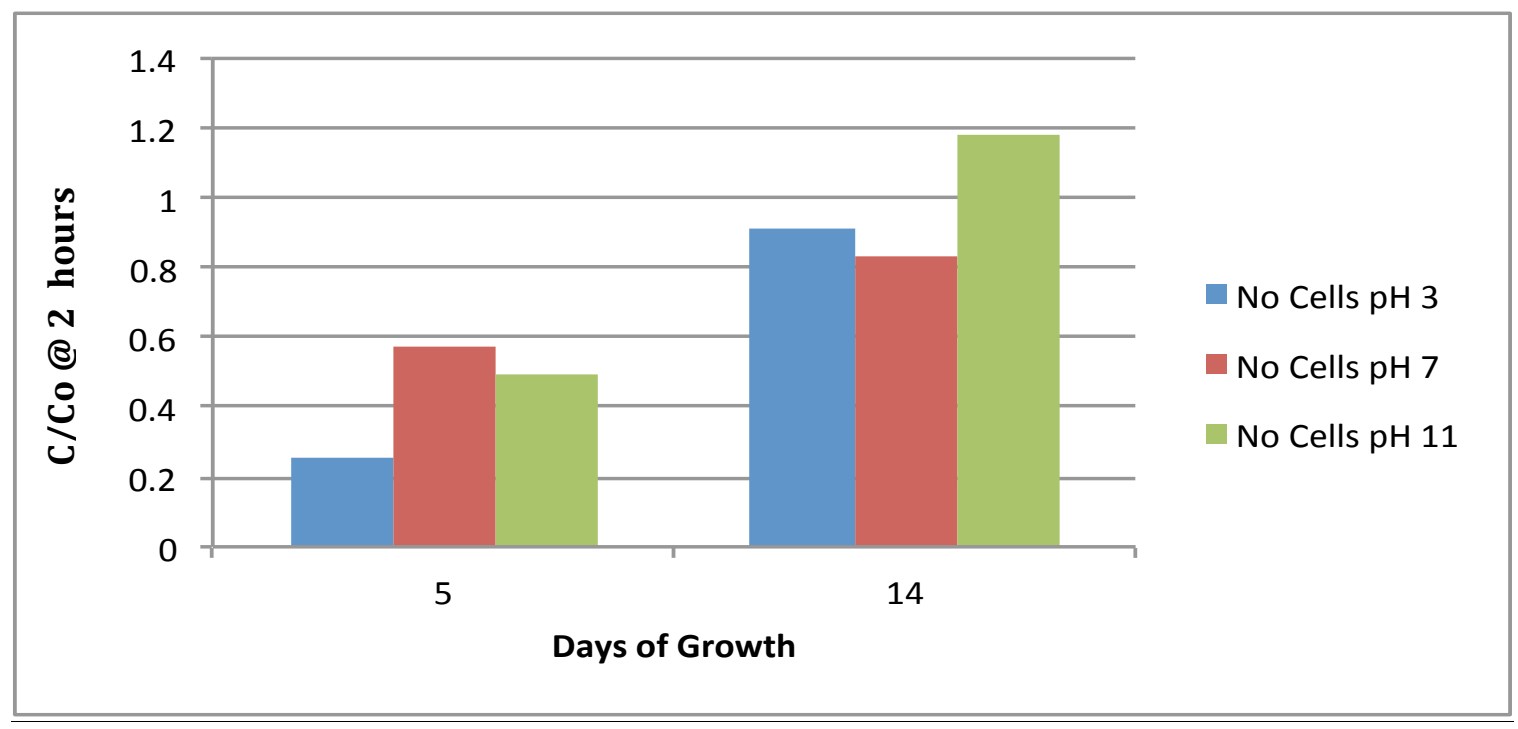

Figure 4.61-Comparison of settling based on normalized cell concentration remaining after a 2-hour settling period with variation in $\mathrm{pH}$ for Scenedesmus without cell addition over a growth period of 14 days

\subsubsection{Effect of Growth Phase on the Settleability of Chlorella with Varying pH}

Without $B$. cepacia filtrate addition, $\mathrm{pH}$ had a consistently strong influence on settling of Chlorella, with the best settling observed at a pH of 3 (Figure 4.62). This was observed for both 24 and 2-hour settling periods (A.25, A.26, 4.62). At a pH of 11, Chlorella settling was poor at both stages of growth (Figure 4.62). Again, results for Chlorella were 
different than those for Scenedesmus. Lowering the $\mathrm{pH}$ to 3 improved settling during later growth stages for Chlorella as compared to early growth stages for Scenedesmus.

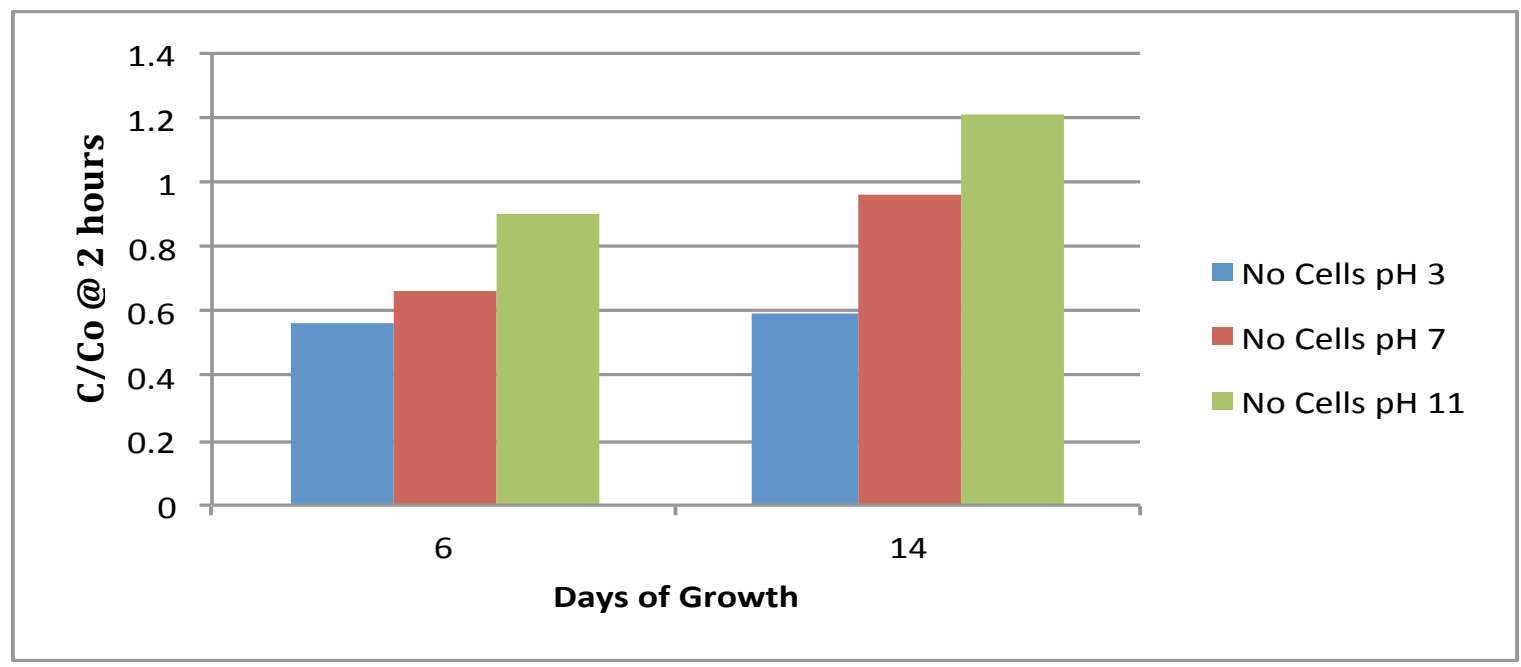

Figure 4.62-Comparison of settling based on normalized cell concentration remaining after a 2-hour settling period with variations in $\mathrm{pH}$ for Chlorella without cell addition over a growth period of 14 days

\subsubsection{Effect of B. cepacia Cell Addition on the Settleability of Scenedesmus with Varying pH}

During earlier stages in Scenedesmus growth, B. cepacia cell addition slightly improved settling at all three $\mathrm{pH}$ values tested, where a $\mathrm{pH}$ of three improved settling the most (Figure $4.63 \mathrm{~A}$ ). Cell addition at pH 11 using a higher mixing intensity did not improve the settling of Scenedesmus early in growth (Figure $4.63 \mathrm{~A}$ ).

For a later growth stage (14 days), B. cepacia cell addition improved settling only at a pH of 3 and 11, and had a negative effect at pH 7 (Figure $4.63 \mathrm{~B}$ ). At a pH of 11, use of a higher mixing intensity markedly improved the settling of Scenedesmus at a later growth stage (Figure $4.63 \mathrm{~B}$ ). At a pH of 3, a greater effect of cell addition on settling was observed as compared to early growth (Figure $4.63 \mathrm{~B}$ ). 

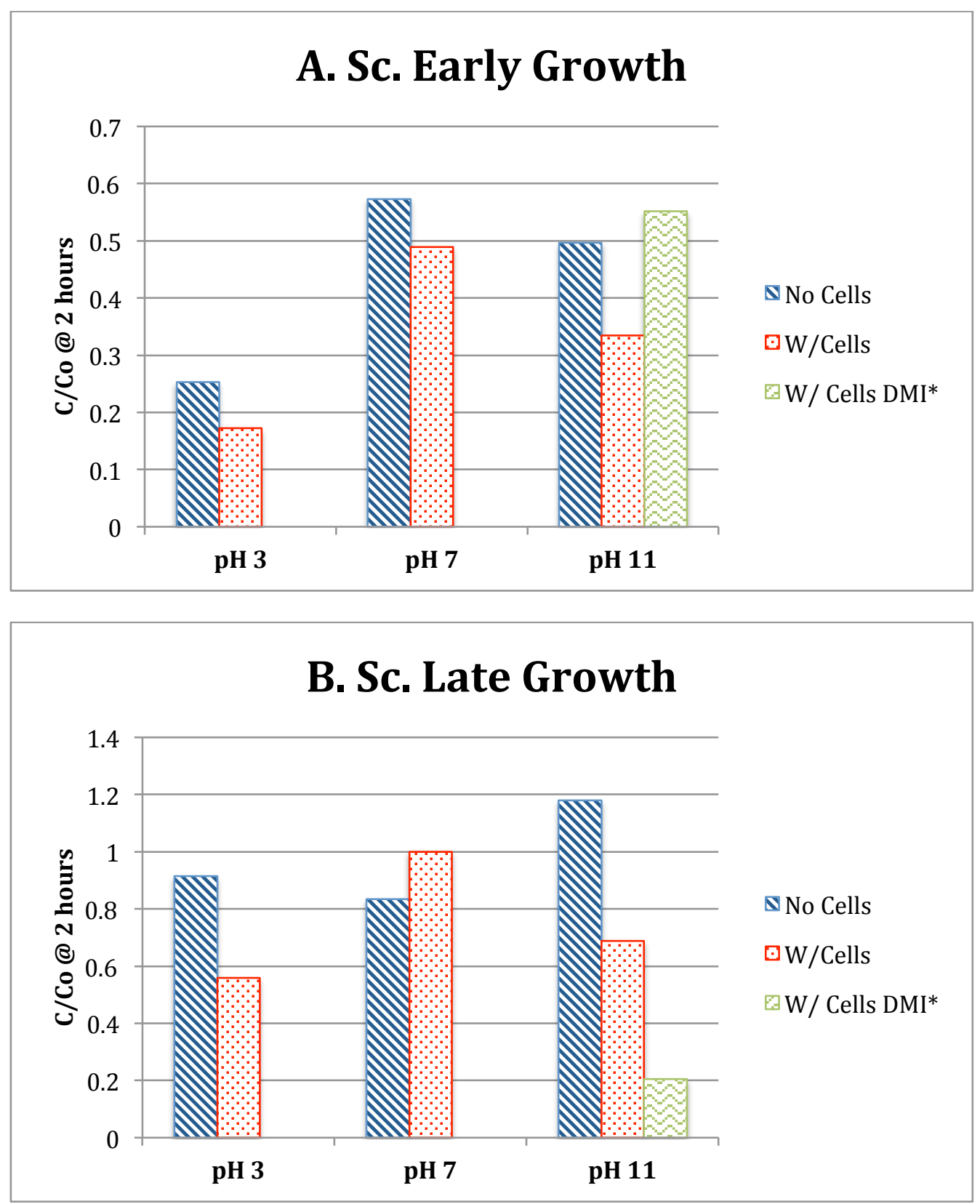

Figure 4.63-Comparison of settling based on normalized cell concentration remaining after a 2-hour settling period for Scenedesmus with B. cepacia cell addition over a wide range in $\mathrm{pH}$ during $A$ ) Early growth (5 days) and B) Late growth (14 days)

* DMI (different mixing intensity)-Indicates the cell addition had a 1,000 rpm initial mixing intensity for 5 minutes followed by a 100-rpm flocculating period for the 25 minutes before settling 


\subsubsection{Effect of B. cepacia Filtrate Addition on the Settleability of Chlorella with Varying pH}

During earlier stages of growth ( 6 days), filtrate addition only minimally improved settling of Chlorella at all pH ranges (Figure 4.64 A). Later in the Chlorella growth curve (14 days), a different trend in effect of filtrate on settling of Chlorella was observed. Filtrate addition at a pH of 11 improved the settleability of Chlorella from $20 \%$ cell removal without filtrate to $40 \%$ removal with filtrate addition (Figure 4.64 B). Filtrate addition at a pH of 7 also improved settling of Chlorella during later stages of growth, but not to the same degree (30\% removal). Filtrate addition at pH 3 actually made settling worse during this later stage of growth. Increasing the mixing intensity with filtrate addition for a $\mathrm{pH}$ of 11 had no impact on settling earlier on in growth, but in later stages of growth the higher mixing intensity made settling worse (Figure 4.64 B). 

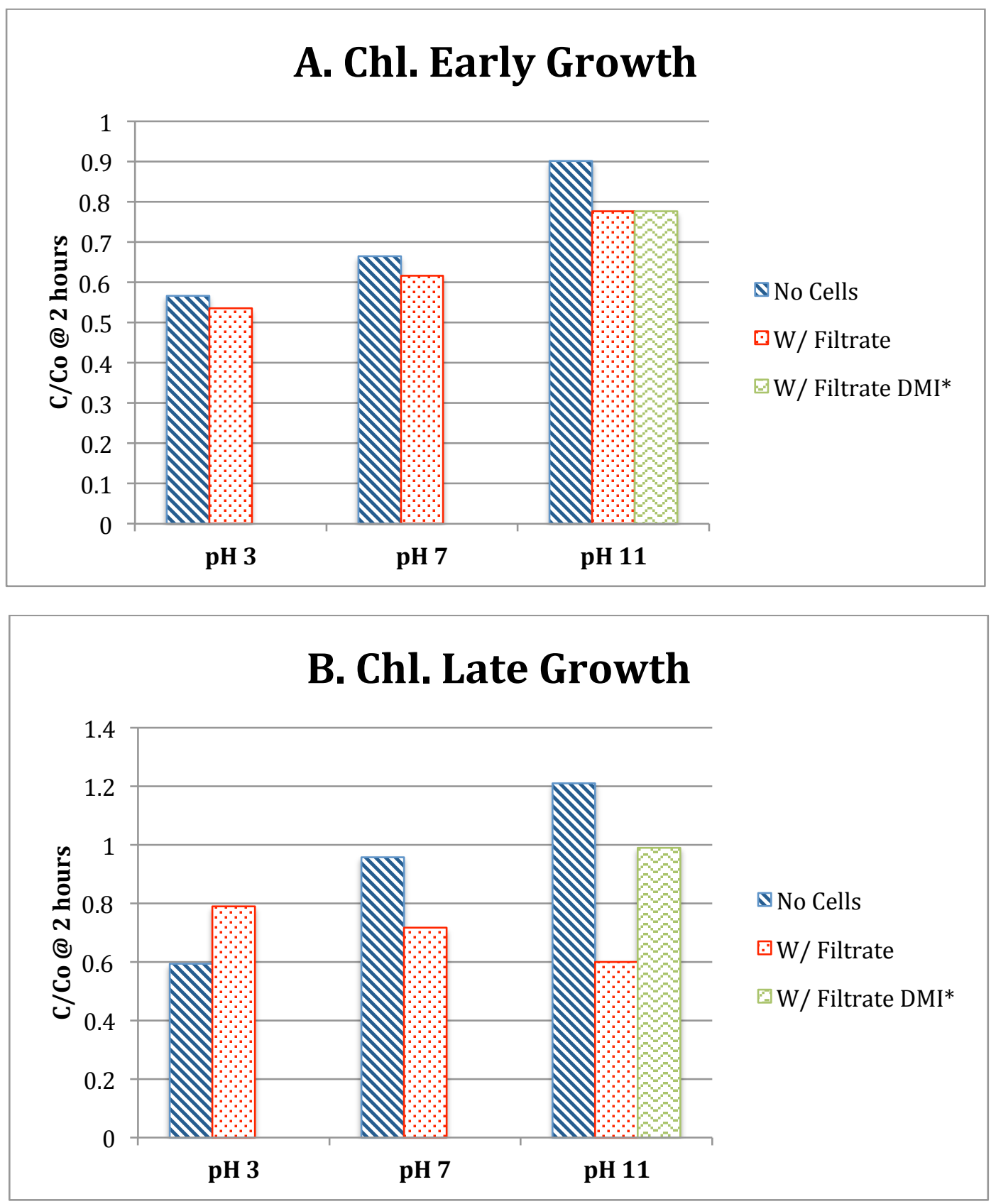

Figure 4.64-Comparison of settling based on normalized cell concentration remaining after a 2-hour settling period for Chlorella over a varied $p H$ range with and without $B$. cepacia filtrate addition during A) Early growth (6 days) and B) Late growth (14 days)

* DMI (different mixing intensity)-Indicates the cell addition had a 1,000 rpm initial mixing intensity for 2 minutes followed by a 100-rpm flocculating period for the remaining 3 minutes before settling 


\subsubsection{EPS Correlation with Settleability of Scenedesmus and Chlorella at Varied pH}

The dissolved EPS produced by the Scenedesmus and B. cepacia cells used for settling tests appears to increase for B. cepacia and to drop slightly for Scenedesmus from 5 to 14 days (Figure 4.65). Settling of Scenedesmus without bioflocculant addition was improved at early stages of growth, when dissolved EPS production was slightly higher. $B$. cepacia cell addition had a greater effect on improving settling later on in growth, and at a higher pH and mixing intensity (Figure 4.63). This shows that larger concentrations of dissolved EPS from B. cepacia improved Scenedesmus settling during later stages of growth. As compared to a neutral $\mathrm{pH}$, a pH of 3 and 11 combined with the larger concentration of dissolved EPS from B. cepacia had some effect in improving the settling of Scenedesmus during later growth stages (Figure 4.63, 4.65).

For the Chlorella experiments with B. cepacia filtrate, both the dissolved EPS of Chlorella and the dissolved EPS of the B. cepacia filtrate were higher during later phases of growth (Figure 4.66). Chlorella settling without filtrate was better at 6 days of growth than at 14 days of growth (Figure 4.64). Since EPS from Chlorella was greater at 14 days than at 6 days (Figure 4.66), this suggests that the increased EPS produced by Chlorella did not improve its own flocculation or settling. However, B. cepacia filtrate addition was much more effective to improve settling for the 14-day culture (at least at pH 7 and 11) (Figure 4.64) when EPS concentration in the filtrate was higher (Figure 4.66). Therefore these preliminary results suggest that dissolved EPS from B. cepacia is a more effective bioflocculant than that of Chlorella, especially at higher $\mathrm{pH}$ ranges and later stages of growth. 


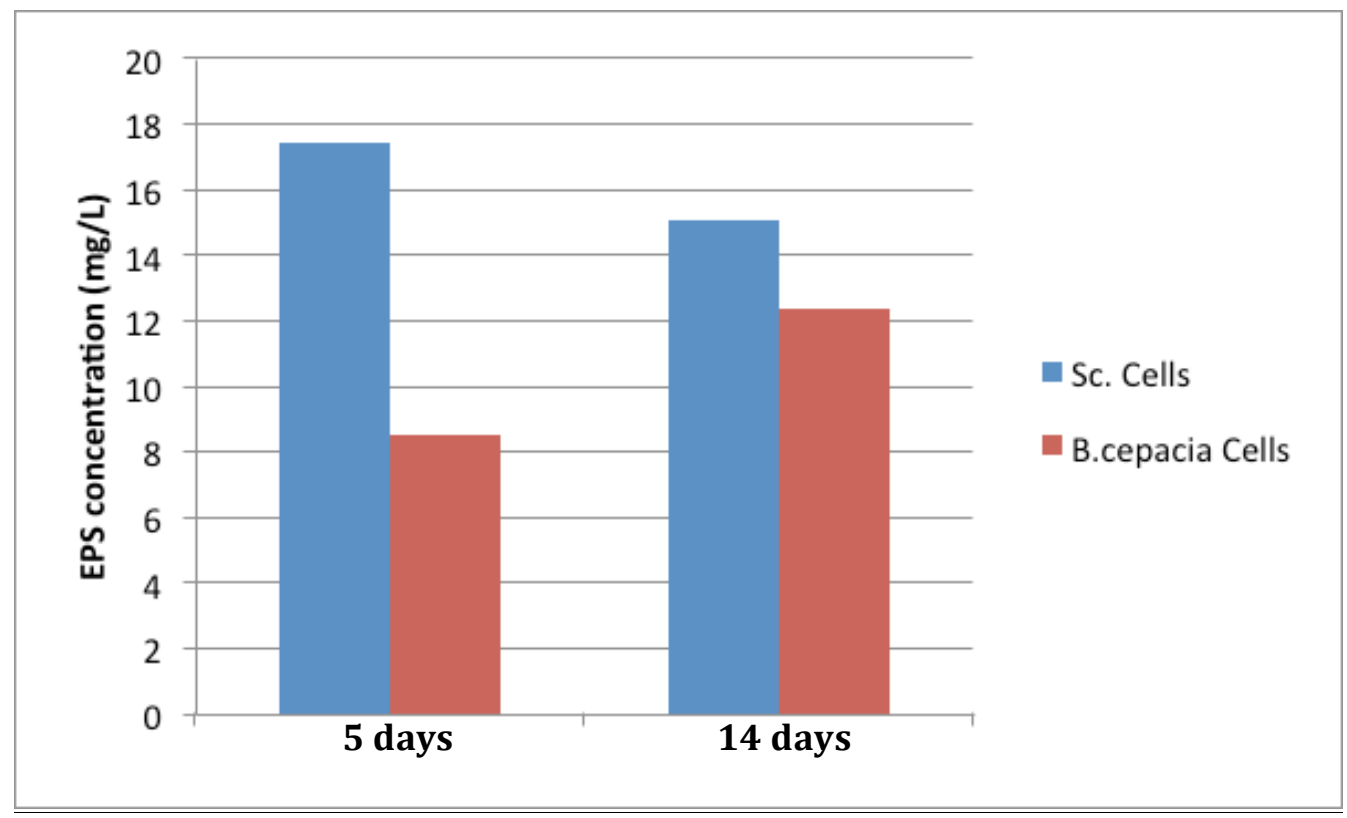

Figure 4.65-Comparison of EPS production for settling tests involving pH changes of both Scenedesmus and B. cepacia cells over 14 days of growth

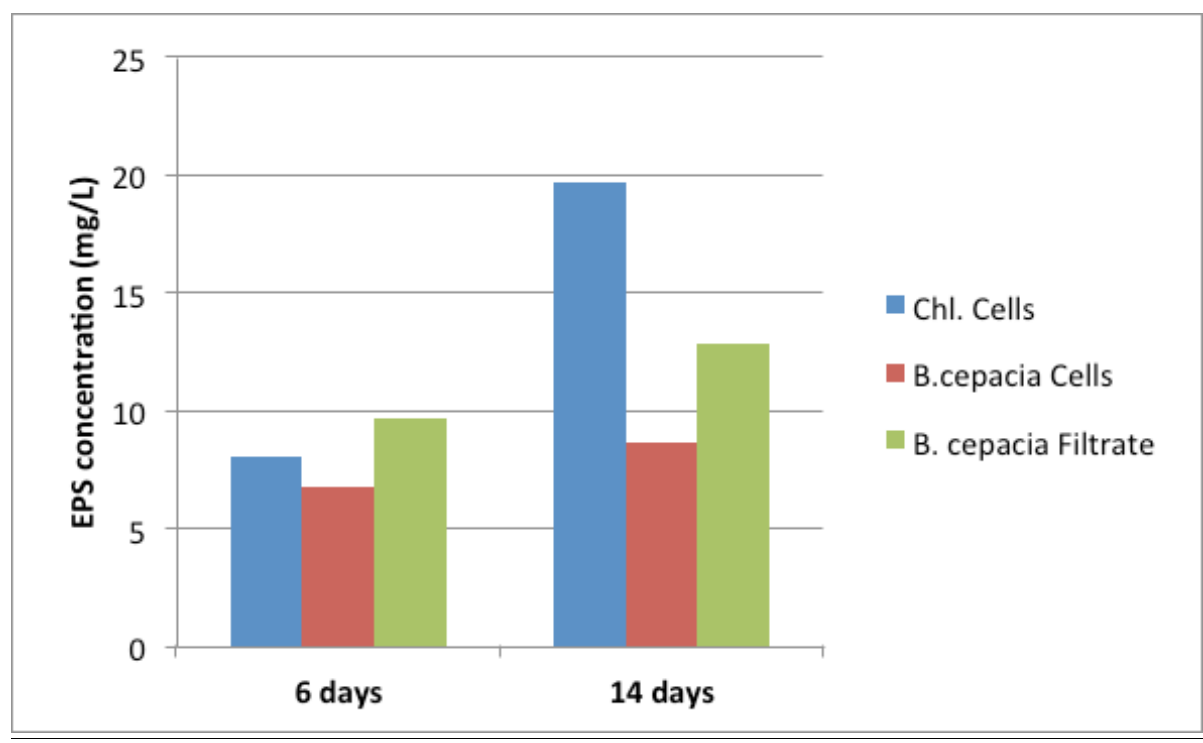

Figure 4.66-Comparison of EPS production for settling tests involving $\mathrm{pH}$ changes of both Chlorella and B. cepacia cells and filtrate over 14 days of growth 


\subsection{Addition of Nutrient Starved B. cepacia Cultures to Improve the Settleability of Scenedesmus and Chlorella}

Nutrient levels during growth of the B. cepacia cultures were reduced to determine if starved B. cepacia cells further improve bioflocculation. In these experiments, the nitrogen and phosphorus in the growth medium were reduced by a factor of ten. The nutrient levels of all algal cultures were not changed as to only observe the effects of nutrient limitation on the bacterial (bioflocculant) cultures. In the literature, nutrient limitation has been shown to increase bacterial biopolymer production and to enhance bioflocculation with algae (Benemann and Oswald, 1996). Thus, algal settling was measured with addition of starved and not starved bacterial cultures and correlated with EPS production.

\subsubsection{Growth Curves of B. cepacia, Scenedesmus, and Chlorella}

Two cultures of Scenedesmus were used for these settling experiments. Growth of these two cultures differed in that growth of Culture 2 was faster than growth of Culture 1 (Figure 4.67). The growth of the Chlorella culture used showed similar behavior to previous growth (Figure 4.68). Growth increased slowly into late stationary phase around 20 days of growth, which is characteristic of previously grown Chlorella cultures.

Growth of the B. cepacia bacterial cultures used for addition to Scenedesmus cells is shown in Figure 4.69. Starved cultures grew much better than the non-starved cultures as the starved cultures reach a peak at an optical density of 0.3 as compared to about 0.18 . Different B. cepacia cultures were grown for the Chlorella experiments. As compared to the bacterial cultures used for Scenedesmus, growth of the non-starved culture seemed much better than the starved culture used (Figure 4.70). However, data for the nutrient starved culture of B. cepacia used in Chlorella settling tests was missing between 4 to 8 days of growth, which may suggest that growth was possibly the same or higher than the non- 
starved culture. Also, data for the non-starved culture is missing past Day 7, making it difficult to compare the growth of nutrient starved and non-starved cultures growth in later stages.

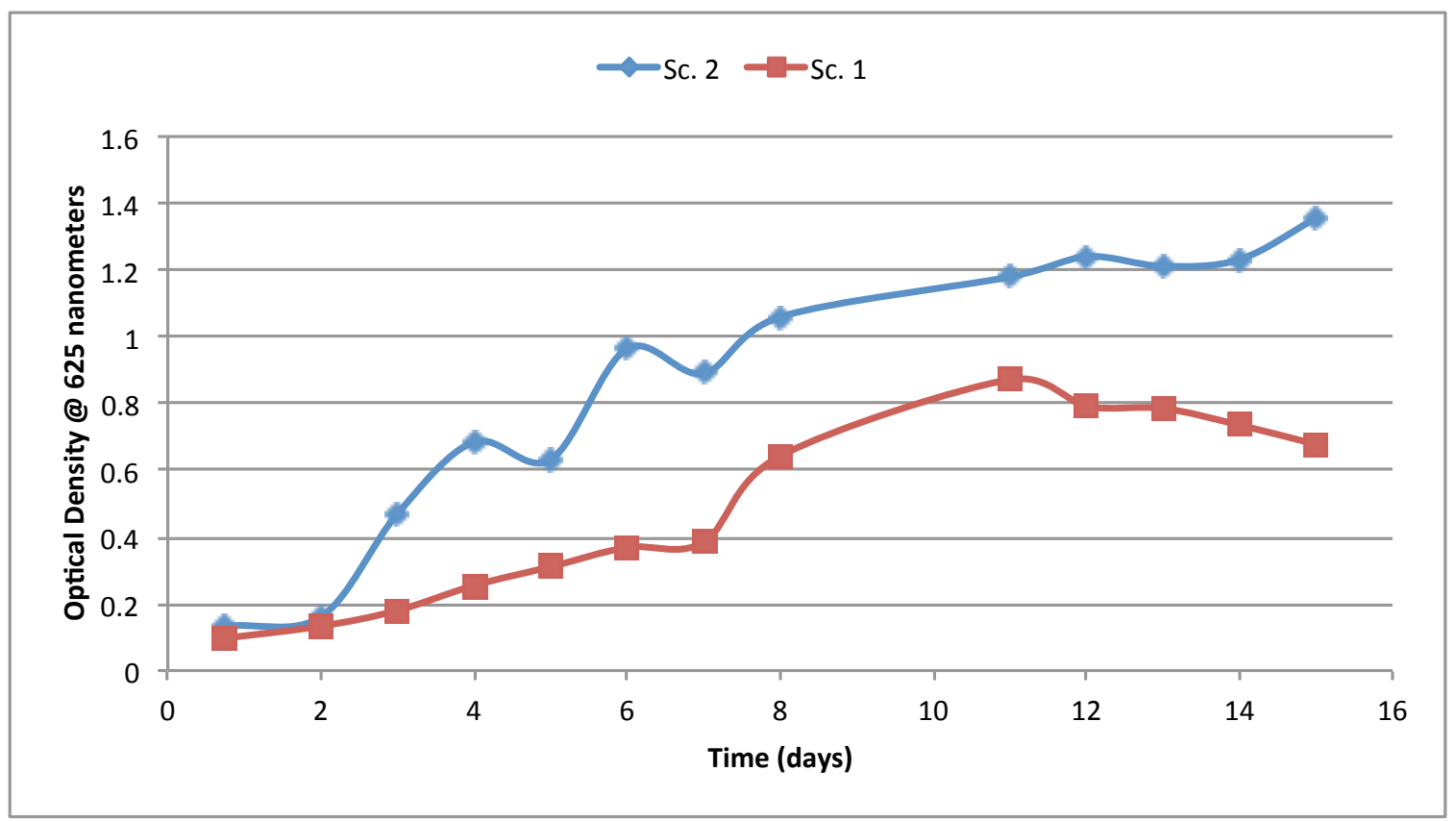

Figure 4.67-Growth curve results for Scenedesmus Cultures 1 and 2 used in bacterial nutrient starved settling tests

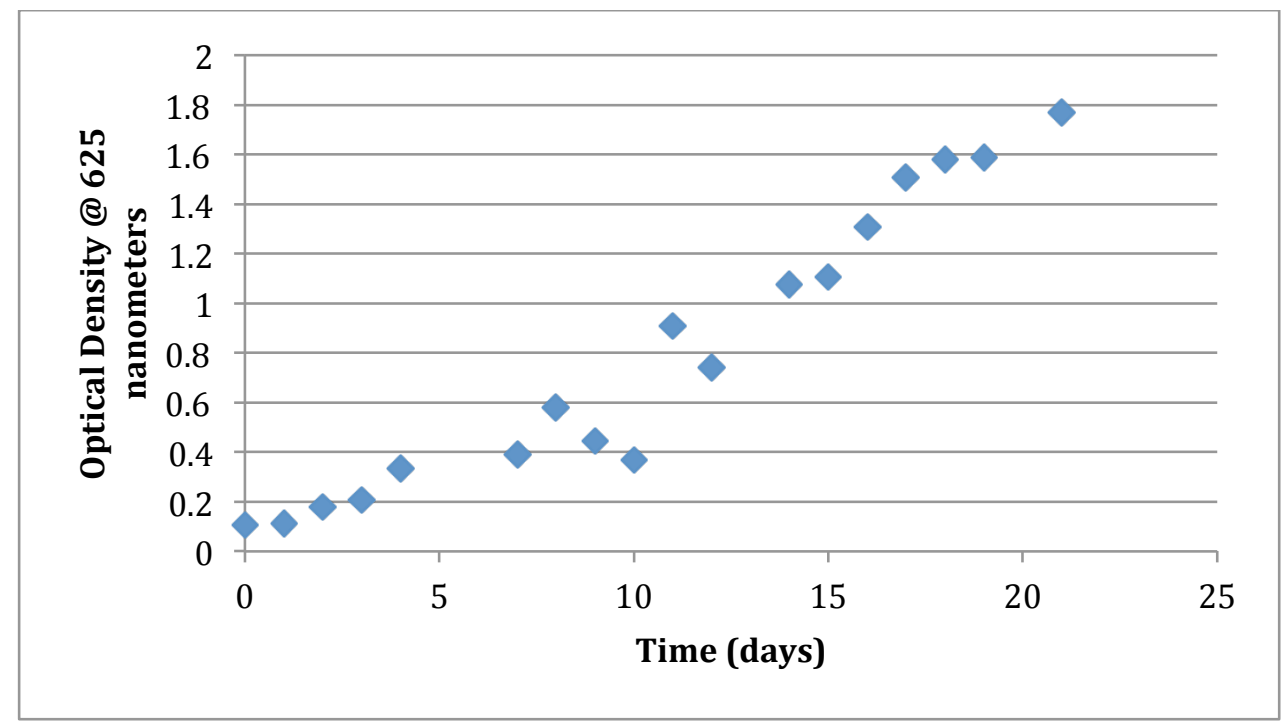

Figure 4.68 -Growth curve results for the Chlorella culture used in bacterial nutrient starved settling tests 


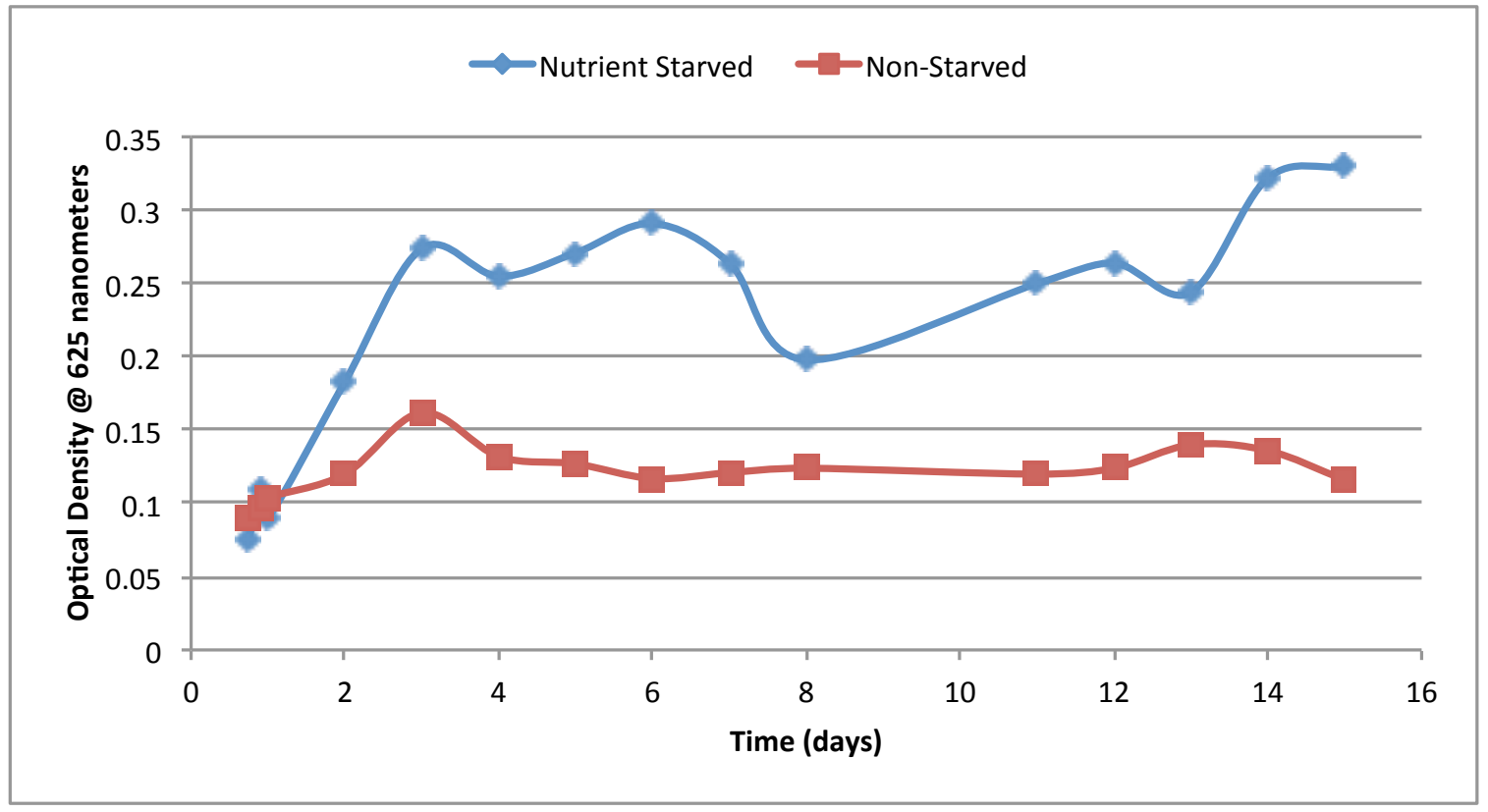

Figure 4.69-Growth curve results for nutrient starved and non-starved B. cepacia cultures used for Scenedesmus settling tests

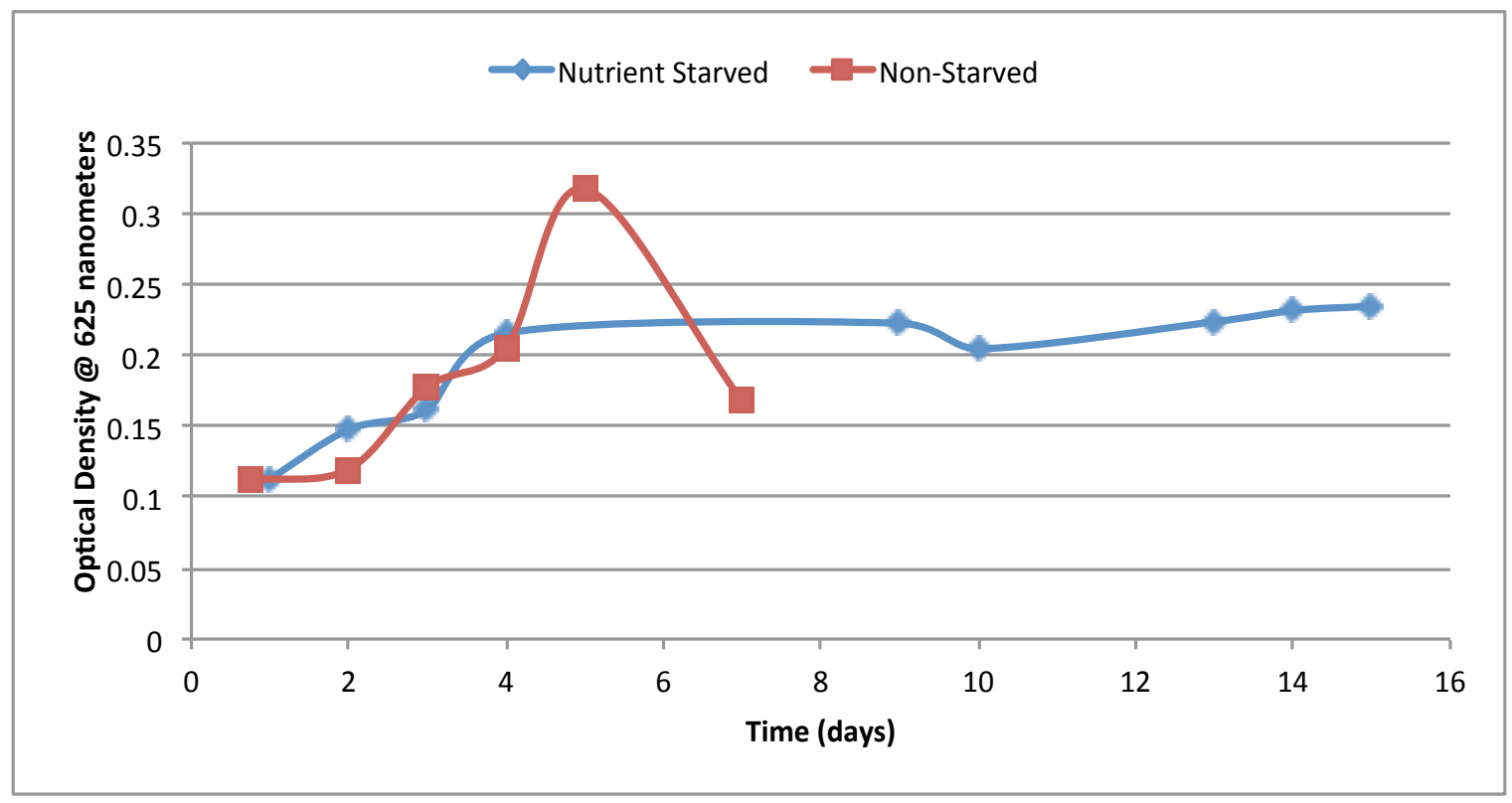

Figure 4.70-Growth curve results for nutrient starved and non-starved B. cepacia cultures used for Chlorella settling tests 


\subsubsection{Effect of Starved B. cepacia Cell addition on the Settleability of Scenedesmus}

Two Scenedesmus cultures were studied for this investigation to provide replicates of the data obtained and error bars in Figure 4.71 indicate which tests were replicated. At 6 days of growth, the non-starved and starved B. cepacia cells both improved settling of Scenedesmus to the same extent (Figure 4.71). At 15 days of growth, the non-starved cells again improved settling of Scenedesmus, but the starved cells did not (Figure 4.71). These results suggest that reducing the Nitrogen and Phosphorus nutrient levels did not provide improved settling. However, these preliminary experiments were conducted only with an arbitrary reduction in Nitrogen and Phosphorus, and it is not known if the cultures were truly nutrient limited (i.e. nutrient levels in the medium were not tested). In addition, the different (higher) mixing intensity used did not affect settling of Scenedesmus for the 6-day cultures or the 15-day cultures (Figure 4.71).

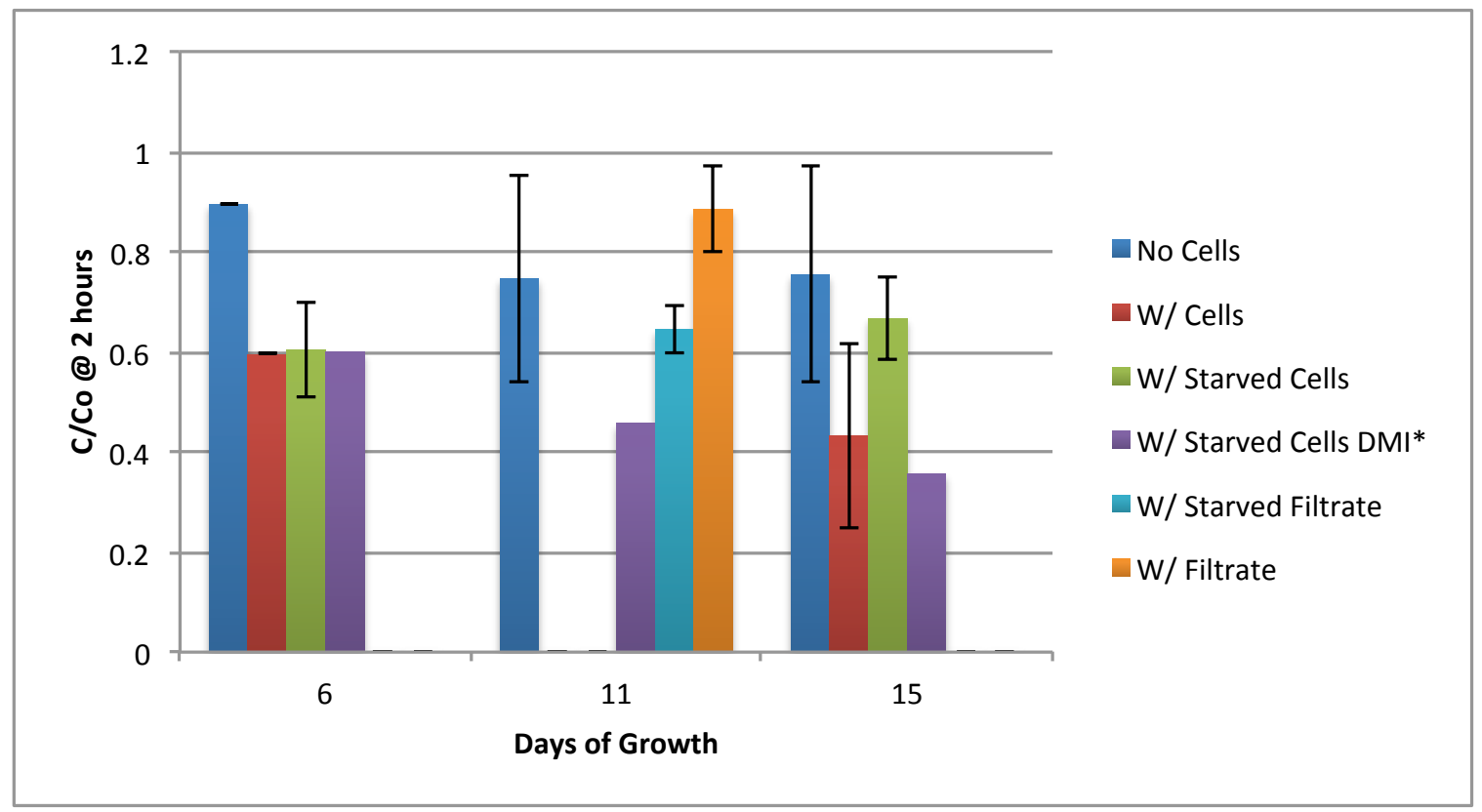

Figure 4.71-Comparison of settling based on normalized cell concentration remaining after a 2-hour settling period between the addition of starved cells, non starved cells, no cell addition, and starved filtrate addition for Scenedesmus 2 over 15 days of growth. Error bars indicate which tests were replicated

* DMI-Indicates the cell addition had a 1,000 rpm initial mixing intensity for five minutes followed by a 100-rpm flocculating period for the remaining twenty five minutes before settling 


\subsubsection{Effect of Nutrient Starved B. cepacia Filtrate Addition on the Settleability of Chlorella}

For Chlorella, the effect of filtrate from starved and non-starved B. cepacia cultures on settling was tested. Replicates were made for starved and non-starved bacterial filtrate addition, as well as settling of Chlorella without bioflocculant addition. Early on in growth, the addition of starved B. cepacia filtrate improved settling of Chlorella as compared to nonstarved filtrate, but this settling was no better than Chlorella without any filtrate (Figure $4.72 \mathrm{~A}$ ). Using $1 / 2$ the dosage of filtrate improved Chlorella settling the most early on in growth, with starved cultures helping the most (Figure $4.72 \mathrm{~A}$ ). However, since a different mixing intensity was used for the $1 / 2$ filtrate with starved cells, this cannot be directly compared. Non-starved cell addition did not have an effect on Chlorella settling during early growth, and starved cell addition actually made settling worse than no cell addition (Figure 4.72 A). Using a different mixing intensity early in growth increased settling of Chlorella with starved cells and decreased settling with non-starved cells, but neither of these settling results was better than Chlorella settling alone (Figure $4.72 \mathrm{~A}$ ).

Later in growth, filtrate additions had little effect on Chlorella settling using either starved or non-starved B. cepacia cultures (Figure 4.72 B). Chlorella settled slightly better with non-starved B. cepacia filtrate than with starved B. cepacia filtrate (Figure 4.72 B). Again, later in growth, halving the filtrate dosage improved settling of Chlorella compared to a full dose, but the settling was still no better than the control with no filtrate addition (Figure 4.72 B). Using a different mixing intensity with non-starved filtrate greatly improved the settling of Chlorella during later stages of growth as compared to starved filtrate addition at this same mixing intensity. Finally, similar to early growth, starved and non-starved cell addition had little or no effect on Chlorella settling later in growth (Figure $4.72 \mathrm{~B})$. 

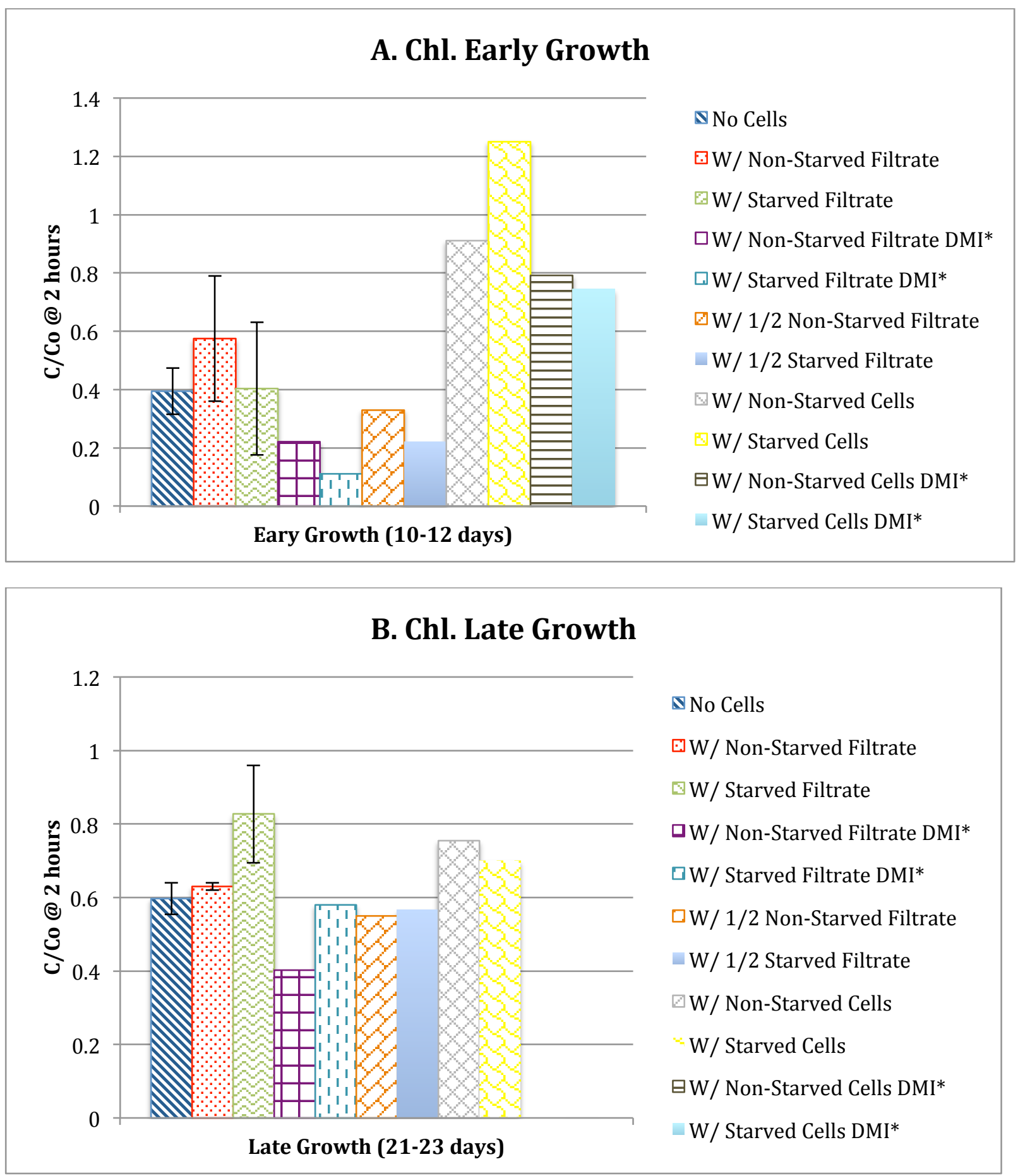

Figure 4.72-Comparison of settling of Chlorella with and without bacterial bioflocculant cell/filtrate addition (starved for nutrients and not-starved for nutrients) based on normalized cell concentration remaining after a 2-hour settling period for Chlorella during A) Early growth (10-12 days) and B) Later growth (21-23). Error bars indicate which settling tests were replicated

* DMI-Indicates the cell addition had a 1,000 rpm initial mixing intensity for 2 minutes followed by a 100-rpm flocculating period for the remaining three minutes before settling 


\subsubsection{EPS Production by Nutrient-Starved B. cepacia cells, Chlorella, and Scenedesmus and Correlation with Improved Settling}

Starved bacterial cells resulted in a higher production of EPS as compared to nonstarved bacterial cells, especially at the beginning of the growth curve (Figures 4.73). This result may be due to the lack of nutrients encountered by the starved cells after around 12 to 15 days of growth. The highest EPS production was observed around 12 days of growth (Figures 4.73). The second highest peak was observed after 48 to 72 hours or once the bacteria encountered early stationary phase of growth (Figure 4.73). Overall, the nutrient starved cells had a higher average EPS production of $9.5 \mathrm{mg} / \mathrm{L}( \pm 4.4 \mathrm{mg} / \mathrm{L})$ as compared to $5.5 \mathrm{mg} / \mathrm{L}( \pm 3.1 \mathrm{mg} / \mathrm{L})$ for the non-starved cells.

The amount of EPS produced is about the same for each Scenedesmus culture on each day of growth (Figures 4.74 and 4.75). Even though EPS production values were similar, measured dry weight values of the second Scenedesmus culture show that it was denser, reaching about $700 \mathrm{mg} / \mathrm{L}$ during mid to late stationary phase of growth (as compared to 400 for Scenedesmus 1). Thus, it appears EPS production was not affected by culture density for Scenedesmus.

Scenedesmus settling increased across the growth curve without cell addition (Figure 4.71), which agrees with earlier observations. EPS production for Scenedesmus was higher later in growth, suggesting that settling was improved by its own dissolved EPS. Results also show that EPS concentrations of Scenedesmus were not significant early on in growth, which further suggest that Scenedesmus may favor the production of its own dissolved EPS to improve settling (Figure 4.75). This result confirms the observations from Experiments 2 and 3. 
According to Figure 4.71, nutrient starved cells either had no effect or made Scenedesmus settling worse compared to non-starved cell addition. Even though, on average, nutrient starved B. cepacia cells produced more EPS, early in growth there was no improvement in Scenedesmus settling with starved B. cepacia versus non-starved B. cepacia cells. Moreover, during the later growth phase (15 days), settling of Scenedesmus was better with non-starved cell addition. Further experiments would be required with more nutrient conditions to completely understand the role of nutrient starvation on EPS production and its effect on algal settling.

EPS production of Chlorella increased throughout growth, peaking in late stationary phase for both trials (Figure 4.76). EPS concentrations in filtrate from starved and nonstarved B. cepacia cells were similar-both in early and late growth (Figure 4.76). Relative to non-starved filtrate, starved filtrate additions improved Chlorella settling in early growth (10-12 days), but not during late growth (21-23 days) (Figure 4.72). Since EPS production was not very different for the starved and non-starved cells, differences in EPS production are not likely to be the cause of the different effects of bacterial cell starvation. 

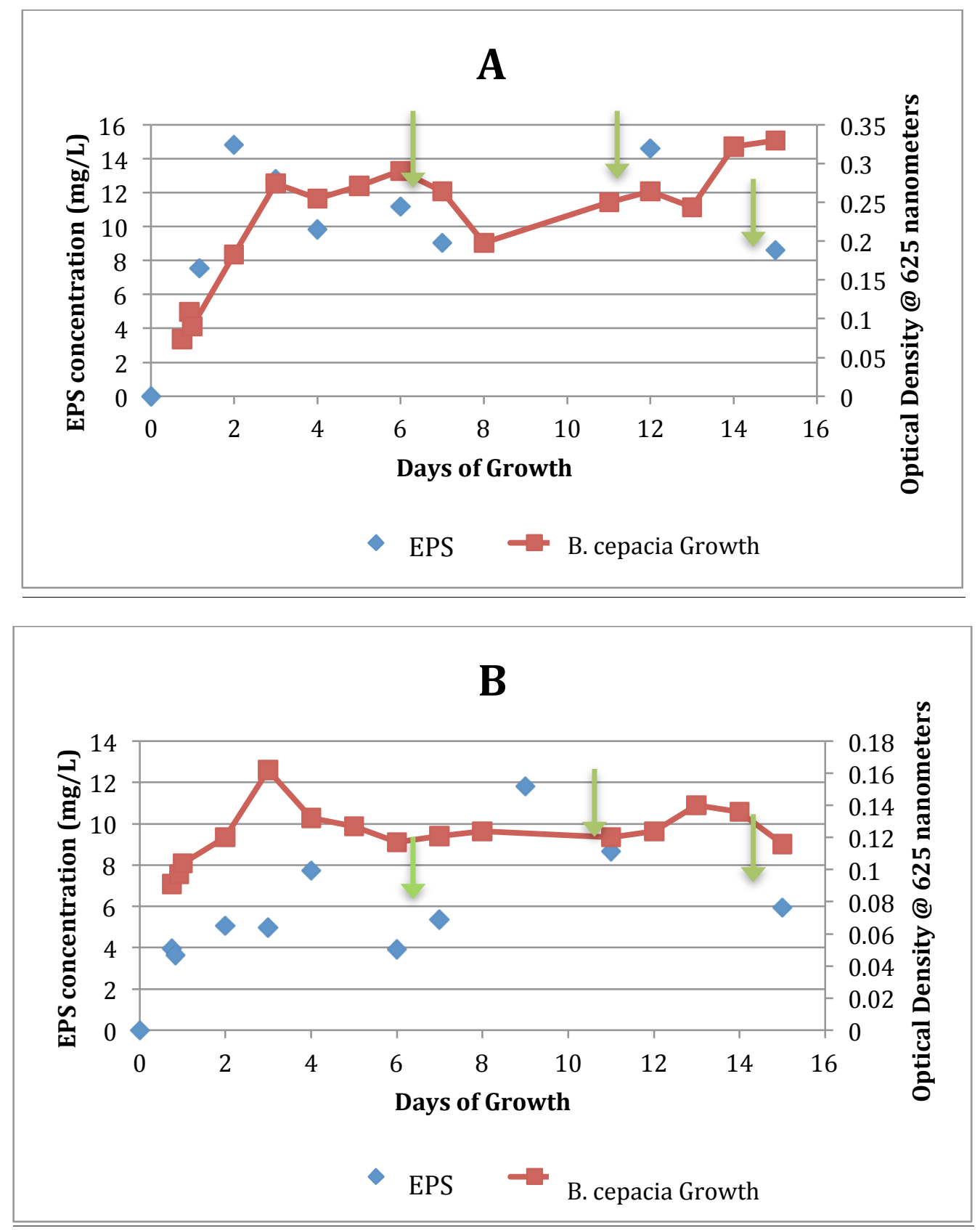

Figure 4.73-EPS production of A) nutrient starved B. cepacia and B) non-starved $B$. cepacia with optical density measurements over the growth curve (green arrows indicate when settling tests were run) 

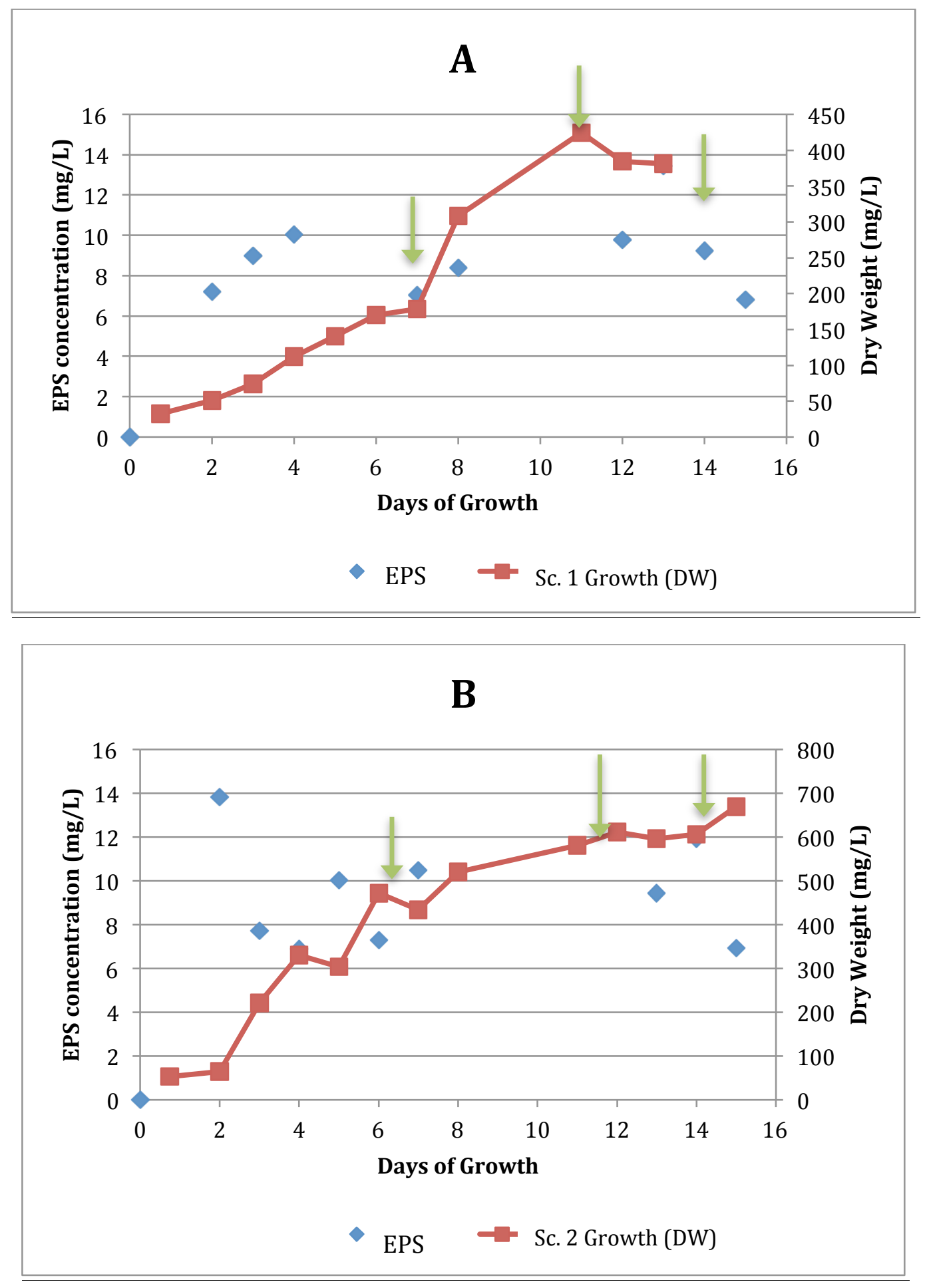

Figure 4.74-EPS production of A) Scenedesmus Culture 1 and B) Scenedesmus Culture 2 with dry weight measurements over the growth curve (green arrows indicate when settling tests were run) 


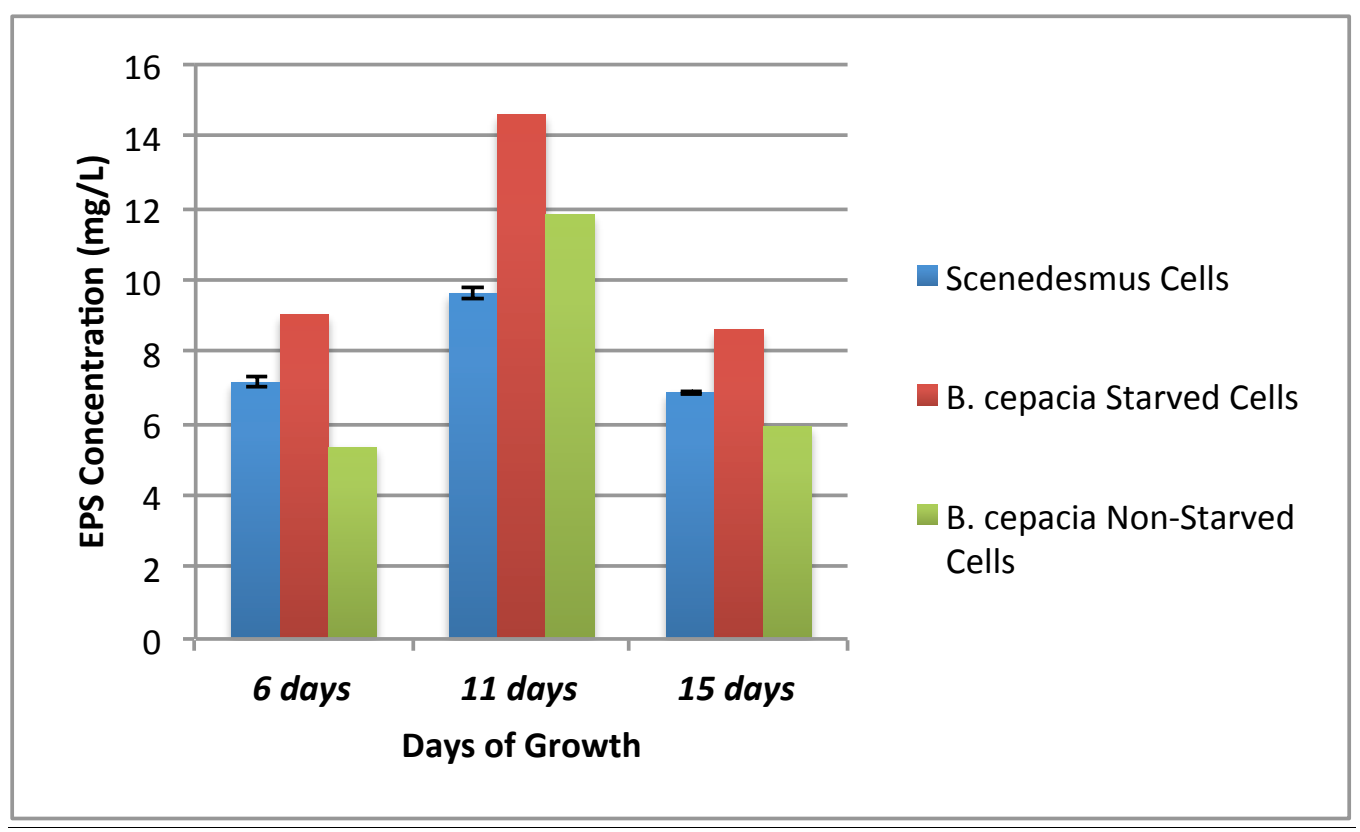

Figure 4.75-Summary of EPS concentrations (Figure 4.117-4.120) plotted over 15 days of growth for both Scenedesmus and B. cepacia cultures used during settling tests. Samples were taken from each culture separately before settling tests were run. Error bars indicate differences in EPS production of both Scenedesmus cultures used

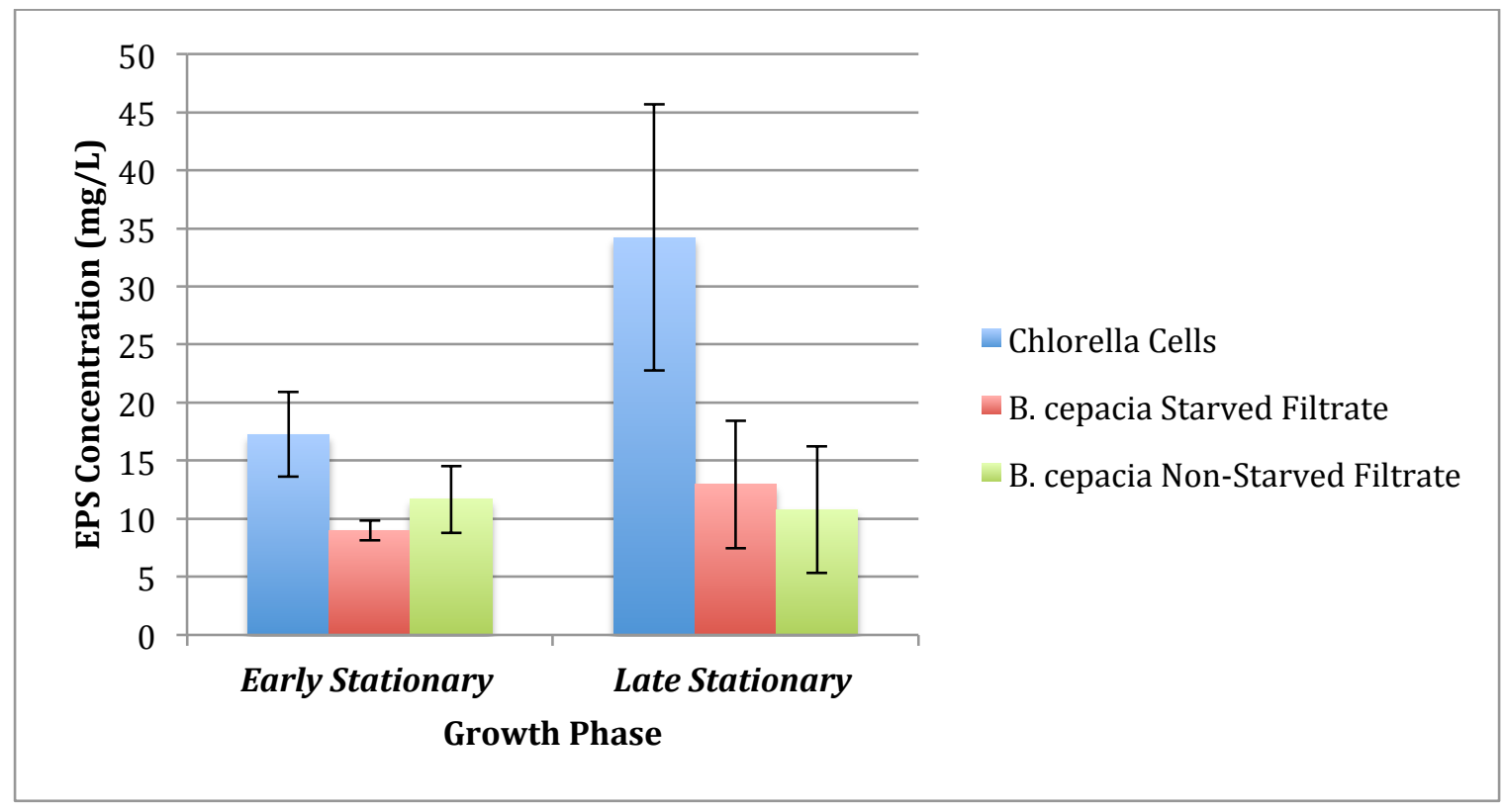

Figure 4.76-Summary of EPS concentrations of Chlorella and B. cepacia cultures used in settling tests for early stationary growth of Chlorella (10-12 days) and later stationary growth of Chlorella (21-23 days). Samples were taken from each culture separately before settling tests were run. Error bars indicate replicates of EPS measurements for both settling experiments 


\subsection{Effect of Carbon Dioxide Addition on the Settleability of Scenedesmus and Chlorella}

Studies covered in the background section suggest that carbon dioxide supplementation in high-rate algal wastewater ponds helped increase the settling efficiency of the dominant algal species present in the wastewater (Craggs, 2011). Past studies at Cal Poly, San Luis Obispo have also indicated that wastewater algal species, when supplemented with concentrations of carbon dioxide below $5 \%(\mathrm{v} / \mathrm{v})$ exhibit increased growth and culture density (Lundquist, 2010). To explore the effect of carbon dioxide on algal settling, this part of the research measured settling efficiencies of both Scenedesmus and Chlorella cultures with and without carbon dioxide supplementation (without bioflocculant addition) (Section 4.72, 4.73). In addition, the effect of B. cepacia bioflocculant addition (filtrate and cells) on increasing the settleability was studied using cultures of algae grown with and without the addition of carbon dioxide (Section 4.74, 4.75). Finally, the correlation between EPS production, improved algal settling and carbon dioxide augmentation was studied (Section 4.76).

\subsubsection{Growth Curves of B. cepacia, Scenedesmus and Chlorella}

Settling of Scenedesmus and Chlorella for a control culture grown on air (without carbon dioxide addition), and cultures grown with 5\% carbon dioxide mixed with air during an 8-hour illuminated period constantly. During this period, the $\mathrm{pH}$ was maintained above 7. Just before settling tests, the amount of carbon dioxide input was increased as follows. The first settling test for both Scenedesmus and Chlorella (during early stationary growth) involved a four-hour constant addition of carbon dioxide prior to settling. The second settling tests used a larger supplementation ( 24 to 48 hours) to possibly induce further flocculation and enhance settleability. 
Scenedesmus cultures with and without carbon dioxide supplementation reached about the same density during all growth phases (Figure 4.77). Chlorella growth was also similar with and without carbon dioxide (Figure 4.78).

Five B. cepacia cultures were grown to provide cells and filtrate for bioflocculation experiments as seen in the figures below (Figure 4.79-83). Both 4.79 and 4.80 were used for settling tests with control cultures of Chlorella (no carbon dioxide addition), where Figure 4.79 culture is not starved. All of the bacterial cultures used were free from contamination and exhibited similar trends in growth to previous results. In addition, all 5 cultures reached an optical density of about 0.2 , indicating minimal growth. For bacterial cultures in 4.80 to 4.83 , missing data between days 4 and 8 accounts for the abnormal representation of growth.

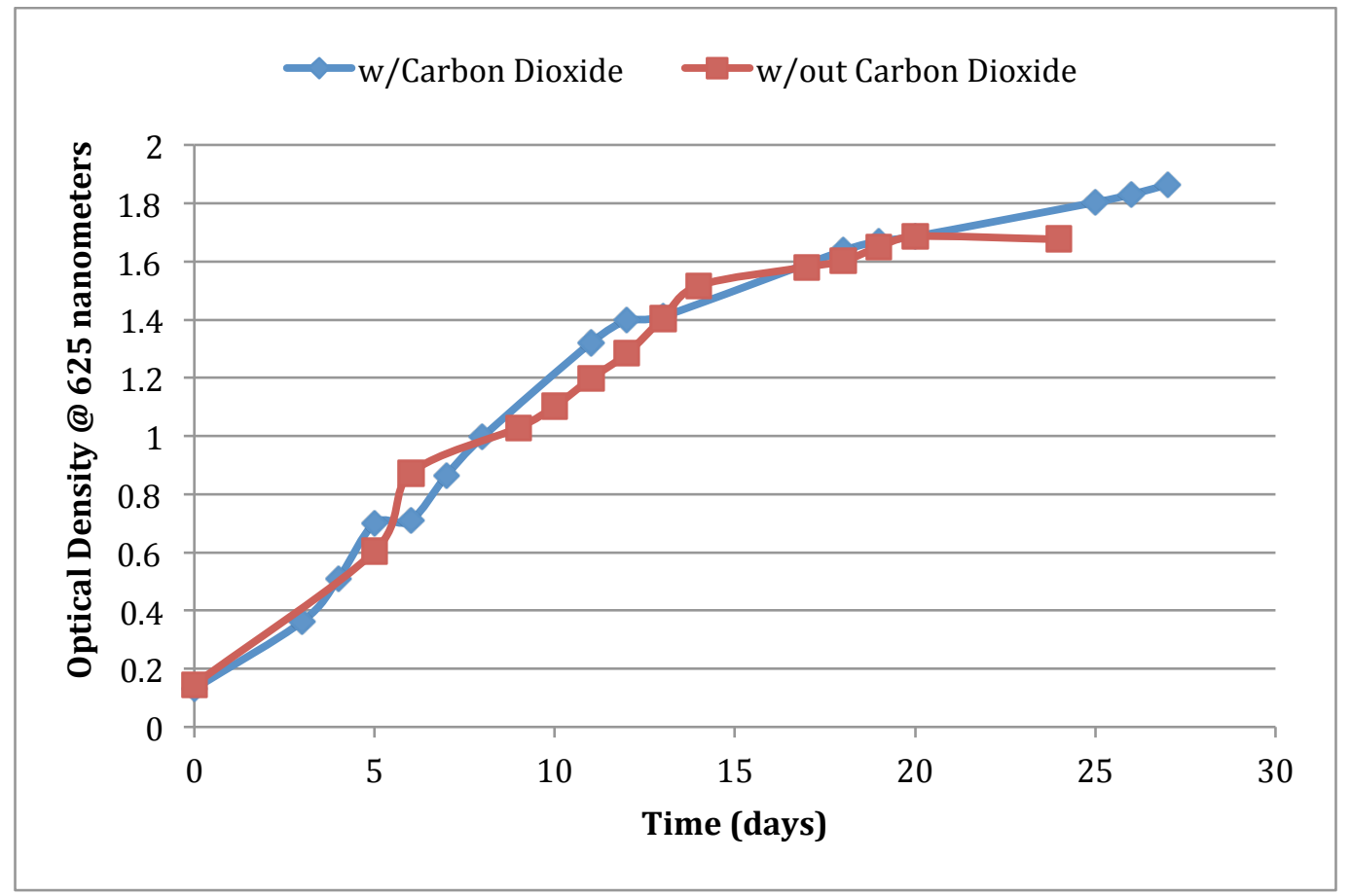

Figure 4.77-Effect of carbon dioxide on growth for Scenedesmus cultures 


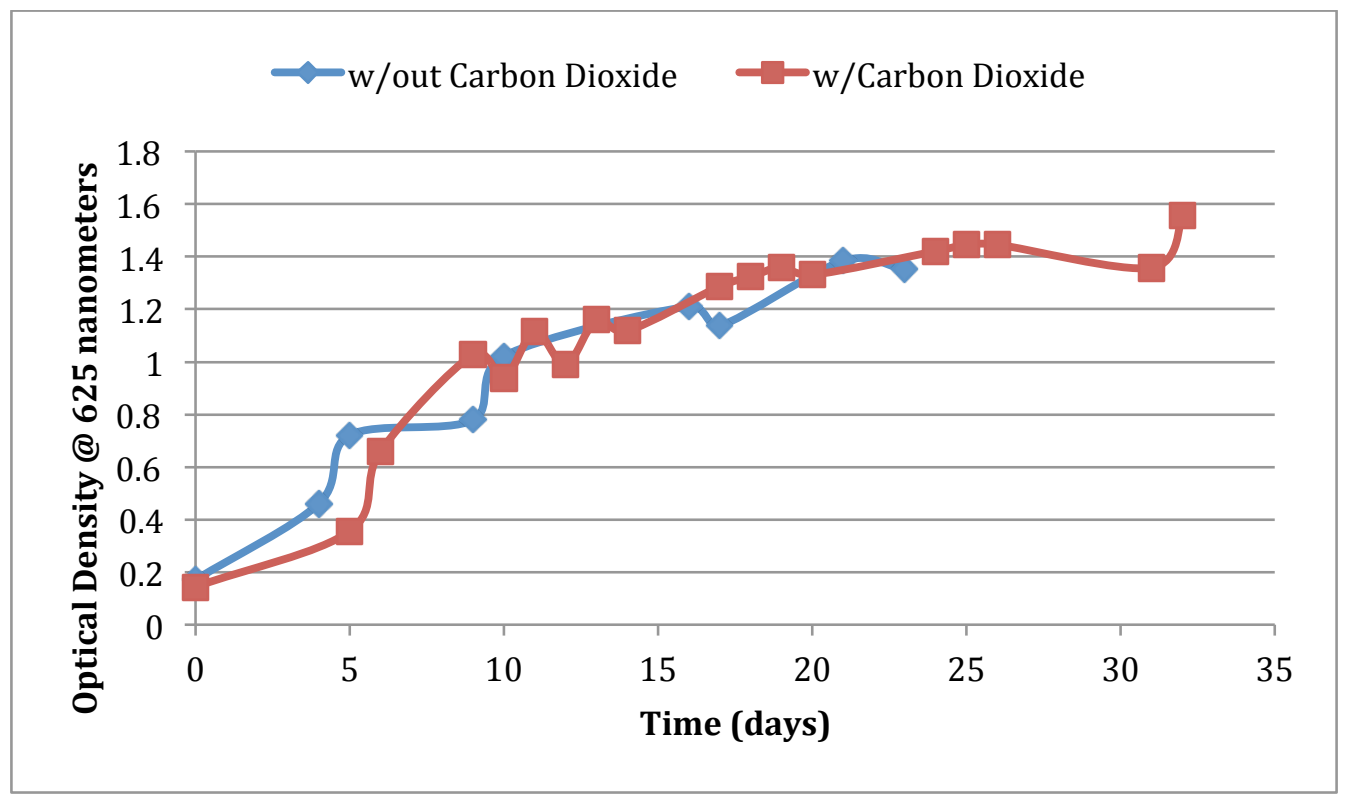

Figure 4.78-Effect of carbon dioxide on growth for Chlorella vulgaris cultures

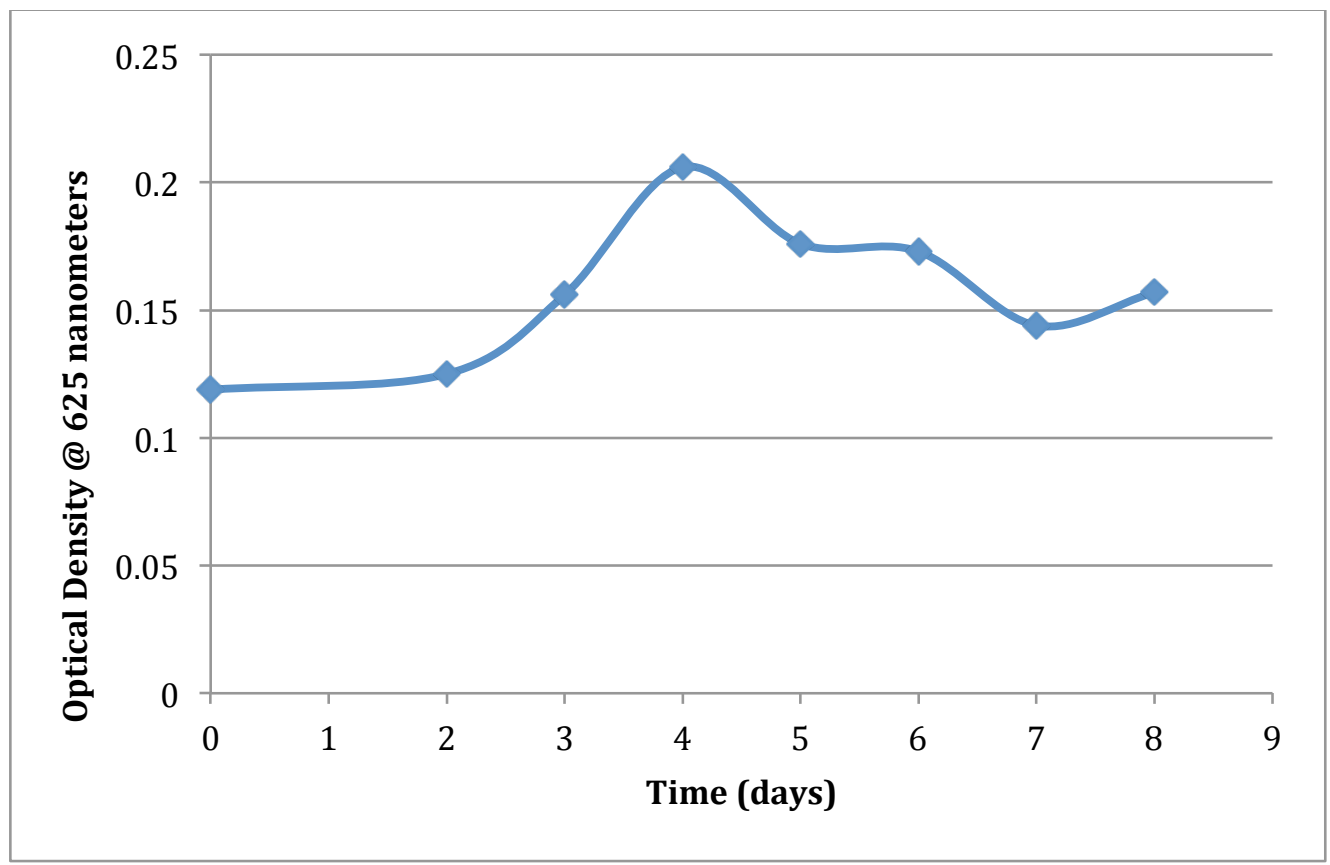

Figure 4.79-Growth of non-starved B. cepacia culture for use in Chlorella settling tests without carbon dioxide addition 


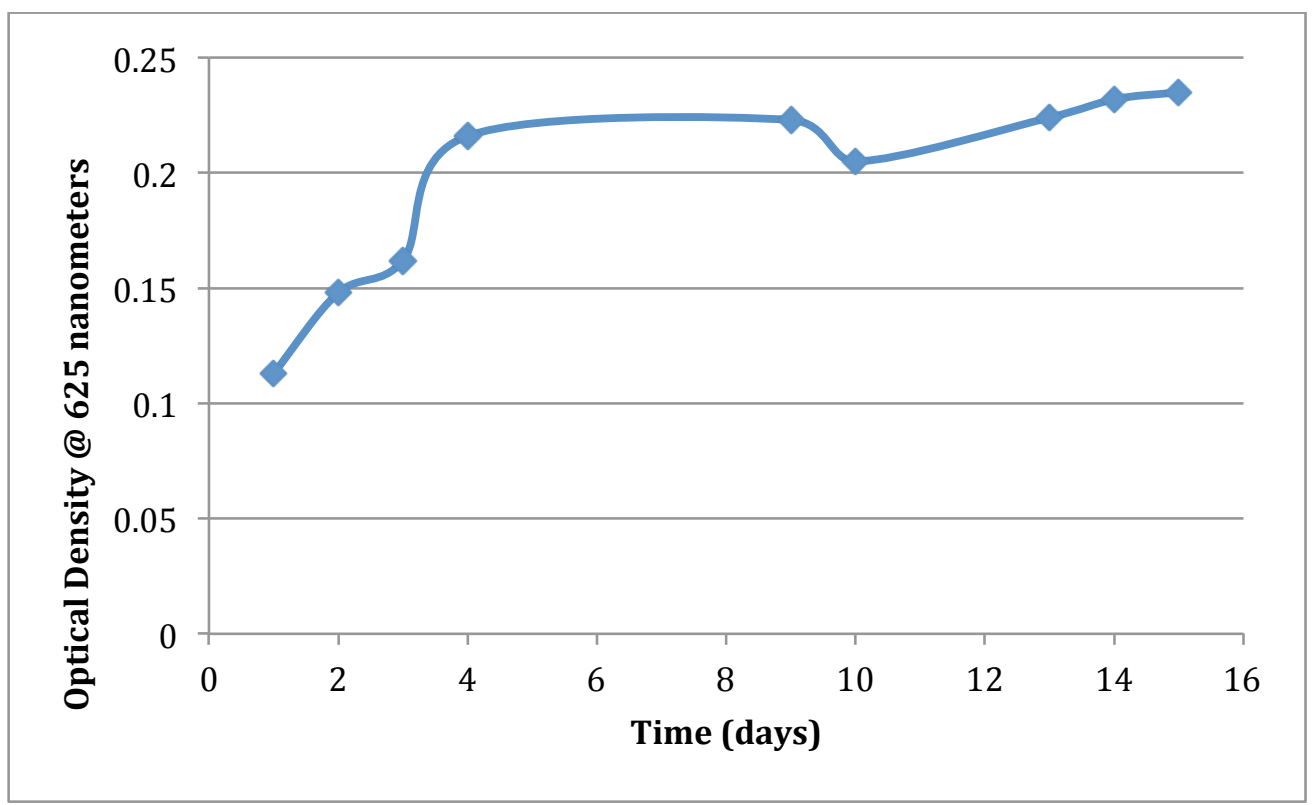

Figure 4.80-Growth of starved B. cepacia culture for use in Chlorella settling tests without carbon dioxide addition

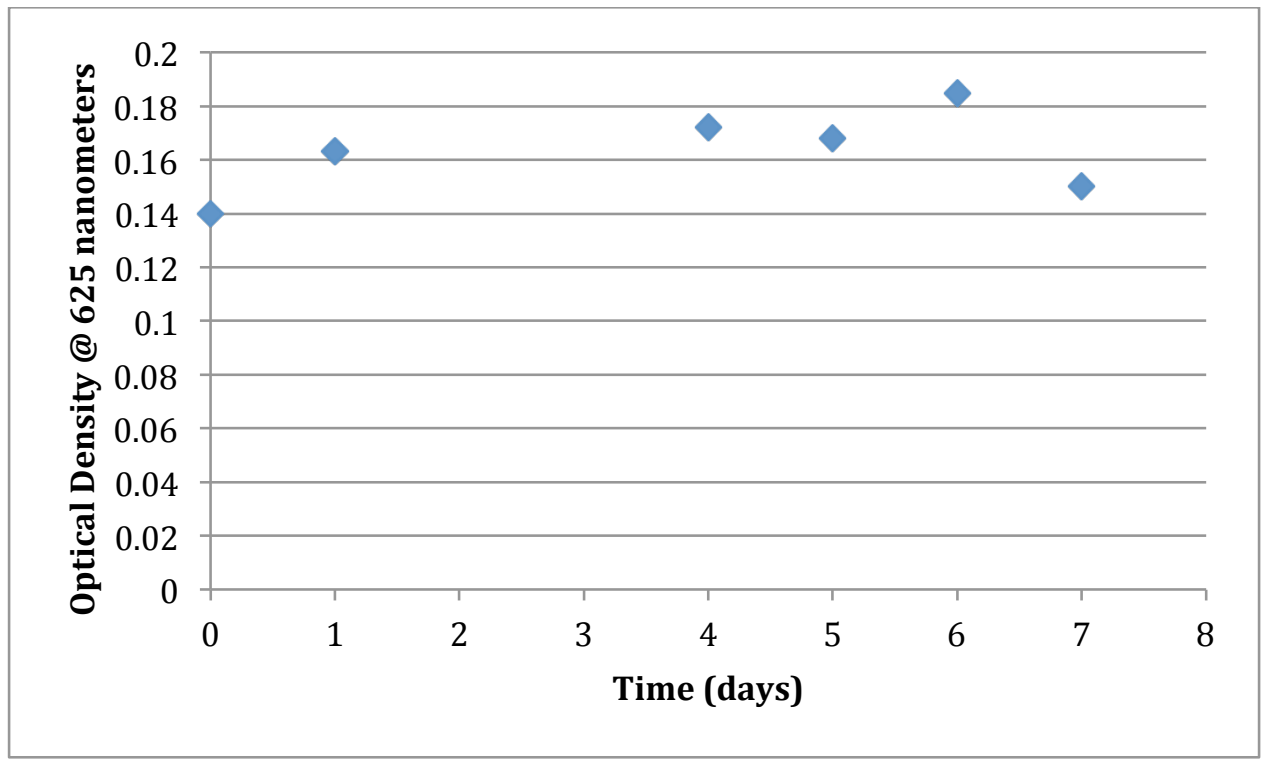

Figure 4.81-Growth of B. cepacia culture for use in Scenedesmus settling tests without carbon dioxide addition 


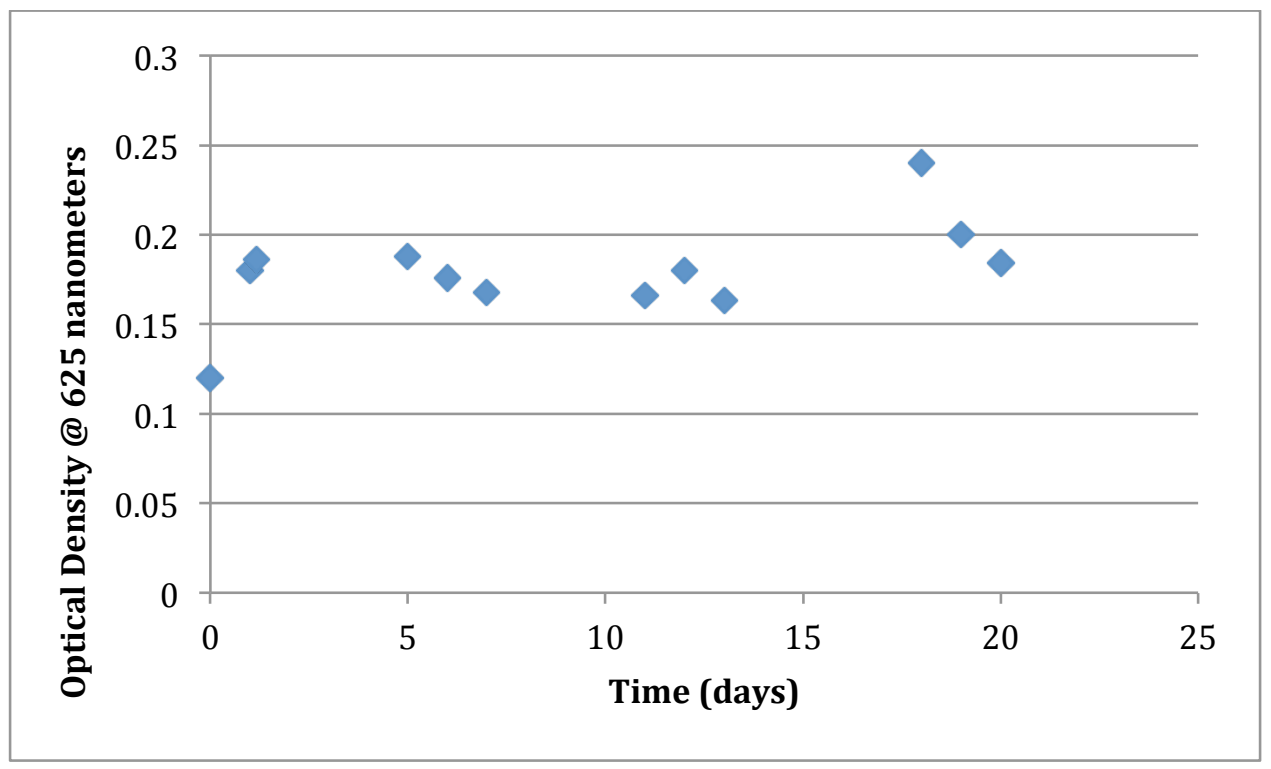

Figure 4.82-Growth of B. cepacia culture for use in Scenedesmus and Chlorella settling tests with carbon dioxide addition

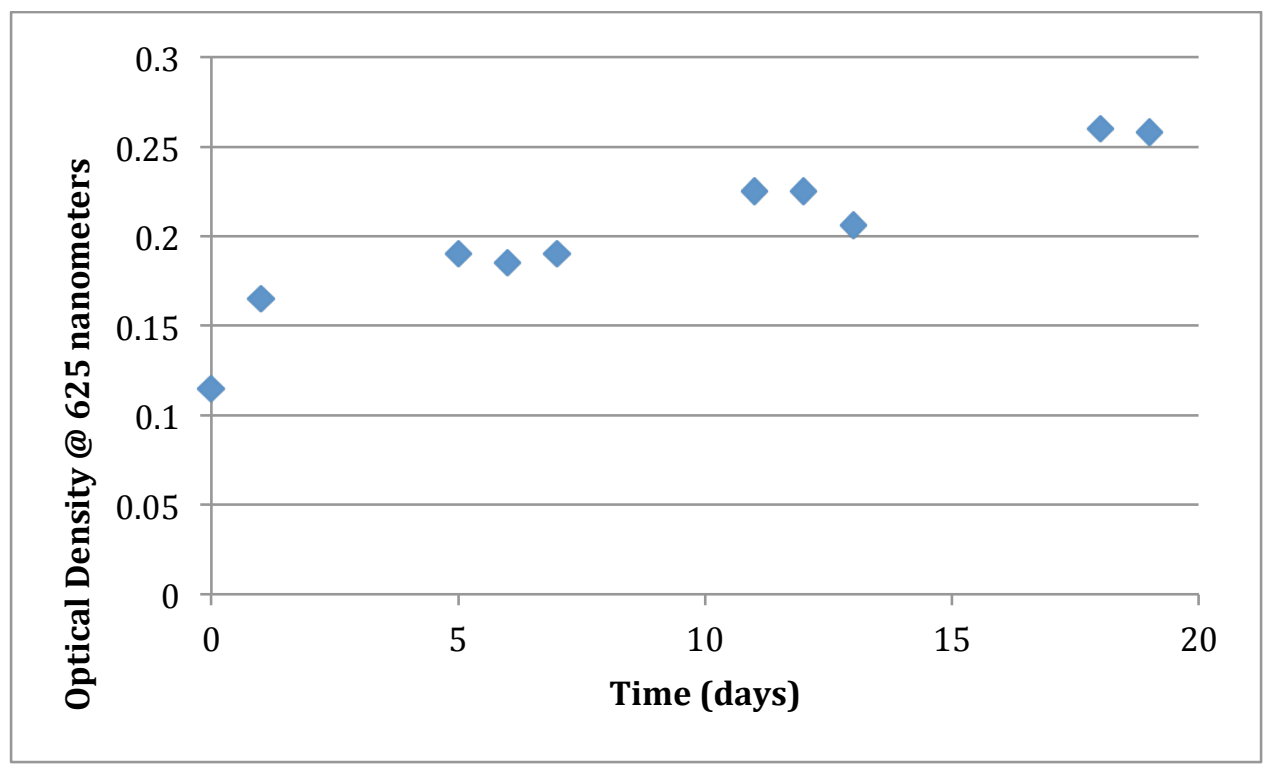

Figure 4.83-Growth of B. cepacia culture for use in Scenedesmus and Chlorella settling tests with carbon dioxide addition 


\subsubsection{Effect of Carbon Dioxide Addition on the Settleability of Scenedesmus}

Scenedesmus settled slightly better without carbon dioxide addition in both early and late growth phases (Figure 4.84). Thus, throughout growth, 2 hour settling based on normalized cell concentrations show that carbon dioxide input has no effect on improving the settleability of Scenedesmus (Figure 4.84).

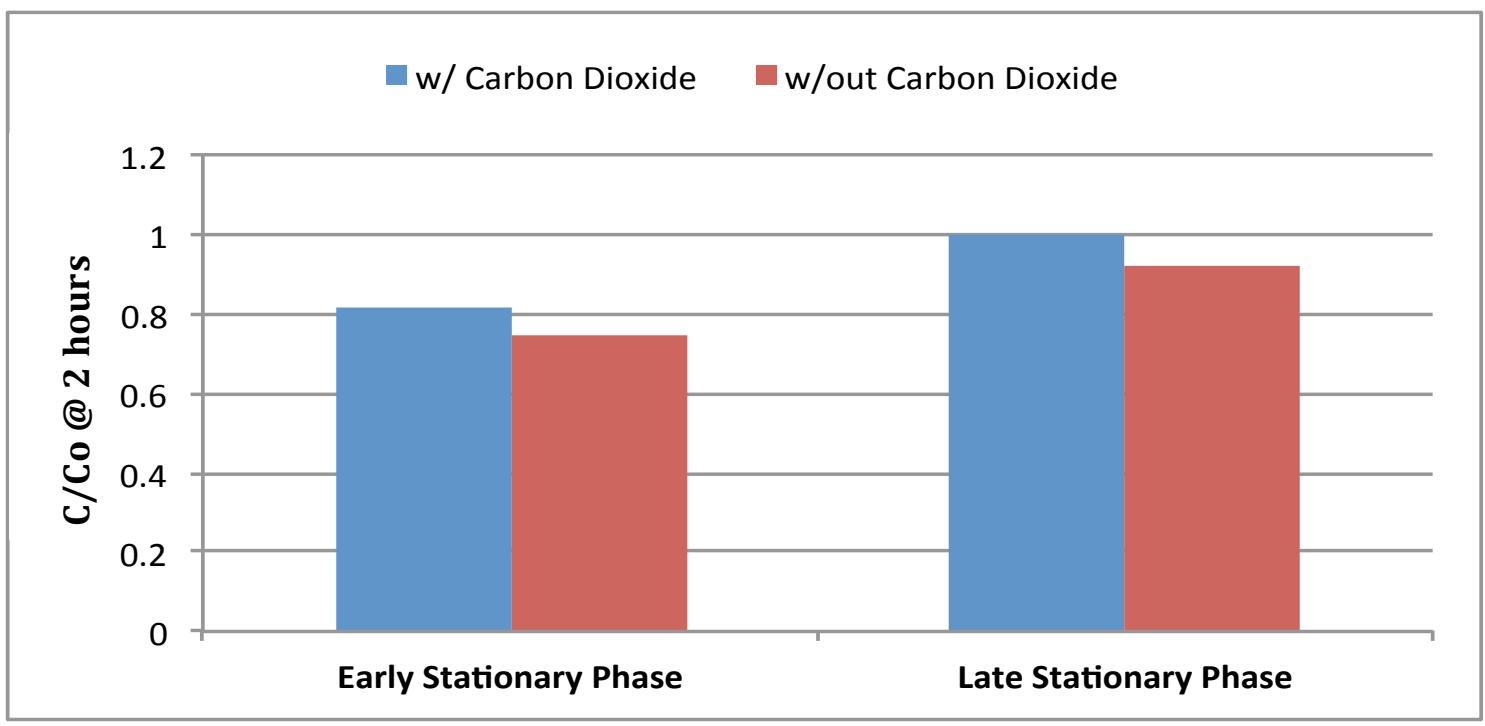

Figure 4.84-Comparison of settling based on normalized cell concentration after a 2hour settling period for Scenedesmus with and without carbon dioxide addition from early (10-11 days) to late stationary phases (24-27 days) of growth

\subsubsection{Effect of Carbon Dioxide Addition on the Settleability of Chlorella}

Chlorella settled much better without carbon dioxide addition in early and late phases of growth (Figure 4.85). Chlorella also settled better in early stages of growth, which corresponds with previous results in Experiments 1,2 and 3 (Figure 4.85). 24- hour period settling results are similar to the 2-hour settling results, where cultures without carbon dioxide addition settled better (Figures A.40, A.41). 


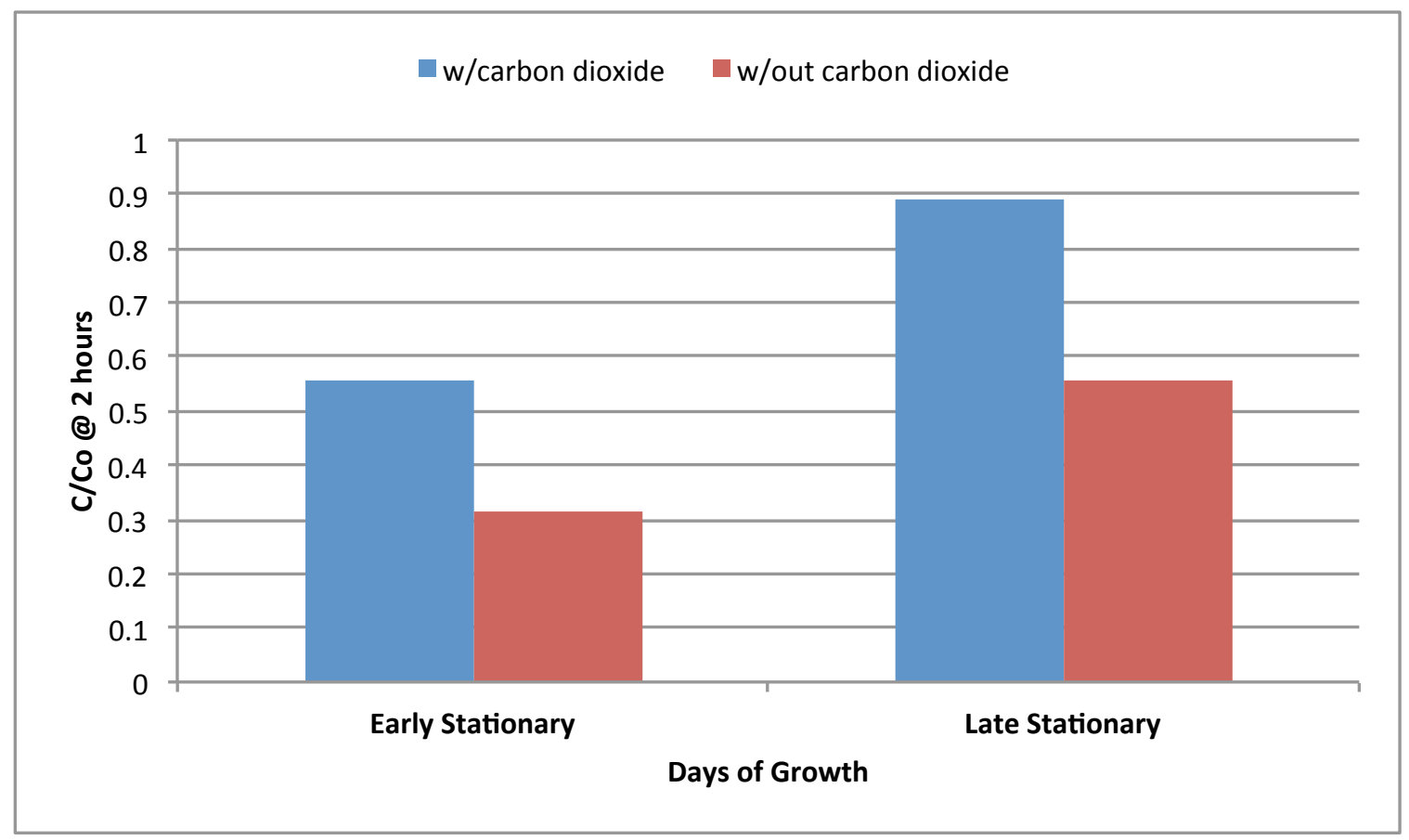

Figure 4.85-Comparison of settling based on normalized cell concentration after a 2hour settling period for Chlorella with and without carbon dioxide addition from early stationary (10-11 days) to late stationary (23-32 days) phases of growth

\subsubsection{Effect of Carbon Dioxide Addition and B. cepacia Cell Addition on the Settleability of Scenedesmus}

For cultures treated with carbon dioxide, B. cepacia cell addition improved settling slightly during early stationary and late stationary phases of growth (Figure $4.86 \mathrm{~A}, \mathrm{~B}$ ). Adding $1 / 2$ the dose of $B$. cepacia cells provided no improvement in settling, and in fact resulted in very poor settling in some cases (Figure 4.86). For the control culture of Scenedesmus without supplemented carbon dioxide, settling was improved by B. cepacia cell addition during late growth phases, but cells had no effect early in the growth curve (Figure 4.86 B). During later growth, cell addition had the same effect on improved settling between cultures with and without carbon dioxide (Figure 4.86 B). Diluting the Scenedesmus cultures only had a significant effect for cultures with carbon dioxide during late stationary growth (Figure 4.86 B). 
Cell addition with a different (higher) mixing intensity also improved settling dramatically during early stages of growth for cultures without carbon dioxide addition; however, changing the mixing intensity did not improve settling when carbon dioxide was supplemented (Figure 4.86). Changing the mixing intensity for both doses $(1 / 2$ and full) had more of an effect on cultures without carbon dioxide early on in growth as compared to cultures with carbon dioxide (Figure 4.86 A). This effect decreased into late stationary phase for both cultures (Figure 4.86 B). 

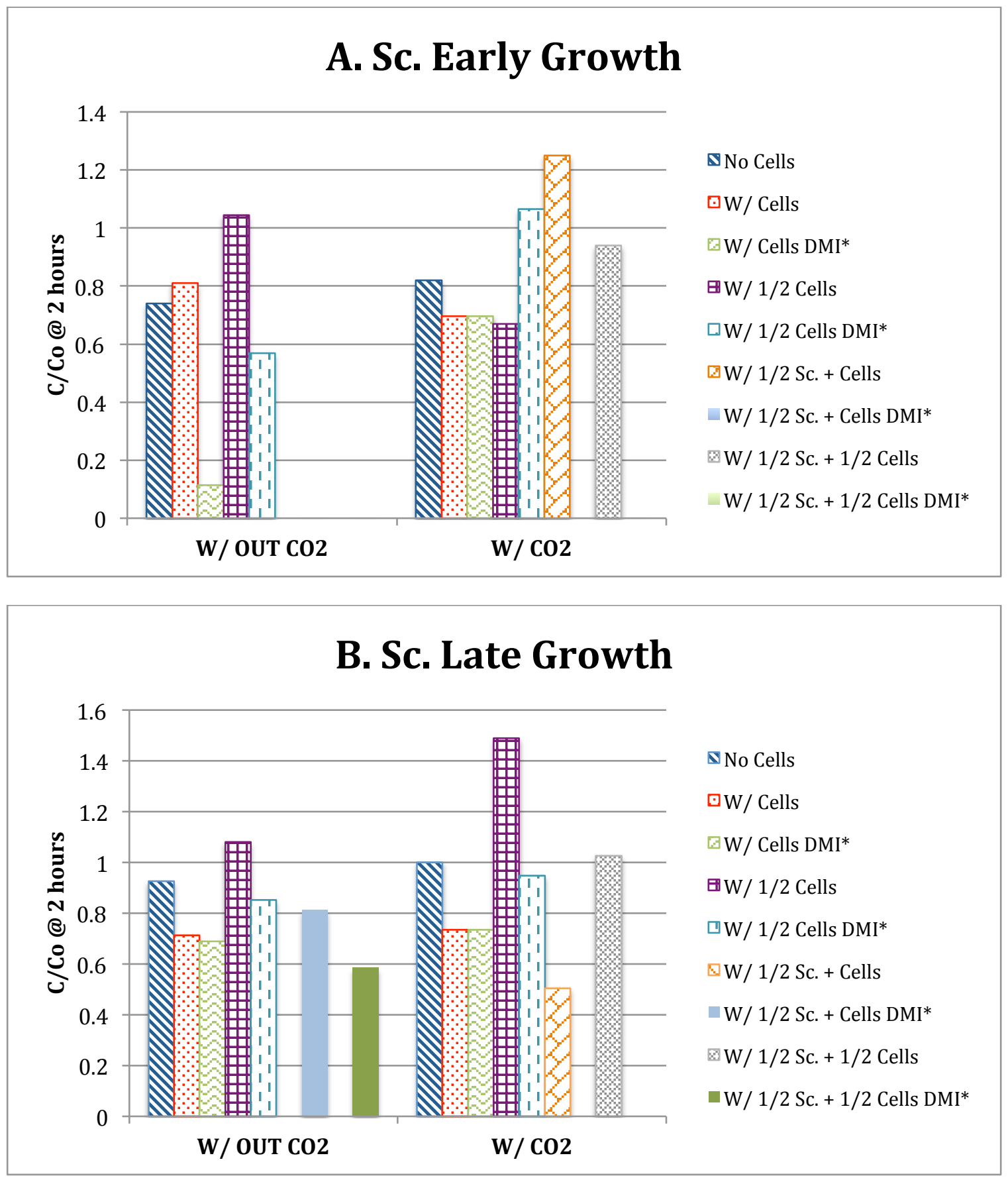

Figure 4.86-Comparison of settling based on normalized cell concentration remaining after a 2-hour settling period for Scenedesmus with and without carbon dioxide addition, with and without $B$. cepacia cell addition at various doses and mixing intensities from $A$ ) Early growth (11-12 days) to B) Late growth (24 to 27 days)

* DMI-Indicates the cell addition had a 1,000 rpm initial mixing intensity for 5 minutes followed by a 100-rpm flocculating period for the remaining 25 minutes before settling 


\subsubsection{Effect of Carbon Dioxide Addition and B. cepacia Filtrate Addition on the Settleability of Chlorella}

Without carbon dioxide addition, B. cepacia filtrate addition had little or no effect on the settling of Chlorella (Figure 4.87 A, B). However, with carbon dioxide supplementation, filtrate addition improved settling in late stationary phase of growth (Figure $4.87 \mathrm{~B}$ ). One half the dose of filtrate for both cultures was better during early growth, especially for cultures without carbon dioxide addition (Figure 4.87 A, B). Diluting algal cultures seemed to have a greater effect on cultures with carbon dioxide addition as compared to without, especially during early growth (Figure 4.87 A, B). In addition, similar to Scenedesmus, using a different (higher) mixing intensity had a greater effect on improved settling for cultures of Chlorella without carbon dioxide addition as compared to with carbon dioxide addition (Figure $4.87 \mathrm{~A}, \mathrm{~B}$ ). 

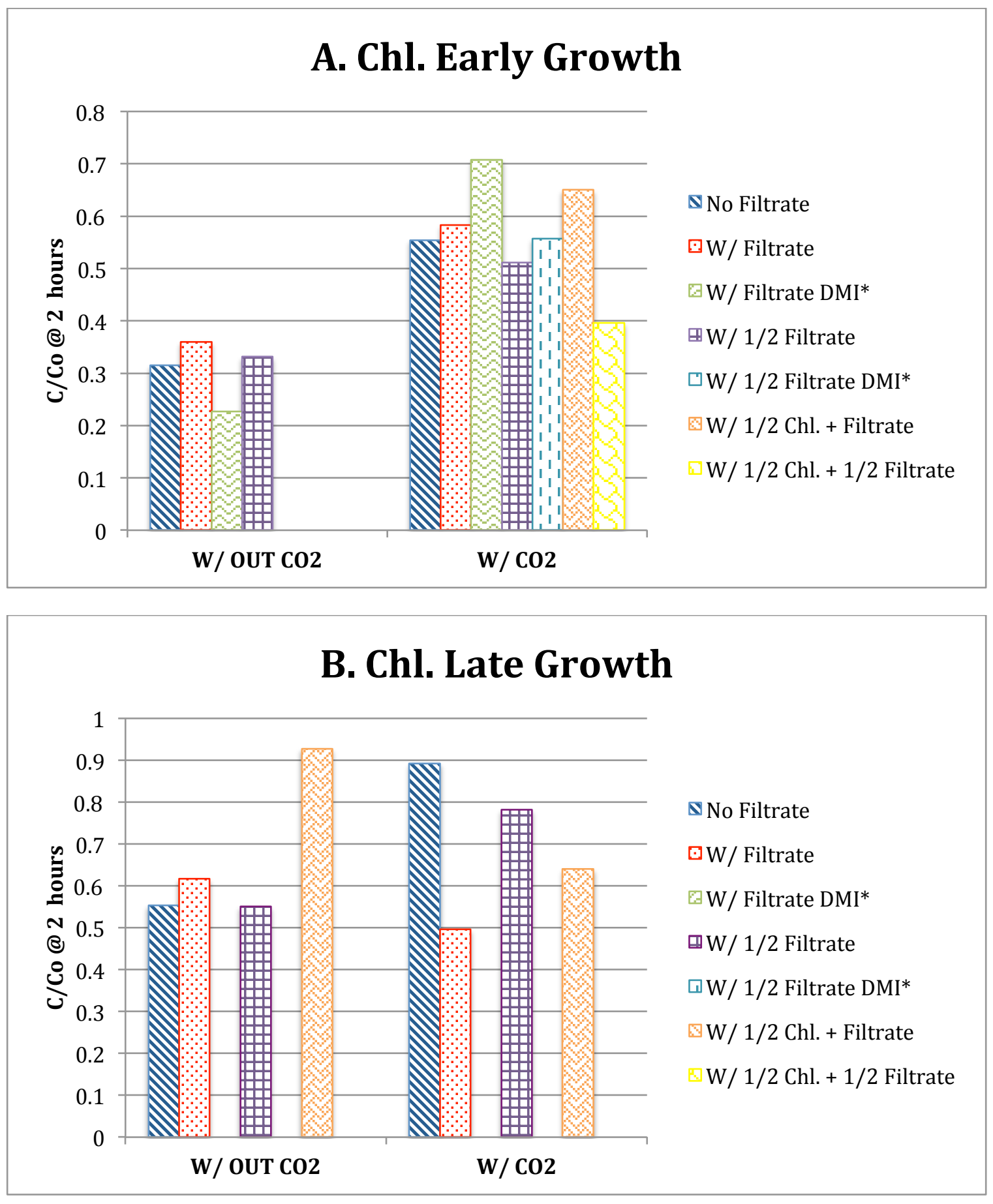

Figure 4.87-Comparing settling based on normalized cell concentration remaining after a 2-hour settling period for Chlorella with and without carbon dioxide addition, with different doses of filtrate, mixing intensities, and diluted samples of Chlorella

(1/2) during A) Early growth (10-11 days) and B) Late growth (23-32 days)

* DMI-Indicates the cell addition had a 1,000 rpm initial mixing intensity for 2 minutes followed by a 100-rpm flocculating period for the remaining 3 minutes before settling 


\subsubsection{Correlation of EPS with Carbon Dioxide Addition on the Settleability of Scenedesmus and Chlorella}

Scenedesmus cultures produced slightly more dissolved EPS when not supplemented with carbon dioxide for early and late growth phases (Figure 4.88). Increased carbon dioxide supplementation prior to settling tests both for 4 hours and 48 hours did not increase EPS production by Scenedesmus. Carbon dioxide supplemented cultures of Scenedesmus also did not settle as well without bioflocculant addition (Figure 4.84), indicating that less EPS produced by the carbon dioxide supplemented cultures decreased settling. Therefore, excess carbon dioxide did not improve the settling of Scenedesmus since less dissolved EPS was produced.

For Chlorella, dissolved EPS production was much lower with carbon dioxide supplementation (Figure 4.89). In addition, Chlorella cultures with carbon dioxide supplementation in general settled poorly as compared to cultures without carbon dioxide during both growth phases (Figure 4.87). Thus, comparing both cultures (with and without carbon dioxide supplementation) Chlorella's settling was shown to improve with more of its own dissolved EPS at each growth stage. However, like previous results, settling was best during early growth phases when its dissolved EPS production was smallest. Adding $B$. cepacia filtrate to both cultures did not significantly improve settling during both growth phases (Figure 4.87). This was similar to previous results with starved/non-starved filtrate, where Chlorella settling was not improved by a larger concentration of dissolved EPS present in the B. cepacia filtrate. 

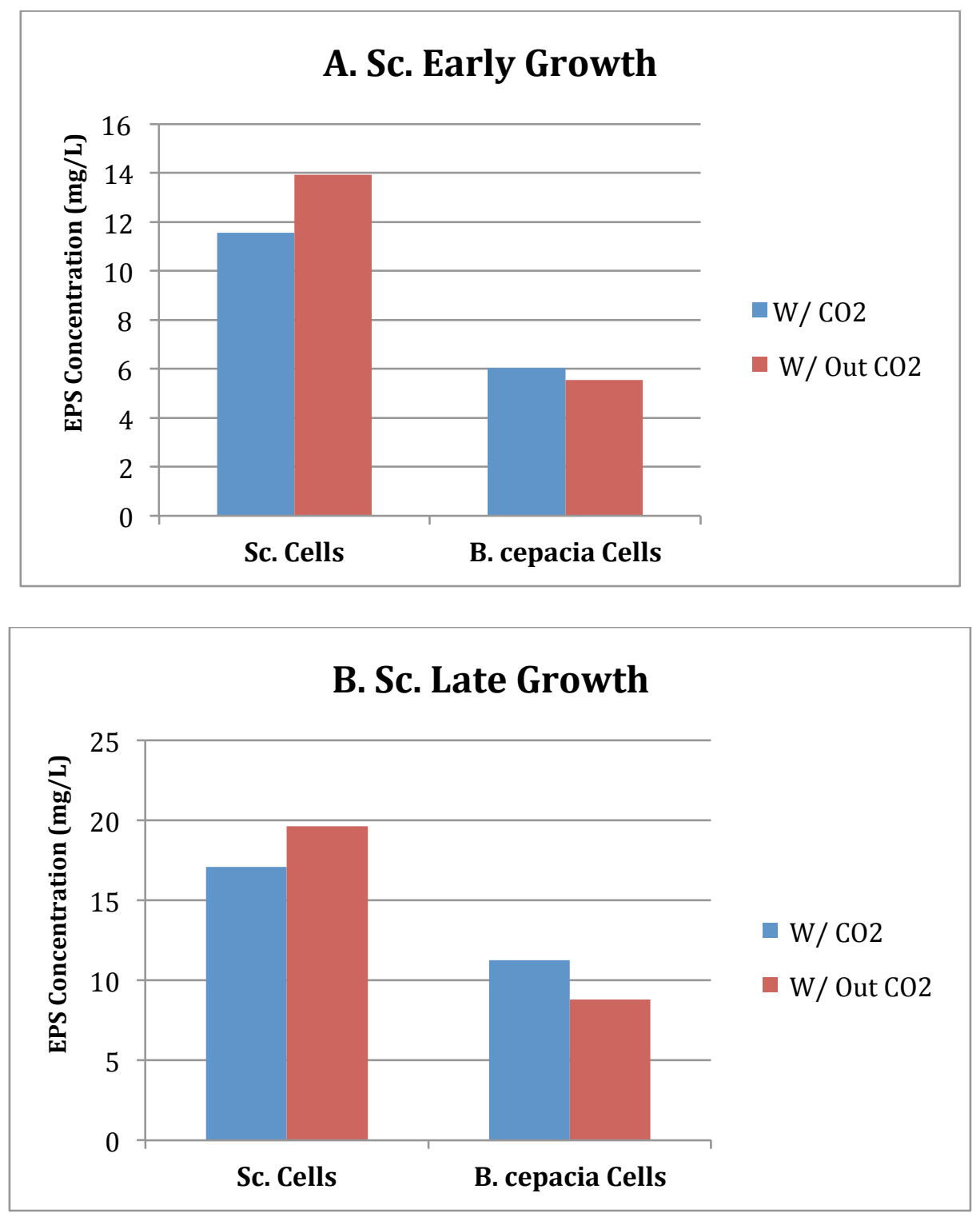

Figure 4.88-EPS concentration of Scenedesmus and B. cepacia cells used in settling tests over A) early stationary phase of growth (10-11 days) and B) late stationary phase of growth (24-27 days). (W or W/Out CO2 for B. cepacia corresponds to EPS production of bacterial cells used with either algal culture during settling tests) 

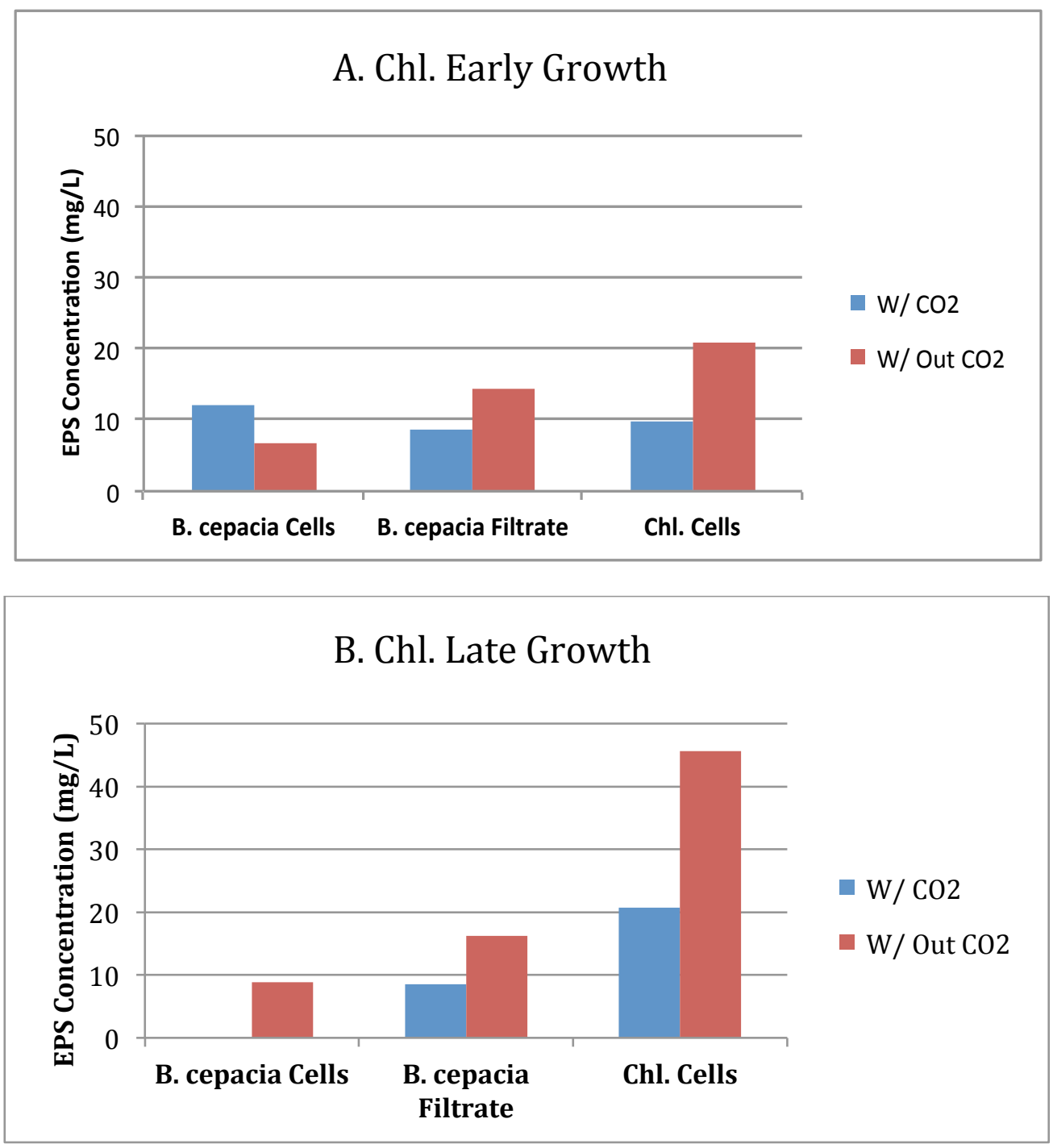

Figure 4.89-EPS concentration of Chlorella and B. cepacia cells used in settling tests over A) early stationary phase of growth (10-11 days) and B) late stationary phase of growth (23-32 days). (W or W/Out CO2 for B. cepacia corresponds to EPS production of bacterial cells or filtrate used with either algal culture during settling tests) 


\section{Chapter 5: Conclusions}

One of the most important observations in this research was that different species of algae, i.e., Scenedesmus and Chlorella vulgaris, exhibit different settling characteristics and that their settling performances are influenced very differently by bioflocculants such as bacterial cells and dissolved EPS. Scenedesmus settled faster in later growth stages, with the best settling observed in stationary phase (14 to 18 days). In contrast, Chlorella settling was less affected by growth phase, with slightly better settling observed in early stages of growth.

Algal EPS production increased with increasing growth for both algal species. Since Scenedesmus settling was greater for mature cultures with more growth and more EPS produced, this suggests that Scenedesmus settling is enhanced by its own EPS. In contrast, observed settling of Chlorella did not increase in later stages of growth when Chlorella EPS production was greater.

Two types of external bioflocculants were tested: Bacterial cell suspensions of $B$. cepacia, and dissolved EPS produced by B. cepacia, which was introduced as a filtrate of the bacterial culture. The cell suspension included both the capsular and dissolved components of B. cepacia EPS. Scenedesmus settling was enhanced significantly by the cell suspension, and to a lesser degree by dissolved EPS in the filtrate. The higher the measured EPS concentration of the added cell suspension, the greater the enhancement of settling of Scenedesmus, especially in early growth phases when EPS production by Scenedesmus itself was low. In comparison, Chlorella settling was improved only by dissolved bacterial EPS in the filtrate, but this effect was variable, depending on the growth phase of the Chlorella. 
Filtrate addition had the most impact on settling of Chlorella during early stationary phase, when settling of cells alone was poor.

In some cases lower concentrations of added B. cepacia cells or filtrate improved settling relative to the higher concentrations originally used. Scenedesmus showed better settling with a reduction of $B$. cepacia filtrate concentration (not cell dose) dosage, especially during mid stationary phase of growth. Comparably, Chlorella demonstrated better settling with a lower B. cepacia cell dosage (not filtrate) that was most effective early on in growth (mid exponential to late exponential phase).

Longer mixing times of algae and bioflocculants improved settling of Scenedesmus. Once again, Chlorella settling behavior was the opposite of Scenedesmus, as better settling was observed at shorter mixing times. Scenedesmus cells settled best with a rapid mix followed by a gentle flocculation period, especially in early growth stages. Chlorella also settled better with this mixing scenario, but this mixing was more effective during later stages of growth (mid stationary).

Light/dark cycles also affected algal settling. Scenedesmus settled best in a dark environment, while Chlorella settled better with more light. Providing the algae cultures with 30-48 hours of continuous light exposure prior to settling tests affected each culture differently. Scenedesmus settled better after this added light exposure under dark conditions during early stages of growth ( 6 days) and under the light during later stages of growth (mid stationary). The extended period of light exposure during the growth of Chlorella improved settling for Chlorella early in early growth stages with and without cell addition using dark settling conditions. The extended period of light exposure did not change he EPS production of either algal culture. 
Lowering the $\mathrm{pH}$ to three improved settling for both algae cultures without $B$. cepacia cell or filtrate addition in early growth stages. This result was similar to conclusions reported by Pavoni (1974) and Tenney (1969), showing that algae reach an isoelectric point (around $\mathrm{pH}$ of 3) where surface charge is reduced and where flocculation was improved significantly with synthetic cationic polymers. The effect of $B$. cepacia cell and filtrate addition, similar to the cationic polymer addition, was considerably greater when the $\mathrm{pH}$ was lowered to 3 for both algae cultures for Scenedesmus in early growth stages and for Chlorella throughout its growth curve.

Increasing the $\mathrm{pH}$ to 11 also improved settling efficiencies (up to 50\%) of Scenedesmus during early stages in growth but had little or no effect on the settling rate of Chlorella. The mechanism for autoflocculation has been postulated as the formation of a net positively charged chemical precipitant that bridges with the negatively charged algal surface due to the presence of specific concentrations of ions (namely calcium, magnesium and phosphate) in the medium at a higher $\mathrm{pH}$ (Sukenik, 1984). When $\mathrm{pH}$ was higher due to increased photosynthesis of algal cultures, orthophosphate becomes deprotonated and precipitates with calcium ions at concentrations of 0.1 to $0.2 \mathrm{mM}$ orthophosphate and 1.5 mM-2.5 mM calcium (Sukenik, 1984). This same effect was observed using Scenedesmus cultures grown on wastewater which early on in growth showed signs of autoflocculation (greater than 50\%) at low orthophosphate levels of around 30-40 uM at a pH of 11 to 12 (Lavoie, 1987). Scenedesmus exhibited this phenomenon early in growth since it had the required concentrations of ions in the medium (specifically orthophosphate) to induce autoflocculation according to the WC media recipe and Lavoie's result. Autoflocculation was not induced in Chlorella, since it was assumed to use up more orthophosphate during earlier stages of growth than what was required to create optimum conditions for this condition to occur. 
For Scenedesmus cultures with B. cepacia cell addition at a higher $\mathrm{pH}$, settling was improved during later stages of growth, especially with a different mixing intensity. Notably, Chlorella did not respond the same way, favoring a pH of 3 with B. cepacia filtrate addition over the growth curve.

Starving the B. cepacia cultures of nutrients resulted in a higher yield of EPS, and this improved bioflocculation of the Scenedesmus cultures. Chlorella settled better in earlier phases with starved B. cepacia filtrate and later with non-starved filtrate, showing settling was more affected by the amount of dissolved EPS added by the bioflocculant.

Carbon dioxide addition during algal growth increased the cell density of Scenedesmus significantly, but did not affect the growth of Chlorella. Carbon dioxide supplementation (up to 24 hours continuously before settling) resulted in poor settling for Chlorella cultures. Carbon dioxide addition also hindered settling of Scenedesmus for 2 hours of settling, but 24-hour settling results were dramatically improved (up to 99\%). Carbon dioxide supplementation did not increase EPS production by either species of algae.

For a comparison of these pure-culture lab results to real-world applications, settling tests were conducted for samples from an algae-based treatment pond mixed with primary wastewater, with and without RAS addition The algae pond water had a large amount of dissolved EPS, and during this sampling Chlorella was the dominant species. Without RAS additions, the cultures settled very poorly, but RAS: algae ratios of 1:3 or 1:6 improved settling. A ratio of algae pond water to primary wastewater of 1:1 with no RAS addition as well as the settling of the pure algal pond water demonstrated improved settling, suggesting that dissolved EPS in the pond wastewater improved algal settling.

RAS is known to contain highly bound capsular EPS and loosely bound dissolved components (Li, 2007). The loosely bound component was shown to negatively affect floc 
formation and settleability as compared to the capsular portion of EPS in RAS (Li, 2007). EPS analysis of the algae pond water used in this study showed that the loosely bound component was not as prevalent as the capsular component of EPS.

From lab scale study, Chlorella are more affected by dissolved EPS (similar to loosely bound components in RAS) in a more concentrated dosage (1:2 ratio of bioflocculant to algae). Chlorella have also been observed to improve settling with small dosages of B. cepcia cell suspensions, suggesting they are more sensitive to capsular bound EPS components of RAS. Thus, increasing the ratio of RAS to algae to 1:6 improves settling since Chlorella are less exposed to this tightly bound component, and are more likely to be influenced by the loosely bound, dissolved portion of RAS.

This was a different conclusion then results from the study by Su (2011) that showed an increase in sludge ratio to algae exhibited better settling (5:1 instead of 1:5 was better). This study also concluded that a 1:1 ratio settled well, which was not observed by the above results. Differences may be due to the algae species present and the RAS composition used (microbial community), which were not presented. Therefore, a feasible explanation and insight exists correlating both the lab experiments and wastewater field experiments on evaluating how one individual species may interact with another species in a complex community of microorganisms.

The first experiment with wastewater field samples also demonstrated the concept of HRT, when Scenedesmus species were dominant. In this experiment, RAS addition helped settling without aeration. Scenedesmus species characteristically do not settle well in early stages of growth. Therefore, improved settling could be achieved by possibly lengthening the HRT with RAS addition, and keeping the dose at or around 1:2 or 1:3 for RAS to algae (this dose was proven optimal for B. cepacia cell addition with Scenedesmus). Similar 
improved settling results could be achieved with Chlorella by shortening HRT, thereby keeping Chlorella in a growth condition favorable for settling to occur.

The observation in this study that a bioflocculant can improve the settling of Chlorella and Scenedesmus species agrees with previous results indicating that bioflocculant addition was effective (Oh, 2001, Kim, 2011). For optimization of bioflocculation, these studies included small concentrations of co-flocculant such as calcium chloride or ferric chloride were required in addition to the bioflocculant. However, these studies were focused on commercial harvesting methods for biofuels and not specifically tailored for use in wastewater treatment. Effects of EPS production by bacteria on settling in wastewater applications has not yet been reported in the literature. The present study also examined the effects of physical factors on settling, such as mixing intensity, dosage, light/dark cycles, carbon dioxide addition, and nutrient starvation for improving the bioflocculation, which have not been widely reported. The results presented here should be useful for future wastewater applications in terms of the harvesting process.

For this research, reproducible results were achieved with the first three experiments. Based on these experiments, general trends in settling for both Chlorella and Scenedesmus were observed to be consistent. At times, for Scenedesmus, the normalized values exceeded one, which was thought to be due to resuspension. This increase in normalized concentration was due, however, to slower settling of algal cells, where more cells from the top of the column had reached the sampling port. A representation of the entire year's research is presented in the appendix compilation section. Repeatability of the second part of the results (focused on environmental conditions) may need to be revisited in future studies. Since this was a "screening" study, emphasis was not placed on achieving 
reproducibility, and instead on studying the largest amount of environmental and physical effects on settling within the given time frame.

The most promising environmental conditions with bioflocculant addition to improve the harvesting of Scenedesmus and Chlorella achieved in this study were reviewed. It appears for Scenedesmus, much improved settling was observed with B. cepacia bioflocculant addition at a higher $\mathrm{pH}$ during later growth, especially with an increased mixing intensity. In addition, dark settling conditions were shown to improve the settling of Scenedesmus cultures during later stages of growth without bioflocculant addition. Increasing the exposure to light intensity followed by dark settling conditions further increased settling of Scenedesmus with bioflocculant addition. This effect was enhanced using a higher mixing intensity with bioflocculant addition. Lastly, adding bioflocculant ( $B$. cepacia cells) followed by a higher mixing intensity at a neutral $\mathrm{pH}$ was shown to produce consistent improved settling of Scenedesmus cultures during early growth stages.

For Chlorella, improved settling at a higher $\mathrm{pH}$ with bioflocculant addition during later growth stages was observed, but not at a higher mixing intensity. Similarly, during later growth, B. cepacia filtrate addition improved settling of carbon dioxide supplemented Chlorella cultures to a greater extent than observed previously. Starved cultures of $B$. cepacia (filtrate) also had a greater impact on improving Chlorella settling during early growth and with a different mixing intensity. Finally, B. cepacia cell addition to cultures of Chlorella experiencing prolonged light exposure improved settling to a greater extent in the dark (during early growth).

Future studies would benefit from more accurate ways to quantify capsular EPS of pure algal cultures as well as RAS, such as EPS extraction methods described by Liu and Fang (2010). This reference concluded that a technique for extraction involving a 
combination of formaldehyde and sodium hydroxide was the most effective and led to the least contamination of intracellular products. This EPS extraction procedure was not possible to use in the current study. More experimentation on optimizing the RAS ratio should also be conducted to correlate with the pure-culture lab studies. Another important addition to this work would be the quantification of surface charge and $\mathrm{pH}$ of zero charge for the algae cultures used, which would help in the interpretation of observed settling phenomena. Investigation into the settling effects of different algal species would extremely help comparison and classification for use in commercial scale applications. This study was a broad synopsis important in determining the fact that algae species can vary much differently in their settling and bioflocculation characteristics. Future studies could pinpoint certain improved, non-variable bioflocculation conditions with certain algal species present.

Research in conjunction with algal species dominance and control of HRT, as studied by Park and Craggs using activated algae, may help further pinpoint these differences and improve bioflocculation on a large scale. Thus, future research into the harvesting process of algae used in wastewater treatment may contribute to finding a suitable, cost-effective, and reliable method to meet the challenging scale up requirements that the production of algal biofuels entail. 


\section{References}

Allen, Mary Belle. "Excretion of Organic Compounds by Chlamydomonas." Archive for Microbiology 24 (1956): 163-68.

Al-Shayji, Y. "Production and Separation of Algae in a High-rate Ponds System." Environment International 20.4 (1994): 541-50.

Andersen, Robert A. "WC Medium." Algal Culturing Techniques. Burlington, MA: Elsevier/Academic, 2005. 474-75.

Avnimelech, Y., B. W. Troeger, and L. W. Reed. "Mutual Flocculation of Algae and Clay: Evidence and Implications." Science 216.4541 (1982): 63-65.

Badireddy, Appala R., Shankararaman Chellam, Paul L. Gassman, Mark H. Engelhard, Alan S. Lea, and Kevin M. Rosso. "Role of Extracellular Polymeric Substances in Bioflocculation of Activated Sludge Microorganisms under Glucose Controlled Conditions." Water Research 44 (2010): 4505516.

Benemann, John. "Development of Microalgae Harvesting and High-Rate Pond Technologies in California." Ed. G. Shelef and C.J. Soeder. Algae Biomass (1980): 457-92.

Benemann, John R., and William J. Oswald. Final Report to the Department of Energy Pittsburgh Energy and Technology Center: Systems and Economic Analysis of Microalgae Ponds For Conversion of Carbon Dioxide to Biomass. Rep. 1996.

Benemann, John R., Dom M. Eisenburg, Ben Koopman, William J. Oswald . "Algal Bioflocculation and Energy Conservation in Microalgal Sewage Ponds." Biotechnology and Bioengineering Symposium 11 (1981): 429-48.

Berman, Tom, and Marina Holenberg. TEP and Biofilm Fouling on Membranes. Rep. 2005.

Berman, Tom, and Uta Pasow. "Transparent Exopolymer Particles (TEP): An Overlooked Factor in the Process of Biofilm Formation in Aquatic Environments." Nature Proceedings (2007).

Brown, Melanie J., and John N. Lester. "Comparison of Bacterial Extracellular Polymer Extraction Methods." Applied and Environmental Microbiology 40.2 (1980): 179-85. 
Buthelezi, Simphiwe E., Ademola O. Olaniran, and Balakrishna Eillay. "Eroduction and Characterization of Bioflocculants from Bacteria Isolated from Wastewater Treatment Plant in South Africa." Biotechnology and Bioprocess Engineering 15 (2010): 874-81.

Christianson L, Sims R. "Production and harvesting of microalgae for wastewater treatment, biofuels, and bioproducts." Biotechnology Advances. Elsevier Inc, 2011. doi:

10,1016/j.biotechadv.2011.05.015

Choi, S.K., J.Y. Lee, D.Y. Kwon, and K.J. Chokshi. "Settling Characteristics of Problem Algae in the Water Treatment Process." Water Science \& Technology 53.7 (2006): 113-19.

Comte, S., G. Guibaud, and M. Baudu. "Effect of Extraction Method on EPS from Activated Sludge: An HPSEC Investigation." Journal of Hazardous Materials 140.1-2 (2007): 129-37. Science Direct. Web. 15 Oct. 2011.

Comte, S., G. Guibaud, and M. Baudu. "Relations between Extraction Protocols for Activated Sludge Extracellular Polymeric Substances (EPS) and EPS Complexation Properties: Part I. Comparison of the Efficiency of Eight EPS Extraction Methods." Enzyme and Microbial Technology 2nd ser. 38.1 (2006). Science Direct. Web. 12 Oct. 2011. <(http://www.sciencedirect.com/science/article/pii/S0141022905002644)>.

Craggs, R.J., S. Heubeck, T.J. Lundquist, and J.R. Benemann. "Algal Biofuels from Wastewater Treatment High Rate Algal Ponds." Water Science and Technology 63.4 (2011): 660-65.

D’Abzac, Paul, François Bordas, Eric Hullebusch, Piet N. L. Lens, and Gilles Guibaud. "Extraction of Extracellular Polymeric Substances (EPS) from Anaerobic Granular Sludges: Comparison of Chemical and Physical Extraction Protocols." Applied Microbiology and Biotechnology 85.5 (2010): 1589-599. SpringerLink. Web. 14 Oct. 2011. $<$ http://www.springerlink.com/content/56625v8r16n07v01/fulltext.pdf $>$.

Fogg, G. E. Algal Cultures and Phytoplankton Ecology. Madison: University of Wisconsin, 1965.

Frost, Dan T. Bioflocculation for Control of Wastewater Pond Microalgae. Thesis. California Polytechnic State University, San Luis Obispo, 2008.

Gerardi, Michael H. Settleability Problems and Loss of Solids in the Activated Sludge Process. New York: Wiley-Interscience, 2002. 
Grossart, Hp, T. Berman, M. Simon, and K. Pohlmann. "Occurrence and Microbial Dynamics of Macroscopic Organic Aggregates (lake Snow) in Lake Kinneret, Israel, in Fall." Aquatic Microbial Ecology 14 (1998): 59-67.

Gutzelt, G., D. Lorch, A. Weber, M. Engels, and U. Nels. "Bioflocculant Algal-bacterial Biomass Improves Low-cost Wastewater Treatment." Water Science \& Technology 52.12 (2005): 9-18.

Ives, K. J. "The Significance of Surface Electric Charge on Algae in Water Purification." Journal of Biochemical and Microbiological Technology and Engineering 1.1 (1959): 37-47.

Kim, Dong-Geol, Hyun-Joon La, Chi-Yong Ahn, Yong-Ha Park, and Hee-Mock Oh. "Harvest of Scenedesmus Sp. with Bioflocculant and Reuse of Culture Medium for Subsequent High-density Cultures." Bioresource Technology 102.3 (2011): 3163-168.

Knight, Randall Dewey. Physics for Scientists and Engineers: A Strategic Approach: With Modern Physics. San Francisco: Pearson Addison Wesley, 2008.

Lavoie, Alain, and J. De La Noue. "Harvesting Of Scenedesmus Obliquus in Wastewaters: Auto- or Bioflocculation?" Biotechnology and Bioengineering 30.7 (1987): 852-59.

Lee, Andrew K., David M. Lewis, and Peter J. Ashman. "Microbial Flocculation, a Potentially Low-cost Harvesting Technique for Marine Microalgae for the Production of Biodiesel." Journal of Applied Phycology 21 (2009): 559-67.

Lewin, Ralph A. "Extracellular Polysaccharides of Green Algae." Canadian Journal of Microbiology 2 (1956): 665-72.

Li, X.Y., and S.F. Yang. "Influence of Loosely Bound Extracellular Polymeric Substances (EPS) on the Flocculation, Sedimentation and Dewaterability of Activated Sludge." Water Research 41.5 (2007): 1022-030.

Liu, Hong, and Herbert H.P. Fang. "Extraction of Extracellular Polymeric Substances (EPS) of Sludges." Journal of Biotechnology 95.3 (2002): 249-56. Science Direct. Web. 12 Oct. 2011.

$<$ https://connect.calpoly.edu/service/home/ /extractionofEPS1.pdf?auth=co\&loc=en_US $\& \mathrm{id}=51473 \&$ part $=2>$. 
Lundquist, Tryg, Ian Woertz, and Laura Fulton. "Nutrient Removal and Greenhouse Gas Abatement with Carbon Dioxide Supplemented Algal High Rate Ponds." Digital Commons. California Polytechnic State University, San Luis Obispo, 2009. Web. $<$ http://works.bepress.com/tlundqui/4/>.

Lundquist, T.J., I.C. Woertz, N.W.T. Quinn, and J.R. Benemann. "A Realistic Technology and Engineering Assessment of Algae Biofuel Production." Digital Commons. California Polytechnic State University, San Luis Obispo, 2010. Web.

$<\mathrm{http}: / /$ digitalcommons.calpoly.edu/>.

Mari, Xavier. "Carbon Content and C:N Ratio of Transparent Exopolymeric Particles (TEP) Produced by Bubbling Exudates of Diatoms." Marine Ecology Progress Series 183 (1999): 59-71. Print.

Mehta, Veela B., and B. S. Vaidya. "Cellular and Extracellular Polysaccharides of the Blue Green Alga Nostoc." Journal of Experimental Botany 29.6 (1978): 1423-430.

McKinney, Ross E. Waste Treatment. Patent 3,462,360. 19 Aug. 1969.

Moore, B. G., and R. G. Tischer. "Extracellular Polysaccharides of Algae: Effects on Life-Support Systems." Science 145.3632 (1964): 586-87.

Nelson, Yarrow M., Leaonard W. Lion, Michael L. Schuler, and William C. Ghiorse. "Modeling Oligotrophic Biofilm Formation and Lead Adsorption to Biofilm Components." Environmental Science and Technology 30.6 (1996): 2027-035.

Oh, Hee-Mock, Seog June Lee, Myung-Hwan Park, Hee-Sik Kim, Hyoung-Chin Kim, Jung-Hoon Yoon, Gi-Seok Kwon, and Byung-Dae Yoon. "Harvesting of Chlorella Vulgaris Using a Bioflocculant from Paenibacillus Sp. AM49." Biotechnology Letters 23 (2001): 1229-234.

http://ceenve3.civeng.calpoly.edu/nelson/Publications/PUBLICATIONS.htm

Oswald, William J. Advanced Integrated Wastewater Pond Systems. Proc. of 1990 ASCE Convention, California, San Francisco. ASCE, 1990. Web. $<$ http://renewwater.com/files/AIWPS\%201990\%20Oswald\%20article.pdf $>$.

Oswald, William J., and Clarence G. Golueke. "Biological Transformation of Solar Energy." Advances in Microbiology 2 (1960): 223-62. 
Pan, Jil Ruhsing, Chihpin Huang, Yao-Chia Chia Chuang, and Chi-Chao Wu. "Dewatering Characteristics of Algae-containing Alum Sludge." Colloids and Surfaces A: Physicochemical and Engineering Aspects 150 (1999): 185-90.

Park, J. B. K., and R. J. Craggs. "Wastewater Treatment and Algal Production in High Rate Algal Ponds with Carbon Dioxide Addition." Water Science \& Technology 61.3 (2010): 633-39.

Park, J.B.K., and R.J. Craggs. "Algal Production in Wastewater Treatment High Rate Algal Ponds for Potential Biofuel Use." Water Science \& Technology 63.10 (2011): 2403-409.

Park, J.B.K., R.J. Craggs, and A.N. Shilton. "Recycling Algae to Improve Species Control and Harvest Efficiency from a High Rate Algal Pond." Water Research45 (2011): 6637-649.

Park, J.B.K., R.J. Craggs, and A.N. Shilton. "Wastewater Treatment High Rate Algal Ponds for Biofuel Production." Bioresource Technology 102.1 (2011): 35-42.

Passow, U. "Transparent Exopolymer Particles (TEP) in Aquatic Environments." Progress In Oceanography 55.3-4 (2002): 287-333.

Passow, U., R.F. Shipe, A. Murray, D.K. Pak, M.A. Brzezinski, and A.L. Alldredge. "The Origin of Transparent Exopolymer Particles (TEP) and Their Role in the Sedimentation of Particulate Matter." Continental Shelf Research 21 (2001): 327-46.

Pavoni, Joseph L. "The Harvesting of Algae as a Food Source from Wastewater Using Natural and Induced Flocculation Techniques." Proc. of Conference on the Use of Wastewater in the Production of Food and Fiber, Trade Winds Motor Inn - Central, Oklahoma City, Oklahoma. CA Polytechnic State University Interlibrary Services, 6 Mar. 1974. Web.

Pavoni, Joseph L., Mark W. Tenney, and Wayne F. Echelberger, Jr. "Bacterial Exocellular Polymers and Biological Flocculation." Water Pollution Control Federation 1st ser. 44.3 (1972): 414-31.

Pieterse, AJH. Metabolic Processes of Algae and Their Ability to Flocculate. Rep. EWISA, 1978. Web. $<$ http://www.ewisa.co.za/literature/files/1998\%20-\%20104.pdf>.

Pieterse, A., and A. Cloot. "Algal Cells and Coagulation, Flocculation and Sedimentation Processes." Water Science and Technology 36.4 (1997): 111-18.

Pittman, Jon K., Andrew P. Dean, and Olumayowa Osundeko. "The Potential of Sustainable Algal Biofuel Production Using Wastewater Resources." Bioresource Technology 102.1 (2011): 17-25. 
Ramus, Joseph S. Algal Biopolymer Production. Mobil Oil Corporation, assignee. Patent 4,236,349. 2 Dec. 1980.

Salehizadeh, H., and S.A. Shojaosadati. "Extracellular Biopolymeric Flocculants: Recent Trends and Biotechnological Importance." Biotechnology Advances 19 (2001): 371-85.

Salim, Sina, Rouke Bosma, Marian H. Vermuë, and René H. Wijffels. "Harvesting of Microalgae by Bioflocculation." Journal of Applied Phycology 23.5 (2011): 849-55.

Schenck, Paula, Patricia L. Foster, William W. Walker Jr., and Samuel Fogel. Production Of Algal Biopolymers. American Bioculture, Inc., assignee. Patent 3,958,364. 25 May 1976.

Schenk, Peer M., Evan Stephens, Clemens Posten, Olaf Kruse, Ute C. Marx, Ben Hankamer, Jan H. Mussgnug, and Skye R. Thoma-Hall. "Second Generation Biofuels: High-Efficiency Microalgae for Biodiesel Production." Bioenergy Resources 1 (2008): 20-43.

Sheehan, J., Dunahay, T., Benemann, J., Roessler, P., (1998) “A Look Back at the U.S. Department of Energy's Aquatic Species Program-Biodiesel from Algae” National Renewable Energy Program.

Shelef, G., A. Sukenik, and M. Green. Microalgae Harvesting and Processing: A Literature Review. Rep. Springfield: n.p., 1984.

Shipin, O.V., P.D. Rose, and P.G.J. Meiring. "Microbial Processes Underlying the PETRO Concept (Trickling Filter Variant)." Water Research 33.7 (1996): 1645-651.

Shipin, O.V., P.G.J. Meiring, R. Phaswana, and H. Kluever. "Integrating Ponds and Activated Sludge Process in the PETRO Concept." Water Research 33.8 (1999): 1767-774.

Su, Yanyan, Artur Mennerich, and Brigitte Urban. "Synergistic Cooperation between Wastewater-born Algae and Activated Sludge for Wastewater Treatment: Influence of Algae and Sludge Inoculation Ratios." Bioresource Technology 105 (2012): 67-73.

Sukenik, A., and G. Shelef. "Algal Autoflocculation? Verification and Proposed Mechanism." Biotechnology and Bioengineering 26.2 (1984): 142-47.

Tago, Yoshitaka, and Ko Aida. "Exocellular Mucopolysacchardie Closely Related to Bacterial Floc Formation." Applied and Environmental Microbiology 34.3 (1977): 308-14.

Tago, Yoshitaka, and Kô Aida. "The Deflocculating Enzyme Produced By A Floc-Forming Bacterium." The Journal of General and Applied Microbiology 21.6 (1975): 365-74. 
Tchobanoglous, George, and Franklin L. Burton. Wastewater Engineering: Treatment, Disposal, and Reuse. New York: McGraw-Hill, 2003.

Tenney, Mark W., Wayne F. Echelberger Jr., Ronald G. Schuessler, and Joseph L. Pavoni. "Algal Flocculation with Synthetic Organic Polyelectrolytes." Applied and Environmental Microbiology 18.6 (1969): 965.

Tenney, Mark W., and Francis H. Verhoff. "Chemical and Autoflocculation of Microorganisms in Biological Wastewater Treatment." Biotechnology and Bioengineering 15.6 (1973): 1045-073.

Tischer, R. G., and Edith B. Davis. "The Effect of Various Nitrogen Sources upon the Production of Extracellular Polysaccharide by the Blue-Green Alga A-37." Journal of Experimental Botany 22.3 (1971): 546-51.

United States. Department of Energy. Biomass Energy Technology. Microalgae Harvesting and Processing: A Literature Review. By G. Sheief, A. Sukenik, and M. Green. Golden, CO: National Renewable Energy Laboratory (U.S.), 1984.

U.S. DOE 2010. National Algal Biofuels Technology Roadmap. U.S. Department of Energy, Office of Energy Efficiency and Renewable Energy, Biomass Program.

US EPA (2008). Clean Watersheds Needs Survey 2004 Report to Congress, U.S. Environmental Protection Agency.

Valigore, Julia M., Peter A. Gostomski, David G. Wareham, and Aisling D. O'Sullivan. "Effects of Hydraulic and Solids Retention times on Productivity and Settleability of Microbial (Microalgal-bacterial) Biomass Grown on Primary Treated Wastewater as a Biofuel Feedstock." Water Research (2012).

Whitton, B. A. "Extracellular Products of Blue -Green Algae." Microbiology 40.1 (1965): 1-11.

Wingender, Jost, Thomas R. Neu, and Hans-C Flemming. Microbial Extracellular Polymeric Substances: Characterization, Structure, and Function. Berlin: Springer, 1999. 


\section{Appendix}

\section{Appendix: Section 1: Compilation of Results}

Four Tables are presented that summarize the research conducted. The first two tables summarize settling effects of environmental conditions without bioflocculant addition for Chlorella and Scenedesmus. The next two tables present a summary of the effect of bioflocculant addition with the different environmental conditions studied. All effects are based on two-hour settling performances (not 24) over the growth curve. Up arrows signify an improved settling performance and down arrows signify a decreased settling performance. In general, for both species of algae: mid exponential phase (6-9 days of growth), early stationary (10-14 days of growth), mid stationary (15-22 days of growth), late stationary (23 to 32 days of growth), and death phase was (33 days and above). A key below each table explains variations in results.

For Tables 3 and 4, settling performance was compared to settling results of no cell or bioflocculant addition for each trial. Settling results were based on normalized cell concentration remaining after two hours of settling. If the bioflocculant addition improved settling performance compared to no cell addition it received an up arrow, while a down arrow signified the environmental condition/type of bioflocculant/physical condition was not favorable for settling. If multiple stages of growth were favorable to increase settling, a pound (\#) sign meant that better settling was observed in that particular growth phase compared to the others studied. 
Table 1: Effect on Settling of Different Environmental Conditions for Scenedesmus sp. Without Bioflocculant Addition

\begin{tabular}{|c|c|c|c|c|c|}
\hline \multirow{2}{*}{$\begin{array}{c}\text { Effect (Environmental } \\
\text { Condition) }\end{array}$} & \multicolumn{5}{|c|}{ Growth Phase } \\
\cline { 2 - 6 } & $\begin{array}{c}\text { Mid } \\
\text { Exponential }\end{array}$ & Early Stationary & Stationary & Late Stationary & Death Phase \\
\hline Settling in the Dark & $?$ & $?$ & & $?$ & $?$ \\
\hline Settling in the Light & $?$ & $?$ & & $?$ & $?$ \\
\hline Settling in the Dark* & $?$ & & & $?$ & $?$ \\
\hline Settling in the Light* & $?$ & & & $?$ & $?$ \\
\hline $\mathrm{pH} \mathrm{7} \mathrm{(neutral)}$ & $?$ & & & $?$ & $?$ \\
\hline $\mathrm{pH} 3$ & $?$ & & & $?$ & $?$ \\
\hline pH 11 & $?$ & & & $?$ & $?$ \\
\hline Carbon Dioxide Addition** & $?$ & & $?$ & & $?$ \\
\hline No Cell Addition & & & & & \\
\hline
\end{tabular}

*-Constant light exposure of 30 and 48 hours before settling in the light or dark for mid to late exponential cultures ( $30 \mathrm{hrs}$ ) and early/mid stationary cultures (48 hrs) respectively

?-Not studied, needs future attention

No Cell Addition-General settling trends without bioflocculant addition (based on normalized cell concentration remaining after two hours of settling)

\#-Best growth phase for settling without bioflocculant addition (based on normalized cell concentration remaining after two hours of settling)

**-Constant carbon dioxide addition of 4 to 24 hours before settling of early ( $4 \mathrm{hrs})$ and late stationary phase (24 hrs) cultures respectively 
Table 2: Effect on Settling of Different Environmental Conditions for Chlorella vulgaris Without Bioflocculant Addition

\begin{tabular}{|c|c|c|c|c|c|}
\hline \multirow{2}{*}{$\begin{array}{c}\text { Effect (Environmental } \\
\text { Condition) }\end{array}$} & \multicolumn{5}{|c|}{ Growth Phase } \\
\cline { 2 - 6 } & $\begin{array}{c}\text { Mid } \\
\text { Exponential }\end{array}$ & Early Stationary & $\begin{array}{c}\text { Mid } \\
\text { Stationary }\end{array}$ & Late Stationary & Death Phase \\
\hline Settling in the Dark & $?$ & $?$ & & $?$ & $?$ \\
\hline Settling in the Light & $?$ & $?$ & & $?$ & $?$ \\
\hline Settling in the Dark* & $?$ & & & $?$ & $?$ \\
\hline Settling in the Light* & $?$ & & & $?$ & $?$ \\
\hline $\mathrm{pH} \mathrm{7} \mathrm{(neutral)}$ & $?$ & & & $?$ & $?$ \\
\hline $\mathrm{pH} 3$ & $?$ & & & $?$ & $?$ \\
\hline pH 11 & $?$ & & & $?$ & $?$ \\
\hline Carbon Dioxide Addition** & $?$ & & $?$ & & $?$ \\
\hline No Cell Addition & $\#$ & & & & $?$ \\
\hline
\end{tabular}

*-Constant light exposure of 30 and 48 hours before settling in the light or dark for mid to late exponential cultures (30 hrs) and early/mid stationary cultures (48 hrs) respectively

?-Not studied, needs future attention

No Cell Addition-General settling trends without bioflocculant addition (based on normalized cell concentration remaining after two hours of settling)

\#-Best growth phase for settling without bioflocculant addition (based on normalized cell concentration remaining after two hours of settling)

**-Constant carbon dioxide addition of 4 to 24 hours before settling of early and late stationary phase cultures respectively 
Table 3: Effect on Settling of Different Environmental Conditions for Scenedesmus sp. With Bioflocculant Addition

\begin{tabular}{|c|c|c|c|c|c|c|}
\hline \multicolumn{3}{|c|}{ Effects of Different Experimental Variables } & \multicolumn{4}{|c|}{ Growth Phase } \\
\hline Type of Bioflocculant & Environmental Condition & Physical Condition & $\begin{array}{l}\text { Mid to Late } \\
\text { Exponential }\end{array}$ & $\begin{array}{c}\text { Early } \\
\text { Stationary }\end{array}$ & $\begin{array}{c}\text { Mid } \\
\text { Stationary }\end{array}$ & $\begin{array}{c}\text { Late } \\
\text { Stationary }\end{array}$ \\
\hline B. cepacia Cells & Settling in the Dark* & None & 18 & $\#$ \# & 18 & $?$ \\
\hline B. cepacia Cells & Settling in the Light* & None & $\sqrt{7}$ & $5 z$ & 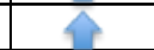 & $?$ \\
\hline B. cepacia Cells & Settling in the Dark* & Different Mixing Intensity (DMI) & $?$ & $\#$ & 1 & $?$ \\
\hline B. cepacia Cells & $\mathrm{pH} 7$ (neutral) & None & 1 & ? & 5 & $?$ \\
\hline B. cepacia Cells & $\mathrm{pH} 3$ & None & St & $?$ & r & $?$ \\
\hline B. cepacia Cells & pH 11 & None & 1 & $?$ & st & $?$ \\
\hline B. cepacia Cells & $\mathrm{pH} 11$ & Different Mixing Intensity (DMI) & 5 & $?$ & 1 & $?$ \\
\hline B. cepacia Cells & Starved Nutrients (bacteria) & None & $\#$ & $?$ & s & $?$ \\
\hline B. cepacia Cells & Starved Nutrients (bacteria) & Different Mixing Intensity (DMI) & 1 & $\widehat{1}$ & 18 & $?$ \\
\hline B. cepacia Cells & None & None & 1 & (1) & 8 & $?$ \\
\hline B. cepacia Cells & None & 30 Minute Contact Time & St & $\#$ & $?$ & $?$ \\
\hline B. cepacia Cells & None & 1/2 Dose & $?$ & $\sqrt{z}$ & $?$ & $\sqrt{7}$ \\
\hline B. cepacia Cells & None & Different Mixing Intensity (DMI) & $?$ & 3 & $?$ & 1 \\
\hline B. cepacia Cells & None & 1/2 Dose + DMl & $?$ & 1 & $?$ & tit \\
\hline B. cepacia Cells & None & 1/2 Algae + 1/2 Dose & $?$ & $?$ & $?$ & 18 \\
\hline B. cepacia Cells & None & 1/2 Algae + Full Dose & $?$ & $?$ & $?$ & 3 \\
\hline B. cepacia Filtrate & None & None & 1 & 1 & 1 & $?$ \\
\hline B. cepacia Filtrate & None & $1 / 2$ Dose & $?$ & 3 & $?$ & $?$ \\
\hline B. cepacia Cells & With Carbon Dioxide (algae) ${ }^{* *}$ & None & $?$ & 1 & $?$ & 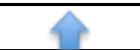 \\
\hline B. cepacia Cells & With Carbon Dioxide (algae) ${ }^{* *}$ & Different Mixing Intensity (DMI) & $?$ & s. & $?$ & 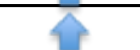 \\
\hline B. cepacia Cells & With Carbon Dioxide (algae)** & 1/2 Dose & $?$ & 1 & $?$ & $\sqrt{2}$ \\
\hline B. cepacia Cells & With Carbon Dioxide (algae)** & 1/2 Dose + DMI & $?$ & $\sqrt{7}$ & $?$ & 1 \\
\hline B. cepacia Cells & With Carbon Dioxide (algae)** & 1/2 Algae + Full Dose & $?$ & 5 & $?$ & 1 \\
\hline B. cepacia Cells & With Carbon Dioxide (algae)** & 1/2 Algae + 1/2 Dose & $?$ & 5 & $?$ & 5 \\
\hline
\end{tabular}

*-Constant light exposure of 30 and 48 hours before settling in the light or dark for mid to late exponential cultures $(30 \mathrm{hrs})$ and early/mid stationary cultures (48 hrs) respectively

?-Not studied, needs future attention

\#-Best growth phase for settling with bioflocculant addition and environmental/physical condition presented (based on normalized cell concentration remaining after two hours of settling)

**-Constant carbon dioxide addition of 4 to 24 hours before settling of early and late stationary phase cultures respectively 
Table 4: Effect on Settling of Different Environmental Conditions for Chlorella vulgaris With Bioflocculant Addition

\begin{tabular}{|c|c|c|c|c|c|c|}
\hline \multicolumn{3}{|c|}{ Effects of Different Experimental Variables } & \multicolumn{4}{|c|}{ Growth Phase } \\
\hline Type of Bioflocculant & Environmental Condition & Physical Condition & $\begin{array}{l}\text { Mid to Late } \\
\text { Exponential }\end{array}$ & $\begin{array}{c}\text { Early } \\
\text { Stationary }\end{array}$ & $\begin{array}{c}\text { Mid } \\
\text { Stationary }\end{array}$ & \begin{tabular}{|c|} 
Late \\
Stationary
\end{tabular} \\
\hline B. cepacia Cells & Settling in the Dark* & None & 1 & $?$ & 8 & $?$ \\
\hline B. cepacia Cells & Settling in the Light* & None & 1 & $?$ & 8 & $?$ \\
\hline B. cepacia Filtrate & Settling in the Dark* & None & 1 & $?$ & 8 & $?$ \\
\hline B. cepacia Filtrate & Settling in the Light* & None & 5 & $?$ & 5 & $?$ \\
\hline B. cepacia Filtrate & Settling in the Dark* & Different Mixing Intensity (DMI) & 5 & $?$ & 马y & $?$ \\
\hline B. cepacia Filtrate & $\mathrm{pH} 11$ & \begin{tabular}{|c|} 
None \\
\end{tabular} & 1 & $?$ & 18 & $?$ \\
\hline B. cepacia Filtrate & pH 11 & Different Mixing Intensity (DMI) & 18 & $?$ & 18 & $?$ \\
\hline B. cepacia Filtrate & $\mathrm{pH} 7$ & \begin{tabular}{|l|} 
None \\
\end{tabular} & 18 & $?$ & 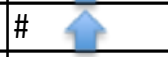 & $?$ \\
\hline B. cepacia Filtrate & $\mathrm{pH} 3$ & None & 1 & $?$ & 5 & $?$ \\
\hline B. cepacia Cells & None & \begin{tabular}{|c|} 
None \\
\end{tabular} & $\sqrt{2}$ & 18 & $\sqrt{2}$ & $?$ \\
\hline B. cepacia Cells & None & Different Mixing Intensity (DMI) & $?$ & $\sqrt{z}$ & $?$ & $?$ \\
\hline B. cepacia Cells & None & 1/2 Dose & 18 & $?$ & $\sqrt{2}$ & $?$ \\
\hline B. cepacia Filtrate & None & None & 1 & $\widehat{1}$ & 5 & 5 \\
\hline B. cepacia Filtrate & None & Different Mixing Intensity (DMI) & $?$ & 1 & 1 & $\sqrt{7}$ \\
\hline B. cepacia Filtrate & Starved Nutrients (Bacteria) & \begin{tabular}{|c|} 
None \\
\end{tabular} & $?$ & 1 & $\sqrt{2}$ & 8 \\
\hline B. cepacia Filtrate & Starved Nutrients (Bacteria) & Different Mixing Intensity (DMI) & $?$ & 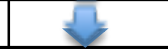 & 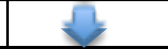 & $\sqrt{2}$ \\
\hline B. cepacia Cells & Starved Nutrients (Bacteria) & \begin{tabular}{|c|} 
None \\
\end{tabular} & $?$ & $\sqrt{7}$ & $\sqrt{7}$ & $?$ \\
\hline B. cepacia Cells & Starved Nutrients (Bacteria) & Different Mixing Intensity (DMI) & $?$ & 8 & $?$ & $?$ \\
\hline B. cepacia Filtrate & None & \begin{tabular}{|c|}
$1 / 2$ Dose \\
\end{tabular} & $?$ & 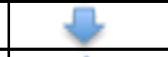 & $?$ & 3 \\
\hline B. cepacia Filtrate & Starved Nutrients (Bacteria) & 1/2 Dose & $?$ & 1 & $?$ & 5 \\
\hline B. cepacia Filtrate & With Carbon Dioxide (algae) & 1/2 Dose & $?$ & 18 & $?$ & 18 \\
\hline B. cepacia Filtrate & With Carbon Dioxide (algae) & None & $?$ & $\sqrt{2}$ & $?$ & 3 \\
\hline B. cepacia Filtrate & With Carbon Dioxide (algae) & Different Mixing Intensity (DMI) & $?$ & $\sqrt{7}$ & $?$ & $?$ \\
\hline B. cepacia Filtrate & With Carbon Dioxide (algae) & 1/2 Algae $+1 / 2$ Dose & $?$ & 1 & $?$ & $?$ \\
\hline B. cepacia Filtrate & With Carbon Dioxide (algae) & 1/2 Algae + Full Dose & $?$ & 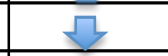 & $?$ & 18 \\
\hline B. cepacia Filtrate & None & 1/2 Algae + Full Dose & $?$ & $?$ & $?$ & 5 \\
\hline
\end{tabular}

*-Constant light exposure of 30 and 48 hours before settling in the light or dark for mid to late exponential cultures (30 hrs) and early/mid stationary cultures (48 hrs) respectively

?-Not studied, needs future attention

\#-Best growth phase for settling with bioflocculant addition and environmental/physical condition presented (based on normalized cell concentration remaining after two hours of settling)

**-Constant carbon dioxide addition of 4 to 24 hours before settling of early and late stationary phase cultures respectively 


\section{Appendix: Section 2: Compilation of Micrographs}

Micrographs were taken of both the bacterial and algal cultures used in this research. The label beneath each micrograph describes the content of each.

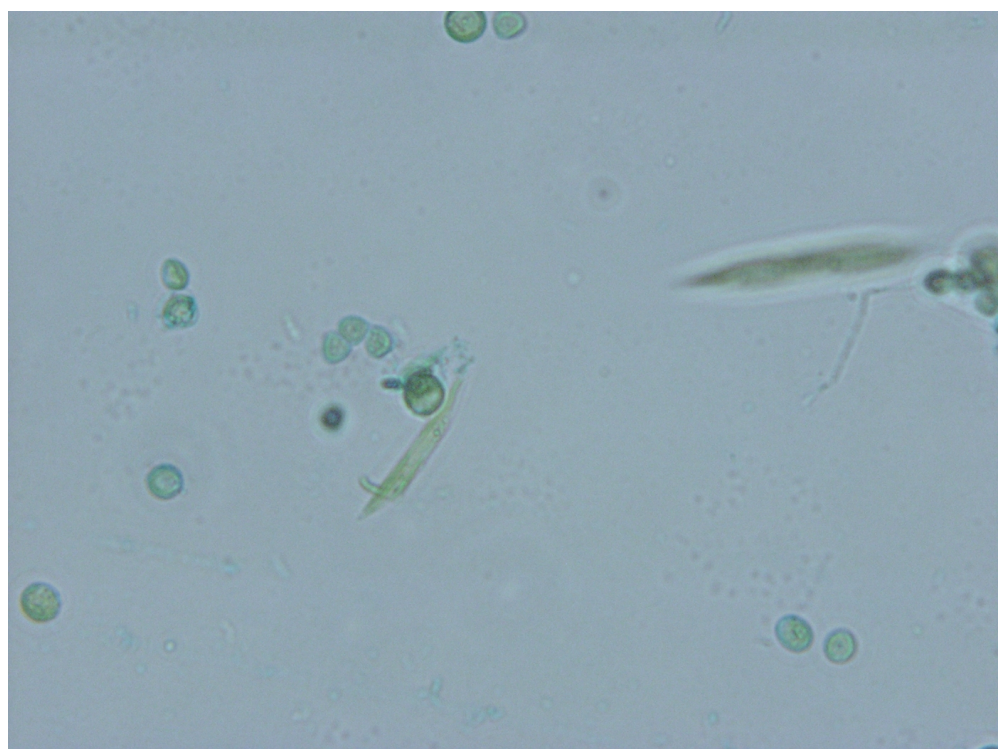

Micrograph 1-Alcian Blue Staining and Visualization of TEP from a Chlorella sample from Dr. Brian Hampson, Cal Poly, San Luis Obispo (1000X) (Phase 3)

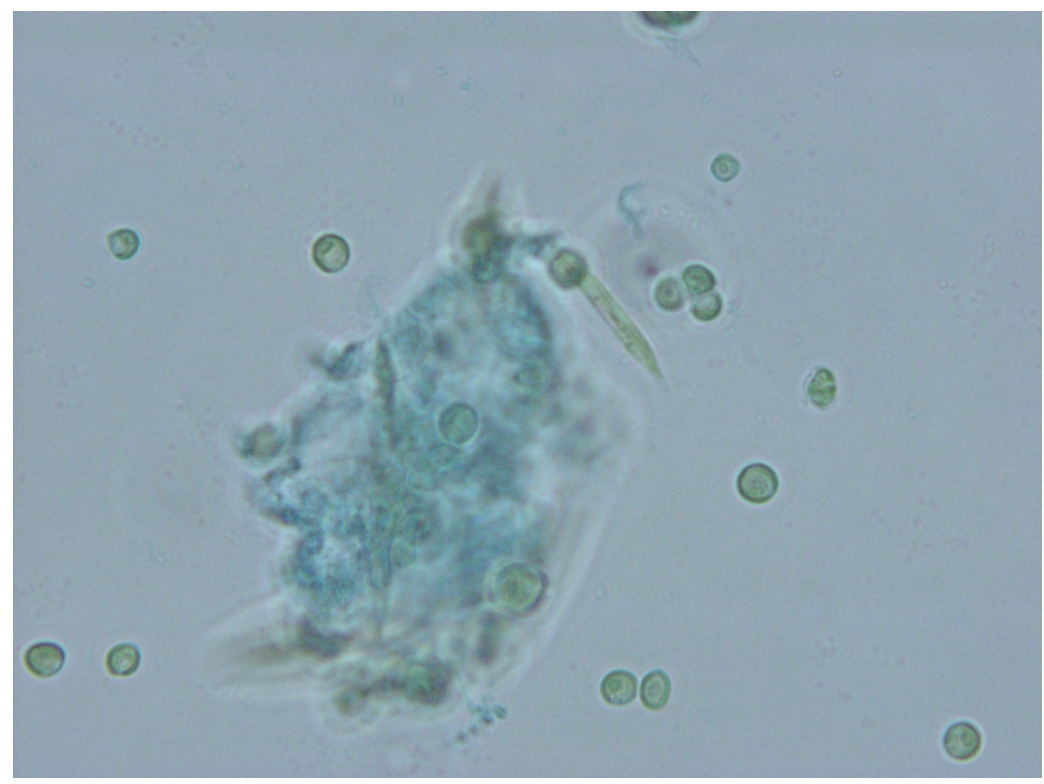

Micrograph 2-Alcian Blue Staining and Visualization of TEP in an algal floc from a Chlorella sample from Dr. Brian Hampson, Cal Poly, San Luis Obispo (1000X) (Phase 


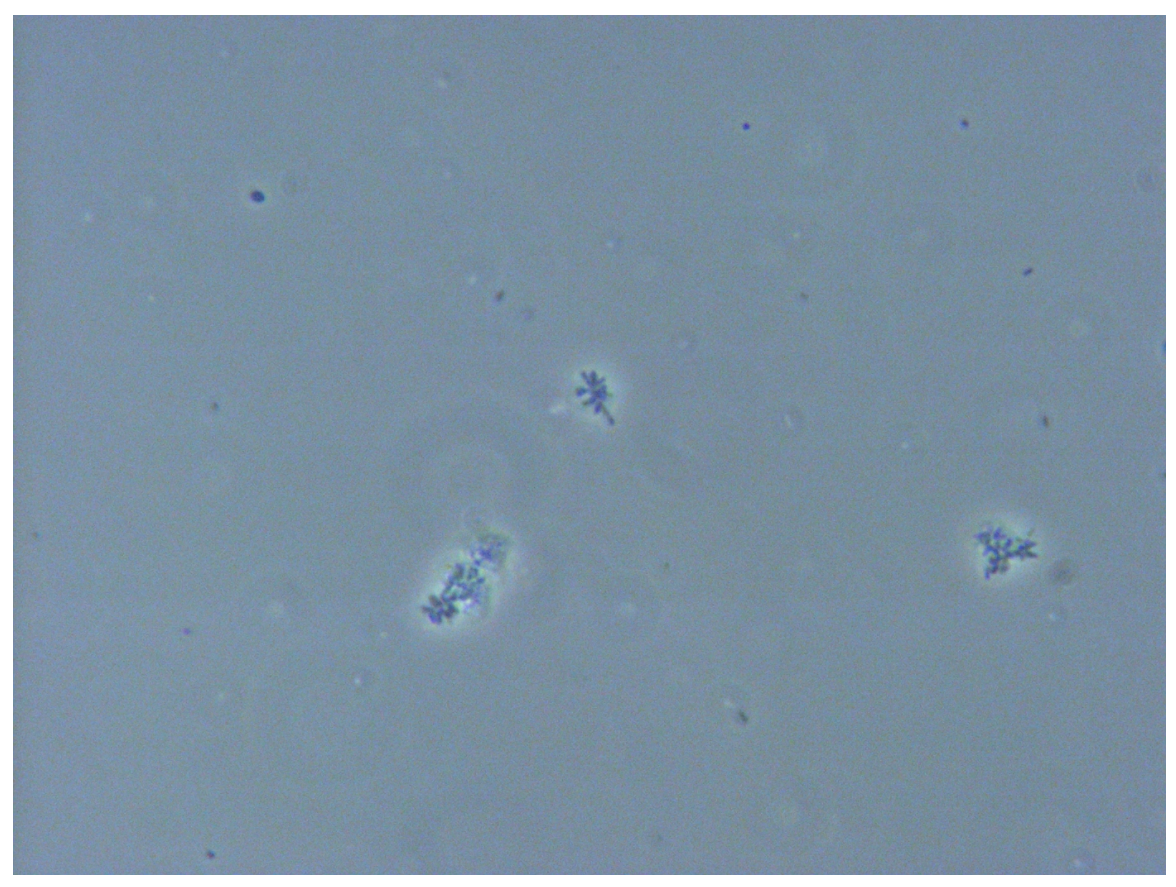

Micrograph 3-Cluster of B. cepacia bacterial cells used as a bioflocculant in research (1000X-No Alcian Blue)

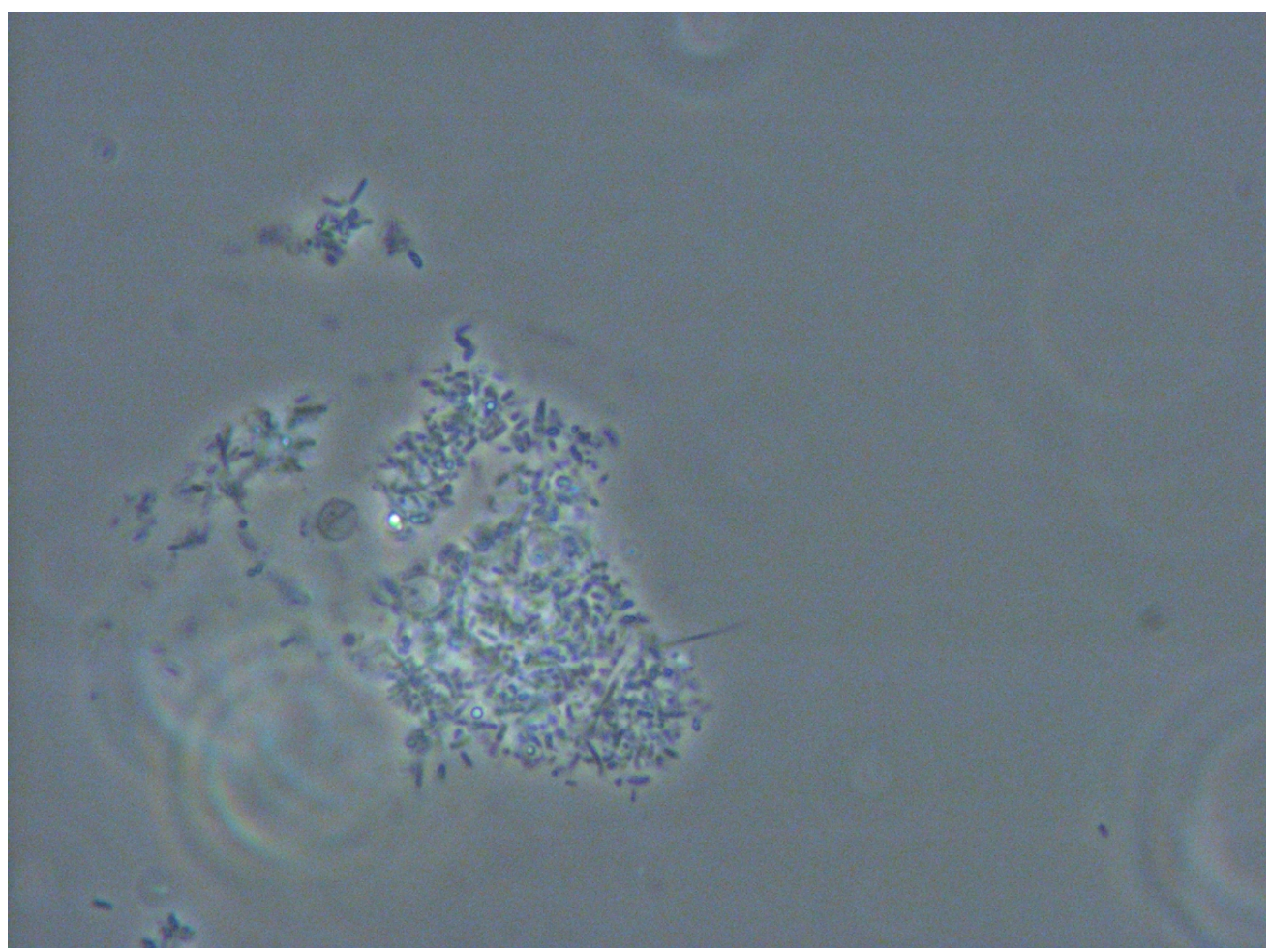

Micrograph 4-Larger floc of B. cepacia bacterial cells used as a bioflocculant in research (1000X-No Alcian Blue) 


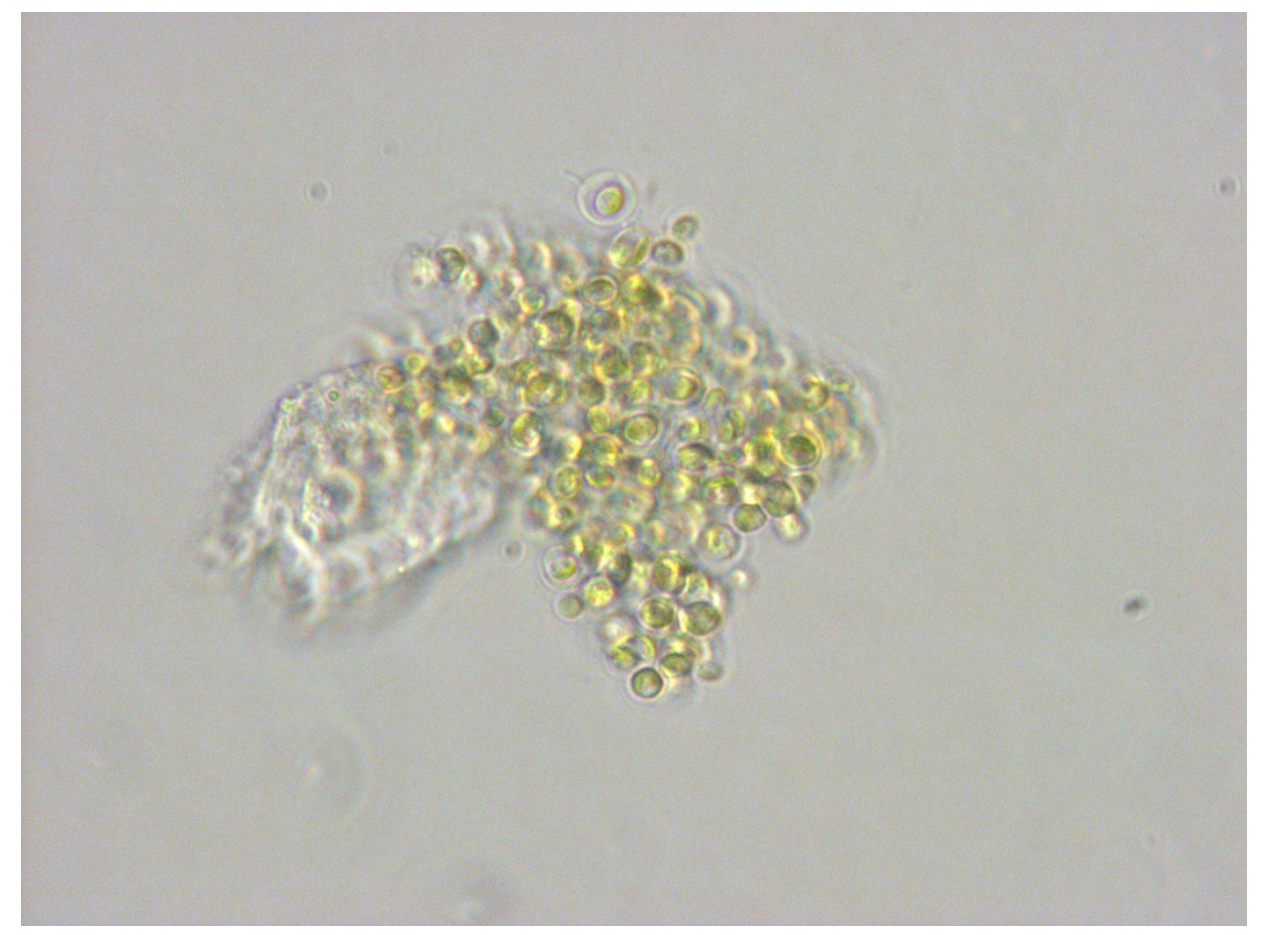

Micrograph 5-A floc of Chlorella vulgaris cells used in research with added bioflocculant (B. cepacia filtrate) (1000X) (Phase 2-No Alcian Blue)

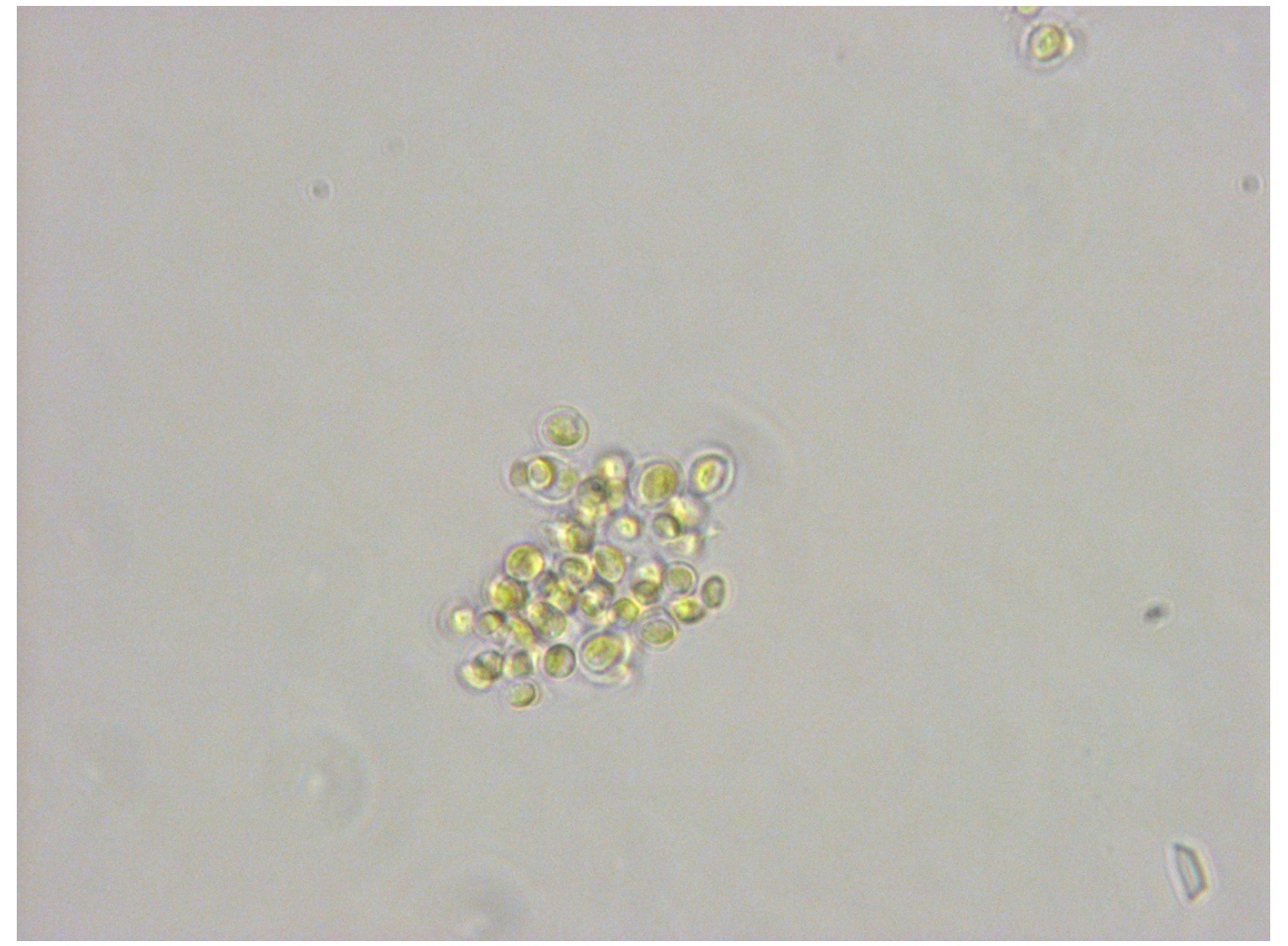

Micrograph 6-A floc of Chlorella vulgaris cells used in research with added bioflocculant (B. cepacia filtrate) (1000X) (Phase 2-No Alcian Blue) 


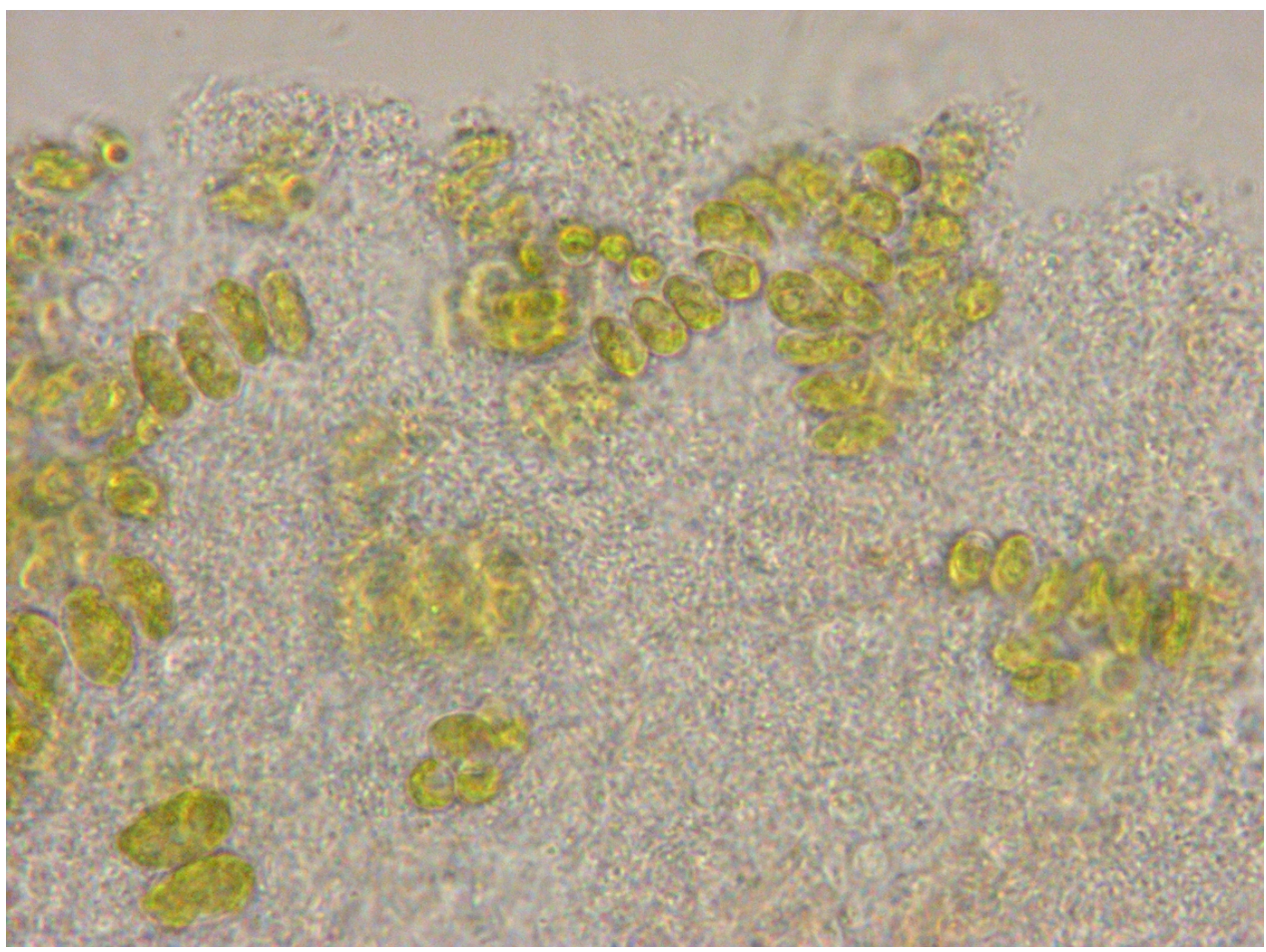

Micrograph 7-A floc of Scenedesmus cells used in research with added bioflocculant (B. cepacia cells) (1000X) (Phase 2-No Alcian Blue)

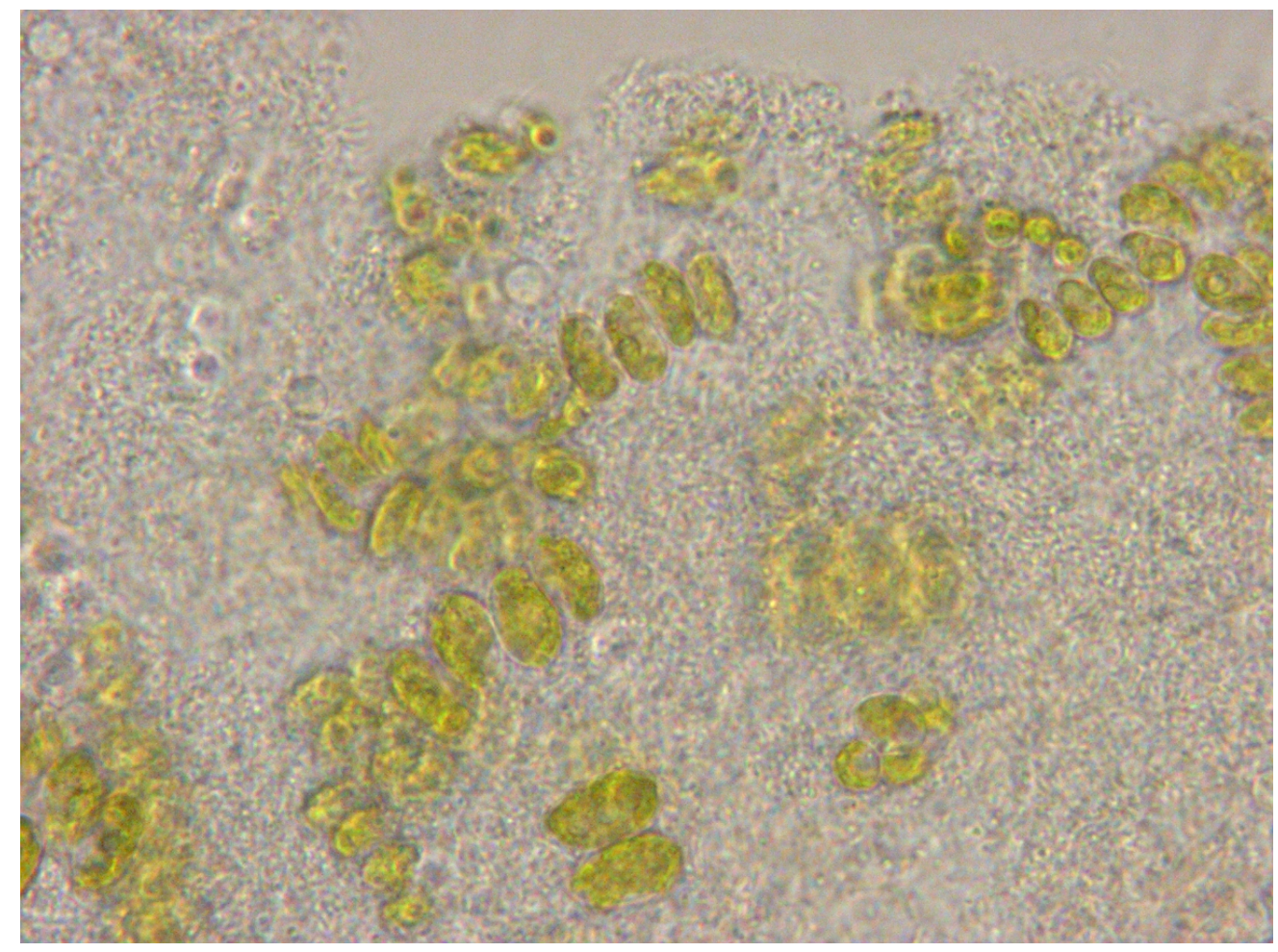

Micrograph 8-A floc of Scenedesmus cells used in research with added bioflocculant (B. cepacia cells) (1000X) (Phase 2-No Alcian Blue) 


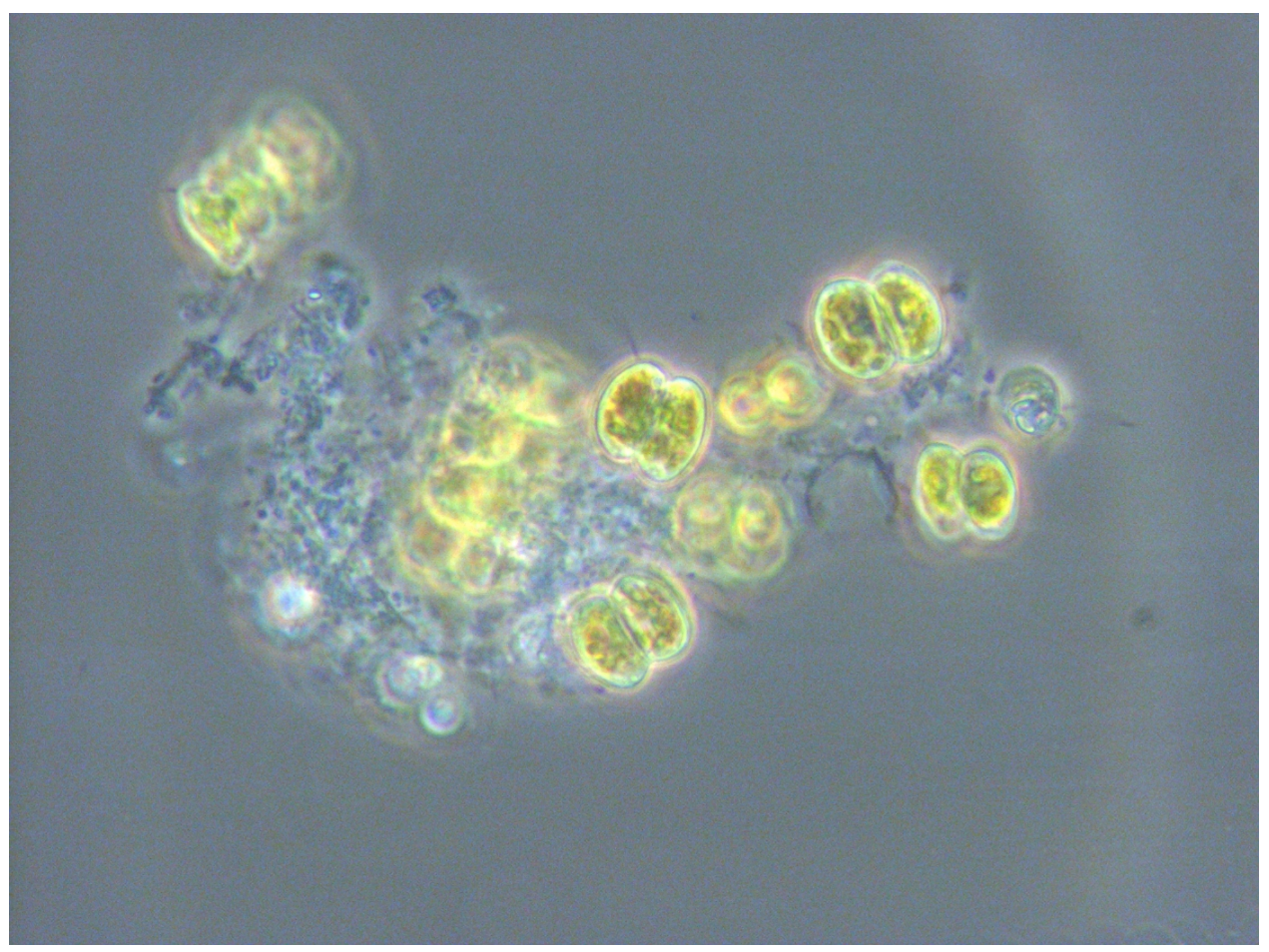

Micrograph 9-A floc of Scenedesmus cells used in research with added bioflocculant (B. cepacia cells) (1000X) (Phase 3-No Alcian Blue)

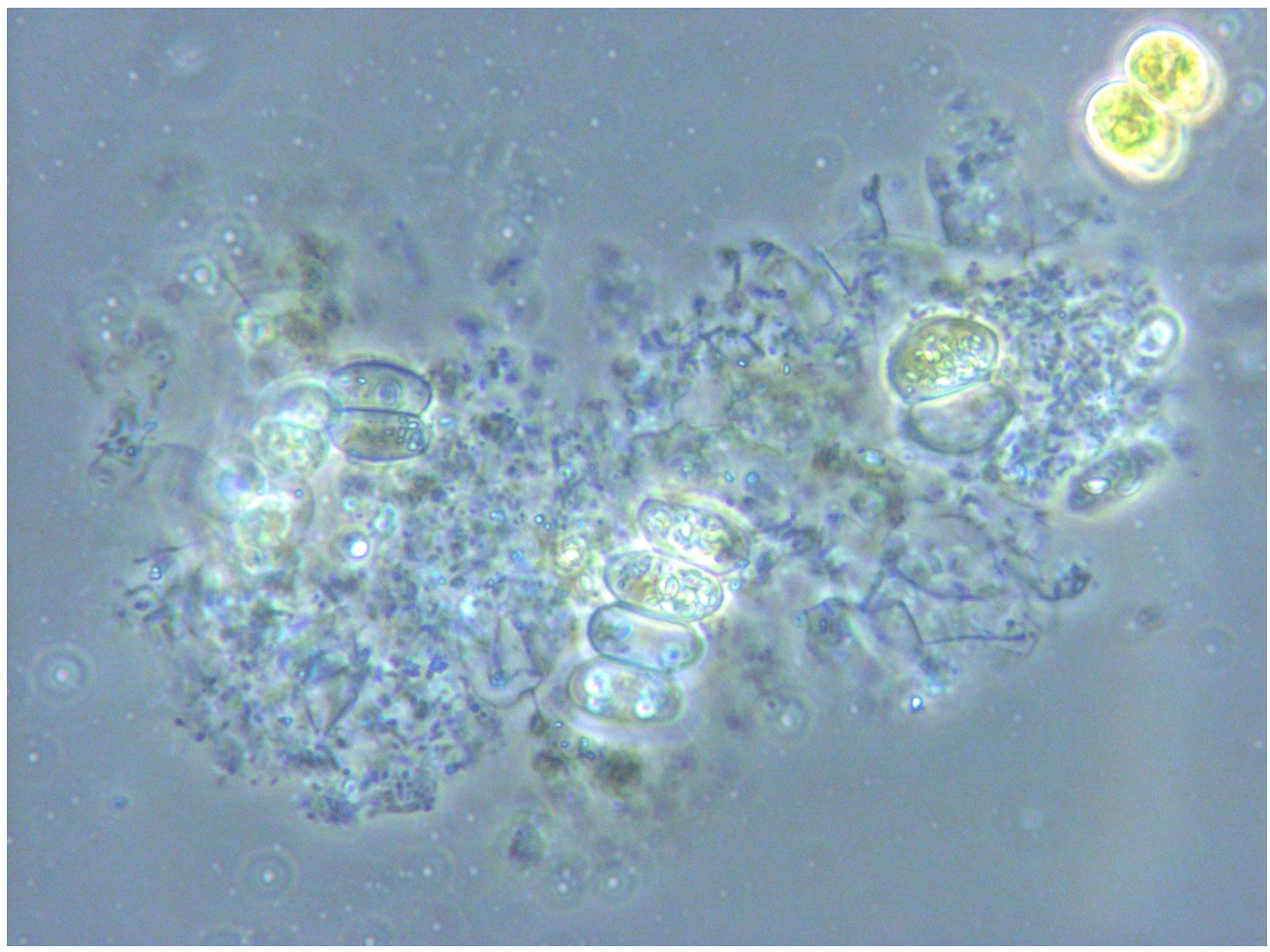

Micrograph 10-A floc of Scenedesmus cells used in research with added bioflocculant (B. cepacia cells) (1000X) (Phase 3-No Alcian Blue) 
Appendix: Section 3: Compilation of Supplemental Figures: Section 4.2.4
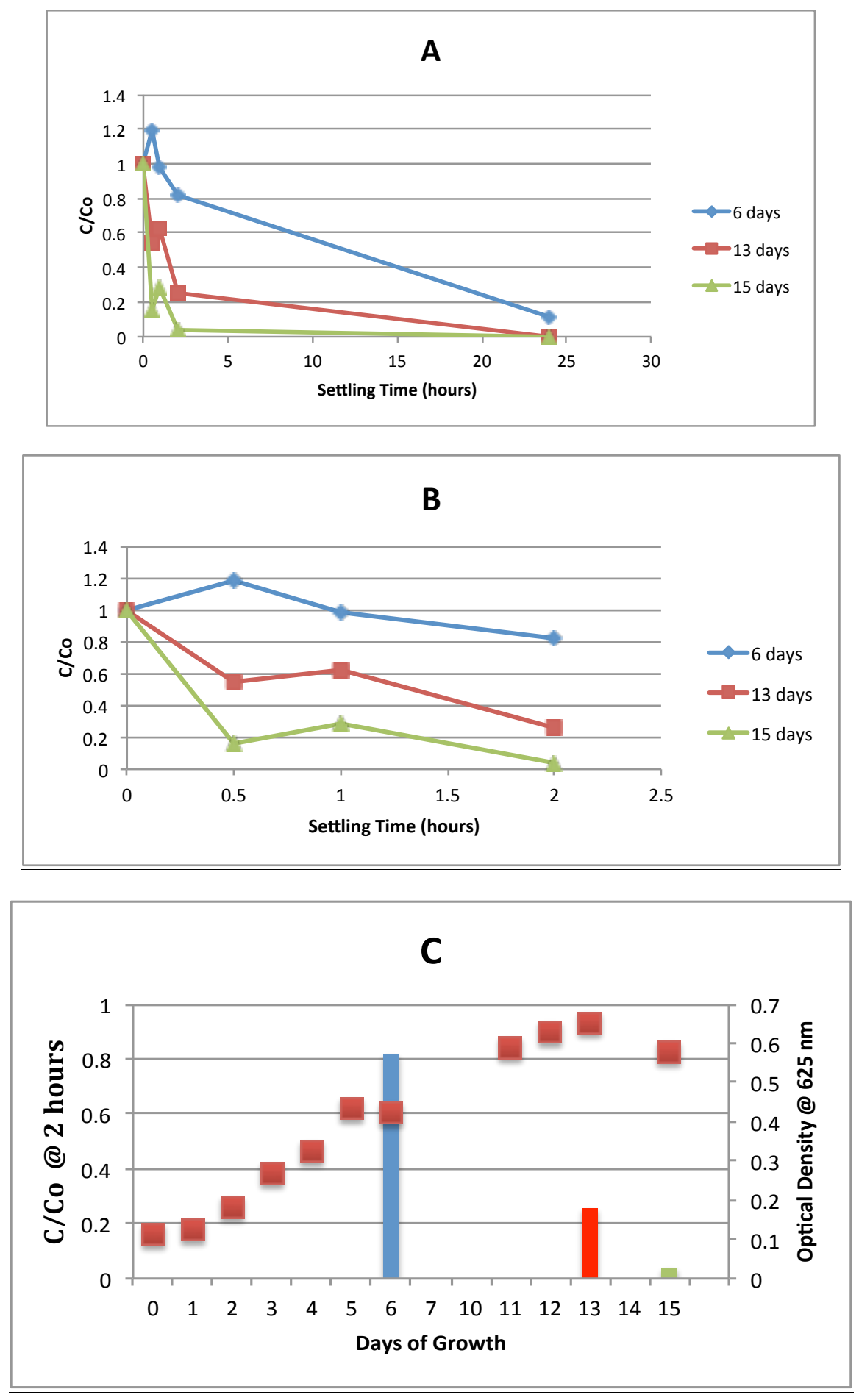

Figure A.1-Settling of Scenedesmus based on normalized cell concentration remaining with B. cepacia cell addition for a A) 24-hour settling period, B) 2-hour settling period and $C$ ) a comparison of growth phase and cell addition (plotted against optical density at $625 \mathrm{~nm}$ ) (Colors refer to days of growth and are the same throughout) 
Supplemental figures for Section 4.2.4
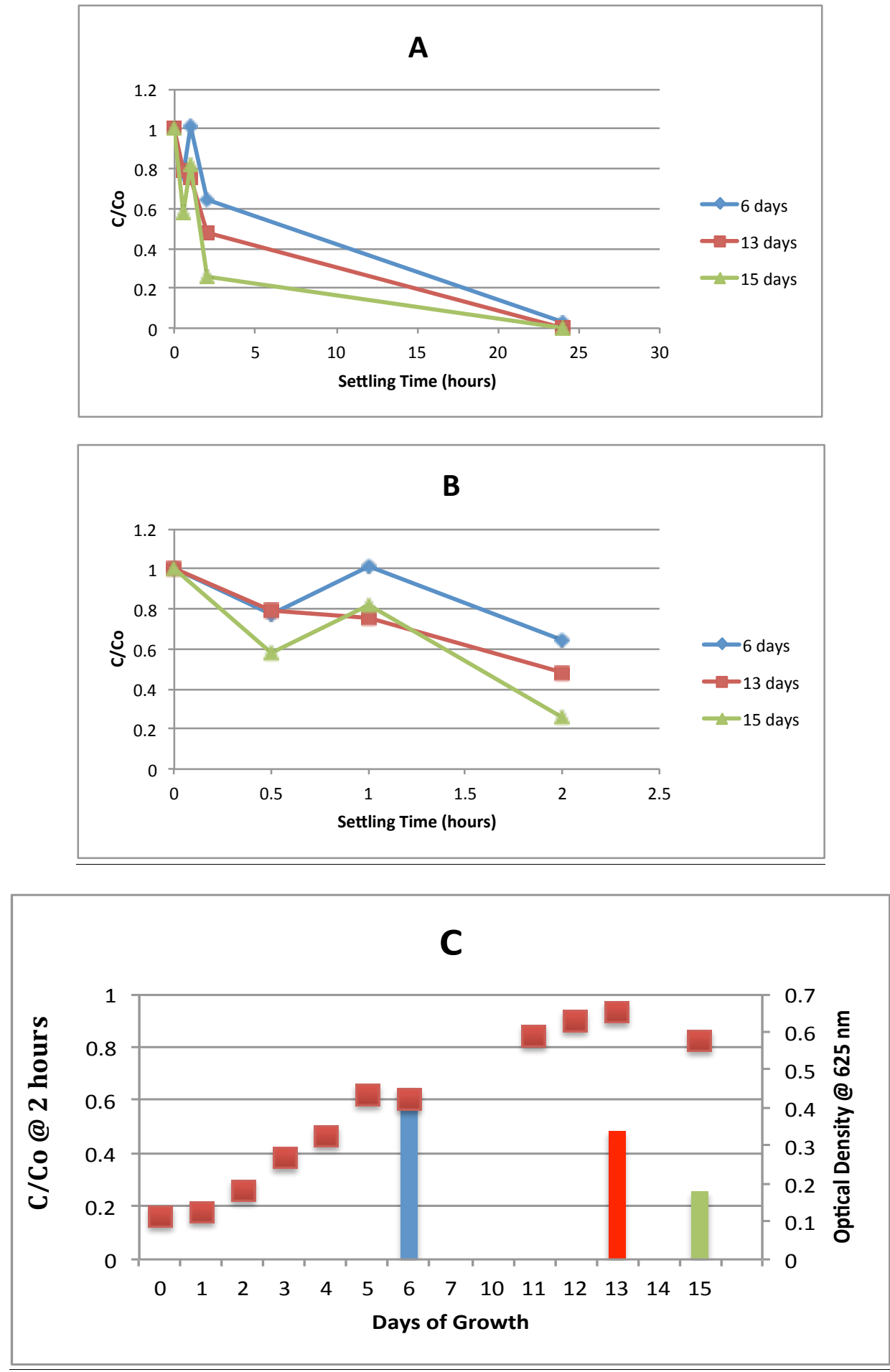

Figure A.2- Settling based of Scenedesmus based on normalized cell concentration remaining for with $B$. cepacia filtrate addition for $a A)$ 24-hour settling period, B) 2hour settling period and C) a comparison of growth phase and cell addition (plotted against optical density at $625 \mathrm{~nm}$ ) (Colors refer to days of growth and are the same throughout) 


\section{Supplemental Figures for Section 4.2.4}
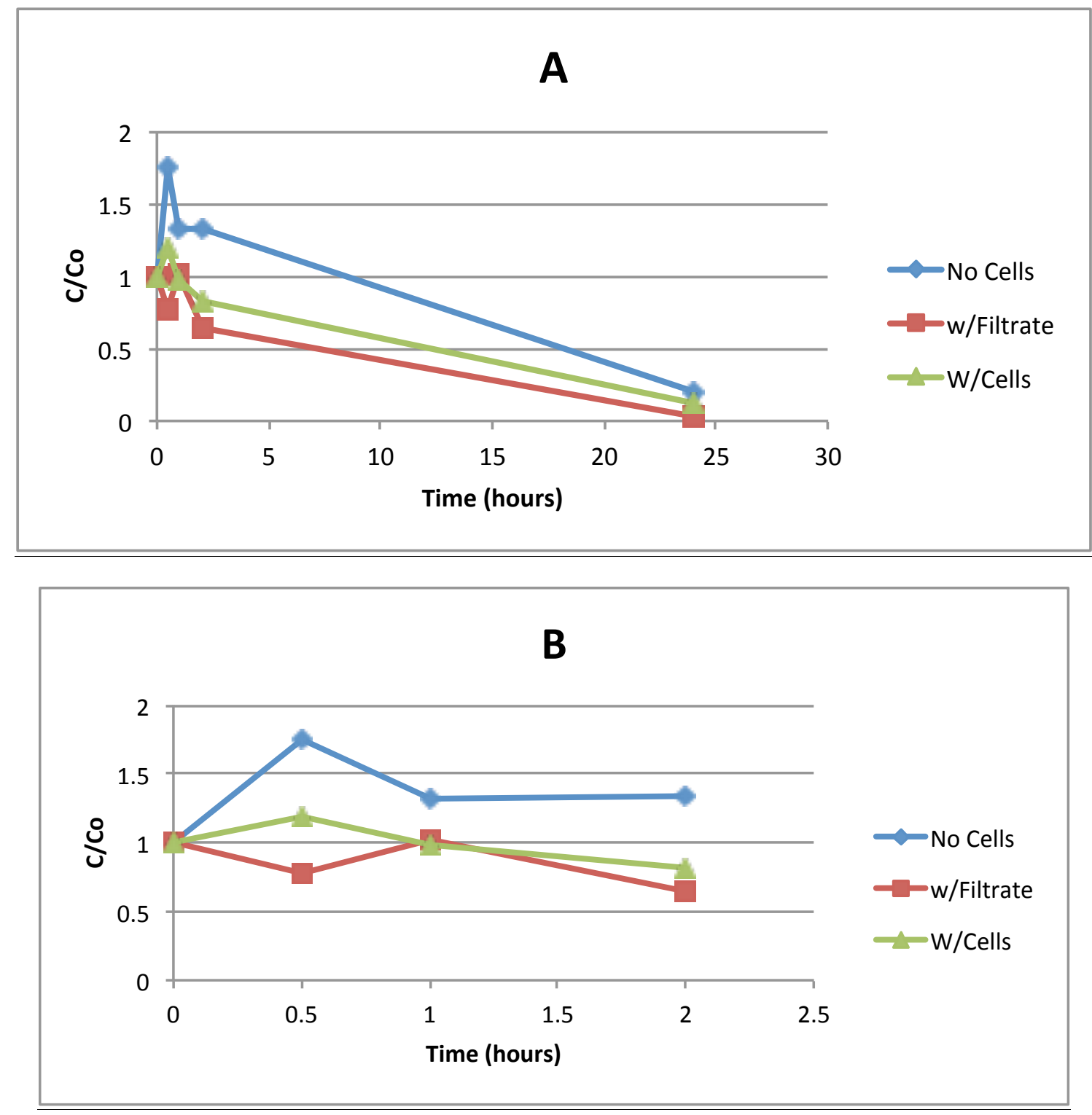

Figure A.3 -Normalized cell concentration remaining as a function of settling time for the same Scenedesmus culture with B. cepacia cell, filtrate, and no cell addition after 6 days of growth over a A) 24-hour settling period and B) 2-hour settling period 


\section{Supplemental Figures for Section 4.2.4}
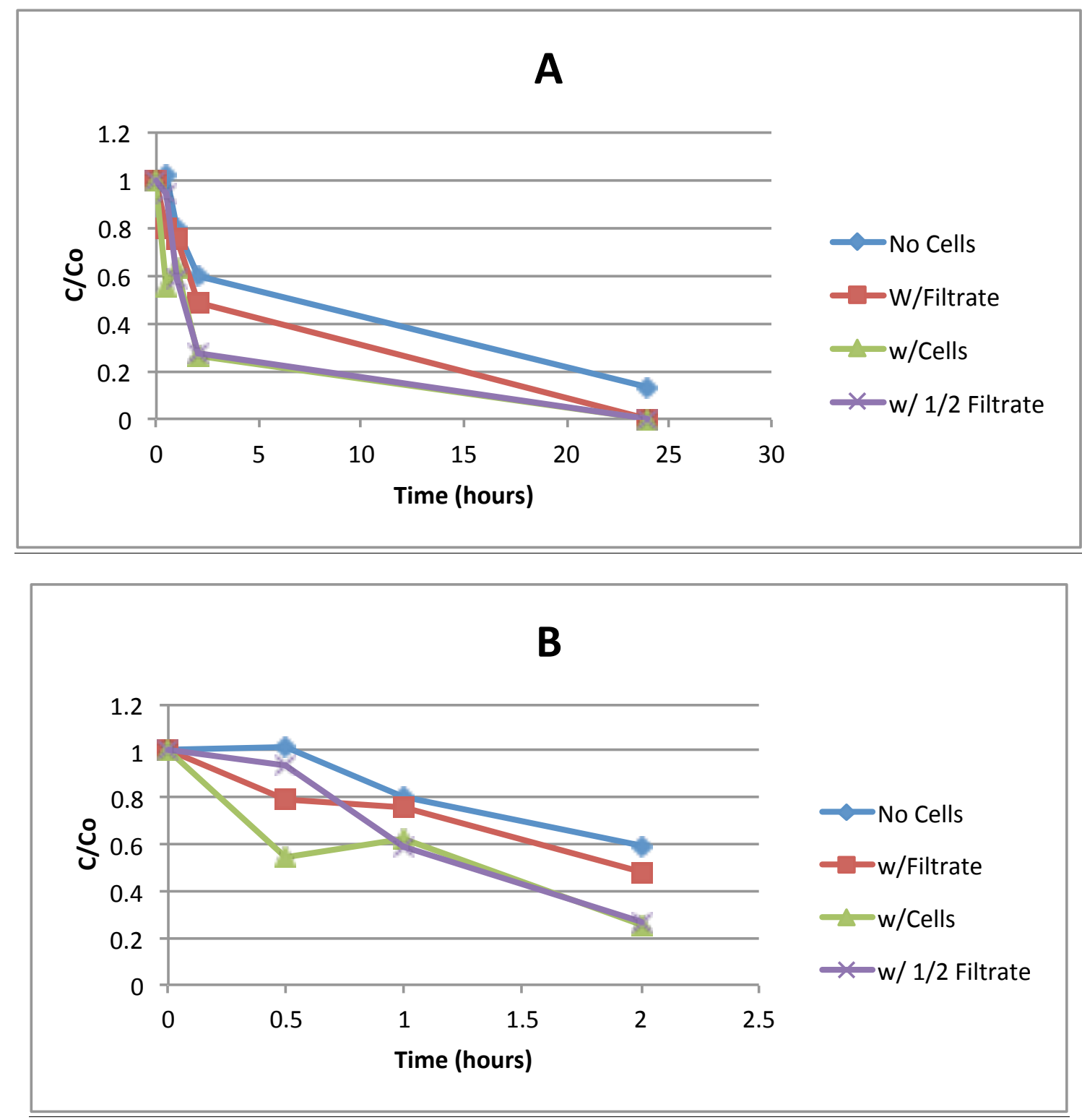

Figure A.4-Normalized Cell Concentration as a function of settling time for the same Scenedesmus culture with $B$. cepacia cell, filtrate, $1 / 2$ filtrate, and no cell addition after 13 days of growth over $a A)$ 24-hour and B) 2-hour settling period 
Supplemental Figures for Section 4.2.4

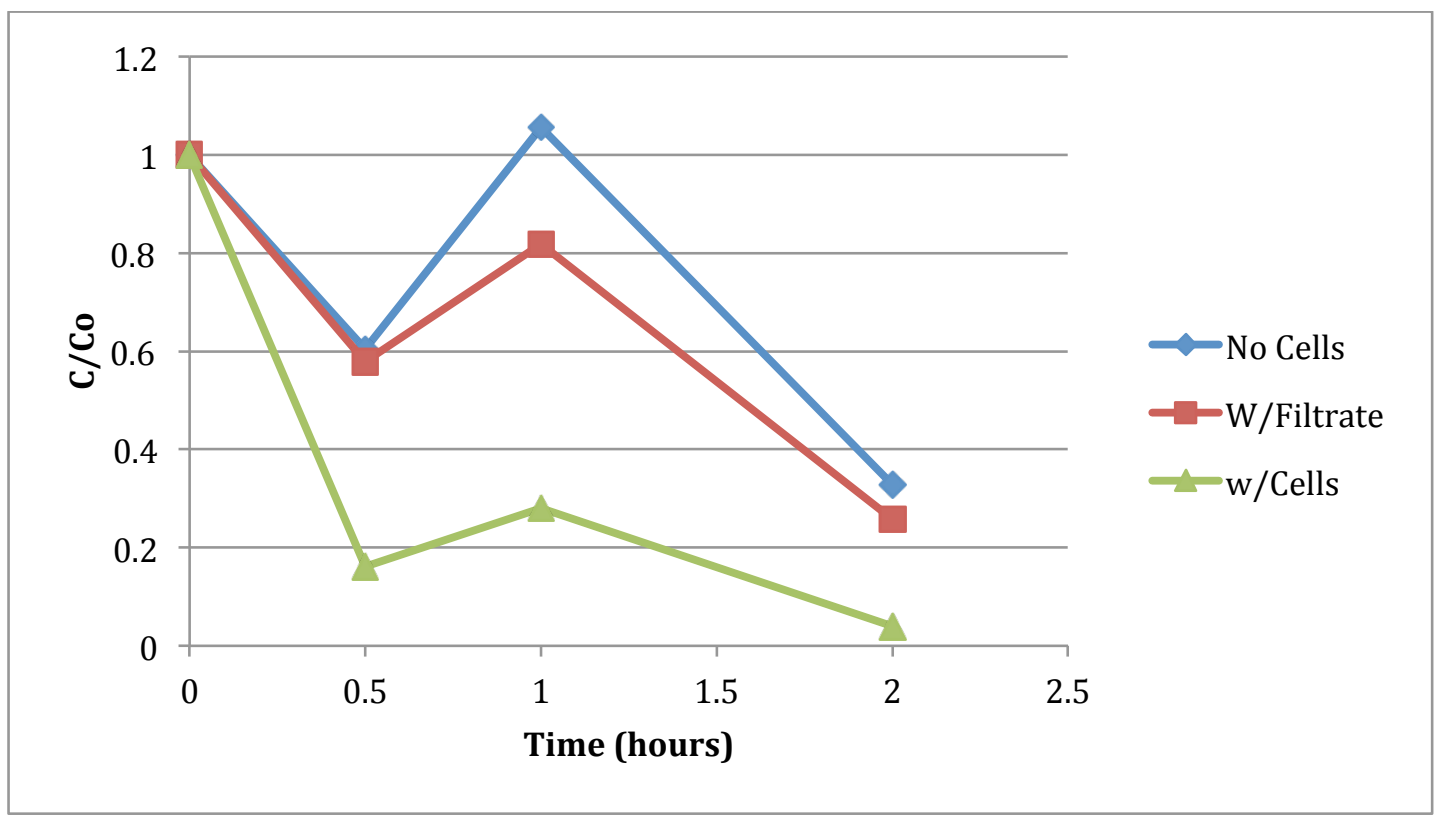

Figure A.5-Normalized cell concentration as a function of settling time over a 2-hour period for the same Scenedesmus culture with B. cepacia cell, filtrate, and no cell addition after 15 days of growth 
Supplemental Figures for Section 4.2.4
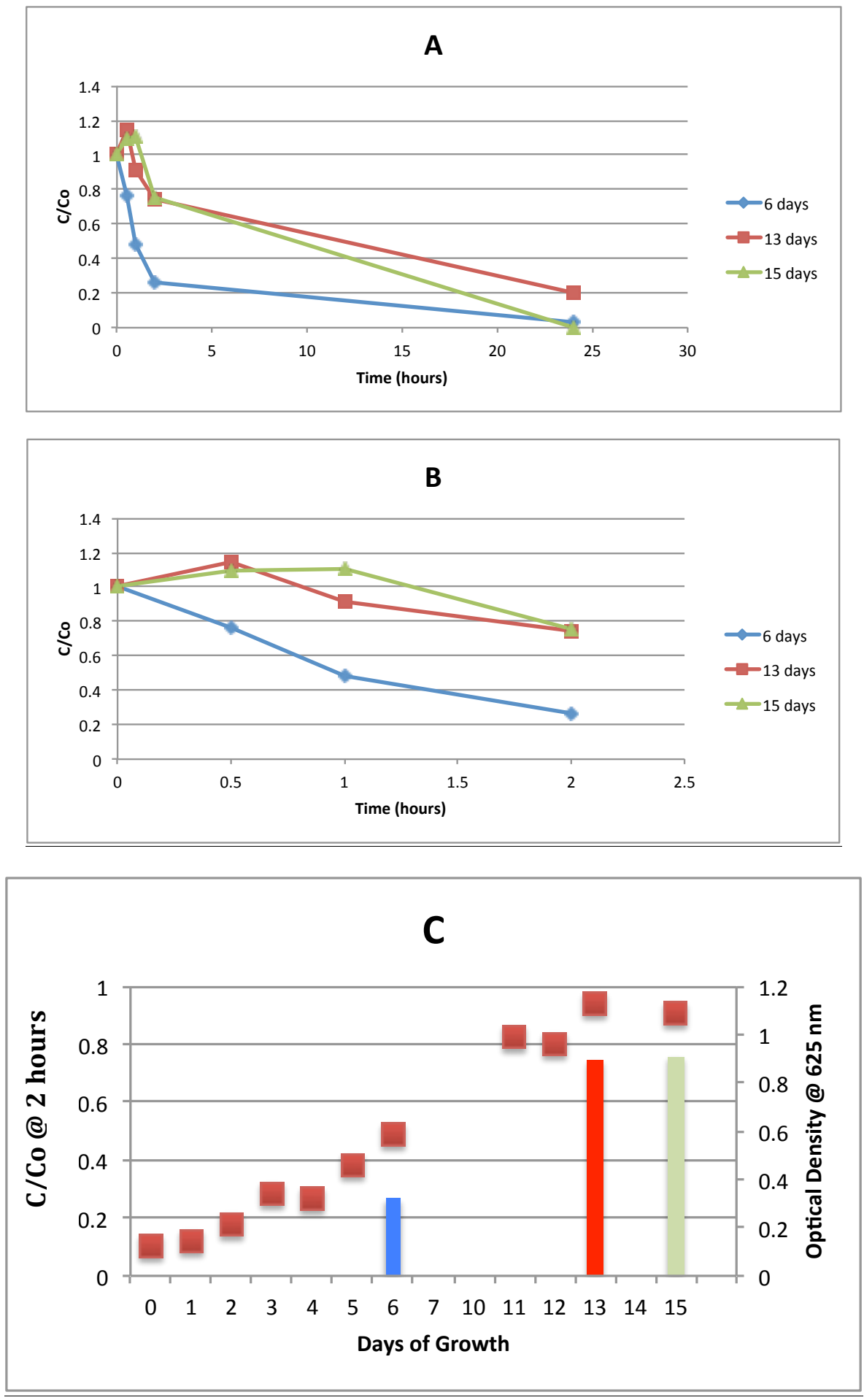

Figure A.6-Settling based on normalized cell concentration remaining for the same Chlorella culture over the growth curve with B. cepacia cell addition for a A) 24-hour settling period, B) 2-hour settling period and C) a comparison of growth phase and cell addition (plotted against optical density at $625 \mathrm{~nm}$ ) (Colors refer to days of growth and are the same throughout) 
Supplemental Figures for Section 4.2.4
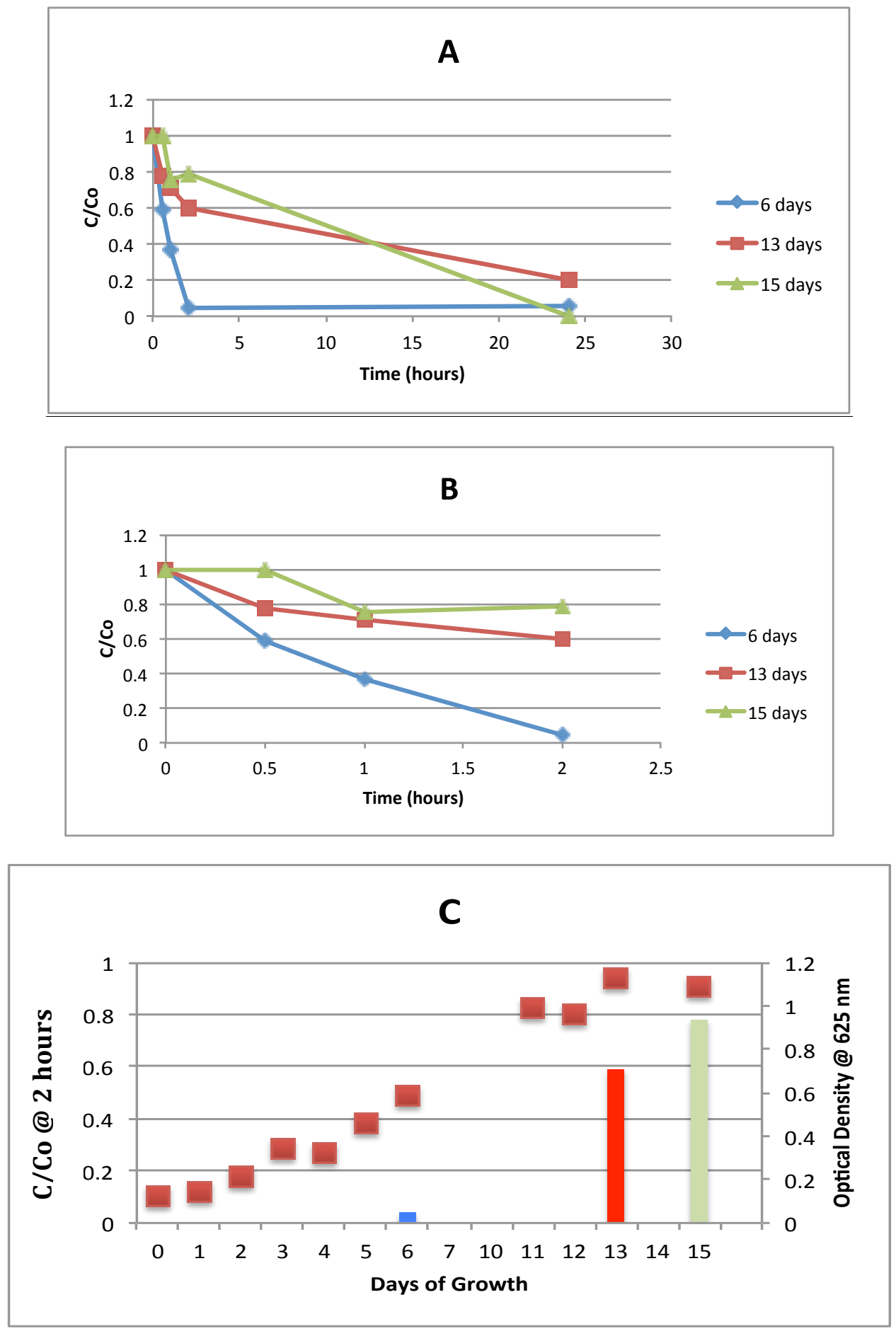

Figure A.7-Settling based on normalized cell concentration remaining for the same Chlorella culture over the growth curve with $B$. cepacia filtrate addition for a A) 24hour settling period, B) 2-hour settling period and C) a comparison of growth phase and filtrate addition (plotted against optical density at $625 \mathrm{~nm}$ ) (Colors refer to days of growth and are the same throughout) 
Supplemental Figures for Section 4.2.4
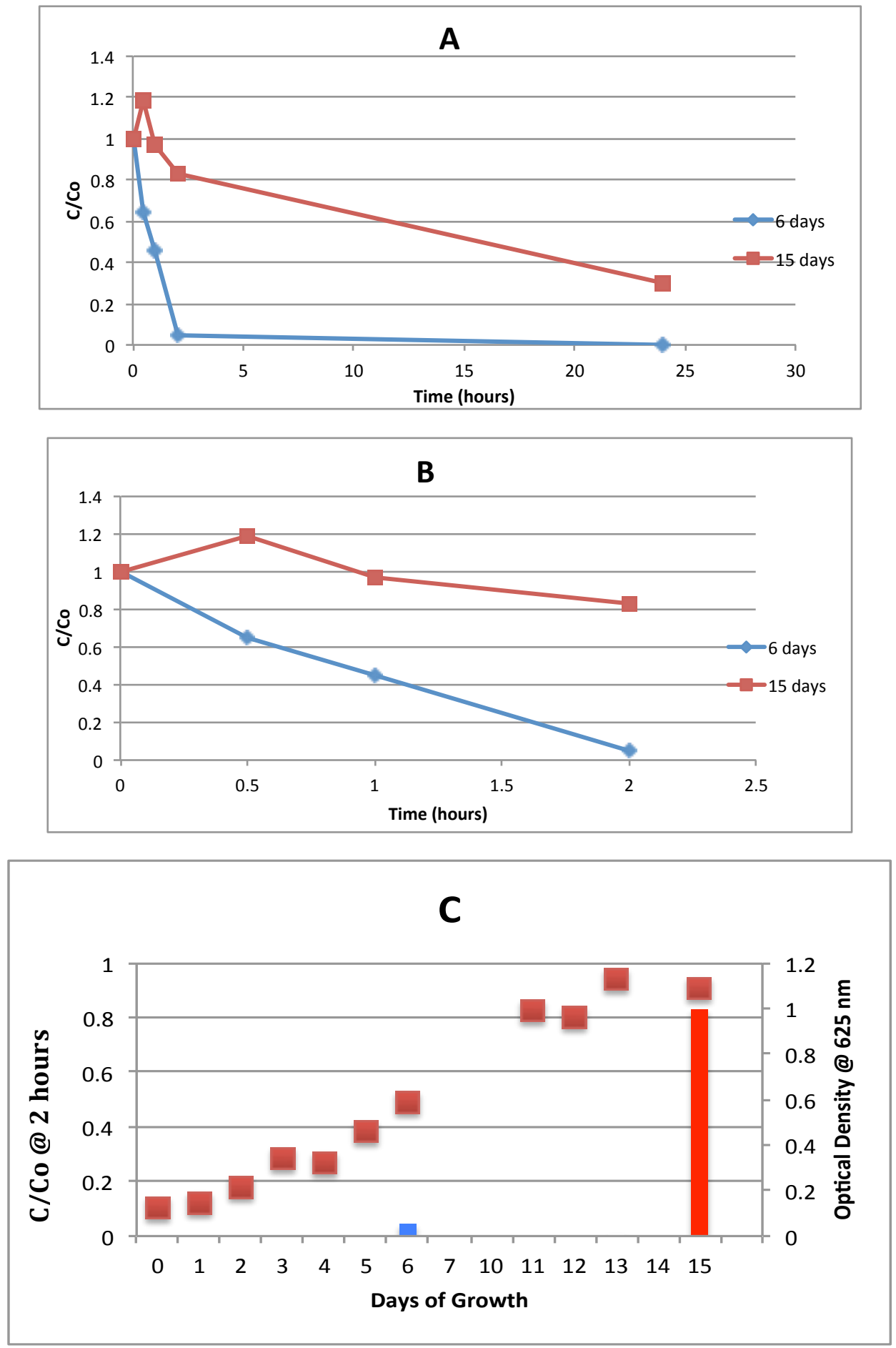

Figure A.8-Settling based on normalized cell concentration remaining for the same Chlorella culture over the growth curve with $1 / 2$ B. cepacia cell addition for a A) 24-hour settling period, $B$ ) 2-hour settling period and C) a comparison of growth phase and $1 / 2$ cell addition (plotted against optical density at $625 \mathrm{~nm}$ ) (Colors refer to days of growth and are the same throughout) 
Supplemental Figures for Section 4.2.4
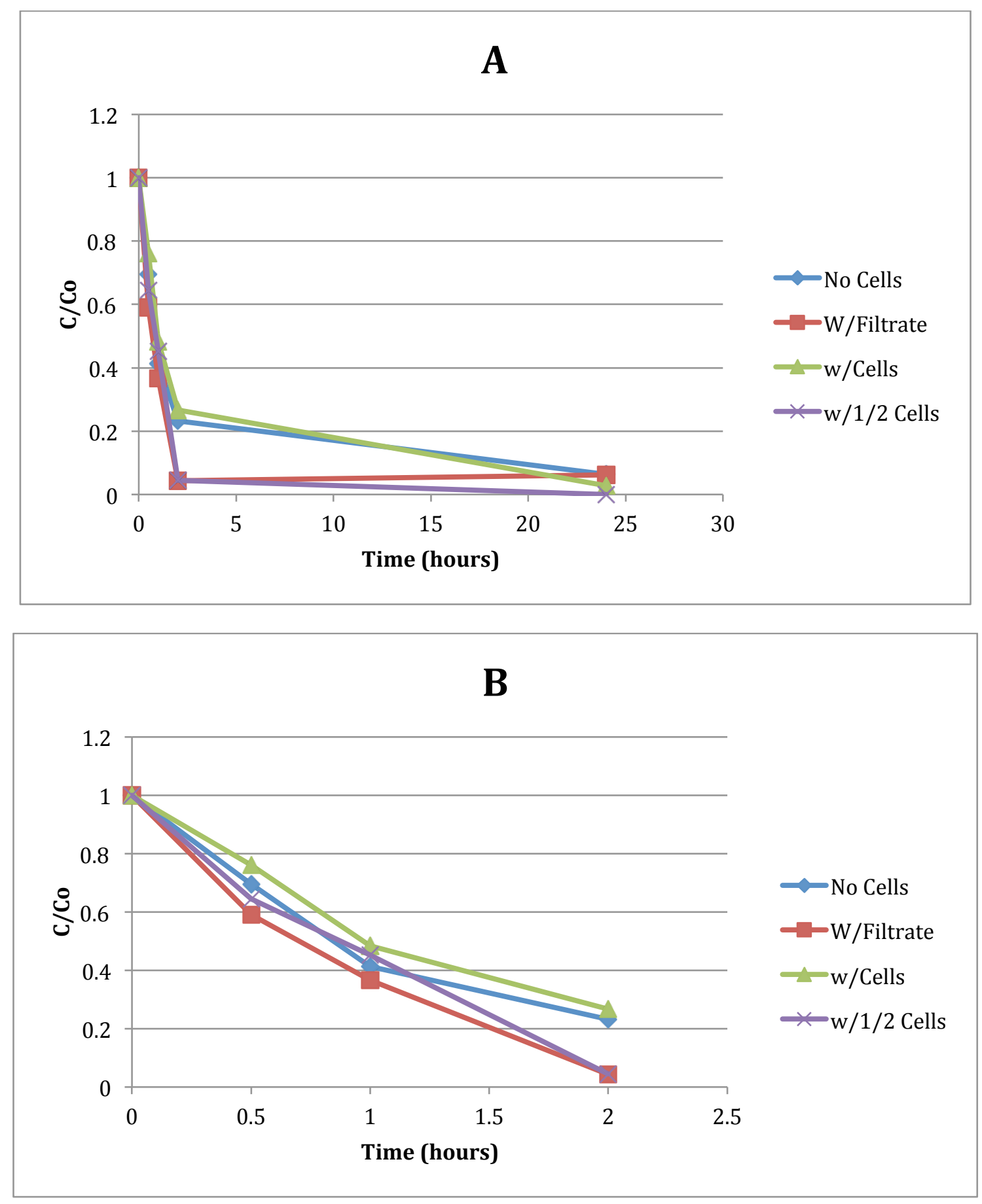

Figure A.9-Normalized cell concentration remaining as a function of settling time for the same Chlorella culture with $B$. cepacia cell, filtrate, $1 / 2$ cells and no cell addition after six days of growth over a A) 24- hour period and B) 2-hour period 


\section{Supplemental Figures for Section 4.2.4}
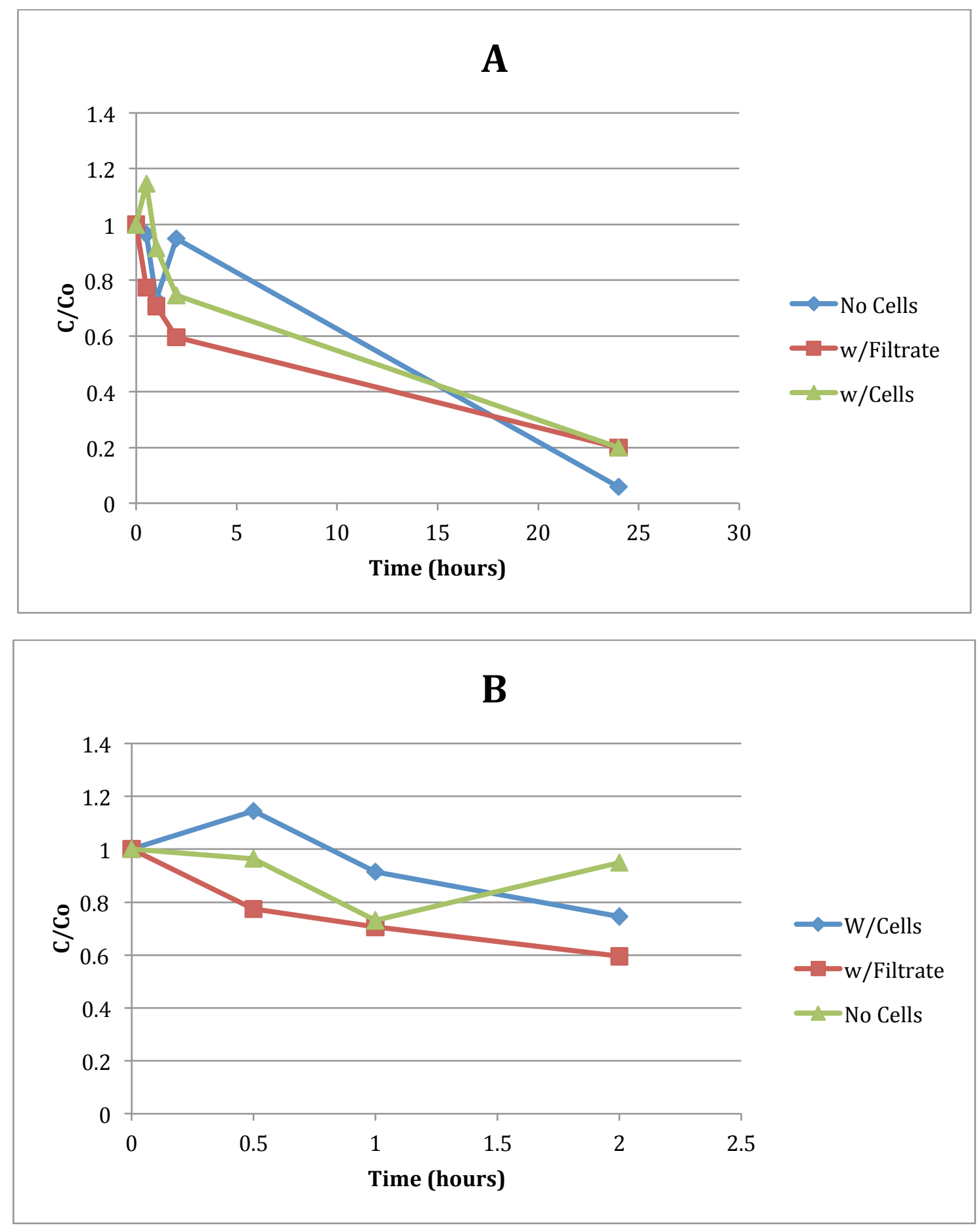

Figure A.10-Normalized cell concentration remaining as a function of settling time for the same Chlorella culture with B. cepacia cell, filtrate, and no cell addition after thirteen days of growth over a A) 24-hour period and B) 2-hour period 
Supplemental Figures for Section 4.2.4

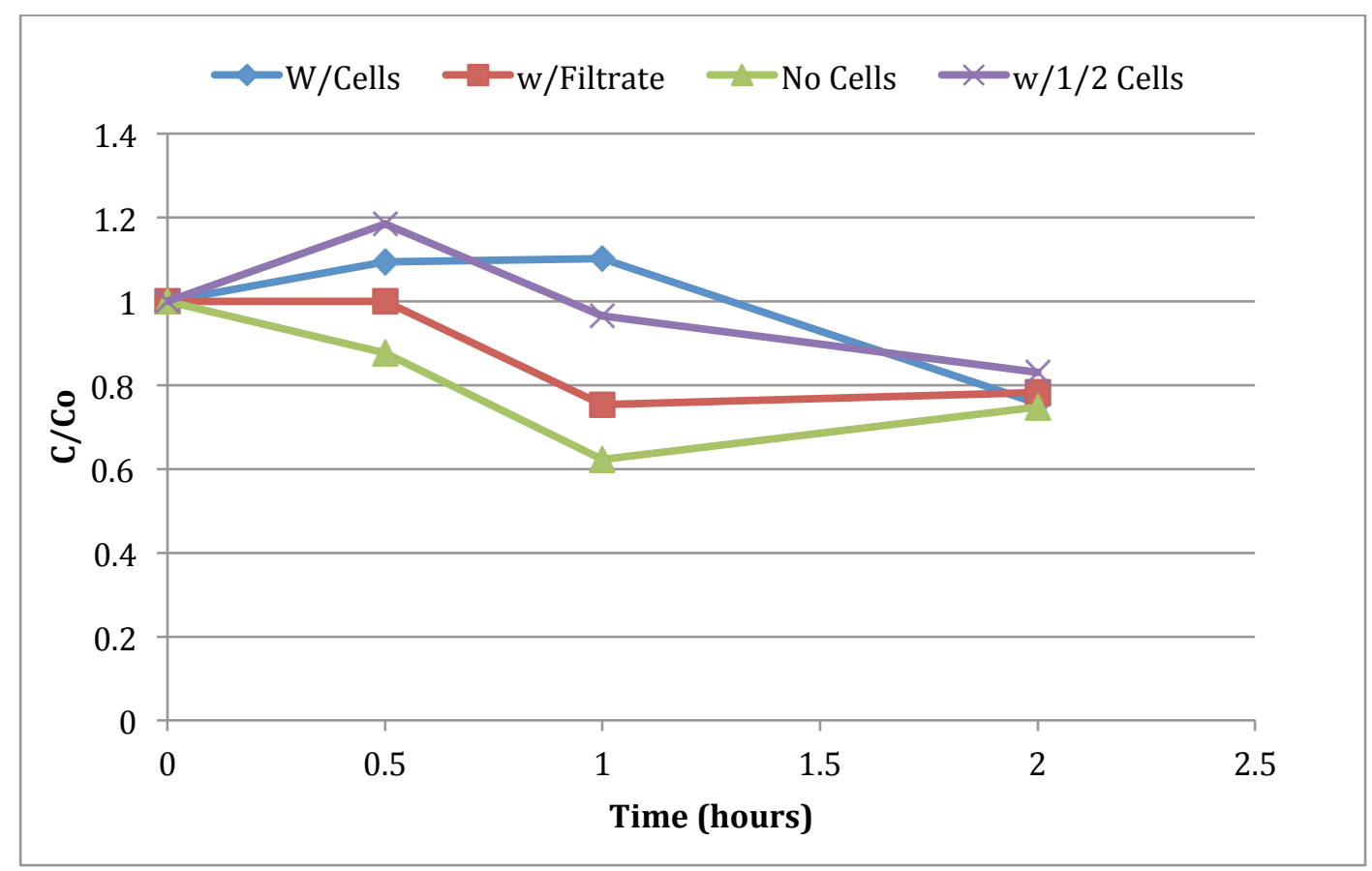

Figure A.11-Normalized cell concentration remaining as a function of settling time over a 2-hour period for the same Chlorella culture with $B$. cepacia cell, filtrate, 1/2 cells, and no cell addition after fifteen days of growth (twenty four hour data was omitted) 
Supplemental Figures for Section 4.4.3
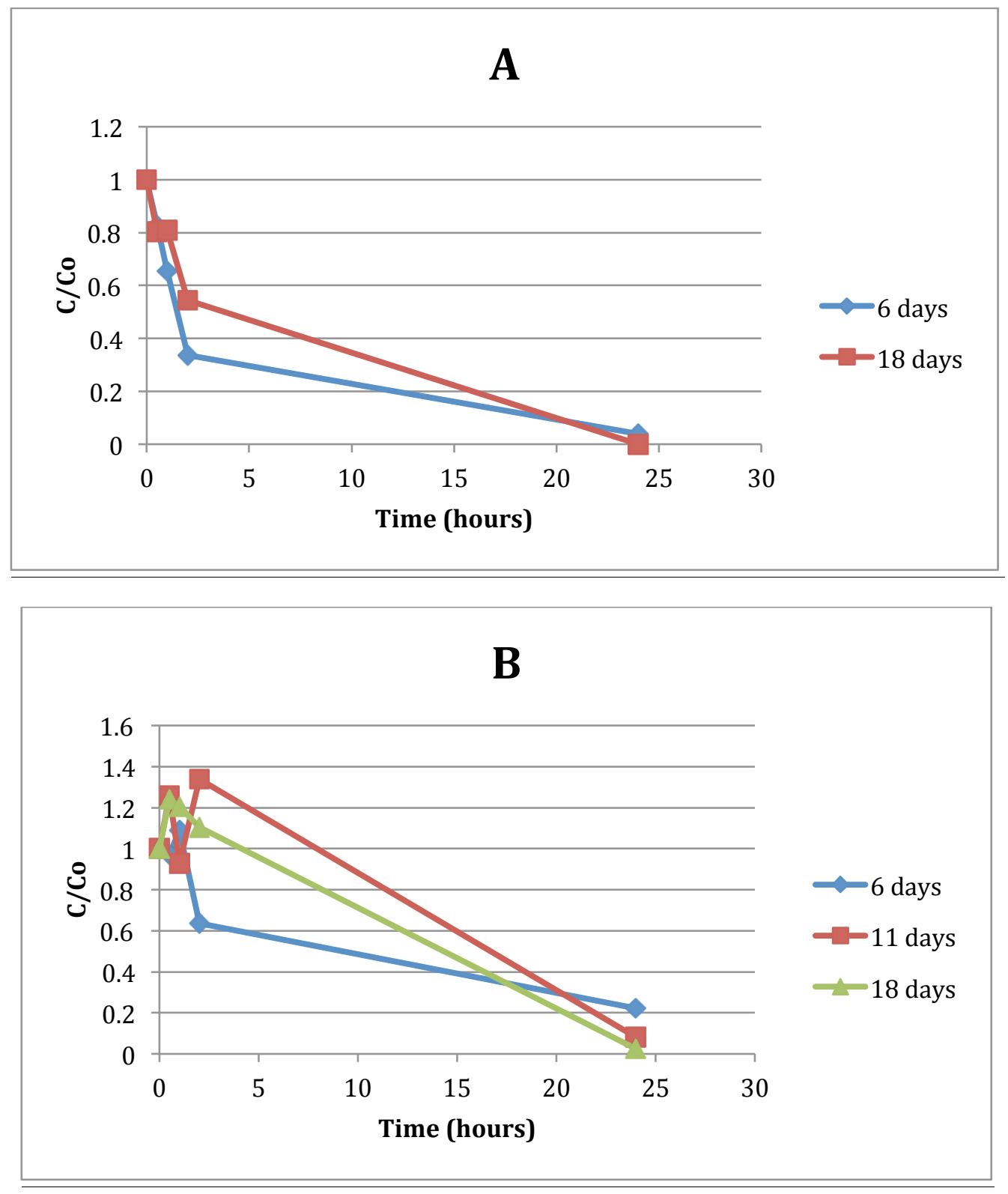

Figure A.12-Effect of growth phase with no cell addition and dark settling conditions on A) Sc. 1 over 18 days of growth and B) Sc. 2 over 18 days of growth throughout a 24hour settling period 
Supplemental Figures for Section 4.4.3
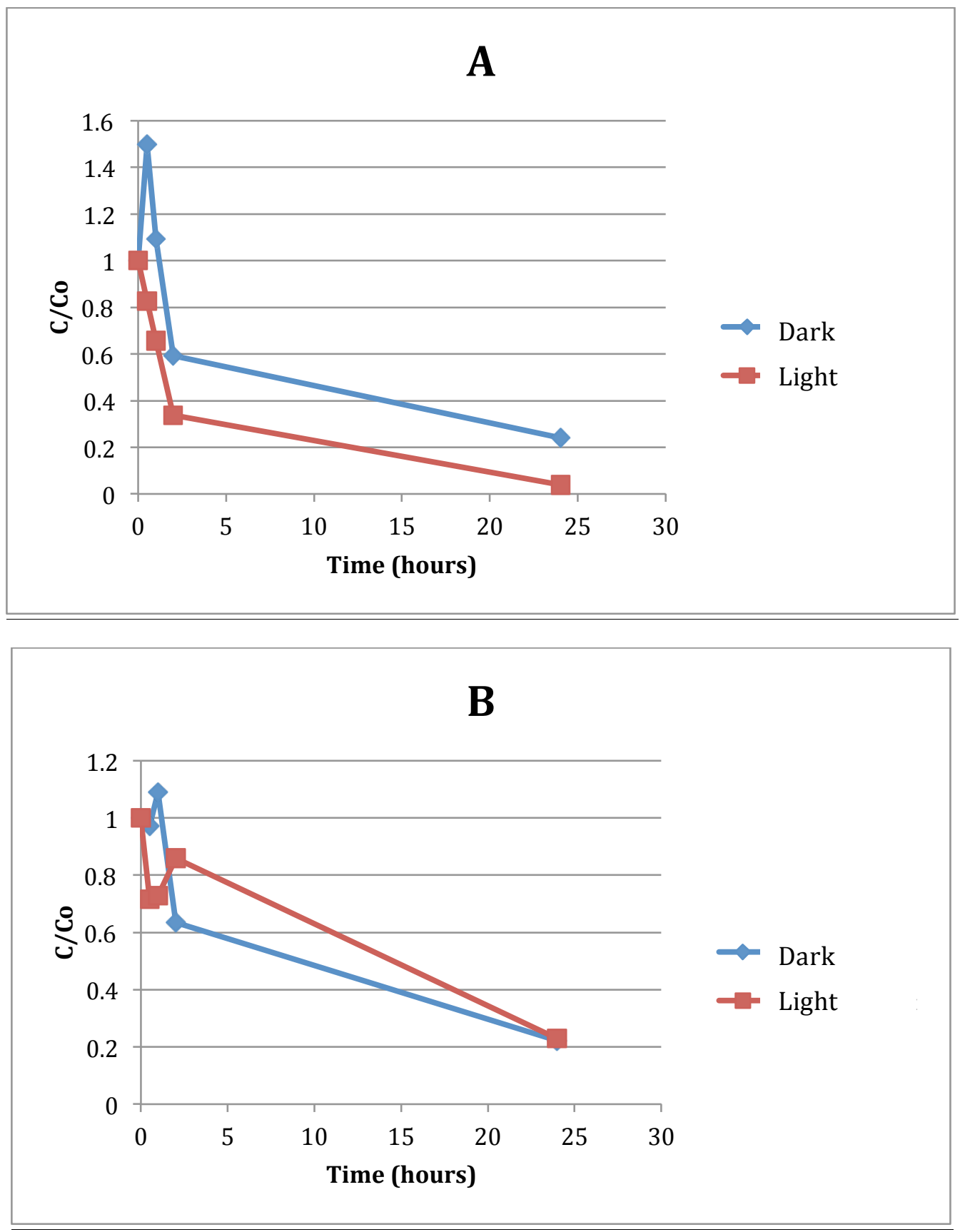

Figure A.13-Effect of light and dark conditions of settling on A) Sc. 1 and B) Sc. 2 after 6 days of growth with no bioflocculant addition 
Supplemental Figures for Section 4.4.3

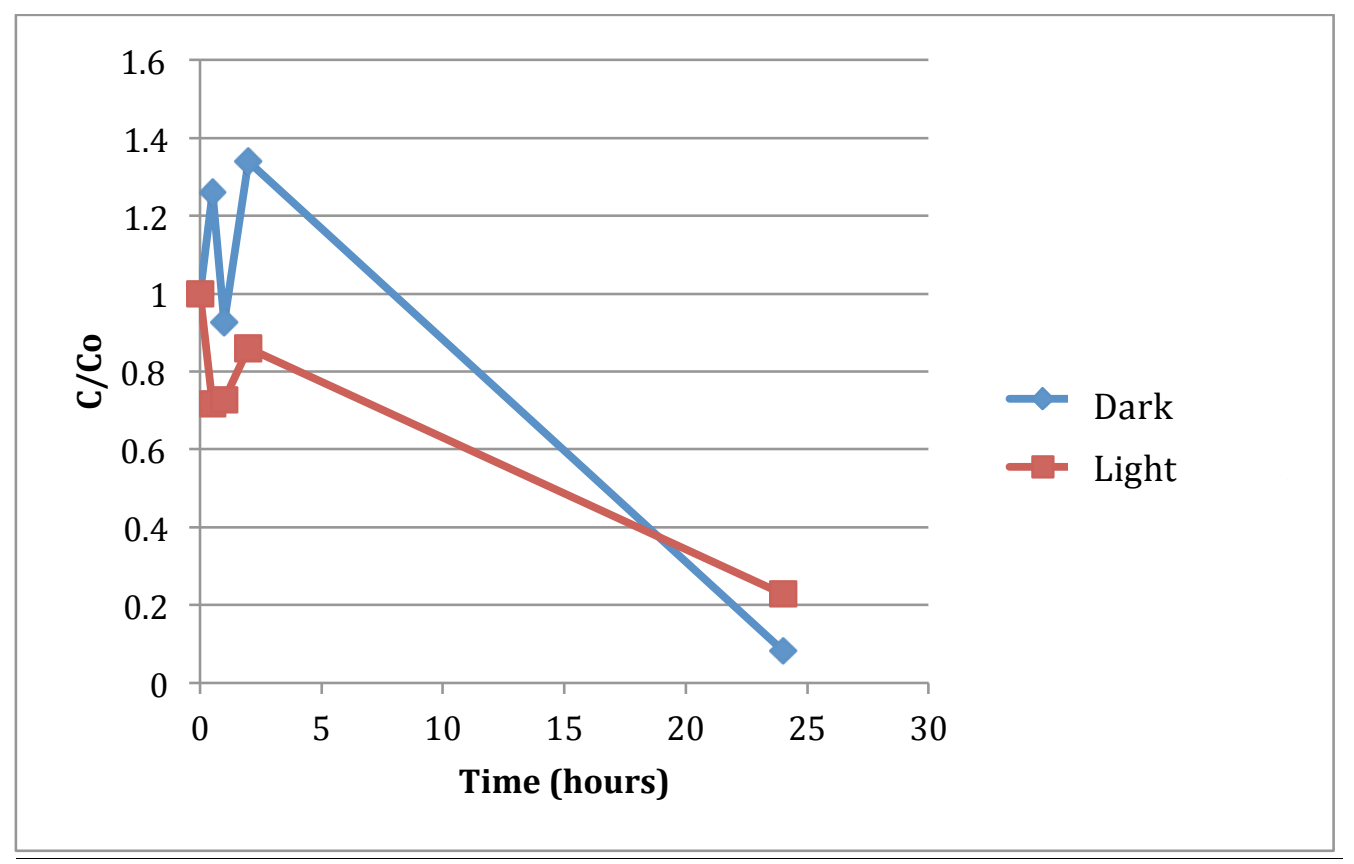

Figure A.14-Effect of Light and Dark conditions of settling for Sc. 2 after 11 days of growth with no bioflocculant addition 
Supplemental Figures for Section 4.4.4
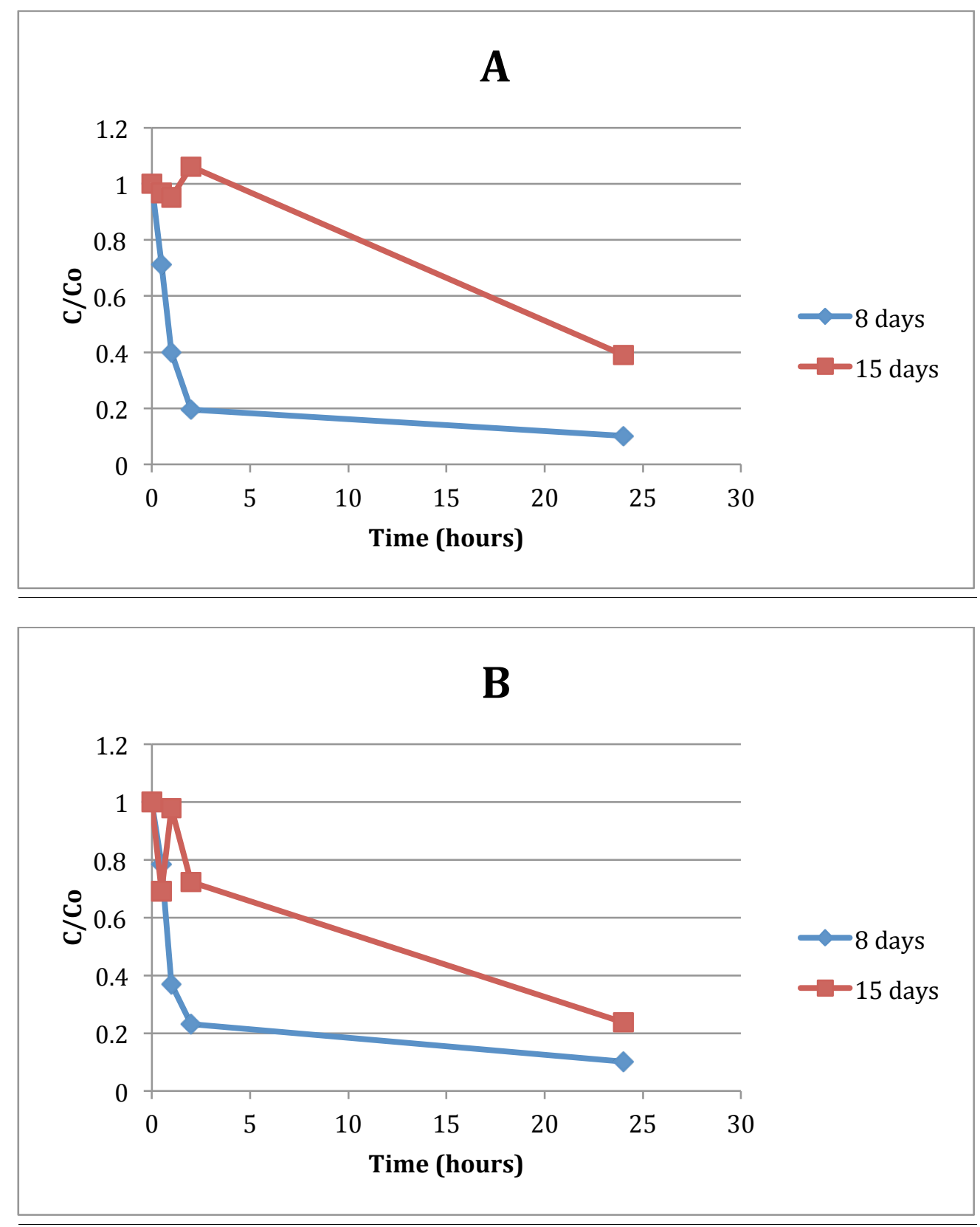

Figure A.15-Effect of A) Light conditions of settling and B) Dark conditions of settling on Chlorella over the growth curve of 15 days after exposure to light intensity of 30 hours before 8 days of growth and 48 hours before 15 days of growth 
Supplemental Figures for Section 4.4.4
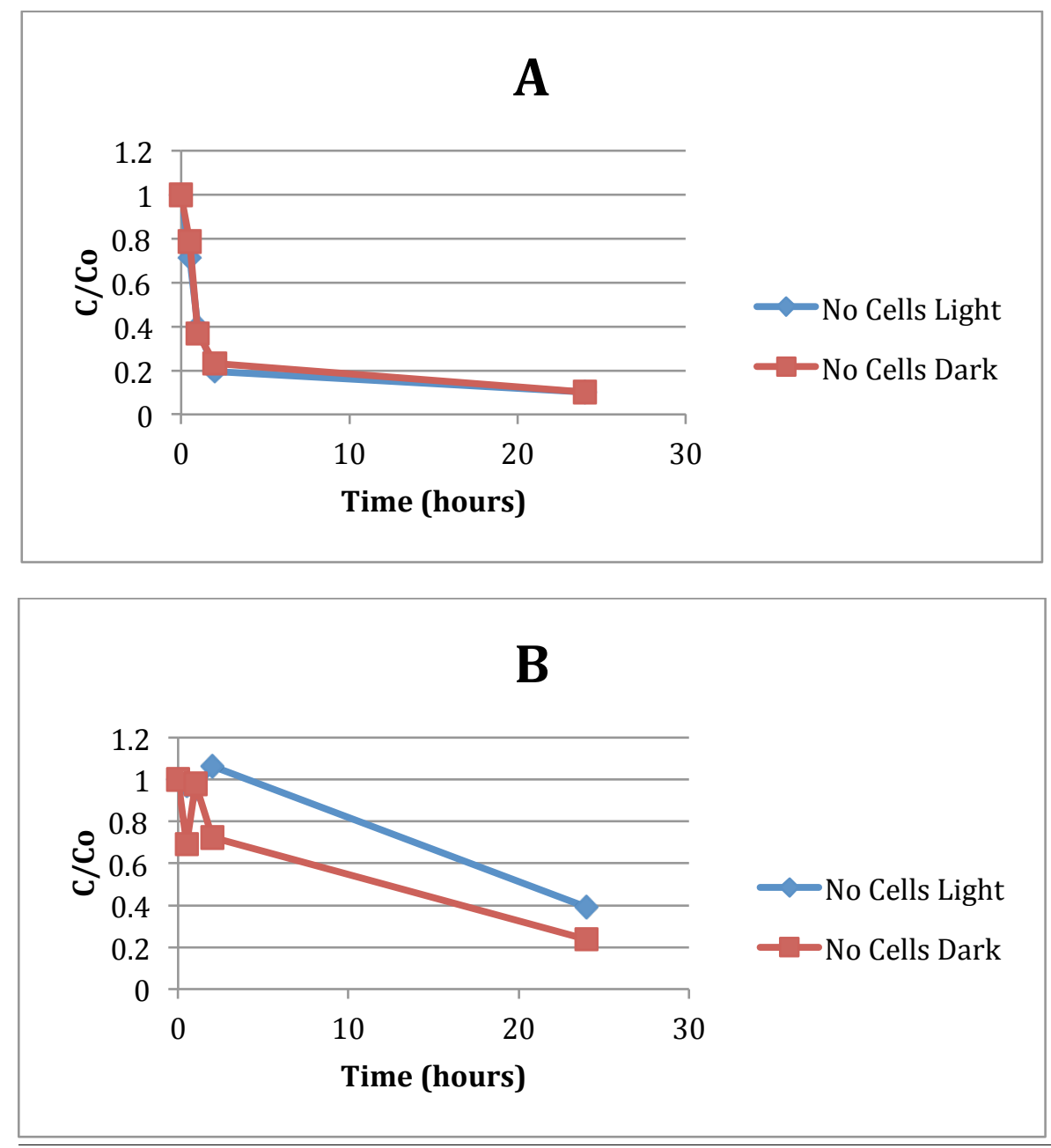

Figure A.16-Effect of Light and Dark settling conditions on Chlorella after A) 8 days of growth and B) 15 days of growth after exposure to light intensity of 30 hours before 8 days of growth and 48 hours before 15 days of growth 
Supplemental Figures for Section 4.4.5
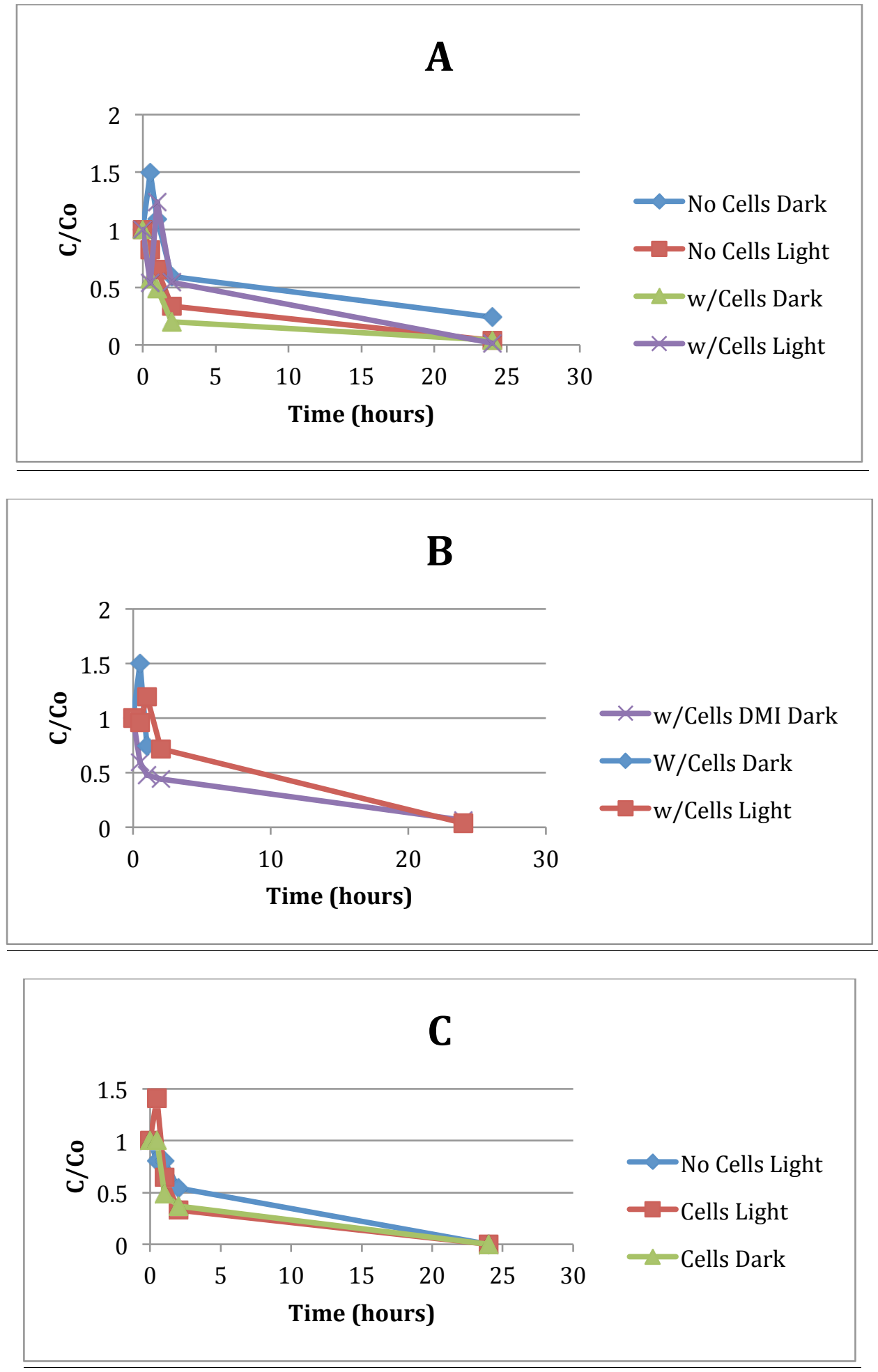

Figure A.17-Settling of Scenedesmus 1 with and without B. cepacia cell addition, different mixing intensity (DMI) and light/dark conditions after A) 6 days of growth B) 11 days of growth and C) 18 days of growth over a 24-hour settling period 
Supplemental Figures for Section 4.4.5


Figure A.18-Settling of Scenedesmus 1 with B. cepacia cell addition and A) Dark settling conditions and B) Light settling conditions over 18 days of growth using a 24-hour settling period 
Supplemental Figures for Section 4.4.5
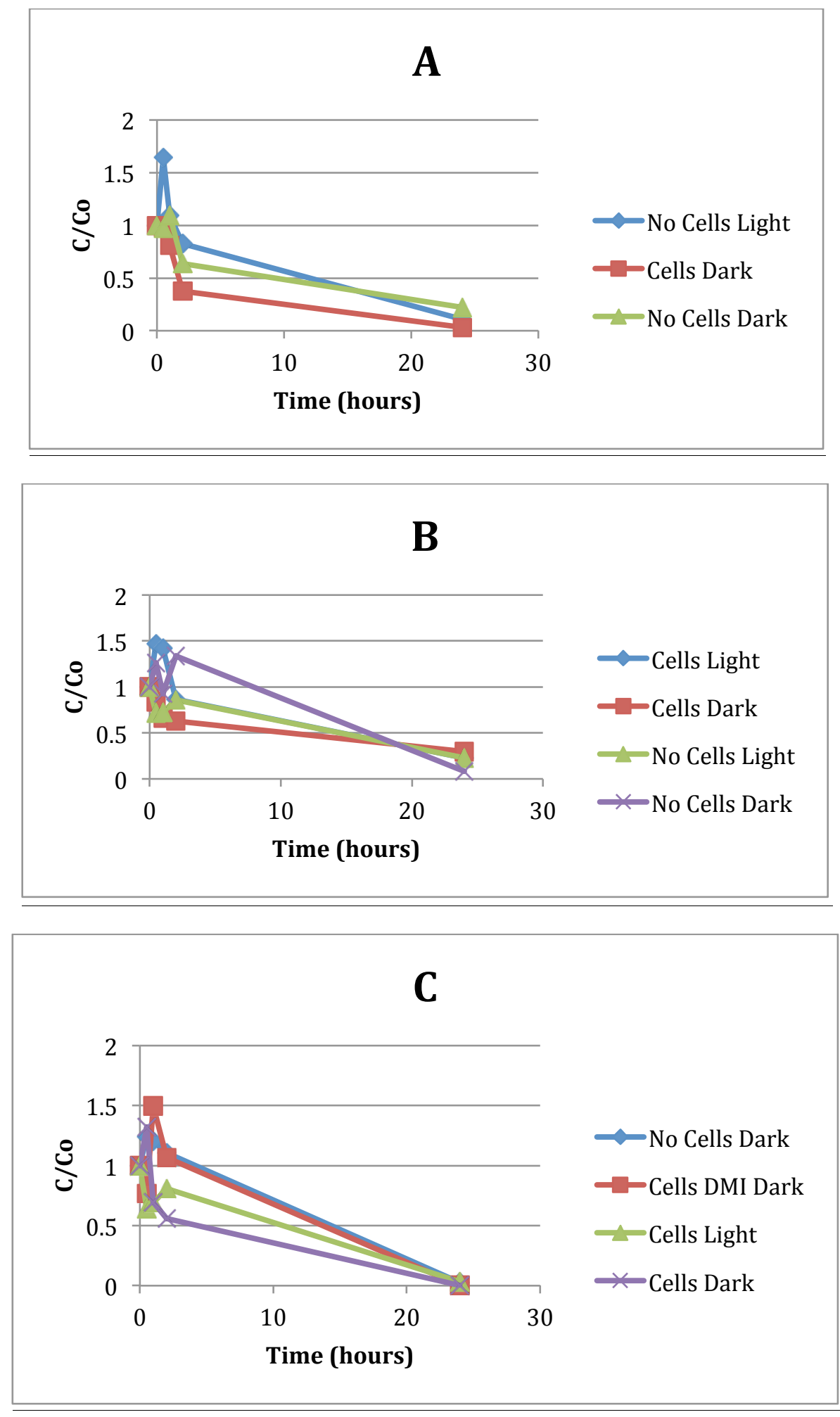

Figure A.19-Settling of Scenedesmus 2 with and without B. cepacia cell addition in light and dark conditions, including a different mixing intensity (DMI) over A) 6 days of growth B) 11 days of growth and C) 18 days of growth using 24-hour settling data 
Supplemental Figures for Section 4.4.5
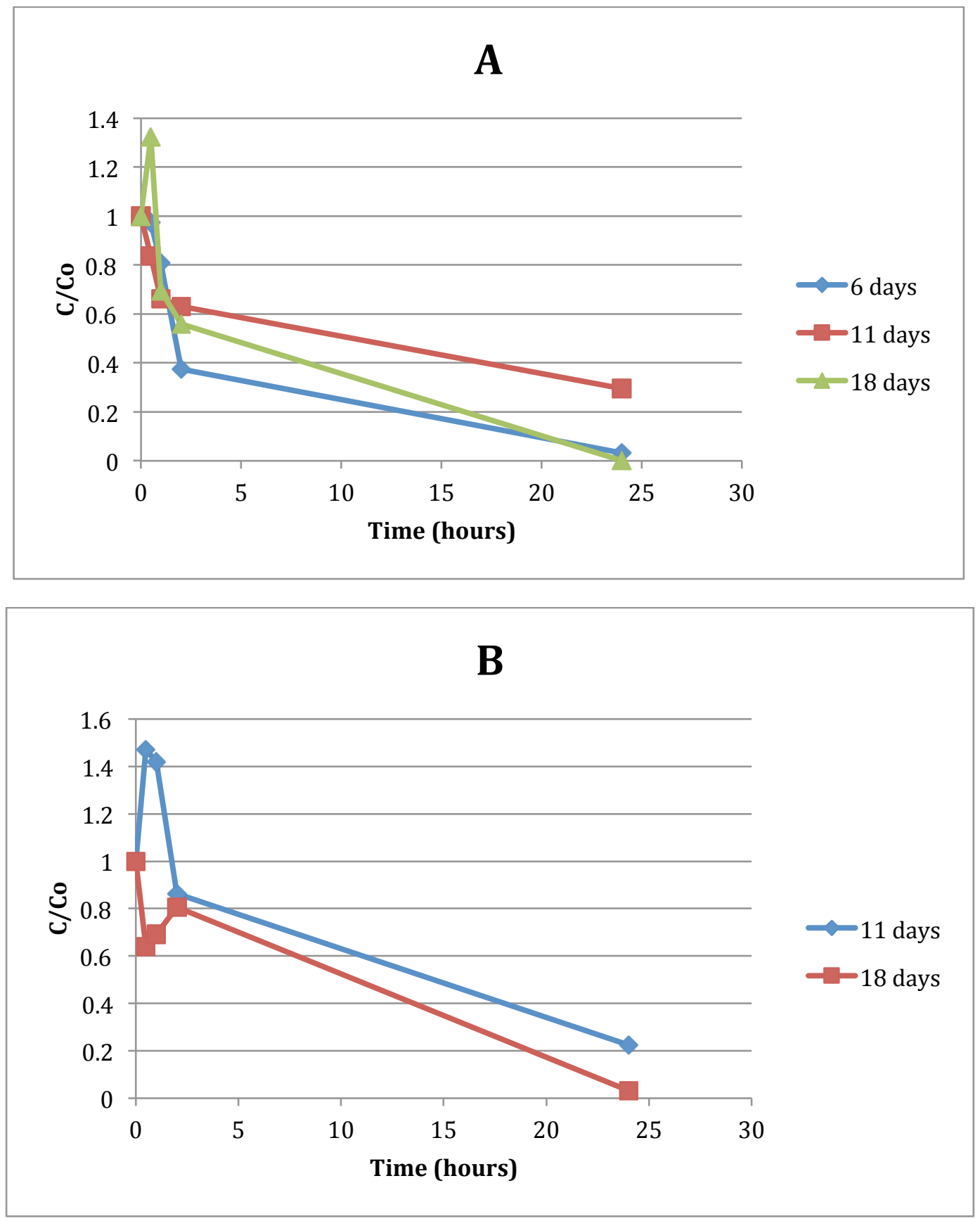

Figure A.20-Settling of Scenedesmus 2 with B. cepacia cell addition under A) Dark settling conditions and B) Light settling conditions over 18 days of growth using 24hour settling data 
Supplemental Figures for Section 4.4.6
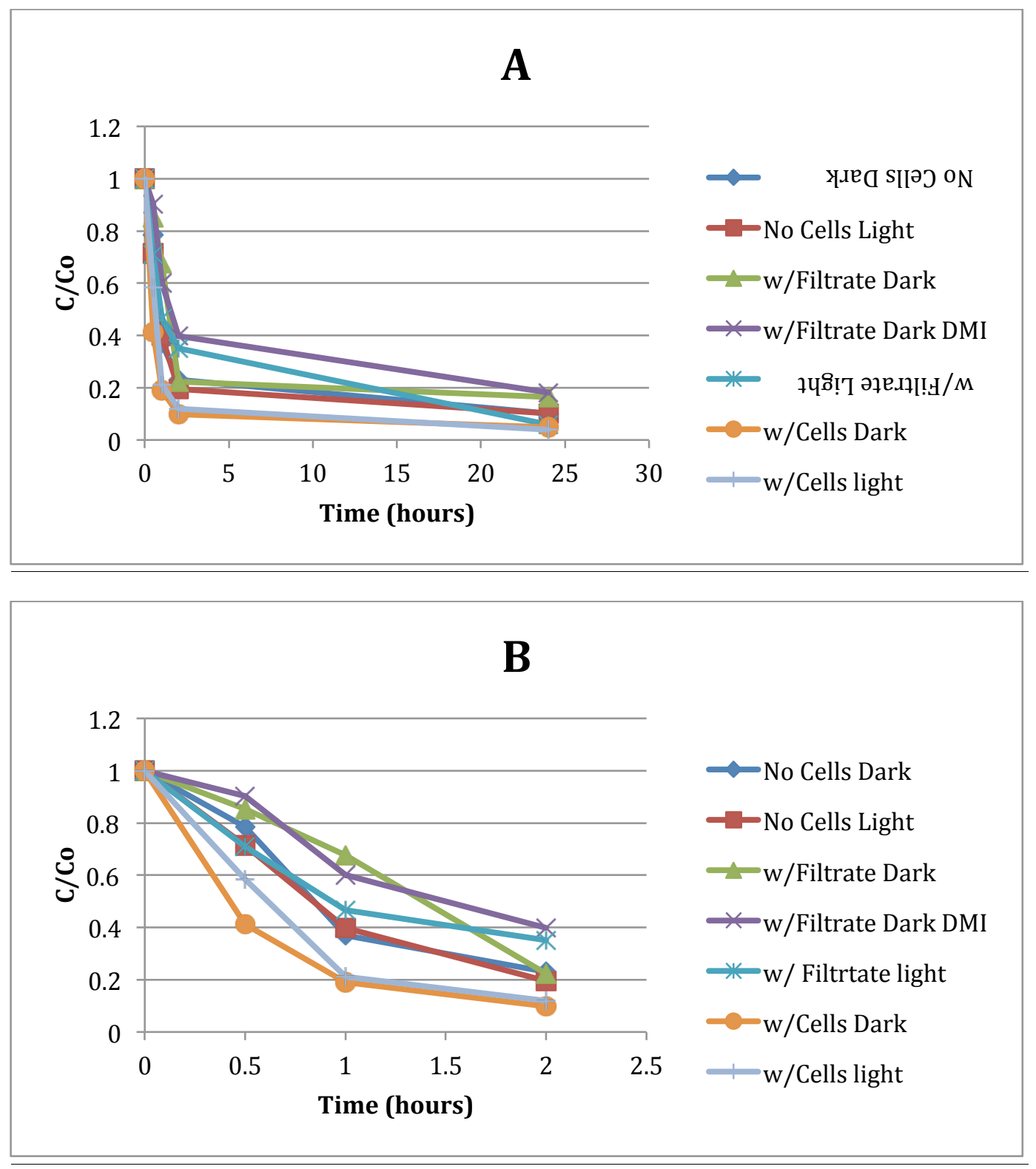

Figure A.21-Settling of Chlorella with B. cepacia cell and filtrate addition with light and dark settling conditions and different mixing intensities over 8 days of growth during A) a 24-hour period and B) a 2-hour period. All Chlorella cultures were treated with 48 hours of constant light exposure prior to settling. 
Supplemental Figures for Section 4.4.6
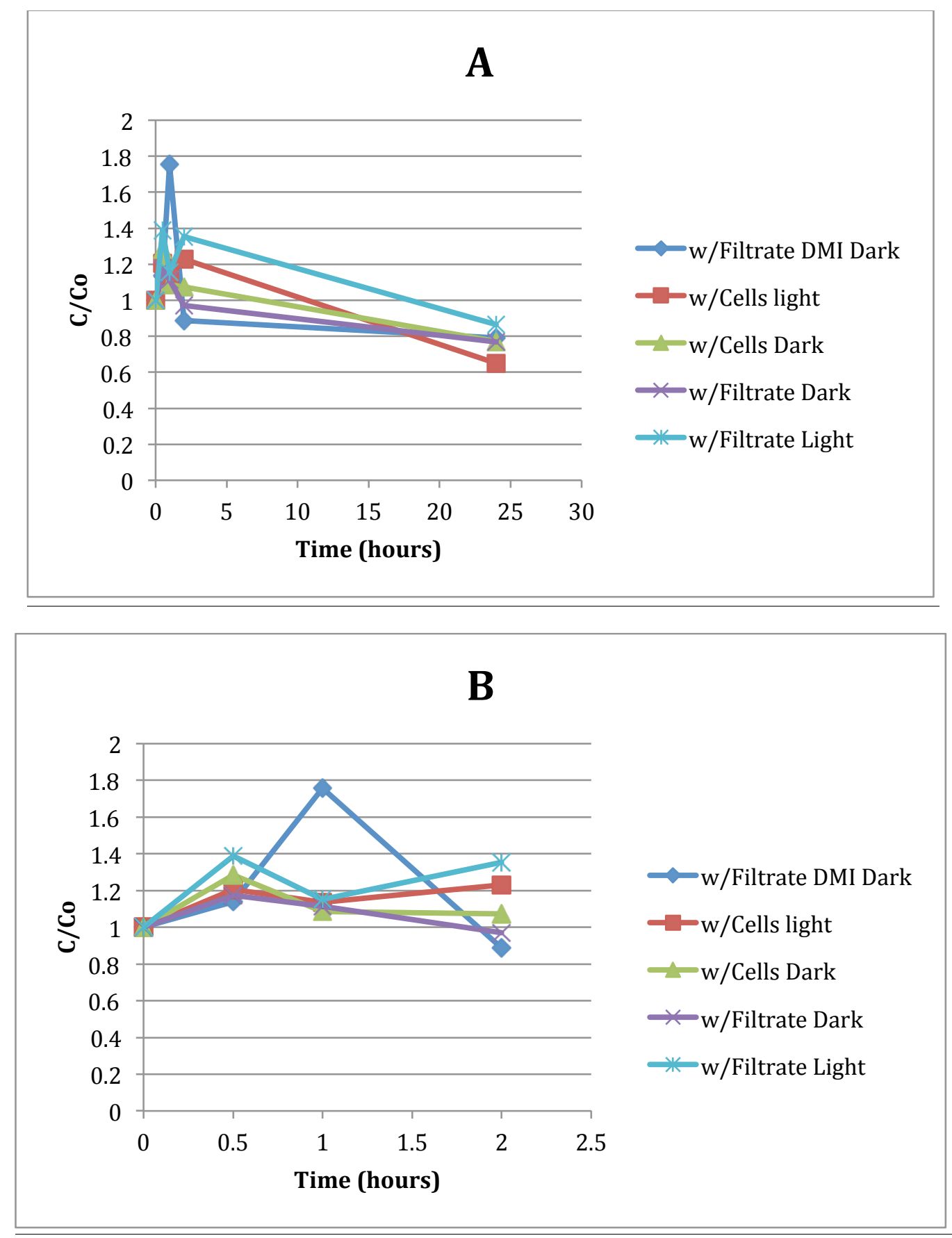

Figure A.22-Settling of Chlorella with B. cepacia cell and filtrate addition with light and dark settling conditions and different mixing intensities over 15 days of growth during A) a 24-hour and B) a 2-hour settling period. All Chlorella cultures were treated with 48 hours of constant light exposure prior to settling. 
Supplemental Figures for Section 4.5.2
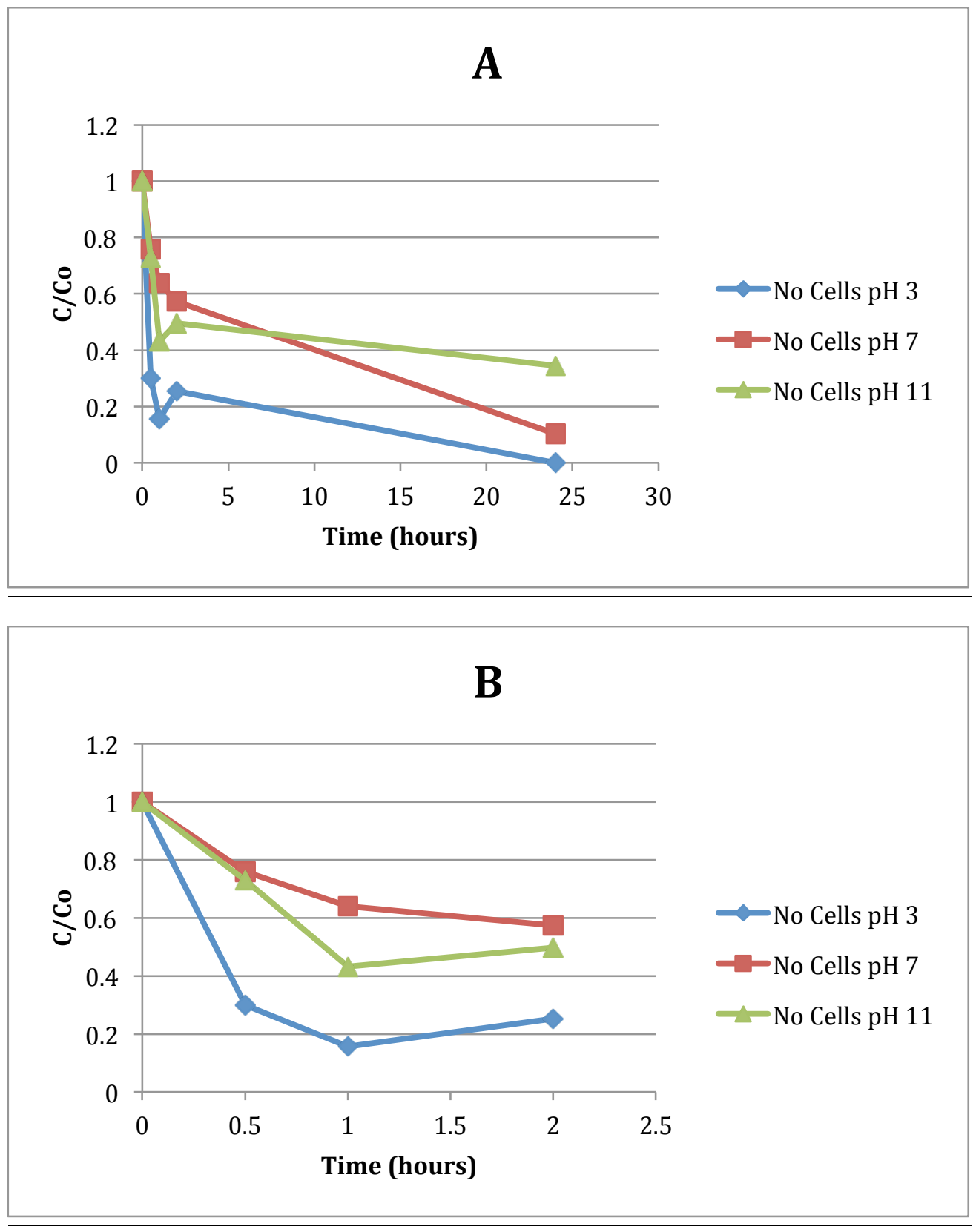

Figure A.23- Effect of pH on Scenedesmus after 7 days of growth over a) 24-hour settling period and B) over a 2-hour settling period 
Supplemental Figures for Section 4.5.2
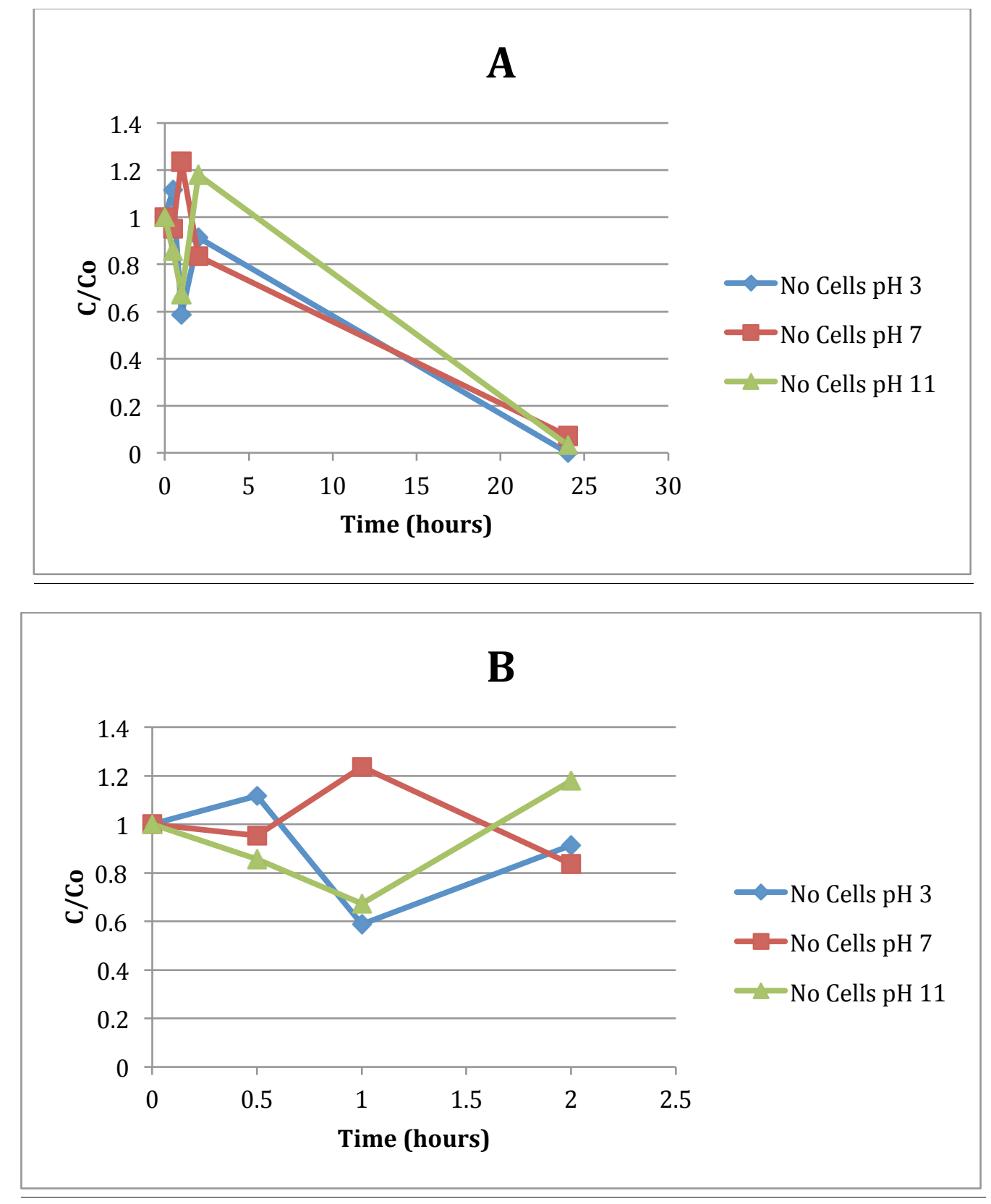

Figure A.24-Effect of $p H$ on Scenedesmus after 16 days of growth over a A) 24-hour settling period and B) over a 2-hour settling period 
Supplemental Figures for Section 4.5.3
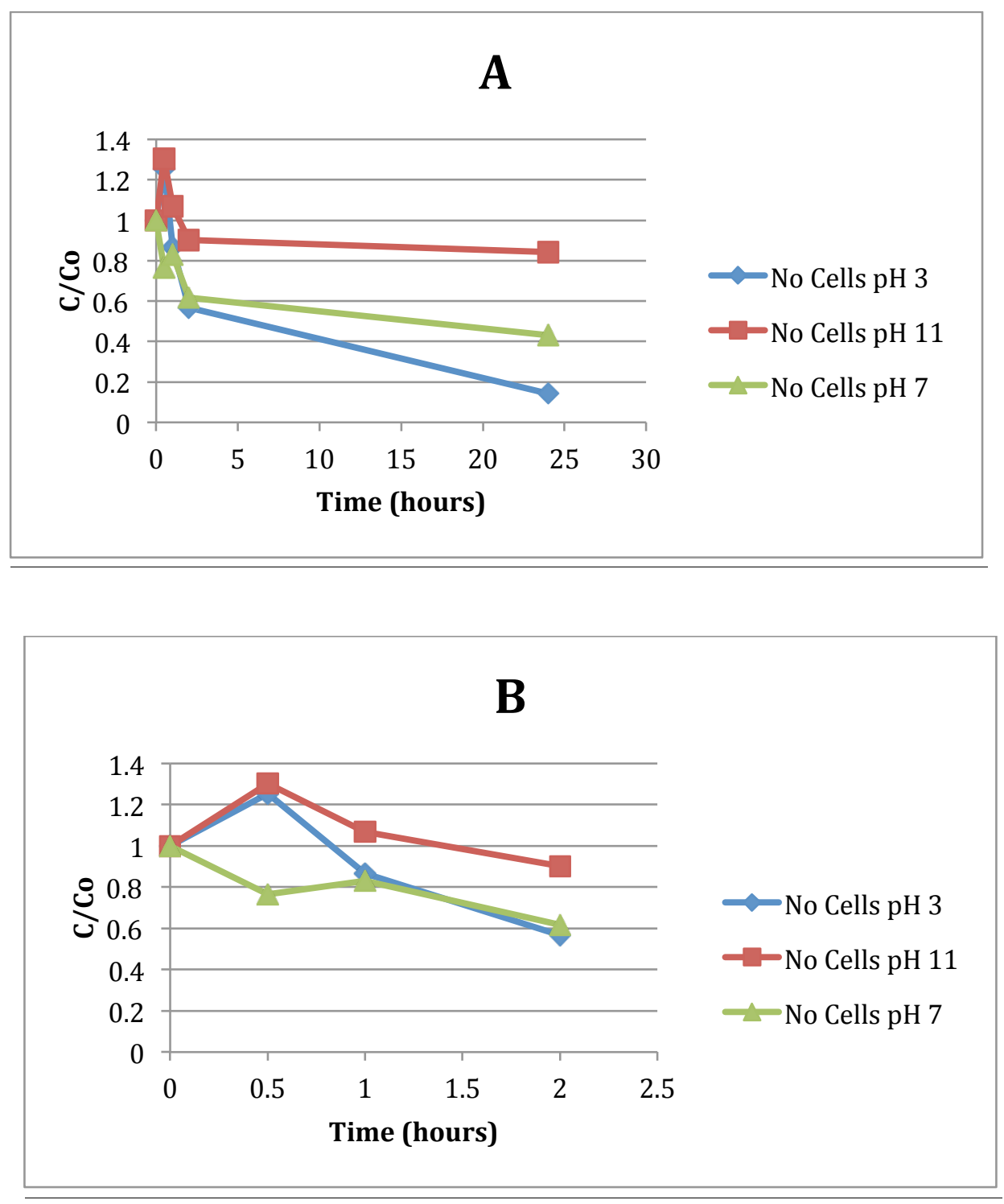

Figure A.25-Effect of pH on Chlorella settling after 6 days of growth over A) a 24 hour settling period and a B) 2-hour settling period 


\section{Supplemental Figures for Section 4.5.3}
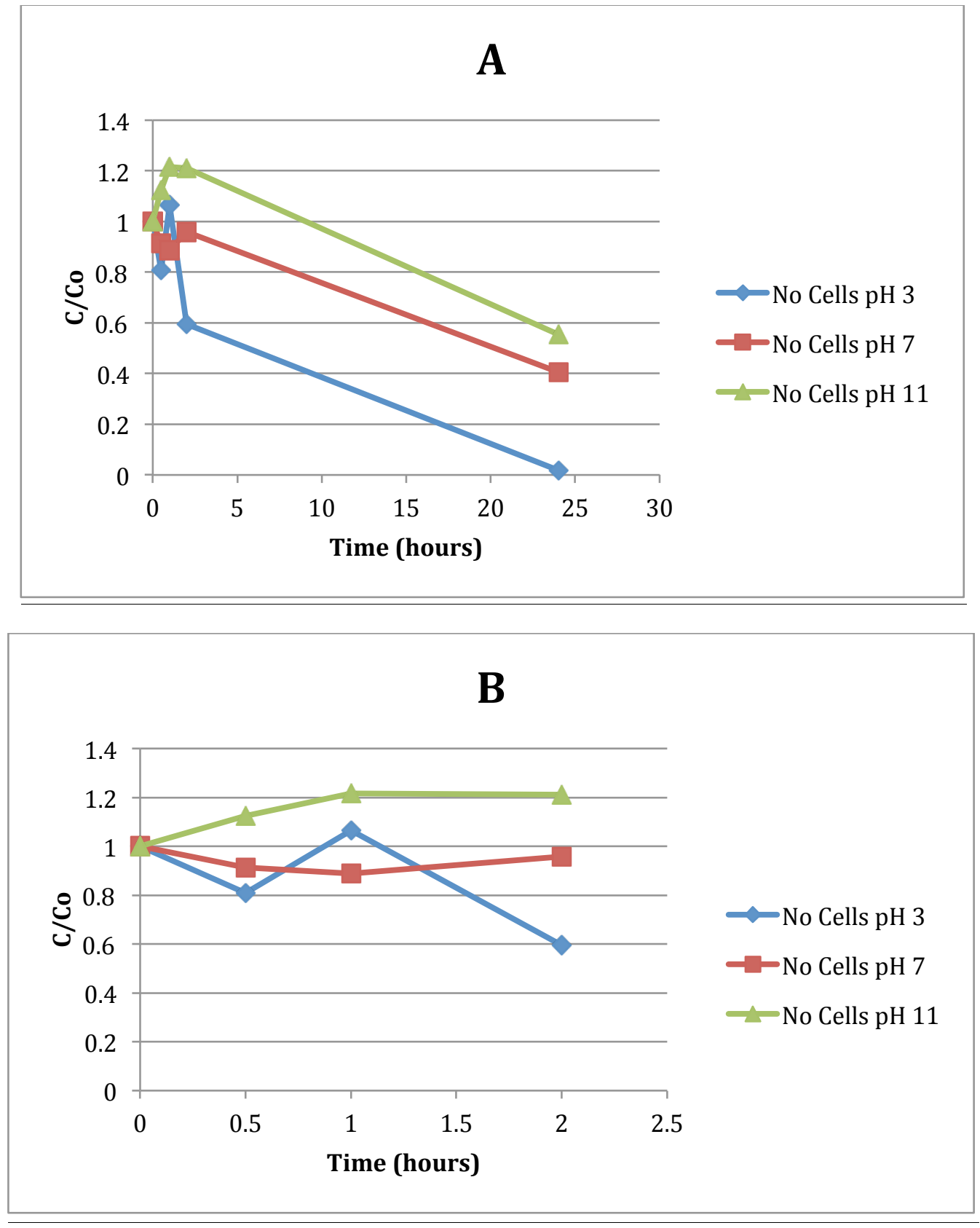

Figure A.26- Effect of $\mathrm{pH}$ on Chlorella settling after 14 days of growth over a A) 24-hour settling period and a B) 2-hour settling period 
Supplemental Figures for Section 4.5.4

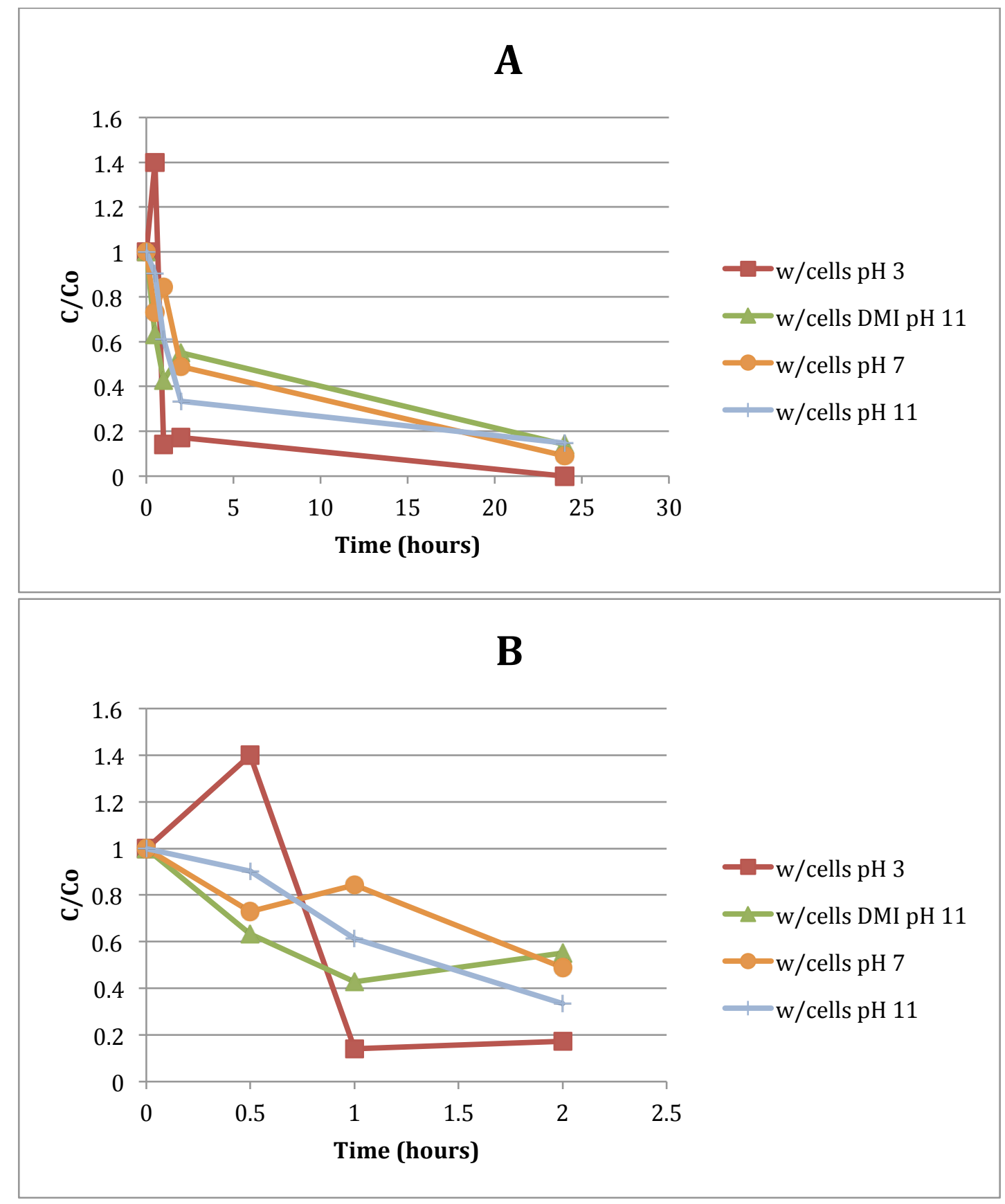

Figure A.27-Effect of settling on Scenedesmus with B. cepacia cell addition over a A) 24hour settling period and B) over a 2-hour settling period at varying $\mathrm{pH}$ levels after 7 days of growth 
Supplemental Figures for Section 4.5.4
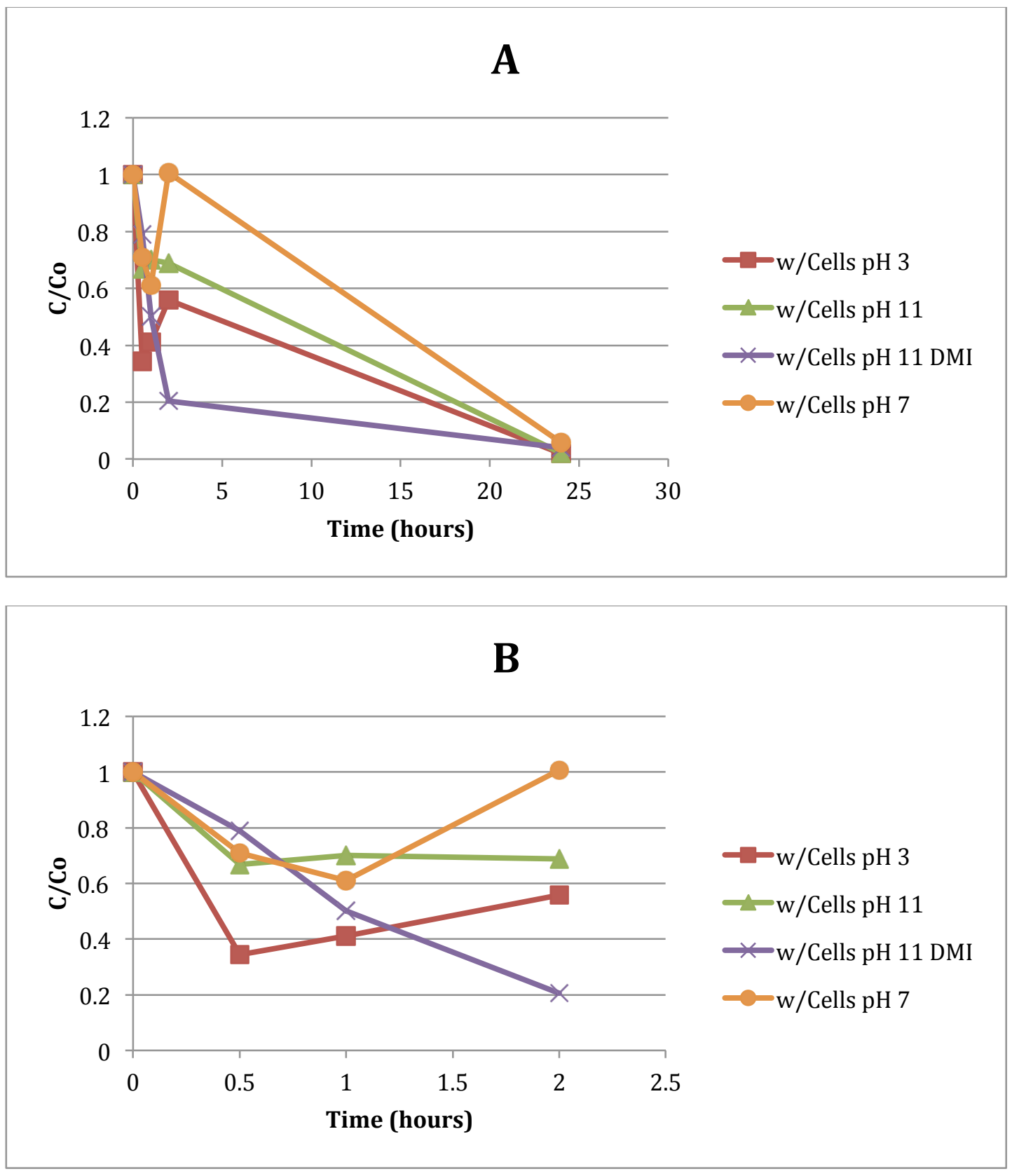

Figure A.28-Effect of settling with B. cepacia cell addition over a A) 24-hour settling period and B) over a 2-hour period at varying $\mathrm{pH}$ levels after 16 days of growth 


\section{Supplemental Figures for Section 4.5.5}
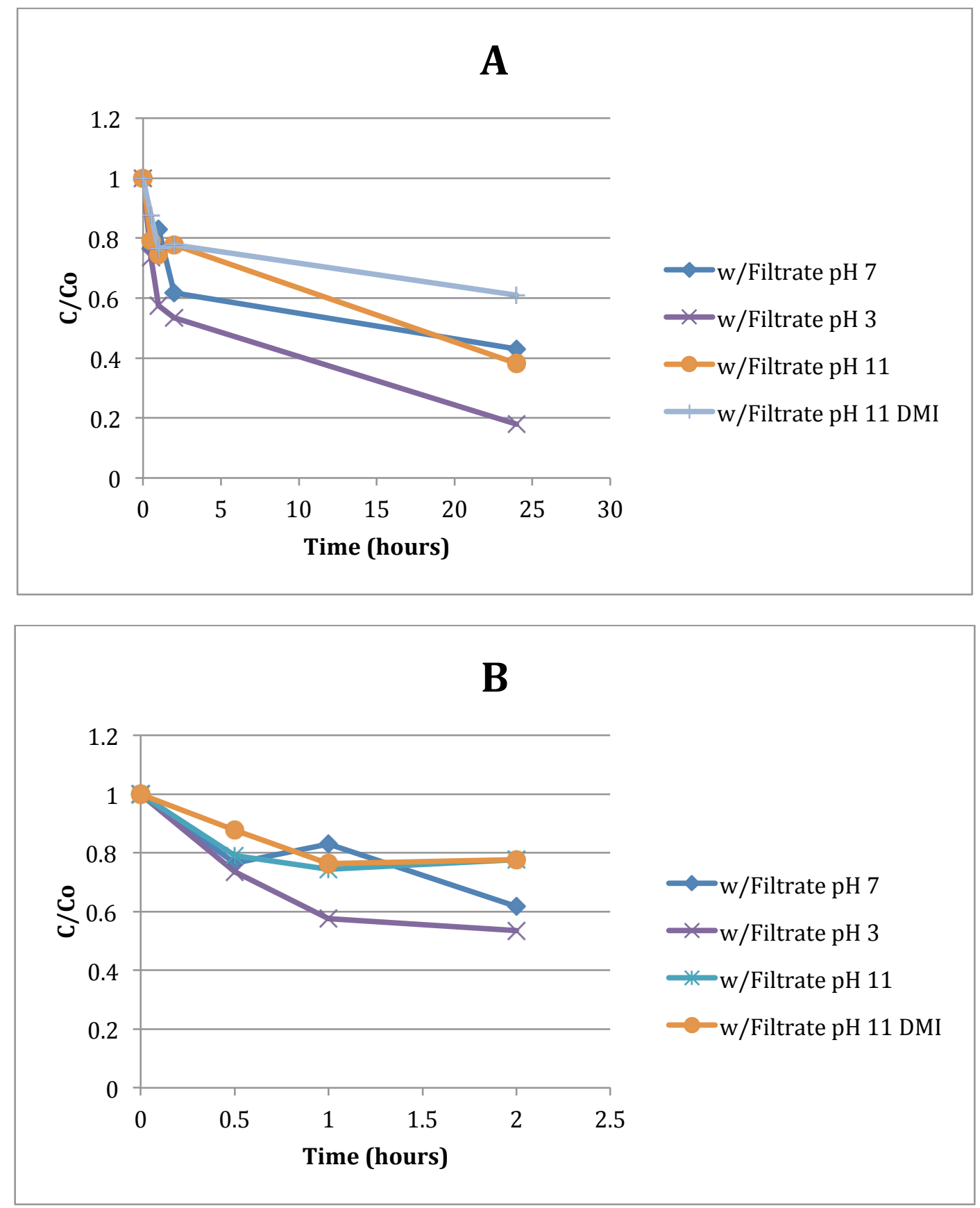

Figure A.29- Effect of varying $\mathrm{pH}$ range on Chlorella with B. cepacia filtrate addition after 6 days of growth over a A) 24-hour settling period and B) over a 2-hour period 


\section{Supplemental Figures for Section 4.5.5}
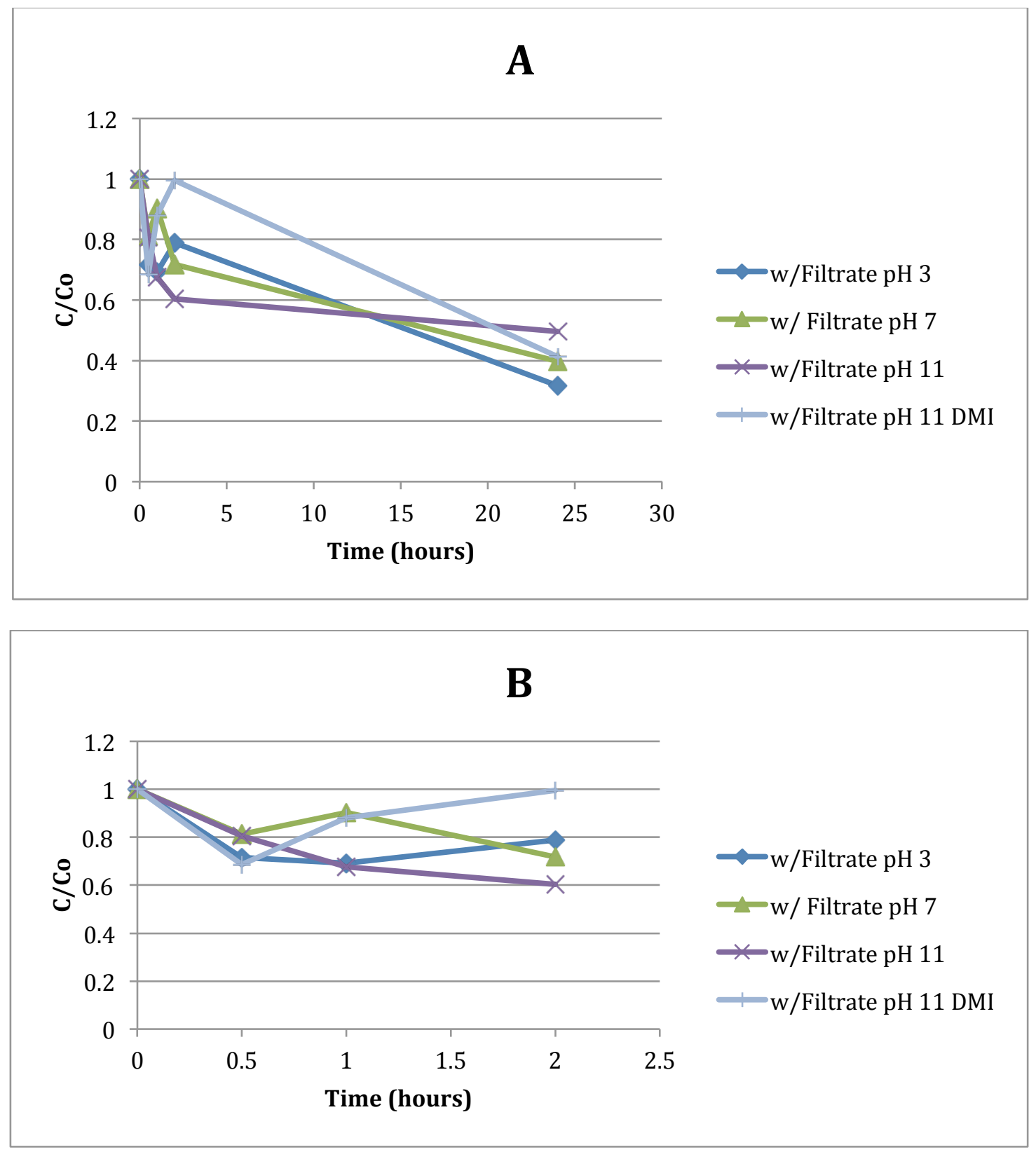

Figure 4.30- Effect of varying $\mathrm{pH}$ range on Chlorella with $B$. cepacia filtrate addition after 14 days of growth over a A) 24-hour settling period and B) over a 2-hour period 
Supplemental Figures for Section 4.6.2
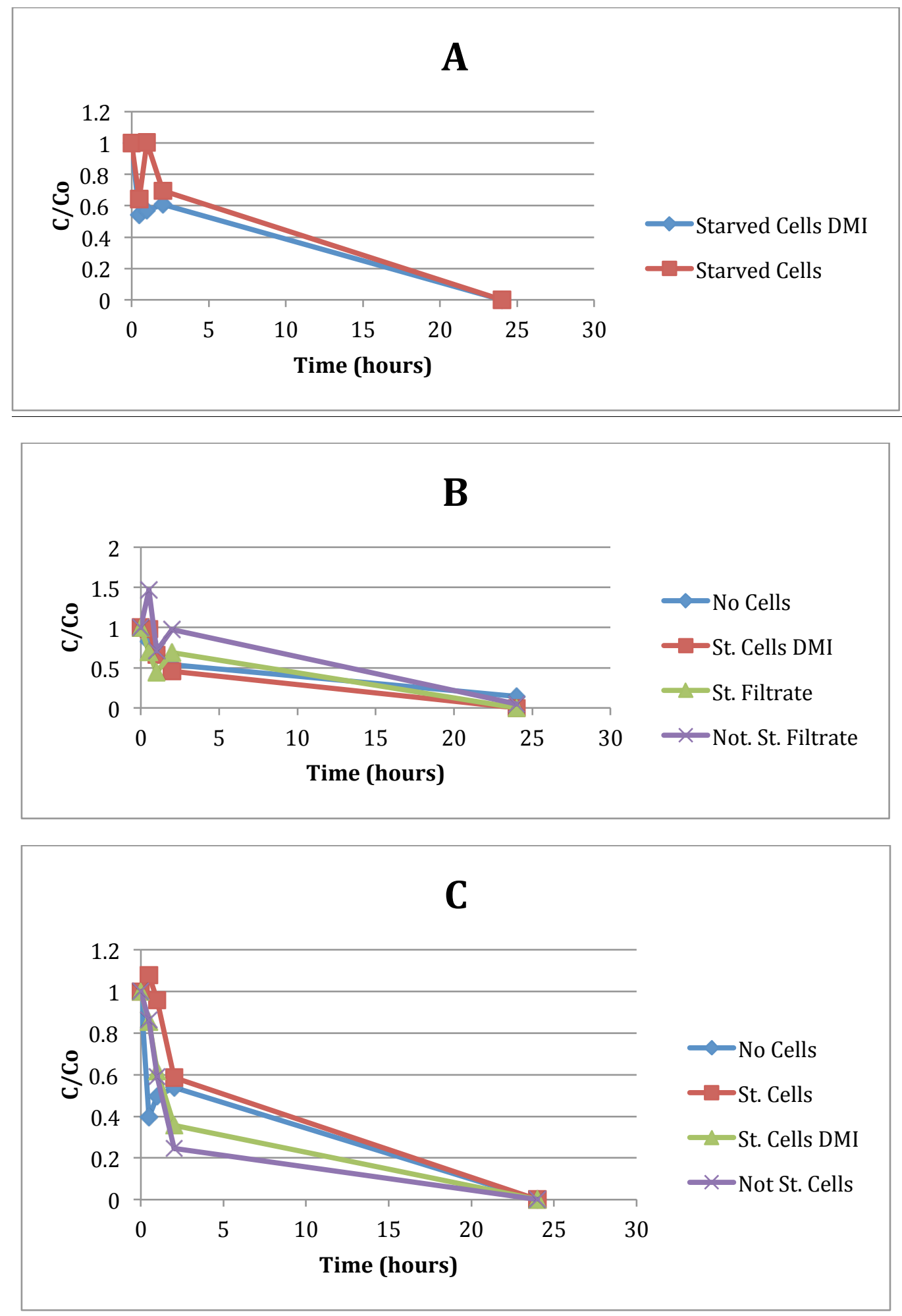

Figure 4.31-Comparison of starved, non-starved and no B. cepacia cell addition, and different mixing intensities over A) 6 days of growth B) 11 days of growth and C) 15 days of growth on the settleability of Scenedesmus 1 
Supplemental Figures for Section 4.6.2
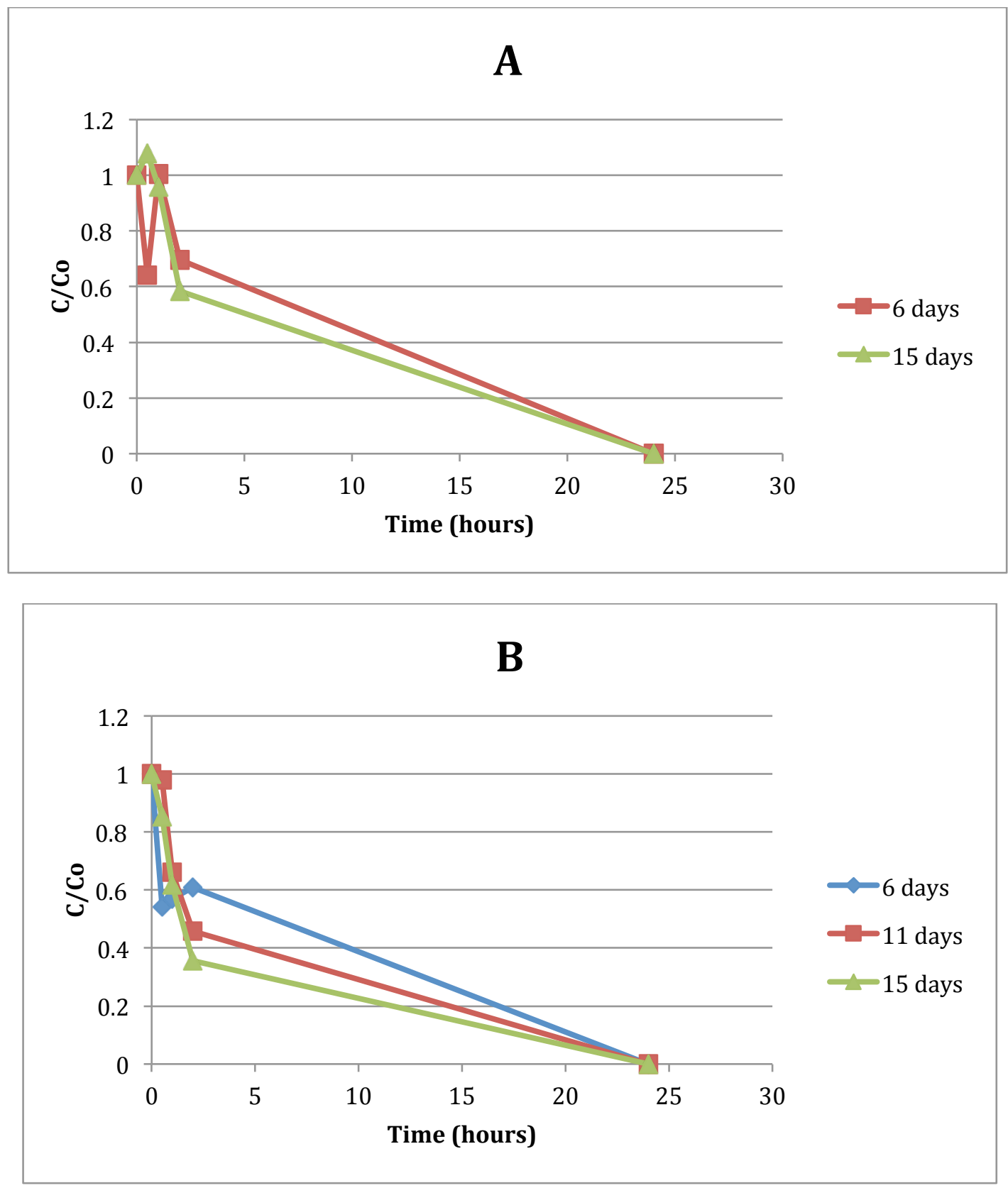

Figure 4.32-Effect of the addition of A) starved cells and B) starved cells at a different mixing intensity on improving the settleability of Scenedesmus 1 over 15 days of growth 
Supplemental Figures for Section 4.6.2
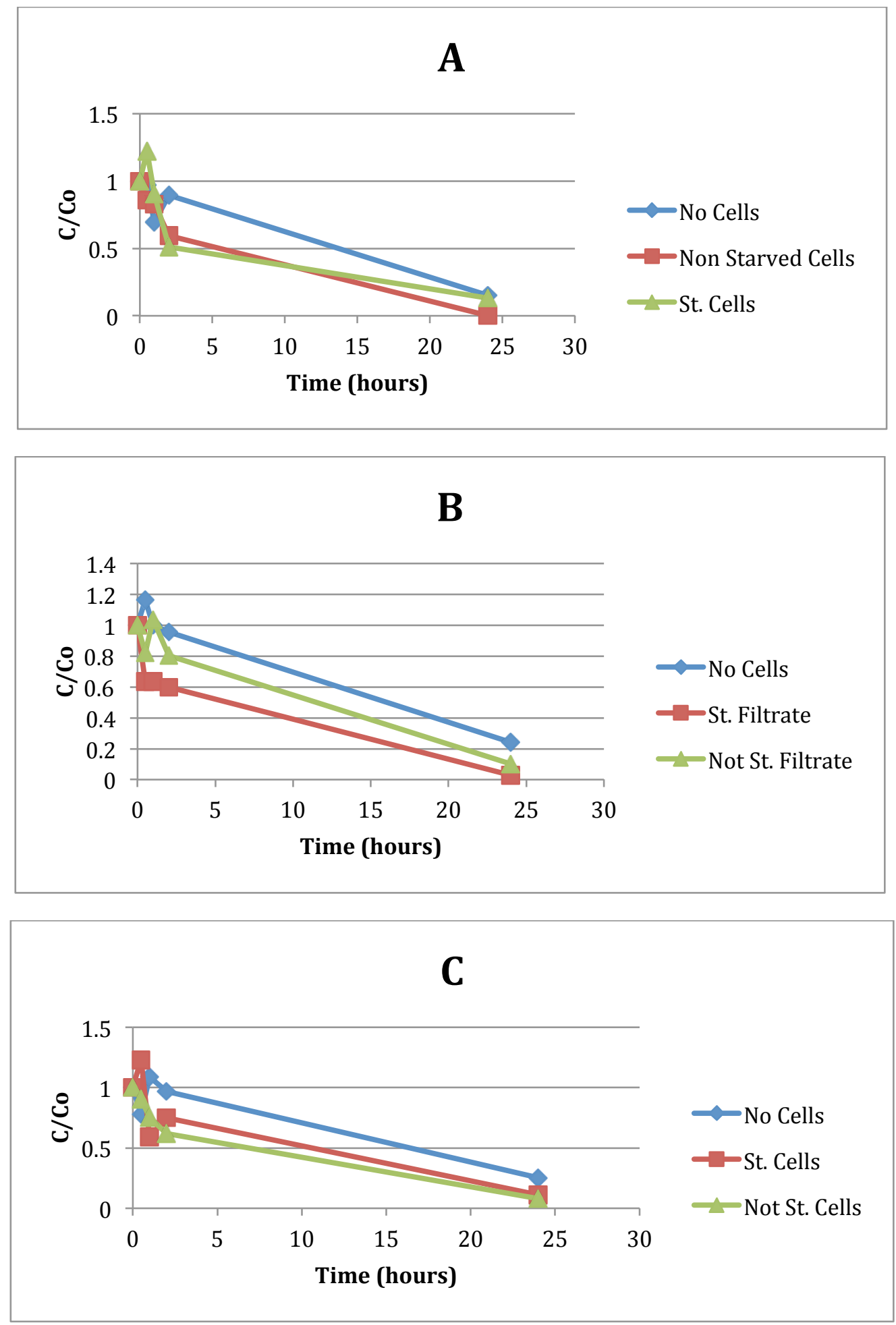

Figure A.33-Comparison of starved, non-starved and no B. cepacia cell addition over A) 6 days of growth, B) 11 days of growth and C) 15 days of growth on the settleability of Scenedesmus 2 
Supplemental Figures for Section 4.6.2
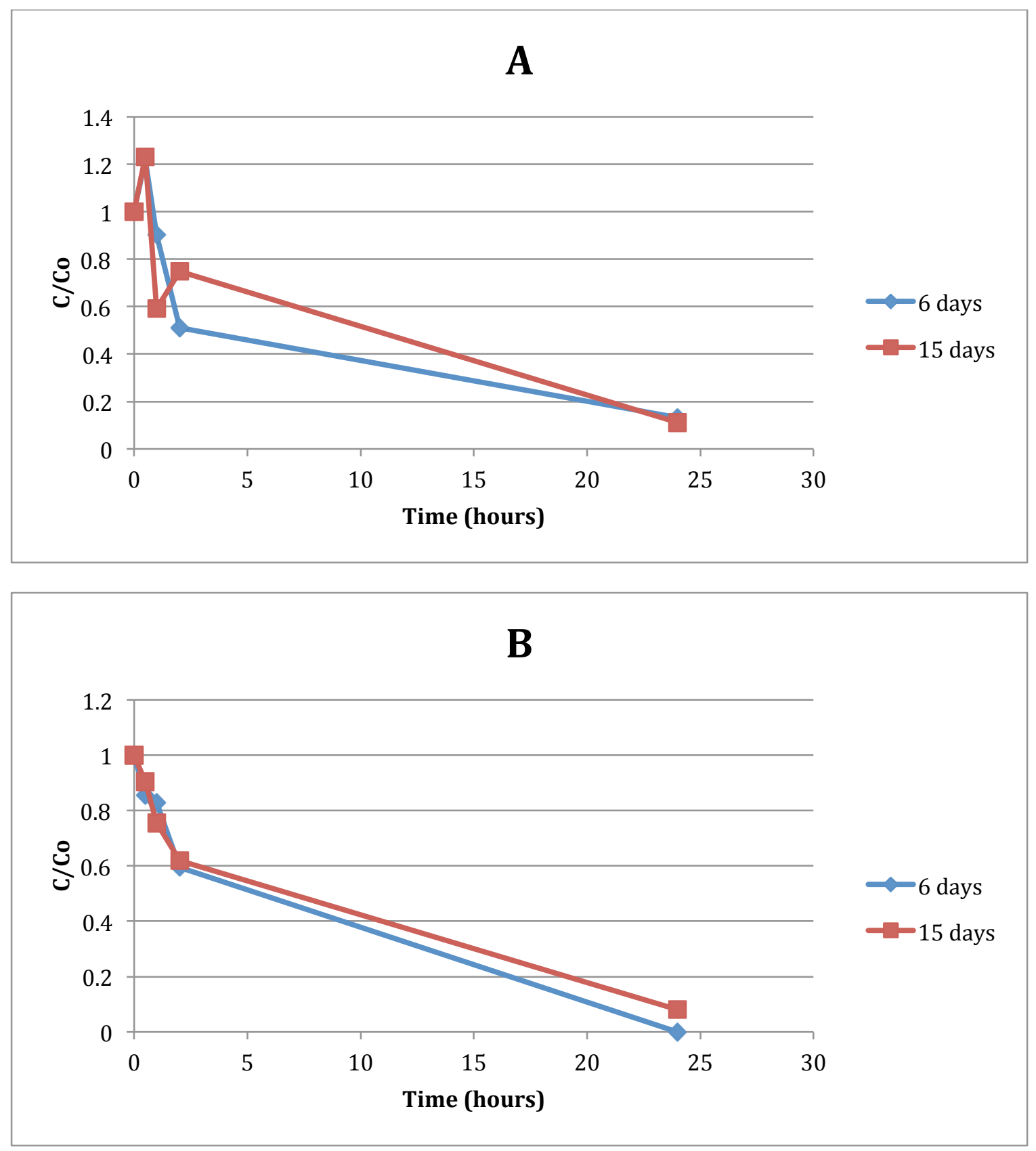

Figure A.34-Effect of the addition of A) starved cells and B) non-starved cells on improving the settleability of Scenedesmus 2 over 15 days of growth 
Supplemental Figures for Section 4.6.3
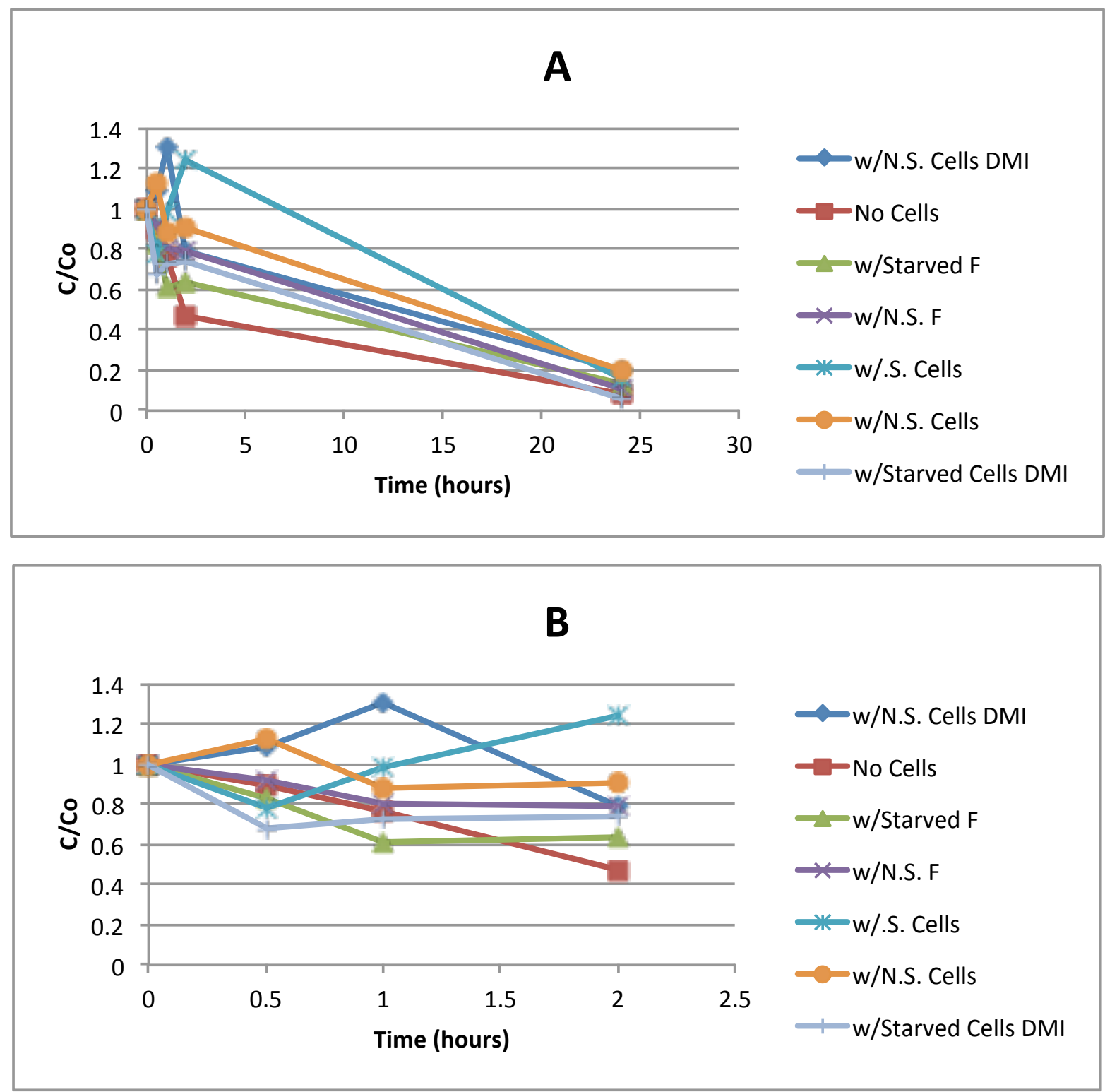

Figure A.35-Effect of B. cepacia starved or non-starved cell and filtrate addition with different mixing intensities (DMI) on settling of Chlorella over a A) 24 hour settling period and B) two hour settling period after 12 days of growth (Trial 1) 
Supplemental Figures for Section 4.6.3
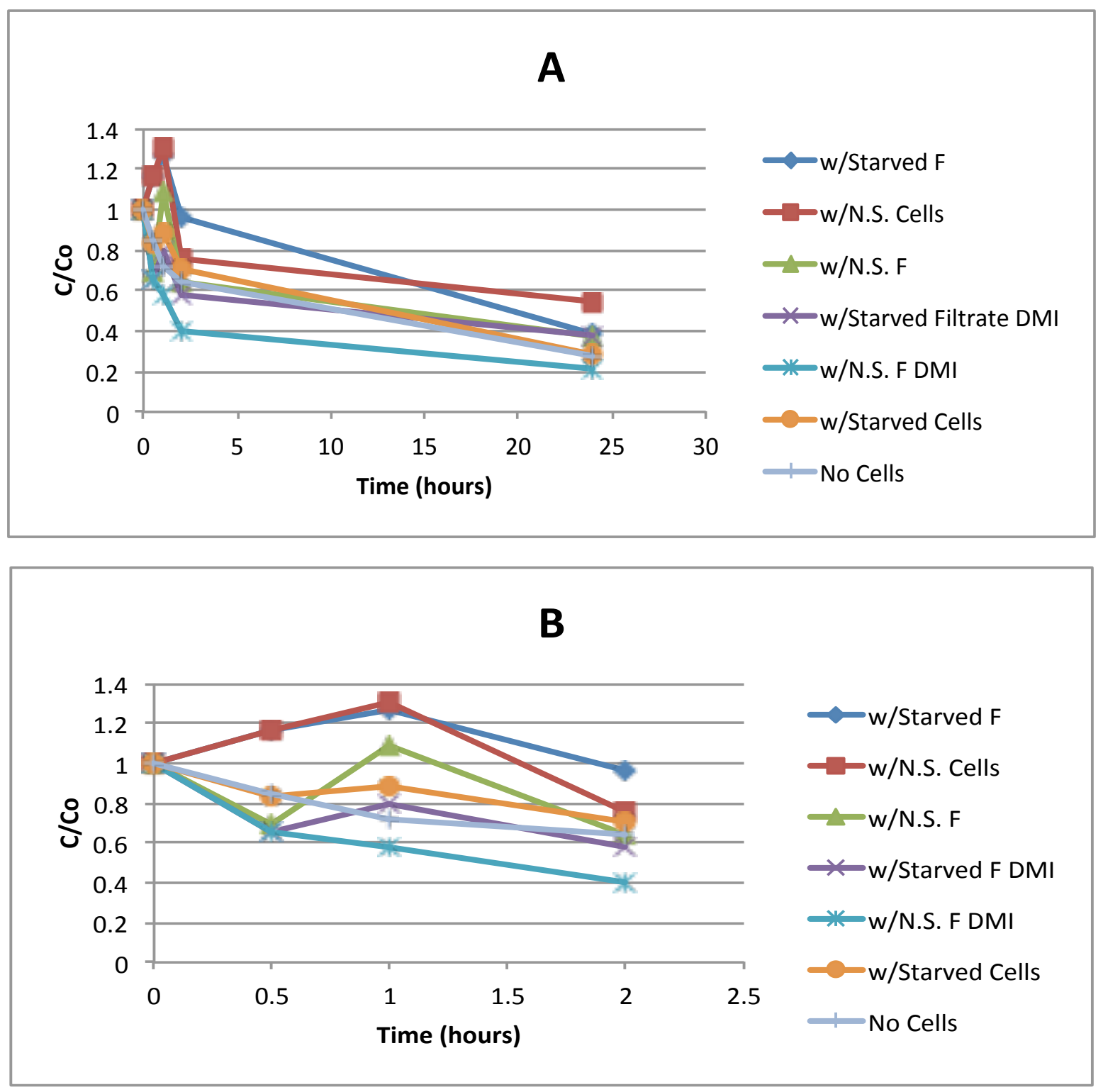

Figure A.36-Effect of B. cepacia starved or non-starved cell and filtrate addition with different mixing intensities (DMI) on settling of Chlorella over a A) 24 hour settling period and B) two hour settling period after 21 days of growth (Trial 1) 


\section{Supplemental Figures for Section 4.6.3}
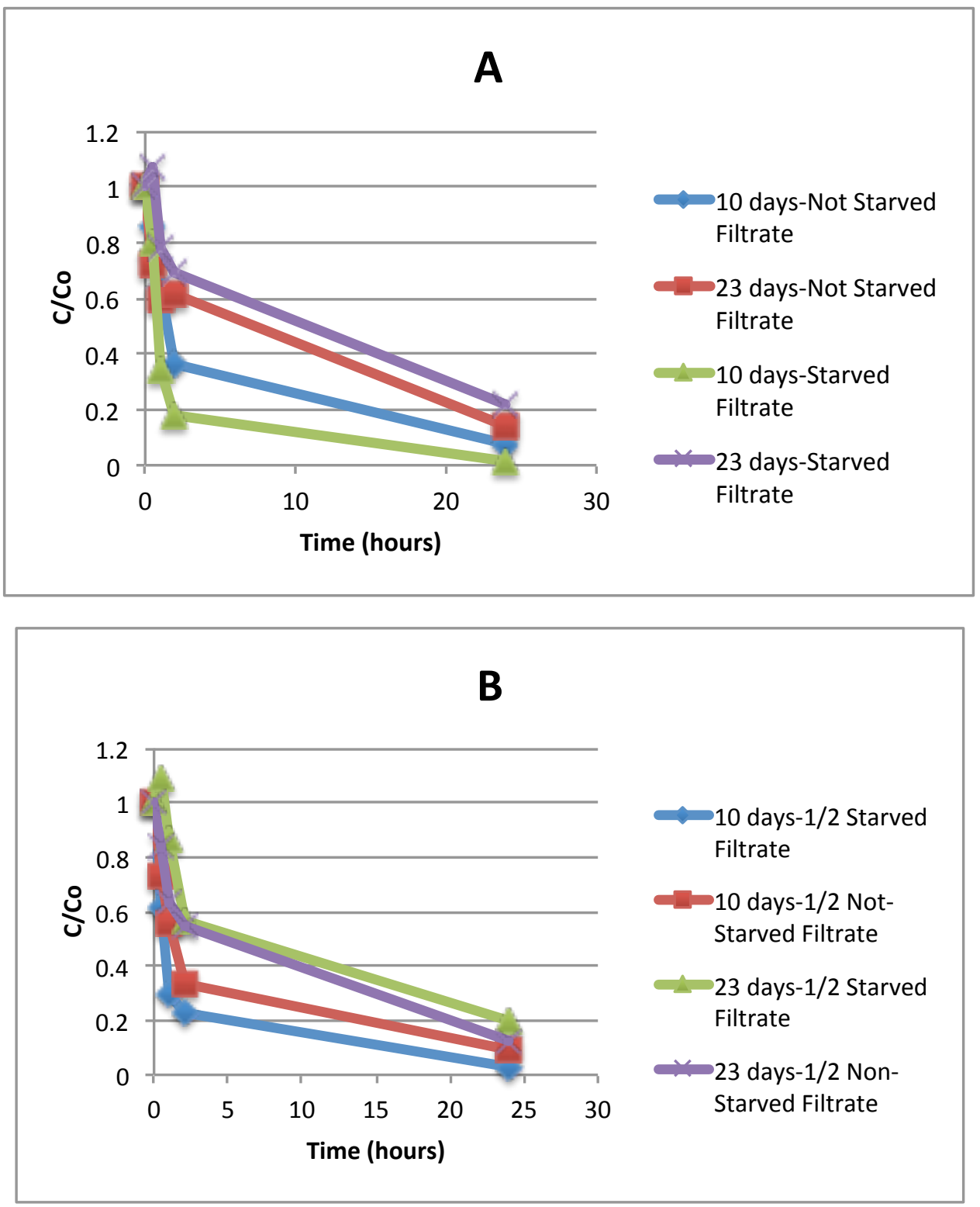

Figure A.37-Comparison of settling of Chlorella based on normalized cell concentration remaining after a 2-hour settling period for A) starved versus non-starved filtrate B) $1 / 2$ the dose of starved/non-starved filtrate 
Supplemental Figures for Section 4.7.2
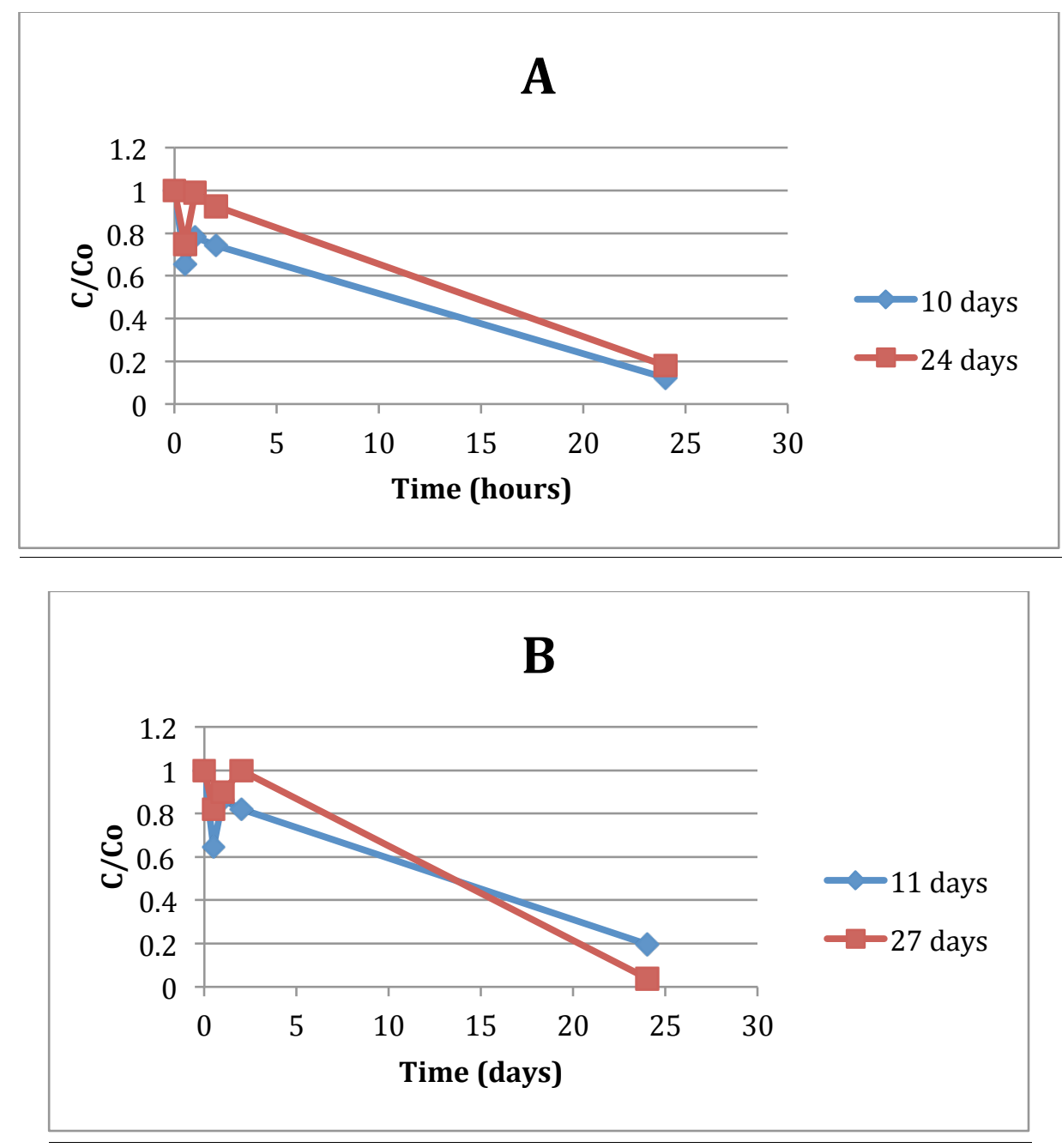

Figure A.38-Normalized cell concentration remaining for pure cultures of Scenedesmus A) without carbon dioxide and B) with carbon dioxide addition over a 24-day period of settling 
Supplemental Figures for Section 4.7.2
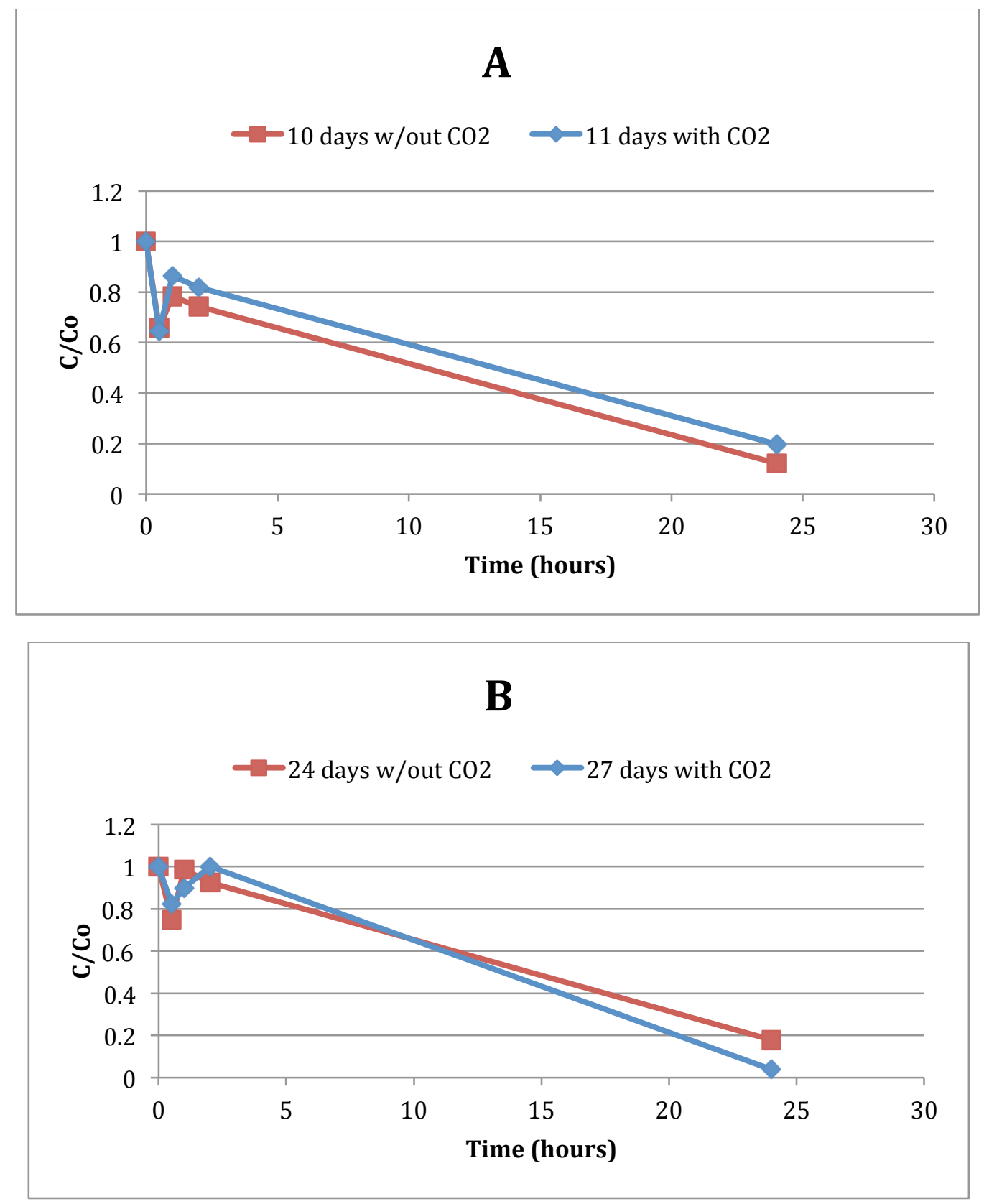

Figure A.39-Normalized cell concentration remaining for pure cultures of Scenedesmus with and without carbon dioxide input at A) early stationary phase and B) later stationary phase of growth over a 24- hour settling period 
Supplemental Figures for Section 4.7.3
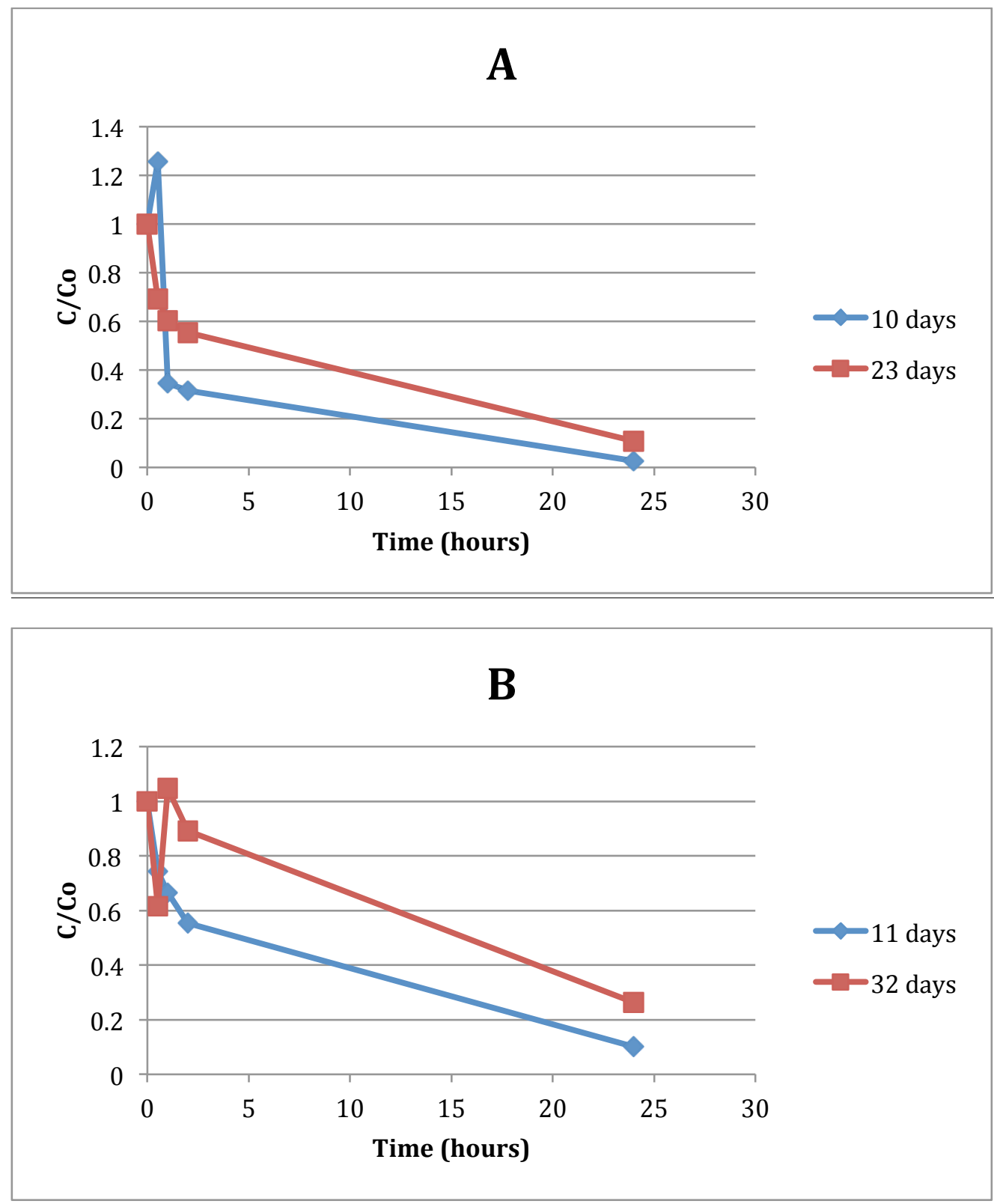

Figure A.40-Normalized cell removal of pure Chlorella A) without carbon dioxide and B) with carbon dioxide addition over the growth curve over a 24-hour settling period 


\section{Supplemental Figures for Section 4.7.3}
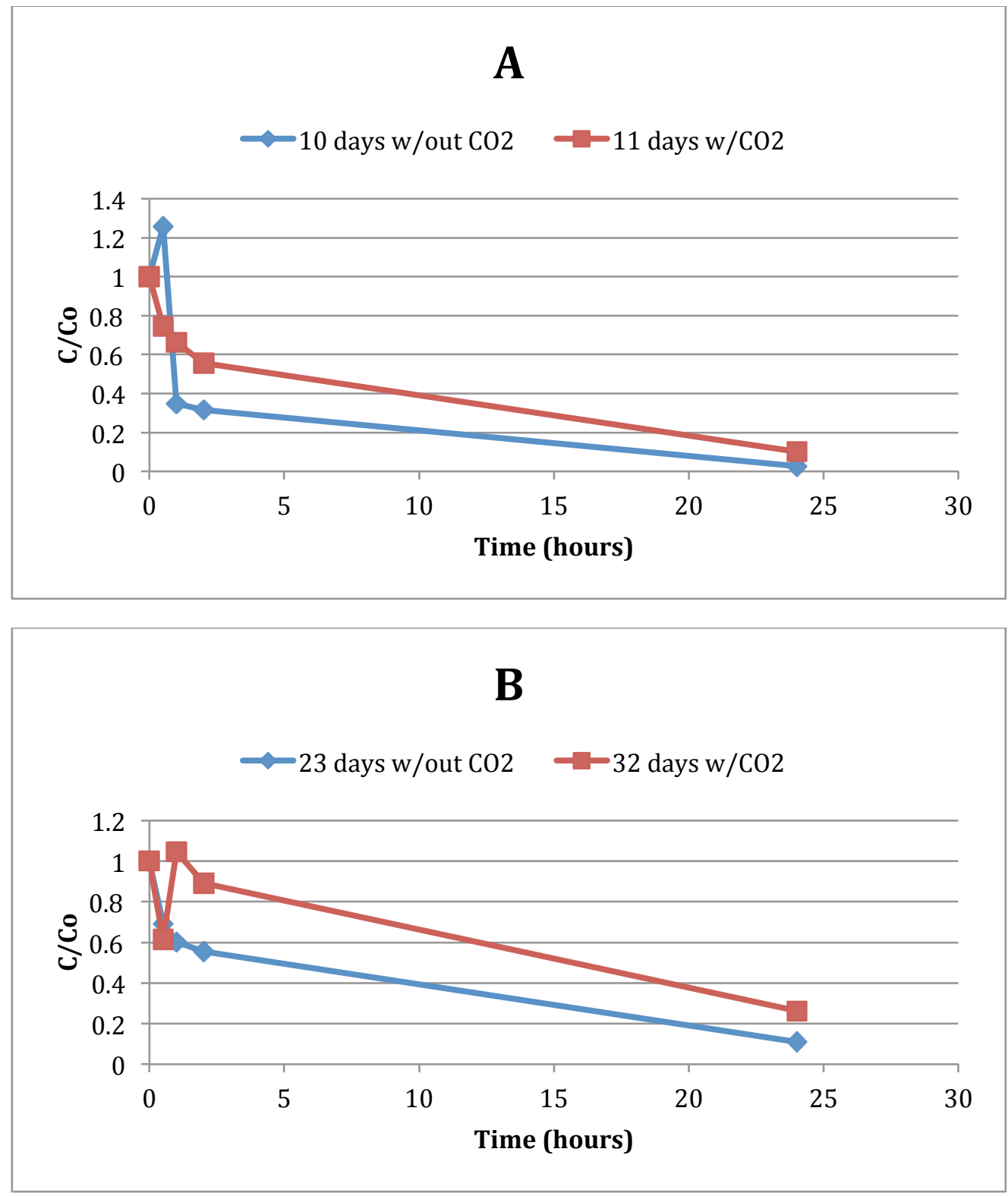

Figure A.41-Normalized cell removal of pure Chlorella with and without carbon dioxide addition during A) early stationary phase of growth and B) later stationary phase of growth over a 24-hour settling period 
Supplemental Figures for Section 4.7.4
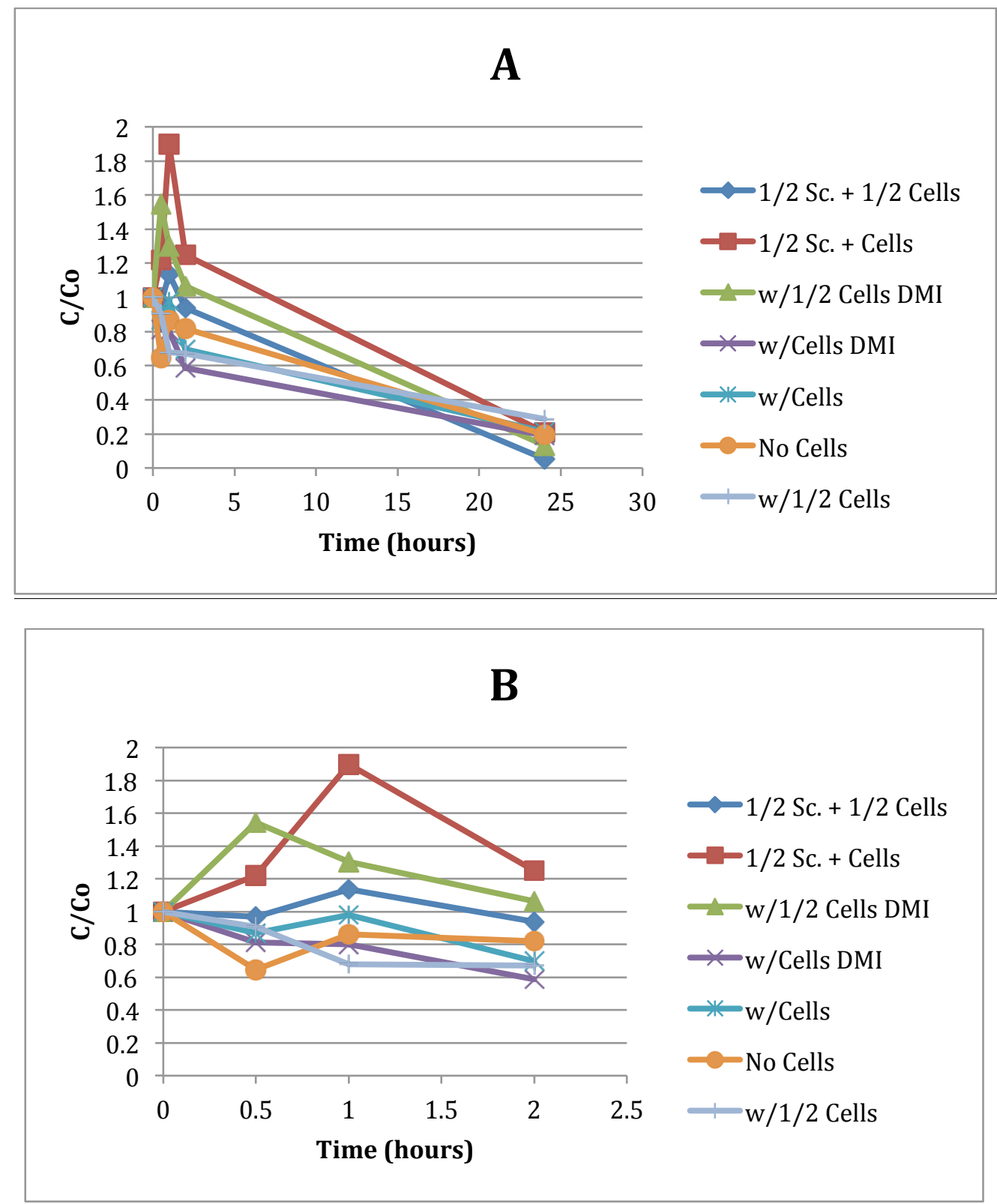

Figure A.42-Normalized cell concentration remaining over a A) 24-hour settling period and B) 2-hour period for Scenedesmus with carbon dioxide and B.cepacia cell addition after 11 days of growth 
Supplemental Figures for Section 4.7.4
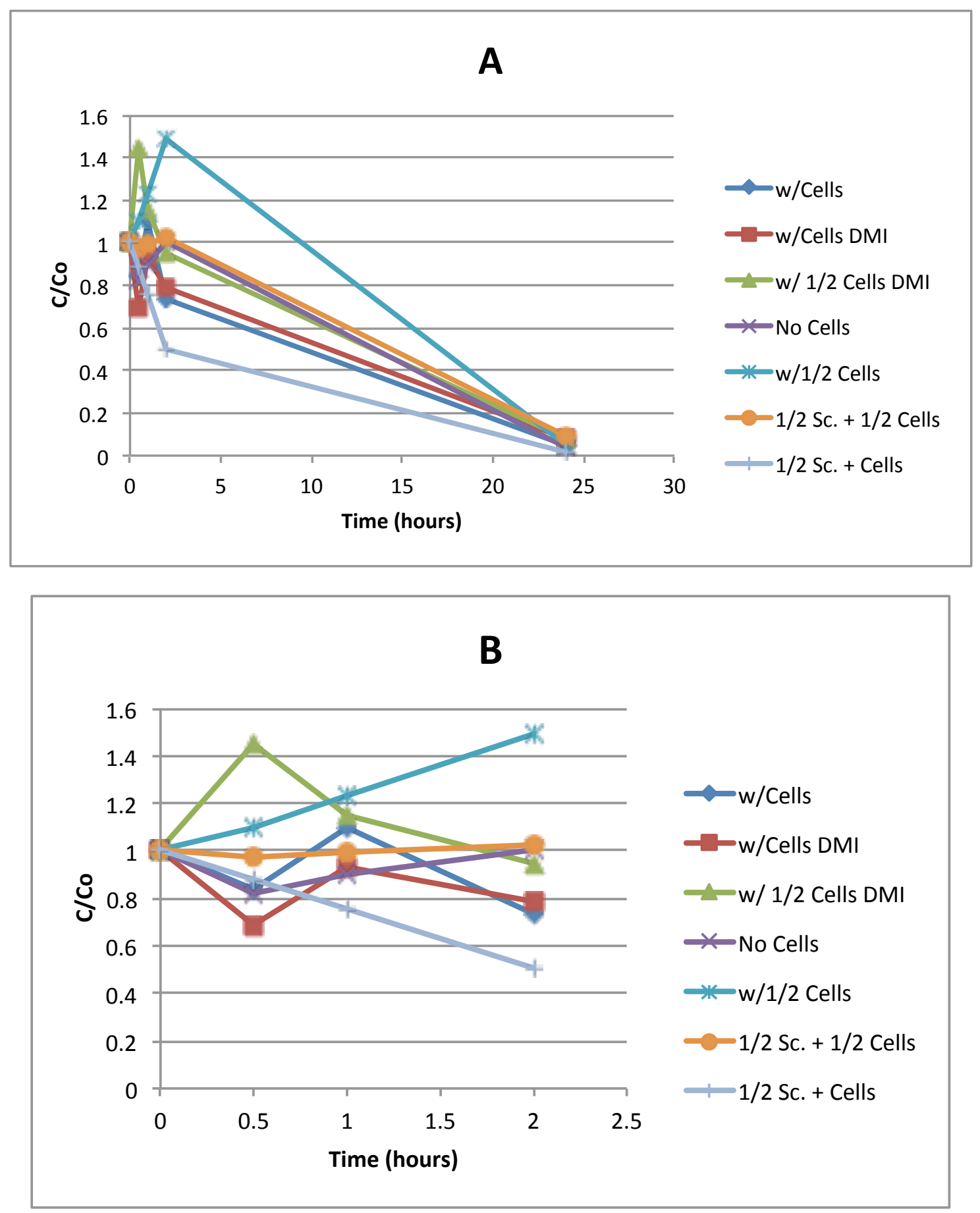

Figure A.43-Normalized cell concentration remaining over A) a 24-hour period and B) a 2-hour period for Scenedesmus with carbon dioxide and B.cepacia cell addition after 27 days of growth 
Supplemental Figures for Section 4.7.4
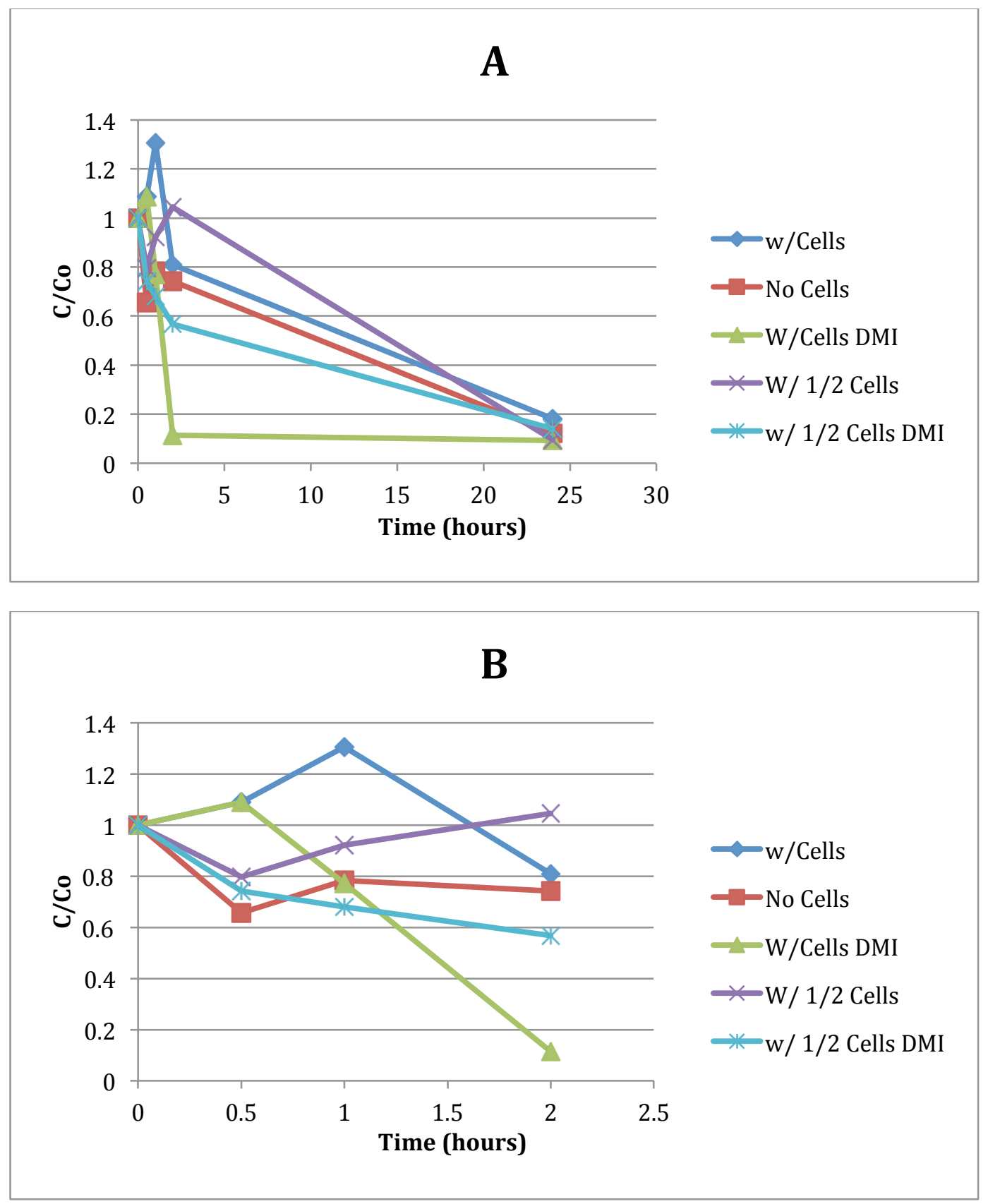

Figure A.44-Normalized cell concentration remaining over a A) 24-hour and B) 2-hour period for Scenedesmus without carbon dioxide addition and B. cepacia addition at different doses and mixing intensities after 10 days of growth 
Supplemental Figures for Section 4.7.4
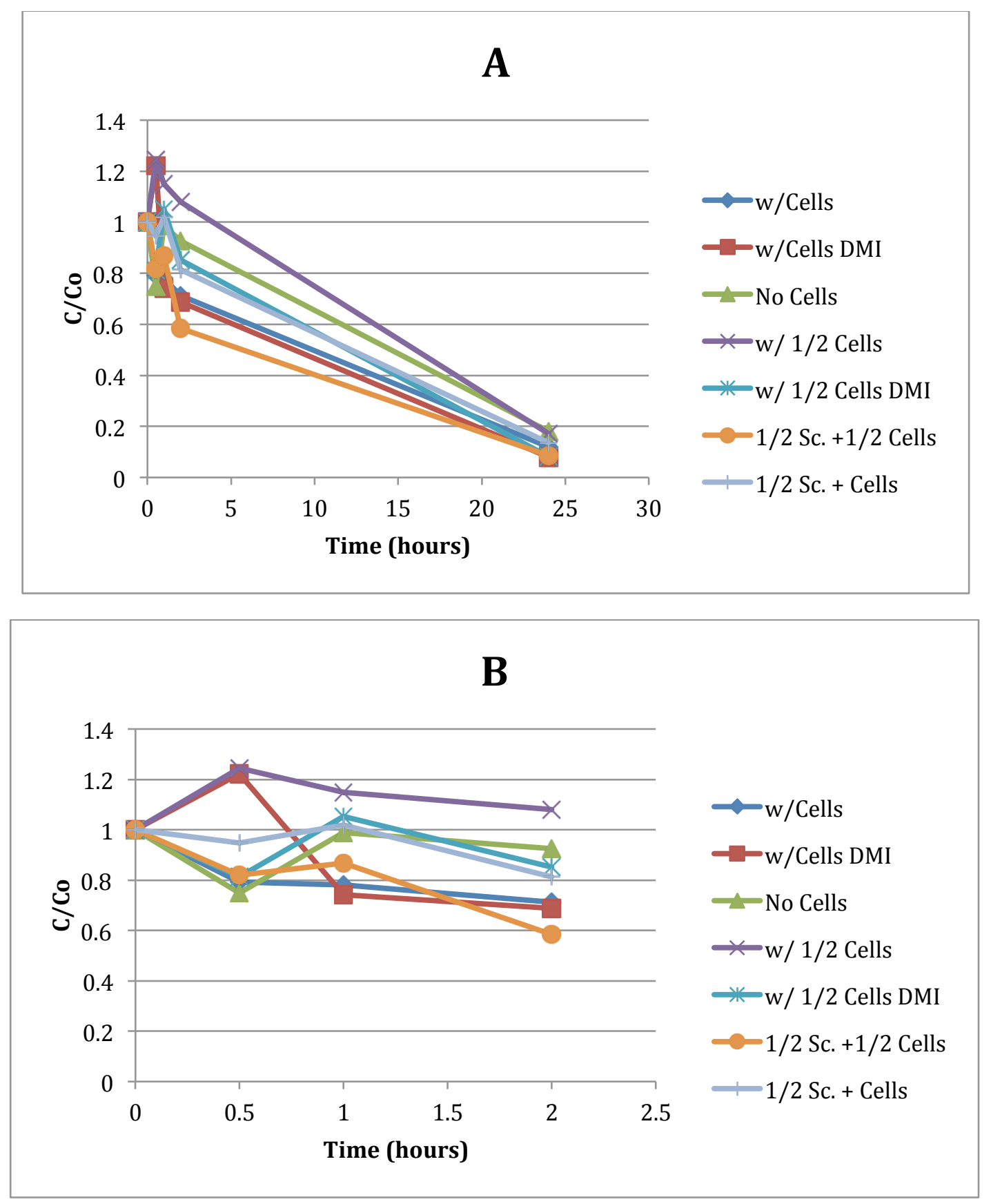

Figure A.45-Normalized cell concentration remaining over a A) 24-hour period and B) a 2-hour period for Scenedesmus without carbon dioxide addition and B. cepacia cell addition at different doses and mixing intensities after 24 days of growth 


\section{Supplemental Figures for Section 4.7.5}
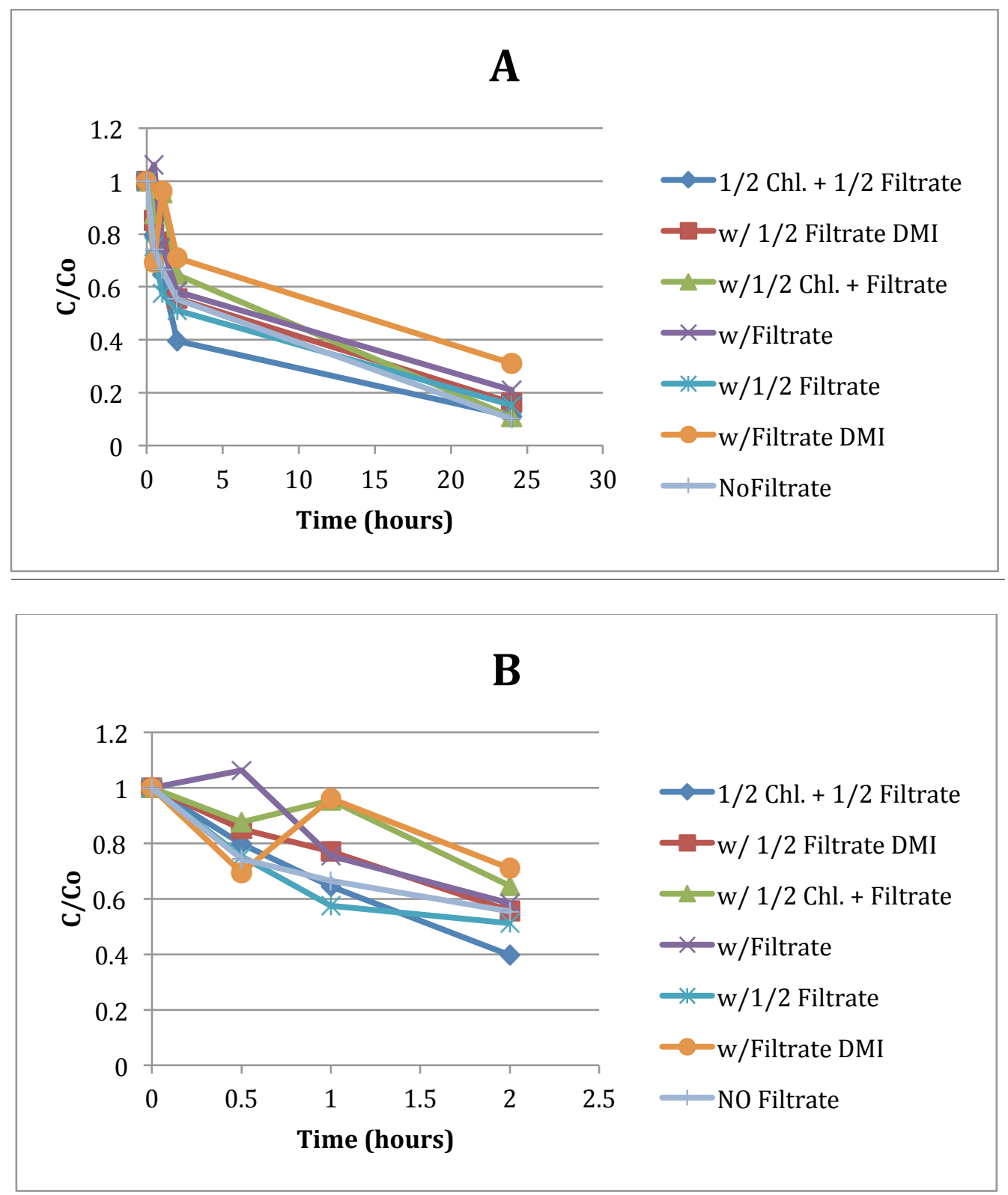

Figure A.46-Normalized cell concentration remaining over a A) 24-hour settling period and B) 2-hour period for Chlorella with carbon dioxide addition (diluted and not diluted) and B. cepacia filtrate additions at various doses and mixing intensities after 11 days of growth 
Supplemental Figures for Section 4.7.5
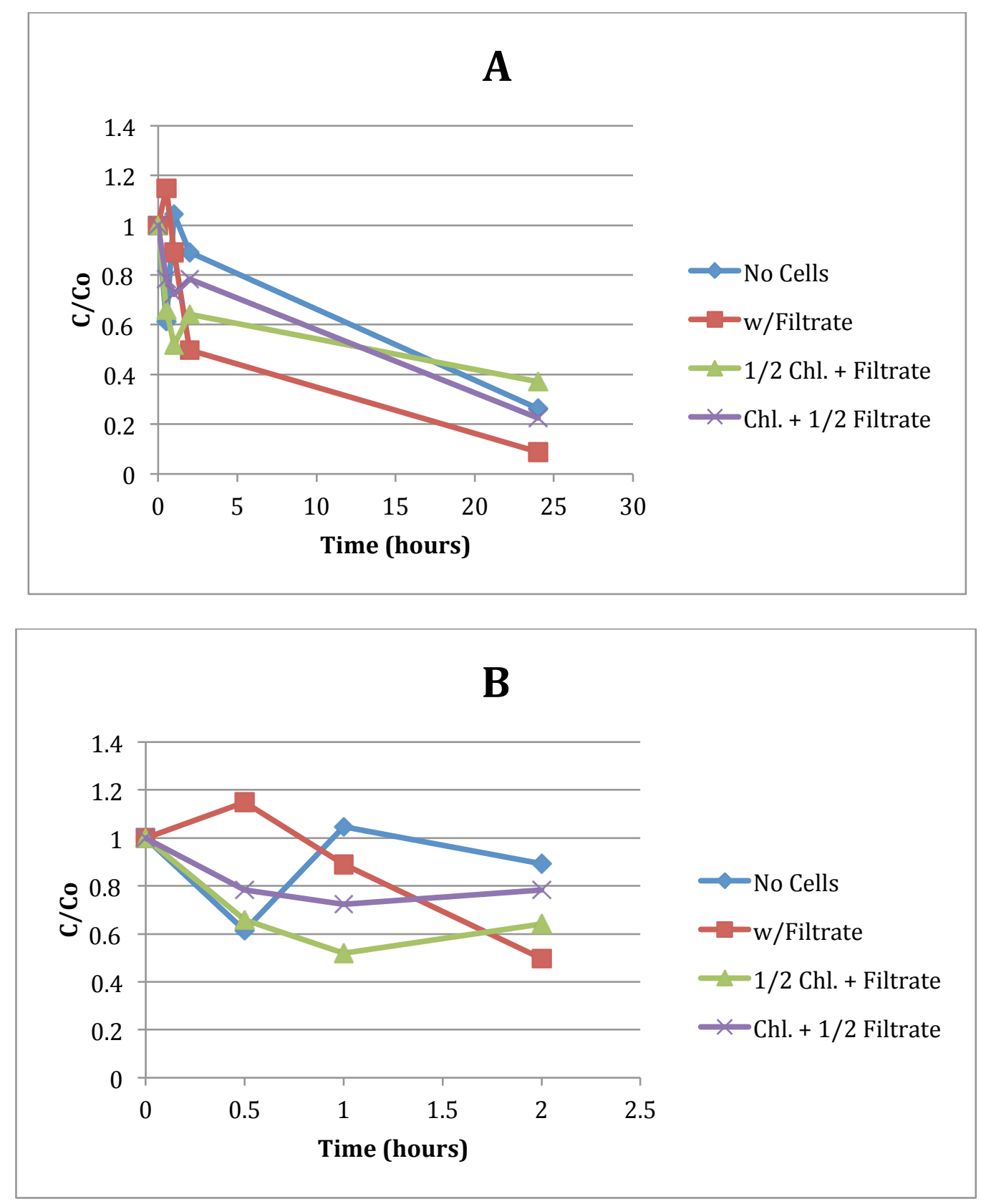

Figure A.47-Normalized cell concentration remaining over a A) 24-hour settling period and B) 2-hour period for Chlorella with carbon dioxide addition (diluted and not diluted) and B. cepacia filtrate additions at various doses after 32 days of growth 


\section{Supplemental Figures for Section 4.7.5}
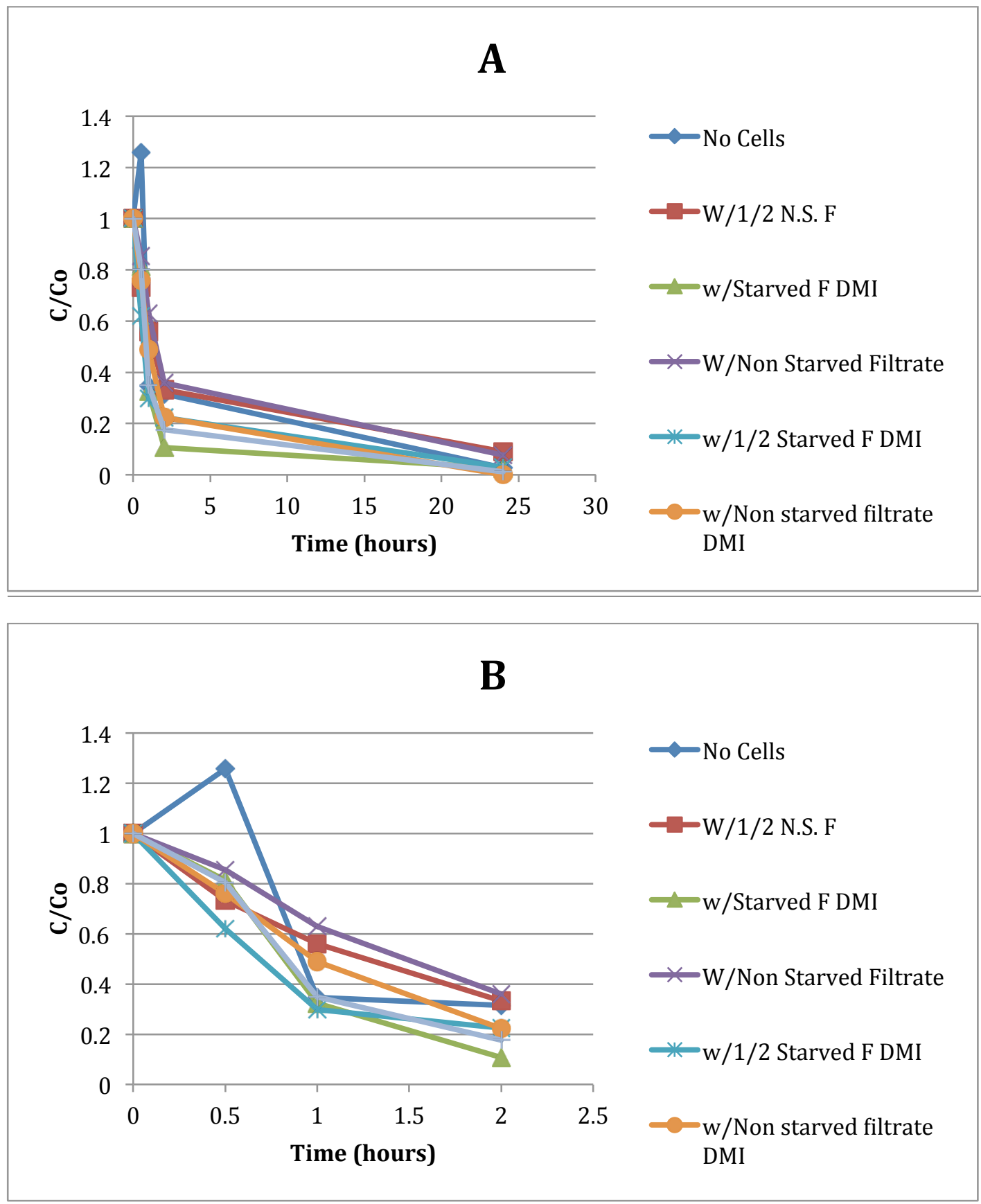

Figure A.48-Normalized cell concentration remaining over a A) 24-hour settling period and B) a 2-hour period for Chlorella without carbon dioxide addition and B. cepacia filtrate additions at varying doses, intensities, and addition of either starved or nonstarved cultures over 10 days of growth 


\section{Supplemental Figures for Section 4.7.5}
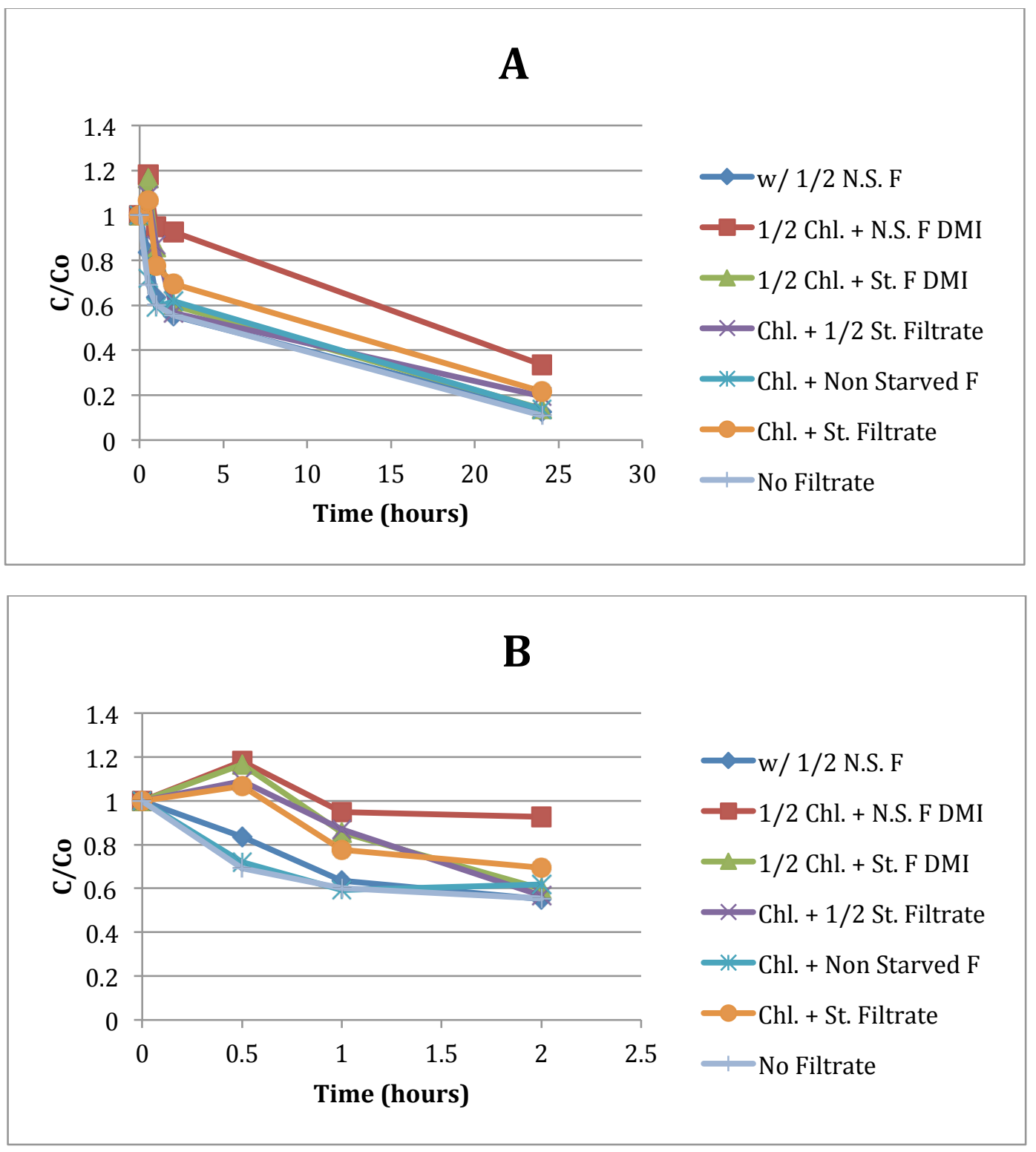

Figure A.49-Normalized cell concentration remaining over a A) 24-hour settling period and B) 2-hour period for Chlorella without carbon dioxide addition and B. cepacia filtrate additions at varying doses, intensities, and addition of either starved or nonstarved cultures over 23 days of growth 